ORNL/TM-2015/72

\title{
Thick Concrete Specimen Construction, Testing, and Preliminary Analysis
}

\section{Approved for public release.}

Distribution is unlimited.
Dwight Clayton

Kyle Hoegh

Lev Khazanovich

March 2015 


\section{DOCUMENT AVAILABILITY}

Reports produced after January 1, 1996, are generally available free via US Department of Energy (DOE) SciTech Connect.

Website http://www.osti.gov/scitech/

Reports produced before January 1, 1996, may be purchased by members of the public from the following source:

National Technical Information Service

5285 Port Royal Road

Springfield, VA 22161

Telephone 703-605-6000 (1-800-553-6847)

TDD 703-487-4639

Fax 703-605-6900

E-mail info@ntis.gov

Website http://www.ntis.gov/help/ordermethods.aspx

Reports are available to DOE employees, DOE contractors, Energy Technology Data Exchange representatives, and International Nuclear Information System representatives from the following source:

Office of Scientific and Technical Information

PO Box 62

Oak Ridge, TN 37831

Telephone 865-576-8401

Fax 865-576-5728

E-mail reports@osti.gov

Website http://www.osti.gov/contact.html

This report was prepared as an account of work sponsored by an agency of the United States Government. Neither the United States Government nor any agency thereof, nor any of their employees, makes any warranty, express or implied, or assumes any legal liability or responsibility for the accuracy, completeness, or usefulness of any information, apparatus, product, or process disclosed, or represents that its use would not infringe privately owned rights. Reference herein to any specific commercial product, process, or service by trade name, trademark, manufacturer, or otherwise, does not necessarily constitute or imply its endorsement, recommendation, or favoring by the United States Government or any agency thereof. The views and opinions of authors expressed herein do not necessarily state or reflect those of the United States Government or any agency thereof. 
Electronics and Electrical Systems Research Division

\title{
THICK CONCRETE SPECIMEN CONSTRUCTION, TESTING, AND PRELIMINARY ANALYSIS
}

\author{
Dwight Clayton \\ Kyle Hoegh \\ Lev Khazanovich
}

Date Published: March 2015

\author{
Prepared by \\ OAK RIDGE NATIONAL LABORATORY \\ Oak Ridge, Tennessee 37831-6283 \\ managed by \\ UT-BATTELLE, LLC \\ for the \\ US DEPARTMENT OF ENERGY \\ under contract DE-AC05-00OR22725
}





\section{CONTENTS}

\section{Page}

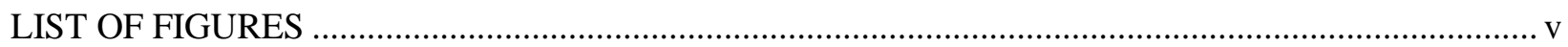

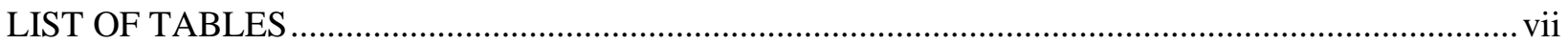

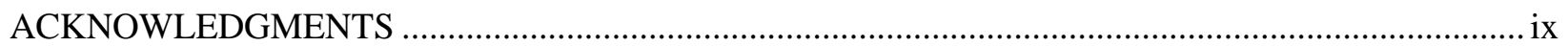

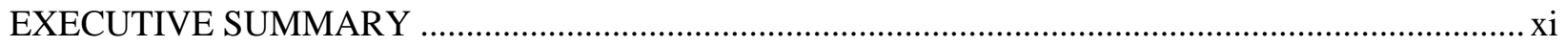

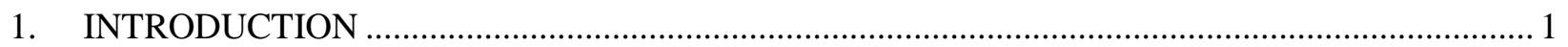

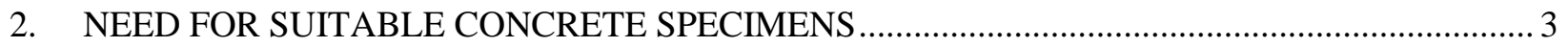

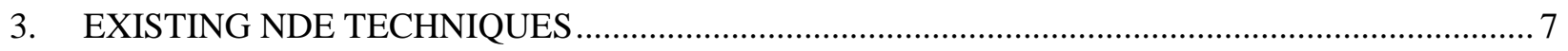

4. TYPICAL PARAMETERS FOR CONCRETE USED IN NPPs …............................................... 11

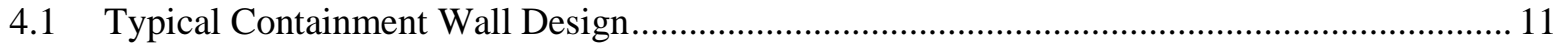

4.2 Previous Concrete Failures in NPP Containment Structures ................................................... 12

5. SPECIMENS WITH DEFECTS APPLICABLE FOR COMPARATIVE NDE .............................. 17

5.1 Containment Structure Concrete Samples ......................................................................... 17

5.2 Infrastructure Concrete Samples with NPP Containment Representative Defects .................. 20

5.2.1 Federal Institute for Materials Research and Testing (BAM) in Berlin, Germany...... 20

5.2.2 NDE Specimens from Journal Publications............................................................. 21

5.2.3 Federal Highway Administration NDE Validation Center at the Turner-

Fairbank Highway Research Center .................................................................. 21

5.3 Florida Department of Transportation NDE Validation Facility .............................................. 25

6. DESIGN REQUIREMENTS FOR The REPRESENTATIVE NPP CONCRETE SAMPLE.............29

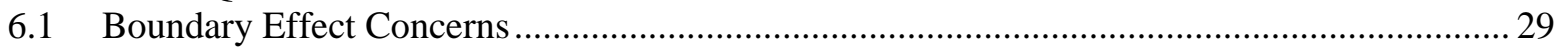

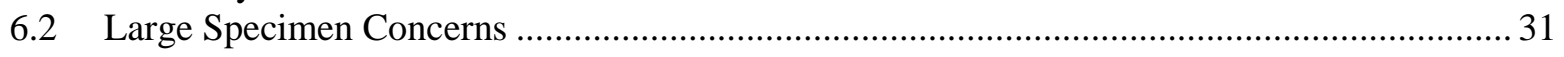

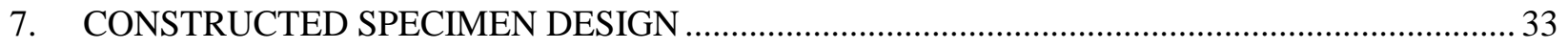

7.1 Specimen Dimensions and Reinforcement ............................................................................ 33

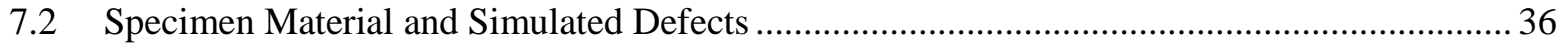

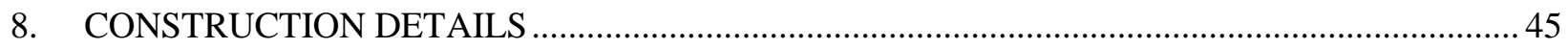

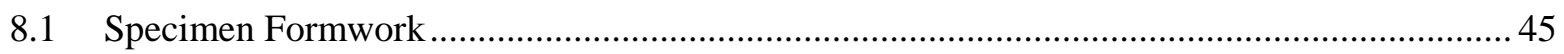

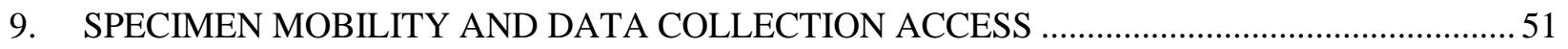

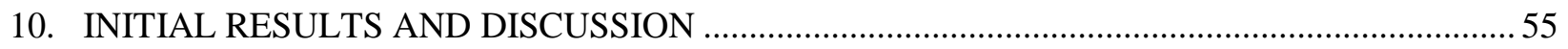

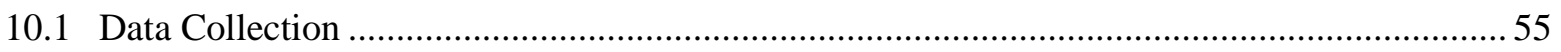

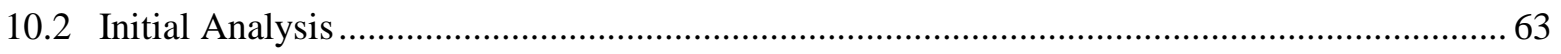

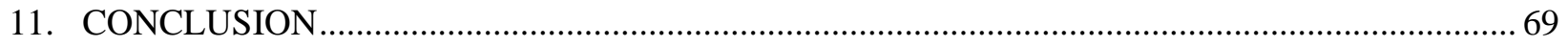

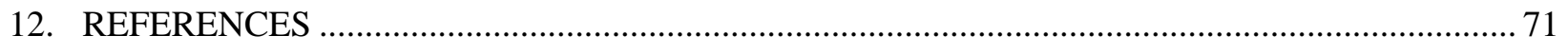

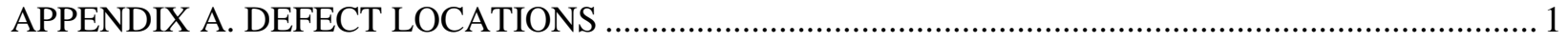

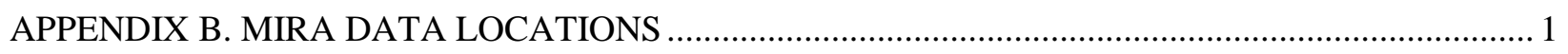

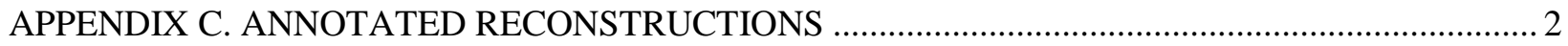





\section{LIST OF FIGURES}

Figure

Page

1. (a) Volumetric imaging relative reflections in relation to the (b) interface showing the actual

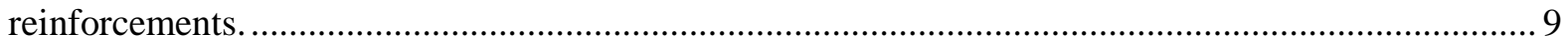

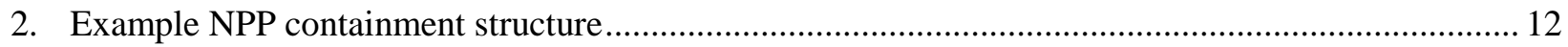

3. Delamination crack running from horizontal tendons at approximately $10 \mathrm{in}$. deep; [A]

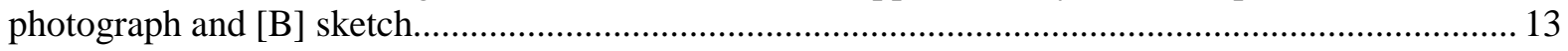

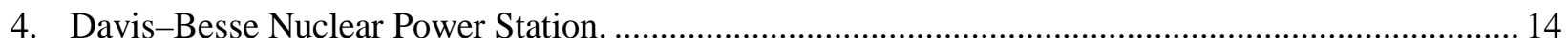

5. View of the Davis-Besse Nuclear Power Station layout and reinforcement scheme ......................... 14

6. Laminar cracking at reinforcements from an interface cut out by hydrodemolition........................... 15

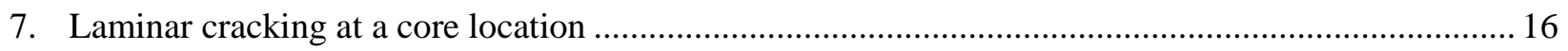

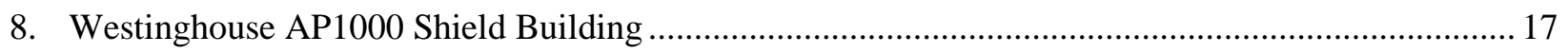

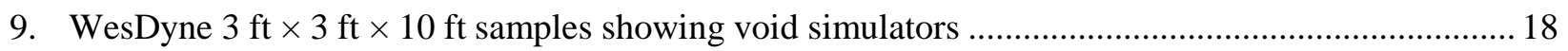

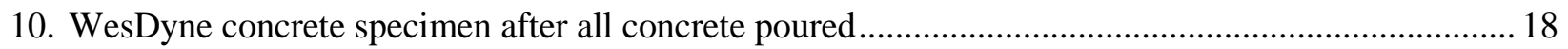

11. WesDyne Westinghouse AP1000 shield building NDE evaluation section........................................ 19

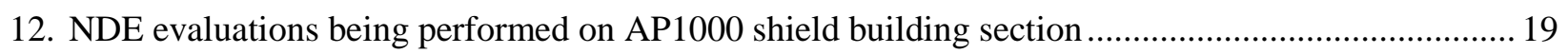

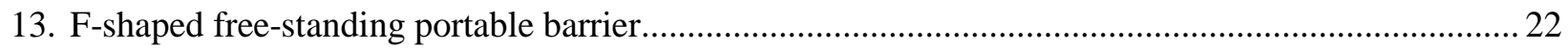

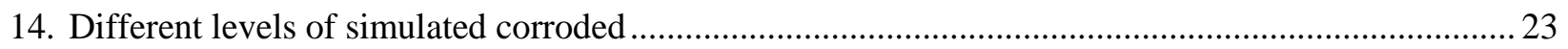

15. Dimensions of the F-shaped bolt-down barrier with different levels of simulated corrosion. .............. 23

16. Different levels of simulated corroded U-shaped rebar................................................................... 24

17. F-shaped bolt-down barrier fabrication with simulated corrosion....................................................... 24

18. F-shaped free-standing portable barrier with simulated voids......................................................... 25

19. Four concrete test specimens. Clockwise from top left: rebar detection, steel post-tensioning duct evaluation, polypropylene post-tensioning duct evaluation, and slab thickness evaluation

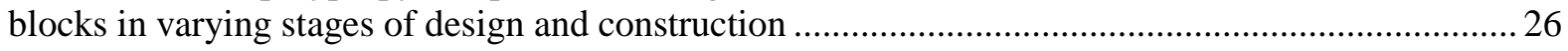

20. Orientation and relative location of rebar mats in the rebar detection block ....................................... 27

21. Installing the surface-level pervious concrete prism and two short boards holding the triangular

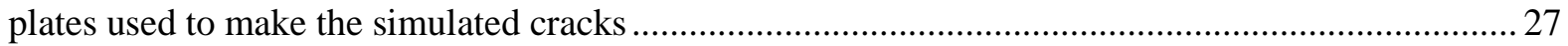

22. Three rebar pieces including the two moving specimens in the void and flaw detection block. The plastic caps marked with the black arrows both keep concrete out of the movement slot in the form boards and indicate in which direction the rebar end is designed....................................... 28

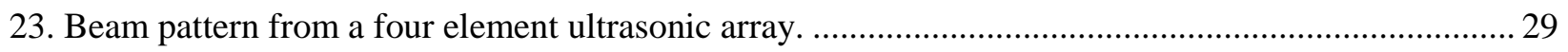

24. [A] Picture of MIRA ultrasound scanner with an approximately 1-m-thick reinforced concrete sample with corresponding reconstructions that indicate the [B] shallow features, [C] deep

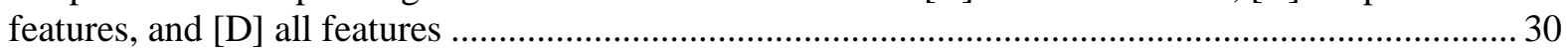

25. \#18 reinforcement used to replicate the large diameter mesh used in NPP containment walls............ 33

26. Concrete dimensions and reinforcement cross section to represent an NPP containment wall............ 34

27. Length/height view of the proposed concrete dimensions and reinforcement to represent an NPP

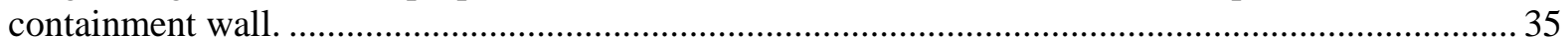

28. Length/depth view of the proposed concrete dimensions and reinforcement to represent an NPP

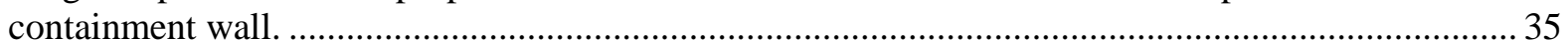

29. Use of SCC to allow for consolidation without affecting simulated defects..................................... 36 


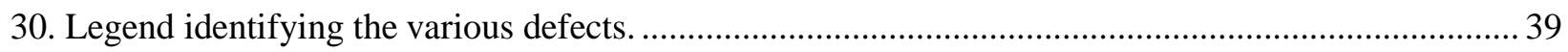

31. Length/height view of the defects outlined in Table 6.................................................................... 40

32. Height/depth view of the defects outlined in Table 6 .................................................................... 41

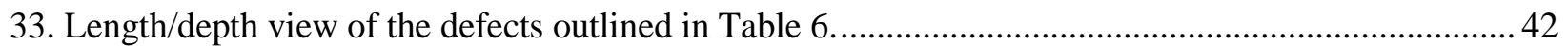

34. Example controlled defect simulating a void with dissolving Styrofoam (D12)............................... 42

35. Example realistic defect simulating concrete damage with embedded porous concrete (D03)........... 43

36. Elevation view of the formwork required to cast the wall lying down............................................... 45

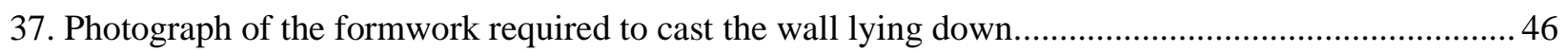

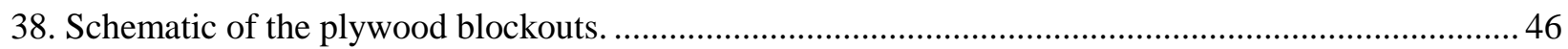

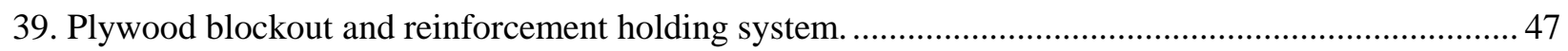

40. Use of tie wires to hold the rebar and defects secure...................................................................... 47

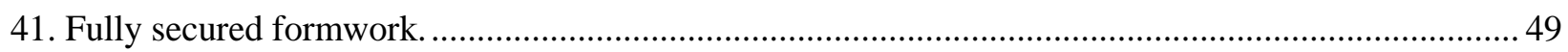

42. Plywood, Stryrofoam, and construction blankets used to insulate the specimen................................ 49

43. Movement of the specimen from the casting location to the testing location...................................... 51

44. Use of a second crane to pick the bottom while the specimen is tilted up.......................................... 52

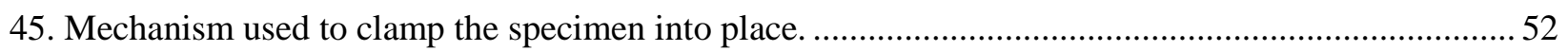

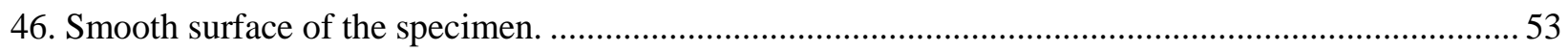

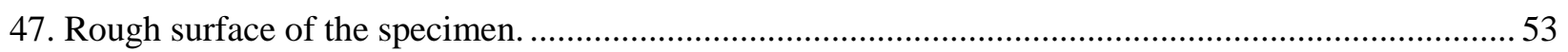

48. Length data collection used to create a SAFT-PAN reconstruction. ................................................... 59

49. Height data collection used to create a SAFT-PAN reconstruction.................................................... 59

50. Rough-side measurement procedure for length orientation measurements. ....................................... 60

51. Smooth-side measurement procedure for length orientation measurements. ........................................ 61

52. Rough-side measurement procedure for height orientation measurements. ....................................... 62

53. Smooth-side measurement procedure for height orientation measurements. ....................................... 63

54. Photograph of defect \#12 with diagrams of the location within the reinforced concrete. .................... 64

55. Photograph and schematics showing the location of Defect \#03 (porous concrete)............................. 65

56. SAFT-PAN reconstruction showing the reflectivity at D12 as tested from the rough side of the specimen (shallower side of the specimen with respect to the defect).............................................. 66

57. SAFT-PAN reconstruction showing the reflectivity at D12 as tested from the smooth side of the specimen (deeper side of the specimen with respect to the defect)................................................... 66

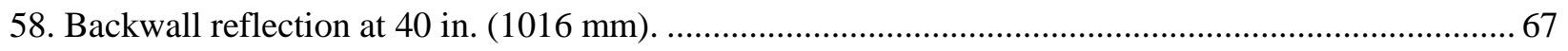

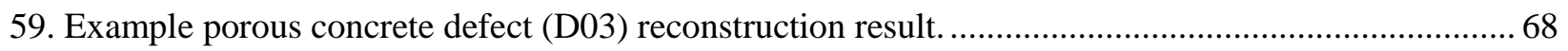




\section{LIST OF TABLES}

Table

Page

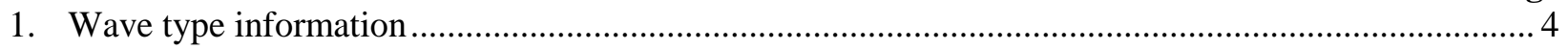

2. Summary of current NDE concrete measurement techniques ............................................................ 8

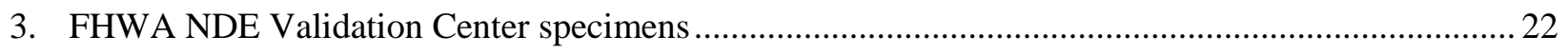

4. Corrosion simulation for each barrier section for Specimens 1 and 2........................................... 22

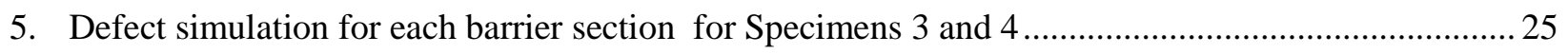

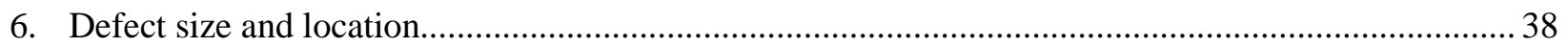

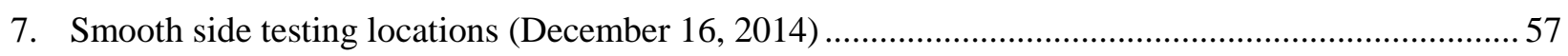

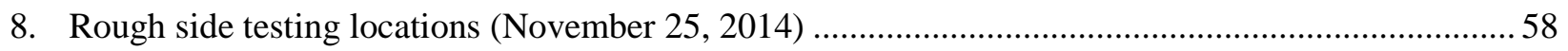





\section{ACKNOWLEDGMENTS}

The structural lab manager, Paul Bergson, oversaw all of the safety-related activities and provided input based on his experiences in casting and moving large specimens. Tom Martin from Advance Shoring provided input to the formwork design and donated all of the formwork necessary for casting of the concrete structure. 



\section{EXECUTIVE SUMMARY}

The purpose of the U.S. Department of Energy Office of Nuclear Energy's Light Water Reactor Sustainability (LWRS) Program is to develop technologies and other solutions that can improve the reliability, sustain the safety, and extend the operating lifetimes of nuclear power plants (NPPs) beyond 60 years [1]. Since many important safety structures in an NPP are constructed of concrete, inspection techniques must be developed and tested to evaluate the internal condition. In-service containment structures generally do not allow for the destructive measures necessary to validate the accuracy of these inspection techniques. This creates a need for comparative testing of the various nondestructive evaluation (NDE) measurement techniques on concrete specimens with known material properties, voids, internal microstructure flaws, and reinforcement locations.

A preliminary report detailed some of the challenges associated with thick reinforced concrete sections and prioritized conceptual designs of specimens that could be fabricated to represent NPP concrete structures for using in NDE evaluation comparisons [2]. This led to the construction of the concrete specimen presented in this report, which has sufficient reinforcement density and cross-sectional size to represent an NPP containment wall. Details on how a suitably thick concrete specimen was constructed are presented, including the construction materials, final nominal design schematic, as well as formwork and rigging required to safely meet the desired dimensions of the concrete structure. The report also details the type and methods of forming the concrete specimen as well as information on how the rebar and simulated defects were embedded. Details on how the resulting specimen was transported, safely anchored, and marked to allow access for systematic comparative NDE testing of defects in a representative NPP containment wall concrete specimen are also given. Data collection using the MIRA Ultrasonic NDE equipment and initial results are also presented along with a discussion of the preliminary findings.

Comparative NDE of various defects in reinforced concrete specimens is a key component in identifying the most promising techniques and directing the research and development efforts needed to characterize concrete degradation in commercial NPPs. This requires access to the specimens for data collection using state-of-the-art technology. The construction of the specimen detailed in this report allows for an evaluation of how different NDE techniques may interact with the size and complexities of NPP concrete structures. These factors were taken into account when determining specimen size and features to ensure a realistic design. The lateral dimensions of the specimen were also chosen to mitigate unrealistic boundary effects that would not affect the results of field NPP concrete testing. Preliminary results show that, while the current methods are able to identify some of the deeper defects, improvements in data processing or hardware are necessary to be able to achieve the precision and reliability achieved in evaluating thinner and less heavily reinforced concrete structures. 



\section{INTRODUCTION}

Extending reactor life of the existing nuclear reactor fleet to 60 years and beyond will likely increase the susceptibility and severity of known forms of degradation, making materials issues a key concern [3][4]. A multitude of concrete-based structures are typically part of a light water reactor (LWR) plant to provide foundation, support, shielding, and containment functions. Concrete has been used in the construction of nuclear power plants (NPPs) because of three primary properties: its inexpensiveness, structural strength, and ability to shield radiation. Examples of concrete structures important to the safety of LWR plants include the containment building, spent fuel pool, and cooling towers. Use of these structures has made concrete's long-term performance crucial for the safe operation of commercial NPPs and creates a need to nondestructively evaluate the current subsurface concrete condition of aging concrete material in NPP containment structures.

The size and complexity of NPP containment structures and heterogeneity of Portland cement concrete (PCC) make characterization of the degradation extent a difficult task. Unlike most metallic materials, reinforced concrete is a composite with a relatively low density matrix; it is a mixture of Portland cement, fine aggregate or sand, aggregate, water, admixtures, and a high density reinforcement (typically 5 percent in NPP containment structures) made up of steel rebar or tendons. NPPs have been typically built with local cement and aggregate fulfilling the design specifications regarding strength, workability, and durability, but as a consequence each plant's concrete composition is unique and complex. In addition, an NPP's concrete structures are often inaccessible, containing large volumes and massively thick concrete structures exposed to different environments (moisture, temperature) and a diversity of degradation mechanisms (high temperatures, radiation exposure, chemical reactions, and other physical mechanisms) at different plant sites, all of which add to the complexity of determining the integrity/quality of the concrete [2]-[4].

Specially designed and fabricated test specimens can provide realistic flaws that are similar to actual flaws in terms of how they interact with a particular NDE technique. Artificial test blocks allow the isolation of certain testing problems as well as the variation of certain parameters. Because conditions in the laboratory are controlled, the number of unknown variables can be decreased, making it possible to focus on specific aspects, investigate them in detail, and gain further information on the capabilities and limitations of each method. To minimize artifacts caused by boundary effects, the dimensions of the specimens should not be too compact. Representative large heavily reinforced PCC specimens would allow for comparative testing to evaluate the state-of-the-art in NDE in this area and to identify additional developments necessary to address the challenges potentially found in NPPs. These types of specimens would also be useful for calibration and validation of new technology and processing techniques. The specimen constructed and detailed in this report provides an opportunity to address these key issues for evaluation of PCC in NPP structures [2]. 



\section{NEED FOR SUITABLE CONCRETE SPECIMENS}

Comparative testing of the various NDE concrete measurement techniques will require concrete specimens with known material properties, voids, internal microstructure flaws, and reinforcement locations. Ideally commercial NPPs undergoing the decommissioning process would be used for NDE comparison, since there are certain characteristics of NPP structures that are difficult to replicate [5]. They are also exposed to known degradation mechanisms, including different levels of radiation, temperature, and chemical reactions that provide the most realistic concrete aging specimens. Concrete fabricated some 40 to 50 years ago is difficult to reproduce using fabricated test blocks, since old cements were generally coarser than present-day cement. Fine cements set and hydrate quickly, generating a high heat release at an early age that can cause thermal cracking and potentially delayed ettringite formation if not cured correctly, and the original admixture (plasticizer, etc.) may no longer be available [6]-[8]. Exclusive use of commercial NPPs to evaluate the effectiveness of NDE techniques is not feasible for a variety of reasons. Commercial NPPs do not always provide the accessibility to collect data using all potential NDE techniques. Destructive forensic activities necessary to validate discrepancies and limitations in the NDE results are also not typically feasible. Alternative methods such as transporting NPP samples to a laboratory environment could theoretically provide the necessary access and forensic capabilities. However, the lateral dimensions required to mitigate boundary effects for NDE specimens over $3 \mathrm{ft}$ thick often make transportation of specimens impractical.

Few applications other than NPPs require critical concrete structures as thick and heavily reinforced. This limits the existing entities with experience in conducting NDE on thick and reinforced concrete structures. Research reactors such as the High Flux Isotope Reactor (HFIR) located at Oak Ridge National Laboratory (ORNL) possess thick, heavily reinforced concrete structures. However, these structures are not as extensive as those of commercial NPPs. This creates a need to construct specimens for performing NDE technique assessments, research, and training.

The environment of specimen construction should represent the access conditions of an in-service containment structure for evaluation of techniques requiring only one-sided testing. Since it is not feasible to build specimens at the scale of in-service structures, compact sample specimens must be built while still replicating the NDE needs of real structures. This includes minimizing artifacts caused by boundary effects. Although significant NDE research has been conducted on thin PCC structures to assess pavement, bridge deck, and other infrastructure applications, construction of large reinforced concrete specimens specifically for NDE comparisons is less common [3][4]. Comparative studies have shown various NDE techniques to be successful in identifying the types of internal characteristics of interest, requiring only one-sided access [9]-[18]. However, these applications are typically conducted to evaluate thin sections ( $1 \mathrm{ft}$ thick), while NPP containment walls are often much thicker (over $3 \mathrm{ft}$ thick). Even though previous results for thinner structures show promise in the ability to nondestructively evaluate internal characteristics, the results need to be validated for thicker and more heavily reinforced structures. There are two major NDE challenges associated with the fabrication and evaluation of thicker structures:

- Low signal-to-noise ratio with greater depths due to heterogeneous material such as PCC with a dense and complex arrangement of reinforcements.

- Effects from vertical boundaries at similar distances to the region of interest (ROI).

A background on elastic wave propagation, which is the basis of the MIRA ultrasonic technique used for initial data collection of the specimen built in this study, allows for a discussion of these challenges. When exposed to a short duration external impact, concrete reacts approximately like an elastic solid medium, where the distortion and subsequent movements in the concrete can be described using three general modes of wave propagation categorized by the coverage and direction of particle motion with respect to propagation direction: P-waves, S-waves, and R-waves. 
The compression (also known as longitudinal or primary) waves (P-waves) have particle motion parallel with the direction of wave propagation. The four transverse (also known as shear) waves (S-waves) have particle motion perpendicular to the wave propagation direction. The Rayleigh waves (R-waves) have retrograde elliptical particle motion. The R-waves propagate along the surface, whereas the P- and S-waves propagate throughout the body of the solid in a hyperbolic nature [19]. The reflection of $\mathrm{P}$ - and $\mathrm{S}$-waves depends on changes in acoustic impedance from internal characteristics of concrete structures. P- and S-waves are useful in evaluating internal characteristics of concrete structures with only one-sided access because changes in subsurface properties such as flaws, inclusions, or layer boundaries cause reflections back to the surface.

If concrete is approximated as an isotropic and elastic medium, the relationship between elastic parameters (Modulus, Poisson's ratio), density, and wave velocity in concrete has the form shown in Eqs. (1) through (3) [19]:

$$
\begin{gathered}
C_{P}=\sqrt{\frac{E(1-\mu)}{(1-\mu)(1-2 \mu) \rho}}, \\
C_{S}=\sqrt{\frac{E}{2(1+\mu) \rho}}, \\
C_{R}=C_{S} \frac{0.87+1.12 \mu}{1+\mu},
\end{gathered}
$$

where $E$ is Young's modulus of elasticity, $\mu$ is Poisson's ratio, $\rho$ is density, $C_{P}$ is the compression or pressure wave (P-wave) velocity, $C_{S}$ is the transverse or shear wave ( $\mathrm{S}$-wave) velocity, and $C_{R}$ is the Rayleigh wave (R-wave) velocity. Assuming the shear wave response is being evaluated and a typical value for Poisson's ratio in concrete, $\mu=0.2$, the velocity of the other wave types has the following relationship with respect to shear waves:

$$
C_{S}=0.61 C_{P}=1.09 C_{R}
$$

A- 1 gives additional information, including the particle motion, relative wave speeds, and energy content of the various wave types [19].

\section{A- 1. Wave type information}

\begin{tabular}{|c|l|l|c|c|}
\hline Wave type & \multicolumn{1}{|c|}{ Particle motion } & $\begin{array}{c}\text { Propagation } \\
\text { medium }\end{array}$ & $\begin{array}{c}\text { Relative wave } \\
\text { speed, } \boldsymbol{\mu}=\mathbf{0 . 2}\end{array}$ & $\begin{array}{c}\text { Energy content } \\
\text { (\%) }\end{array}$ \\
\hline P-wave & $\begin{array}{l}\text { Parallel to propagation } \\
\text { direction }\end{array}$ & $\begin{array}{l}\text { Solid, liquid, or } \\
\text { gas body wave }\end{array}$ & 0.61 & 7 \\
\hline S-wave & $\begin{array}{l}\text { Perpendicular to } \\
\text { propagation direction }\end{array}$ & Solid body wave & 1 & 26 \\
\hline R-wave & Retrograde elliptical & Surface wave & 1.09 & 67 \\
\hline
\end{tabular}

A few observations can be made from these relationships with regard to use of elastic waves for evaluation of thick reinforced concrete structures. Since acoustic impedance is positively correlated to the stiffness of the material, elastic waves are extremely proficient at characterizing interfaces such as cracks, voids, or delamination where the change in acoustic impedance from concrete to air is extremely high. However, since PCC is composed of air voids and aggregates, elastic waves can also experience significant attenuation that limits the penetration depth. For example, since the P-wave has the lowest amount of energy from a point source impact, it may not achieve the necessary penetration depth required to characterize the thick concrete specimen due to the low energy content. However, the ability to propagate in all types of media may provide air-coupled possibilities [14]. S-waves have significantly 
higher energy content, allowing for greater penetration depth in heterogeneous media such as concrete. However, they require a solid material for propagation, creating a need for ground coupling. Moreover, because they are similar in velocity to R-waves, boundary effect interference may be a problem.

The Elastodynamic Finite Integration Technique (EFIT), developed at the University of Kassel, is an effective tool for investigating both the penetration depth and the boundary effect challenges in evaluating thick reinforced concrete structures [20]. The tool has been used to compare elastic wave propagation in a 2D concrete model assuming $0 \%$ and $1 \%$ air porosity from a $200 \mathrm{kHz}$ center frequency point source. It was reported that the reflections from simulated inclusions and back wall reflections were less clear with porosity and that the signal-to-noise ratio decreased with depth. While evaluation based on lower frequency content may resolve this difficulty, the general trend of increased attenuation and a decreased signal-to-noise ratio with depth holds true. Therefore, the same internal defects that can be identified in thin concrete structures may require improved filtering or processing techniques for identification at greater depth due to the decreased signal-to-noise ratio. This is especially true for heavily reinforced concrete structures where scattering and reflection of the wavefront occurs at the boundaries between concrete and steel [21]. This decreasing signal-to-noise ratio with depth is a significant challenge that needs to be addressed for effective nondestructive characterization of aging concrete material in NPP containment structures.

Unlike the loss of signal-to-noise ratio with greater penetration depth problem, which needs to be addressed solely by the NDE technique, the boundary effect problem is less of an issue for in-service inspection of commercial NPP containment structures, where lateral boundaries are less prevalent. However, boundary effects are more critical for thicker concrete structures with regards to specimen design. For many NDE techniques, the first reflected wave received is assumed to be from internal changes in acoustic impedance, or the rear surface, assuming the structure is infinitely expanded in the lateral direction. This assumption is generally valid for evaluation of continuous structures such as NPP containment walls and for internal interrogation of specimens of thin structures such as bridge decks or pavements. However, to use this assumption and properly represent NPP containment structures, thicker concrete structure specimens require higher restrictions for allowable vertical boundaries. If a vertical boundary is located sufficiently close to the sensor position in relation to the depth of interrogation interest, reflections of surface and body waves are present within the same time window [22]. In these cases, the boundary effects must either be eliminated through specimen and/or equipment design, or be taken into account in time-domain signal and spectrum analysis to mitigate systematic errors.

Since the ability of each NDE technique to account for boundary effects is not critical for in-service inspection, it is preferable to design the specimen to mitigate boundary effects, which are also representative of the lack of vertical boundaries for NPP containment structures. The exact lateral dimensions required of the specimen for this assumption to be valid are directly related to the ROI depth (often the thickness of the specimen) and the NDE technique used. For example, an NDE technique based on point-source elastic wave propagation used to evaluate a $3 \mathrm{ft}$ long, $3 \mathrm{ft}$ tall, $4 \mathrm{ft}$ thick specimen of a containment wall may have difficulty detecting a defect at $3 \mathrm{ft}$ depth due to boundary effects. However, the same technique may be able to detect the same defect when testing an in-service containment wall where the boundary effects do not affect the measurements.

Since specimens should be designed to test the ability of the technique to mitigate boundary effects, the most extreme case, evaluation of S-waves from a point source, should be taken into account for specimen design considerations. This is considered the most extreme case since a point source creates elastic waves with a full 180 degree divergence, and the S-wave velocity is very similar to the surface R-wave velocity, which also contains the highest energy content, as noted in Table 1 . In this case, the distance from the source location to the rear surface must be the minimum dimension. This type of challenge was investigated using 3D EFIT simulation of a point-source elastic wave field in a $2 \times 1.5 \times 0.5 \mathrm{~m}^{3}$ steel-reinforced concrete model with polystyrene inclusions [19]. Considering the energy content of R-waves shown in A-1, it follows that the circular R-wave reflected by the lateral boundaries in the simulation lead to geometrical effects in time-domain signal and spectrum analysis. These boundary effects can cause systematic errors in internal flaw detection or thickness determination. This 
need to mitigate boundary effects creates transportation challenges for the use of concrete specimens removed from operating reactors to accommodate an increased lateral-to-depth dimension ratio that allows for representative testing.

Fortunately, concrete specimens fabricated under laboratory conditions to control various properties can be used as substitutes for specimens obtained from nuclear structures. Fabricated test blocks allow the isolation, as well as the variation, of certain test parameters. Under controlled laboratory conditions, the number of variables can be decreased, making it possible to investigate specific defects in detail as well as gain further information on the capabilities and limitations of the techniques. The laboratory environment also allows for forensic investigation of the specimen in locations where there are suspected discrepancies in as-built characteristics compared to as-designed features, although these activities should be limited so that the specimen is available for future calibration/verification of other methods after the initial comparative testing. The reinforced PCC specimen was constructed as part of this study to address the limitations discussed in this section. 


\section{EXISTING NDE TECHNIQUES}

The types of NDE techniques used for testing were accommodated in the specimen design and construction. In-service inspection programs for NPP structures have the primary goal of ensuring that the structures have sufficient margins to continue to perform safely and reliably. A secondary goal is to identify environmental stressors or aging factor effects before they reach sufficient intensity to potentially degrade structural components. One of the conditions of all operating licenses for US water-cooled power reactors is that the primary reactor containment meet the containment leakage test requirements set forth in Appendix J, "Primary Reactor Containment Leakage Testing for Water-Cooled Power Reactors,” to Title 10, "Energy,” Part 50 of the Code of Federal Regulations (10 CFR 50).

NDE techniques are not typically employed as part of in-service inspection and testing of containments. NDE of containment structures is generally conducted to determine if degradation has occurred or to quantify degradation known to be present. A- 2 summarizes the traditional NDE techniques for measuring concrete degradation [3].

Ultrasonic testing techniques have a wide range of applications, including measuring thickness, locating steel reinforcement and tendon ducts, and characterizing surface cracks. It also shows promise for investigating grouting conditions inside grouted tendon ducts. Unlike electromagnetic waves, acoustic waves are capable of penetrating metal components such as liners

[23]. Ultrasonic techniques can also use the Synthetic Aperture Focusing Technique (SAFT) to produce an image when multiple impulse time histories are combined.

Coda wave interferometry (CWI) is a technique that allows one to observe differences in the coda portion of the recorded waveform of a diffuse field. When an ultrasonic wave is emitted into a concrete specimen, the heterogeneous nature of the concrete causes the wave to become highly scattered and a diffuse field is created. A diffuse field consists of two parts, the first arrival and the diffuse portions, which includes the late coda contribution. Diffuse waves undergo multiple scattering, which causes them to arrive much later than the first arrival. However, diffuse waves are much more sensitive to small changes in the concrete medium and carry more information than the first arrival. CWI compares two different time series of coda waves, the stressed state and unstressed state, and determines the degree of correlation. Comparing the difference between the two states allows one to monitor damage progression in the concrete specimen [24]. There are two types of CWI: the doublet technique and the stretching technique. The stretching technique is the more advanced of the two and is more commonly used. In this technique, the time axis is stretched or compressed until it has much in common with a reference time signal. Since time and velocity are proportional, the relative velocity can be calculated from the scaling factor. CWI appears to be quite useful for detecting changes and monitoring the progression of damage in concrete. However, it does not seem to be able to locate defects. It also requires a high signal-to-noise ratio to be effective in the field [24].

Ultrasonic pulse echo uses the same impulse echo principle as radar. Ultrasonic waves are reflected at interfaces where acoustic impedance differs, and the propagation time to the interface and back can be measured to learn about the interior of the structure. This technique is a bit more flexible than ultrasonic pulse velocity because it only requires one transducer that both transmits and receives. This means it also only requires access to one side of the structure, which is invaluable in an environment such as an NPP. The one drawback to this technique is that the speed of sound in the concrete to be tested must be known before testing can begin. This often, but not always, requires drilling cores for testing [25]. Ultrasonic pulse echo can benefit from the use of multi-sensor arrays. These arrays typically use 10-40 sensors that can both transmit and receive. Only one transducer acts as the transmitter at a time, while the rest act as receivers. Once the first has transmitted, the next sensor becomes the transmitter. This cycle continues until each transducer has acted as a transmitter. Multi-sensor arrays are quite promising in that they offer an increased sensing area as well as increased depth of penetration, reportedly up to $2 \mathrm{~m}$ [26]. 
A- 2. Summary of current NDE concrete measurement techniques

\begin{tabular}{|c|c|c|}
\hline NDE Method & Advantages & Disadvantages \\
\hline Visual Inspection & Simple, fast & Relies on experience \\
\hline Ground-Penetrating Radar & $\begin{array}{l}\text { Rapid; non-contact; can obtain depth } \\
\text { and thickness measurements; good at } \\
\text { locating embedded metals and fluids }\end{array}$ & $\begin{array}{l}\text { Limited depth of penetration }(0.6 \mathrm{~m}) \text {; } \\
\text { subjective to data interpretation; cannot } \\
\text { see behind metal }\end{array}$ \\
\hline Ultrasonic - General & $\begin{array}{l}\text { Thickness measurement; embedded } \\
\text { metal location; imaging capability }\end{array}$ & $\begin{array}{l}\text { See below different ultrasonic } \\
\text { techniques }\end{array}$ \\
\hline Ultrasonic Pulse Velocity & $\begin{array}{l}\text { Can be one-sided measurement (indirect } \\
\text { transmission); void/defect location; } \\
\text { simple }\end{array}$ & Requires transmitter and receiver \\
\hline Ultrasonic Pulse Echo & $\begin{array}{l}\text { Single transducer; can be multi-sensor } \\
\text { array }\end{array}$ & $\begin{array}{l}\text { Speed of sound in concrete being tested } \\
\text { must be measured }\end{array}$ \\
\hline $\begin{array}{l}\text { Ultrasonic Coda Wave } \\
\text { Interferometry }\end{array}$ & $\begin{array}{l}\text { Quite useful for detecting changes and } \\
\text { monitoring damage }\end{array}$ & $\begin{array}{l}\text { Does not appear to located defects; } \\
\text { requires high signal-to-noise ratio in the } \\
\text { field }\end{array}$ \\
\hline Impact Echo & $\begin{array}{l}\text { Simple; can locate large voids and } \\
\text { delaminations in plate }\end{array}$ & Results can be difficult to interpret \\
\hline Acoustic Emission & $\begin{array}{l}\text { Can provide real-time feedback on } \\
\text { crack propagation }\end{array}$ & $\begin{array}{l}\text { Can only detect change in state; high } \\
\text { variability in signal strength; } \\
\text { background noise can have sufficient } \\
\text { effect on the measurement }\end{array}$ \\
\hline Infrared Thermography & $\begin{array}{l}\text { Area testing technique; good for finding } \\
\text { near-surface voids }\end{array}$ & $\begin{array}{l}\text { Requires a thermal gradient through the } \\
\text { concrete }\end{array}$ \\
\hline Radiographic & $\begin{array}{l}\text { Deep penetration; visualization of } \\
\text { density changes }\end{array}$ & $\begin{array}{l}\text { Requires access to both sides of the } \\
\text { concrete being tested; costly; safety } \\
\text { concerns }\end{array}$ \\
\hline Half-Cell Potential & $\begin{array}{l}\text { Quick; simple; qualitative information } \\
\text { on steel rebar risk of corrosion }\end{array}$ & $\begin{array}{l}\text { Relative readings; subjective to data } \\
\text { interpretation; rebar being tested must } \\
\text { be exposed; steel coatings can be } \\
\text { problematic; complicated if saturated } \\
\text { with water }\end{array}$ \\
\hline Polarization Resistance & $\begin{array}{l}\text { Measures instantaneous metal corrosion } \\
\text { rate }\end{array}$ & $\begin{array}{l}\text { Polarized area of metal surface being } \\
\text { tested must be known; requires direct } \\
\text { connection to metal }\end{array}$ \\
\hline Electrical Resistivity & $\begin{array}{l}\text { Indirect measurement of concrete's } \\
\text { porosity and the connectivity of pores; } \\
\text { can be used to detect wet areas in } \\
\text { concrete; measures resistivity }\end{array}$ & $\begin{array}{l}\text { One point method requires direct } \\
\text { connection to rebar }\end{array}$ \\
\hline
\end{tabular}

To perform accurate cross-sectional and 3D reconstruction of PCC in more complex environments, Kirchoff-based migration, most notably SAFT, has been used for locating material degradation and defects under these conditions [27]-[31]. Although the traditional SAFT technique is simple and heuristically formulated, when combined with the use of dry-point contact (DPC) low-frequency $(\sim 50 \mathrm{kHz}) \mathrm{S}$-wave ultrasonic transducers, this technology has been successfully used for evaluation of various concrete infrastructure [32] -[33]. Further generalization using phase information has improved evaluation of reinforcements in bridge decks using ultrasonic pulse-echo data applied along a single axis of symmetry [34].

Extension of the pulse-echo hardware for multiple channel linear array technology provides added redundancy in evaluating PCC aging and defects. This technology, applied with traditional SAFT, qualitatively detects PCC defects at the level of reinforcement [35]. Extending the SAFT reconstruction 
for overlapping virtual arrays allows for detection of PCC degradation below reinforcements [36]. Additionally, the signature analysis method from [19] has been generalized for quantitative PCC flaw and degradation detection using the reconstruction results of ultrasonic linear array signals [37].

A recent study conducted by ORNL and various NDE research teams provides a baseline performance indication of various NDE techniques in evaluating reinforced PCC structures [9]. The study showed that the various methods generally performed well. However, the results of the study also identified that advanced signal processing techniques should be developed to improve the performance of NDE on thick aging concrete structures such as LWRs. The results of this study are summarized here to provide the design needs for the conceptual design of the larger, more heavily reinforced structure presented in this report. For the limited size of the test specimens utilized and the types of internal structure and anomalies existing within each specimen, the state-of-the-art techniques-ground penetrating radar (GPR), air-coupled and semi-coupled ultrasonics, as well as two versions of ultrasonic linear array-perform reasonably well.

Figure 1 shows various sizes of reinforcement embedded in the specimen and the resulting linear ultrasonic array volumetric imaging reconstruction showing the different sizes of reinforcement. The normalized relative reflectivity threshold ranged from 45 on the leftmost and smallest reinforcement, up to 90 on the rightmost and largest reinforcement. These relative reflectivity values are color coded according to a traditional red-green-blue (RGB) color map for visualization, where blue is the lowest reflectivity and red is the highest reflectivity. Lower relative reflectivity threshold values are more sensitive to changes in acoustic impedance but also include more structural noise, whereas higher relative reflectivity threshold values are less sensitive to changes in acoustic impedance but include less structural noise. The size and required threshold values indicate the relative size of the reinforcements. While this type of volumetric imaging has been successful for identifying various attributes of thinner/less heavily reinforced structures, the specimen constructed in this study will better represent conditions of NPP reinforced concrete containment structures.

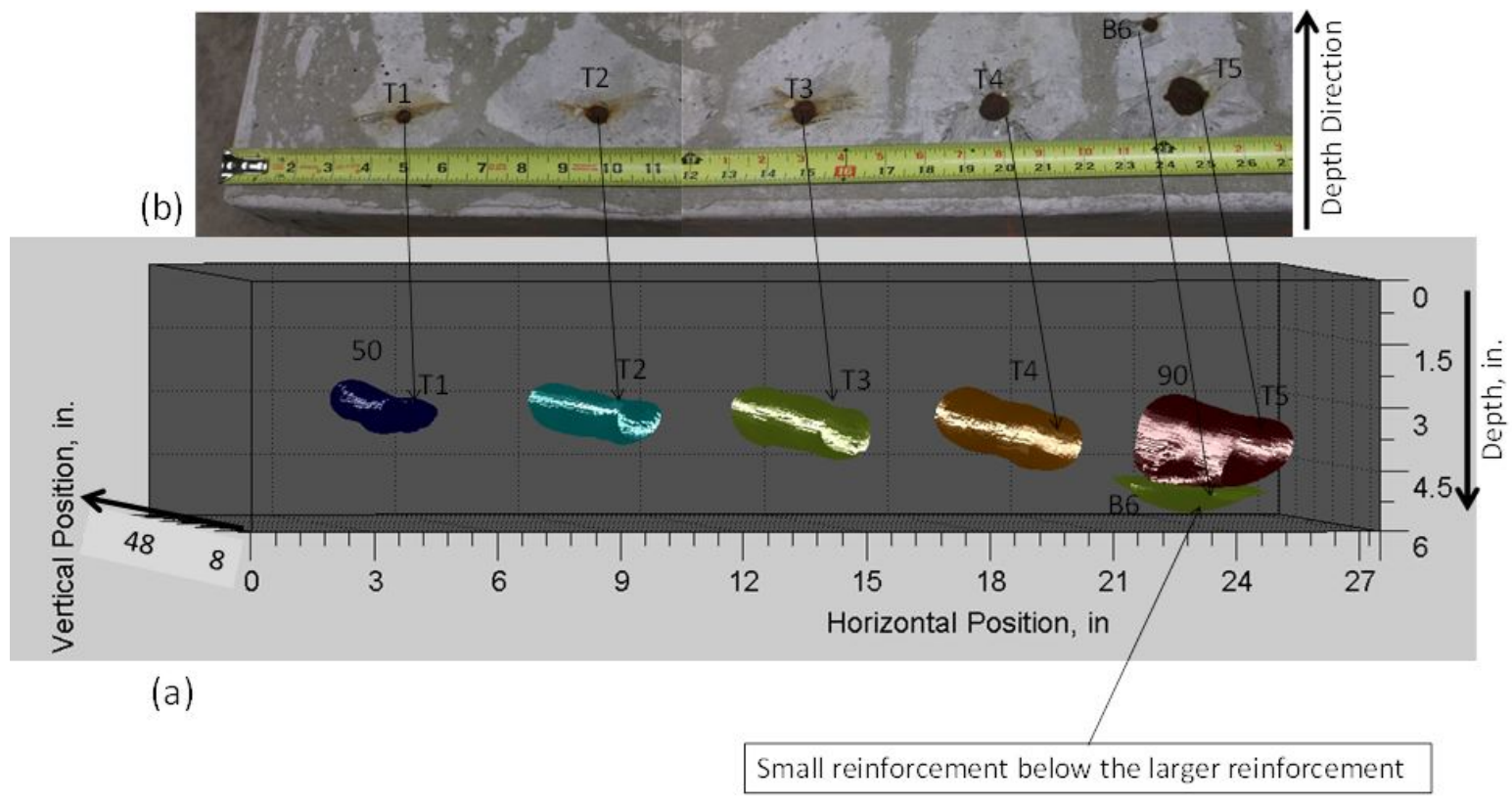

Fig. 1. (a) Volumetric imaging relative reflections in relation to the (b) interface showing the actual reinforcements.

Each technique has limitations, and it remains to be seen how each of these techniques will perform on thick, heavily reinforced concrete structures such as those in commercial NPPs. The specimen constructed in this study with fabricated internal structure and anomalies will provide answers to some of 
those ambiguities through comparative testing. The baseline of performance established in [9] for the different ultrasonic techniques can then be applied and compared to performance on the thick, heavily reinforced specimen. Development of advanced signal processing algorithms may be important to the performance of these techniques when applied to thick, heavily reinforced concrete structures like those in commercial NPPs. The specimen constructed in this report should be critical in directing these developments, especially towards addressing the decreasing signal-to-noise ratio with depth. 


\section{TYPICAL PARAMETERS FOR CONCRETE USED IN NPPS}

\subsection{TYPICAL CONTAINMENT WALL DESIGN}

The concrete structures in NPP are thick in cross section and heavily reinforced with steel. Figure 2 illustrates one type of NPP concrete and steel reinforced containment structure, which has the following specifications [5]:

- Wall thickness: 3 to $4 \mathrm{ft}$

- Dome thickness: $3 \mathrm{ft}$

- Floor thickness: $2 \mathrm{ft}$ if there are rock anchors; if not, $10 \mathrm{ft}$

- Inside diameter: $150 \mathrm{ft}$

- Liner thickness: $1 / 4$ to $3 / 8$ in.

- Height: 150 to $200 \mathrm{ft}$

- Volume: $2.5 \times 10^{6}$ cubic ft

- Liner material: carbon steel

- Containment shape: vertical right cylinder with hemispherical or shallow dome

- Concrete cover over bottom liner: 2 to $3 \mathrm{ft}$

- Reinforcing material: mild steel

o \#18 bars (2.257 in. diameter, 4.00 in. $^{2}$ cross-sectional area)

o \#8 bars (1.000 in. diameter, 0.79 in. $^{2}$ cross-sectional area)

In this typical containment structure, the upper reinforced concrete containment is typically $3.5 \mathrm{ft}$ thick with two layers of \#18 steel reinforcing bars on 12 in. centers vertically and horizontally on each face at a distance of $6 \mathrm{in}$. from each face of a containment structure ranging from 150 to $200 \mathrm{ft}$ tall with a diameter of approximately $150 \mathrm{ft}$. The lower cylindrical walls of the containment are even larger in order to carry the entire dead load, including the upper containment, to the base slab. The walls are at least $4 \mathrm{ft}$ thick with \#18 vertical bars at 12 in. spacing for each face and \#18 horizontal bars on both sides of the vertical reinforcing; the ties are made of \#8 bars. 


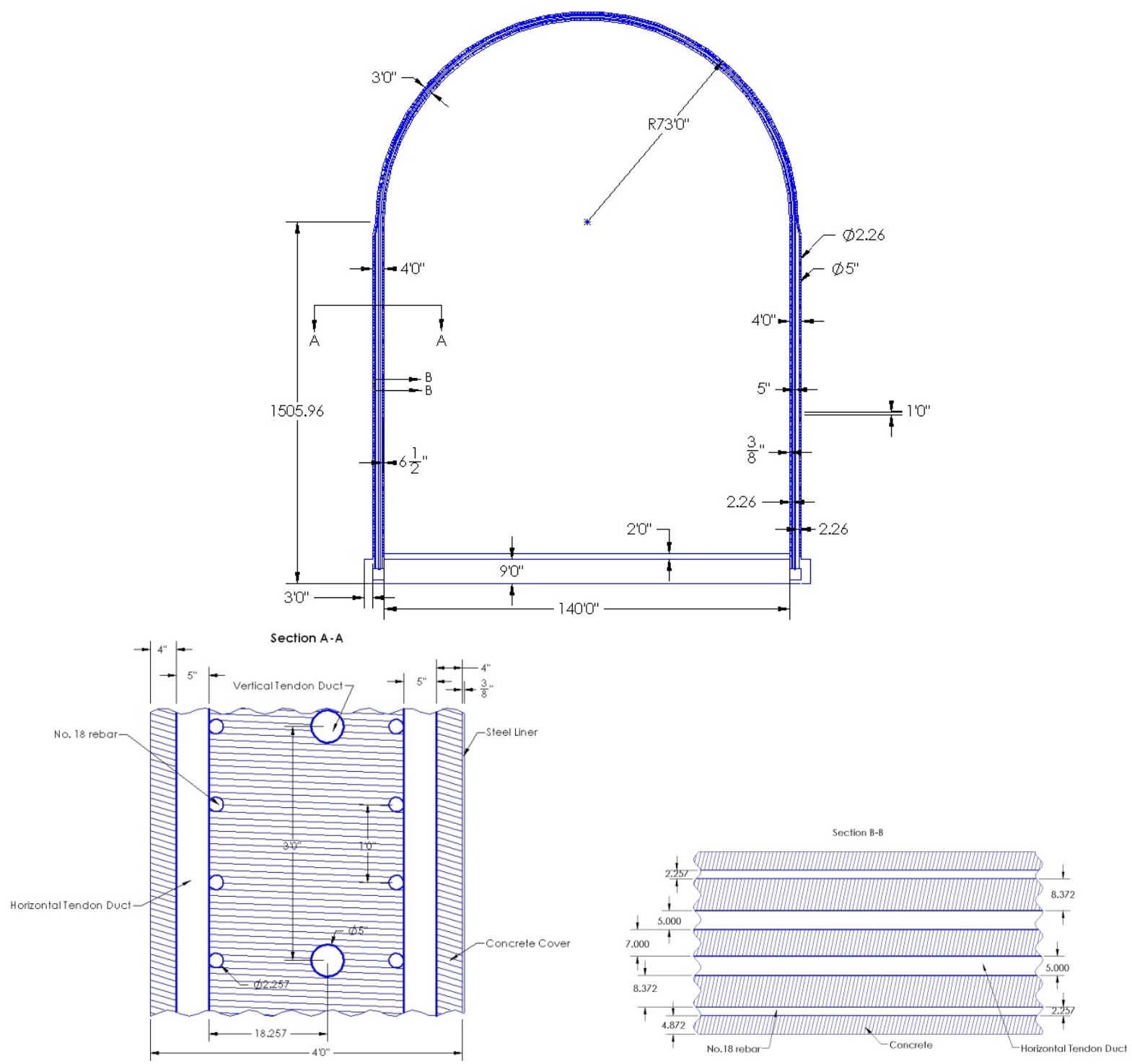

Fig. 2. Example NPP containment structure [4].

\subsection{PREVIOUS CONCRETE FAILURES IN NPP CONTAINMENT STRUCTURES}

Ideally, from an NDE point of view, the NPP specimen should have realistic and known distress. A few representative sections have experienced known distress. Concrete defects observed in power plant containment structures are tabulated by Braverman et al. [38]. It is observed that degradation in the form of cracking, spalling, and general deterioration was commonly observed, and the technique of identification was typically visual inspection. Delamination in the form of stress-corrosion cracks at the level of reinforcements is also generally a concern for the nuclear containment structures [39]-[42].

Figure 3 shows in situ the cross section of the Crystal River Nuclear Plant (CR3) containment structure with tendon ducts and reinforcements where a delamination gap was observed in the vertical plane of the horizontal tendons, approximately $10 \mathrm{in}$. from the outer surface, of the CR3 containment wall [39]. One form of subsurface defect (delamination at the level of tendon ducts) that is possible for this type of containment structure can be observed in Fig. 3. 


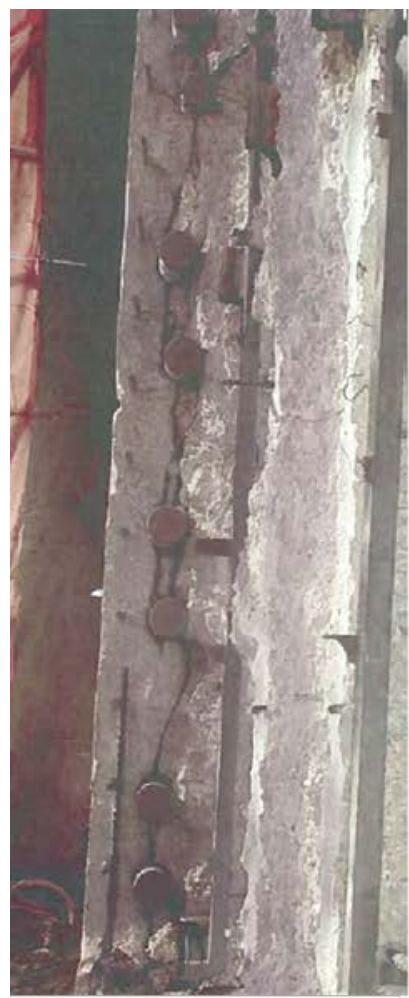

[A]

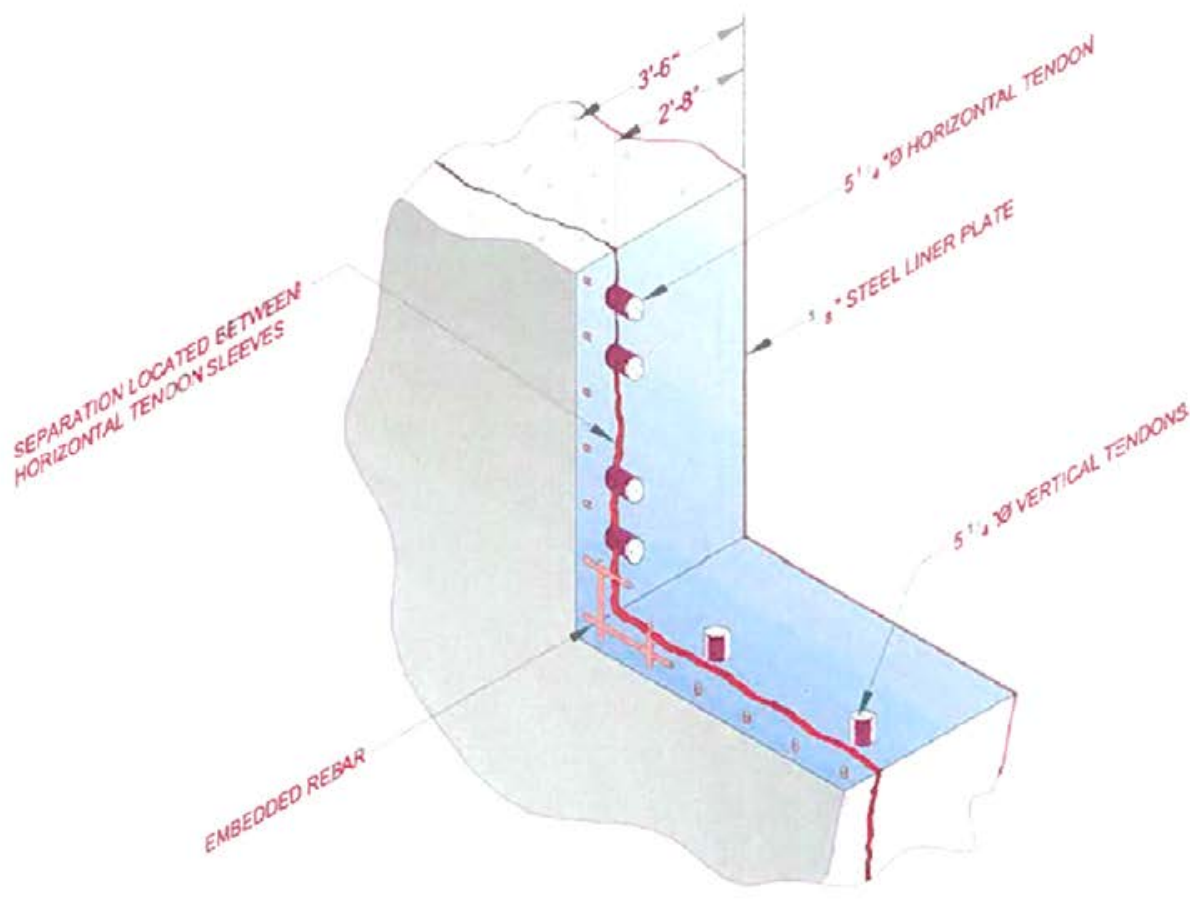

$[B]$

Fig. 3. Delamination crack running from horizontal tendons at approximately 10 in. deep; [A] photograph and [B] sketch [39].

Figure 4 shows the Davis-Besse Nuclear Power Station [43]. Figure 5 shows the general layout of the structure with reinforcements. Figure 6 shows example laminar subsurface cracking at the depth of the reinforcement. This interface was visible due to hydro demolition to create an opening in the shield building, and the crack width is possibly larger than the delaminated condition prior to the cutting. Core bore samples, such as that shown in Fig. 7, show the crack condition unaffected by the hydro demolition process. 


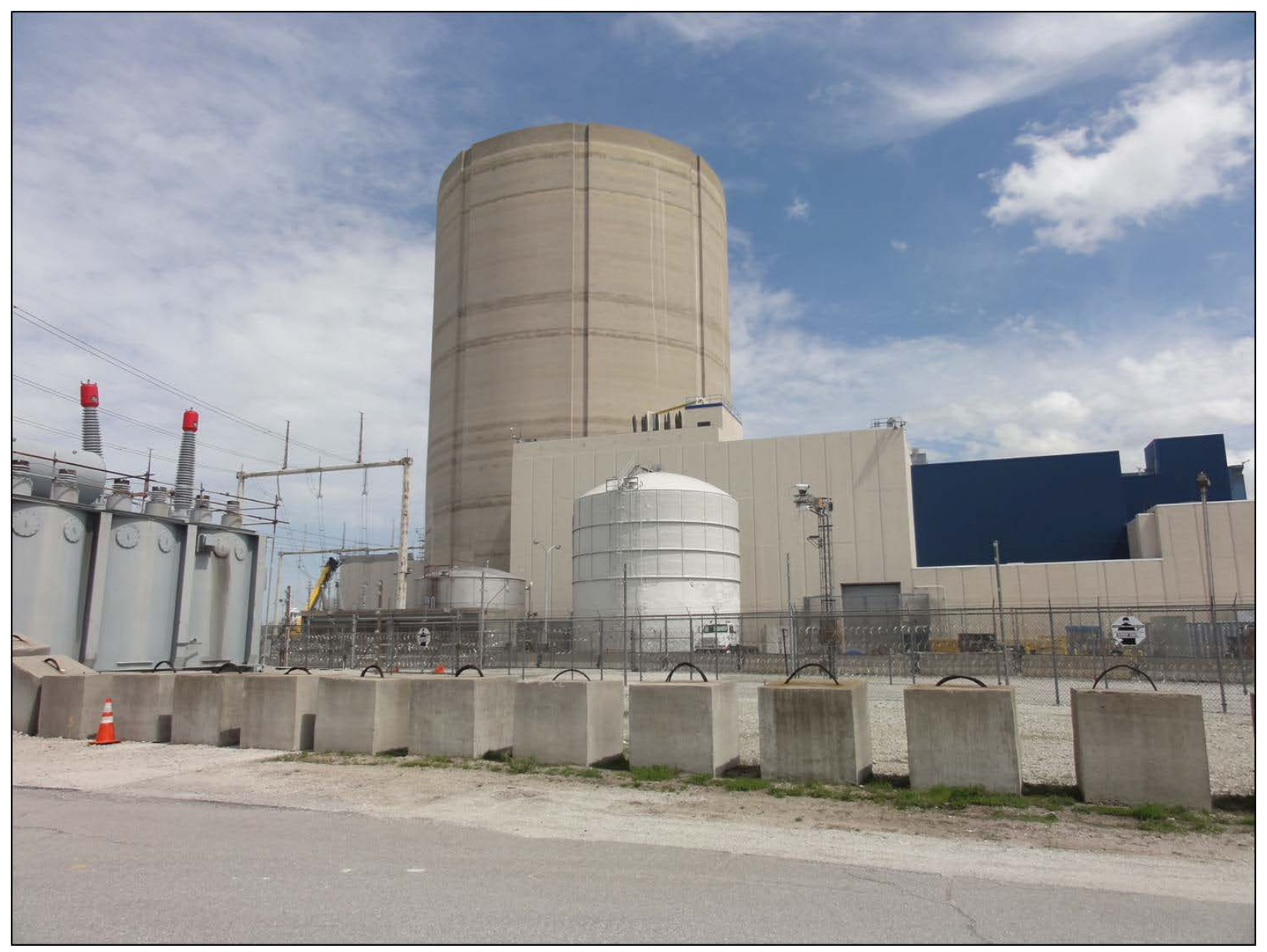

Fig. 4. Davis-Besse Nuclear Power Station [43].

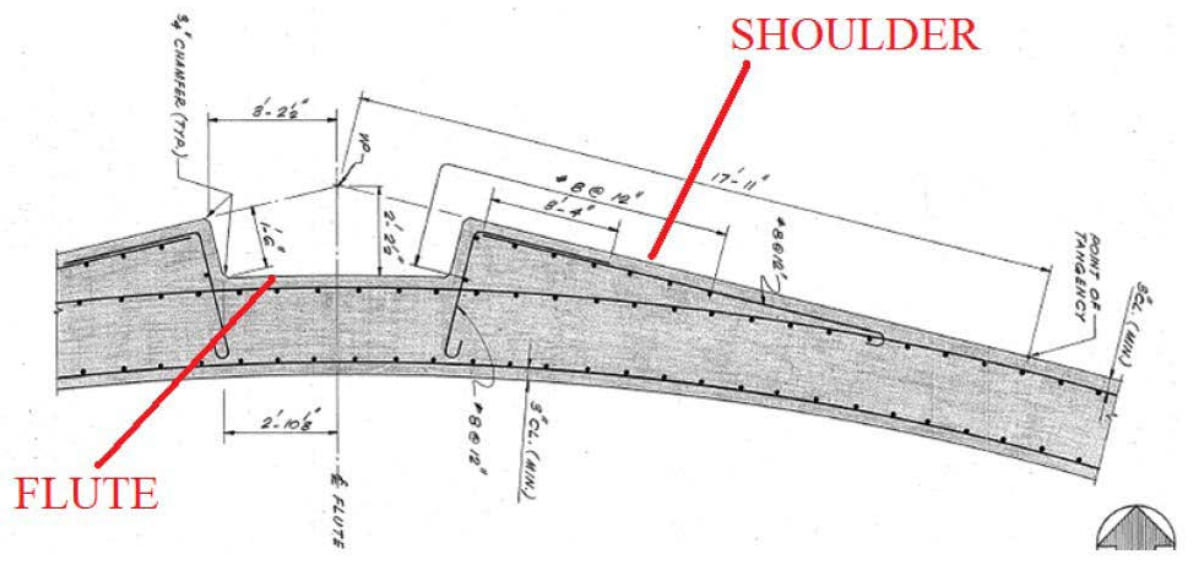

Fig. 5. View of the Davis-Besse Nuclear Power Station layout and reinforcement scheme [43]. 


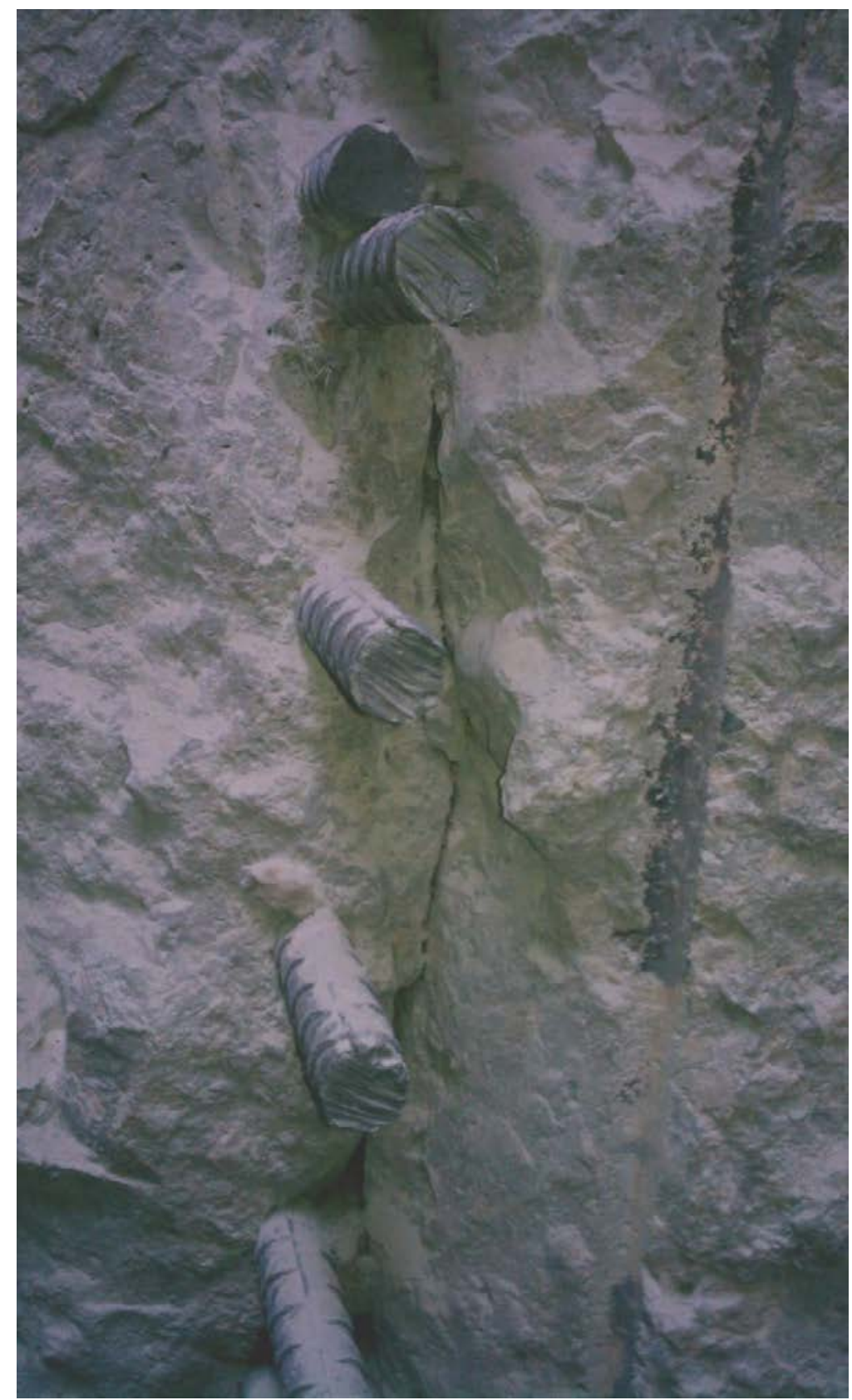

Fig. 6. Laminar cracking at reinforcements from an interface cut out by hydrodemolition [43]. 


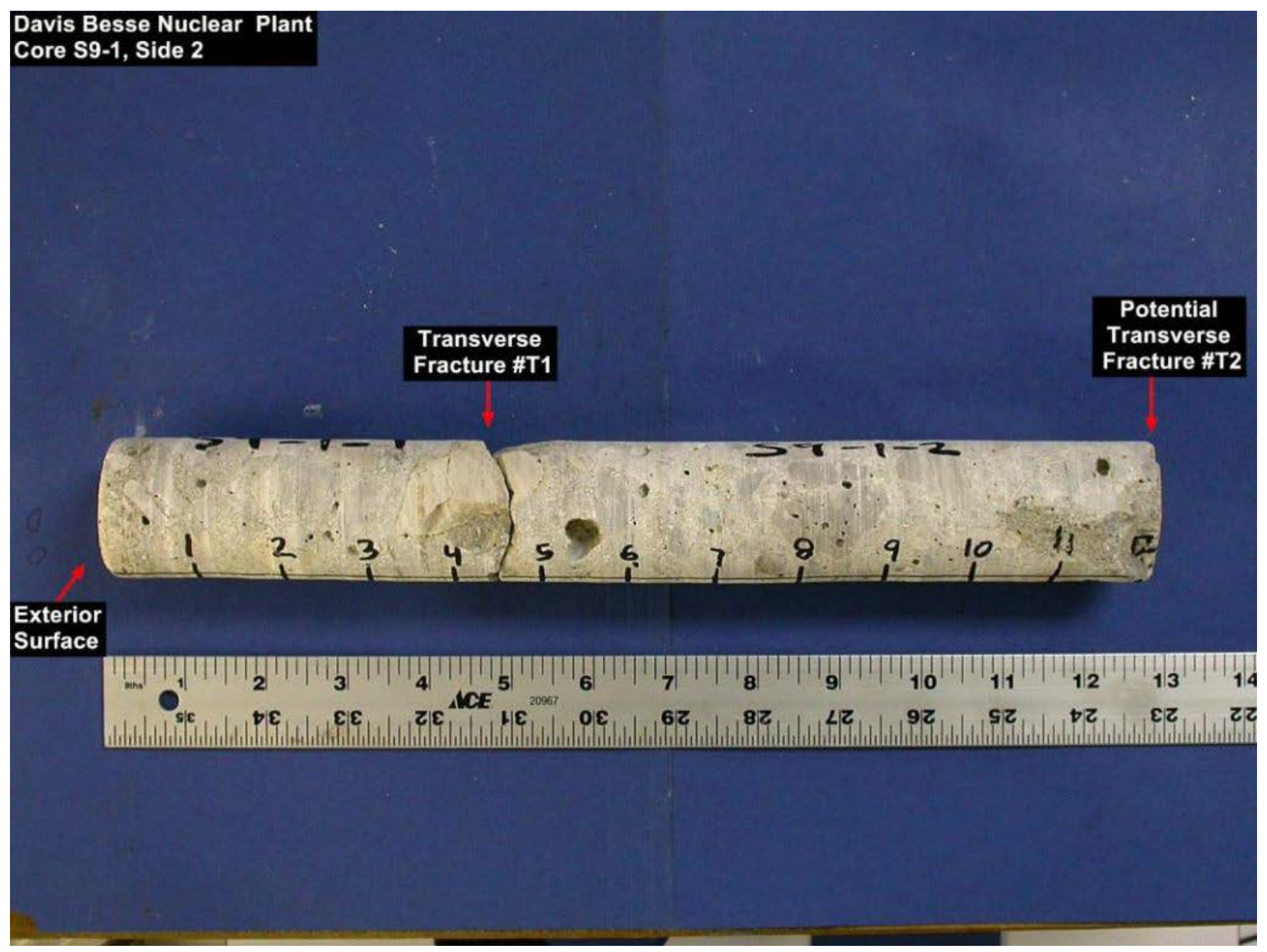

Fig. 7. Laminar cracking at a core location [43].

However, as detailed in ORNL/TM-2013/223 [4] and discussed in the "Need for Suitable Concrete Specimens" section, there are problems associated with use of in-service specimens for validation of NDE methods. The acquisition of such samples can be prohibitive due to the costs of transporting such a large concrete structure, lack of on-site access for research teams to collect data for comparative testing, lack of an ability to verify internal characteristics, and, in some cases, problems with transfer of ownership for a potentially radioactive specimen [3]-[4]. This leads to the lack of readily available samples of thick and heavily reinforced concrete for performing NDE, research, and training. 


\section{SPECIMENS WITH DEFECTS APPLICABLE FOR COMPARATIVE NDE}

To determine what concrete specimens are suitable and available in the United States for NDE of NPP concrete, ORNL utilized its contacts established through the LWRS Concrete NDE Workshop conducted in August 2013 [3].

\subsection{CONTAINMENT STRUCTURE CONCRETE SAMPLES}

Wesdyne Corporation is working with Westinghouse in certifying the AP1000 containment, which is a nontraditional, sectional, steel and concrete containment structure as shown in Fig. 8 [3].

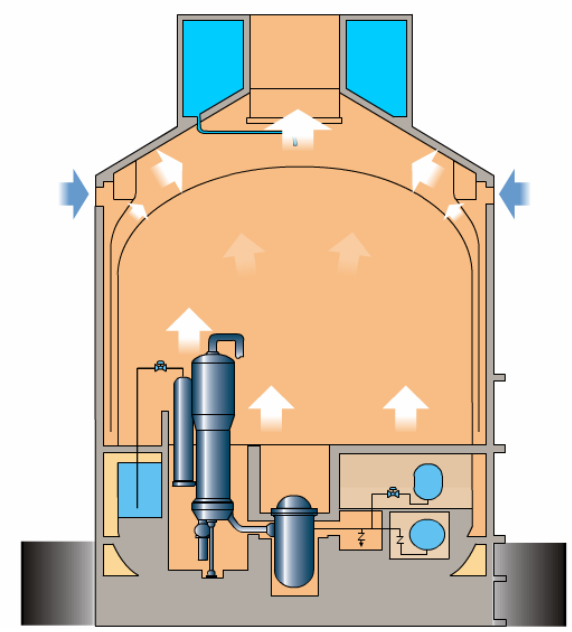

Fig. 8. Westinghouse AP1000 Shield Building [3].

The Westinghouse Shield Building was constructed of $30 \mathrm{ft} \times 30 \mathrm{ft}$ sections of preassembled steel forms. These steel forms have 1-in.-thick steel inner and outer walls separated by $3 \mathrm{ft}$ of space that will be filled with concrete. The inner and outer steel walls are connected by steel struts, and partial length concrete anchors are attached to both the inner and outer steel walls. These preassembled steel forms are welded together, forming the shield building. Concrete is then continuously poured into the $3 \mathrm{ft}$ space to provide rigidity, shielding, and impact (airplane) protection.

Initially, WesDyne fabricated a $3 \mathrm{ft}$ wide $\times 3 \mathrm{ft}$ deep $\times 10 \mathrm{ft}$ long concrete specimen to use for NDE. This specimen is shown in Fig. 9 and Fig. 10. The 1-in.-thick inner and outer steel walls, along with the steel cross struts and partial length concrete anchors, can be seen in Fig. 9. Figure 10 illustrates the specimen after all the concrete was poured. WesDyne evaluated the ultrasonic and impulse-echo NDE techniques using this specimen and found that the physical dimensions limit the testing being performed. Presumably, the limitations involved difficulties accounting for the boundary effects described in the previous sections. Therefore, the decision was made to fabricate a full $30 \mathrm{ft} \times 30 \mathrm{ft}$ shield building section. 


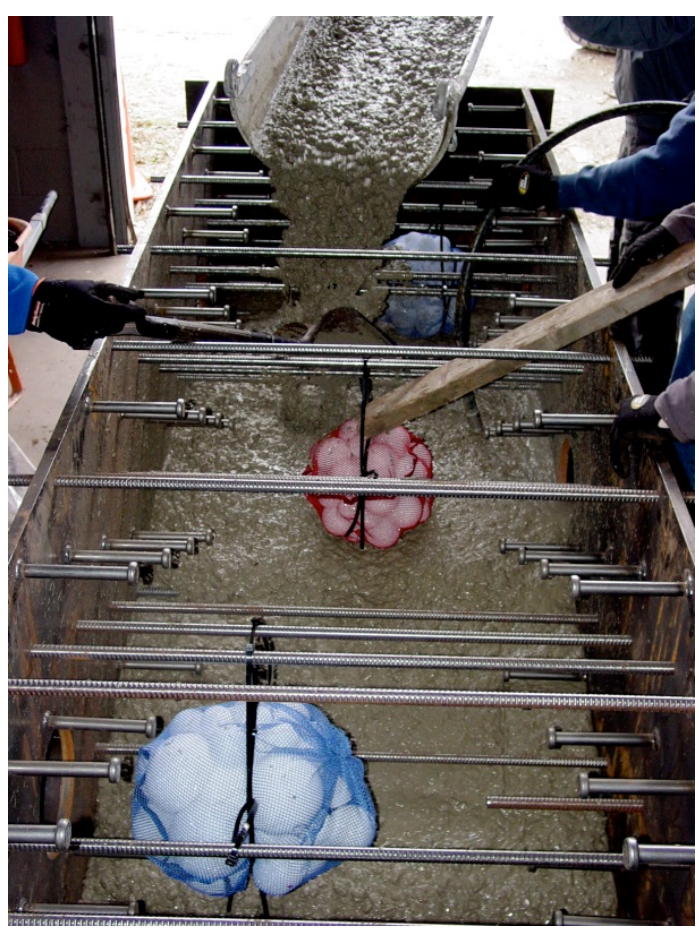

Fig. 9. WesDyne $3 \mathrm{ft} \times 3 \mathrm{ft} \times 10 \mathrm{ft}$ samples showing void simulators [3].

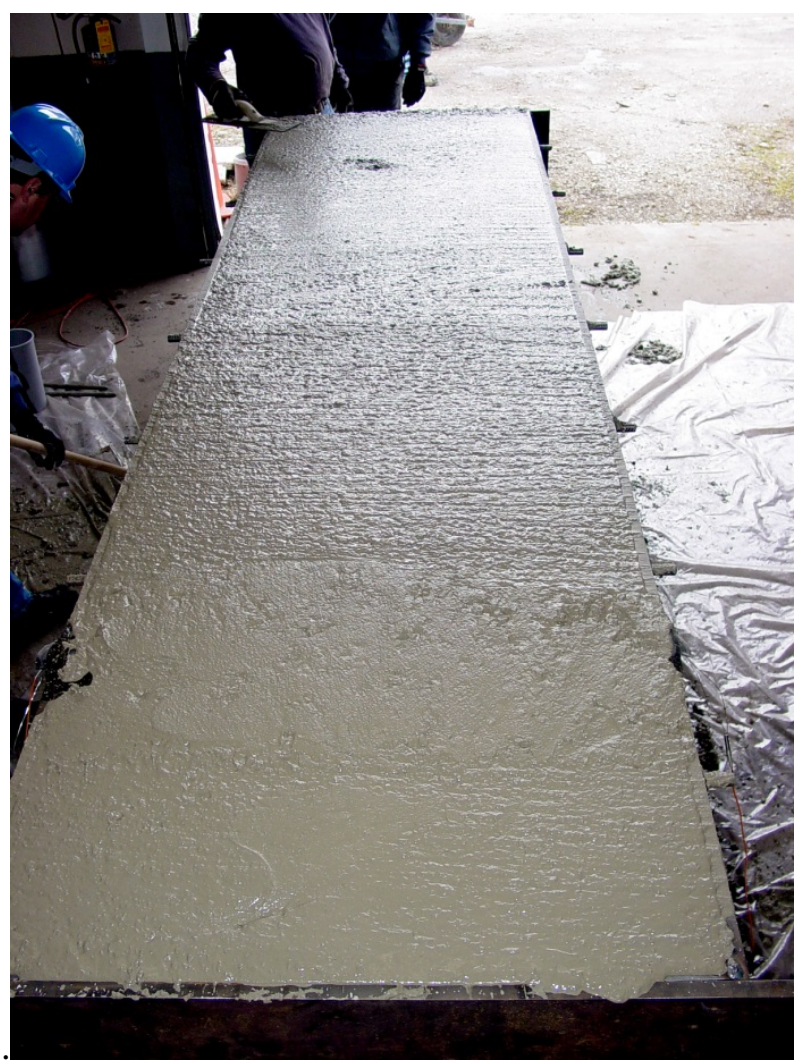

Fig. 10. WesDyne concrete specimen after all concrete poured [3]. 
The WesDyne single $30 \mathrm{ft} \times 30 \mathrm{ft}$ shield building section for NDE is shown in Fig. 11 and Fig. 12 . Shrinkage of the poured concrete away from the inner and outer steel walls during curing of the concrete is of concern because any air gap will prohibit nondestructive inspection of the concrete from the external steel faces of the walls. In this section, WesDyne again tied plastic mesh bags containing foam balls to a limited number of specific steel cross struts before the concrete was poured to simulate voids within the concrete.

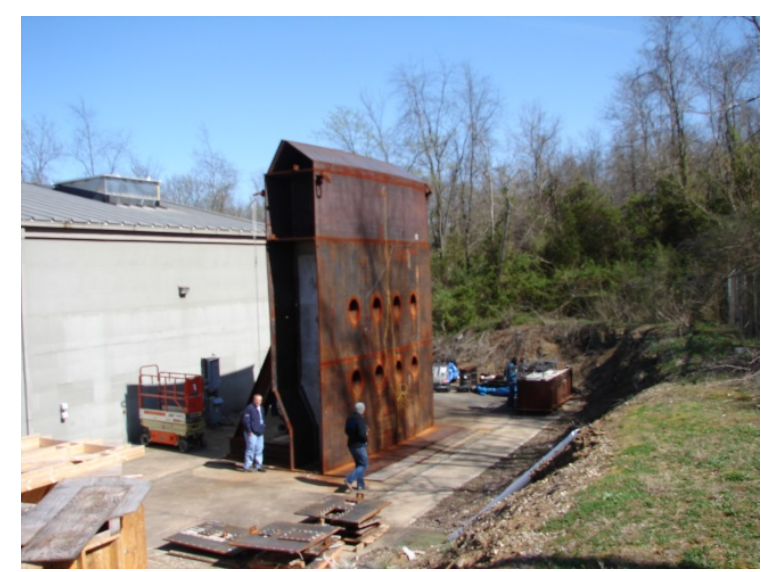

Fig. 11. WesDyne Westinghouse AP1000 shield building NDE evaluation section [3].

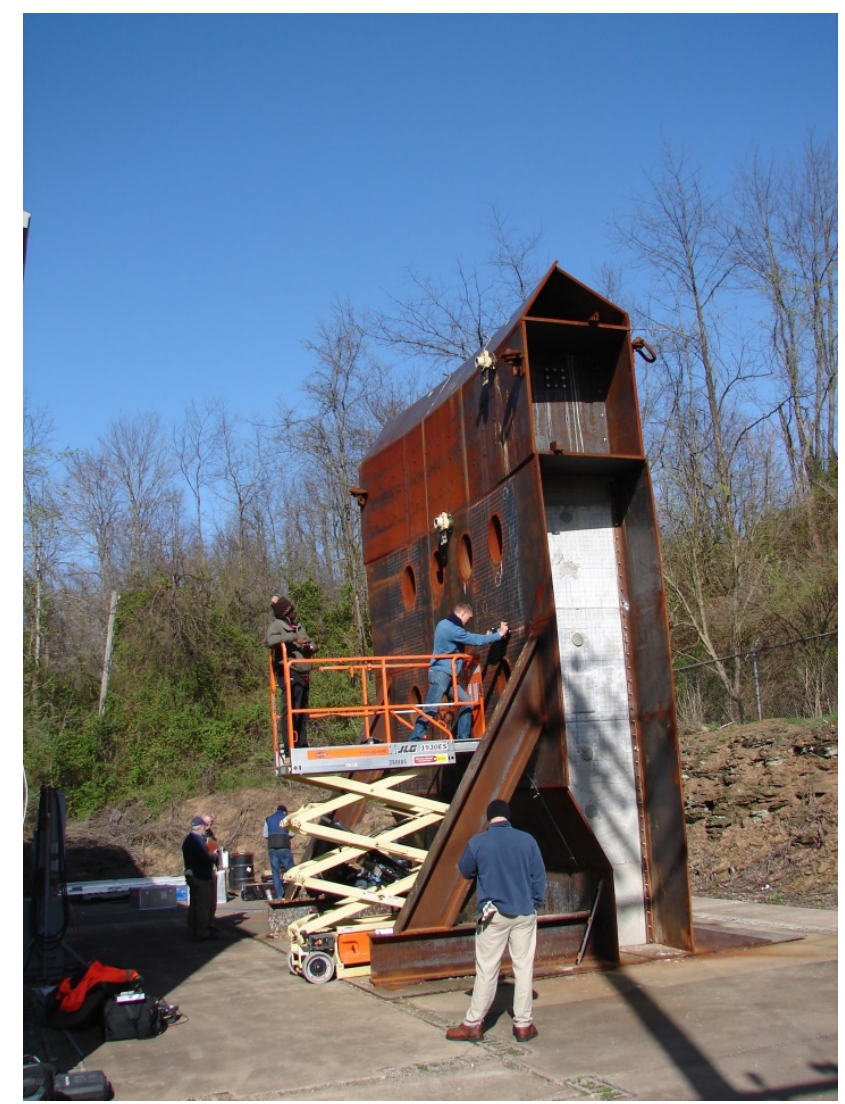

Fig. 12. NDE evaluations being performed on AP1000 shield building section [3]. 
The shield building section that WesDyne fabricated is the very top section of the Shield Building, which contains the cooling ducts that cool the reactor in case of emergency. They chose to fabricate this section because of the interference that the cooling ducts have on the flow of concrete into the section. All of the sections of the Shield Building below this section were of reduced thickness [3]. WesDyne evaluated the ultrasonic and impact-echo methods of the NDE inspection on this fabricated section, and they were able to detect the formed-in void simulations. However, there was also shrinkage of the concrete away from the steel inner and outer walls, which was problematic for nondestructive inspection at those locations where shrinkage occurred.

These types of concrete samples are useful for NDE testing, technology evaluation, and technician training, but the WesDyne sample was scheduled for demolition in 2013. Additionally, while the $3 \mathrm{ft} \times$ $3 \mathrm{ft} \times 10 \mathrm{ft}$ specimen could be shipped by truck, the $30 \mathrm{ft} \times 30 \mathrm{ft}$ AP1000 shield building section would be impractical to ship by any means and would have to be used at its current location at WesDyne's Watts' Mill Service Center in Pittsburg, Pennsylvania. While both of these samples are typical of AP1000 Shield Building construction, they are not typical of earlier nuclear power reactor shield building construction, and the void simulators were not in line with the desired defect simulators in this report.

\subsection{INFRASTRUCTURE CONCRETE SAMPLES WITH NPP CONTAINMENT REPRESENTATIVE DEFECTS}

The industry typically performing NDE on concrete structures is the bridge and roadway industry. While bridge and roadway structures are thinner and typically contain less steel reinforcement, they provide a good base of NDE research with which to support their field NDE programs to detect, identify, and repair concrete failures. A summary of concrete structures in this discipline specifically designed for the purposes of NDE validation is given here.

\subsubsection{Federal Institute for Materials Research and Testing (BAM) in Berlin, Germany}

In 2002, a Large Concrete Slab (LCS) was designed and constructed at the Federal Institute for Materials Research and Testing (BAM) in Berlin, Germany [18]. BAM has accomplished major achievements in research and development in regards to NDE of concrete structures [3]. There is a great variety of mostly artificial but also field-removed test blocks addressing various testing problems. Other large-scale test blocks are located at their secondary test site in Horstwalde, outside of Berlin. Practical experience in NDE for more than ten years and urgent research topics from investigations and applications defined the construction of the LCS. The concrete slab has an area of $10 \times 4 \mathrm{~m}^{2}$ with a regular thickness of $30 \mathrm{~cm}$. The large dimensions of the specimen are necessary to minimize boundary effects on the measured signals and to establish well-defined defects with varying properties [18].

The concrete slab is partitioned in two sections, with one section containing tendon ducts of different diameters and grouting defects along the prestressing steel and the other section providing areas with varying thickness and voids. Auxiliary elements like thermo-elements, water inlet, and reinforcement mats are implemented to allow for a detailed testing. The thickness of the slab was also varied in geometry and dimension along with the following parameters:

- Reduced slab thickness from $30 \mathrm{~cm}$ to $25 \mathrm{~cm}$ and $20 \mathrm{~cm}$

- Variation of the geometry

- Slant backside from $30 \mathrm{~cm}$ down to $15 \mathrm{~cm}$

- Roughness of the backside surface

- Variation of the slab thickness

- Compaction fault/honeycombing simulation

- Grouting faults in tendon ducts

BAM was the testing site for another reinforced concrete specimen with embedded defects for NDE purposes in the form of a standing wall [15]. Polystyrene cuboids were embedded to simulate voids and 
compaction faults in concrete. It should be noted that some of the Polystyrene bodies tilted orientation during construction due to buoying upwards during concreting. The specimen constructed in this report accounted for this difficulty through the use of tie wires to the reinforcement in most cases, and in two cases manually pushing down the specimens during construction so any movement from the desired position could be limited.

\subsubsection{NDE Specimens from Journal Publications}

Various test blocks have also been constructed for evaluation of impact echo [12]-[14]. In addition to various grouting, delamination, and other defects, Popovics et al. simulated internal voids by embedding 300- and 100-mm-diameter soft foam blocks. The foam blocks were secured to the wire mesh with tie wire [14]. Asano et al. fabricated approximately 8 in. concrete slab specimens with disk-shaped artificial defects (styrene, $0.5 \mathrm{~cm}$ thickness) [13]. The concrete size was chosen to be large enough to not be affected by elastic wave reflection from the sides. The diameters of artificial defects were 5, 10, 15, 20, 30 , and $50 \mathrm{~cm}$ with depths of 3, 5, 7, and $10 \mathrm{~cm}$ from the surface. Yehia et al. created a sample for detection of concrete bridge deck defects using various NDE techniques [11]. This included void simulation using PVC pipes that ran through the specimen and were pulled out to leave a void behind. Crack simulation was conducted by embedding Plexiglas of different lengths and thicknesses.

\subsubsection{Federal Highway Administration NDE Validation Center at the Turner-Fairbank Highway Research Center}

The Federal Highway Administration (FHWA) NDE Validation Center is tasked with validating commercial concrete NDE systems for use by state inspectors on highway structures. Their tasking was established by the National Bridge Inspection Program through the Federal Highway Act of 1968, which required states to periodically inventory and inspect all highway structures on the federal aid system. Since then, Congress has expanded this inspection program to include all structures on public roads, including those not on the federal aid system. This mandate by Congress is the reason states have their massive inspection, rating, and inventory programs [44]. While visual inspection has been the principal technique for inspecting bridges, a number of NDE technologies such as infrared thermographic imaging, ground penetrating radar (GPR) imaging, laser-radar scanning, acoustic emission monitors, electromagnetic acoustic transducers, embedded corrosion microsensors, and vibrometers are also being used. The NDE Validation Center was established by the FHWA in 1996 and is the only center in the world dedicated entirely to the evaluation and validation of NDE technologies for highway structures.

In August 2008, a tractor trailer fatally crashed through a bridge barrier on the William Preston Lane, Jr. Memorial Bridge in Maryland after a section of the bridge barrier was dislodged by the impact. Investigations of this incident revealed significant corrosion of the anchor bolts, which attached the bridge railing to the bridge deck. However, this corrosion was not visible during inspections before the accident. As a result, the FHWA NDE Validation Center has been investigating the feasibility of using four NDE technologies - GPR, ultrasonic pulse-echo, digital radiography, and infrared thermal imaging - to develop bridge inspection methods to augment visual inspections. To this end, the Center procured five specimens from Smith-Midland, a cast concrete products manufacturer in Midland, Virginia, as shown in A- 3. 
A- 3. FHWA NDE Validation Center specimens

\begin{tabular}{|c|l|l|}
\hline Specimen & \multicolumn{1}{|c|}{ Description } & \multicolumn{1}{c|}{ Defect } \\
\hline 1 & F-shaped free-standing portable & Simulated corrosion \\
\hline 2 & F-shaped bolt down & Simulated corrosion \\
\hline 3 & F-shaped free-standing portable & Embedded voids \\
\hline 4 & F-shaped bolt-down & Embedded voids \\
\hline 5 & Bridge deck slab & Embedded voids \\
\hline
\end{tabular}

\subsubsection{Specimen 1 - F-Shaped Free-Standing Portable with Simulated Corrosion}

Figure 13 shows the dimensions of Specimen 1, an F-shaped free-standing portable barrier that is $12 \mathrm{ft}$ long and $2 \mathrm{ft} 8 \mathrm{in}$. high. This custom fabricated barrier has three specially prepared \#5 rebars through the middle of the barrier as well as wire mesh attached to the rebars. The $12 \mathrm{ft}$ length of the barrier was segmented into six $2 \mathrm{ft}$ sections as shown in the figure. Over each $2 \mathrm{ft}$ section of rebar, the diameter was machined to simulate different levels of corrosion as identified in A- 4 and shown in Fig. 14.

\section{A- 4. Corrosion simulation for each barrier section} for Specimens 1 and 2

\begin{tabular}{|c|l|}
\hline $\begin{array}{c}\text { Section } \\
\text { identification }\end{array}$ & \multicolumn{1}{c|}{ Corrosion simulation } \\
\hline $\mathrm{a}$ & No corrosion \\
\hline $\mathrm{b}$ & Mild corrosion \\
\hline $\mathrm{c}$ & $5 \%$ diameter reduction \\
\hline $\mathrm{d}$ & $10 \%$ diameter reduction \\
\hline $\mathrm{e}$ & $25 \%$ diameter reduction \\
\hline $\mathrm{f}$ & $50 \%$ diameter Reduction \\
\hline
\end{tabular}

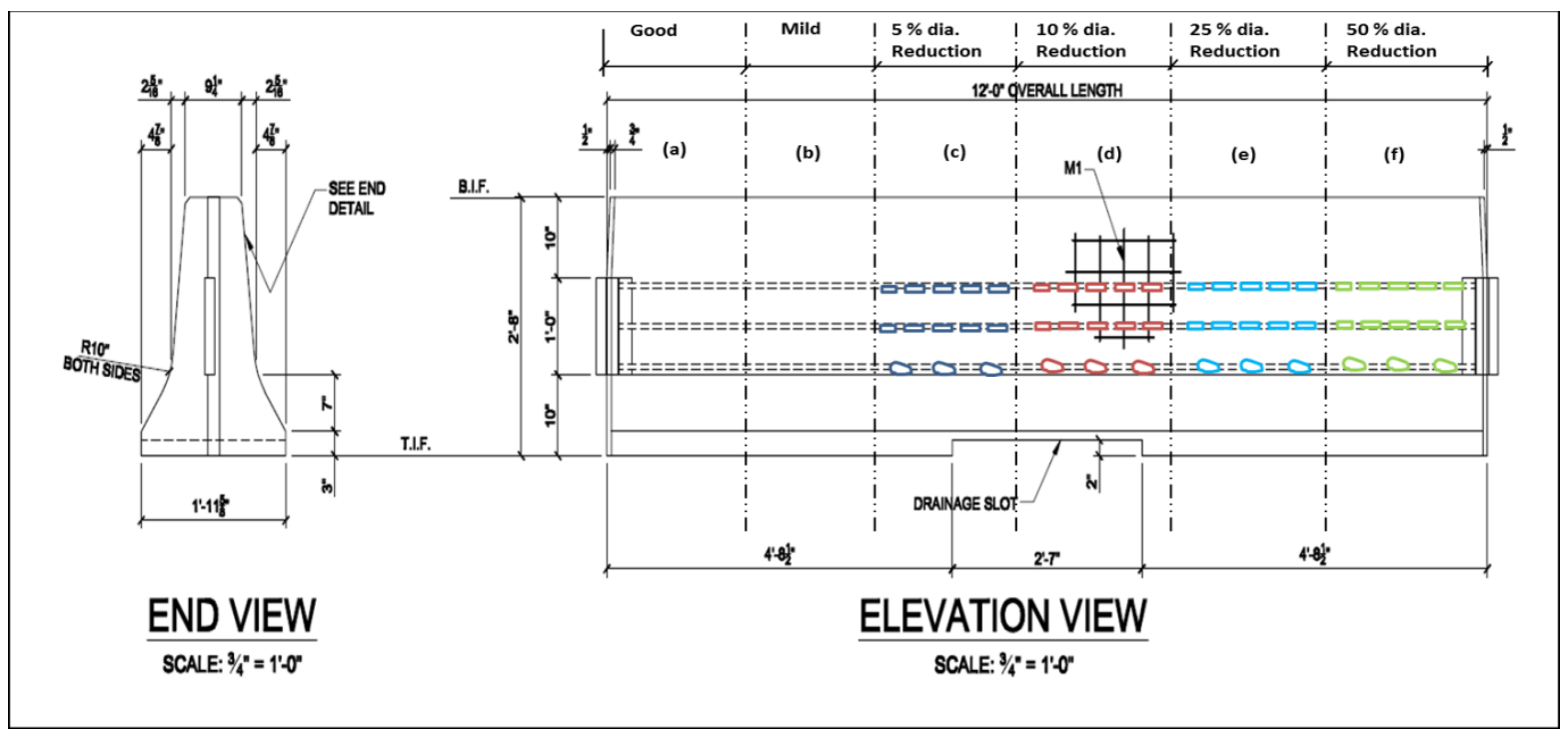

Fig. 13. F-shaped free-standing portable barrier. 

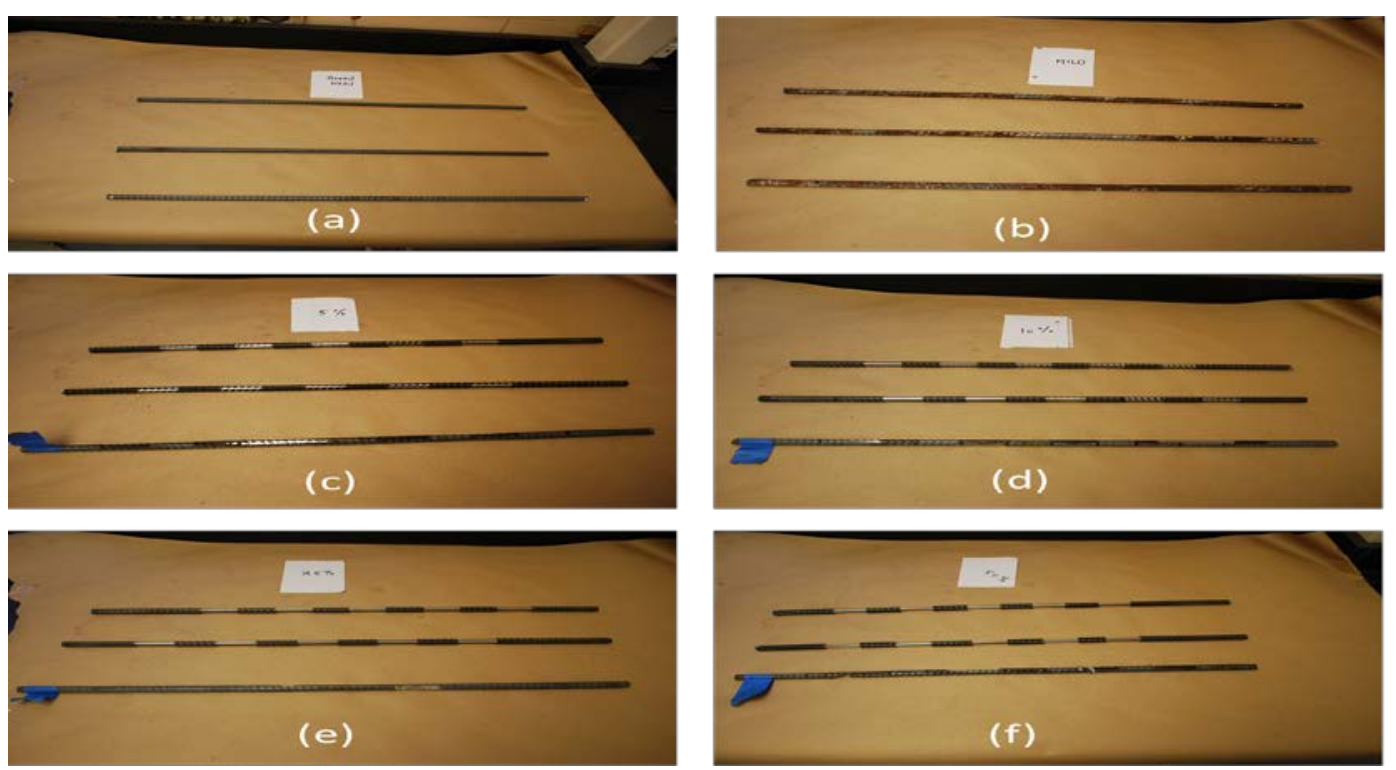

Fig. 14. Different levels of simulated corroded.

\subsubsection{Specimen 2 - F-Shaped Bolt Down with Simulated Corrosion}

Figure 15 shows the dimensions of Specimen 2, an F-shaped bolt down barrier that is $12 \mathrm{ft}$ long and $2 \mathrm{ft} 8 \mathrm{in}$. high. This custom fabricated barrier has three specially prepared \#4 rebars through the middle of the barrier and twelve U-shaped \#5 rebars placed every foot as shown in the end view of Fig. 15. Photos of the U-shaped rebars are shown in Fig. 16 and Fig. 17. The $12 \mathrm{ft}$ length of the barrier was segmented into six $2 \mathrm{ft}$ sections as shown in the figure. All \#4 rebars were full diameter, but varying amounts of the diameter of the U-shaped rebars were machined to simulate different levels of corrosion as identified in Table 2.

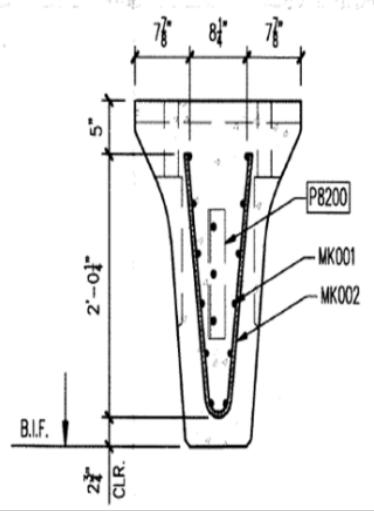

END VIEW

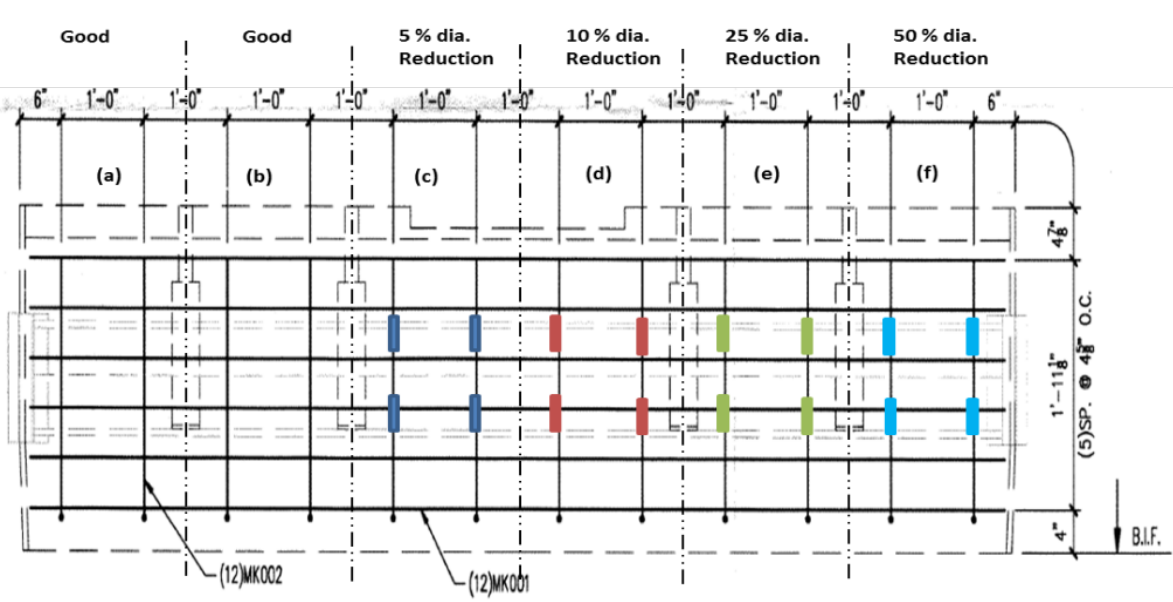

ELEVATION VIEW

Fig. 15. Dimensions of the F-shaped bolt-down barrier with different levels of simulated corrosion. 

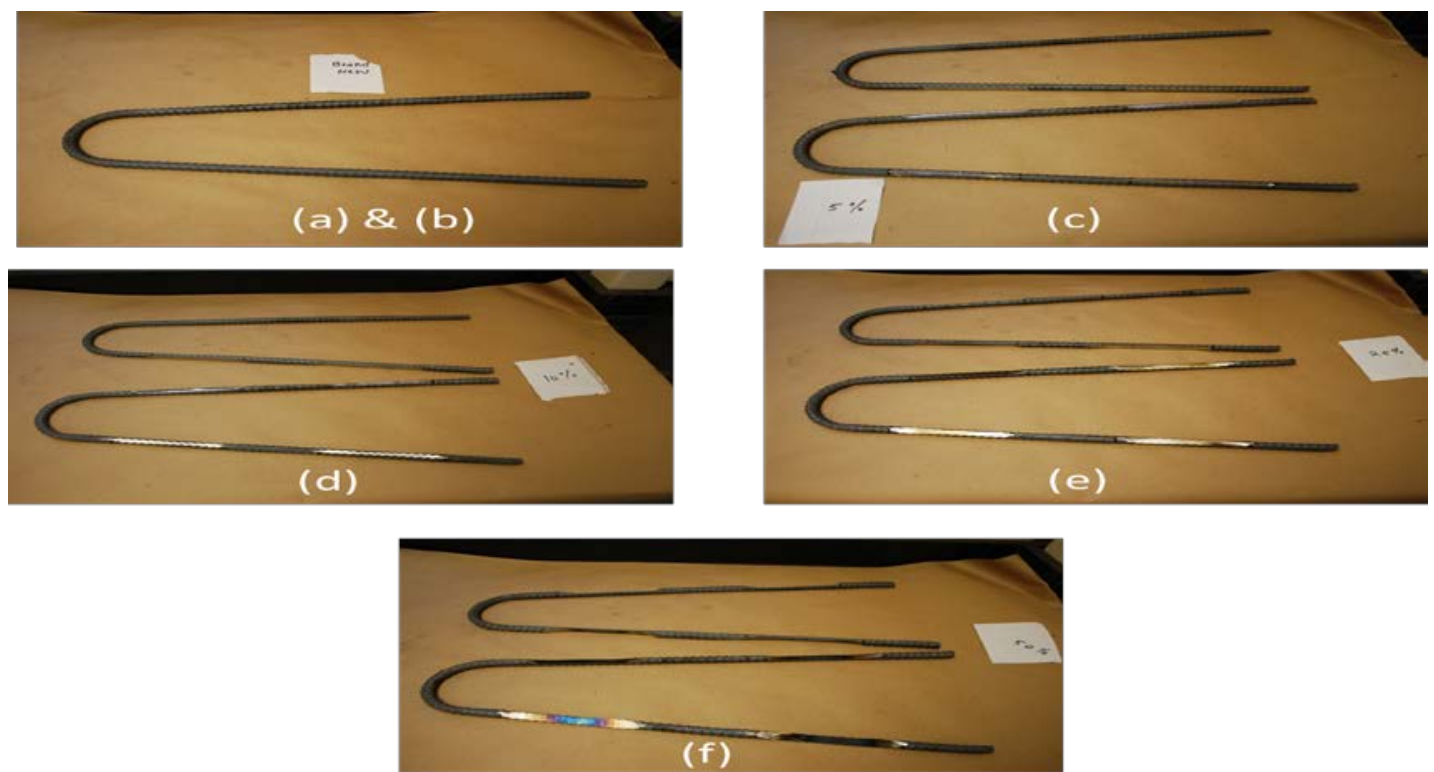

Fig. 16. Different levels of simulated corroded U-shaped rebar.

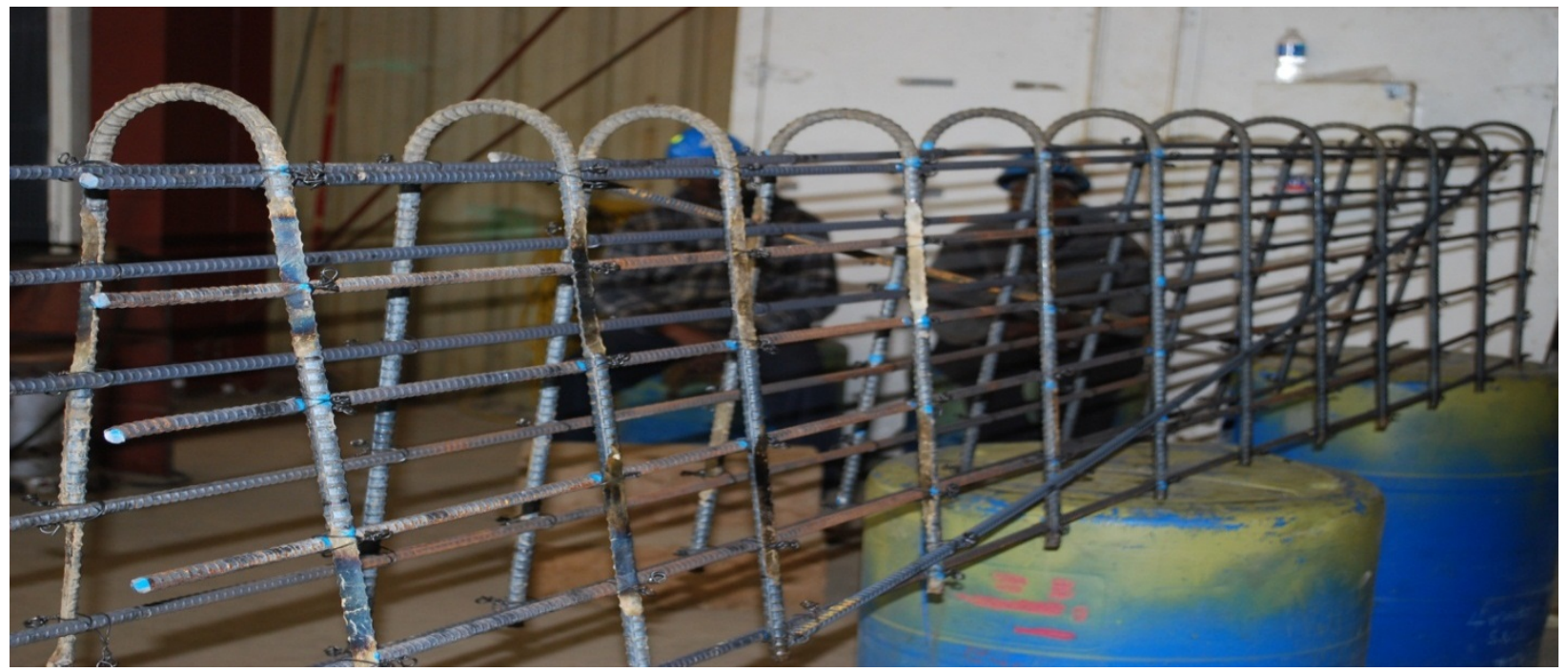

Fig. 17. F-shaped bolt-down barrier fabrication with simulated corrosion.

\subsubsection{Specimen 3 - F-Shaped Free-Standing Portable with Embedded Voids}

Figure 18 shows the dimensions of Specimen 3, an F-shaped free-standing portable barrier that is $12 \mathrm{ft}$ long and $2 \mathrm{ft} 8 \mathrm{in}$. high. This custom fabricated barrier has three specially prepared \#5 rebars through the middle of the barrier as well as wire mesh attached to the rebars. The $12 \mathrm{ft}$ length of the barrier was segmented into six $2 \mathrm{ft}$ sections as shown in Fig. 17. Over each $2 \mathrm{ft}$ section of rebar, hollow balls, loose gravel, and foam of different shapes and sizes were attached to the wire mesh to simulate voids, segregation, and delamination of different shapes and sizes, respectively, as identified in A- 5. A photo of F-shaped freestanding portable barrier fabrication is shown in Fig. 18. 
A- 5. Defect simulation for each barrier section

for Specimens 3 and 4

\begin{tabular}{|c|l|}
\hline $\begin{array}{c}\text { Section } \\
\text { identification }\end{array}$ & \multicolumn{1}{c|}{ Defect simulation } \\
\hline $\mathrm{a}$ & Control \\
\hline $\mathrm{b}$ & Hollow balls to simulate voids \\
\hline $\mathrm{c}$ & Foam to simulate voids \\
\hline $\mathrm{d}$ & Foam to simulate delamination \\
\hline $\mathrm{e}$ & Foam balls to simulate voids \\
\hline $\mathrm{f}$ & Gravel to simulate segregation \\
\hline
\end{tabular}

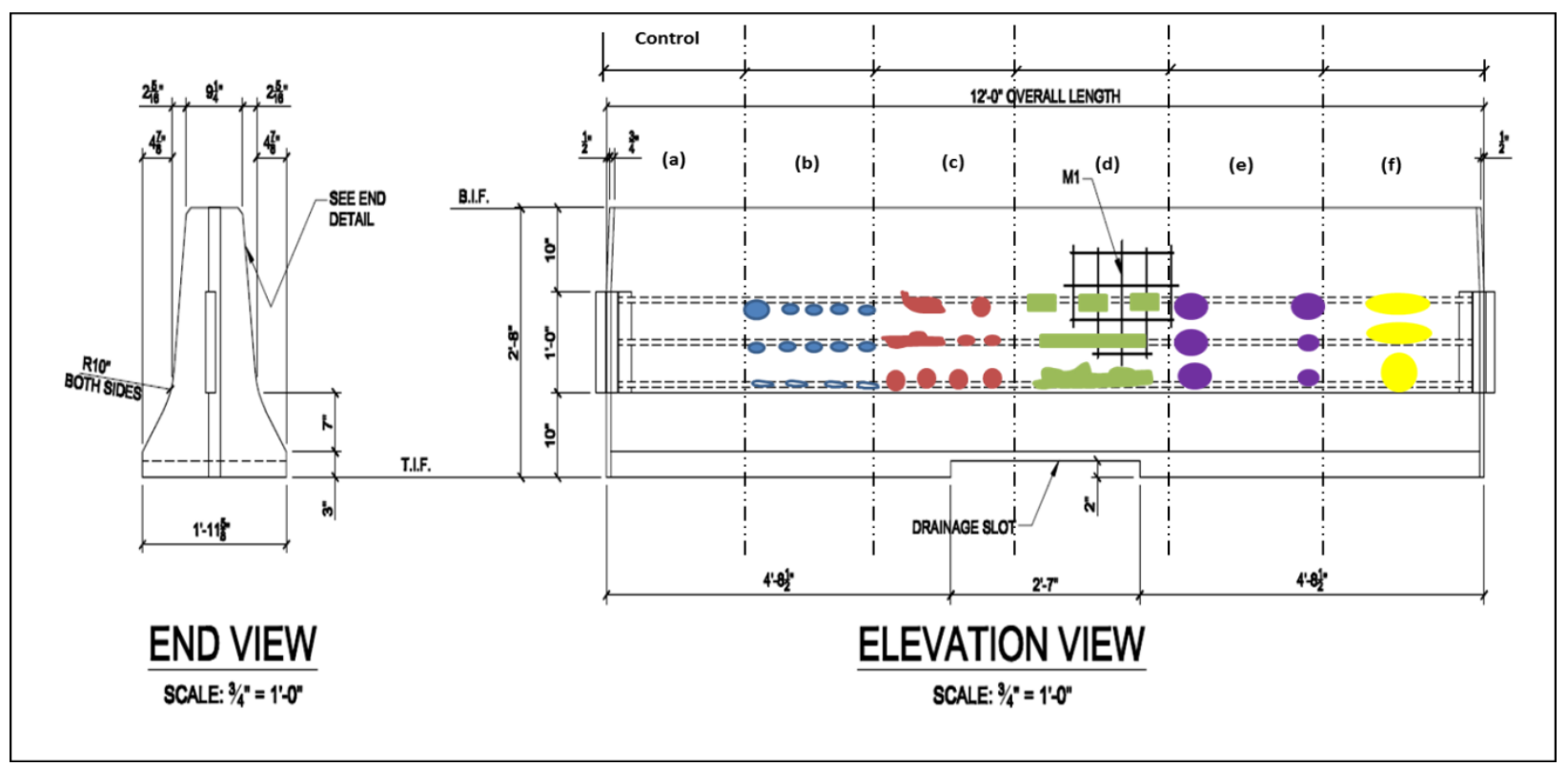

Fig. 18. F-shaped free-standing portable barrier with simulated voids.

\subsection{FLORIDA DEPARTMENT OF TRANSPORTATION NDE VALIDATION FACILITY}

The Florida Department of Transportation NDE Validation Facility in conjunction with the Department of Civil and Coastal Engineering Department University of Florida, Gainesville constructed various concrete specimens for the purposes of NDE comparisons and validation [10]. Six unique validation blocks were fabricated to evaluate the capabilities of instruments for reinforcing steel detection, elastic property estimation, post-tensioning duct investigation, internal void detection, and surface flaw evaluation. The six validation blocks, four of which are shown in Fig. 19, are

1. control block (monolithic concrete),

2. rebar detection block,

3. internal post-tensioning (PT) duct block (galvanized steel ducts),

4. slab thickness block,

5. asymmetric internal PT duct block (polypropylene ducts), and

6. Void and flaw detection block. 


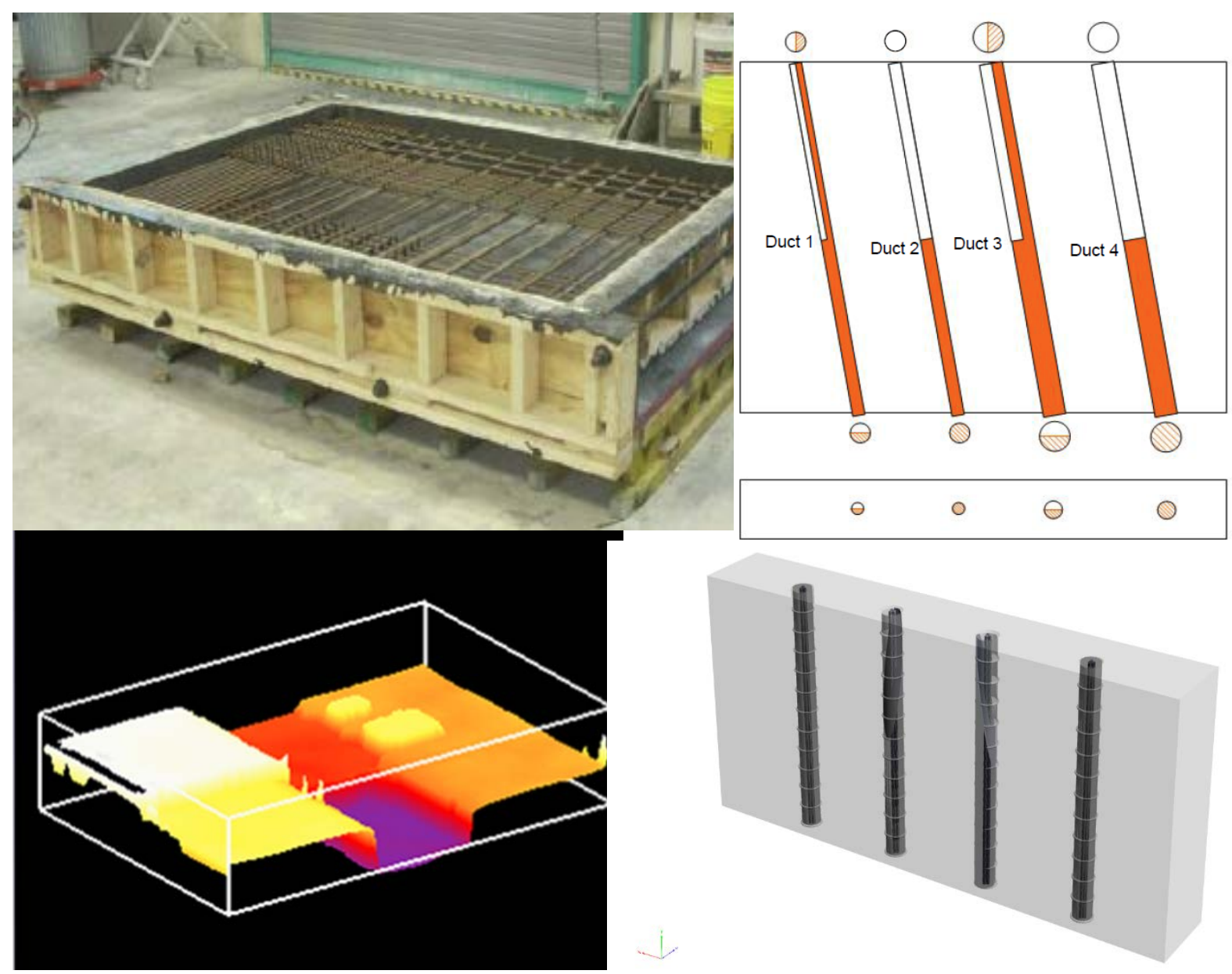

Fig. 19. Four concrete test specimens. Clockwise from top left: rebar detection, steel post-tensioning duct evaluation, polypropylene post-tensioning duct evaluation, and slab thickness evaluation blocks in varying stages of design and construction [10].

Since Specimen 2 (rebar detection block) was the most heavily reinforced with rebar and Specimen 6 (void and flaw detection block) represented several visible and hidden "defects" typical of aging concrete structures, these were evaluated as part of an ORNL study [9]. The rebar detection block allowed for evaluation of the effectiveness of NDE instruments in locating rebar of various diameters with changing spacings and depths. The overall rebar mats can be observed in Fig. 20. 


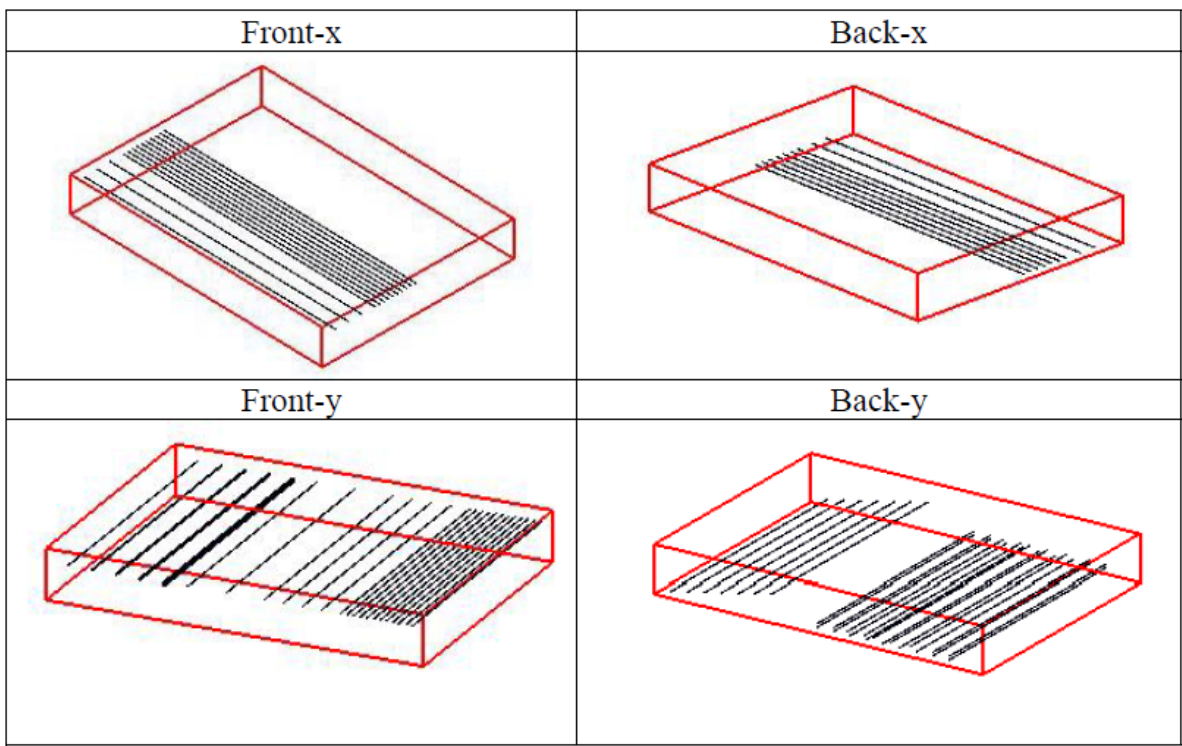

Fig. 20. Orientation and relative location of rebar mats in the rebar detection block [5].

Specimen 6 was designed to evaluate defects such as the quality of consolidation in a completed concrete structure. Movement of rebar after initial set, over/under vibration, mix segregation, and development of bleed water pockets and cracking were simulated in this specimen. This included a prism of pervious concrete placed at surface level during concrete placement along with two simulated angled cracks, which can be observed in Fig. 21.

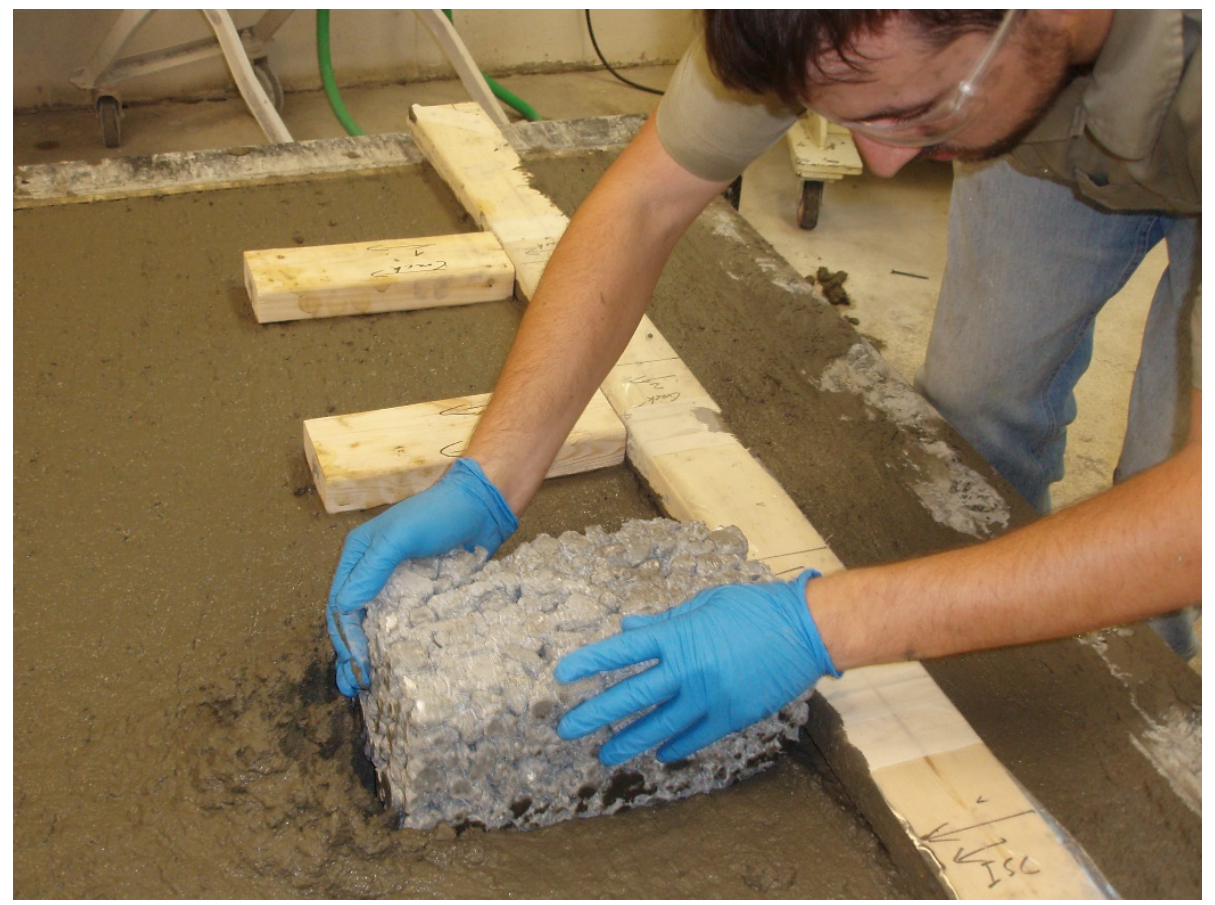

Fig. 21. Installing the surface-level pervious concrete prism and two short boards holding the triangular plates used to make the simulated cracks [9].

The three sections of \#6 rebar, shown in Fig. 22, were suspended in place by recessing the last $50 \mathrm{~mm}$ of their length on either end into a layer of polymer-coated form board installed. The rebar pieces to be 
moved after initial set of the concrete had one end moved in the mold after initial set of the concrete, through installation into a slot rather than a hole in the inner form board. In this manner, only one end of the rebar was moved after concrete placement, allowing for an increasingly severe "trail" of disturbed concrete behind the path of the rebar. The laterally moving rebar specimen had a more complicated cable system guided through a lubricated tube into the formwork itself. It should be noted that this system failed to move the rebar as desired, and it was confirmed after measurement that this rebar piece moved only $8 \mathrm{~mm}$.

While the results of ORNL Report "Evaluation of Ultrasonic Techniques on Concrete Structures" using these types of defects showed the promise of various techniques in determining the location and extent of these defects, the lack of required penetration depth and heavy reinforcement creates a need for similar evaluations and comparisons on a larger, more heavily reinforced specimen [9]. This created a need to design and build a new concrete specimen for qualifying NDE concrete instrumentation and evaluating the state of current NPP concrete structure characterization capabilities. The conceptual design in this study should do a more realistic job of adequately reflecting the existing large concrete structures for NPP containment and shielding. A recommendation from [9] was that at least one concrete test sample representative of the cross section of a commercial NPP be fabricated for NDE [4]. One such specimen was constructed as part of this study and detailed below.

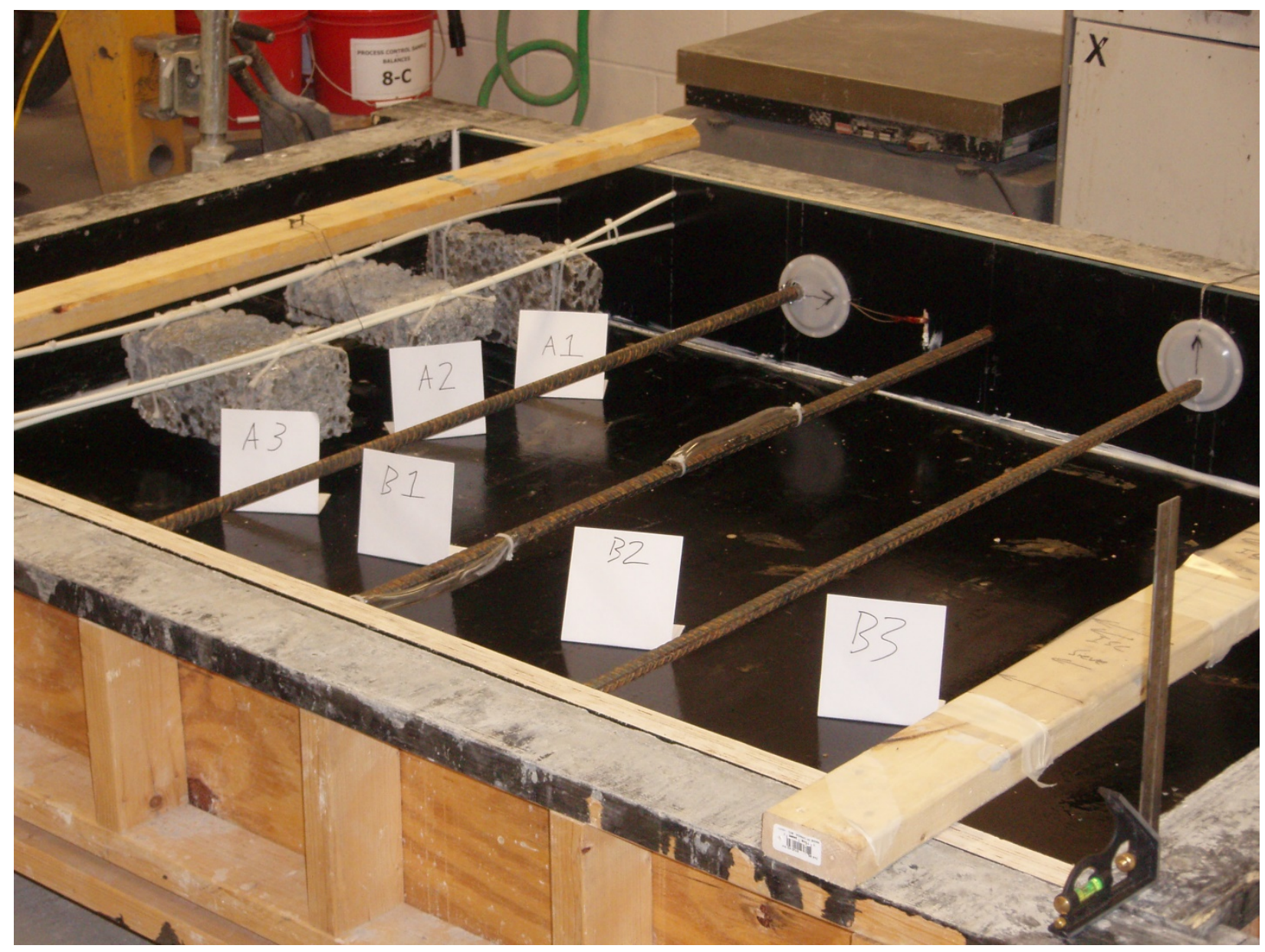

Fig. 22. Three rebar pieces including the two moving specimens in the void and flaw detection block. The plastic caps marked with the black arrows both keep concrete out of the movement slot in the form boards and indicate in which direction the rebar end is designed [9]. 


\section{DESIGN REQUIREMENTS FOR THE REPRESENTATIVE NPP CONCRETE SAMPLE}

Suitable concrete specimens that are representative of NPP concrete cross sections are needed for NDE and testing of instrumentation and measurement techniques. Adequate test blocks/specimens play a key role, since they can provide defined conditions under which the different NDE concrete measurement methods can be evaluated. Material properties as well as the location of reinforcement, tendon ducts, and test flaws must be well documented. The artificial blocks can provide more defined conditions, since the critical parameters can be controlled during the block fabrication.

Due to the controlled conditions in the laboratory, the number of unknown variables can be decreased, making it possible to focus on specific aspects, investigate them in detail, and gain further information on the capabilities and limitations of the techniques. Comparative testing on the various NDE techniques will require concrete specimens with known material properties, voids, internal microstructure flaws, and reinforcement locations. These specimens can be artificially created under laboratory conditions where the various properties can be controlled. Since no available large concrete specimens are representative of NPP concrete structures or available for forensic verification activities, a detailed design is presented in this section after two major design concerns are reviewed.

\subsection{BOUNDARY EFFECT CONCERNS}

To minimize artifacts caused by boundary effects discussed in the previous sections, the dimensions of the specimen should not be too compact. The minimum dimensions of the test specimen are directly related to the thickness of the specimen. If the ultrasonic wave is modeled as a spherical propagation from the point source (as shown in previous sections), the distance from the source location to the rear surface must be the minimum dimension. However, the exact size of the specimen needed to address boundary effects depends on the NDE technique used. For example, multiple ultrasonic transducers can be utilized to beamform the generated ultrasonic wave to give it more directional propagation properties (Fig. 23) for a four element beamformed wave with no shading. If shading is applied, additional directionality is obtained.

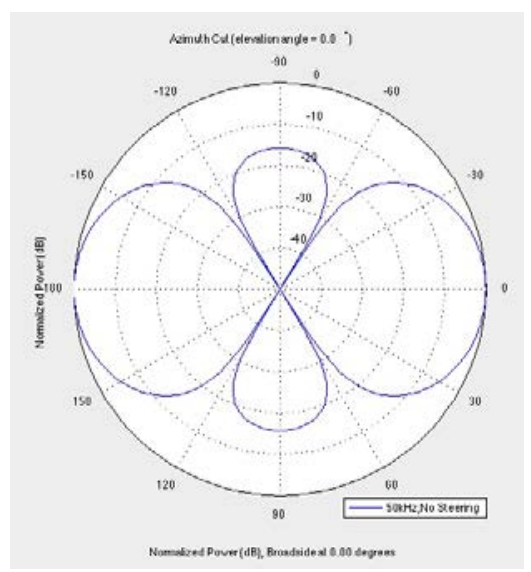

Fig. 23. Beam pattern from a four element ultrasonic array.

This type of focusing can assist in both boundary effects and depth of penetration concerns. To illustrate this, a simple example scan was taken by an ultrasonic linear array system, MIRA (shown in Fig. 24[A]), at the University of Minnesota Structures Laboratory. The scan was taken for an approximately 1-m-thick reinforced concrete specimen with inclusions at approximately $0.15 \mathrm{~m}$ and $0.4 \mathrm{~m}$ depths, respectively. Figures $24[\mathrm{~B}]-[\mathrm{D}]$ give cross-sectional imaging reconstructions of the same scan data showing the relative reflectivity throughout the depth using different inputs. It can be observed from Fig. 24[B] that 
the shallower inclusion (bordered by the solid black box) is properly represented by a round black increase in reflectivity, while the deeper inclusion and interface at the reinforced concrete structure thickness depth are underrepresented (bordered by the dashed box). It can be observed from Fig. 24[C] that the shallower inclusion (bordered by the dashed black box) is not properly represented due to a saturation in reflectivity, while the deeper inclusion and interface at the reinforced concrete structure thickness depth (bordered by the solid black box) are properly represented by a round black increase in reflectivity and oblong increase in reflectivity, respectively. By properly accounting for attenuating effects, the volumetric imaging and signal interpretation strategies can be adjusted accordingly. Figure 24[D] shows how a volumetric reconstruction accounting for these types of effects might be applied to properly represent both shallow and deep characteristics, showing proper reflectivity at both inclusions and the back wall reflection at the thickness of the concrete structure.

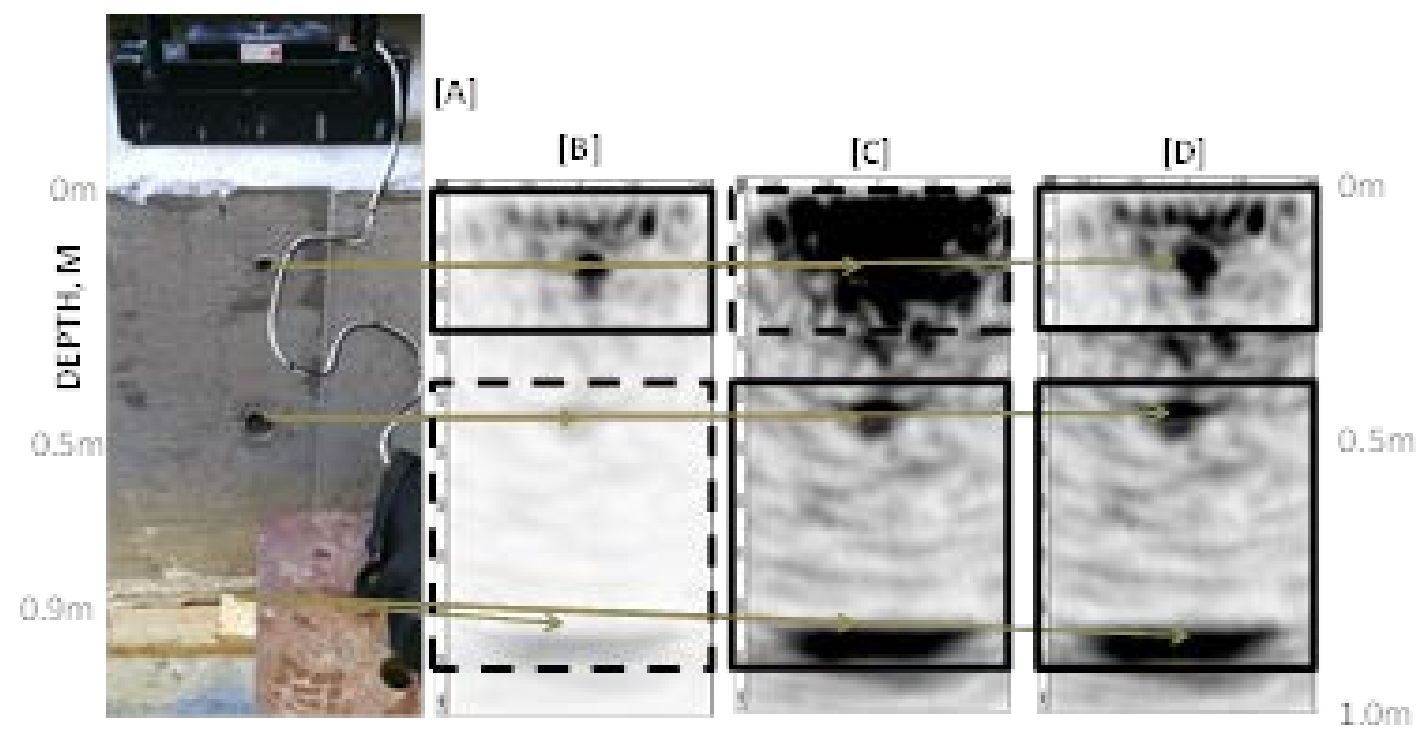

Fig. 24. [A] Picture of MIRA ultrasound scanner with an approximately 1-m-thick reinforced concrete sample with corresponding reconstructions that indicate the $[B]$ shallow features, [C] deep features, and [D] all features.

It is clear that using ultrasonic arrays for NDE with volumetric imaging techniques may reduce the necessary size of the concrete specimen; the lateral distance from the ultrasonic linear array is over five times smaller than the depth to the clear back wall reflection at the thickness of the specimen. However, since there are not a large number of vertical boundaries in aging concrete in NPP structures, an inability to handle boundary effects should not eliminate a technique from potential use for in-service inspection (also described in the Section 2). Therefore, the specimen should also be designed to evaluate techniques that do not have directional capabilities. A major design requirement is that the depth of the ROI in the specimen should be significantly larger than the remaining lateral dimensions. The ability of each technique to handle vertical boundary effects will not affect the validation activities if designed using this constraint, especially for defects near the center of the lateral boundaries of the specimen.

It should also be noted that, while boundary effects from finite lateral structure dimensions are generally not a concern in NPP containment structures, this does not suggest that directional capabilities do not affect the ability of various NDE methods to evaluate thick reinforced structures, even at locations where no lateral vertical boundaries are present. Signal directionality can assist in evaluating defects near or below reinforcement, especially if the signal is focused along a plane of interest parallel and centered between adjacent reinforcement. Beyond mitigation of interference of internal structure characteristics, such as reinforcement patterns for evaluation of defects, the focusing can also allow for greater penetration depth by increasing the energy along the focused plane. Therefore, since focusing capabilities 
are of interest, defects were also placed in locations that approach the lateral boundaries, in addition to the defects with no potential boundary effects near the center of the lateral dimensions of the various specimens. This will leverage the availability of an already cast specimen to increase the number and type of defects that can be tested by methods with directional capabilities and provide information about the extent of the focusing capabilities. Defects near a free vertical boundary provide the most controlled evaluation of the extent of directional focusing capabilities of the various techniques. In this case, care must be taken to separate the portion of the results that provide information on beam focusing capabilities of the various methods versus results that provide information about the ability of the methods to evaluate degradation assuming infinite lateral dimensions. It should be ensured that comparisons made near finite lateral dimensions do not lead to conclusions that negatively direct a realistic assessment of the current capabilities of each method to assess in-service NPP containment walls.

\subsection{LARGE SPECIMEN CONCERNS}

While the design of the large concrete specimen mitigates some of the boundary effect concerns, it creates some additional complexities involved with forming such a large reinforced concrete specimen. Beyond the efforts required to cast and properly consolidate a large concrete specimen, the ability to maneuver and transport the specimen can be restrictive. Often specimens need to be tilted to allow for actuator loading at the correct orientation or, in this case, NDE data collection access. Additionally, at times the specimen needs to be cast in a different location than the testing location to mitigate concrete truck or other access issues. The weight of the specimen is a major factor in this regard, where reinforced concrete is typically $150 \mathrm{lb} / \mathrm{ft}^{3}$ and $162 \mathrm{lb} / \mathrm{ft}^{3}$ assuming a reported NPP 5\% steel by volume ratio [4]. This can be restrictive for the use of a typical structural laboratory crane having 20 ton (40,000 lb) load capacity. There can also be restrictions due to the large specimen dimensions even if the specimen is cast in the location and orientation necessary to conduct the testing. While infrastructure specimens can easily be cut to desired dimensions along the thickness cross section for disposal, this technique is not straightforward for disposal of specimens meeting NPP containment structure thickness requirements. This can also create restrictions beyond the weight limits of crane operation. For example, the smallest dimension of the specimen and crane fixture mechanism is required to be less than the smallest dimension of clearance between the crane and floor along the path to the disposal site, assuming the specimen is instrumented to allow for rotation to the desired specimen orientation.

Fortunately, laboratories such as the University of Minnesota (UMN) Department of Civil Engineering have facilities that specialize in large concrete structure construction and testing. This includes the Theodore V. Galambos Structural Engineering Laboratory (UMN-TGL) and the Multi-Axial Subassemblage Testing (MAST) System laboratory. These facilities frequently test various heavily reinforced concrete structures up to $28.75 \mathrm{ft}(8.7 \mathrm{~m})$ in height and $20 \times 20 \mathrm{ft}(6.1 \times 6.1 \mathrm{~m})$ and provide large-scale concrete specimens for research that can be nondestructively evaluated and compared with forensics at various damage stages. 



\section{CONSTRUCTED SPECIMEN DESIGN}

The specimen constructed in this study is based on the prioritized conceptual designs from the preliminary report as well as a more detailed look at the mobility and safety implications of constructing the specimen at the University of Minnesota.

\subsection{SPECIMEN DIMENSIONS AND REINFORCEMENT}

Concrete structures in NPPs are typically 3 to $4 \mathrm{ft}$ thick along the wall and dome of the containment structure. Therefore, a specimen thickness of $3 \mathrm{ft} 4 \mathrm{in}$. $(1.016 \mathrm{~m})$ was chosen. This thickness is consistent with NPP containment wall specifications. The height and width of the specimen was constricted to $7 \mathrm{ft}$ to accommodate use of a maximum 20 ton crane while still mitigating boundary effects.

NPP concrete is normally embedded with heavily reinforced cross sections using mild steel \#18 bars (2.257 in. diameter, 4.00 in. $^{2}$ cross-sectional area) and \#8 bars (1.000 in. diameter, 0.79 in. $^{2}$ crosssectional area) at 6 to $12 \mathrm{in}$. spacing. The type and spacing of the reinforcement has a significant effect on the shielding evaluation of defects below the level of reinforcements, especially when using GPR, since electromagnetic waves are extremely sensitive to metal. While elastic wave-based methods are less sensitive to reinforcement than GPR, characterization of defects within more heavily reinforced structures are more difficult than for less heavily reinforced structures. The constructed specimen contained \#18 rebar at $12 \mathrm{in}$. spacing in both horizontal and vertical orientation. This provides a realistic reinforcement size that also allows for space between reinforcement for semi-controlled evaluation of the effects of concrete depth on defect characterization. This will also allow for differentiation between complexities caused by dense levels of reinforcement versus complexities caused by depth of penetration within concrete, while still observing the effects of the uniquely large diameter reinforcement used in NPP structures. Figure 25 is a photograph of the \#18 reinforcement size and arrangement at an intermediate stage of the formwork process.

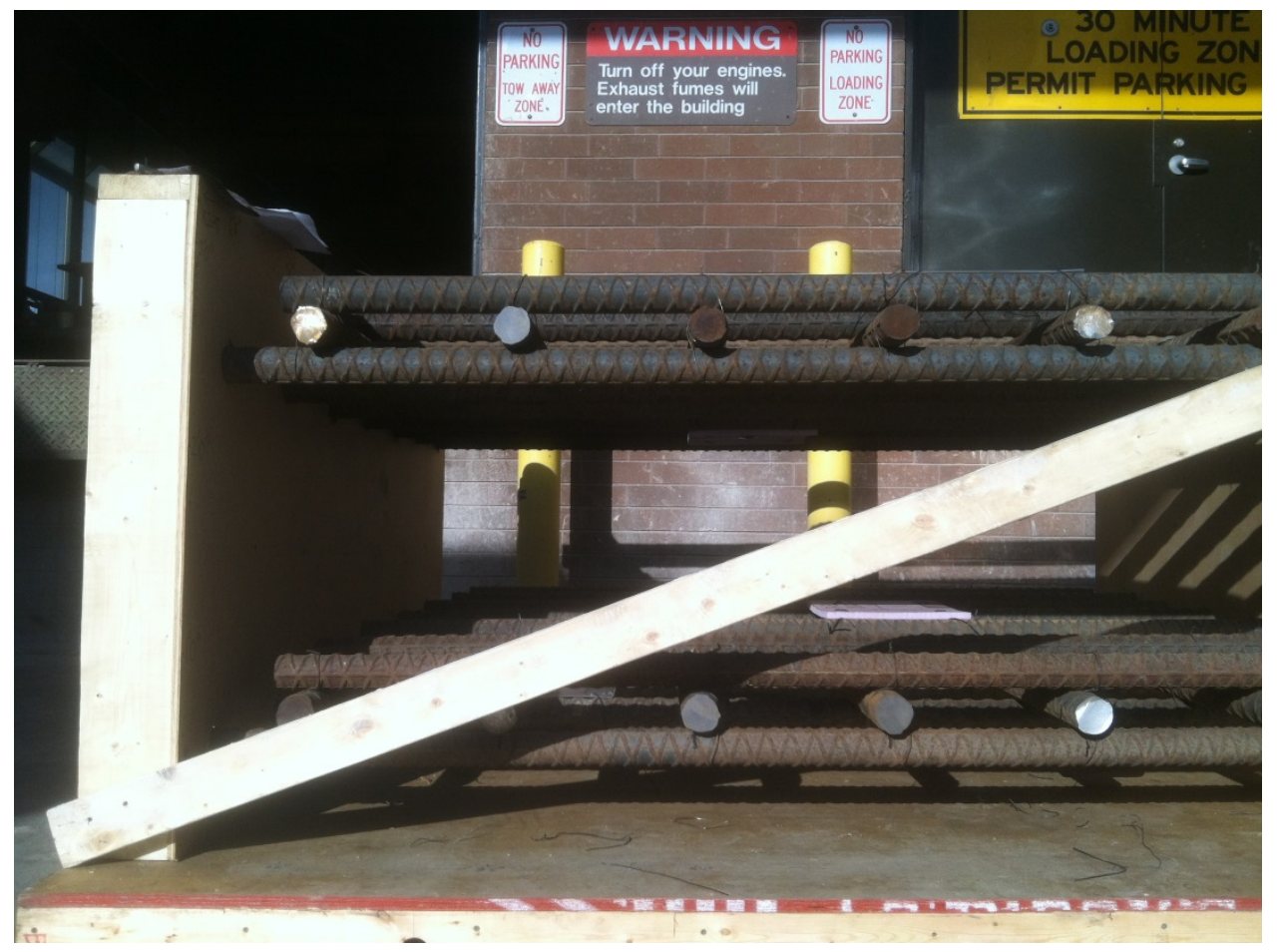

Fig. 25. \#18 reinforcement used to replicate the large diameter mesh used in NPP containment walls. 
The constructed concrete dimensions and reinforcement pattern chosen to represent a typical NPP containment structure in this report are shown in Fig. 26, Fig. 27, and Fig. 28. The cross-sectional view shown in Fig. 26 shows the two vertical rebar, 7 in. from edge to center, and horizontal rebar placed throughout the length of the wall, leaving 4 in. of concrete cover from the shallowest rebar edge to the testing surface. The horizontal rebar is designed to have $5 \mathrm{in}$. of concrete cover from both ends in each direction to allow for proper concrete cover as can be observed from Fig. 27. One rebar on each side of the vertical rebar creates a shadowing effect test for the NDE methods while mimicking the reinforcement pattern of a typical NPP containment wall. Some of the reinforcement extended to the outside of the specimen to allow for fixing the reinforcement and defects to the correct location within the formwork. However, all schematics show the reinforcements ending within the evaluated area. The reinforcement pattern is similar for both sides of access, allowing evaluation of the effect of different depths using only one defect by comparing results of testing on both sides of the specimen. While testing and preliminary analysis were conducted on both sides of the specimen, it should be noted that each data set is treated independently and any potential method should not require two-sided access to ensure that the specimen is used to simulate realistic containment wall access conditions.

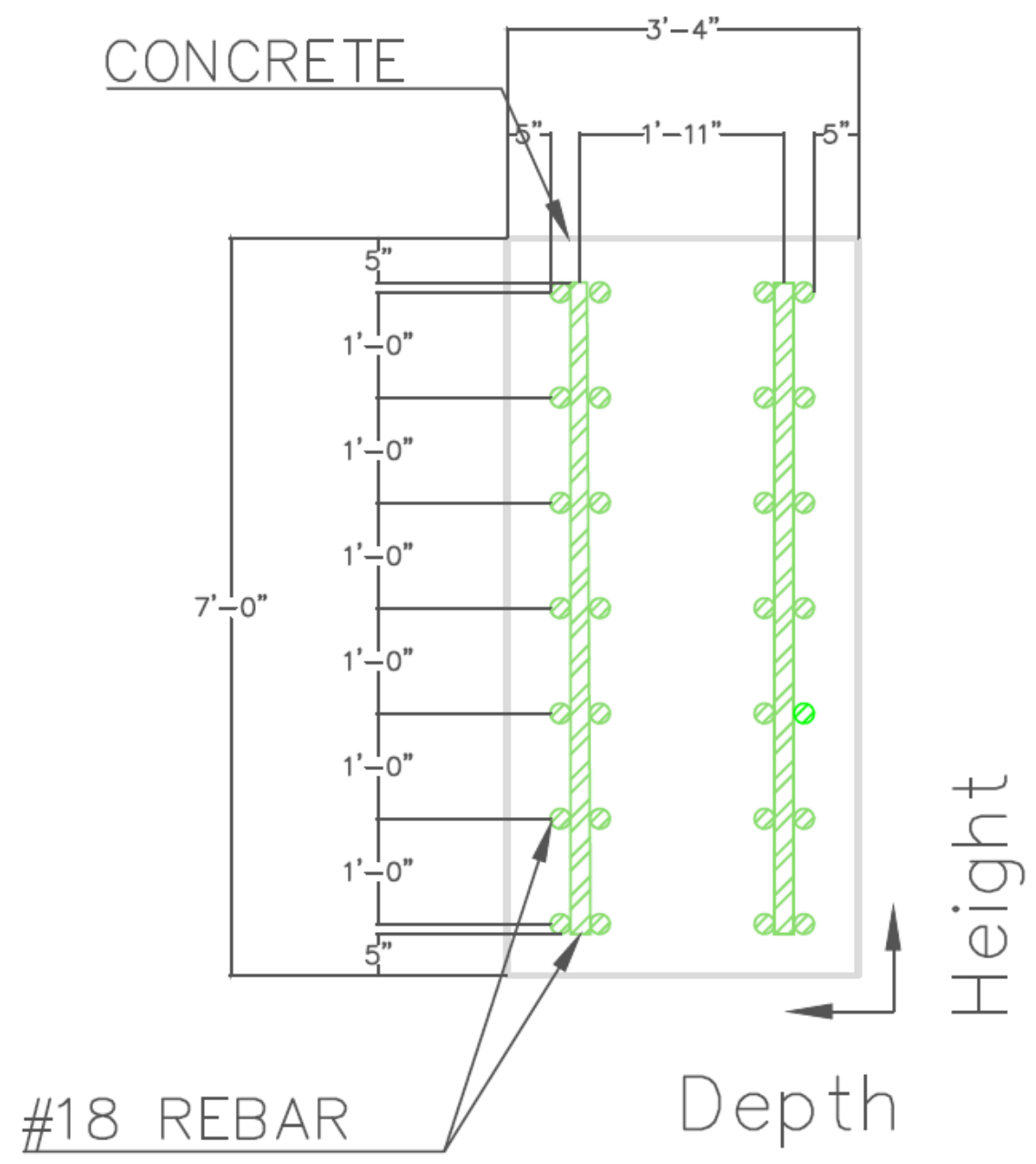

Fig. 26. Concrete dimensions and reinforcement cross section to represent an NPP containment wall. 


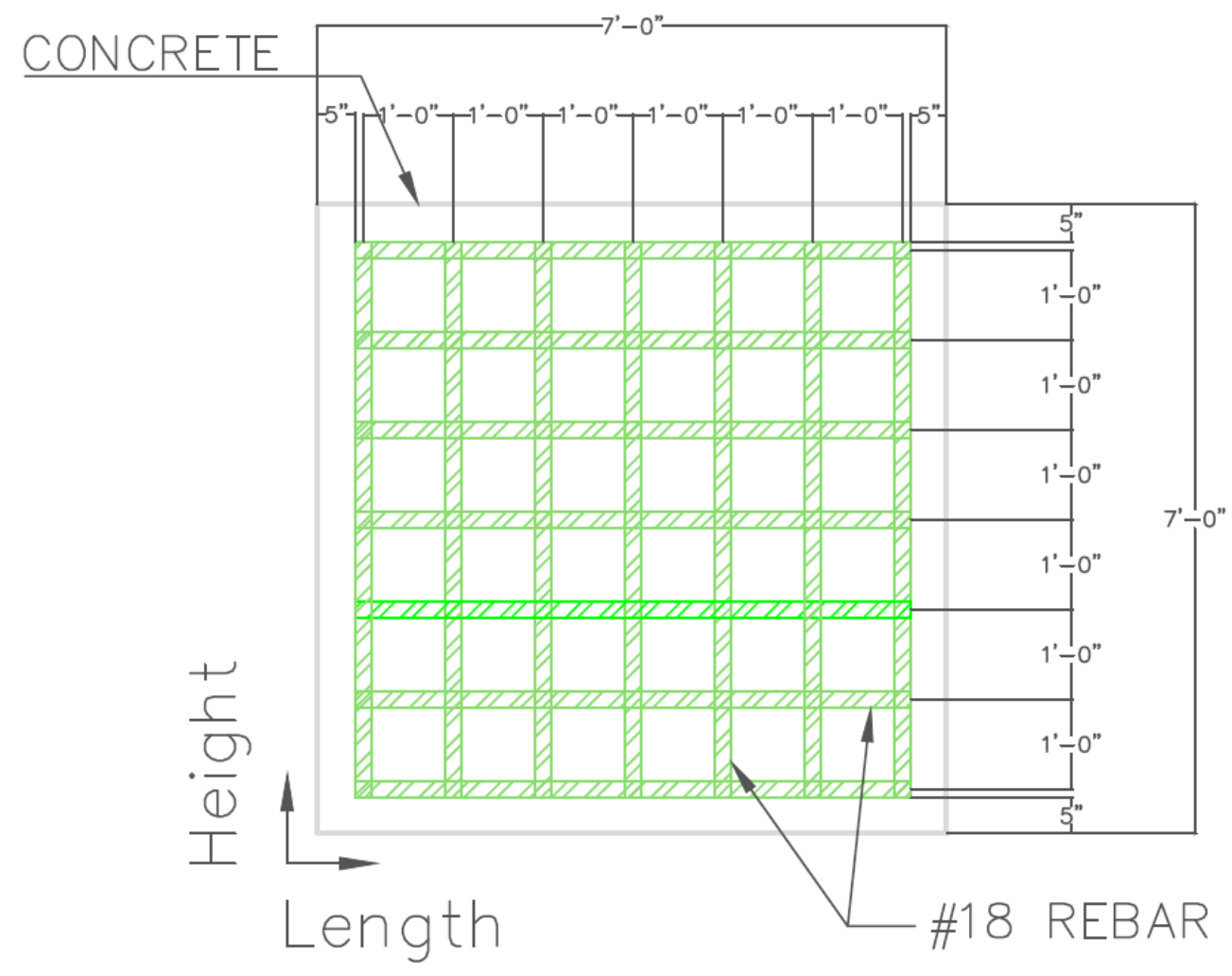

Fig. 27. Length/height view of the proposed concrete dimensions and reinforcement to represent an NPP containment wall.

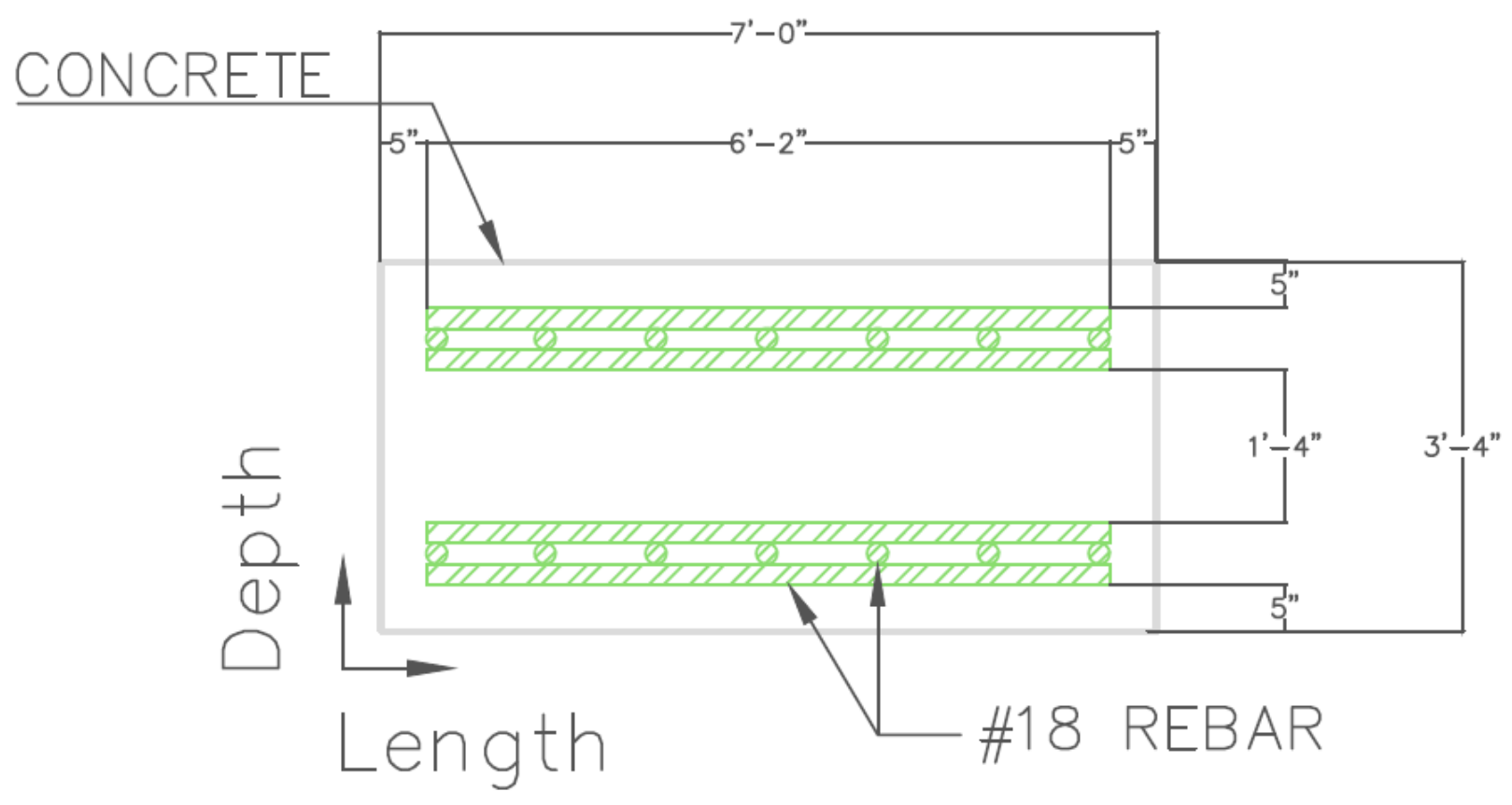

Fig. 28. Length/depth view of the proposed concrete dimensions and reinforcement to represent an NPP containment wall. 


\subsection{SPECIMEN MATERIAL AND SIMULATED DEFECTS}

Concrete material properties of the various NPP concrete structures depend on the materials used during construction of the specimen. The material used at each NPP site is variable depending on the distance from aggregate and cement sources in the area. Additionally, the early age material properties resulting from each mix design are different than the material properties 50 years after the beginning of the curing process. Theoretically, the mix design of example NPP locations could be replicated to determine the effect of material properties on NDE techniques. However, since the mix designs are variable from site to site, materials from 50 years ago are not easily obtained, and early age properties are not representative of older concrete, the proposed mix was designed to make the PCC matrix surrounding the simulated defects and reinforcement pattern as controlled and consistent as possible. By taking into account the large size of the specimen, complex nature of the reinforcement and simulated defects, and goals of limiting the variables other than the known defect and reinforcement locations, a selfconsolidating (SCC) performance-based mix was chosen. The placement of the proprietary Cemstone SCC mix provided consistent consolidation and low stress on embedded defects without the need for vibration. This also mitigated concerns of the simulated defects damaging or moving from their desired location during the pour. A photograph of the SCC pouring process is shown in Fig. 29. The spread of the SCC mix allowed for minimal movement during placement.

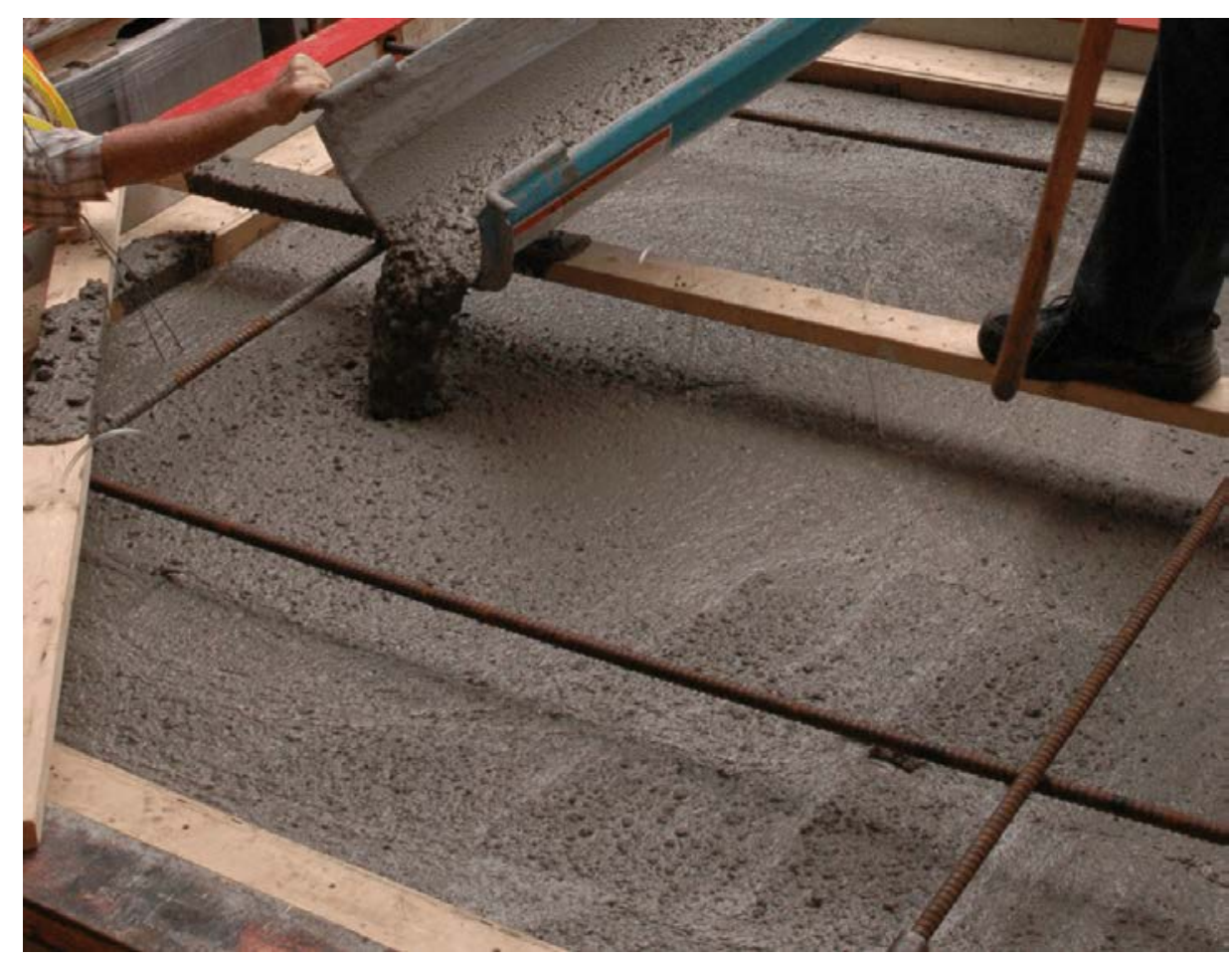

Fig. 29. Use of SCC to allow for consolidation without affecting simulated defects.

The simulated defects were embedded to determine how the current state-of-the-practice NDE techniques will be able to determine various forms of degradation in NPP concrete structures. This is a difficult task since, to date, limited comparisons of state-of-the-art methods have been conducted at the size and reinforcement density of LWR containment structures on controlled specimens, or verified through forensic activities. The constructed specimen is designed to allow for assessment of controlled benchmark defects from previous studies in a more heavily reinforced concrete structure as well as evaluation of realistic defects to ensure that the correct type of features for effective NPP NDE are included. 
The controlled defects embedded in the proposed wall sample include sufficiently challenging inclusions to ensure that limitations of even the most advanced methods can be quantified. At the same time, some of the proposed defects are designed to be identifiable by a majority of the methods. This will ensure that the methods not close to the desired achievement can be eliminated from consideration, while the baseline level of achievement of the methods performing well can be identified.

The realistic defects are designed to represent activities that could have occurred during the construction process and/or cumulative deterioration and degradation of the concrete with time. Some of the aging-related degradation mechanisms cannot be reproduced due to time constraints, while more realistic construction defect simulation can cause less repeatable results and can be difficult to quantify. However, designing the defects solely to be repeatable and not realistic can lead to the wrong conclusions when evaluating the various NDE techniques. For example, the NDE attributes determined to be desirable based on good performance on the test block may not be useful for evaluation of commercial concrete NPP structures if the defects are not realistic enough.

With these factors in mind, the defects are designed to give a mix of realistic and controlled defects for assessment of both the necessary measures needed to overcome the challenges with more heavily reinforced concrete structures, while also ensuring that the correct type of features for effective NPP evaluation. Photographs and schematics in Appendixes A through $\mathrm{C}$ can be referenced for more details about the location, dimensions, and types of defects. Many of the defects match the defects referenced above in this report from previous studies of thinner structures. The following list gives the defect type associated with each ID number shown in A- 6 .

1. Porous half cylinder (no cover)

2. Porous half cylinder (no cover)

3. Porous half cylinder (no cover)

4. Porous half cylinder (cover)

5. Porous half cylinder (cover and crack)

6. PVC

7. PVC

8. Dissolving Styrofoam (thick)

9. Foam (thick)

10. Styrofoam (thin)

11. Plexiglass

12. Dissolving Styrofoam (medium)

13. Styrofoam (medium)

14. Plexiglass

15. Dissolving Styrofoam (thin)

16. Lumber $(2 \times 4)$

17. Gloves

18. Debond duct tape (one layer)

19. Debond duct tape (multi-layer)

20. Moving rebar 
A- 6. Defect size and location

\begin{tabular}{|c|c|c|c|c|c|c|c|}
\hline & \multicolumn{5}{|c|}{ Center location, mm } & \multicolumn{3}{c|}{ Specimen dimensions, mm } \\
\hline ID & Length, $\mathbf{x}$ & Height, $\mathbf{y}$ & $\mathbf{R} \_$Depth, $\mathbf{z}$ & S_Depth, $\mathbf{z}$ & Length, $\mathbf{x}$ & Height, $\mathbf{y}$ & Thickness, $\mathbf{z}$ \\
\hline D01 & 610 & 1676 & 930 & 86 & 152 & 102 & 51 \\
\hline D02 & 1372 & 610 & 140 & 876 & 102 & 229 & 51 \\
\hline D03 & 1067 & 1524 & 876 & 140 & 127 & 102 & 51 \\
\hline D04 & 1524 & 457 & 86 & 930 & 152 & 102 & 51 \\
\hline D05 & 610 & 1372 & 194 & 822 & 152 & 102 & 51 \\
\hline D06 & 711 & 1067 & 508 & 508 & 2134 & 51 & 51 \\
\hline D07 & 1422 & 1067 & 508 & 508 & 2134 & 51 & 51 \\
\hline D08 & 914 & 914 & 197 & 819 & 203 & 203 & 51 \\
\hline D09 & 1219 & 1219 & 248 & 768 & 203 & 203 & 51 \\
\hline D10 & 1219 & 305 & 908 & 108 & 305 & 305 & 6 \\
\hline D11 & 914 & 1829 & 111 & 905 & 305 & 305 & 2 \\
\hline D12 & 1219 & 914 & 283 & 733 & 305 & 305 & 13 \\
\hline D13 & 914 & 1219 & 733 & 283 & 305 & 305 & 13 \\
\hline D14 & 1600 & 1600 & 848 & 168 & 152 & 152 & 2 \\
\hline D15 & 533 & 533 & 168 & 848 & 152 & 152 & 6 \\
\hline D16 & 1753 & 1829 & 197 & 819 & 330 & 89 & 38 \\
\hline D17 & 1372 & 1524 & 168 & 848 & 102 & 102 & 57 \\
\hline D18 & 1905 & 1067 & 140 & 876 & 127 & 57 & 57 \\
\hline D19 & 1753 & 1067 & 140 & 876 & 127 & 57 & 57 \\
\hline D20 & 1067 & 762 & 140 & 876 & 1981 & 57 & 76 \\
\hline
\end{tabular}

The embedded defects arrangement for the specimen can be observed in Fig. 31, Fig. 32, and Fig. 33 (Fig. 30 is a legend identifying the various defects). Figure 31 shows the length and height view of the specimen. Figure 32 shows the height and depth view of the defects, while Fig. 33 shows the length and depth face view of the defect arrangement. It can be observed that the defects are spaced to the extent possible to decrease the chance of adjacent inclusions affecting the measurements while concentrating the defects away from boundaries. It should also be noted that none of the defects are overlapping, although some appear to be, if the spacing between them is in the dimension not shown in the figure. The vertical reinforcement in the lighter green color denotes Defect 20, which is designated for movement during the casting process to simulate increasingly disturbed concrete. Appendixes A through C include the location of each individual defect in all three cross-sectional schematics. 


\begin{tabular}{|c|c|c|}
\hline \multicolumn{3}{|c|}{ DEFECT TABLE } \\
\hline ID NUMBER & DESCRIPTION & LABE \\
\hline D1 & $\begin{array}{l}\text { POROUS HALF CYUNDER } \\
\text { (NO COVER) }\end{array}$ & \\
\hline D2 & $\begin{array}{c}\text { POROUS HALF CYUNDER } \\
\text { (COVER) }\end{array}$ & \\
\hline D3 & $\begin{array}{l}\text { POROUS HALF CYUNDER } \\
\text { (NO COVER) }\end{array}$ & \\
\hline D4 & $\begin{array}{c}\text { POROUS HALF CYUNDER } \\
\text { (COVER) }\end{array}$ & \\
\hline D5 & $\begin{array}{l}\text { POROUS HALF CYUNDER } \\
\text { (COVER \& CRACK) }\end{array}$ & \\
\hline D6 & PVC & \\
\hline D7 & PVC & \\
\hline D8 & $\begin{array}{l}\text { DISSOLVNG STYROFOAM } \\
\text { (THICK) }\end{array}$ & 曲些肃 \\
\hline D9 & STYROFOAM (THICK) & \\
\hline D10 & STYROFOAM (THIN) & \\
\hline D11 & PLEXIGLASS & 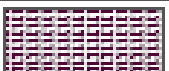 \\
\hline D12 & $\begin{array}{l}\text { DISSOLVNG STYROFOAM } \\
\text { (MEDIUM) }\end{array}$ & DDP \\
\hline D13 & STYROFOAM (MEDIUM) & \\
\hline D14 & PLEXIGLASS & 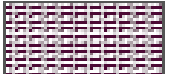 \\
\hline D15 & $\begin{array}{c}\text { DISSOLUNG STYROFOAM } \\
(T H I N)\end{array}$ & 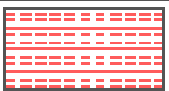 \\
\hline D16 & LUMBER (2X4) & \\
\hline D17 & GLOVES & \\
\hline D18 & $\begin{array}{l}\text { DEBOND DUCT TAPE } \\
\text { (ONE LAYER) }\end{array}$ & \\
\hline D19 & $\begin{array}{l}\text { DEBOND DUCT TAPE } \\
\text { (MULT-LAYER) }\end{array}$ & \\
\hline D20 & MOUNG REBAR & \\
\hline
\end{tabular}

Fig. 30. Legend identifying the various defects. 


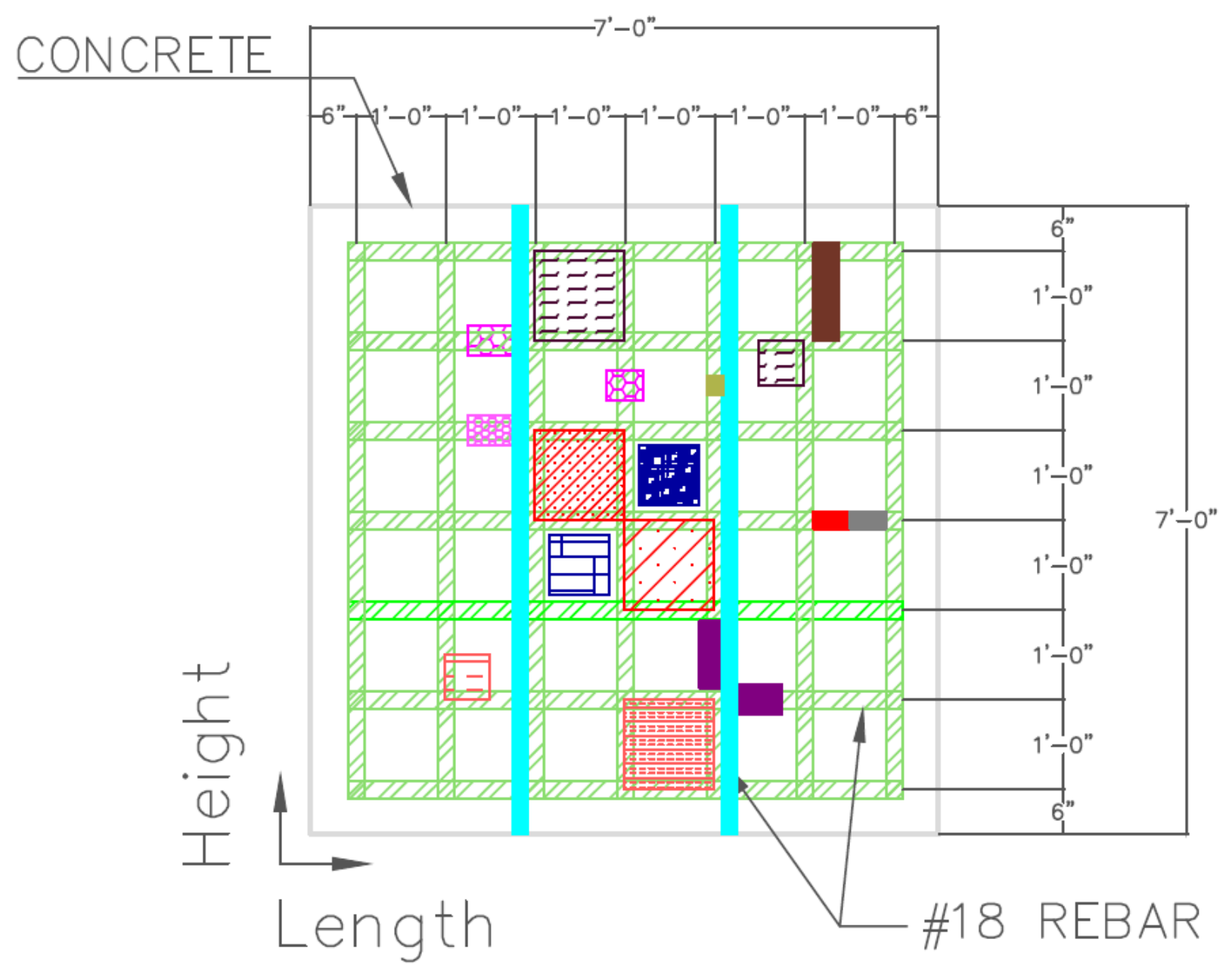

Fig. 31. Length/height view of the defects outlined in A- 6. 


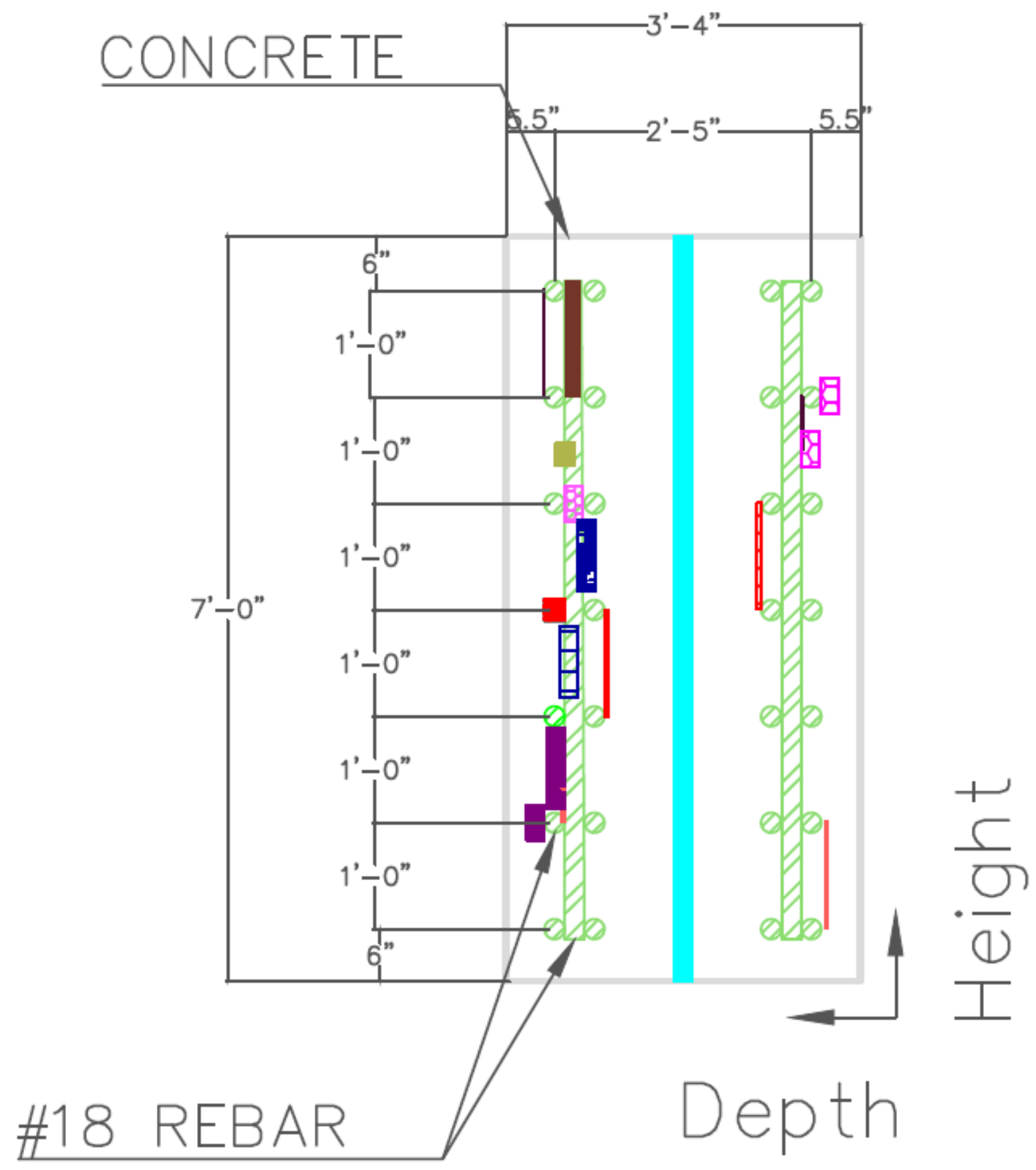

Fig. 32. Height/depth view of the defects outlined in A- 6. 


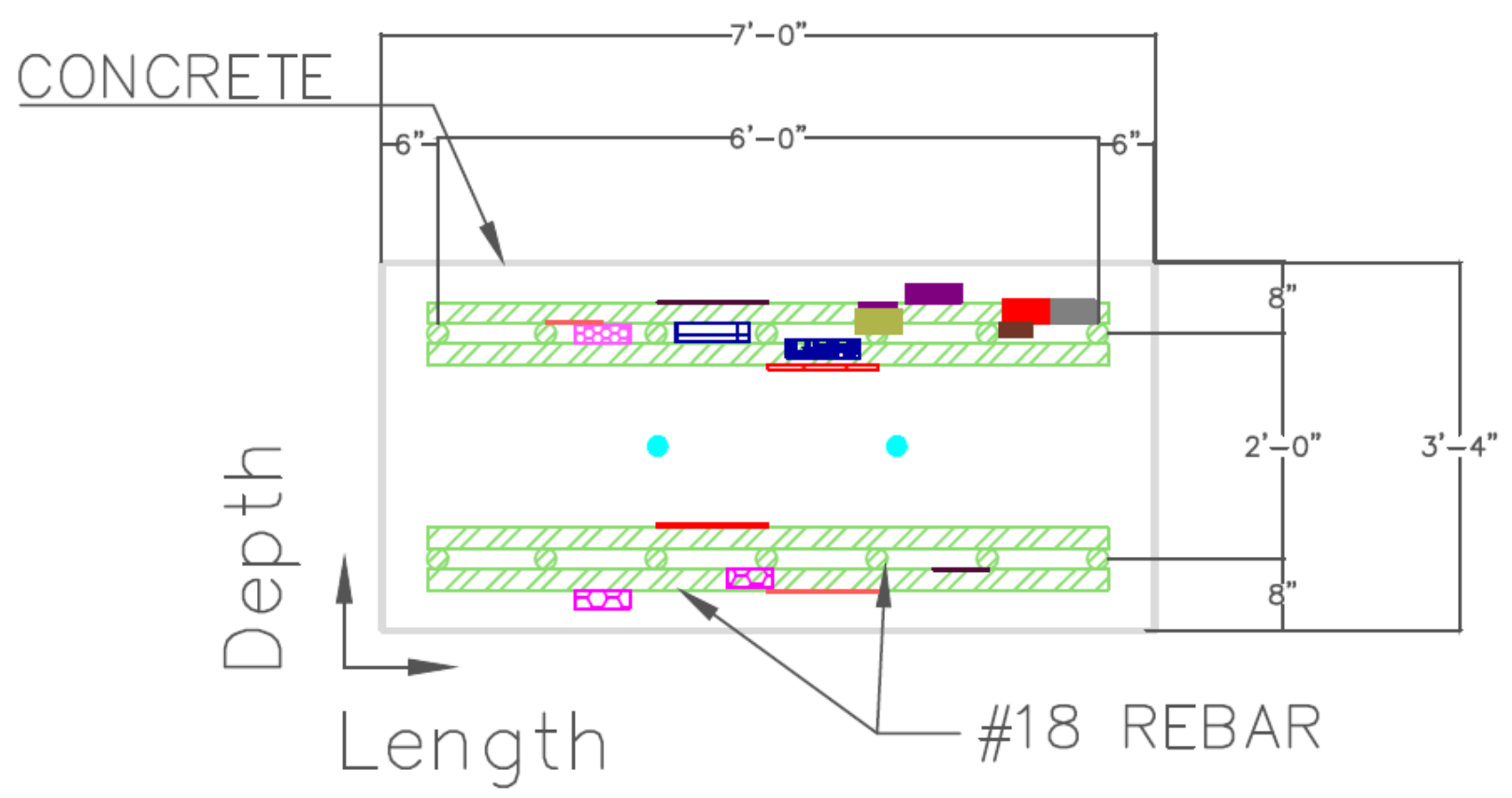

Fig. 33. Length/depth view of the defects outlined in A- 6.

Figures 34 and 35 show example controlled (D12) and realistic (D03) defects, respectively. Similar to some of the defects from Yehia et al., D12 is made of Styrofoam with a tube inserted. The tube was placed to allow for pouring acetone into the Styrofoam after the concrete pour. This is designed to leave a controlled voided area in the specimen similar to the large delaminations shown in Fig. 3. Similar to the distress shown in Fig. 21, porous concrete such as D03 was embedded to create more realistic smaller voids that can be caused by many different concrete aging mechanisms such as alkali-silica reaction or deterioration. Some of these defects were pre-covered with concrete paste to keep the SCC from infiltrating the concrete voids during construction.

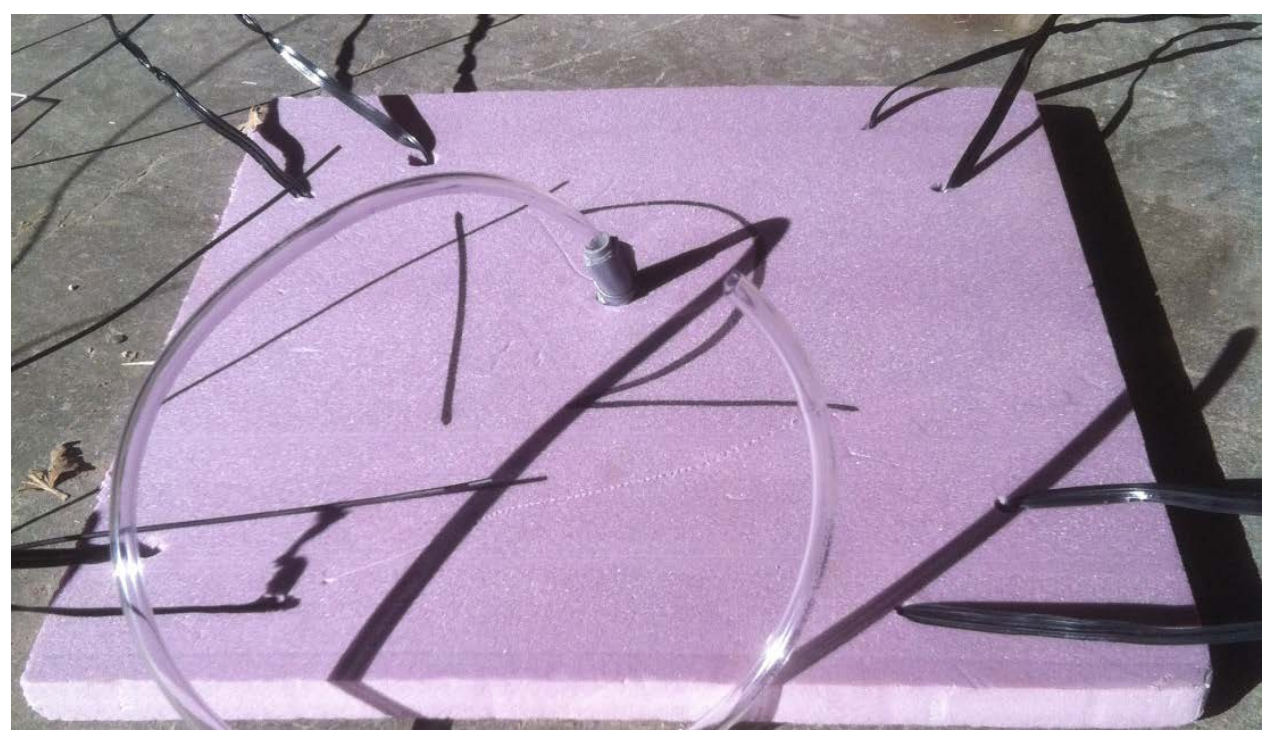

Fig. 34. Example controlled defect simulating a void with dissolving Styrofoam (D12). 


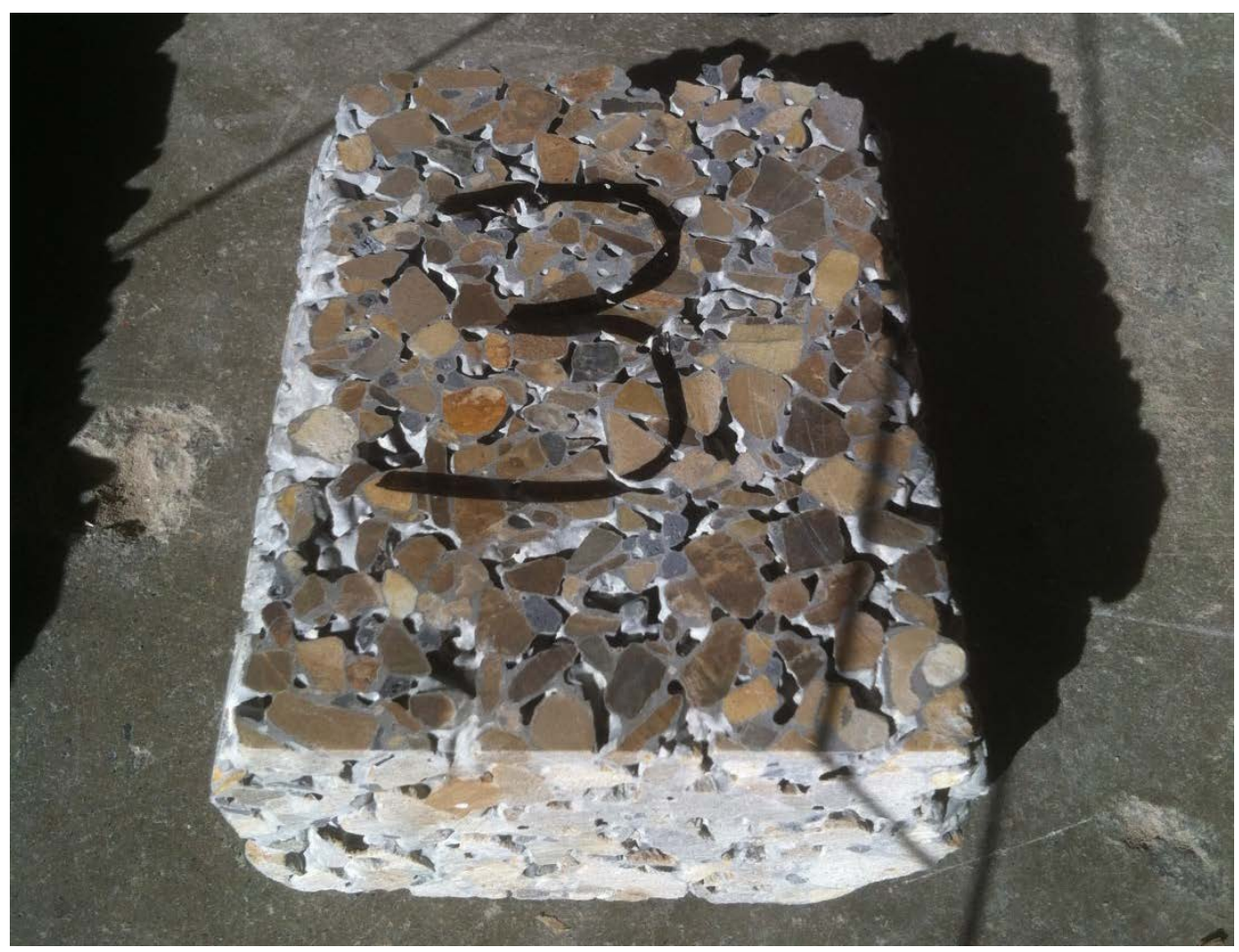

Fig. 35. Example realistic defect simulating concrete damage with embedded porous concrete (D03). 



\section{CONSTRUCTION DETAILS}

Detailed planning of the formwork and associated figures was required to safely mitigate the complexities involved with construction of a large reinforced concrete specimen such as the sample containment wall discussed in this report and allowed for the specimen to be cast and maneuvered as planned.

\subsection{SPECIMEN FORMWORK}

The final version used for formwork design for casting the proposed structure is presented in Fig. 36. This option required the wall to be tilted after casting since it was cast with the wall thickness side lying down (see Fig. 37) and the curing properties of concrete specimens often depend on their orientation during casting. However, this was the most attractive design due to less interference with the defects and less potential consolidation issues. The existing formwork clamping mechanism at this orientation allows for the use of PVC holes around the Meva Clamp and Dayton steel assembly for removal after casting. In this case, the PVC was in locations that allowed for simulated inclusions at the originally planned locations. The 2 in. $(50.8 \mathrm{~mm})$ inner diameter PVC was used to allow for a safe crane fixing for tipping and mobility. Due to these factors, the formwork option that allowed for casting the specimen lying down was chosen for use during construction. These details were provided to a local company, Advance Shoring, who agreed to donate their forms for use during the specimen casting process.

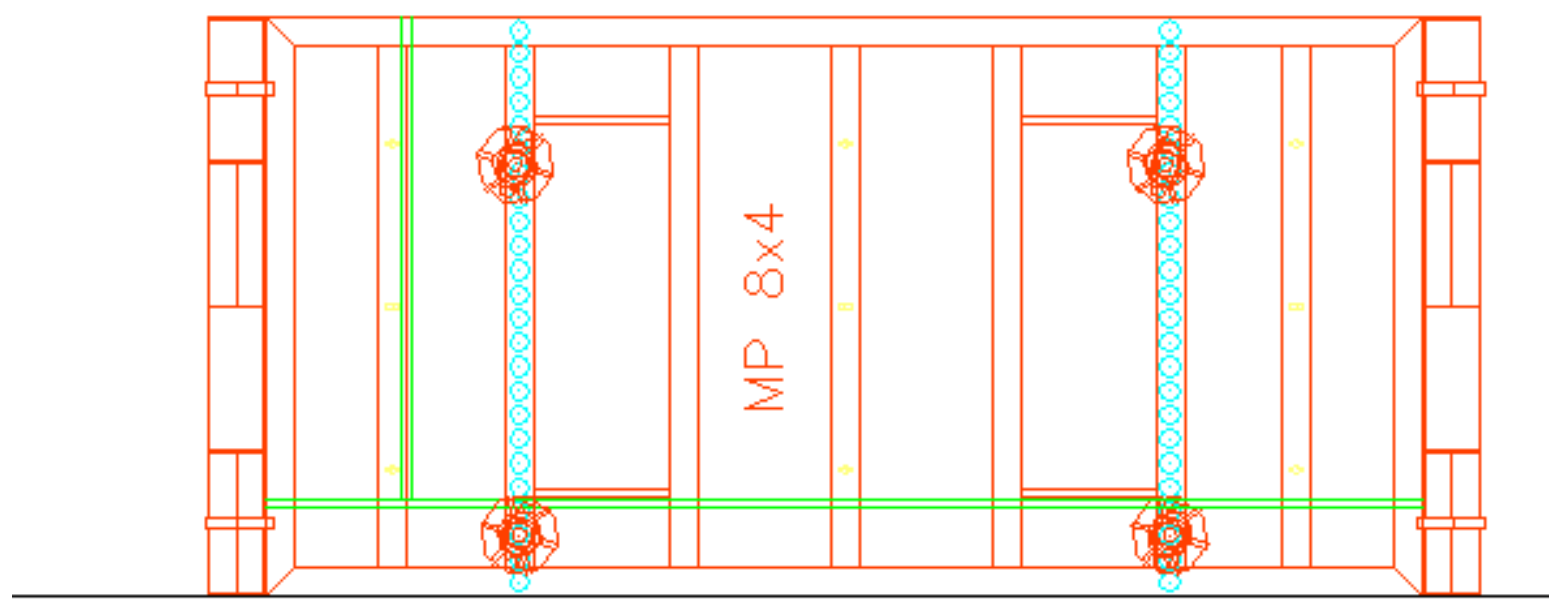

Fig. 36. Elevation view of the formwork required to cast the wall lying down. 


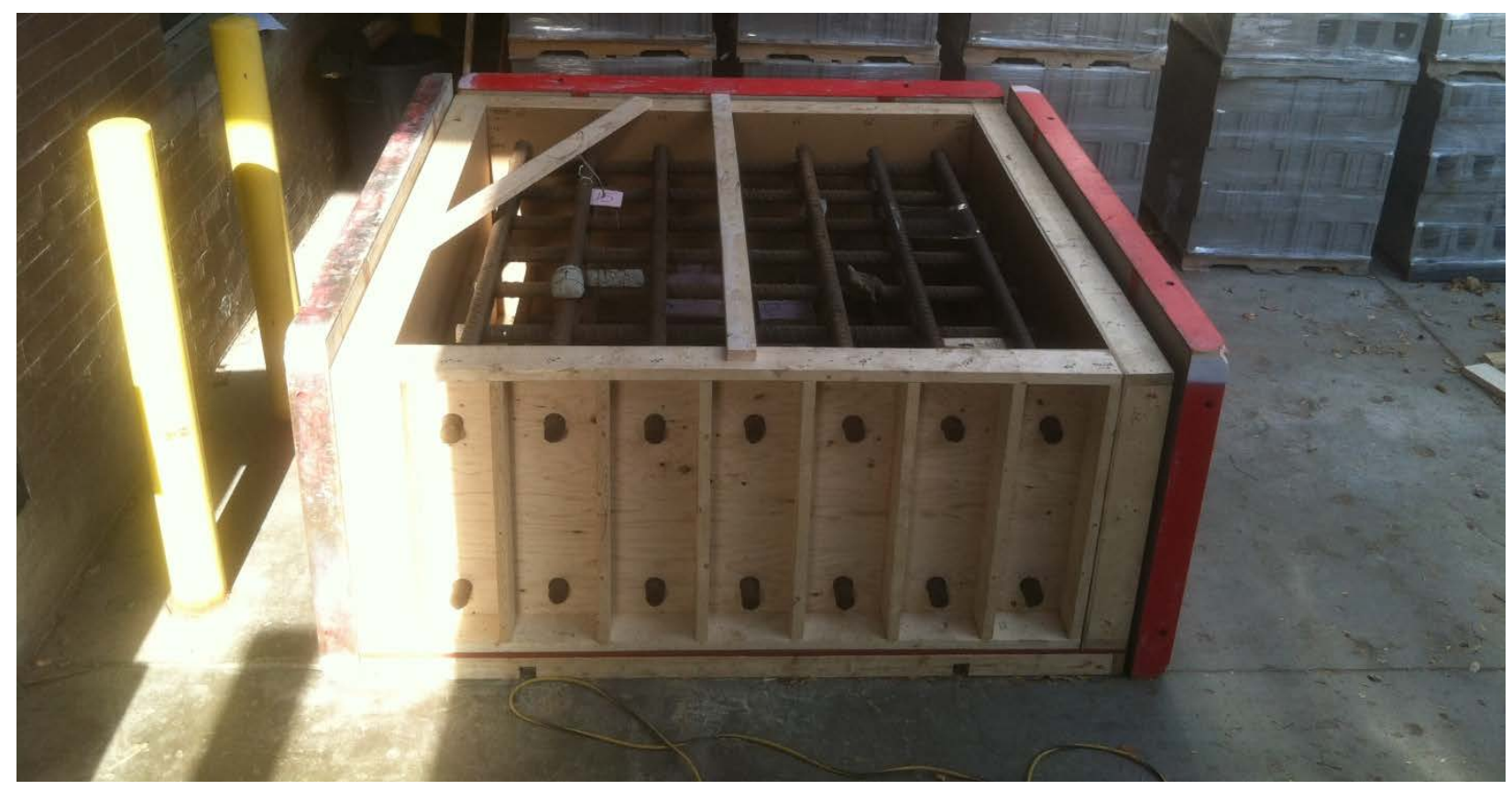

Fig. 37. Photograph of the formwork required to cast the wall lying down.

A plywood blockout system was required to hold the reinforcement in place, space the formwork to the necessary dimensions, and insulate the sides of the specimen from cold weather during curing (see Fig. 38). A false-bottom base was fabricated to allow for a clamping process on the outside of the specimen (see Fig. 39). It can also be observed from Fig. 39 that the side wall blockouts were fabricated to hold the reinforcement in place. Similar fabrications were made to the remaining side wall to hold the PVC inserts in place. As can be observed from Fig. 40, tie wires were used to secure the reinforcement and defects in place.
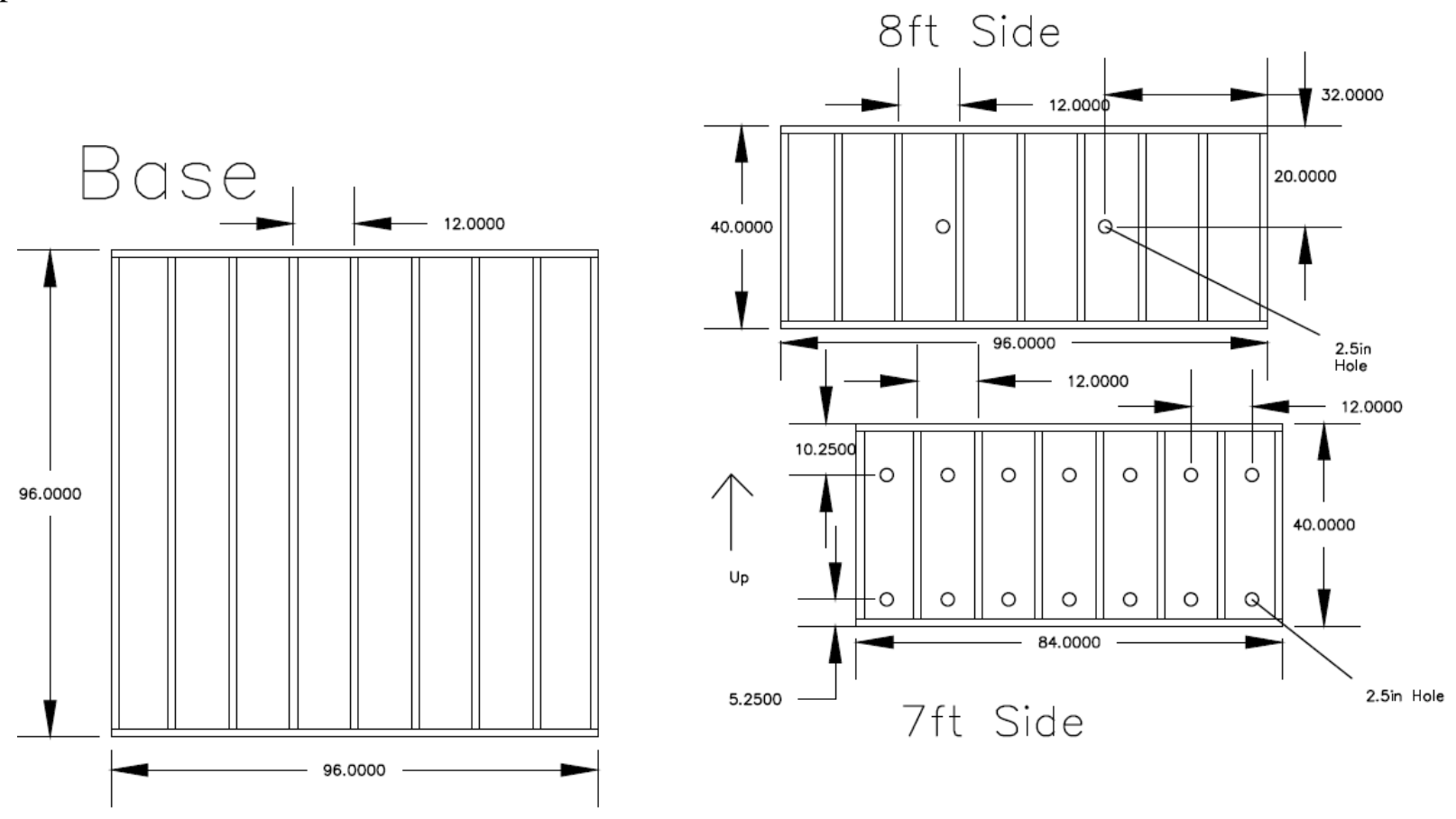

Fig. 38. Schematic of the plywood blockouts. 


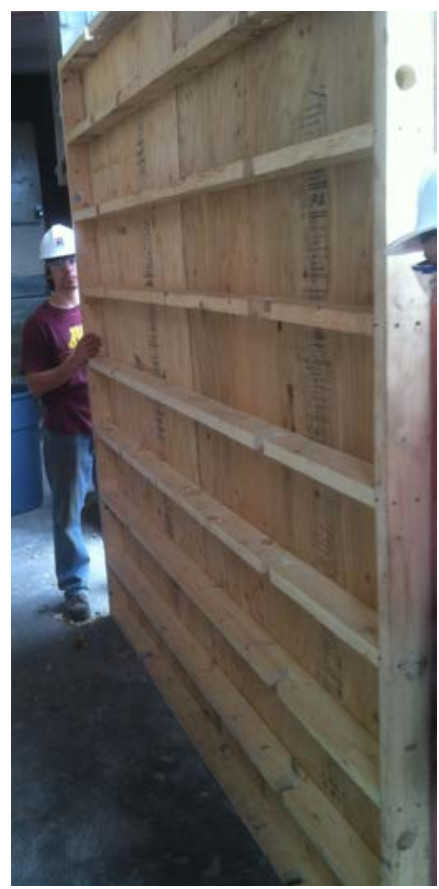

(a)

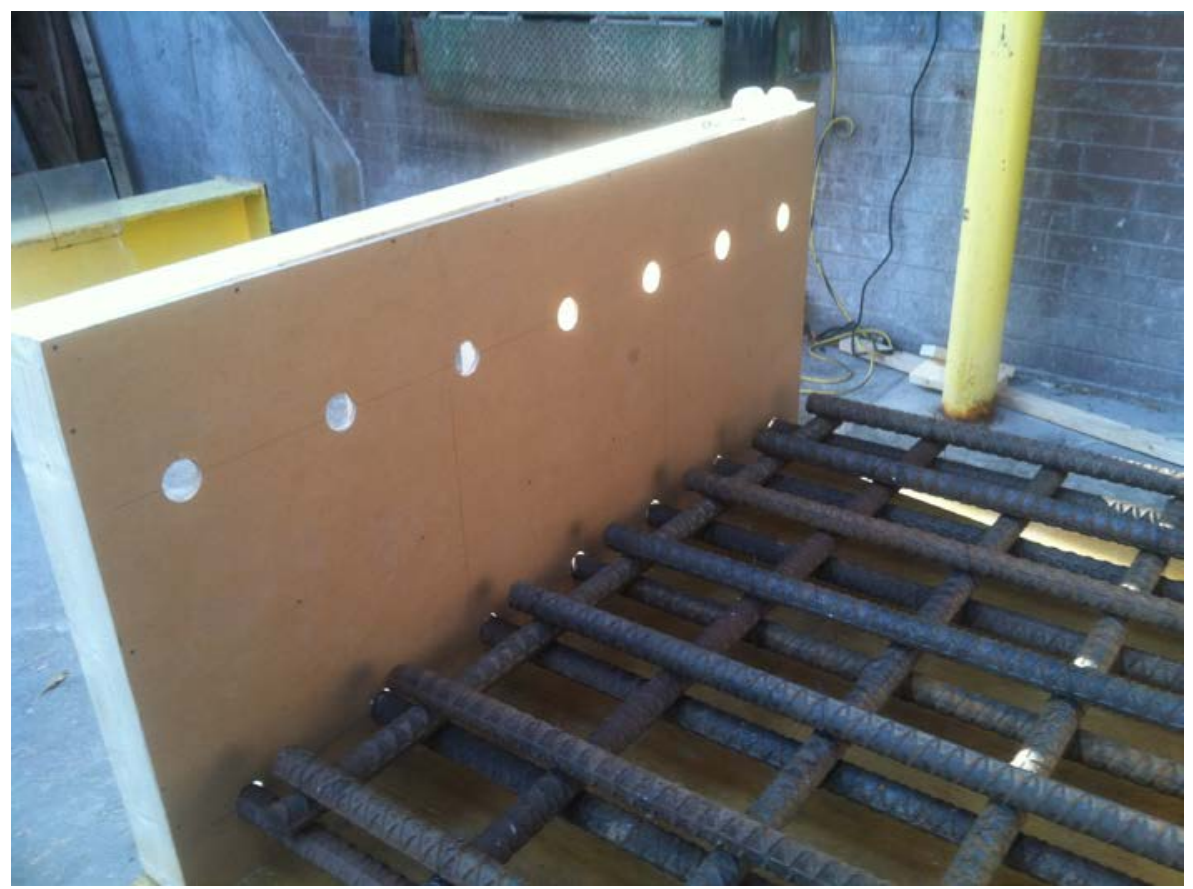

(b)

Fig. 39. Plywood blockout and reinforcement holding system.

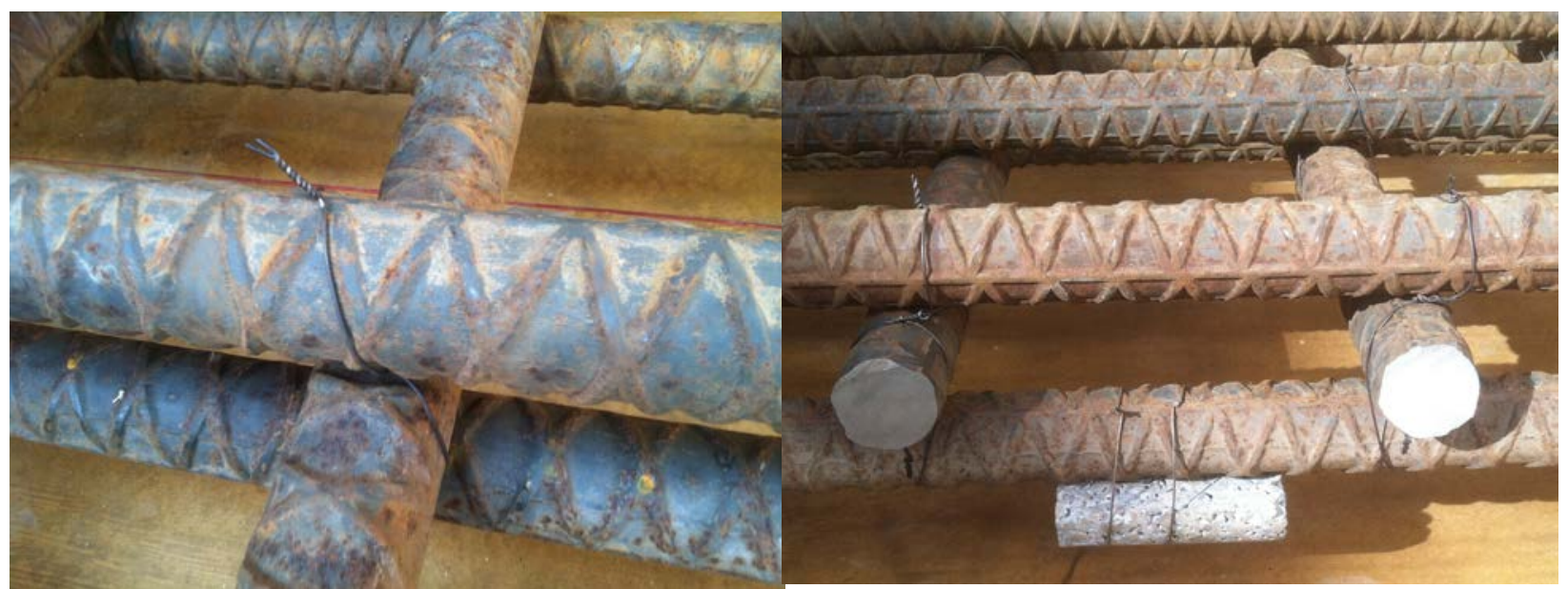

(a)

(b)

Fig. 40. Use of tie wires to hold the rebar and defects secure. 
Once the cuts were made and formwork and related materials were obtained, the following general procedure allowed for safe preparation for the pour.

1. Assemble individual plywood frames according to diagrams.

2. Screw plywood onto the frames, confirming frames are square with the plywood attached.

3. Cut holes and slots in base formwork according to the diagram.

4. Mark and cut the holes on the 7 and $8 \mathrm{ft}$ sides according to the diagrams.

5. Cut \#18 rebar to length:

- $14 @ 7 \mathrm{ft} 6$ in. (to allow for securing in the plywood blockouts)

- $28 @ 6 \mathrm{ft} 4$ in.

6. Set up $7 \mathrm{ft}$ side forms.

- $\quad$ Place them on top of the base on opposite sides.

- $\quad$ Make sure they are centered.

- $\quad$ Screw the bottom $2 \times 6$ into the base frame.

7. Set up temporary $2 \times 4$ bracing between the two $7 \mathrm{ft}$ side forms to provide stability when the rebar is placed.

8. Place and tie rebar.

- Start with the bottom set of rebar.

- $\quad$ Place rebar through holes in $7 \mathrm{ft}$ side formwork first.

- Place next level of rebar on top of that.

- Rebar should be tied at all joints.

9. Set up $8 \mathrm{ft}$ side forms.

- Screw the bottom $2 \times 6$ into the base form.

- Screw the sides into the sides of the $7 \mathrm{ft}$ side form.

10. Set up the sides of the shoring formwork.

- Clamp all four corners.

- Use two clamps per connection.

11. Place through rods through the shoring forms.

- $\quad$ They should go through the very bottom and very top holes of the shoring formwork.

- $\quad$ For the bottom rods, special nuts are required to clear the ground when tightened.

- Screw couples onto the rod and push through the bottom holes.

- Double-check tightened nuts with a wrench.

The form was assembled ahead of time to ensure that all simulated defects could be properly secured prior to casting of the specimen. Figure 41 shows the final clamped formwork setup after assembly, including lumber and fixing mechanisms for the defects and associated features. The temperature was around $41^{\circ} \mathrm{F}$ during casting, with overnight temperatures approaching freezing. To mitigate negative effects on the hydration process, additional insulation was added to the top of the specimen after the pour to supplement the plywood blockout insulation (see Fig. 42). Ultrasound velocity measurements and the warm surface after two days suggested proper hydration of the specimen. 


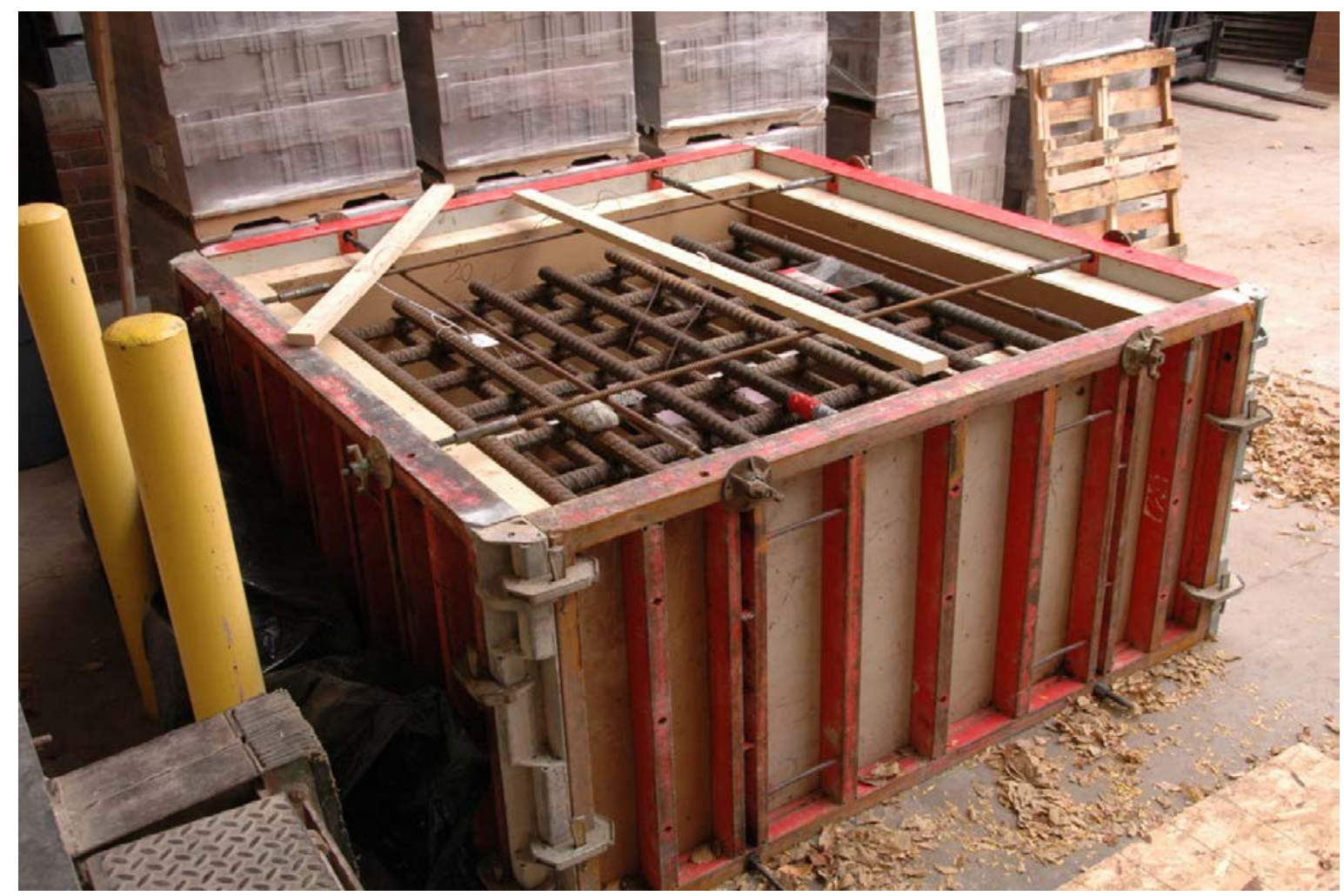

Fig. 41. Fully secured formwork.

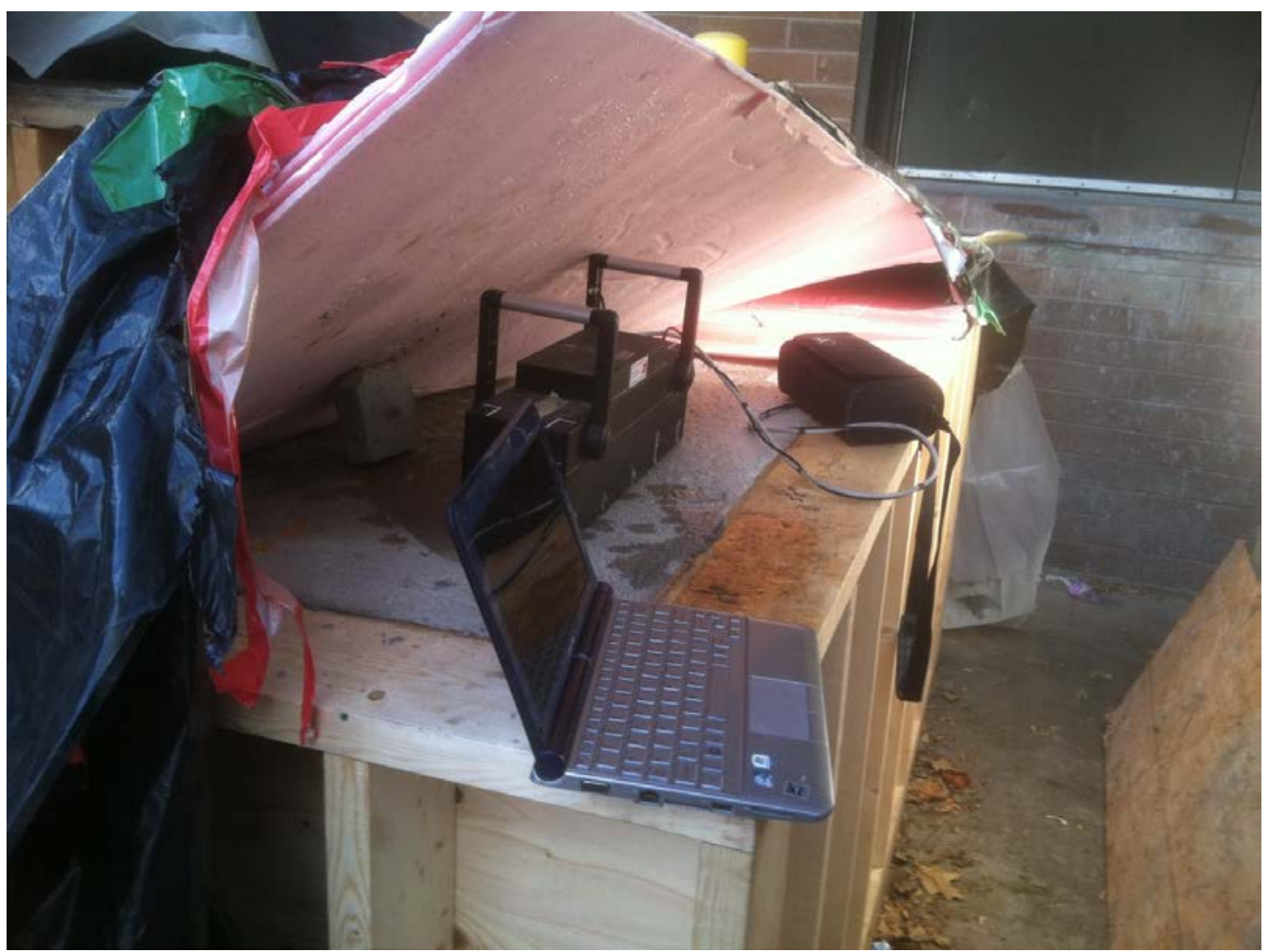

Fig. 42. Plywood, Stryrofoam, and construction blankets used to insulate the specimen. 



\section{SPECIMEN MOBILITY AND DATA COLLECTION ACCESS}

Detailed planning of the formwork and associated fixtures allowed for safe mitigation of the complexities involved with construction and movement of a large reinforced concrete specimen. Placement of the PVC pipe within the specimen allowed for the crane operation required to move and tilt the specimen. As can be observed from Fig. 43, transport involved use of a flatbed truck to crane the specimen into the testing location at the MAST lab. The tilting process also required special precaution since there is no confining force along the depth axis of the wall, and there was a potential for laminar cracking to occur (similar to the distresses observed in Fig. 3, Fig. 6, and Fig. 7) along the reinforcement and simulated defect locations during the crane tilting and transport process. Tilting was controlled by including a second crane to pick up the bottom of the specimen while the top was tilted up (see Fig. 44). Once the specimen was placed in position, it was secured to prevent potential tipping of the specimen (see Fig. 45).

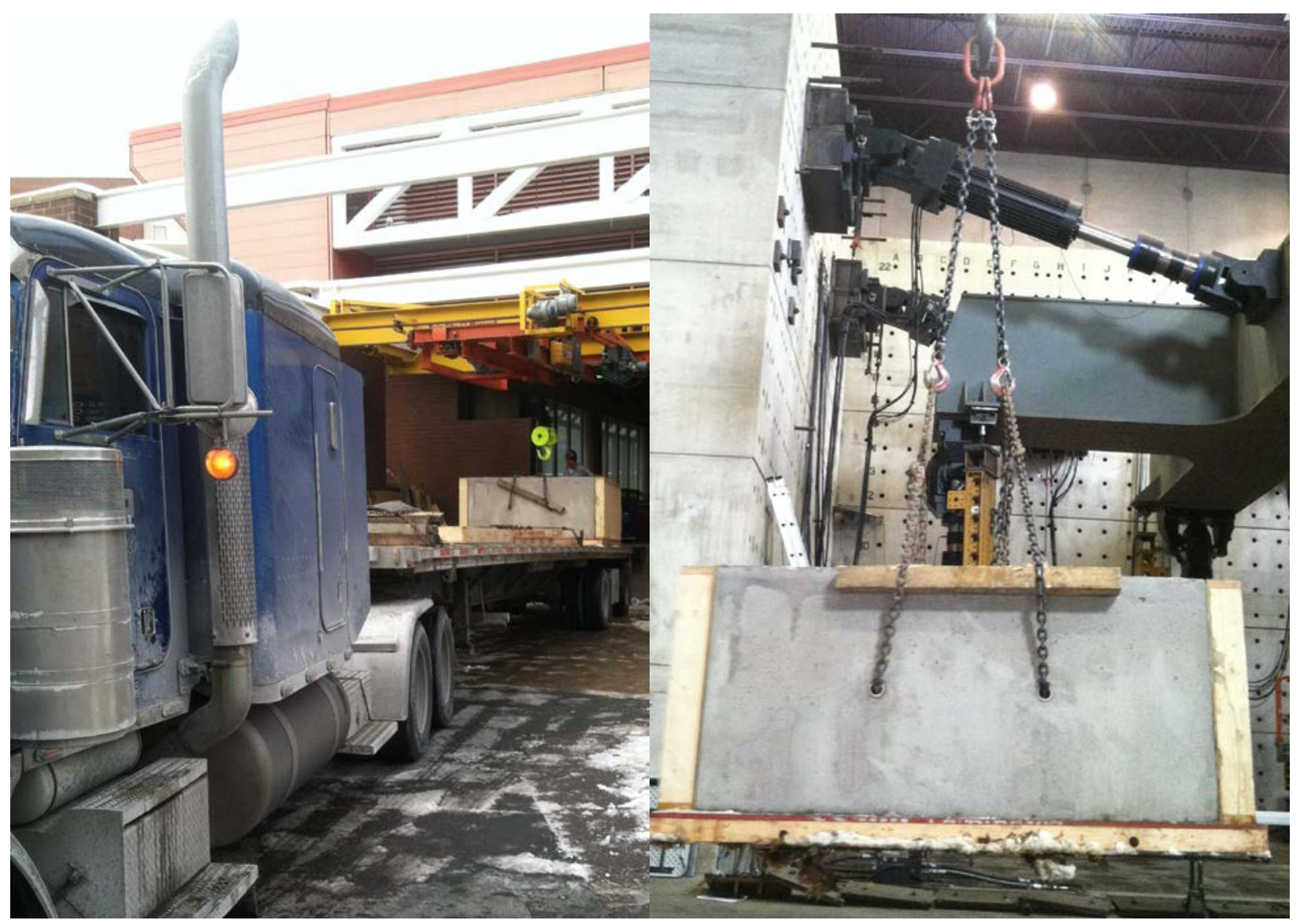

(a)

(b)

Fig. 43. Movement of the specimen from the casting location to the testing location. 


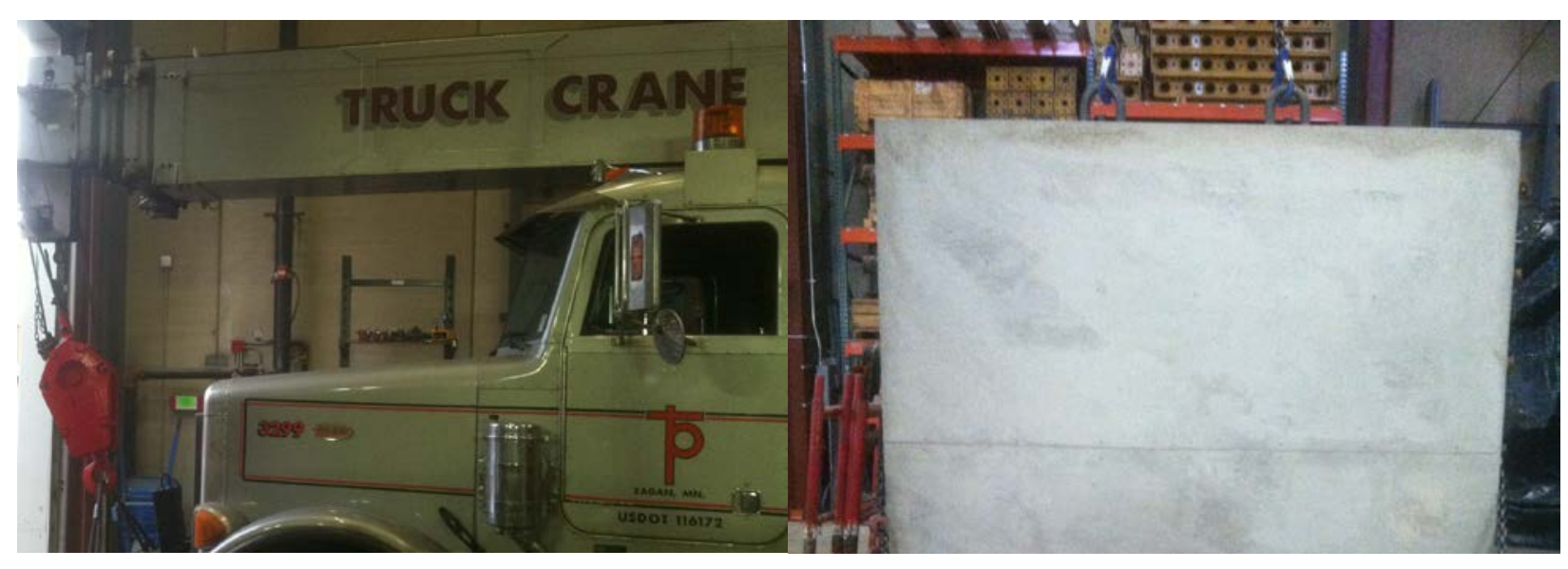

(a)

(b)

Fig. 44. Use of a second crane to pick the bottom while the specimen is tilted up.

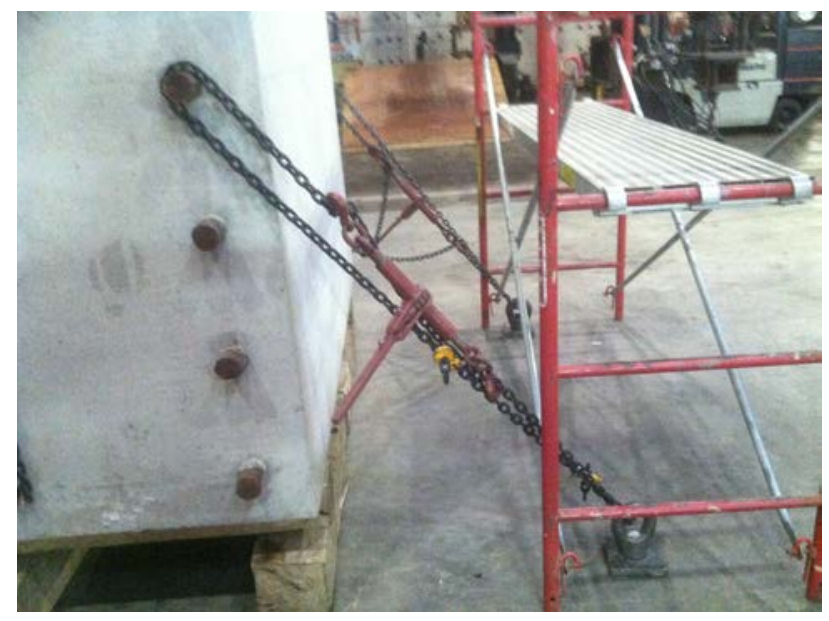

(a)

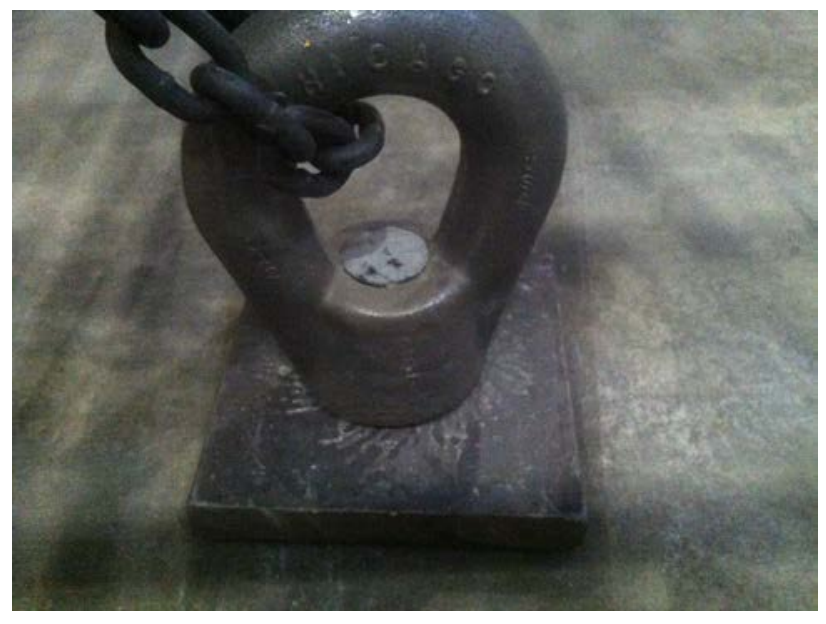

(b)

Fig. 45. Mechanism used to clamp the specimen into place.

The specimen was propped up on blocks for testing the lower portions, and necessary platforms were available for testing of the higher portions. The specimen was also marked to allow for productive systematic testing of both sides, to permit comparative analysis. The height and length origin was constant for both data sides, while the depth origin was set equal to the testing surface location, with "R_Depth” denoting the depth from the rough (finished) surface and S_Depth" denoting the depth from the smooth (original formwork floor during casting) surface. These surfaces were both marked with 4 in. (101.6 mm) by 4 in. (101.6 mm) grids to allow for precise systematic testing on each side in both height and length orientations. Figures 46 and 47 show the smooth and rough surfaces, respectively. 


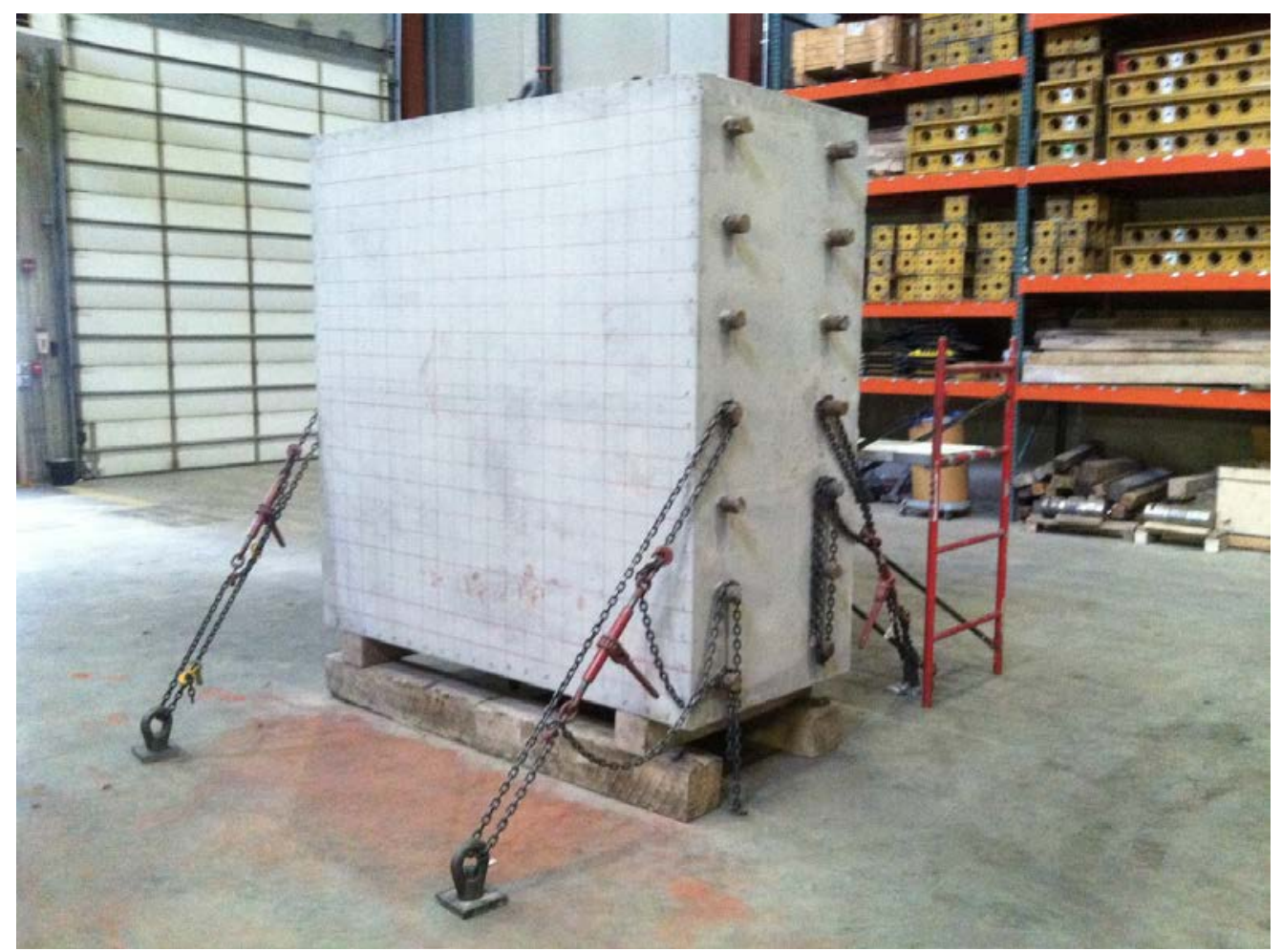

Fig. 46. Smooth surface of the specimen.

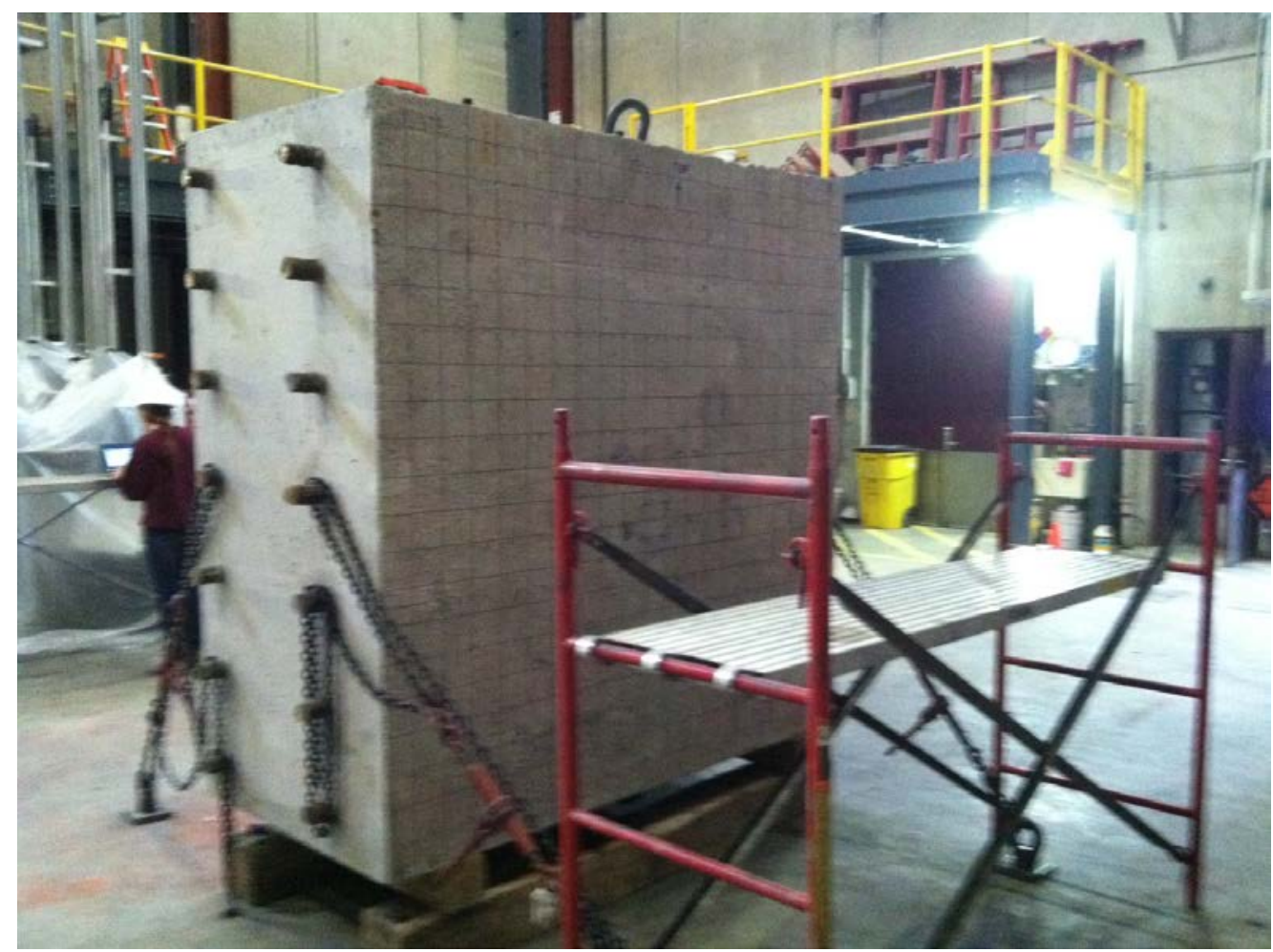

Fig. 47. Rough surface of the specimen. 



\section{INITIAL RESULTS AND DISCUSSION}

\subsection{DATA COLLECTION}

MIRA ultrasound measurements were taken independently on both sides of the specimen thickness. The ultrasonic tomography method presented in this report eliminates some of the issues associated with use of ultrasound to evaluate complex structures like reinforced concrete. One improvement is the use of dry point contact (DPC) transducers, which eliminates the issues associated with using liquid couples and only one signal. The dry point contact is possible due to the small size of the contact zone of each transducer (less than 1-2 mm [0.04-0.08 in.]). For this contact zone size, the transducer produces an oscillating force that can be treated as a point force. In this case, a contact liquid couple is not required for transmission of the shear wave to the tested medium [45].

The transducers have been developed with the capability of transmitting relatively low frequency (operating at $50 \mathrm{kHz}$ in this study) shear waves to penetrate to the necessary depths without relying on liquid coupling. Each transducer consists of two parallel piezoelectric elements surrounded by a liquid composite material. The transducer can be used as a transmitter or receiver. Each transmitting-receiving pair radiates and receives a transformable short duration shear wave impulse. The shear wave impulses are generated by oscillating the piezo-elements at a 180 degree time lag (antiphase). Self-reverberation noise is kept to a low level by damping with a liquid composite material that surrounds the piezoelements [45].

Use of these transducers allows for multiple measurement pairs in each scan, with the version used in this study (MIRA version 1) incorporating 10 channels, each composed of four transmitting and receiving transducers in a linear array. This linear array operates in a multi-static nature, allowing for 45 transmitting and receiving pair time-of-flight measurements in less than three seconds per scan. The spacing between adjacent transducer channels is $40 \mathrm{~mm}$ (1.6 in.). Thus, horizontally spaced measurement pairs in each MIRA scan include nine pairs at $40 \mathrm{~mm}$ (1.6 in.) spacing, eight pairs at $80 \mathrm{~mm}$ (3.1 in.) spacing, seven pairs at $120 \mathrm{~mm}$ (4.7 in.) spacing, six pairs at $160 \mathrm{~mm}$ (6.3 in.) spacing, five pairs at $200 \mathrm{~mm}$ (7.9 in.) spacing, four pairs at $240 \mathrm{~mm}$ (9.4 in.) spacing, three pairs at $280 \mathrm{~mm}$ (11.0 in.) spacing, two pairs at $320 \mathrm{~mm}$ (12.6 in.) spacing, and one pair at $360 \mathrm{~mm}$ (14.2 in.) spacing.

The data obtained from the transducers can be processed using SAFT to produce an image called a SAFT B-scan, which gives a visual representation of the cross section of the scanned area from multiple measurement pairs in each scan. The superposition of multiple transducer pair measurements and calculation of instantaneous amplitude along each reconstruction column allow for a dimensionless relative reflectivity map of changes in acoustic impedance below the scan locations [9]. The use of overlapping measurements along the cross section of each individual SAFT-B scan can allow for an extended reconstruction of the entire width and length of the specimen. To allow for a systematic testing procedure, the specimen was gridded in 4 in. $(102 \mathrm{~mm})$ squares covering the $84 \mathrm{in} . \times 84 \mathrm{in}$. total length and width of the specimen. Since the width of the device is approximately $16 \mathrm{in}$. (407 mm), the first and last measurement of each reconstruction was centered 8 in. $(203.2 \mathrm{~mm})$ from the edge, resulting in a total of 18 overlapping measurements within each extended reconstruction covering the entire dimension of the specimen in the direction of the current set of scans. Due to boundary effects near the edge of the specimen, the first and last extended scans were taken centered 6 in. away from the edge perpendicular to the scan orientation, resulting in a total of 19 extended reconstructions per orientation. The extended ultrasound reconstruction of an entire span is referred to herein as a synthetic aperture focusing technique panoramic (SAFT-PAN). Tables 7 and 8 give the data information as well as the orientation and location of each SAFT-PAN. The first and last SAFT-PAN in each orientation was centered 6 in. (152.4 mm) from the edge. Representations of data collection for both orientations of the device used to generate SAFT-PAN are given in Fig. 48 and Fig. 49. Figure 48 represents the data collected to create a SAFTPAN reconstruction spanning the length direction on the smooth surface. Figure 49 represents the data collected to create a SAFT-PAN reconstruction spanning the height direction. Each individual scan covers 
approximately 16 in. Measurements were taken in 4 in. step sizes within each SAFT-PAN, allowing for use of overlapping measurements to create the full reconstruction. The scans were taken following two rules for consistency in creating and labeling SAFT-PAN. All scans within a panoramic reconstruction moved left to right in the direction of increasing length or height, depending on the current orientation, and subsequent SAFT-PAN move in the direction the device is facing. To fulfill these criteria, the testing procedure included increasing SAFT-PAN moving in opposite directions when testing on the rough and smooth side. Schematics for the testing procedure to create SAFT-PAN for rough and smooth side measurements are shown in Fig. 50 through Fig. 53. Figures 50 and 51 show the length orientation SAFTPAN for the rough and smooth sides, respectively. Figures 52 and 53 show the height orientation SAFTPAN for the rough and smooth sides, respectively. Appendixes B and C gives more details on the data collection and reconstruction results. 
A- 7. Smooth side testing locations (December 16, 2014)

\begin{tabular}{|c|c|c|c|c|c|c|c|}
\hline Time & Band & Orientation & $\begin{array}{l}\text { Starting } \\
\text { position }\end{array}$ & $\begin{array}{l}\text { Ending } \\
\text { position }\end{array}$ & Pan\# & $\begin{array}{l}\text { Height } \\
\text { location } \\
\text { (mm) }\end{array}$ & $\begin{array}{l}\text { Length } \\
\text { location } \\
\text { (mm) }\end{array}$ \\
\hline 9:08 & 1 & length & 1 & 18 & 1 & 1981 & all \\
\hline 9:08 & 2 & length & 19 & 36 & 2 & 1880 & $\overline{\text { all }}$ \\
\hline 9:08 & 3 & length & 37 & 54 & 3 & 1778 & all \\
\hline 9:08 & 4 & length & 55 & 72 & 4 & 1676 & all \\
\hline 9:08 & 5 & length & 73 & 90 & 5 & 1575 & all \\
\hline 9:08 & 6 & length & 91 & 108 & 6 & 1473 & all \\
\hline 9:08 & 7 & length & 109 & 126 & 7 & 1372 & all \\
\hline 9:08 & 8 & length & 127 & 144 & 8 & 1270 & all \\
\hline 9:08 & 9 & length & 145 & 162 & 9 & 1168 & all \\
\hline 9:08 & 10 & length & 163 & 180 & 10 & 1067 & all \\
\hline 9:08 & 11 & length & 181 & 198 & 11 & 965 & all \\
\hline 9:08 & 12 & length & 199 & 216 & 12 & 864 & all \\
\hline 9:08 & 13 & length & 217 & 234 & 13 & 762 & all \\
\hline 9:08 & 14 & length & 235 & 252 & 14 & 660 & all \\
\hline 9:08 & 15 & length & 253 & 270 & 15 & 559 & $\overline{\text { all }}$ \\
\hline 9:08 & 16 & length & 271 & 288 & 16 & 457 & all \\
\hline 9:08 & 17 & length & 289 & 306 & 17 & 356 & all \\
\hline 9:08 & 18 & length & 307 & 324 & 18 & 254 & all \\
\hline 10:03 & 1 & length & 325 & 342 & 19 & 152 & all \\
\hline 10:08 & 1 & height & 1 & 18 & 1 & $\overline{\text { all }}$ & 152 \\
\hline $10: 08$ & 2 & height & 19 & 36 & 2 & all & 254 \\
\hline $10: 08$ & 3 & height & 37 & 54 & 3 & all & 356 \\
\hline $10: 08$ & 4 & height & 55 & 72 & 4 & all & 457 \\
\hline $10: 08$ & 5 & height & 73 & 90 & 5 & all & 559 \\
\hline 10:08 & 6 & height & 91 & 108 & 6 & all & 660 \\
\hline $10: 08$ & 7 & height & 109 & 126 & 7 & all & 762 \\
\hline $10: 08$ & 8 & height & 127 & 144 & 8 & all & 864 \\
\hline $10: 08$ & 9 & height & 145 & 162 & 9 & all & 965 \\
\hline 10:08 & 10 & height & 163 & 180 & 10 & all & 1067 \\
\hline 10:08 & 11 & height & 181 & 198 & 11 & all & 1168 \\
\hline 10:08 & 12 & height & 199 & 216 & 12 & all & 1270 \\
\hline 10:08 & 13 & height & 217 & 234 & 13 & all & 1372 \\
\hline $10: 08$ & 14 & height & 235 & 252 & 14 & all & 1473 \\
\hline $10: 08$ & 15 & height & 253 & 270 & 15 & all & 1575 \\
\hline $10: 08$ & 16 & height & 271 & 288 & 16 & all & 1676 \\
\hline $10: 08$ & 17 & height & 289 & 306 & 17 & all & 1778 \\
\hline 10:08 & 18 & height & 307 & 324 & 18 & all & 1880 \\
\hline 10:08 & 19 & height & 325 & 342 & 19 & all & 1981 \\
\hline
\end{tabular}


A- 8. Rough side testing locations (November 25, 2014)

\begin{tabular}{|c|c|c|c|c|c|c|c|}
\hline Time & Band & Orientation & $\begin{array}{l}\text { Starting } \\
\text { position }\end{array}$ & $\begin{array}{l}\text { Ending } \\
\text { position }\end{array}$ & Pan\# & $\begin{array}{l}\text { Height } \\
\text { location } \\
\text { (mm) }\end{array}$ & $\begin{array}{l}\text { Length } \\
\text { location } \\
\text { (mm) }\end{array}$ \\
\hline 10:49 & 1 & length & 1 & 18 & 1 & 152 & all \\
\hline 10:49 & 2 & length & 19 & 36 & 2 & 254 & all \\
\hline 10:49 & 3 & length & 37 & 54 & 3 & 356 & all \\
\hline $10: 49$ & 4 & length & 55 & 72 & 4 & 457 & all \\
\hline $10: 49$ & 5 & length & 73 & 90 & 5 & 559 & all \\
\hline 10:49 & 6 & length & 91 & 108 & 6 & 660 & all \\
\hline 10:49 & 7 & length & 109 & 126 & 7 & 762 & all \\
\hline $10: 49$ & 8 & length & 127 & 144 & 8 & 864 & all \\
\hline $10: 49$ & 9 & length & 145 & 162 & 9 & 965 & all \\
\hline 10:49 & 10 & length & 163 & 180 & 10 & 1067 & all \\
\hline $10: 49$ & 11 & length & 181 & 198 & 11 & 1168 & all \\
\hline 10:49 & 12 & length & 199 & 216 & 12 & 1270 & all \\
\hline 10:49 & 13 & length & 217 & 234 & 13 & 1372 & all \\
\hline 10:49 & 14 & length & 235 & 252 & 14 & 1473 & all \\
\hline 10:49 & 15 & length & 253 & 270 & 15 & 1575 & all \\
\hline 10:49 & 16 & length & 271 & 288 & 16 & 1676 & all \\
\hline $10: 49$ & 17 & length & 289 & 306 & 17 & 1778 & all \\
\hline $10: 49$ & 18 & length & 307 & 324 & 18 & 1880 & all \\
\hline $10: 49$ & 19 & length & 325 & 342 & 19 & 1981 & all \\
\hline $11: 32$ & 1 & height & 1 & 18 & 1 & all & 1981 \\
\hline 11:32 & 2 & height & 19 & 36 & 2 & all & 1880 \\
\hline $11: 43$ & 1 & height & 37 & 54 & 3 & all & 1778 \\
\hline 11:43 & 2 & height & 55 & 72 & 4 & all & 1676 \\
\hline $11: 43$ & 3 & height & 73 & 90 & 5 & all & 1575 \\
\hline 11:43 & 4 & height & 91 & 108 & 6 & all & 1473 \\
\hline 11:43 & 5 & height & 109 & 126 & 7 & all & 1372 \\
\hline $11: 43$ & 6 & height & 127 & 144 & 8 & all & 1270 \\
\hline 11:43 & 7 & height & 145 & 162 & 9 & all & 1168 \\
\hline 11:43 & 8 & height & 163 & 180 & 10 & all & 1067 \\
\hline 11:43 & 9 & height & 181 & 198 & 11 & all & 965 \\
\hline 11:43 & 10 & height & 199 & 216 & 12 & all & 864 \\
\hline $11: 43$ & 11 & height & 217 & 234 & 13 & all & 762 \\
\hline 11:43 & 12 & height & 235 & 252 & 14 & all & 660 \\
\hline 11:43 & 13 & height & 253 & 270 & 15 & all & 559 \\
\hline 11:43 & 14 & height & 271 & 288 & 16 & all & 457 \\
\hline 11:43 & 15 & height & 289 & 306 & 17 & all & 356 \\
\hline $11: 43$ & 16 & height & 307 & 324 & 18 & all & 254 \\
\hline 11:43 & 17 & height & 325 & 342 & 19 & all & 152 \\
\hline
\end{tabular}




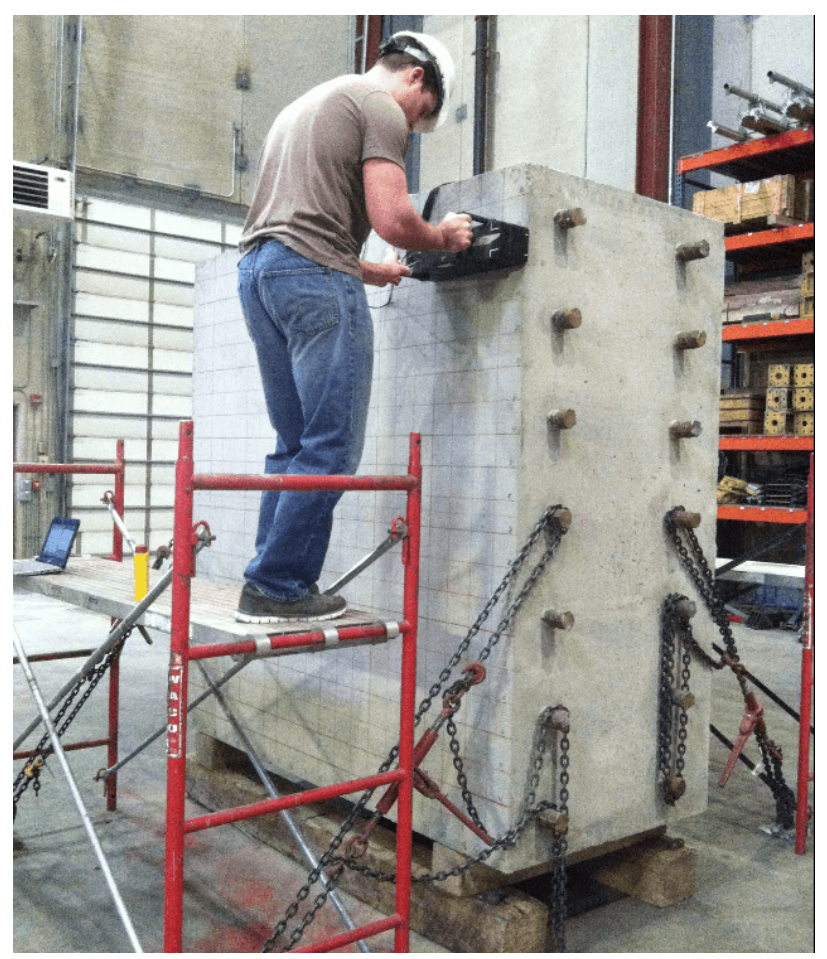

Fig. 48. Length data collection used to create a SAFT-PAN reconstruction.

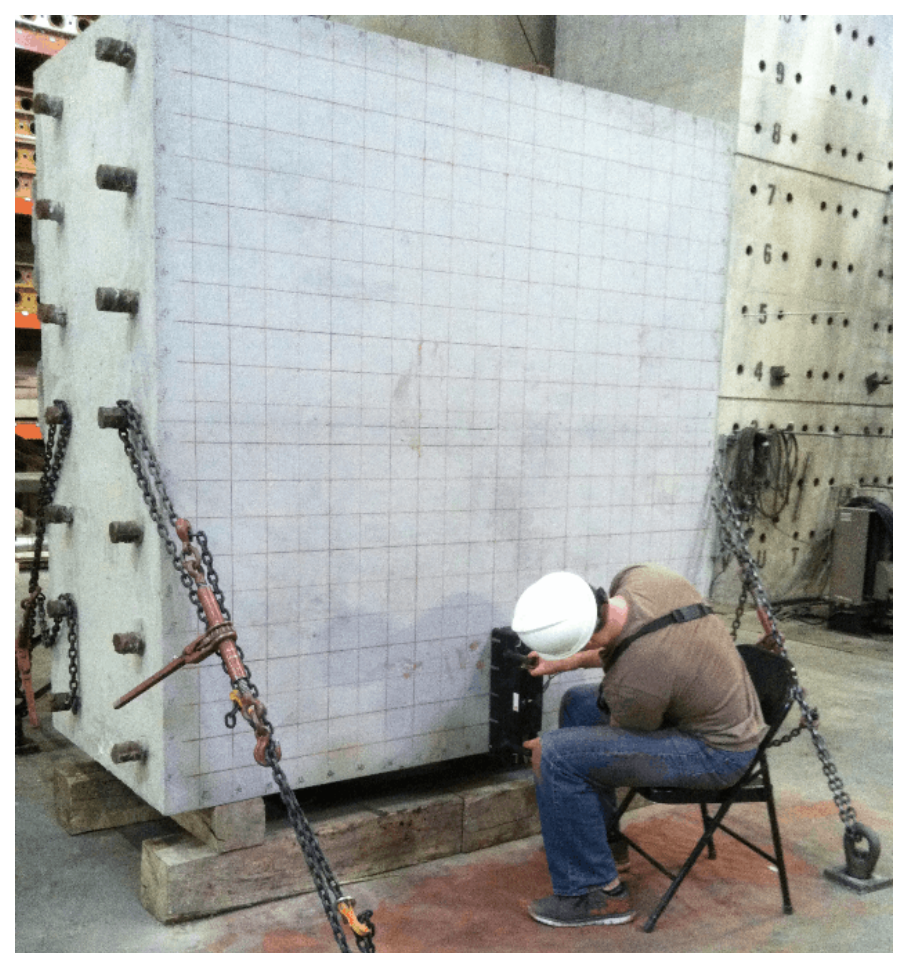

Fig. 49. Height data collection used to create a SAFT-PAN reconstruction. 


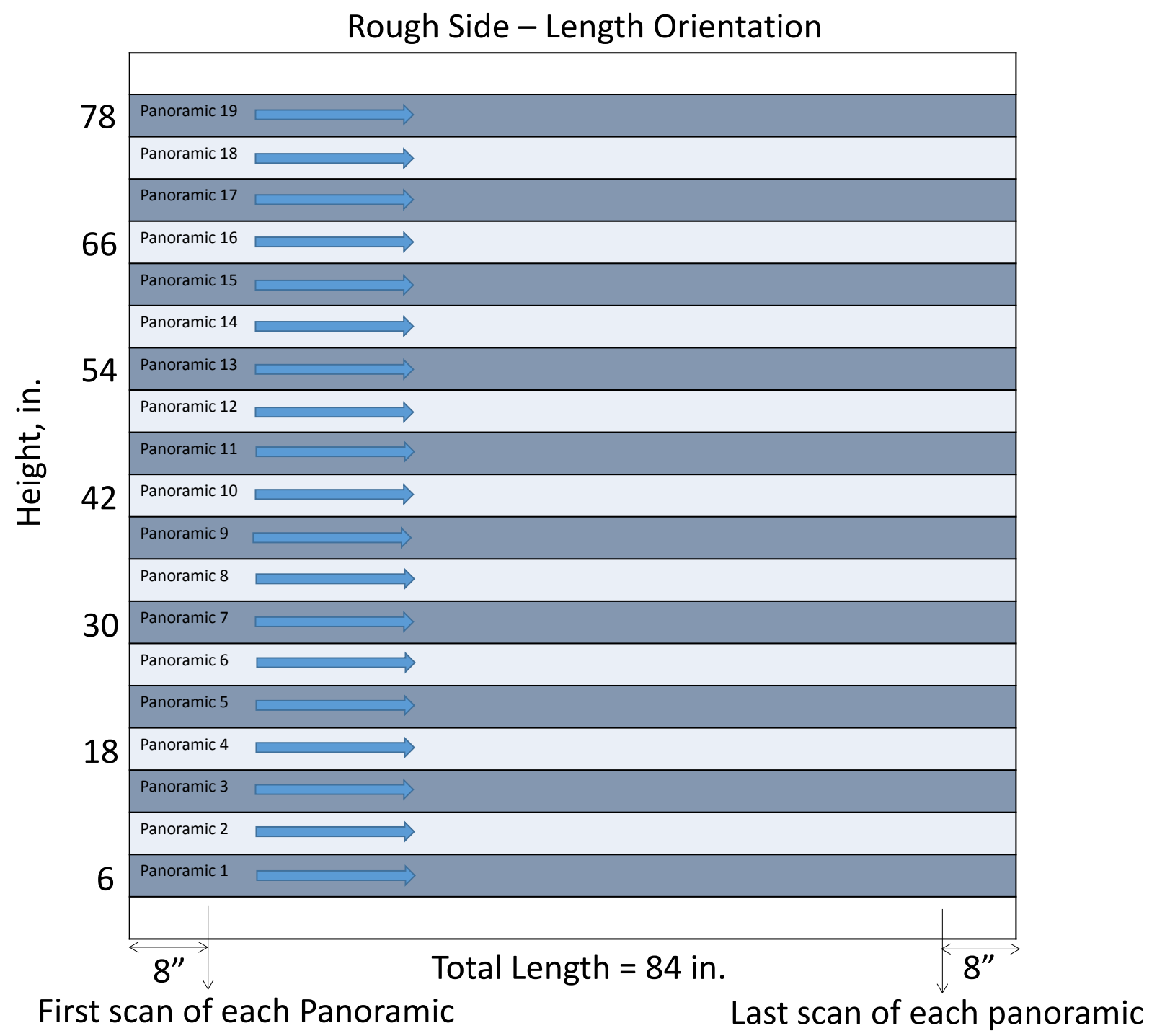

Fig. 50. Rough-side measurement procedure for length orientation measurements. 


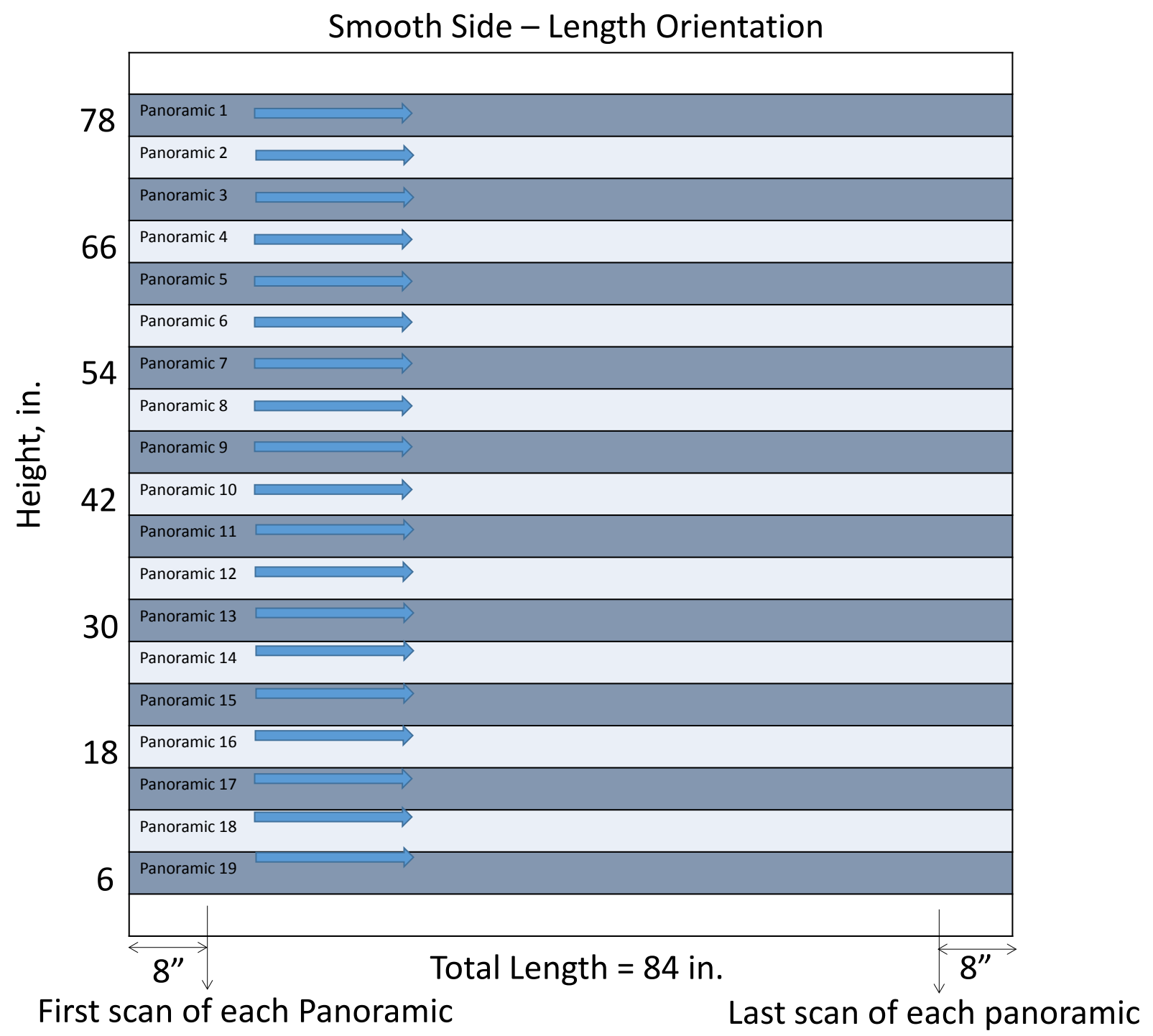

Fig. 51. Smooth-side measurement procedure for length orientation measurements. 


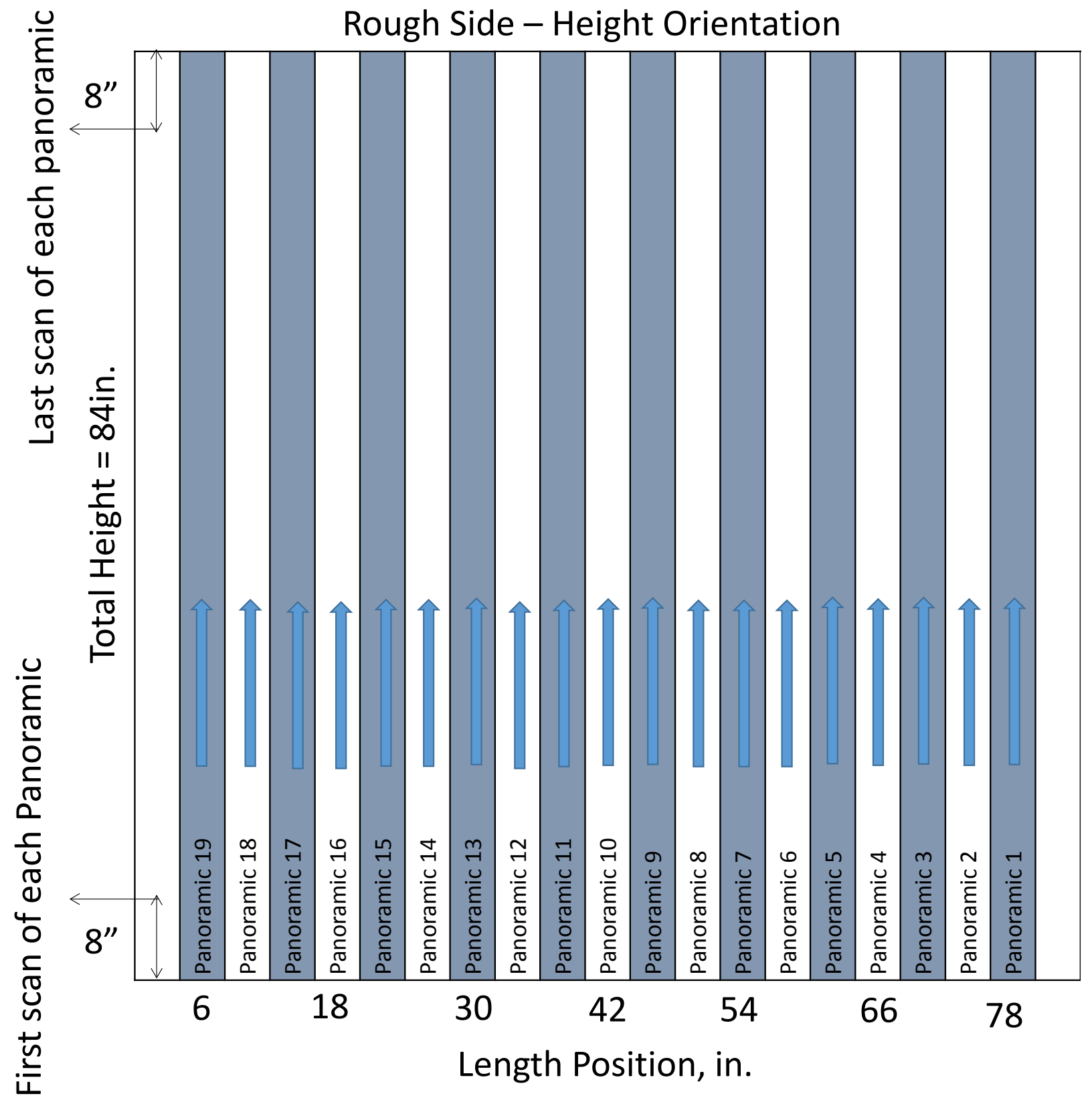

Fig. 52. Rough-side measurement procedure for height orientation measurements. 


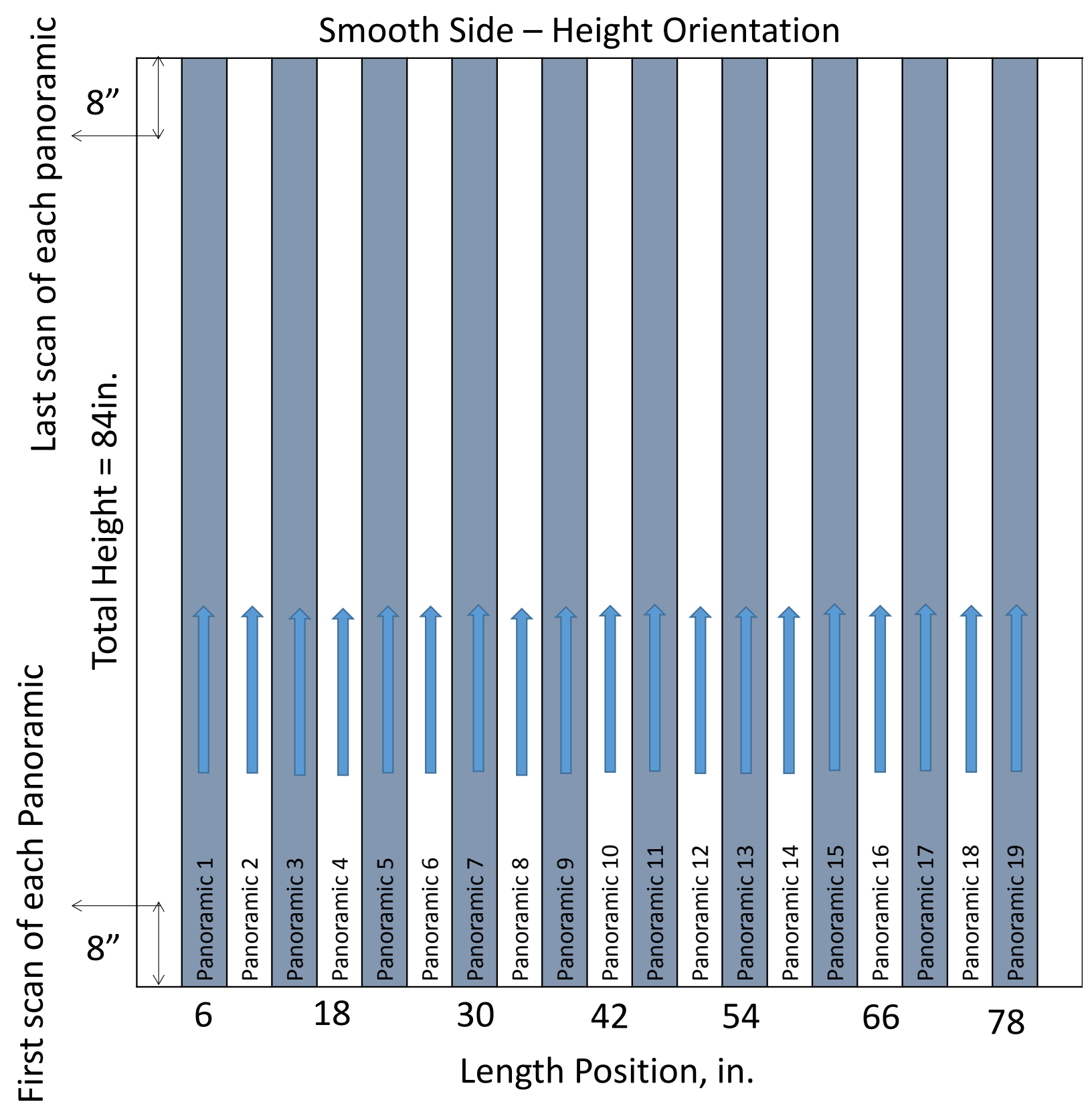

Fig. 53. Smooth-side measurement procedure for height orientation measurements.

\subsection{INITIAL ANALYSIS}

The systematic data collection process allows for SAFT-based reconstructions of subsurface characteristics. This type of analysis has been successfully used to create volumetric imaging of the type of defects embedded in this specimen, although for a smaller, less heavily reinforced specimen [9]. Initial analysis shows that a similar type of analysis can be applied to the larger, more heavily reinforced specimen in this study when the defects are relatively shallow $(\leq 400 \mathrm{~mm})$, especially if the defect is located between reinforced concrete locations. Appendixes A and B can be referenced for details of all defects, and all of the SAFT-PAN reconstructions can be observed in Appendix C. In this section, an 
example defect with supporting reconstructions are given to illustrate the effect of the large reinforced concrete structure as it relates to preliminary analysis.

Defect 12 (D12) consisted of a 12 in. $\times 12$ in. $\times 0.5$ in. $(305 \mathrm{~mm} \times 305 \mathrm{~mm} \times 13 \mathrm{~mm})$ Styrofoam block centered between reinforcements. The specimen was dissolved after the reinforced concrete specimen was cast by pouring acetone into an embedded tube (see Fig. 54). Figure 54 also shows a schematic of the defect location within the specimen. It should be noted that that the depth given in the schematic is from the smooth side of the specimen, while the depth of the corresponding reconstructions are given from the surface where MIRA was placed during testing.
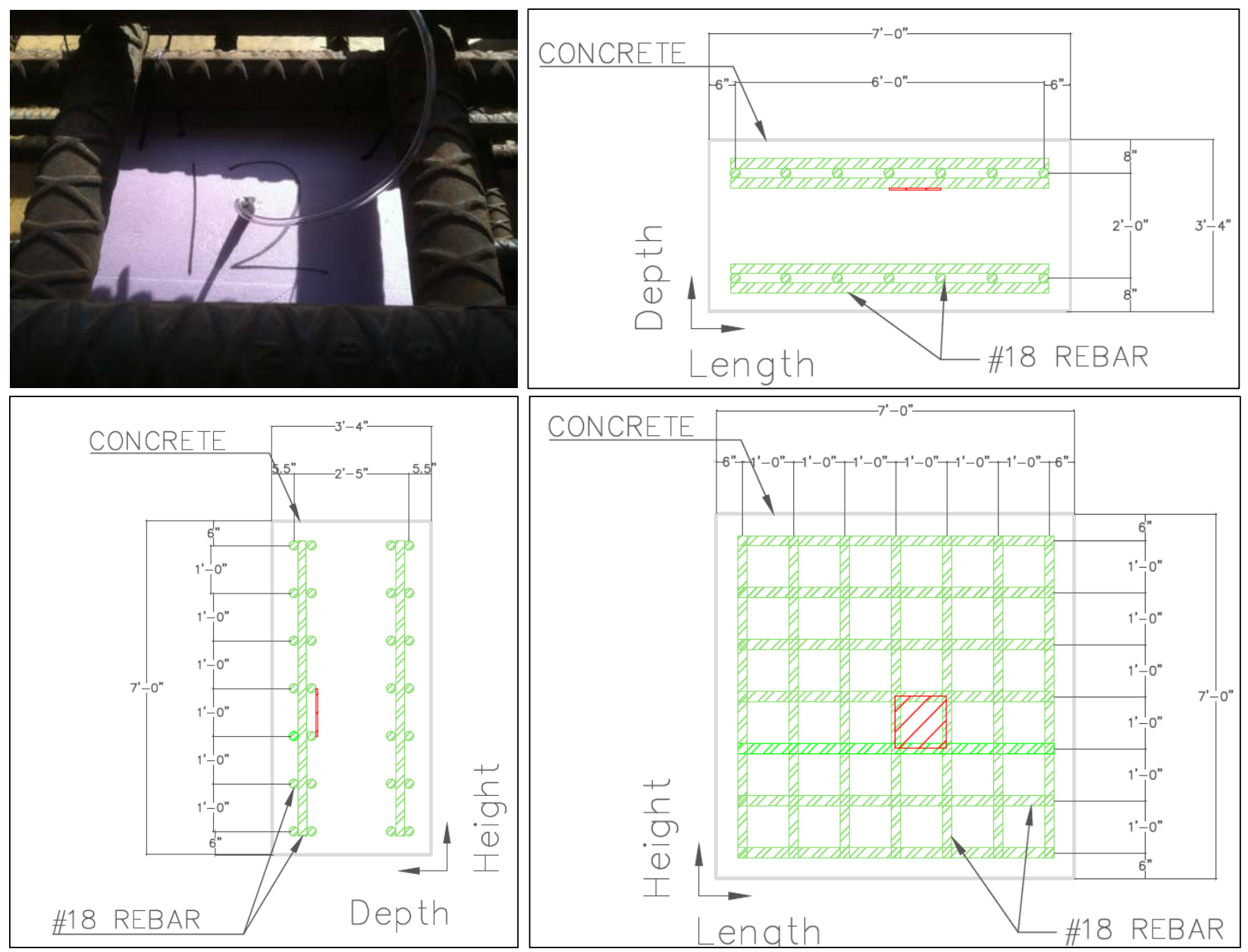

Fig. 54. Photograph of defect \#12 with diagrams of the location within the reinforced concrete.

Defect 3 (D03) consisted of a 5 in. $\times 4$ in. $\times 2$ in. $(127 \mathrm{~mm} \times 103 \mathrm{~mm} \times 51 \mathrm{~mm})$ porous concrete cube attached to a reinforcement. Figure 55 also shows a schematic of the defect location within the specimen. The depth given in the schematic is from the smooth side of the specimen, which also is the depth of the corresponding reconstruction shown in Fig. 59, since MIRA was placed on the smooth side of the specimen during testing for that example reconstruction. 

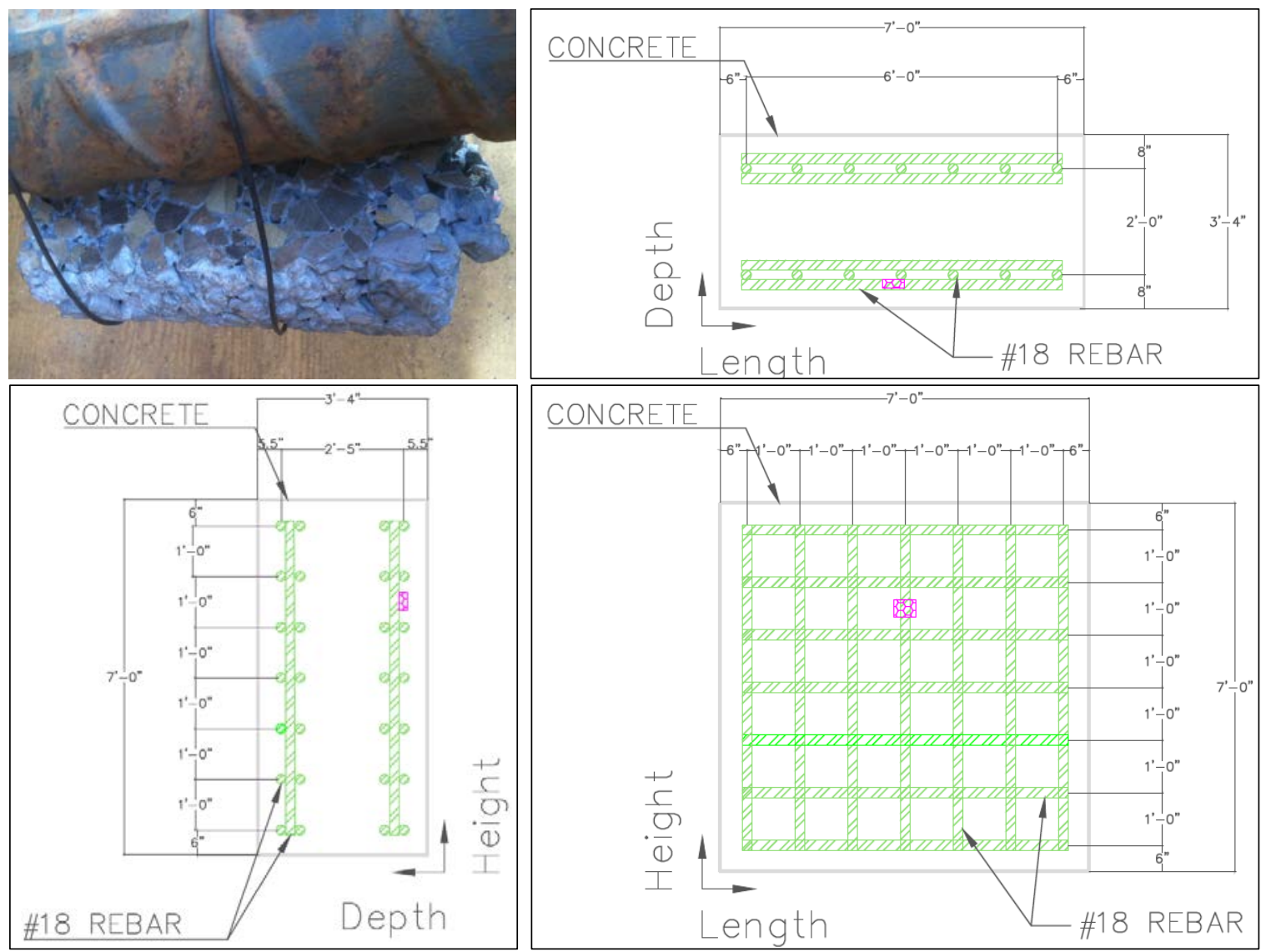

Fig. 55. Photograph and schematics showing the location of Defect \#03 (porous concrete).

It can be observed from the schematics and A- 6 that D12 was located closer to the rough surface as the distance from the smooth side at $283 \mathrm{~mm}$ and $733 \mathrm{~mm}$, respectively. Figure 55 shows the SAFT-PAN reconstruction showing the reflectivity at D12 as tested from the rough side of the specimen (shallower side of the specimen with respect to the defect) in the length orientation. SAFT-PAN 8 of Fig. 50 shows the location of this reconstruction within the block. Figure 56 shows the SAFT-Pan reconstruction showing the reflectivity at D12 as tested from the smooth side of the specimen (deeper side of the specimen with respect to the defect) in the length orientation. SAFT-PAN 12 of Fig. 57 shows the location of this SAFT-Pan reconstruction within the block. While an increase in reflectivity is observed in both cases, the threshold to be able to see the deeper defect is significantly lower ( $\sim 150$ relative reflectivity versus $\sim 250$ relative reflectivity). The need for a lower threshold can cause signal to noise issues as structural noise (such as aggregate and nominal air void content) becomes more prevalent in the reconstruction. This is especially true at the specimen thickness depth of $40 \mathrm{in}$. (1016 mm). Figure 58 shows an example SAFT-PAN showing the back wall reflection using a threshold of about 80 . It can be observed that, while there is an increase in reflectivity at the thickness of the specimen around $1016 \mathrm{~mm}$, there are also observable peaks in reflectivity at locations where no designed inclusions are present. 


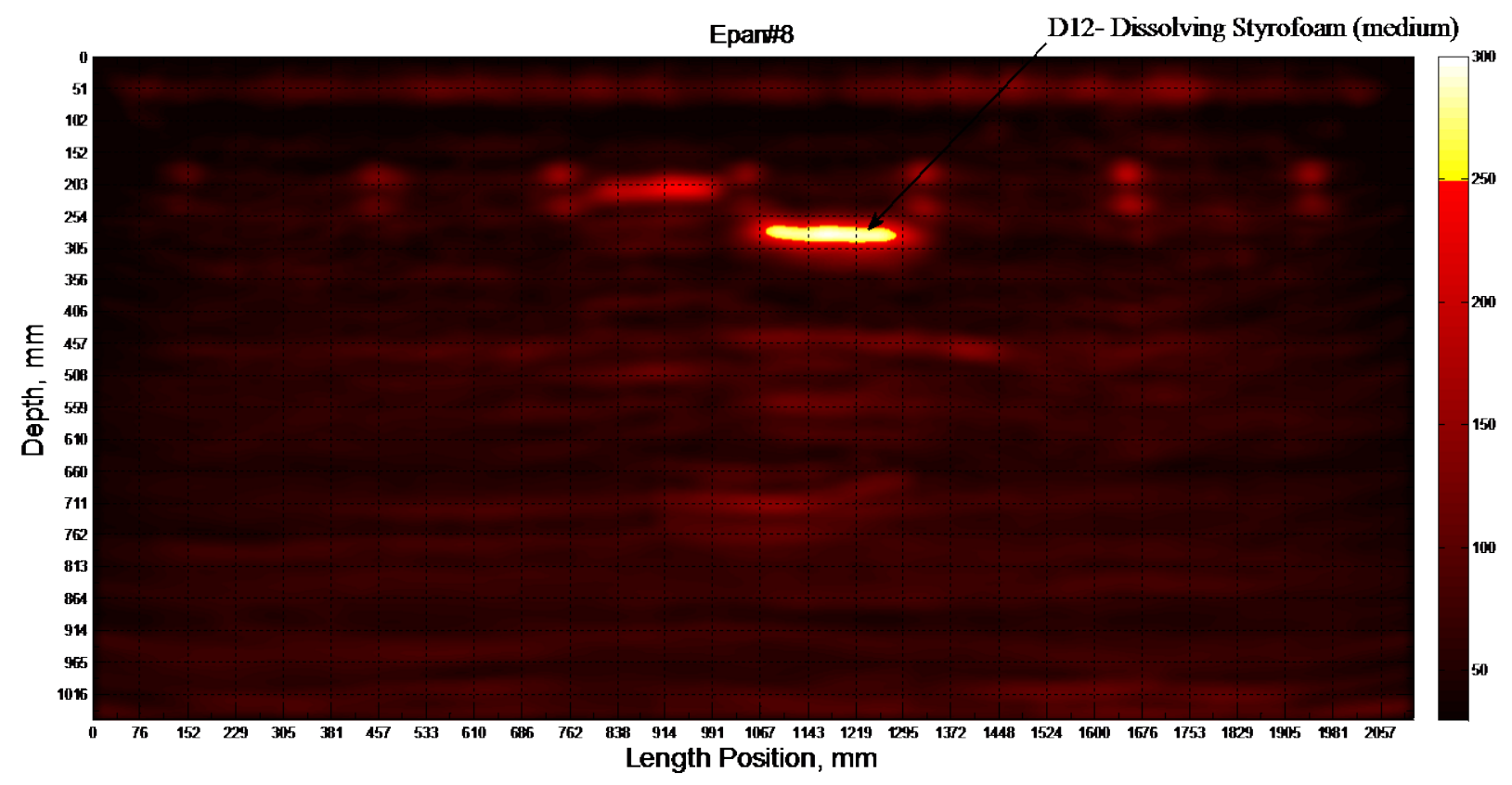

Fig. 56. SAFT-PAN reconstruction showing the reflectivity at D12 as tested from the rough side of the specimen (shallower side of the specimen with respect to the defect).

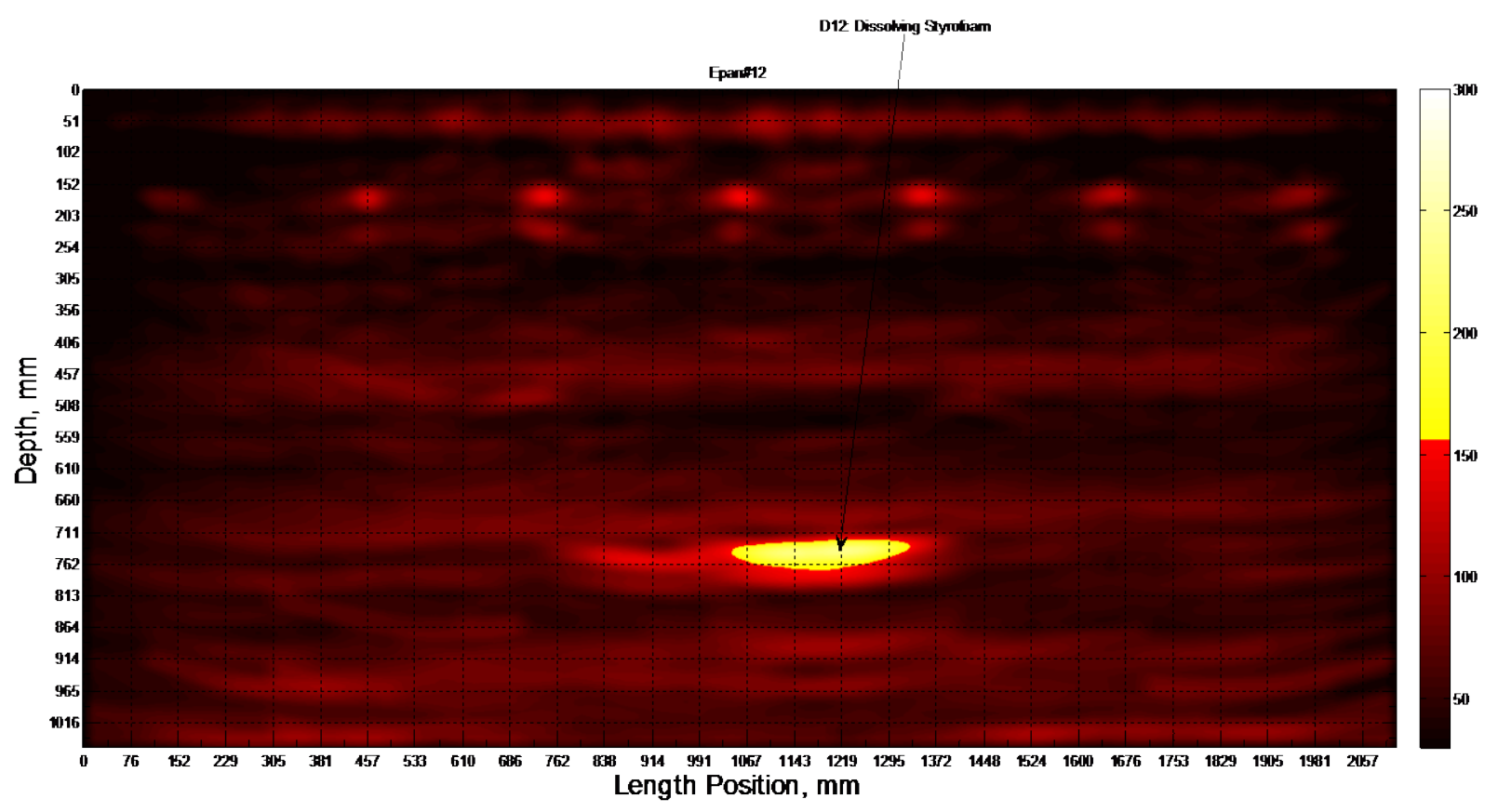

Fig. 57. SAFT-PAN reconstruction showing the reflectivity at D12 as tested from the smooth side of the specimen (deeper side of the specimen with respect to the defect). 


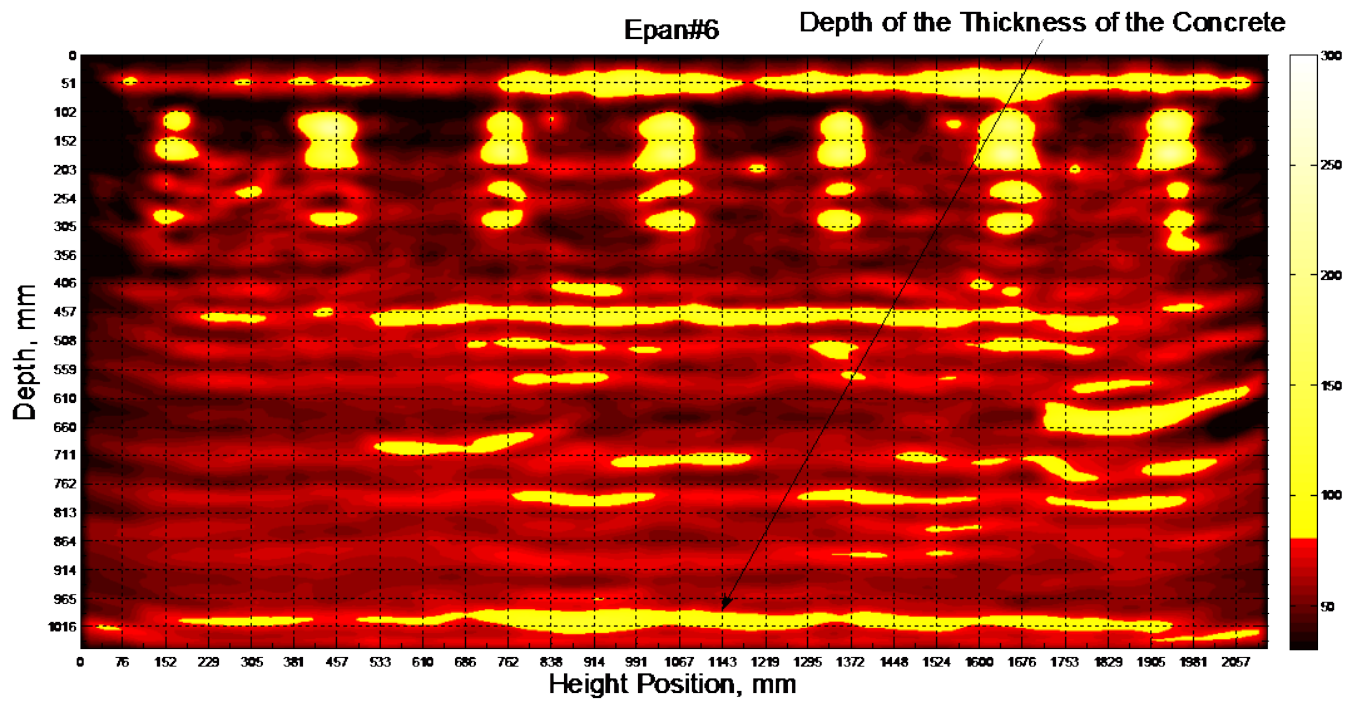

Fig. 58. Backwall reflection at 40 in. (1016 mm).

As observed in the schematics and A- 6, Defect 3 (D03) was located closer to the smooth surface at $140 \mathrm{~mm}$ and $876 \mathrm{~mm}$ depths for the smooth and rough side, respectively. Since this type of defect was designed and proved to be more difficult to detect, the less challenging (shallower depth) reconstruction is given for illustrative purposes. Figure 59 shows the SAFT-PAN reconstruction, showing the reflectivity at D03 as tested from the smooth side of the specimen (shallower side of the specimen with respect to the defect). While an increase in reflectivity is observed in the vicinity of the defect, it is deeper than the designed location and near the depth of the reinforcement it was tied to. This ambiguity suggests that the use of traditional linear SAFT-based reconstructions is not sufficient to directly evaluate the presence of microdamage or honeycombing-type defects using conventional analysis. It can also be observed (using the dotted line as a reference) that the reflection at the reinforcement below D03 is deeper than the reflection of the same reinforcement along all other locations of the scanned line. This indirect signal of the presence of honeycombing using traditional linear reconstructions shows promise that the current dataset collected using ultrasound tomography can be used in the future to indicate difficult defects such as honeycombing or micro-damage. However, it also suggests that a more rigorous testing protocol, analysis, and reconstruction scheme is necessary to reliably identify this type of defect consistently. 


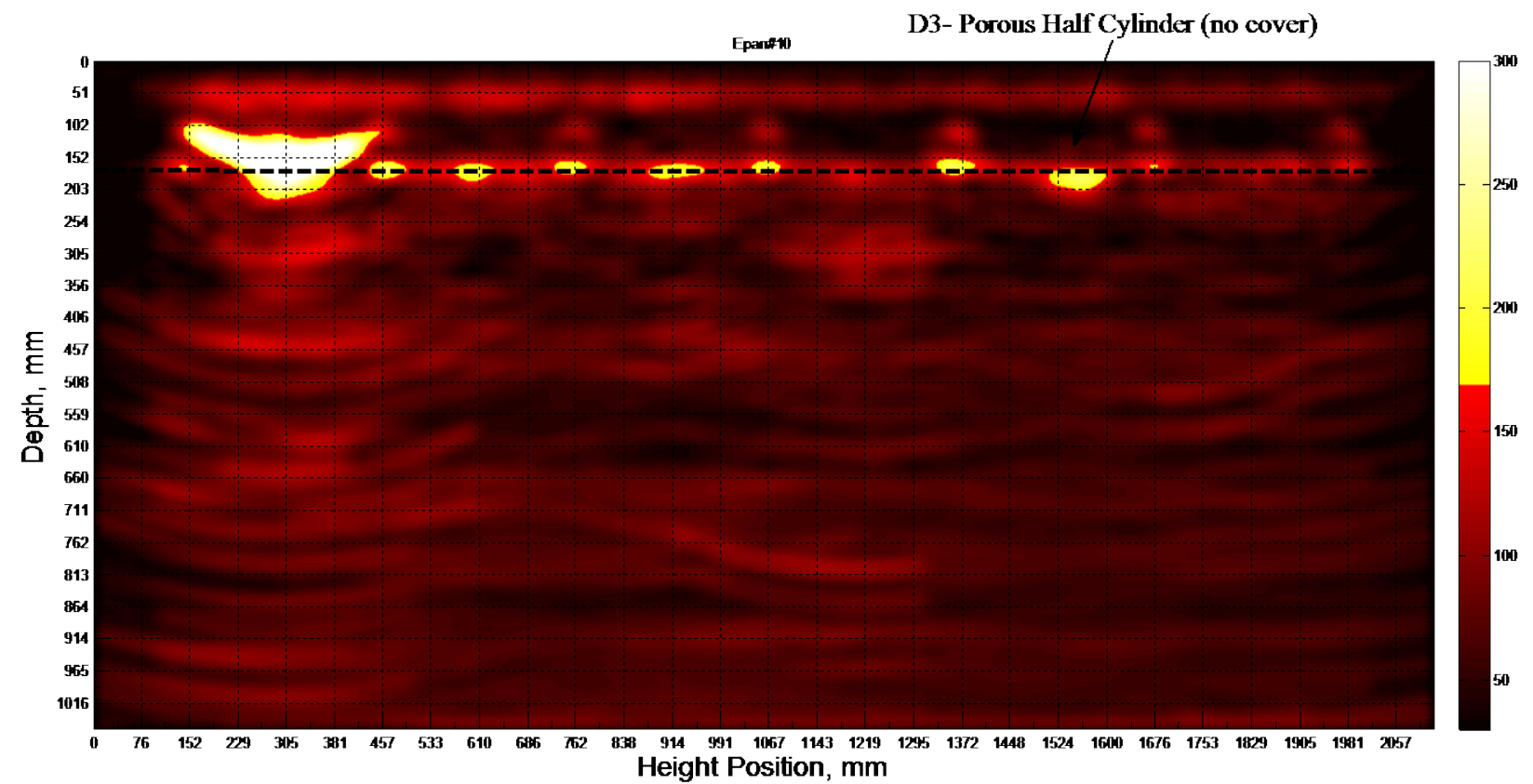

Fig. 59. Example porous concrete defect (D03) reconstruction result.

While it is clear from the preliminary analysis that the current tools translate fairly well to large and heavily reinforced concrete structures, the resolution and reliability of the analysis is inversely proportional to the depth of defect characterization and amount of reinforcement between the measurement point and defect location. Nonetheless, this specimen provides an important validation block for development of the necessary hardware and analysis tools. Additionally, the data will be valuable in calibrating elastic-wave based tools to potentially allow for extended simulations of additional defects in multiple structural arrangements to advance the current knowledge without the need to construct a specimen each time. 


\section{CONCLUSION}

Comparative NDE of various defects in reinforced concrete specimens is a key component in identifying the most promising techniques and directing the research and development efforts needed to characterize concrete degradation in commercial NPPs. This requires access to the specimens for data collection using state-of-the-art technology. Validation data is needed to properly evaluate the effectiveness of the techniques. In this case, the various defects should be created, well defined, and/or feasible to evaluate forensically. It is also critical that the evaluation specimen and embedded defects are representative of in-service NPP structure concrete. Past studies have shown that it is not feasible to meet all of these needs through field removal or evaluation of currently available fabricated specimens.

In the past, multiple comparative NDE studies have been conducted on reinforced concrete structures that are not as thick or heavily reinforced as typical commercial NPP reinforced concrete structures. Results of the comparative studies on these specimens showed the promise of various techniques in evaluating concrete degradation, providing the basis of the conceptual designs from this study. The results from the comparative testing on the thinner structures must be validated under NPP reinforced concrete conditions, where difficulties such as a lower signal-to-noise ratio with greater depth of penetration need to be resolved.

The construction of the specimen detailed in this report allows for an evaluation of how different NDE techniques may interact with the size and complexities of NPP concrete structures. These factors were taken into account when determining specimen size and features to ensure a realistic design. The lateral dimensions of the specimen were also chosen to mitigate unrealistic boundary effects that would not affect the results of field NPP concrete testing. Preliminary results show that, while the current methods are able to identify some of the deeper defects, improvements in data processing or hardware are necessary to be able to achieve the precision and reliability achieved in evaluating thinner and less heavily reinforced concrete structures. 



\section{REFERENCES}

1. L. J. Bond, "Old Reactors, New Tricks," IEEE Spectrum 49(8), 30-35 (2012).

2. D. A. Clayton K. Hoegh, L. Khazanovich, and M. S. Hileman, "Preliminary Conceptual Design of Thick Concrete Nondestructive Evaluation Specimen” ORNL/TM-2014/136, Oak Ridge National Laboratory, 2014.

3. D. A. Clayton and M. S. Hileman, "Light Water Reactor Sustainability Non-Destructive Evaluation for Concrete Research and Development Roadmap,” ORNL/TM-2012/360, Oak Ridge National Laboratory, 2012.

4. D. A. Clayton and C. M. Smith, "Summary of Large Concrete Samples,” ORNL/TM-2013/223, Oak Ridge National Laboratory, 2013.

5. D. J. Naus et al., "Summary and conclusions of a program addressing aging of nuclear power plant concrete structures," Nuclear Engineering and Design 194(1), 73-96 (1999).

6. D. J. Naus, C. B. Oland, and E. G. Arndt, "Ageing management of safety-related concrete structures to provide improved bases for continuing the service of nuclear power plants." Materials and Structures 24(4), 308-316 (1991).

7. J. I. Braverman, C. A. Miller, B. R. Ellingwood, D. J. Naus, C. H. Hofmayer, P. Bezler, and T. Y. Chang, "Structural performance of degraded reinforced concrete members," in Transaction 17th International Conference on Structural Mecha, March 2001.

8. D. J. Naus, C. B. Oland, and E. G. Arndt, "Ageing management of safety-related concrete structures to provide improved bases for continuing the service of nuclear power plants," Materials and Structures 24(4), 308-316 (1991).

9. Dwight A. Clayton, Cyrus M. Smith, Christopher Ferraro, Jordan Nelson, Lev Khazanovich, Kyle Hoegh, Satish Chintakunta, John Popovics, Hajin Choi, and Suyun Ham, "Evaluation of Ultrasonic Techniques on Concrete Structures,” ORNL/TM-2013/430, Oak Ridge National Laboratory, 2013.

10. D. Algernon, D. Hiltunen, and C. Ferraro, "Validation of Nondestructive Testing Equipment for Concrete," University of Florida Department of Civil and Coastal Engineering, 2010.

11. Sherif Yehia et al., "Detection of common defects in concrete bridge decks using nondestructive evaluation techniques," Journal of Bridge Engineering 12(2), 215-225 (2007).

12. Mary Sansalone and Nicholas J. Carino, "Detecting delaminations in concrete slabs with and without overlays using the impact-echo method," ACI Materials Journal 86(2) (1989).

13. Masanori Asano et al., "Impact acoustics methods for defect evaluation in concrete," NDT-CE 2003, Proc., BB 85-CD, DGZIP, 2003.

14. Jinying Zhu and John S. Popovics, "Imaging concrete structures using air-coupled impact-echo," Journal of Engineering Mechanics 133(6), 628-640 (2007).

15. F. Weritz et al., "Investigation of concrete structures with pulse phase thermography," Materials and Structures 38(9), 843-849 (2005).

16. Ralf Beutel et al., "Comparative performance tests and validation of NDT methods for concrete testing," Journal of Nondestructive Evaluation 27(1-3), 59-65 (2008).

17. Christiane Maierhofer et al., "Complementary application of radar, impact-echo, and ultrasonics for testing concrete structures and metallic tendon ducts," Transportation Research Record: Journal of the Transportation Research Board 1892(1), 170-1 (2004).

18. Alexander Taffe, Kerstin Borchardt, and Herbert Wiggenhauser, "Specimen for the improvement of NDT methods - Design and construction of a Large Concrete Slab for NDT methods at BAM," International Symposium Non-Destructive Testing in Civil Engineering, (2003). 
19. Frank Schubert and Bernd Köhler, "Ten lectures on impact-echo," Journal of Nondestructive Evaluation 27(1-3), 5-21 (2008).

20. P. Fellinger et al., "Numerical modeling of elastic wave propagation and scattering with EFITelastodynamic finite integration technique," Wave Motion 21(1), 47-66 (1995).

21. Frank Schubert and René Marklein, "Numerical computation of ultrasonic wave propagation in concrete using the elastodynamic finite integration technique (EFIT)," Ultrasonics Symposium, 2002. IEEE Proceedings Vol. 1, 2002.

22. Frank Schubert, Herbert Wiggenhauser, and Regine Lausch, "On the accuracy of thickness measurements in impact-echo testing of finite concrete specimens-numerical and experimental results," Ultrasonics 42(1), 897-901 (2004).

23. G. Zacher, C. Kohl, J. Wostmann, and C. Maierhofer, "Evaluation of radar and complementary echo methods for NDT of concrete elements, J. Nondestructive Evaluation, Vol. 27, p. 47-57.

24. Dennis P. Schurr et al. "Damage detection in concrete using coda wave interferometry," NDT \& E International 44(8), 728-735 (2011).

25. International Atomic Energy Agency, "Guidebook on non-destructive testing of concrete structures, IAEA-TCS-17, 2002.

26. J. Popovics, "Ultrasonic and X-ray Imaging," in Short Course on NDE for the Infrastructure, 2011.

27. F. Schubert, R. Lausch, and H. Wiggenhauser, "Geometrical effects on impact-echo testing of finite concrete specimens," Proceedings of International Symposium on Non-Destructive Testing in Civil Engineering (NDT-CE), 2003, pp. 16-19.

28. K.J. Langenberg, R. Marklein, and K. Mayer, “Applications to nondestructive testing with ultrasound,” in R. Pike and P. Sabatier (eds.), Scattering \& Inverse Scattering in Pure and Applied Science, Academic Press, 2002, pp. 594-617.

29. M. Spies and W. Jager, "Synthetic aperture focusing for defect reconstruction on anisotropic media," Ultrasonics 41, 125-131 (2003).

30. C. Engstrand and R. Kline, “Application of SAFT to layered, anisotropic, media,” Rev QNDE 24B, 1151-1158 (2005).

31. A. Shlivinski and K.J. Langenberg, "Defect imaging with elastic waves in inhomogeneousanisotropic materials with composite geometries," Ultrasonics 46, 89-104 (2007).

32. R. Marklein, et al., "Linear and nonlinear inversion algorithms applied in nondestructive evaluation,” Inverse Problems 18, 1733-1759 (2002).

33. M. Schickert, M. Krause, and W. Müller, "Ultrasonic imaging of concrete elements using reconstruction by synthetic aperture focusing technique,” Journal of Materials in Civil Engineering 15, 235-246 (2003).

34. K. Mayer, K. J. Langenberg, M. Krause, B. Milmann, and F. Mielentz, "Characterization of reflector types by phase-sensitive ultrasonic data processing and imaging,” Journal of Nondestructive Evaluation 27, 35-45 (2008).

35. P. Shokouhi and H. Wiggenhauser, "Multiprobe Ultrasonic Testing for Detection of Delamination in Concrete Bridge Decks,” Transportation Research Board 91st Annual Meeting, 2012.

36. K. Hoegh, B. Worel, T. Yu, and L. Khazanovich, "Detection of Subsurface Joint Deterioration,” Transportation Research Record: Journal of the Transportation Research Board 2367(1), 3-12 (2013).

37. K. Hoegh and L. Khazanovich, "Correlation Analysis of 2D Tomographic Images for Flaw Detection in Pavements," Journal of Testing and Evaluation, American Society for Testing and Materials 40(2), JTE103765 (2012). 
38. J. L. Braverman, C. A. Miller, C. H. Hofmayer, B. R. Ellingwood, D. J. Naus, and T. Y. Chang, "Degradation assessment of structures and passive components at nuclear power plants," Nuclear Engineering and Design 228(1), 283-304 (2004).

39. C. Chiu et al., Performance Improvement International, "Root Cause Assessment Crystal River Unit 3 Containment Concrete Delamination,” Crystal River Nuclear Plant - Special Inspection Report 05000302/2009007, US Nuclear Regulatory Commission (NRC) Special Inspection at Crystal River Unit 3 Nuclear Plant, 2010.

40. H. Ashar and G. Bagchi, "Assessment of inservice conditions of safety-related nuclear plant structures,” Washington, DC: US Nuclear Regulatory Commission, 1995.

41. Frederick L. Moreadith and Richard E. Pages, "Delaminated prestressed concrete dome: investigation and repair," Journal of Structural Engineering 109(5), 1235-1249 (1983).

42. Shen Wang and Javeed A. Munshi, "Design of radial reinforcement for prestressed concrete containments," Nuclear Engineering and Design 255, 153-161 (2013).

43. S.A. Reynolds, "Davis-Besse Nuclear Power Station - Inspection to Evaluate the Root Cause Evaluation and Corrective Actions for Cracking in the Reinforced Concrete Shield Building of the Containment System,” Nuclear Regulatory Commission Inspection Report 05000346/2012009(DRS), 2012.

44. Federal Highway Administration, "Non-Destructive Inspection Protocol for Reinforced Concrete Highway Barriers and Bridge Railings,” Federal Highway Administration NDE Validation Center, McLean, VA, 2013.

45. V. G. Shevaldykin, A. A. Samokrutov, and V. N. Kozlov, "Ultrasonic Low-Frequency Transducers with Dry Dot Contact and Their Applications for Evaluation of Concrete Structures," IEEE Ultrasonics Symposium Proceedings 1 \& 2, pp. 793-798, 2002. 

APPENDIX A. DEFECT LOCATIONS 

A large reinforced concrete specimen was constructed with artificial defects at predefined locations. AutoCAD drawings and supporting photographs are supplied to detail the type and location of the simulated defects within the specimen, with 10 figures corresponding to each defect. The first four figures are close-up pictures of the defect as well as relative height, length, and depth information respectively. The following six figures show the three different autocad cross-sectional views with and without the defect legend. The filepaths and filenames given as the caption of the figures are an artifact of the batch mode appendix creation, but contain some information about each figure based on the photograph folder name cataloging procedure. The following list gives the defect type and its ID number.

D01 Porous half cylinder (no cover)

D02 Porous half cylinder (no cover)

D03 Porous half cylinder (no cover)

D04 Porous half cylinder (cover)

D05 Porous half cylinder (cover and crack)

D06 PVC

D07 PVC

D08 Dissolving Styrofoam (thick)

D09 Foam (thick)

D10 Styrofoam (thin)

D11 Plexiglass

D12 Dissolving Styrofoam (medium)

D13 Styrofoam (medium)

D14 Plexiglass

D15 Dissolving Styrofoam (thin)

D16 Lumber (2x4)

D17 Gloves

D18 Debond duct tape (one layer)

D19 Debond duct tape (multi-layer)

D20 Moving rebar 


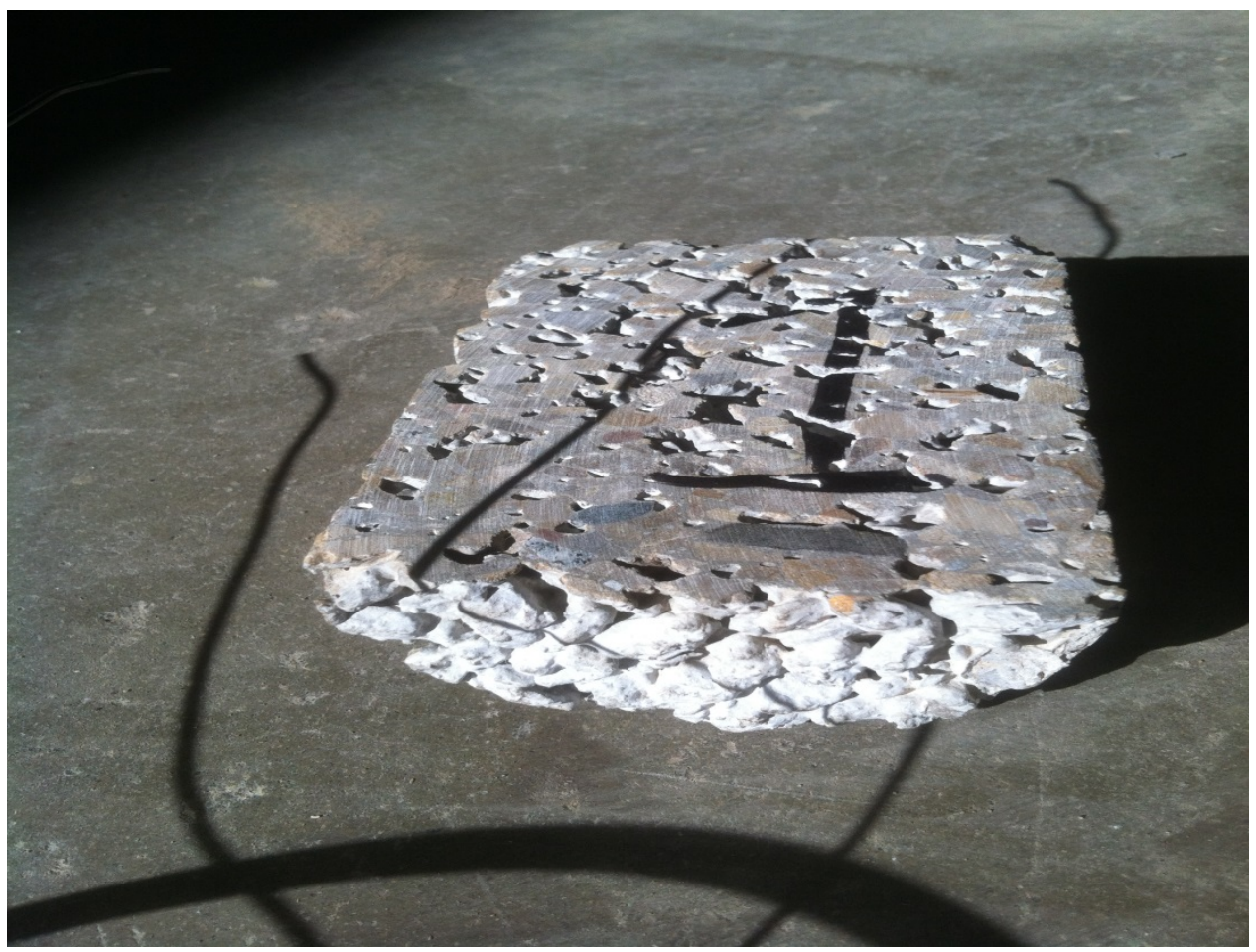

Fig. A.1. D01 close-up.

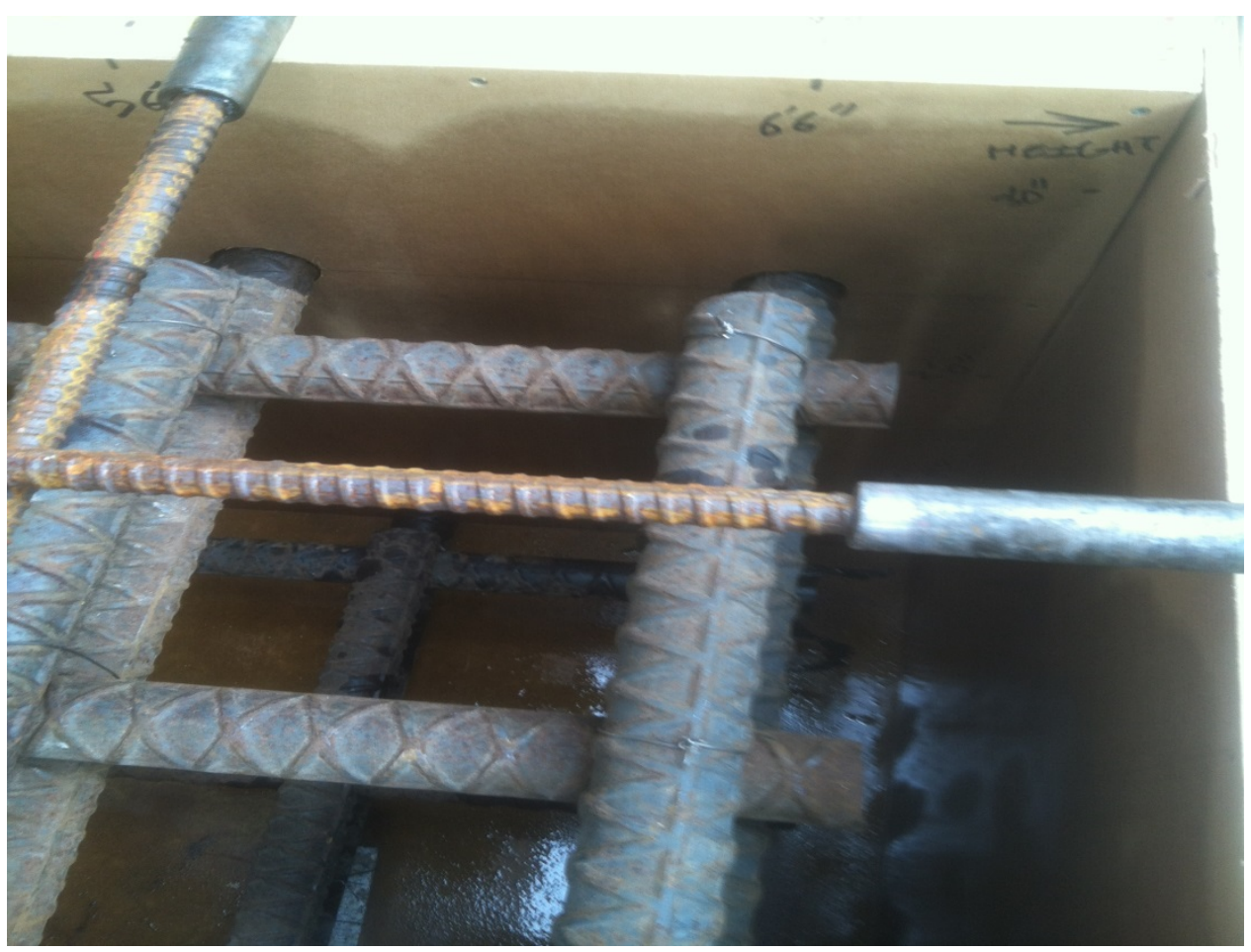

Fig. A.2. D01 length 2.5 bars $2 \mathrm{ft} \times 610 \mathrm{~mm}$. 


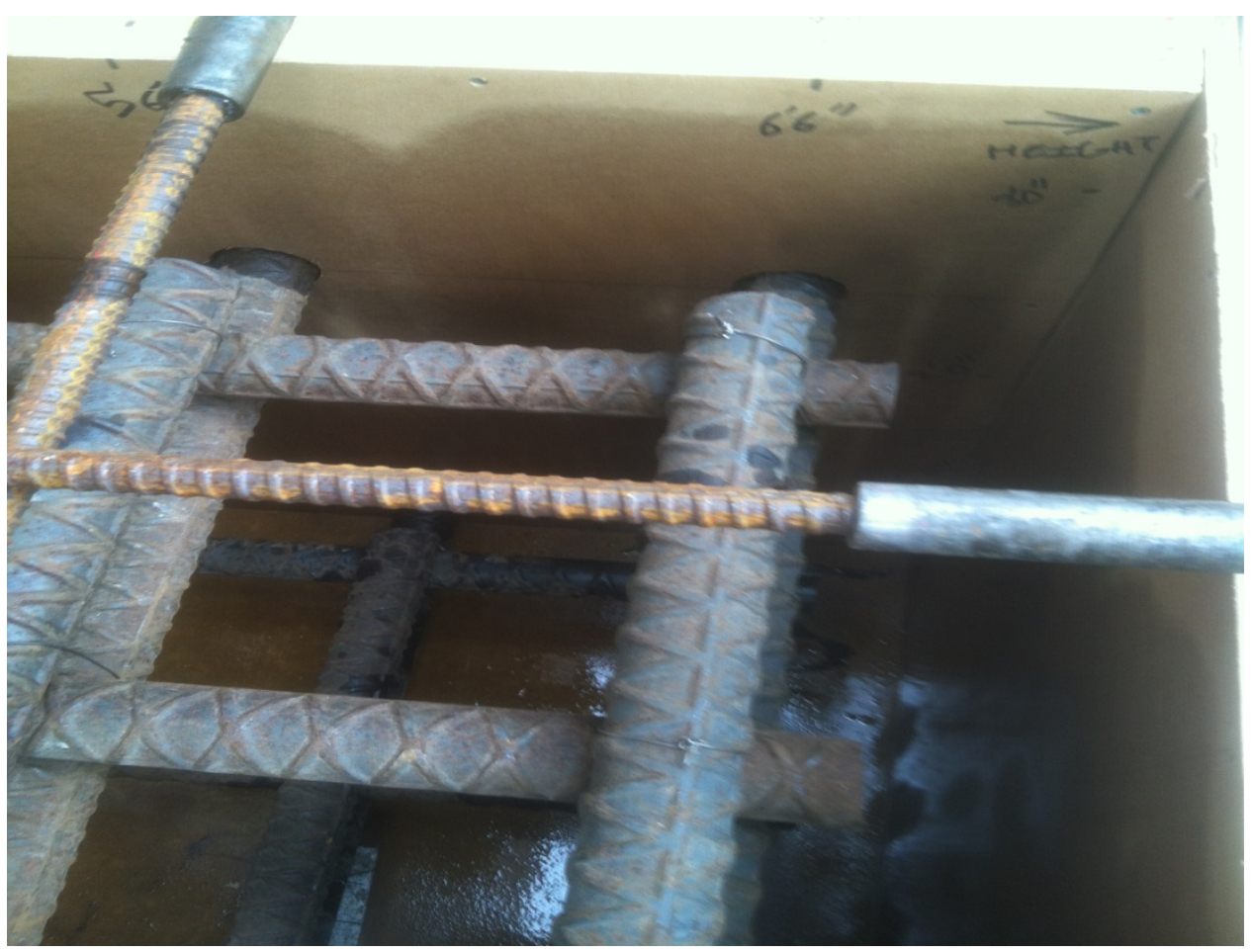

Fig. A.3. D01 R-depth bottom of bottom bar $930 \mathrm{~mm}$.

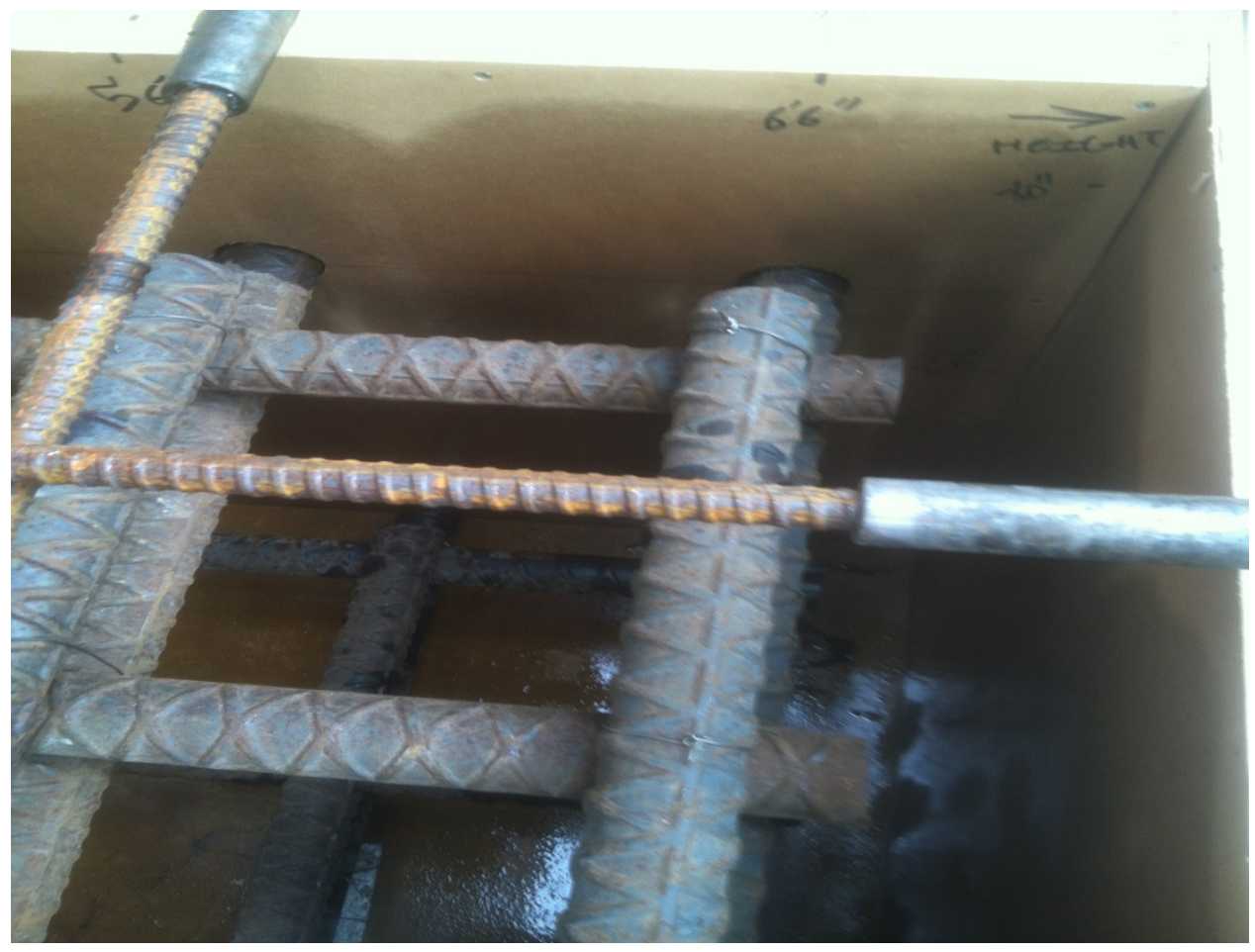

Fig. A.4. D01 height 6 bars 5.5ft $\times 1676 \mathrm{~mm}$. 


\begin{tabular}{|c|c|c|}
\hline \multicolumn{3}{|c|}{ DEECCT TABLE } \\
\hline 10 NUMBER & DESCRIPTION & LABE \\
\hline D1 & $\begin{array}{l}\text { POROUS HALF CYINDER } \\
\text { (NO COVER) }\end{array}$ & \\
\hline D2 & $\begin{array}{l}\text { POROUS HALF CYINDER } \\
\text { (COVER) }\end{array}$ & \\
\hline 03 & $\begin{array}{l}\text { POROUS HALF CYINDER } \\
\text { (NO COVER) }\end{array}$ & \\
\hline 04 & $\begin{array}{l}\text { POROUS HALF CYINOER } \\
\text { (COVER) }\end{array}$ & \\
\hline D5 & $\begin{array}{l}\text { POROUS HALF CYUNDER } \\
\text { (COVER \& CRACK) }\end{array}$ & \\
\hline D6 & PVC & \\
\hline 07 & PVC & \\
\hline D8 & \begin{tabular}{|c||} 
DISSOLUNG STYROFOAM \\
(THICK)
\end{tabular} & \\
\hline D9 & STYROFOAM (THIOK) & \\
\hline 010 & STTROFOAM (THIN) & \\
\hline 011 & PLEXIGLASS & \\
\hline D12 & $\begin{array}{l}\text { DISSOLUNG STYROFOAM } \\
\text { (MEDUMM) }\end{array}$ & \\
\hline 013 & STRROFOAM (MEDIUM) & \\
\hline D14 & PLEXIGLASS & \\
\hline 015 & \begin{tabular}{|} 
DISSOLUNG STRROFOAM \\
(THN)
\end{tabular} & \\
\hline 016 & LUMBER $(2 \times 4)$ & \\
\hline 017 & GLovES & \\
\hline D18 & $\begin{array}{l}\text { DEBONO DUCT TAPE } \\
\text { (ONE LAYCR) }\end{array}$ & \\
\hline 019 & $\begin{array}{l}\text { OEBONO DUCT TAPE } \\
\text { (MULT-LAYRR) }\end{array}$ & \\
\hline 020 & MOUNG REBAR & \\
\hline
\end{tabular}

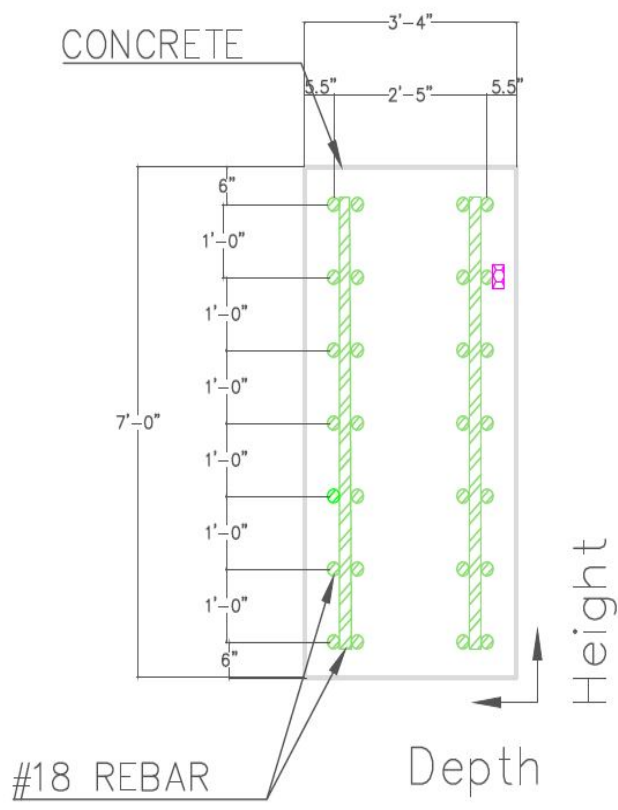

Fig. A.5. D01 height by depth.

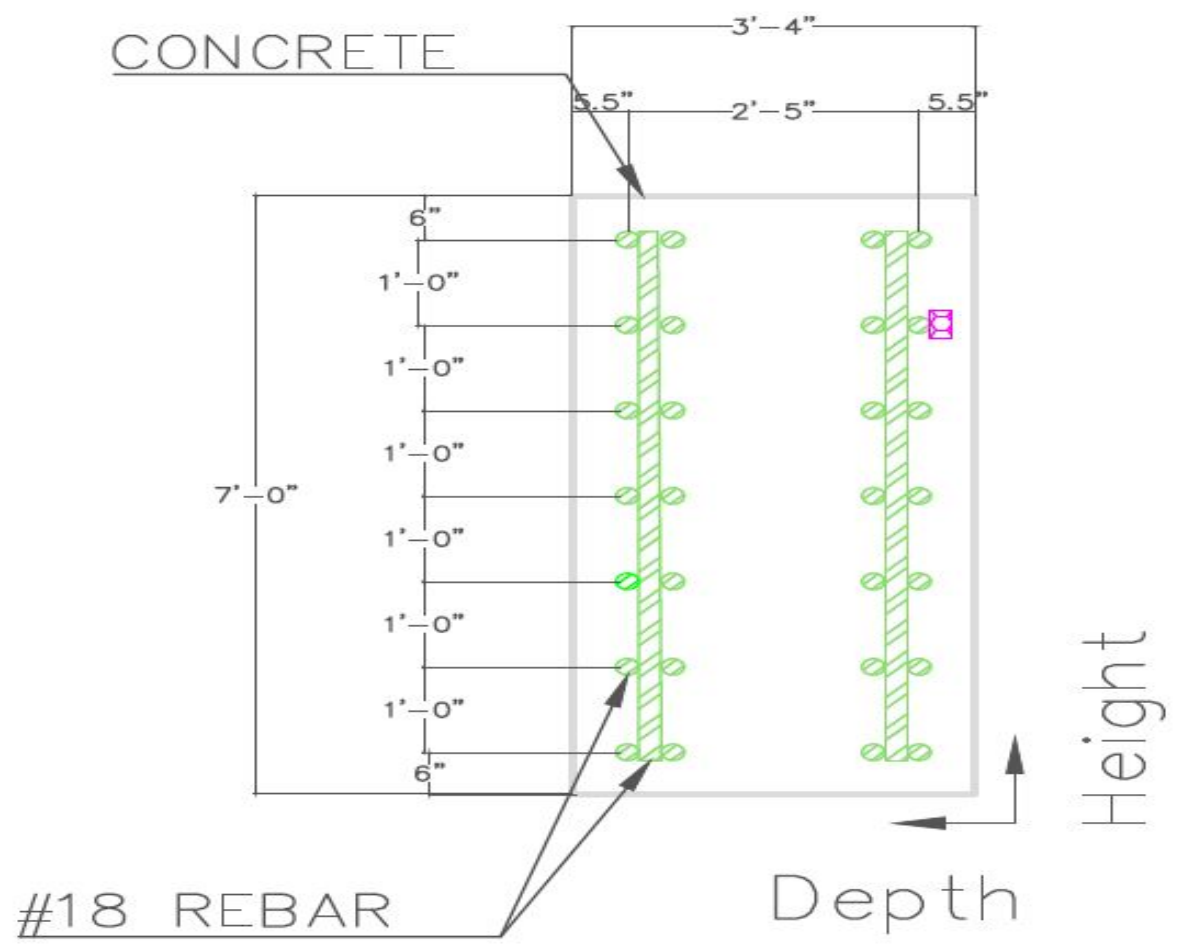

Fig. A.6. D01 height by depth NL. 


\begin{tabular}{|c|c|c|}
\hline \multicolumn{3}{|c|}{ DGSECT TRRE, } \\
\hline o nuesa & OESCQPTTON & U8. \\
\hline or & 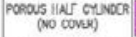 & \\
\hline 02 & 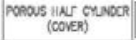 & \\
\hline os & 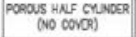 & \\
\hline of & 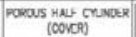 & \\
\hline os & 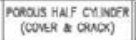 & \\
\hline$\infty$ & $\mathrm{PC}$ & \\
\hline a7 & px: & \\
\hline$\infty$ & 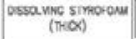 & \\
\hline$\infty$ & Strocolum (THOX) & \\
\hline ono & srooroun (IHAN) & \\
\hline ont & puevouss & \\
\hline 012 & 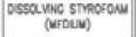 & \\
\hline 013 & STrmeronu (NCOUN) & \\
\hline 014 & PLoveuss & \\
\hline 015 & 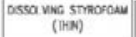 & \\
\hline 0.6 & weot $(2 x)$ & \\
\hline 017 & acoves & \\
\hline 010 & $\begin{array}{l}\text { DERONO DUCT TNEE } \\
\text { (ONC LARD) }\end{array}$ & \\
\hline 010 & 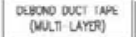 & \\
\hline 020 & WOWW ReBne & \\
\hline
\end{tabular}

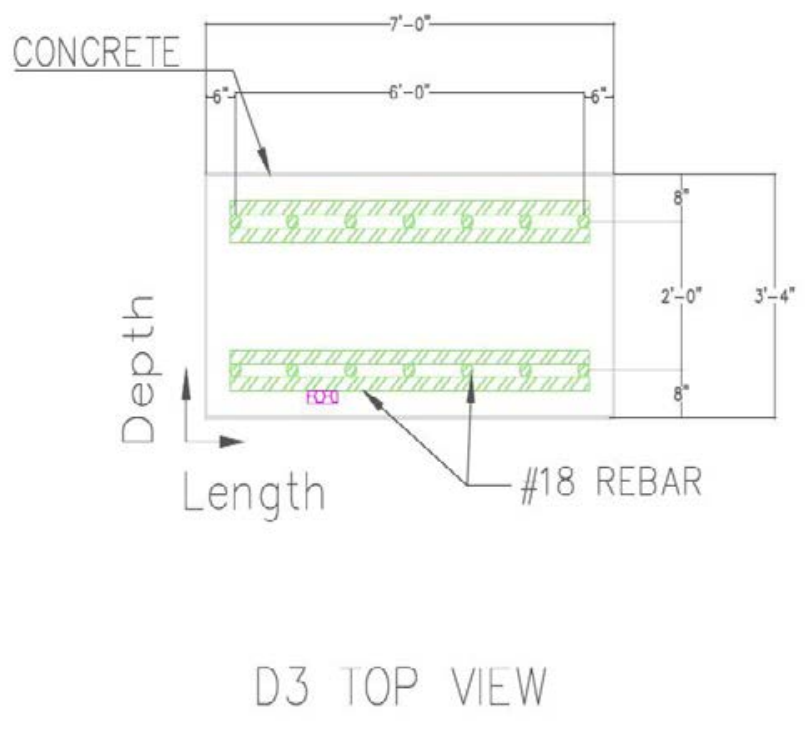

Fig. A.7. D01 length by depth.

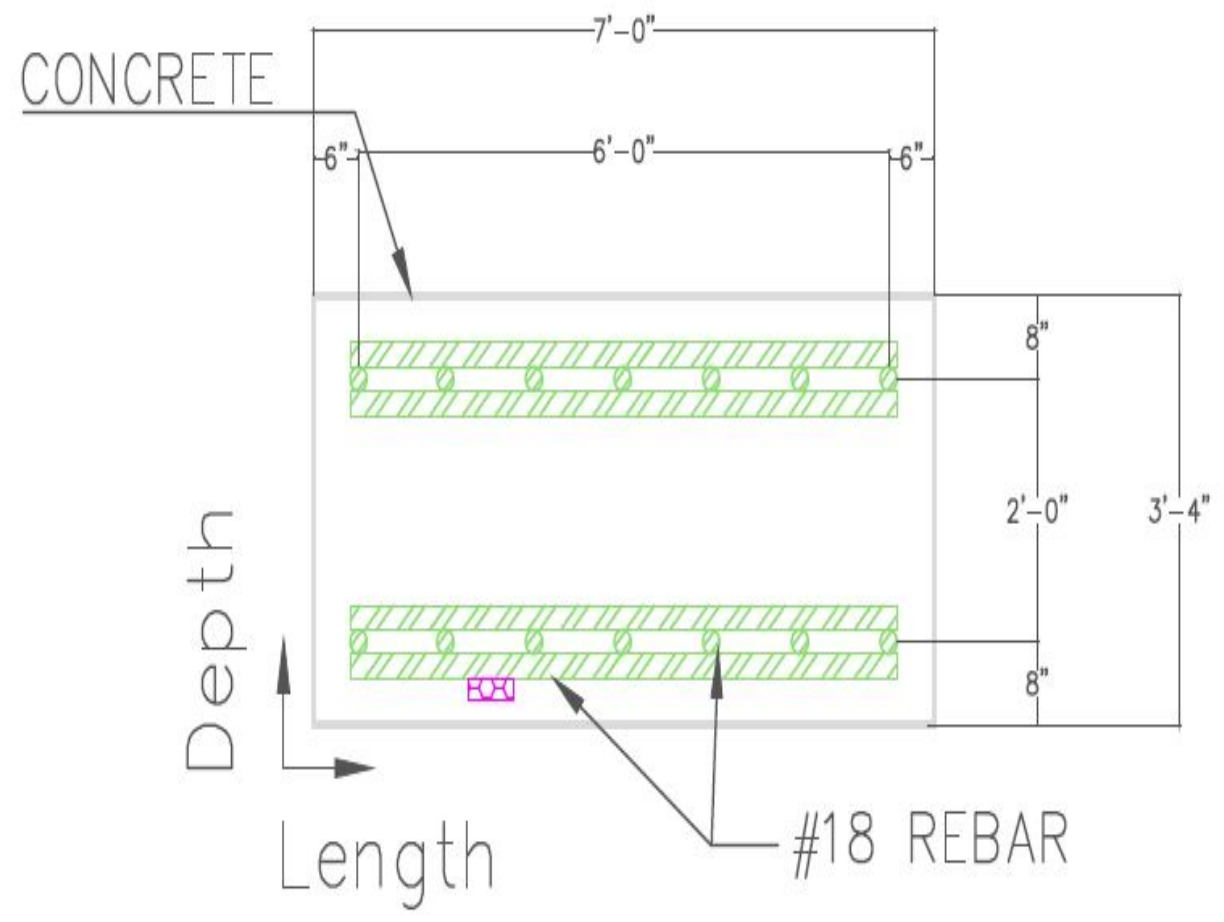

Fig. A.8. D01 length by depth NL. 

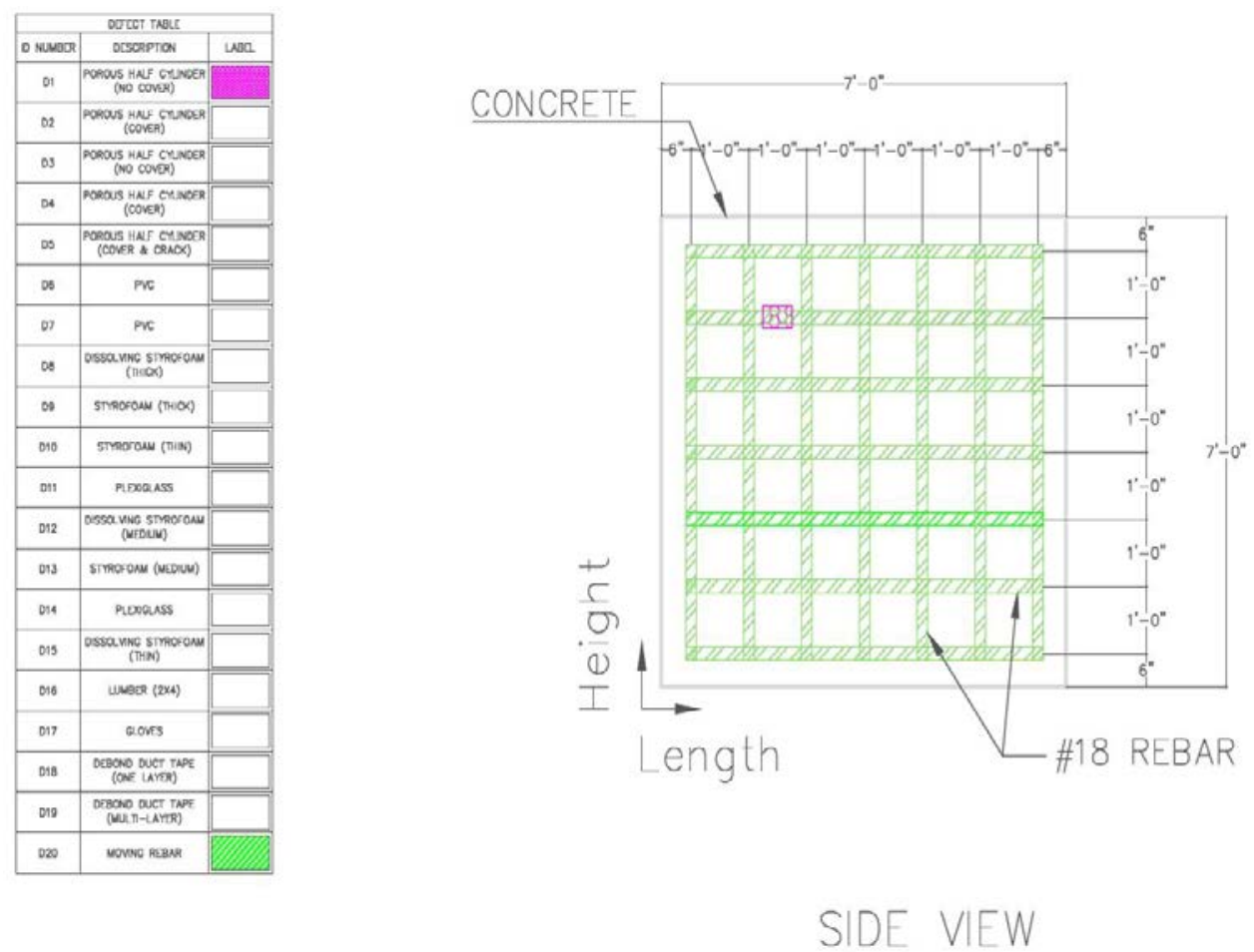

Fig. A.9. D01 length by height.

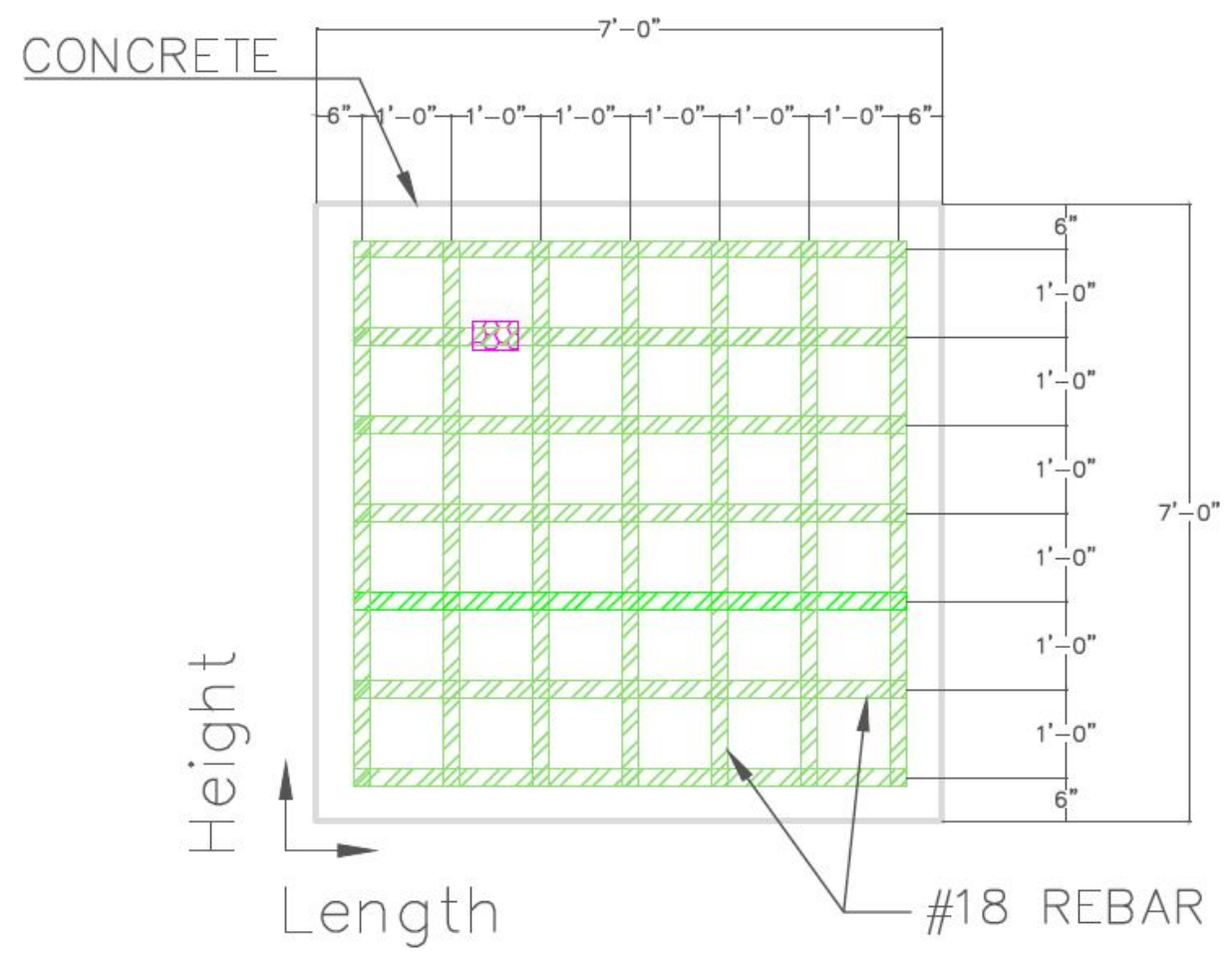

Fig. A.10. D01 length by height NL. 


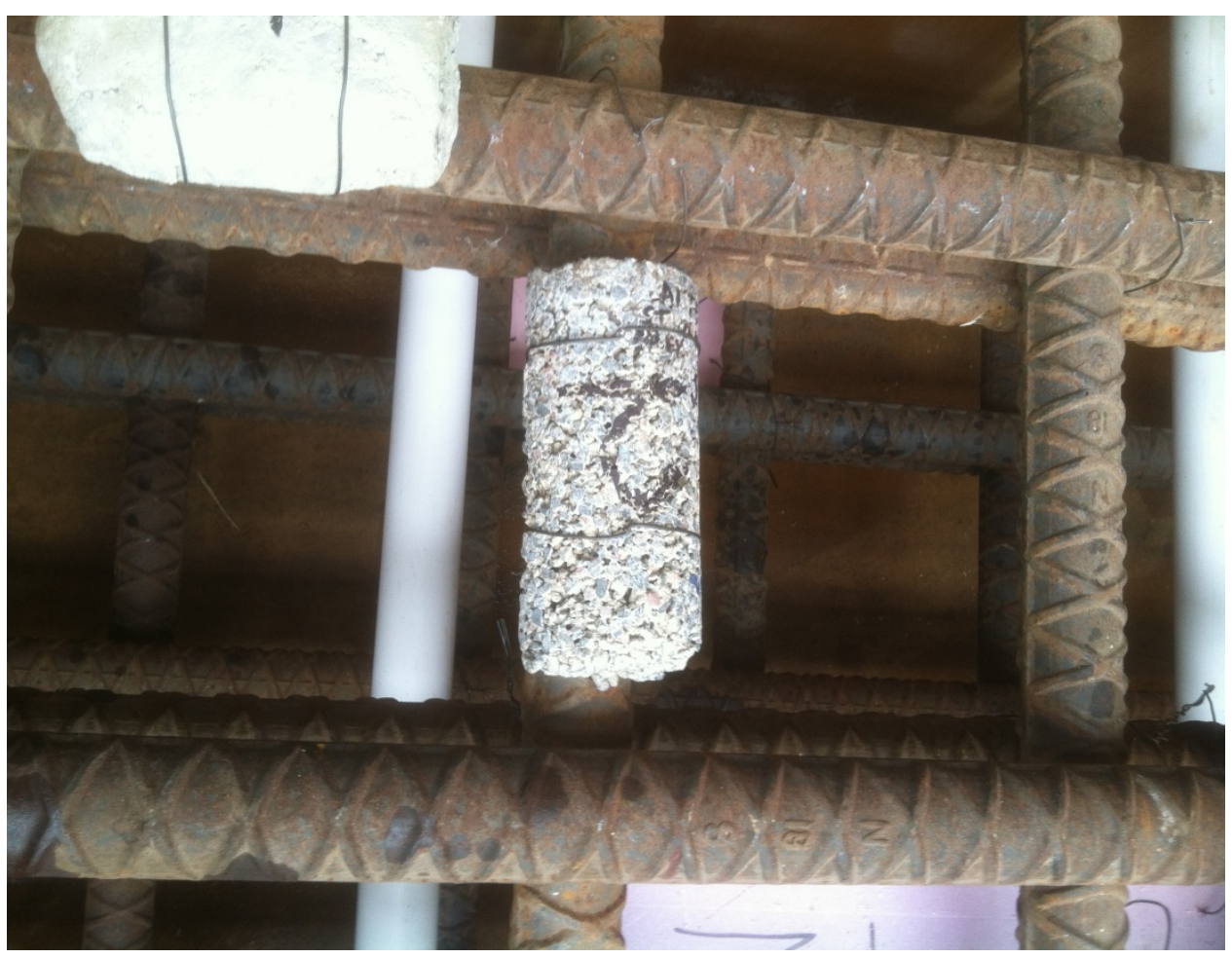

Fig. A.11. D02 close-up.

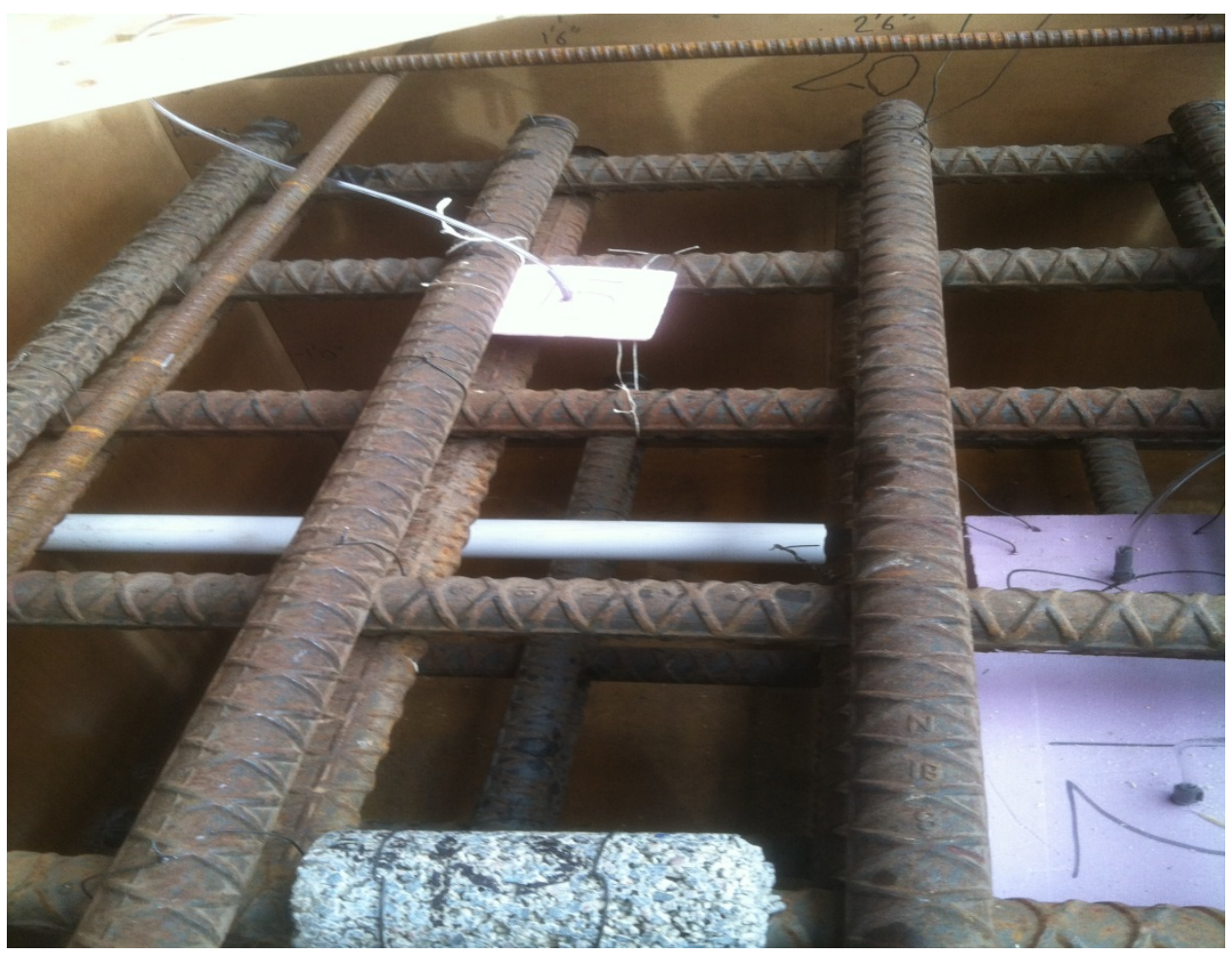

Fig. A.12. D02 height 2.5 bars $2 \mathrm{ft} \times 610 \mathrm{~mm}$. 


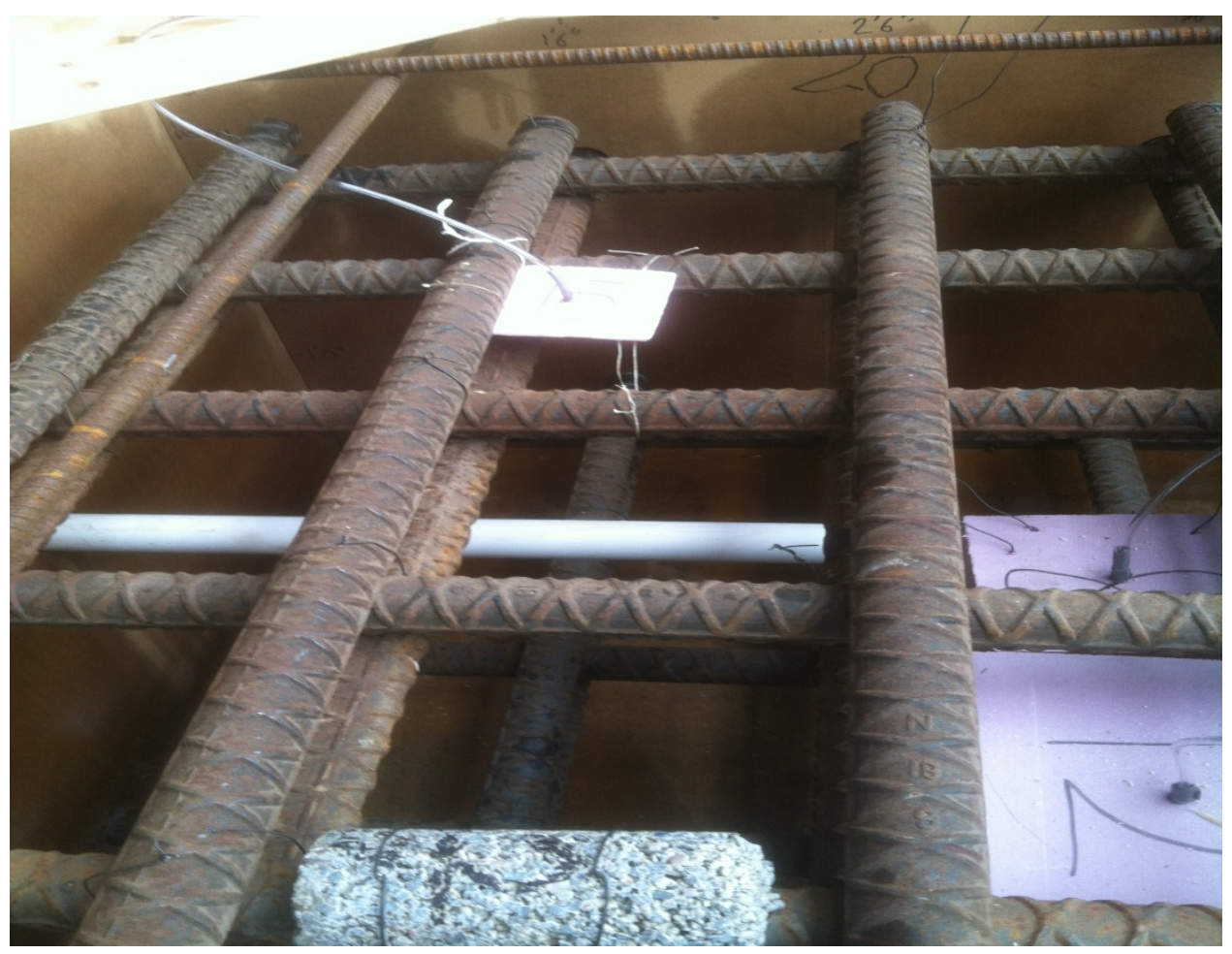

Fig. A.13. D02 length 5 bars $4.5 \mathrm{ft} \times 1372 \mathrm{~mm}$.

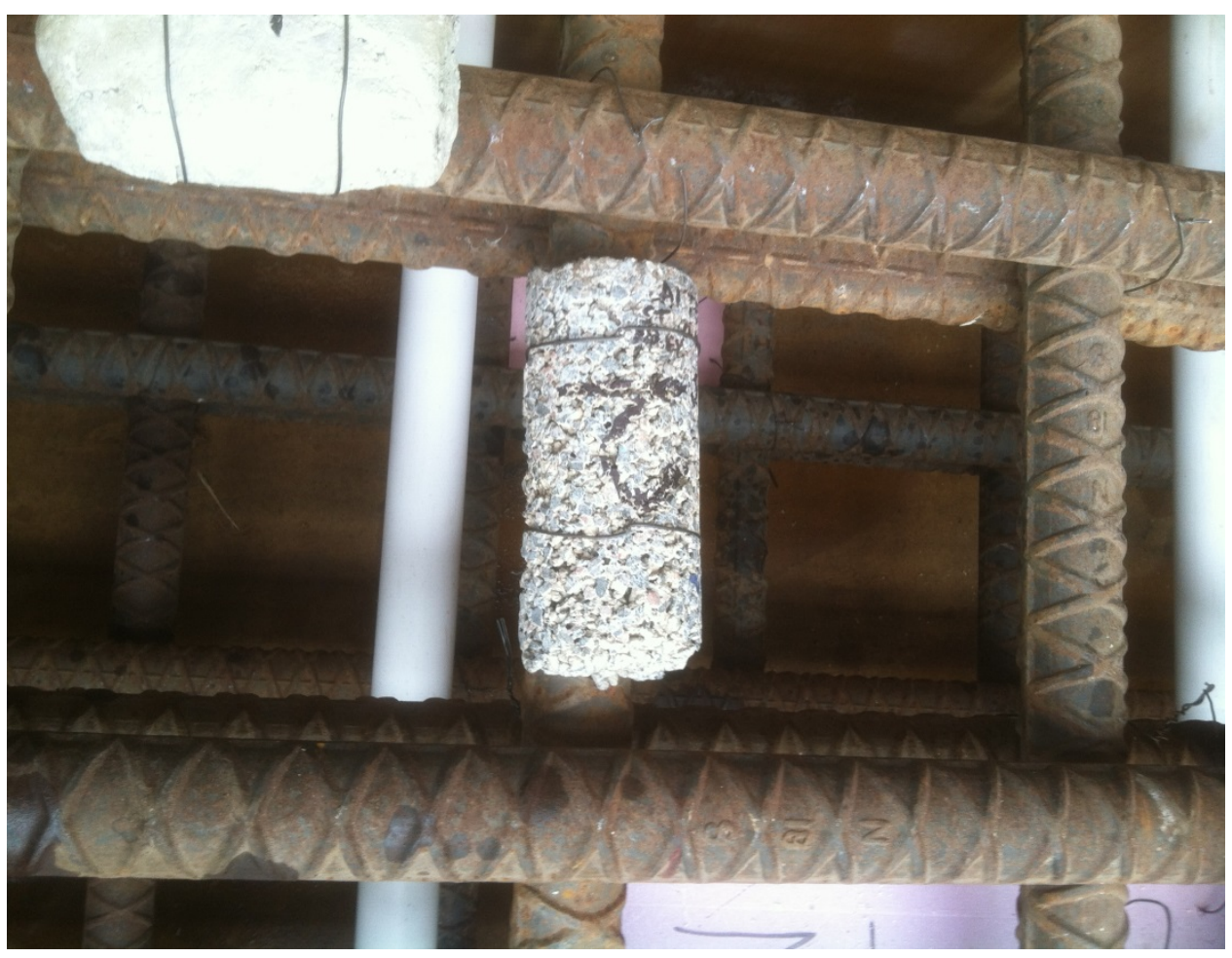

Fig. A.14. D02 R-depth top of 2nd bar 140mm. 


\begin{tabular}{|c|c|c|}
\hline \multicolumn{3}{|c|}{ DEFECT TABLE } \\
\hline ID NUMBER & DESCRIPTION & LAB! \\
\hline D1 & $\begin{array}{l}\text { POROUS HALF CYNNDER } \\
\text { (NO COVER) }\end{array}$ & \\
\hline 02 & $\begin{array}{l}\text { POROUS HALF CYINDER } \\
\text { (COVER) }\end{array}$ & \\
\hline D3 & $\begin{array}{l}\text { POROUS HALF CYINDER } \\
\text { (NO COVER) }\end{array}$ & \\
\hline 04 & $\begin{array}{l}\text { POROUS HALF CYINDER } \\
\text { (COVER) }\end{array}$ & \\
\hline 05 & $\begin{array}{l}\text { POROOS HALF CYINDER } \\
\text { (COVER \& CRACK) }\end{array}$ & \\
\hline D6 & PVC & \\
\hline 07 & PVC & \\
\hline DB & $\begin{array}{l}\text { DISSOLUNG STYROFOAM } \\
\text { (THICK) }\end{array}$ & \\
\hline Dg & STTROFOAM (THICK) & \\
\hline 010 & STYROFOAM (THIN) & \\
\hline D11 & PLEXGLLASS & \\
\hline 012 & $\begin{array}{l}\text { DISSOLUNG STYROFOAM } \\
\text { (MEDUUM) }\end{array}$ & \\
\hline 013 & STYROFOAM (MEDIUM) & \\
\hline 014 & PLEXGLASS & \\
\hline 015 & $\begin{array}{l}\text { DISSOLUNG STYROFOAM } \\
\text { (THIN) }\end{array}$ & \\
\hline 016 & LUMEER (2X4) & \\
\hline 017 & GLOVES & \\
\hline 018 & $\begin{array}{l}\text { DEBONO DUCT TAPE } \\
\text { (ONE LAYER) }\end{array}$ & \\
\hline 019 & $\begin{array}{l}\text { DEBONO DUCT TAPE } \\
\text { (MULT-LAYRR) }\end{array}$ & \\
\hline 020 & MOUNG REBAR & \\
\hline
\end{tabular}

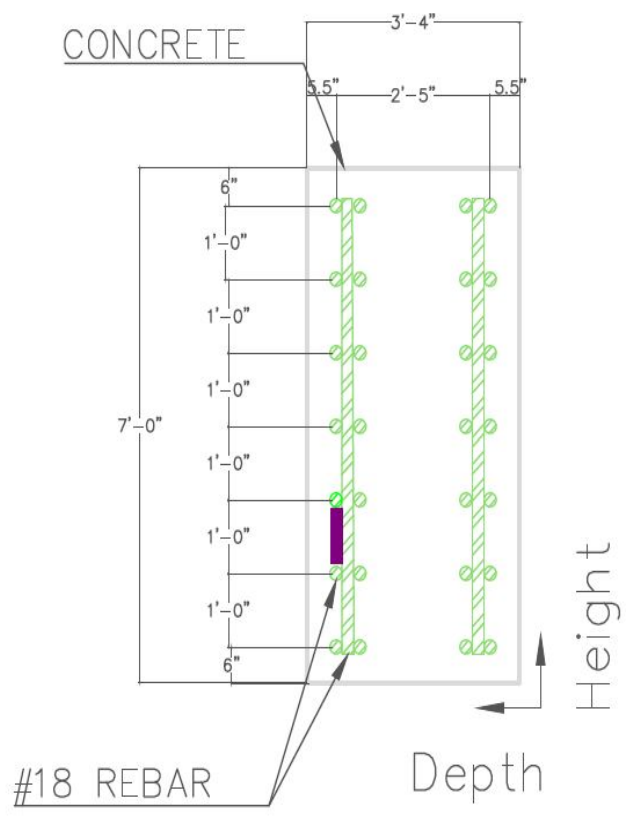

Fig. A.15. D02 height by depth.

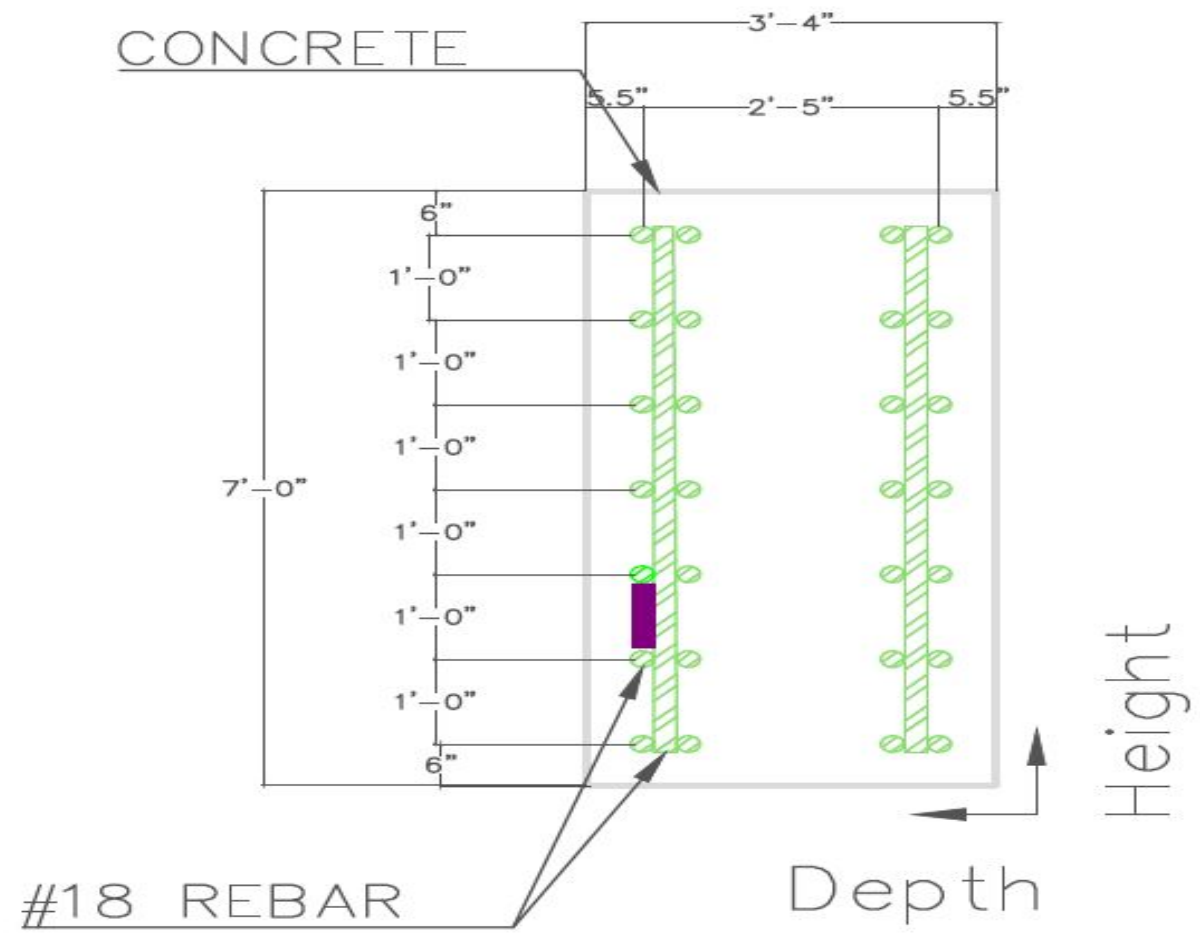

Fig. A.16. D02 height by depth NL. 


\begin{tabular}{|c|c|c|}
\hline \multicolumn{3}{|c|}{ OEFECT TRQLE } \\
\hline O Neves: & oescopion & were \\
\hline or & 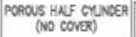 & \\
\hline 02 & 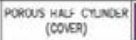 & \\
\hline as & 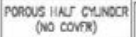 & \\
\hline D4 & 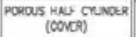 & \\
\hline Do & 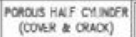 & \\
\hline$\infty$ & pre & \\
\hline 07 & PNC & \\
\hline$\infty$ & $\begin{array}{c}\text { DSsavano smaronu } \\
\text { (Tion) }\end{array}$ & \\
\hline$D$ & strecorow (nilon) & \\
\hline 010 & Sincocoun (IHN) & \\
\hline ou & mexanss & \\
\hline 012 & 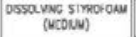 & \\
\hline 073 & Singorous (votu) & \\
\hline 014 & provauss & \\
\hline 015 & $\begin{array}{c}\text { Dessa vac smporow } \\
\text { (HNN) }\end{array}$ & \\
\hline 016 & IINARR (2xa) & \\
\hline 097 & a.0ves & \\
\hline 018 & 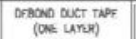 & \\
\hline 019 & 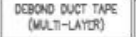 & \\
\hline 020 & NOUNC RERYR & \\
\hline
\end{tabular}

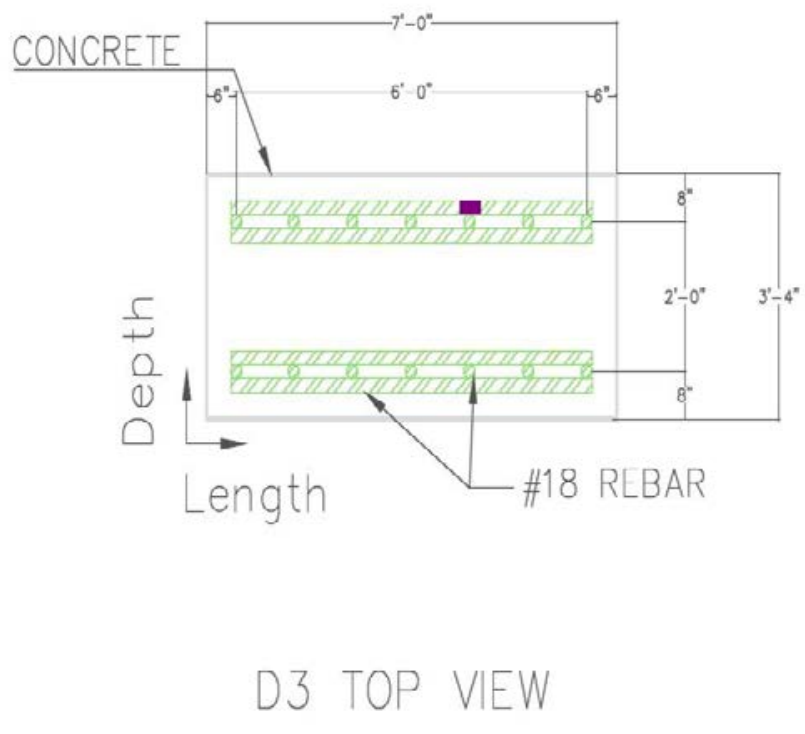

Fig. A.17. D02 length by depth.

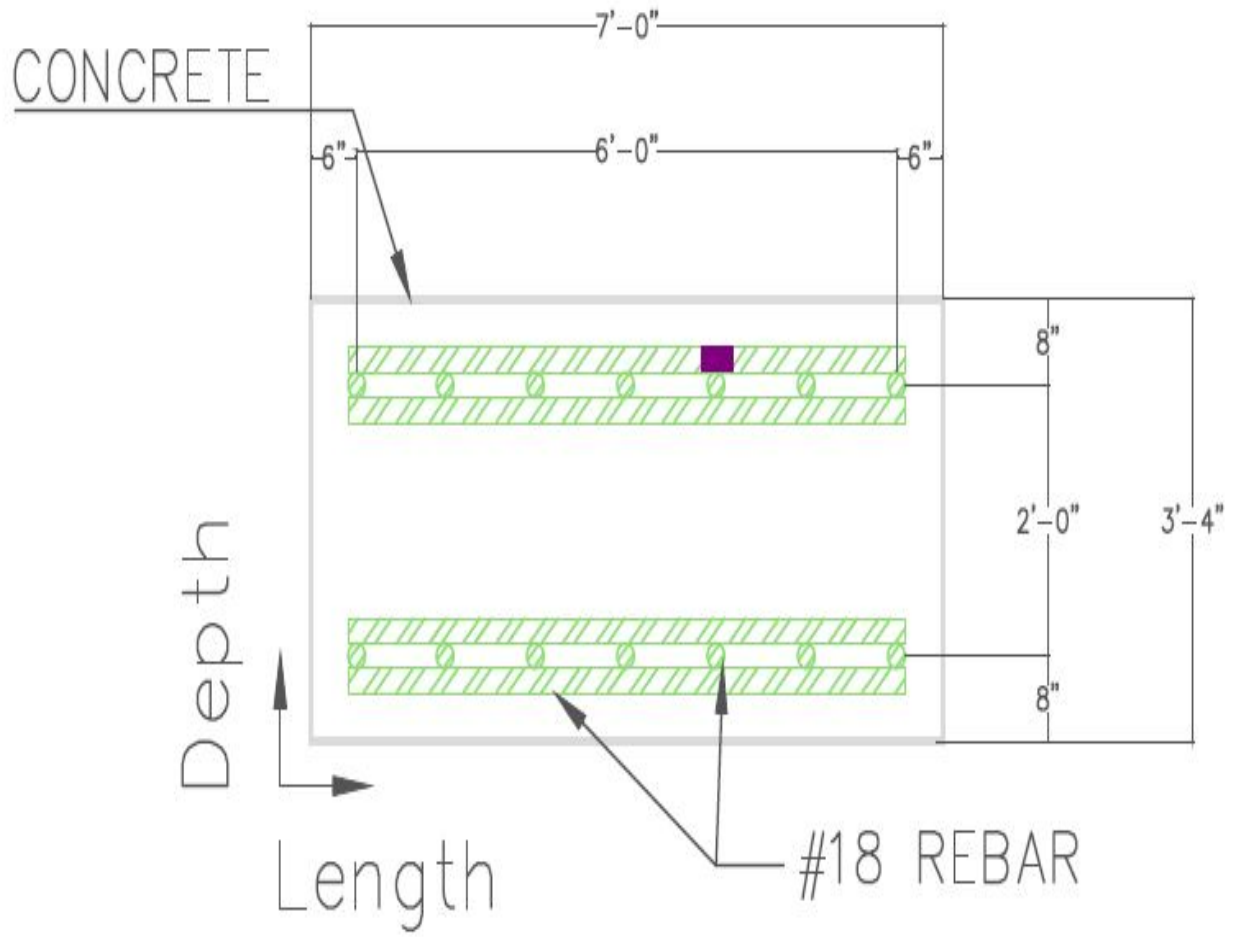

Fig. A.18. D02 length by depth NL. 


\begin{tabular}{|c|c|c|}
\hline \multicolumn{3}{|c|}{ ofrert that } \\
\hline D Muvor & OCsorpton & wan \\
\hline or & 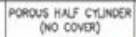 & \\
\hline 02 & $\begin{array}{l}\text { POROUS HNE CYMWOSR } \\
\text { (CONCR) }\end{array}$ & \\
\hline as & 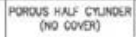 & \\
\hline ou & 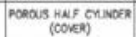 & \\
\hline os & 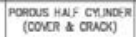 & \\
\hline$\infty$ & pec & \\
\hline 0 & PNe & \\
\hline$\infty$ & 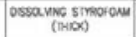 & \\
\hline$\infty$ & stmorow (тіо) & \\
\hline 010 & 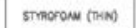 & \\
\hline on1 & provouss & \\
\hline 012 & $\begin{array}{l}\text { ossa ving smeoroum } \\
\text { (Mfoiv) }\end{array}$ & \\
\hline 013 & stracoum (neaw) & \\
\hline ord & provans & \\
\hline ors & $\begin{array}{l}\text { ossa ung smmorow } \\
\text { (IFM) }\end{array}$ & \\
\hline 096 & U⿻上丨 $(2 x t)$ & \\
\hline 017 & a.oves & \\
\hline 010 & 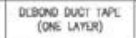 & \\
\hline 19 & 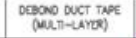 & \\
\hline 020 & 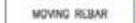 & \\
\hline
\end{tabular}
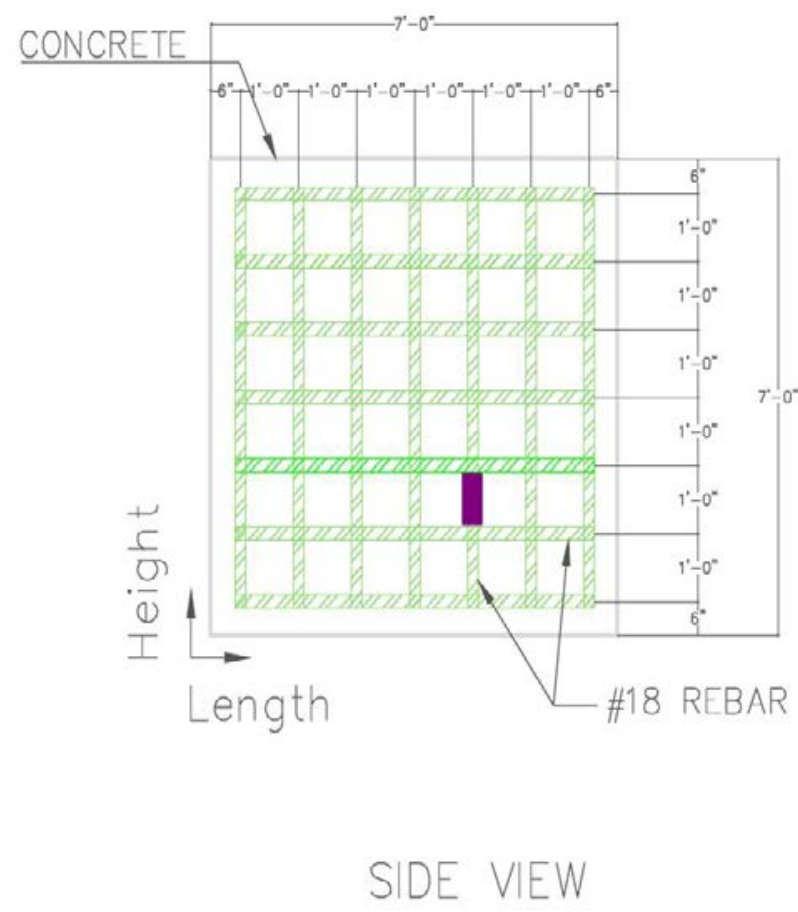

Fig. A.19. D02 length by height.

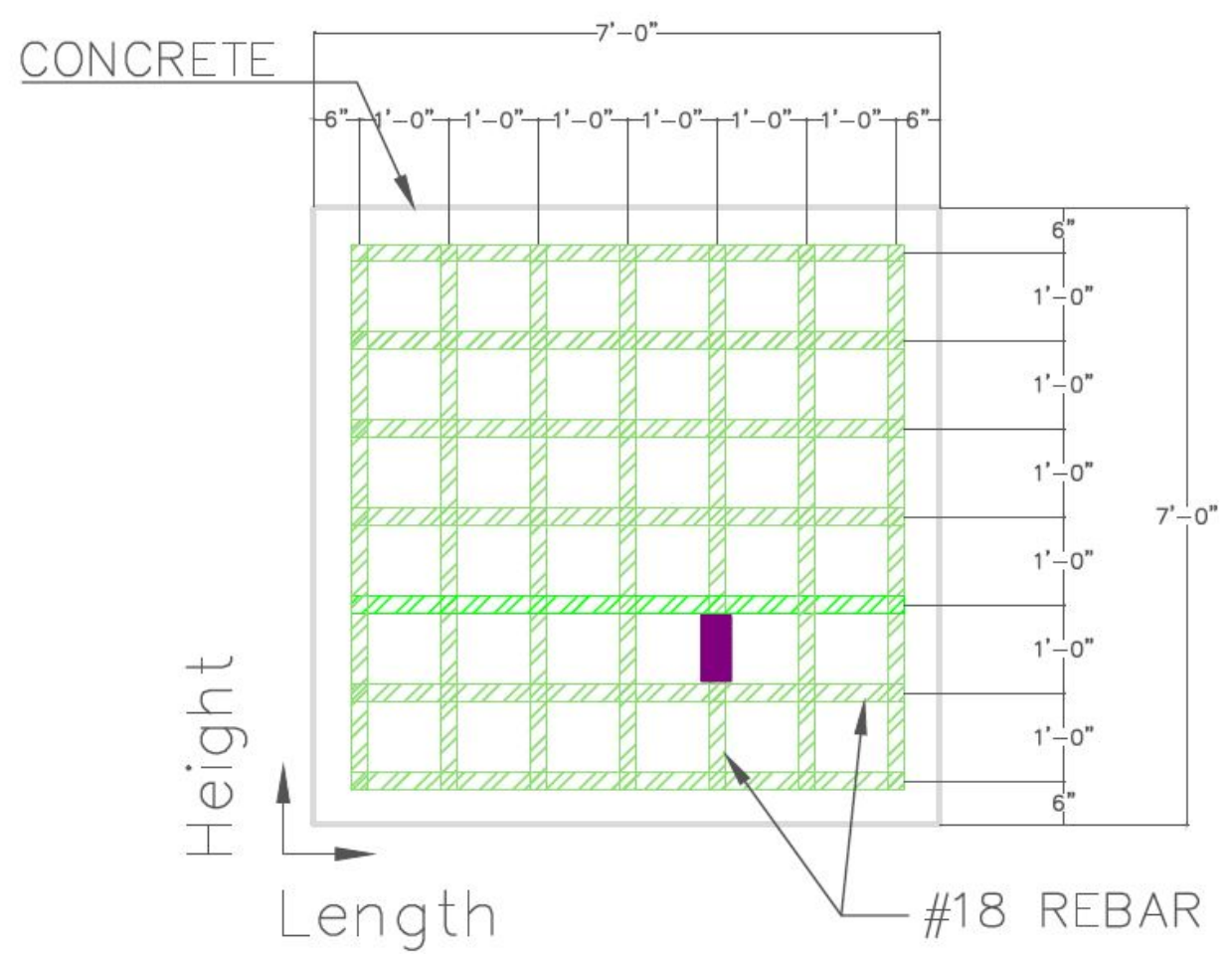

Fig. A.20. D02 length by height NL. 


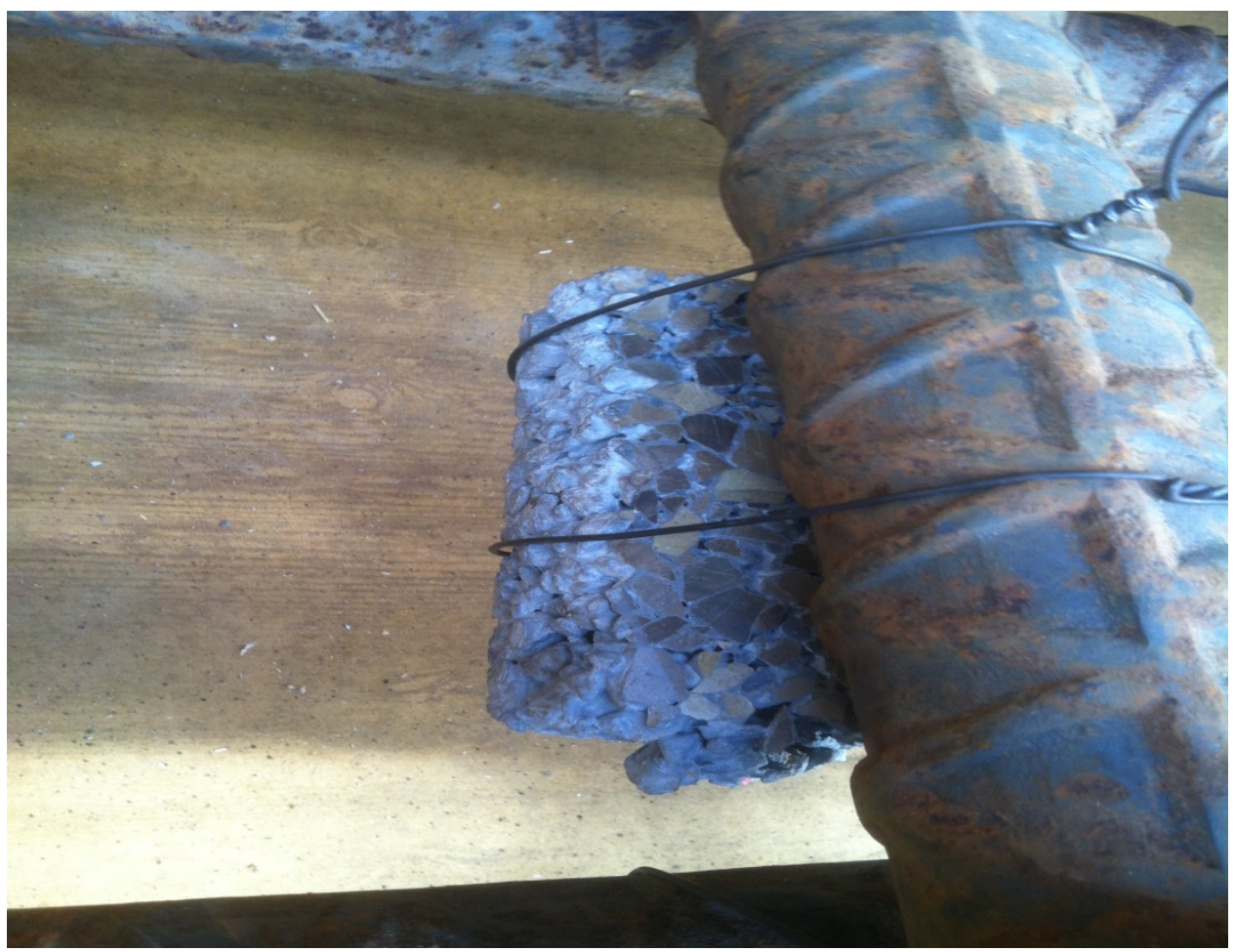

Fig. A.21. D03 close-up.

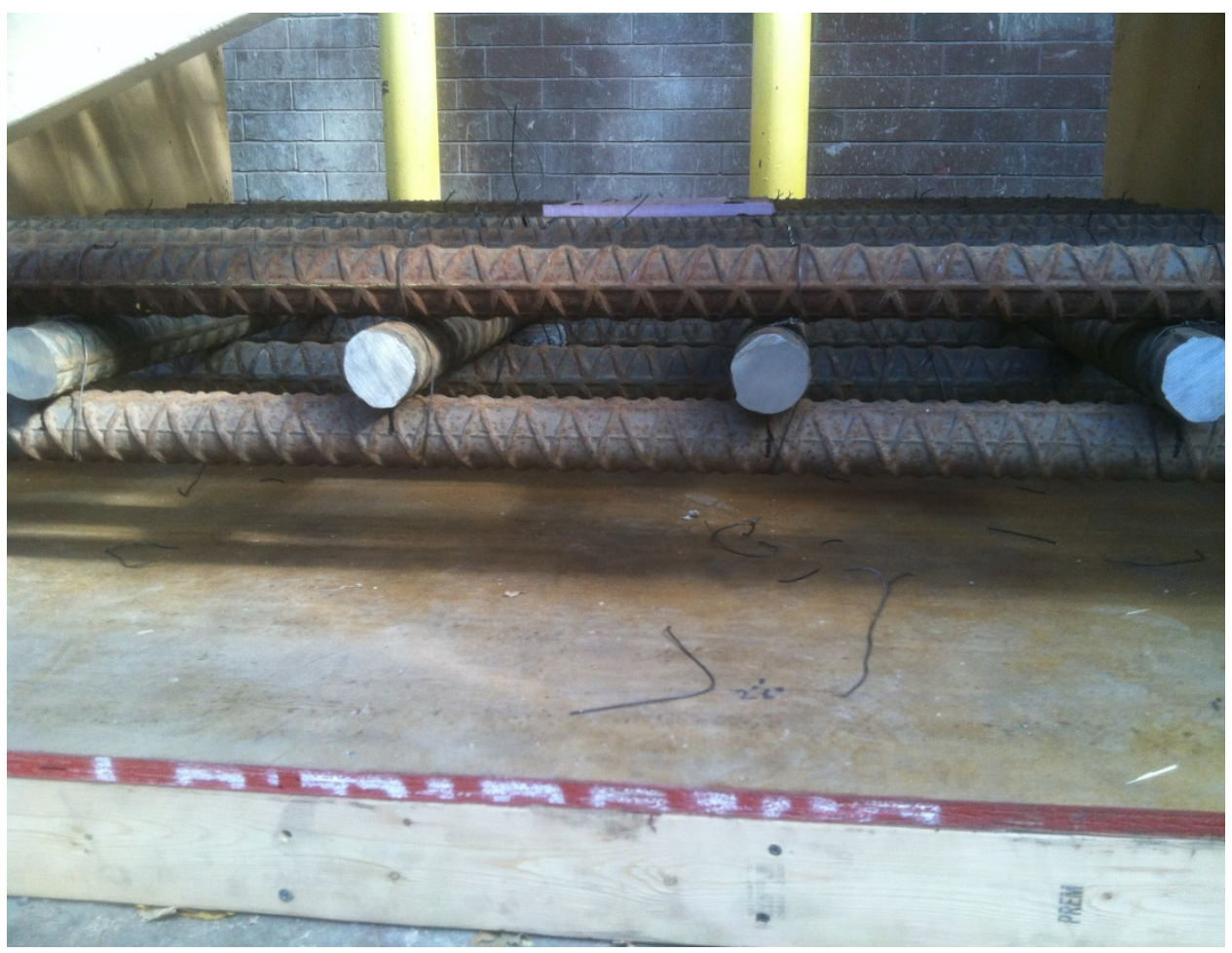

Fig. A.22. D03 height 5.5 bars $5 \mathrm{ft} \times 1676 \mathrm{~mm}$. 


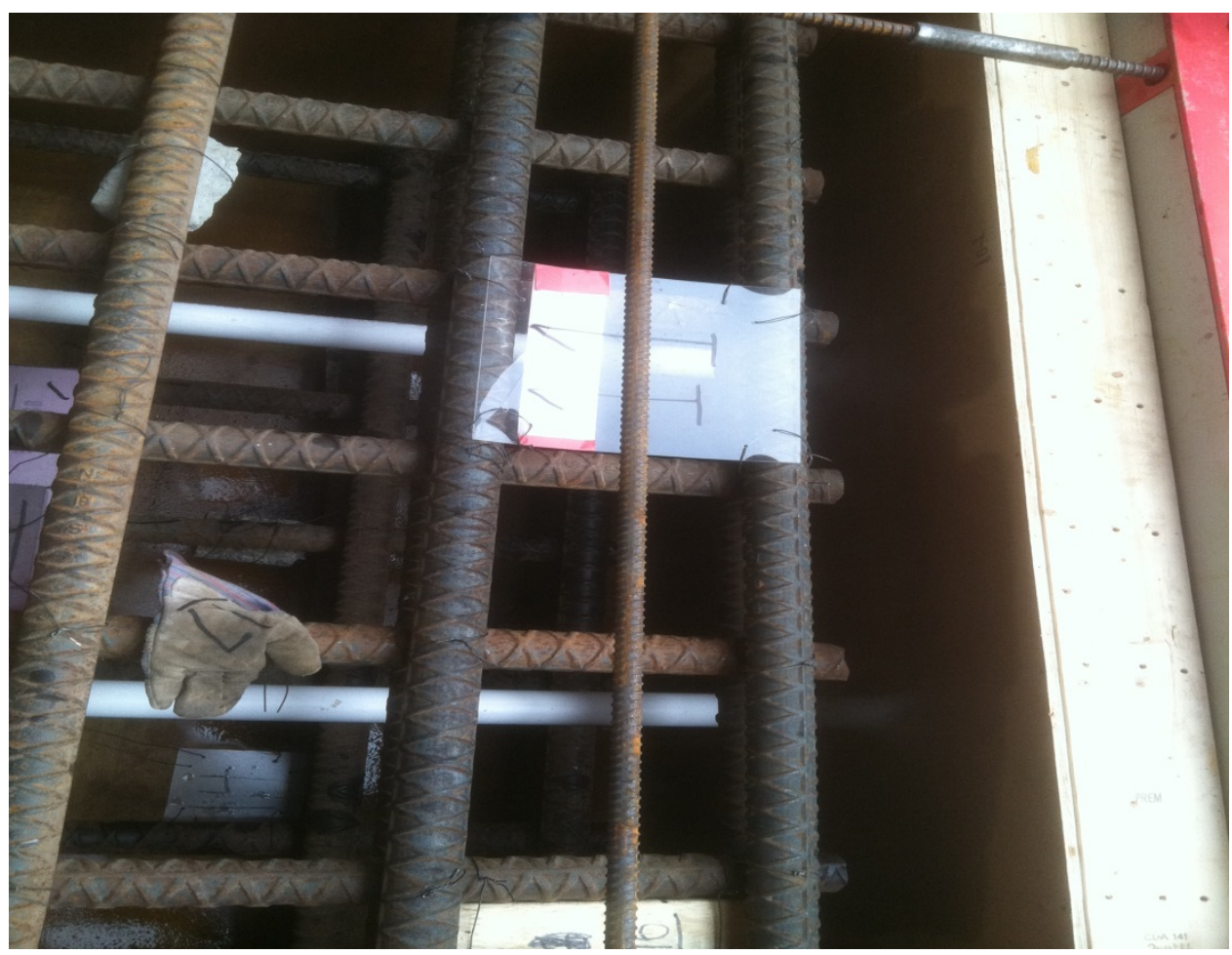

Fig. A.23. D03 length 4 bars 3.5ft $\times 1067 \mathrm{~mm}$.

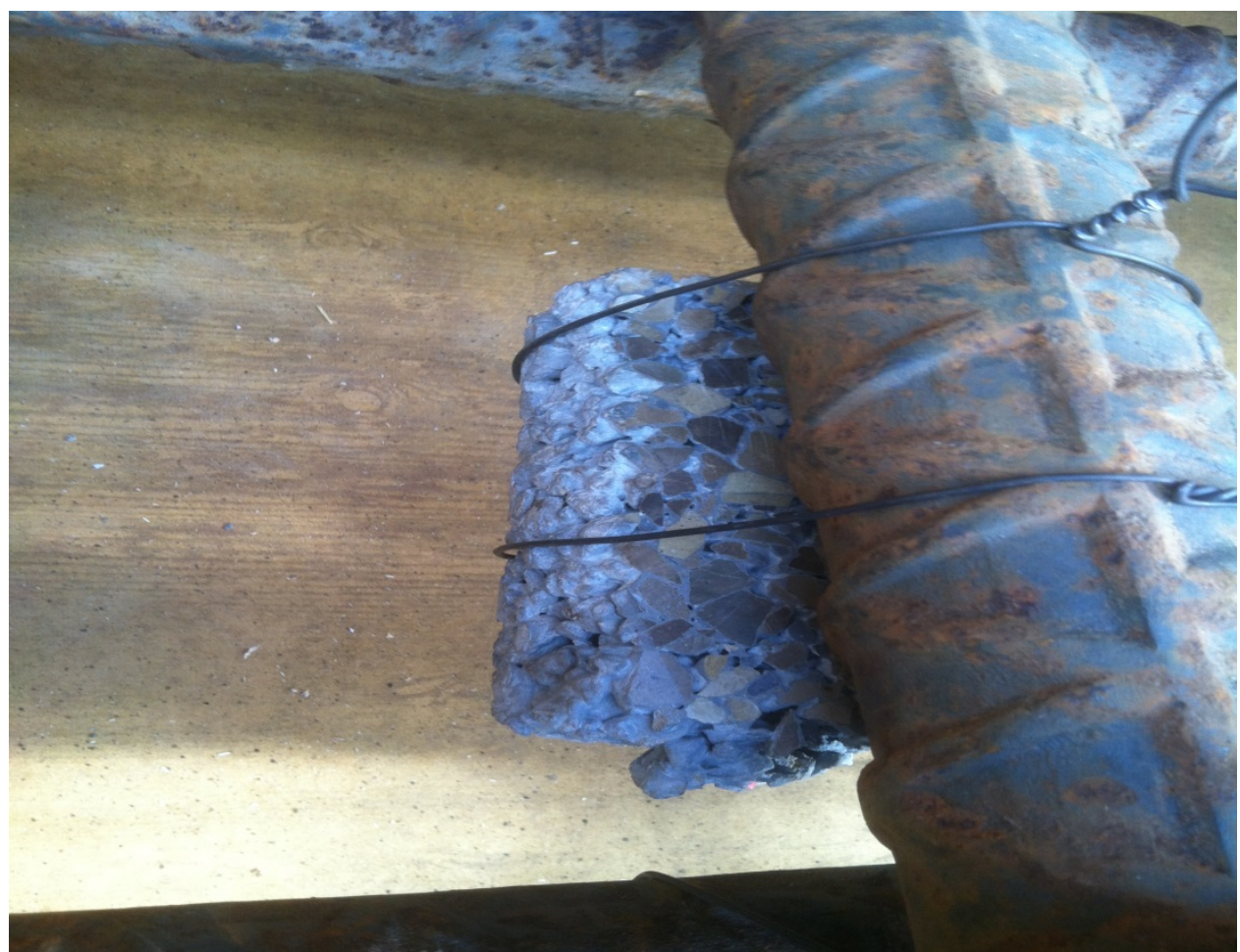

Fig. A.24. D03 R-depth bottom of 5th bar $876 \mathrm{~mm}$. 


\begin{tabular}{|c|c|c|}
\hline \multicolumn{3}{|c|}{ DEEECT TABLE } \\
\hline ID NUMBER & DESCRPTION & LABE \\
\hline 01 & $\begin{array}{l}\text { POROUS HALF CYMNDER } \\
\text { (NO COVER) }\end{array}$ & \\
\hline 02 & $\begin{array}{l}\text { POROUS HALF CYINDER } \\
\text { (COVER) }\end{array}$ & \\
\hline D3 & $\begin{array}{l}\text { POROUS HALF CYINDER } \\
\text { (NO COVER) }\end{array}$ & \\
\hline 04 & $\begin{array}{l}\text { POROUS HALF CYINDER } \\
\text { (COVER) }\end{array}$ & \\
\hline 05 & $\begin{array}{l}\text { POROUS HALF CYINDER } \\
\text { (COVER \& CRACK) }\end{array}$ & \\
\hline 06 & PVC & \\
\hline 07 & PVC & \\
\hline DB & $\begin{array}{l}\text { DISSOLUNG STRROFOAM } \\
\text { (THICK) }\end{array}$ & \\
\hline Dg & STTROFOAM (THIOK) & \\
\hline 010 & STYROFOAM (THIN) & \\
\hline 011 & PLEXIGLASS & \\
\hline 012 & $\begin{array}{l}\text { DISSOLUNG STRROFOAM } \\
\text { (MEDIUM) }\end{array}$ & \\
\hline 013 & STYROFOAM (MEDIUM) & \\
\hline 014 & PLEXYGLASS & \\
\hline 015 & $\begin{array}{l}\text { DISSOLUNG STROFOAM } \\
(\mathrm{THN})\end{array}$ & \\
\hline 016 & LUMBER (2X4) & \\
\hline 017 & GLOVES & \\
\hline 018 & $\begin{array}{l}\text { DEBONO DUCT TAPE } \\
\text { (ONE LAYER) }\end{array}$ & \\
\hline D19 & $\begin{array}{l}\text { DEBOND DUCT TAPE } \\
\text { (MULT-LAYRR) }\end{array}$ & \\
\hline 020 & MOUNG REBAR & \\
\hline
\end{tabular}

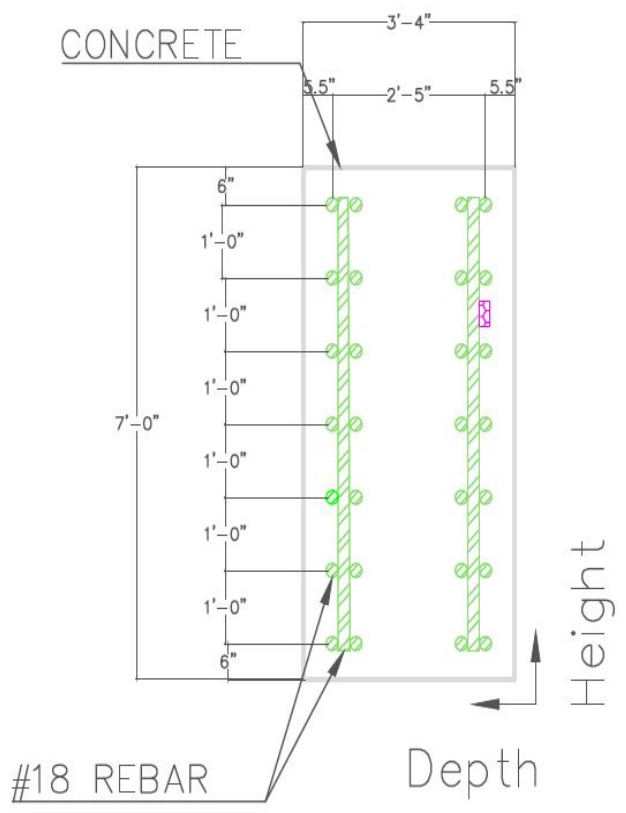

Fig. A.25. D03 height by depth.

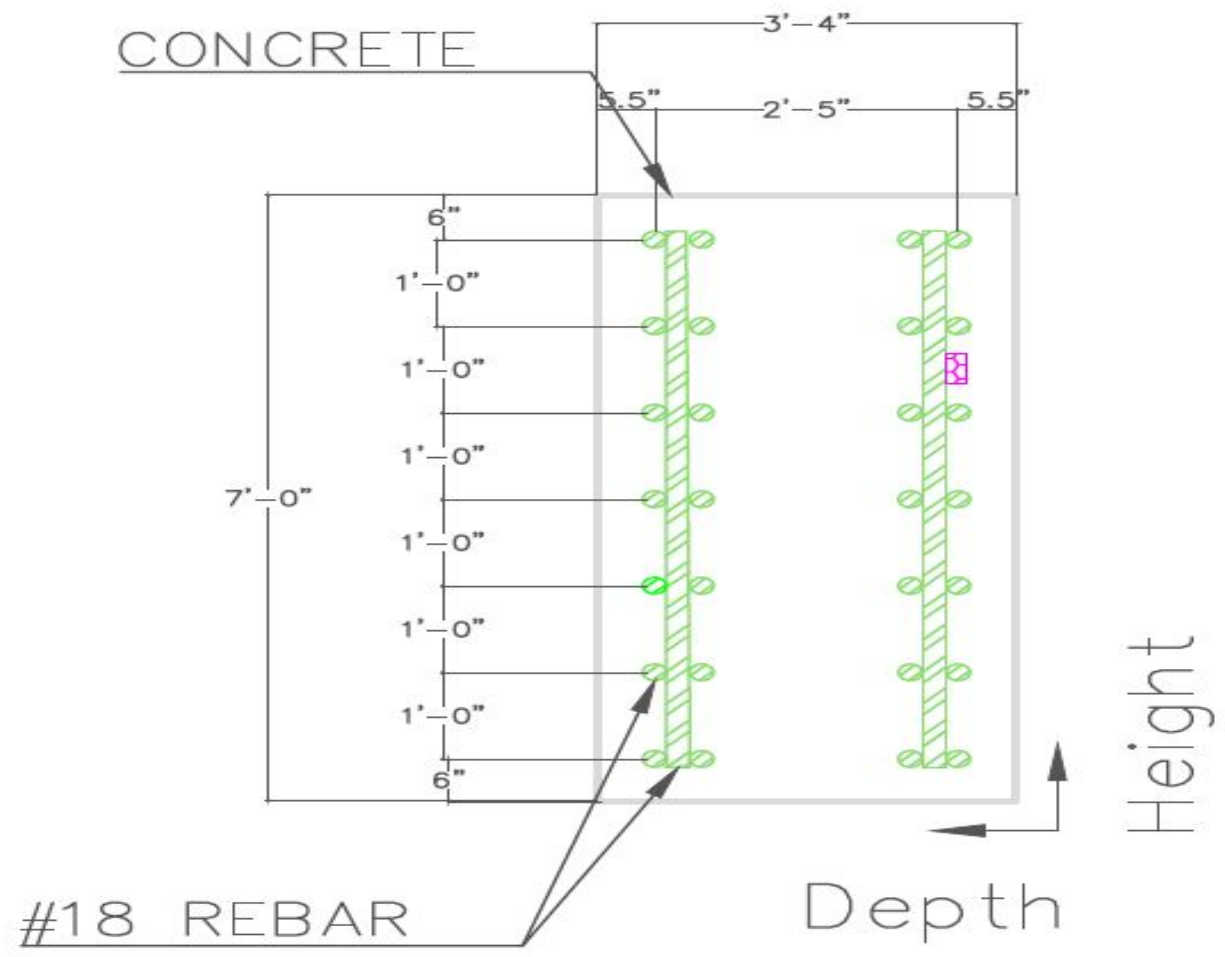

Fig. A.26. D03 height by depth NL. 


\begin{tabular}{|c|c|c|}
\hline \multicolumn{3}{|c|}{ DEFECT TABLE } \\
\hline O NuOCR & OCSORPTON & $\omega 0$ \\
\hline on & 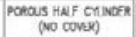 & \\
\hline 02 & 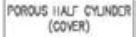 & \\
\hline os & 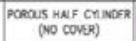 & \\
\hline$\infty$ & 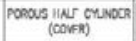 & \\
\hline DS & $\begin{array}{l}\text { PGROUS HNL CNUNOCR } \\
\text { (CONCR \& OROO) }\end{array}$ & \\
\hline$\infty 6$ & $P \mathbf{P C}$ & \\
\hline or & $p x$ & \\
\hline DO & $\begin{array}{l}\text { assa vang snmorow } \\
\text { (THO) }\end{array}$ & \\
\hline$\infty$ & 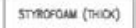 & \\
\hline 010 & STradoun (TiM) & \\
\hline 011 & piovouss & \\
\hline 012 & 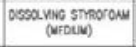 & \\
\hline 013 & STMESONU (NEDUN) & \\
\hline 014 & prevacuss & \\
\hline 015 & $\begin{array}{c}\text { Dssa unc sproosonu } \\
\text { (TiN) }\end{array}$ & \\
\hline OH & แMesx (2x) & \\
\hline 017 & aoves & \\
\hline 010 & $\begin{array}{l}\text { DERONO DUCT TNPE } \\
\text { (ONC LARR) }\end{array}$ & \\
\hline 019 & $\begin{array}{l}\text { DCBONO DUCT TAPE } \\
\text { (MULLII-LARE) }\end{array}$ & \\
\hline 020 & NONNG вEAнR & \\
\hline
\end{tabular}

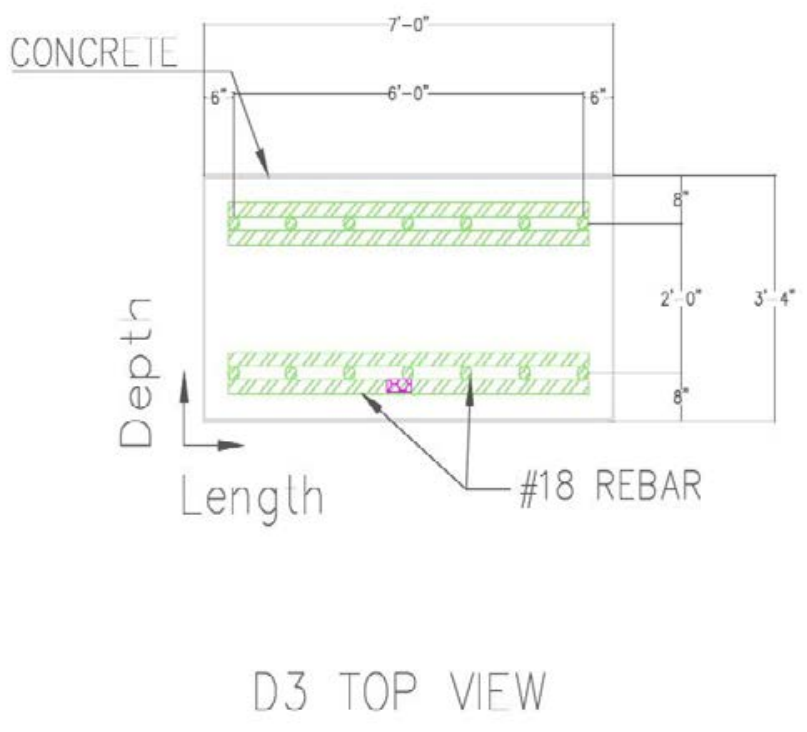

Fig. A.27. D03 length by depth.

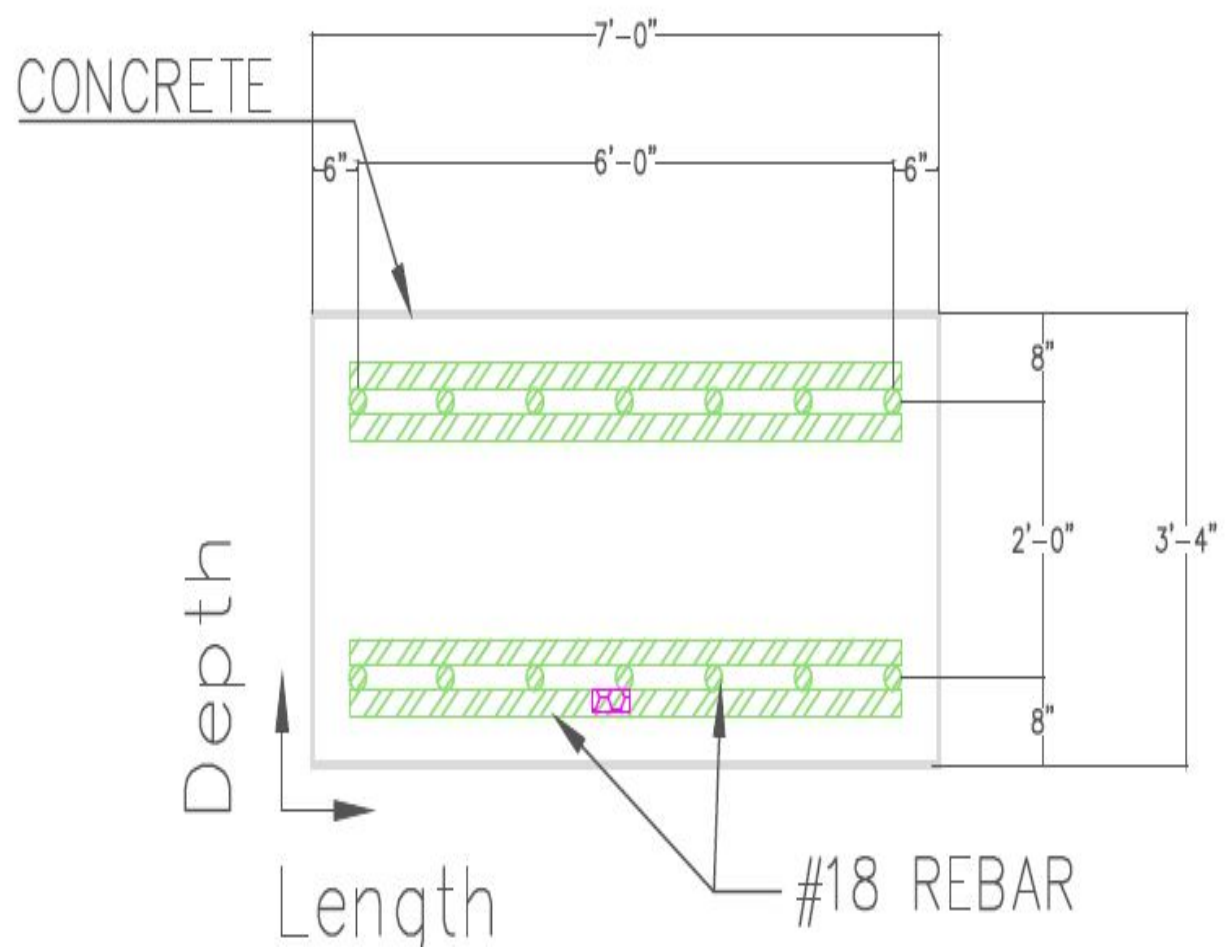

Fig. A.28. D03 length by depth NL. 

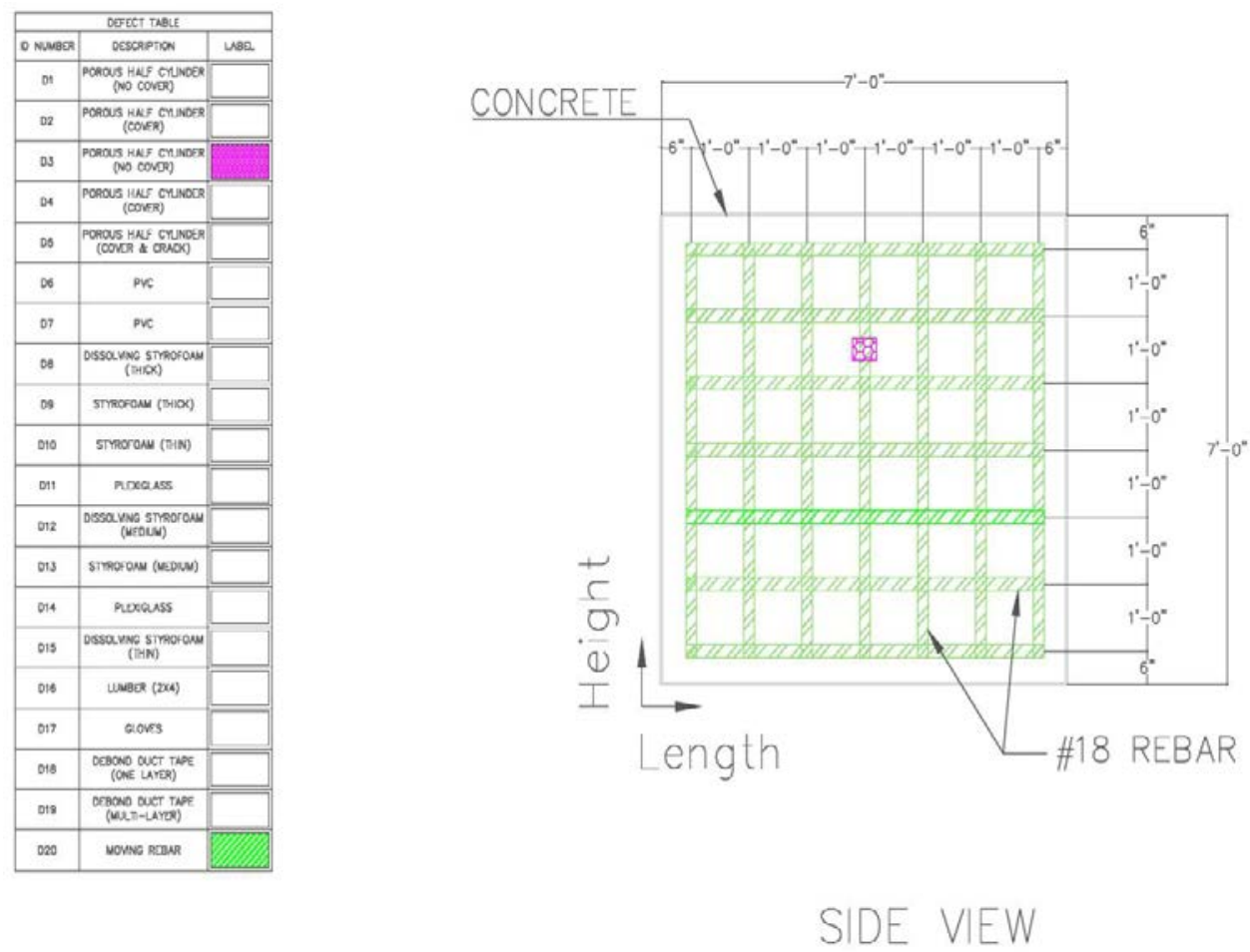

Fig. A.29. D03 length by height.

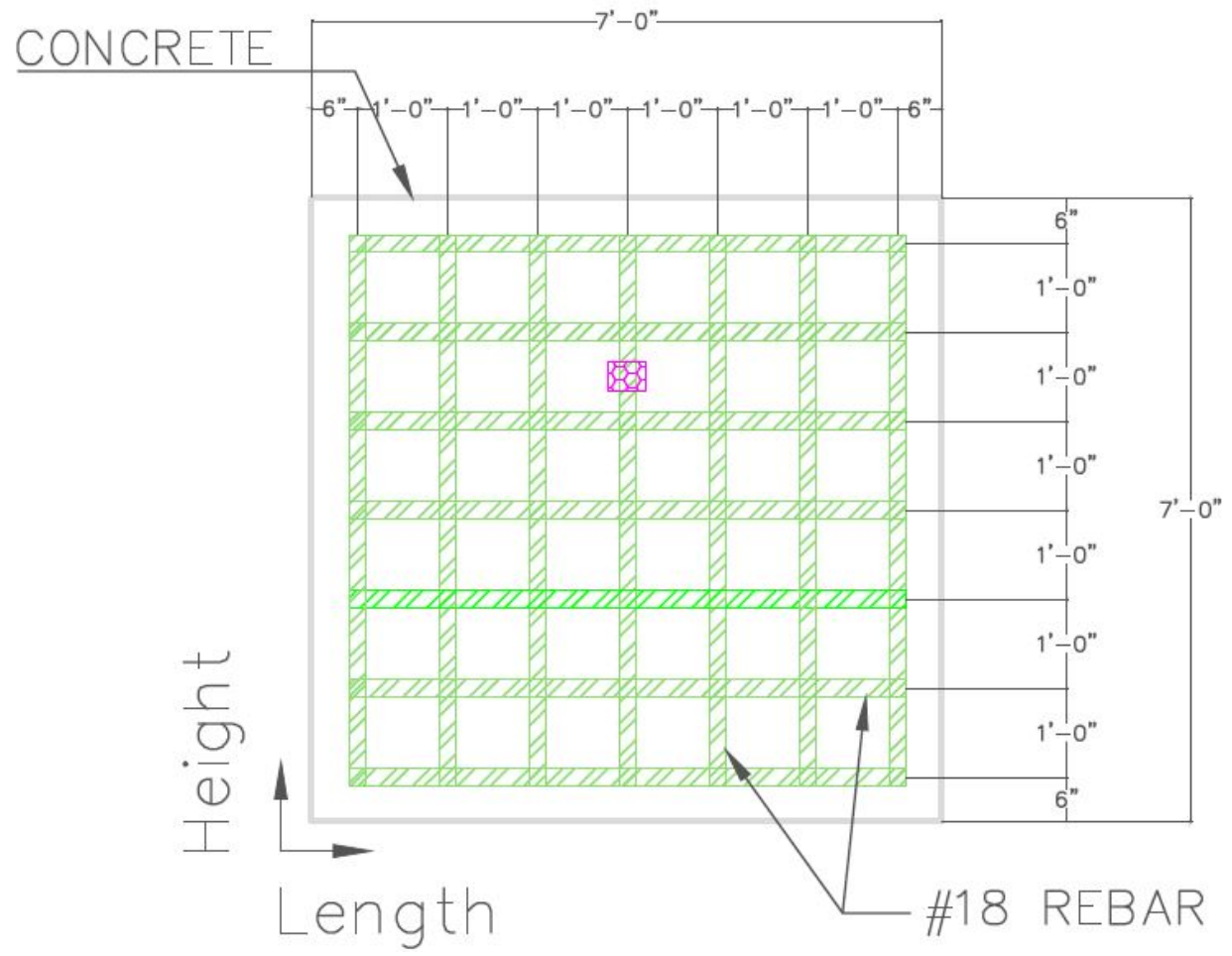

Fig. A.30. D03 length by height NL. 


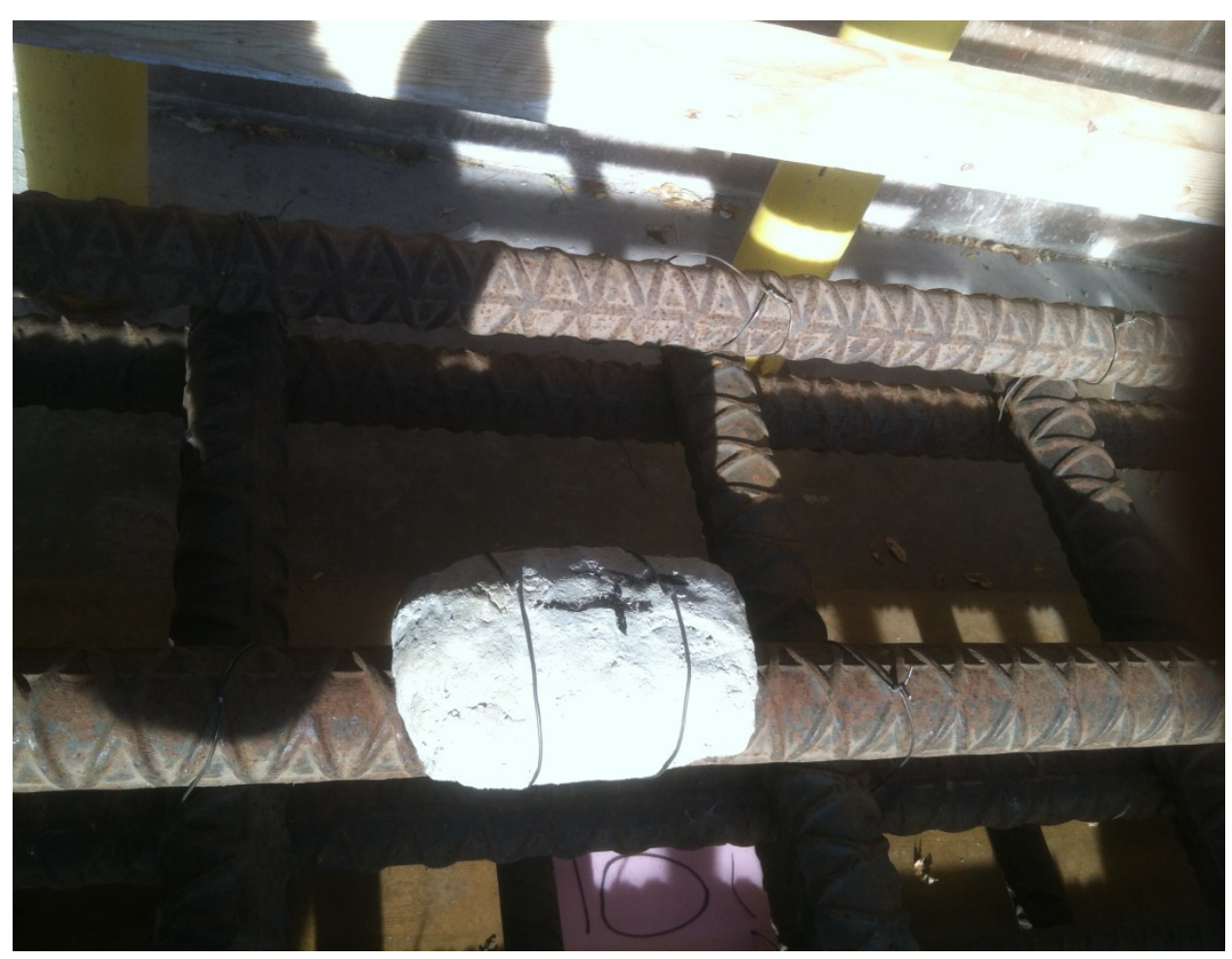

Fig. A.31. D04 close-up.

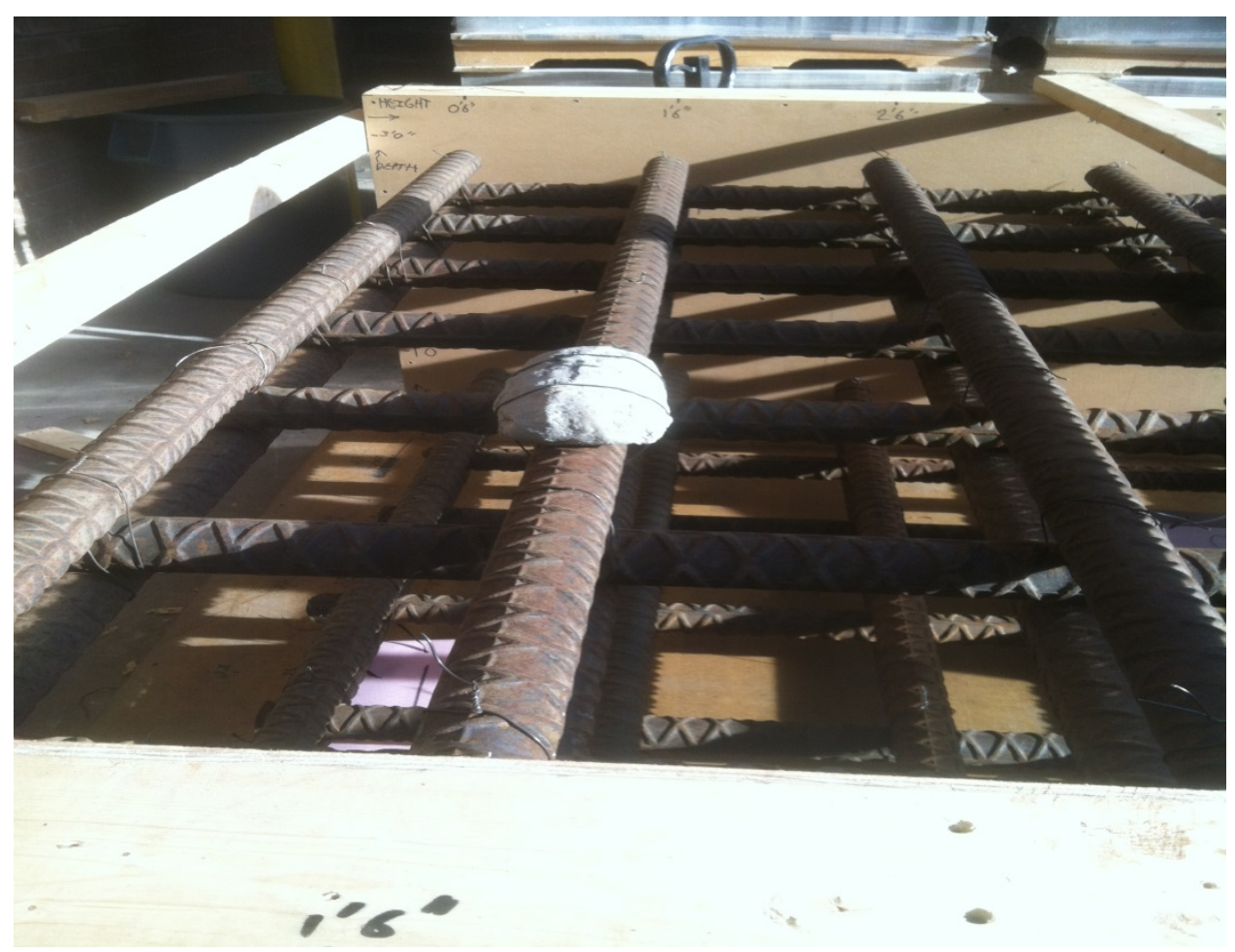

Fig. A.32. D04 height 2 bars $1.5 \mathrm{ft} \times 457 \mathrm{~mm}$. 


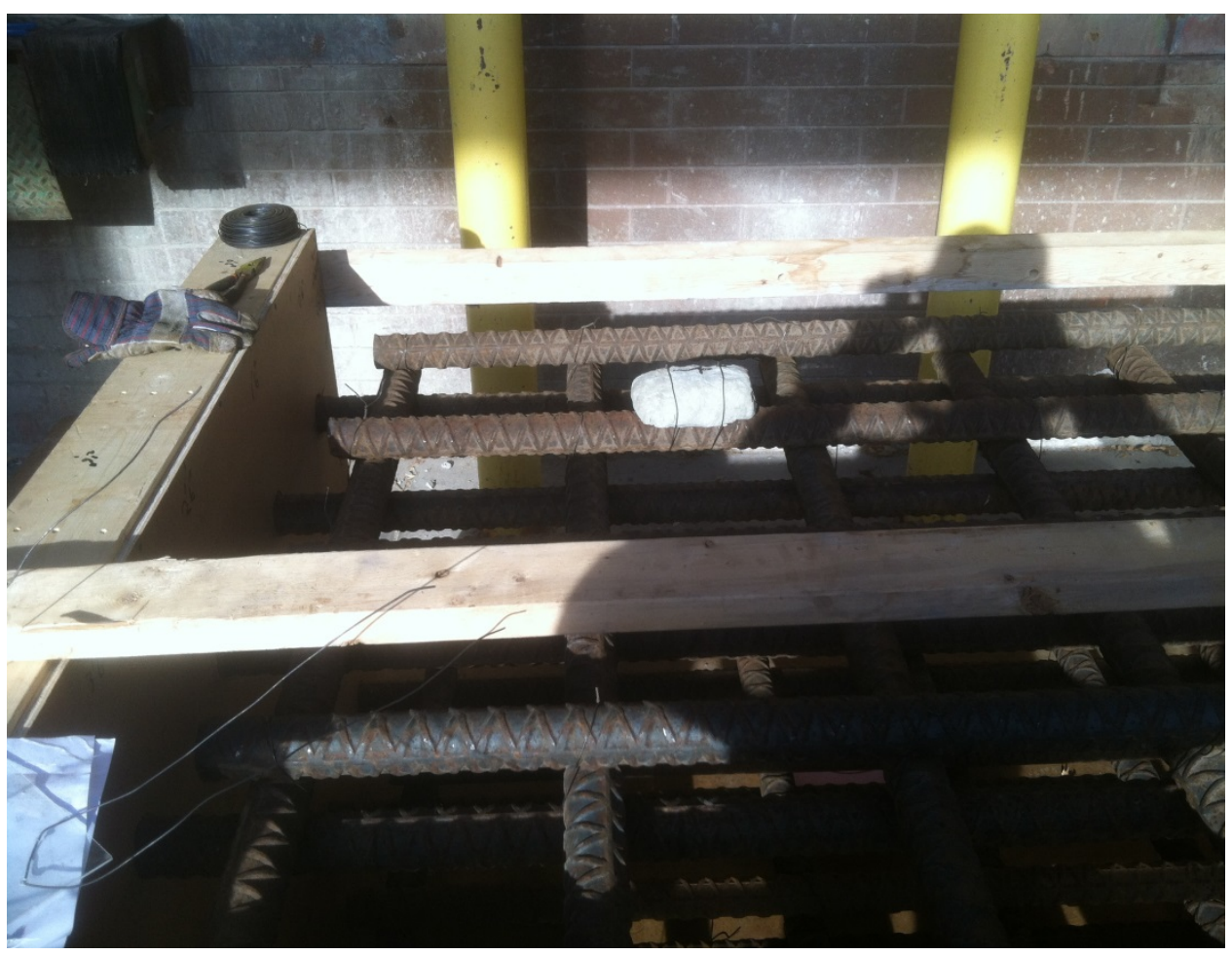

Fig. A.33. D04 length 5.5bars $5 \mathrm{ft} \times 1524 \mathrm{~mm}$.

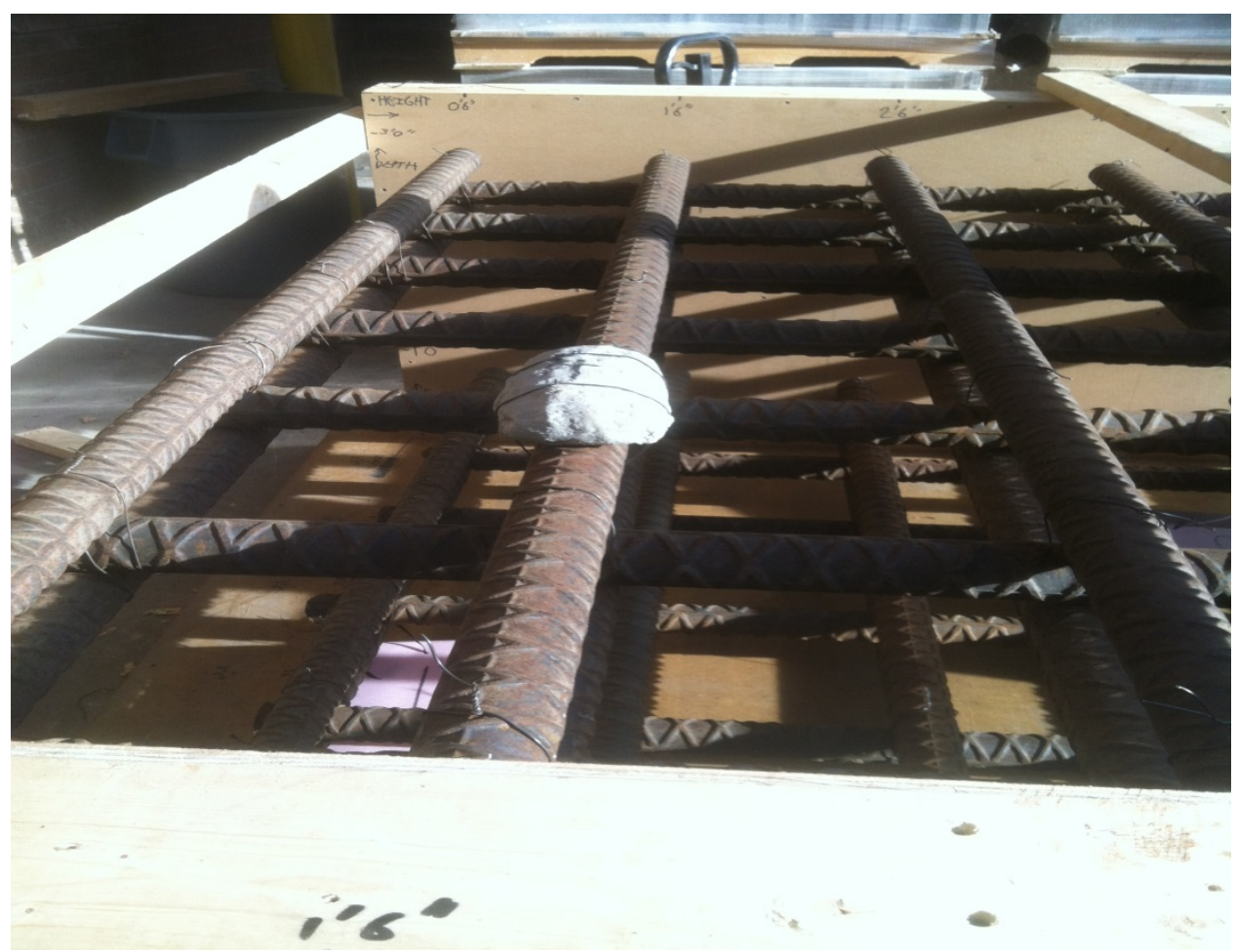

Fig. A.34. 04 R-depth top of top bar 86mm. 


\begin{tabular}{|c|c|c|}
\hline \multicolumn{3}{|c|}{ DEFECT TABLE } \\
\hline ID NUMBER & DESCRPTION & LABE \\
\hline D1 & $\begin{array}{l}\text { POROUS HALF CYINDER } \\
\text { (NO COVER) }\end{array}$ & \\
\hline 02 & $\begin{array}{l}\text { POROUS HALF CYINDER } \\
\text { (COVER) }\end{array}$ & \\
\hline D3 & $\begin{array}{l}\text { POROUS HALF CYNNDER } \\
\text { (NO COVER) }\end{array}$ & \\
\hline 04 & $\begin{array}{l}\text { POROUS HALF CYINDER } \\
\text { (COVER) }\end{array}$ & \\
\hline 05 & $\begin{array}{l}\text { POROUS HALF CYNNDER } \\
\text { (COVER \& CRACK) }\end{array}$ & \\
\hline D6 & PVC & \\
\hline 07 & PVC & \\
\hline DB & $\begin{array}{l}\text { DISSOLUNG STYROFOAM } \\
\text { (THIC) }\end{array}$ & \\
\hline 09 & STTROFOAM (THICK) & \\
\hline 010 & STYROFOAM (THIN) & \\
\hline 011 & PLENGLASS & \\
\hline 012 & $\begin{array}{l}\text { DISSOLYNG STRROFOAM } \\
\text { (MEDIUM) }\end{array}$ & \\
\hline 013 & STYROFOAM (MEDIUM) & \\
\hline 014 & PLEX:GLASS & \\
\hline 015 & $\begin{array}{l}\text { DISSOLUNG STYROFOAM } \\
\text { (THN) }\end{array}$ & \\
\hline 016 & LUMBER $(2 \times 4)$ & \\
\hline 017 & GLOVES & \\
\hline D18 & $\begin{array}{l}\text { DEBONO DUCT TAPE } \\
\text { (ONE LAYER) }\end{array}$ & \\
\hline 019 & $\begin{array}{c}\text { DEBOND DUCT TAPE } \\
\text { (MULT-LAYER) }\end{array}$ & \\
\hline 020 & MOUNG REBAR & \\
\hline
\end{tabular}

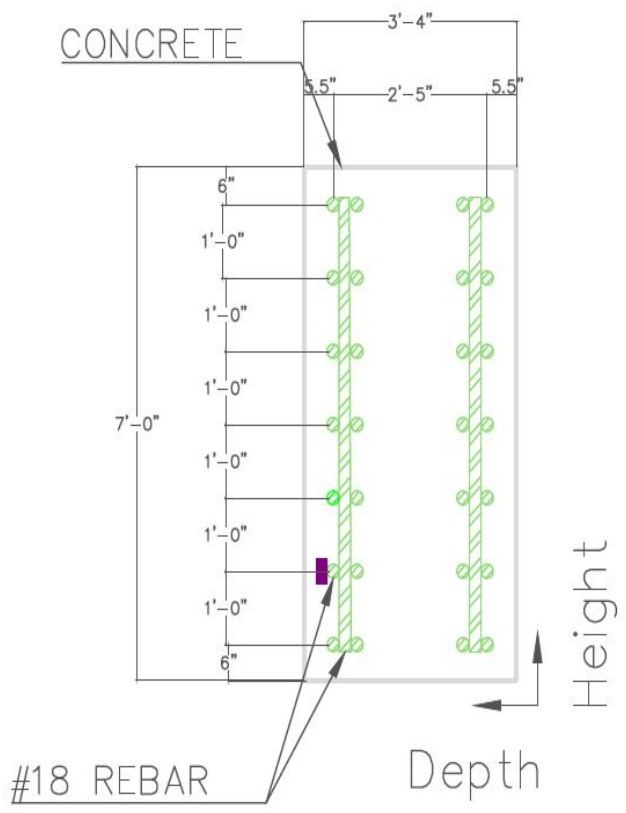

Fig. A.35. D04 height by depth.

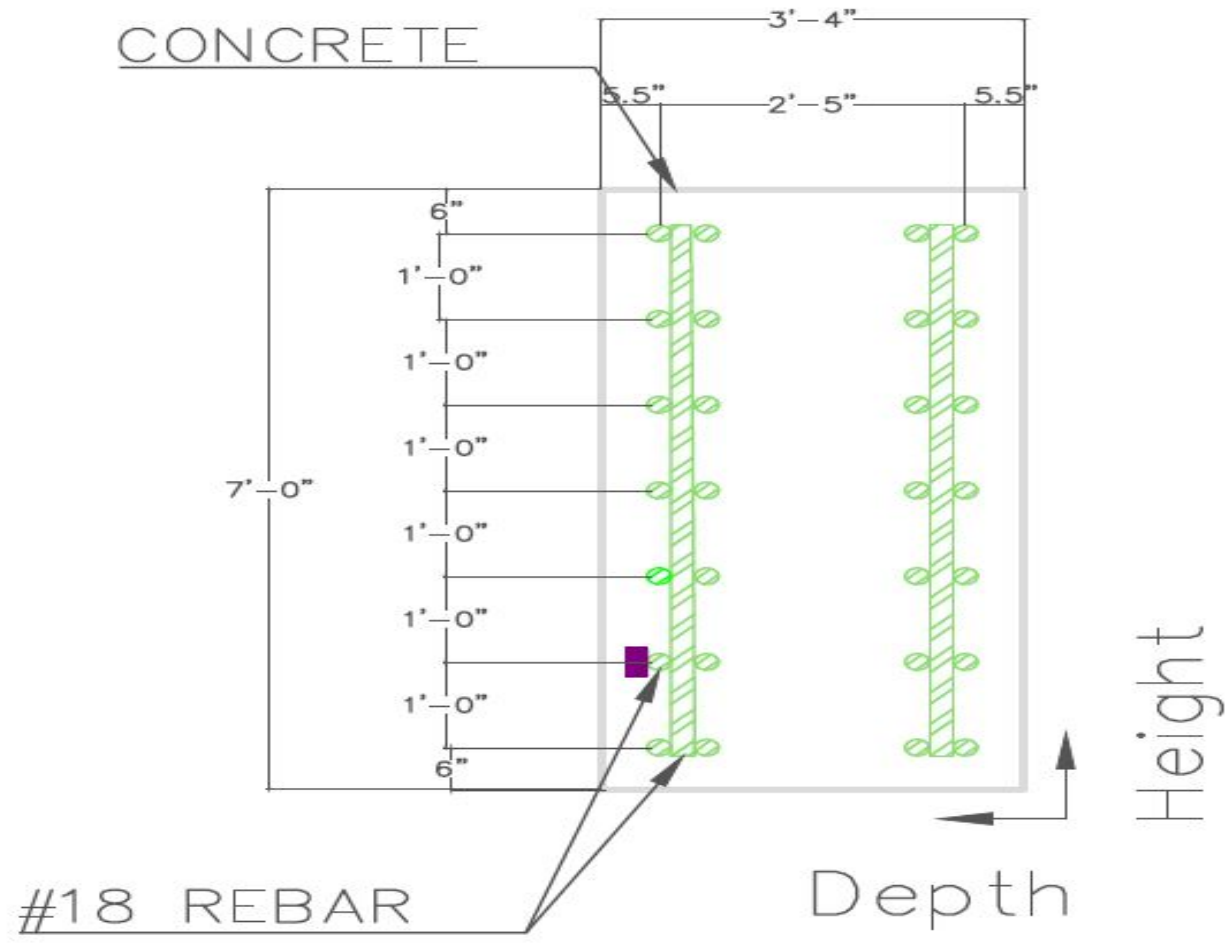

Fig. A.36. D04 height by depth NL. 


\begin{tabular}{|c|c|c|}
\hline \multicolumn{3}{|c|}{ CEECT TABLE } \\
\hline O NUNOCR & OCSORPTON & wa. \\
\hline on & 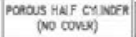 & \\
\hline 02 & $\begin{array}{l}\text { Fonous HNS CYNOCR } \\
\text { (COVER) }\end{array}$ & \\
\hline os & 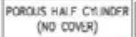 & \\
\hline$\infty$ & $\begin{array}{l}\text { POROUS INS CUNDCR } \\
\text { (CONEA) }\end{array}$ & \\
\hline 05 & 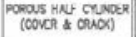 & \\
\hline 06 & $\mathbf{P C C}$ & \\
\hline 07 & $P x$ & \\
\hline 08 & 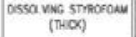 & \\
\hline$\infty$ & STracosed (Thox) & \\
\hline 010 & streorow (tian) & \\
\hline DII & pidvenss & \\
\hline on & 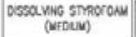 & \\
\hline 013 & STROCONU (NESU) & \\
\hline 014 & Renceass & \\
\hline 015 & $\begin{array}{c}\text { ossa vie smaorom } \\
\text { (TiN) }\end{array}$ & \\
\hline 016 & LUEgR $(2 x t)$ & \\
\hline 017 & goves & \\
\hline 010 & $\begin{array}{l}\text { OEBOPO OUCT TNDE } \\
\text { (ONC LATRR) }\end{array}$ & \\
\hline 19 & 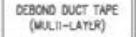 & \\
\hline 020 & NOWVO REBMR & \\
\hline
\end{tabular}

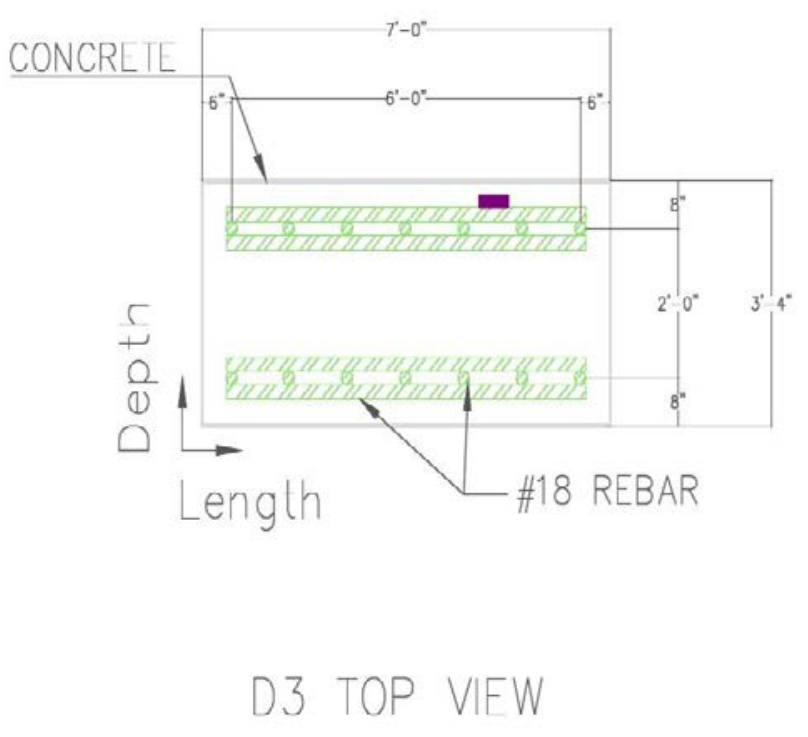

Fig. A.37. D04 length by depth.

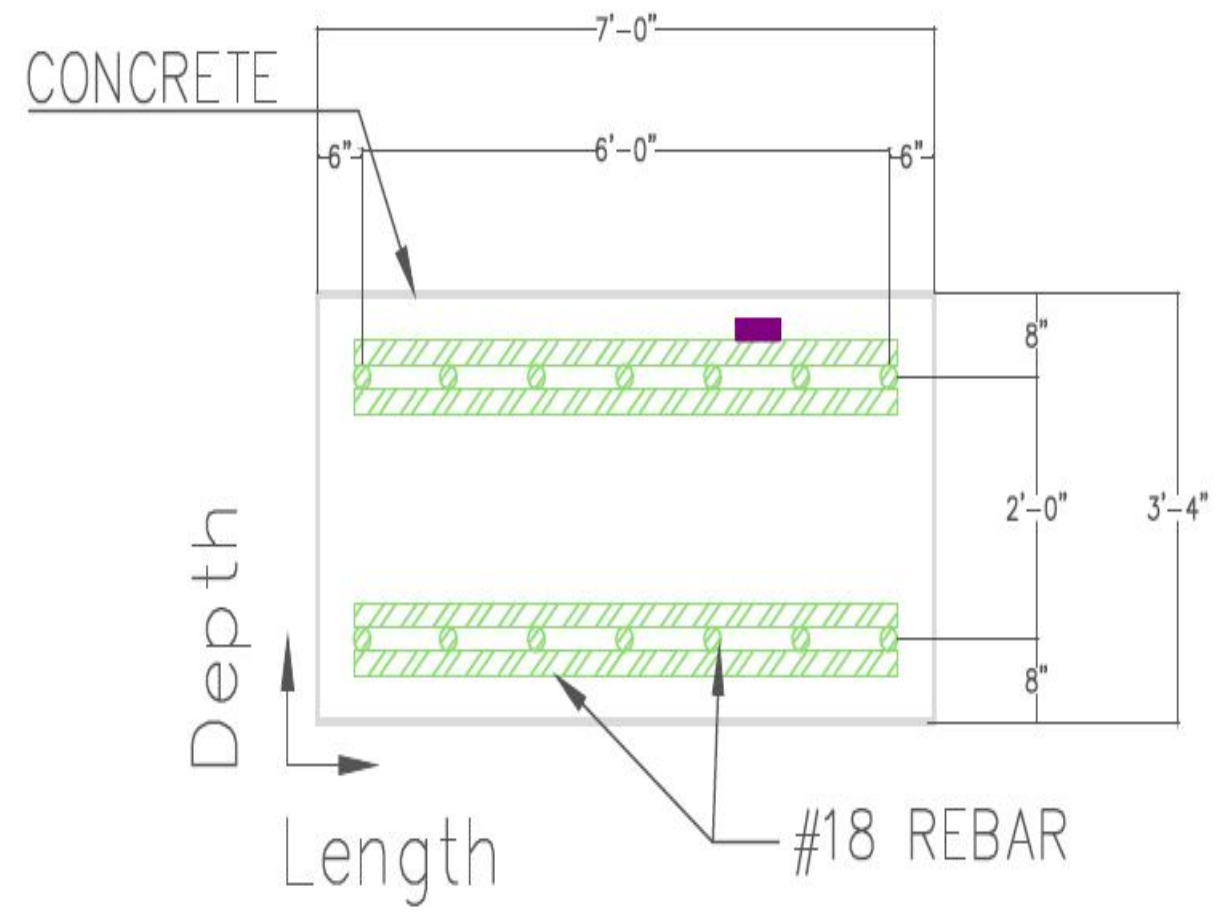

Fig. A.38. D04 length by depth NL. 

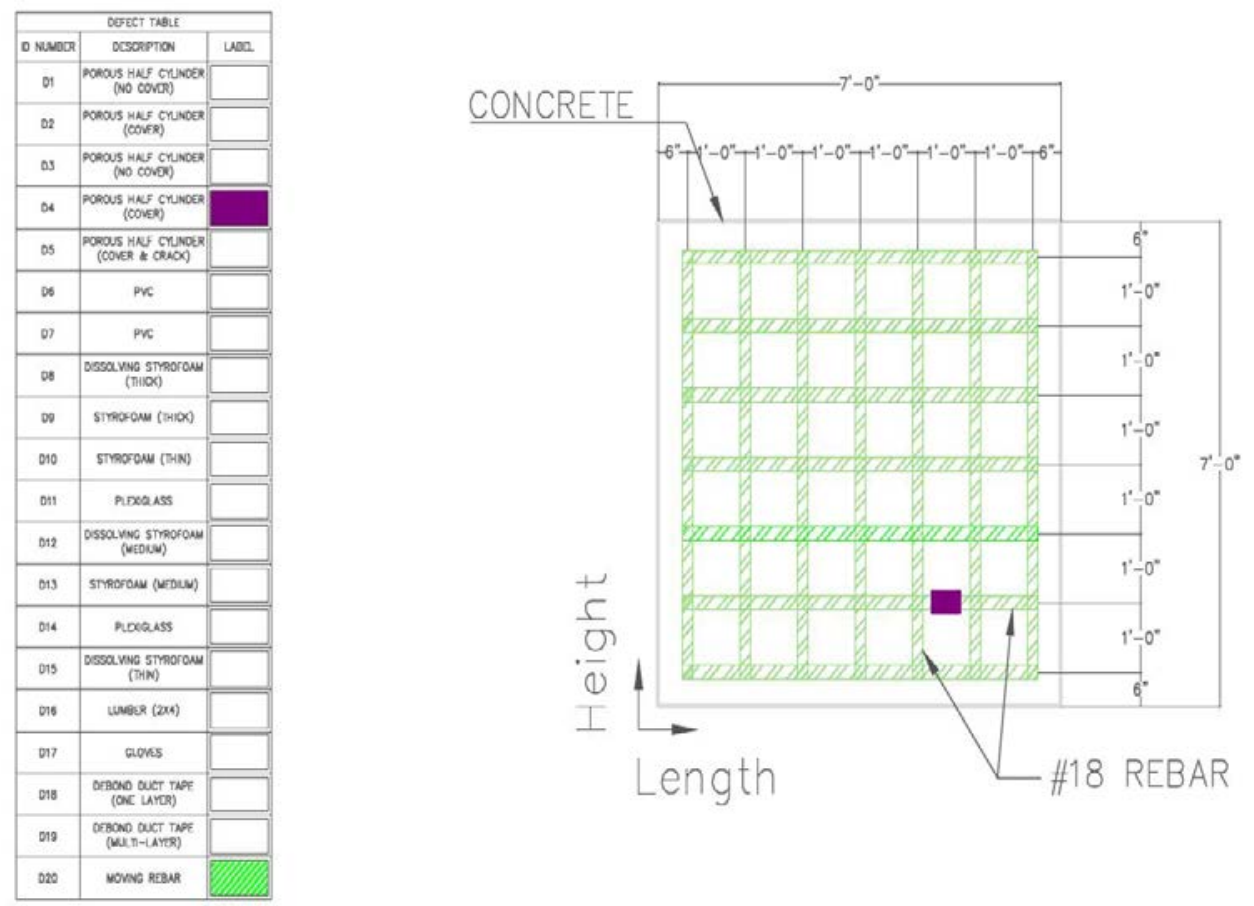

GIDF \/FW

Fig. A.39. D04 length by height.

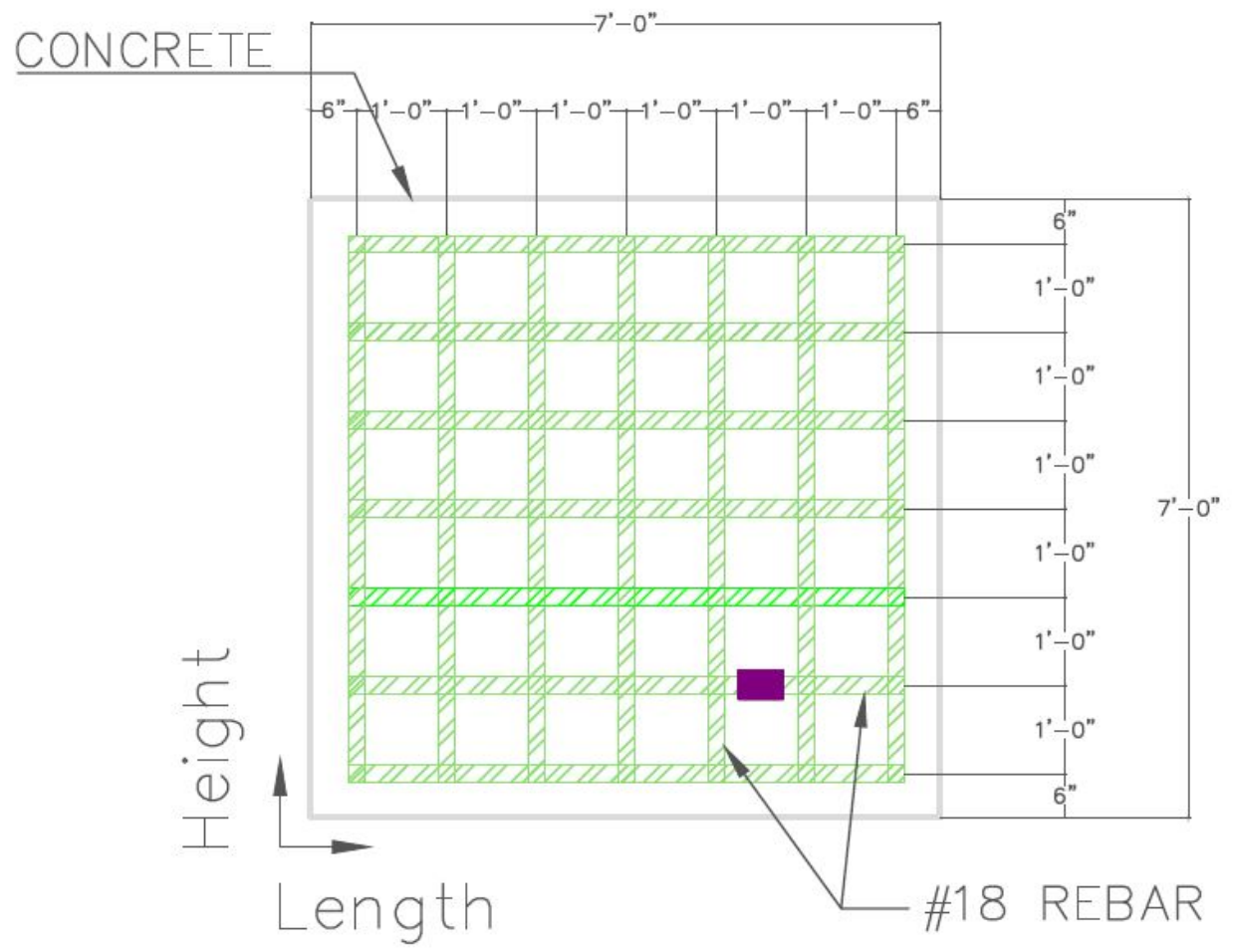

Fig. A.40. D04 length by height NL. 


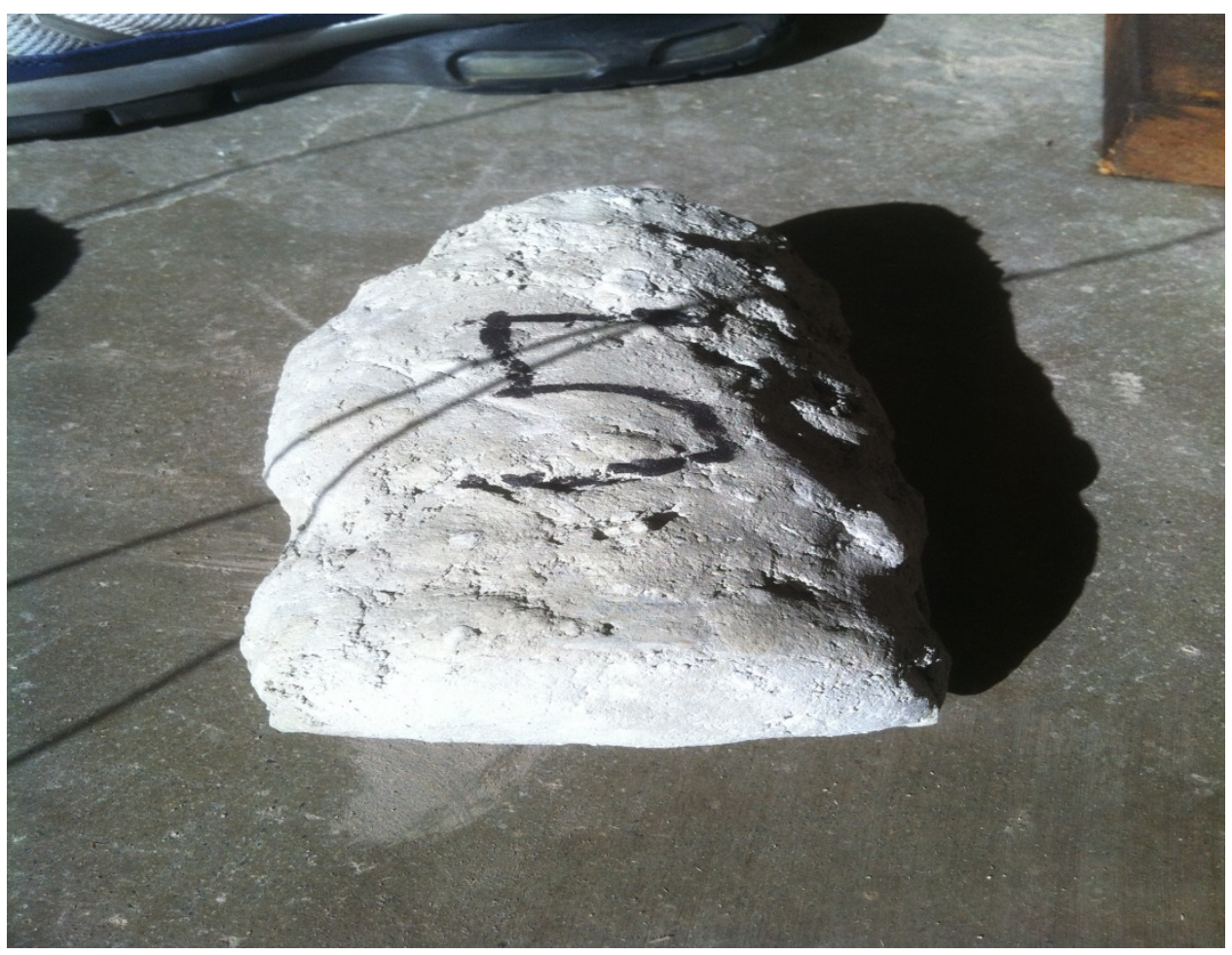

Fig. A.41. D05 close-up.

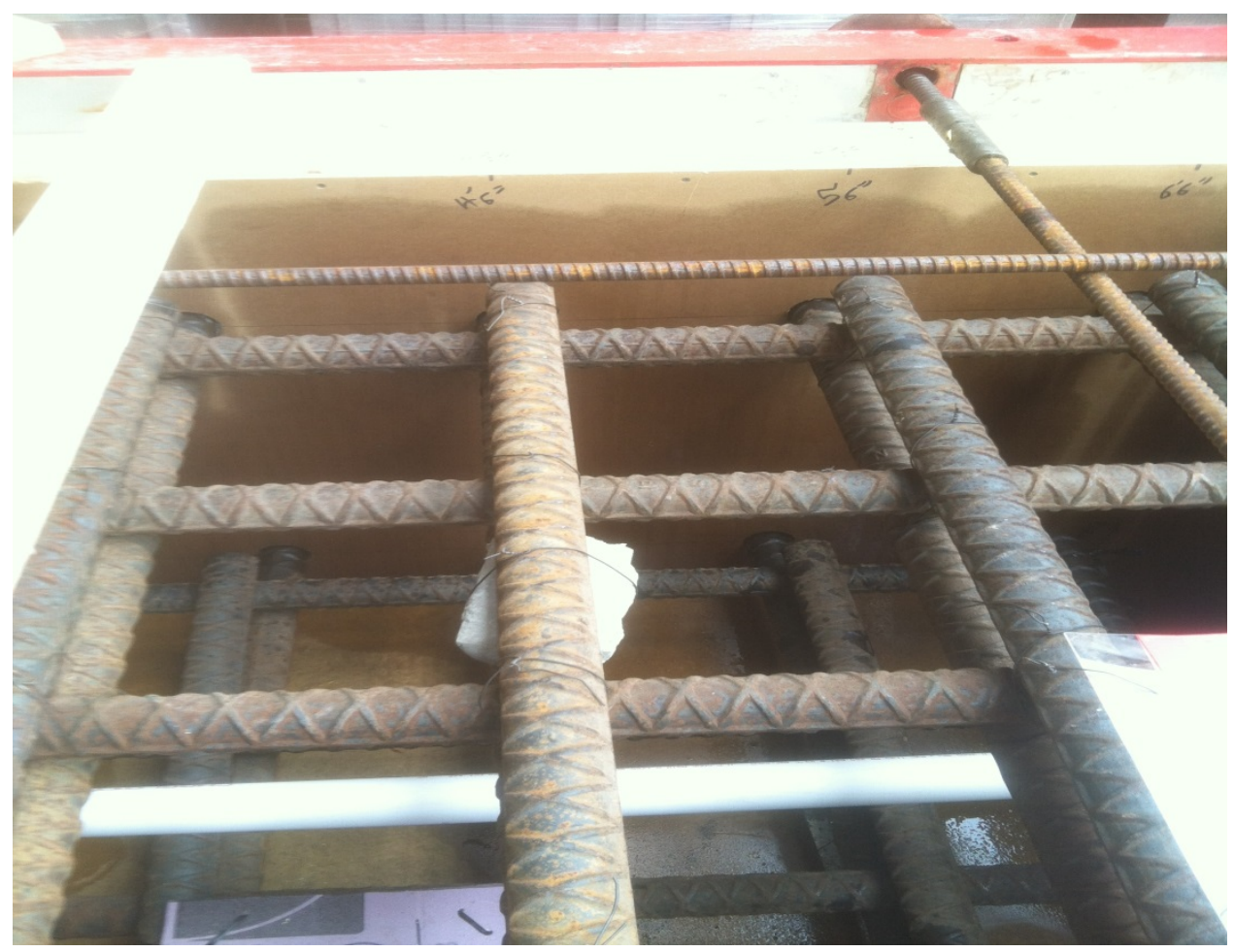

Fig. A.42. D05 height 5 bars $4.5 \mathrm{ft} \times 1372 \mathrm{~mm}$. 


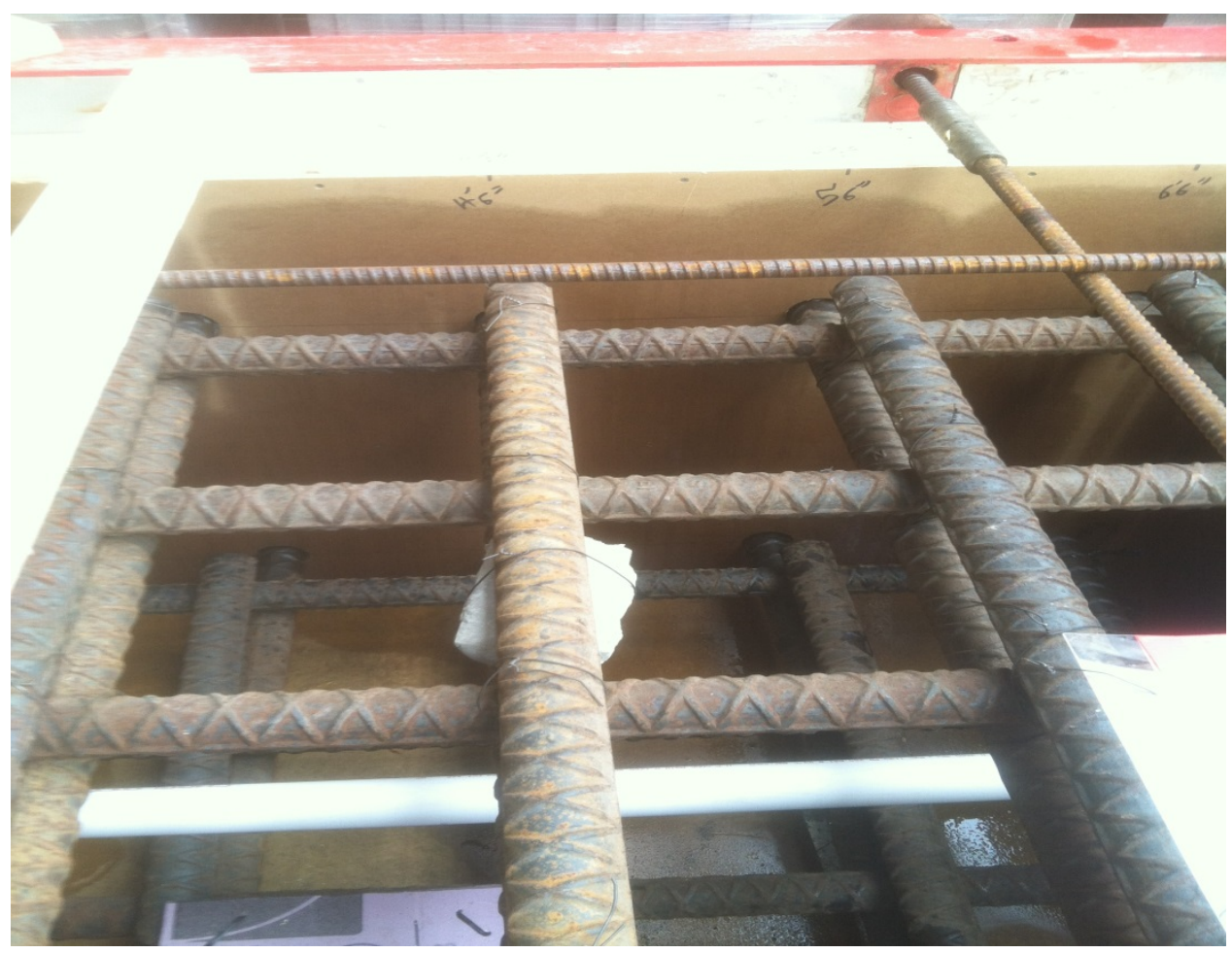

Fig. A.43. D05 length 2.5bars $2 \mathrm{ft} \times 610 \mathrm{~mm}$.

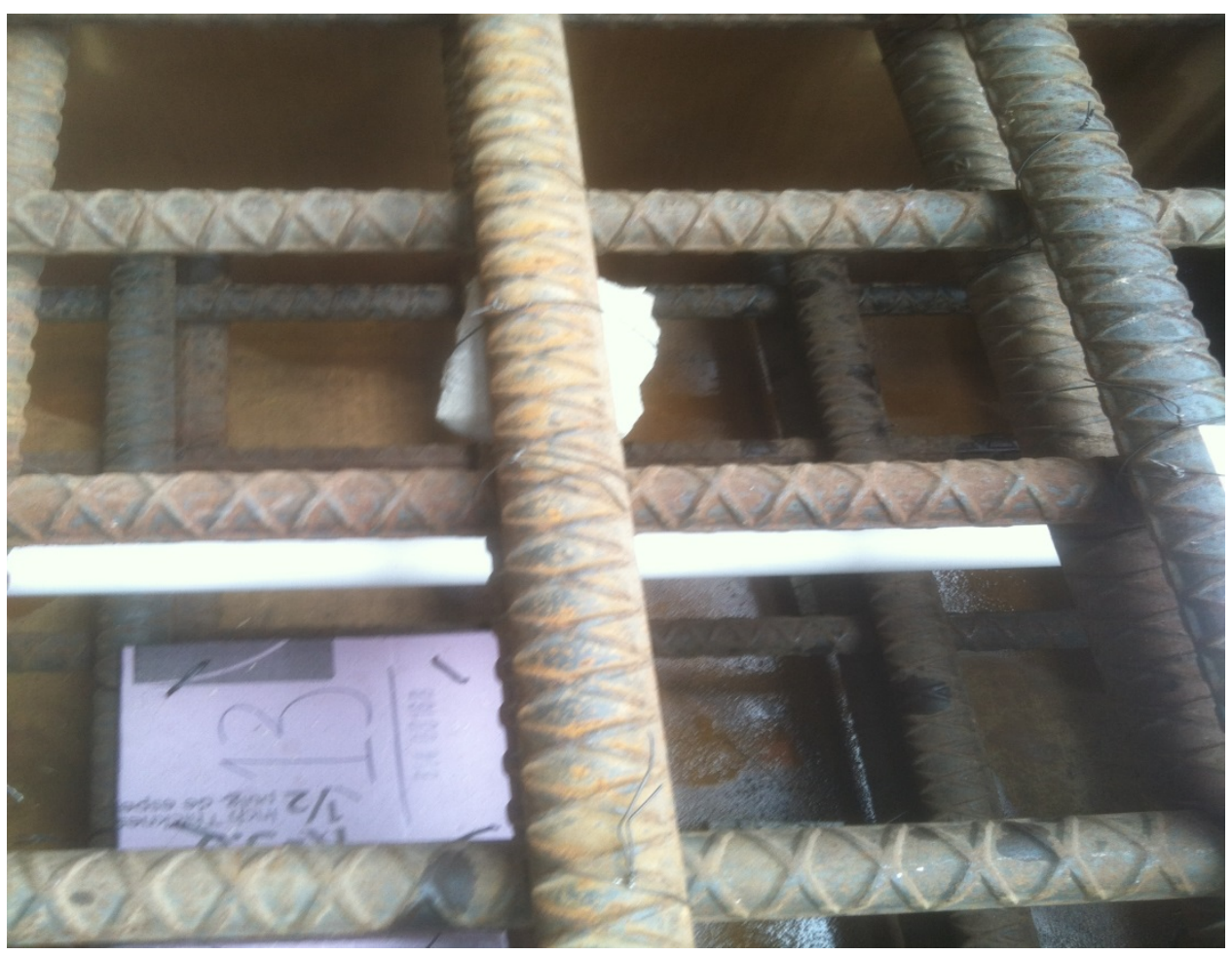

Fig. A.44. D05 R-depth bottom of top bar 194mm. 


\begin{tabular}{|c|c|c|}
\hline \multicolumn{3}{|c|}{ DEFECT TABLE } \\
\hline ID NUMBER & OESCRPTION & LABE \\
\hline D1 & $\begin{array}{l}\text { POROUS HALF CYINOER } \\
\text { (NO COVER) }\end{array}$ & \\
\hline 02 & $\begin{array}{l}\text { POROUS HALF CYINDER } \\
\text { (COVER) }\end{array}$ & \\
\hline D3 & $\begin{array}{l}\text { POROUS HALF CYINOER } \\
\text { (NO COVER) }\end{array}$ & \\
\hline 04 & $\begin{array}{c}\text { POROUS HALE CYINOER } \\
\text { (COVER) }\end{array}$ & \\
\hline D5 & $\begin{array}{l}\text { POROOS HALF CYNNOER } \\
\text { (COVER \& CRACK) }\end{array}$ & \\
\hline 06 & PVC & \\
\hline 07 & PVC & \\
\hline D8 & \begin{tabular}{|} 
DISSOLUNG STRROFOAM || \\
(THICK)
\end{tabular} & \\
\hline D9 & STYROFOAM (THICK) & \\
\hline 010 & STRROFOAM (THIN) & \\
\hline D11 & PLENGLASS & \\
\hline 012 & $\begin{array}{c}\text { DISSOLYNG STYROFOAM } \\
\text { (MEDUMM) }\end{array}$ & \\
\hline 013 & STYROFOAM (MEDIUM) & \\
\hline 014 & PLDXIG_ASS & \\
\hline 015 & $\mid \begin{array}{c}\text { DISSOLUNG STYROFOAM } \\
\text { (THN) }\end{array}$ & \\
\hline 016 & LUMEER (2X4) & \\
\hline 017 & GLOVES & \\
\hline 018 & $\begin{array}{l}\text { DEBOND DUCT TAPE } \\
\text { (ONE LAYER) }\end{array}$ & \\
\hline 019 & $\begin{array}{l}\text { DEBBND DUCT TAPE } \\
\text { (MULT-LAYCR) }\end{array}$ & \\
\hline 020 & MOUNG REBAR & \\
\hline
\end{tabular}

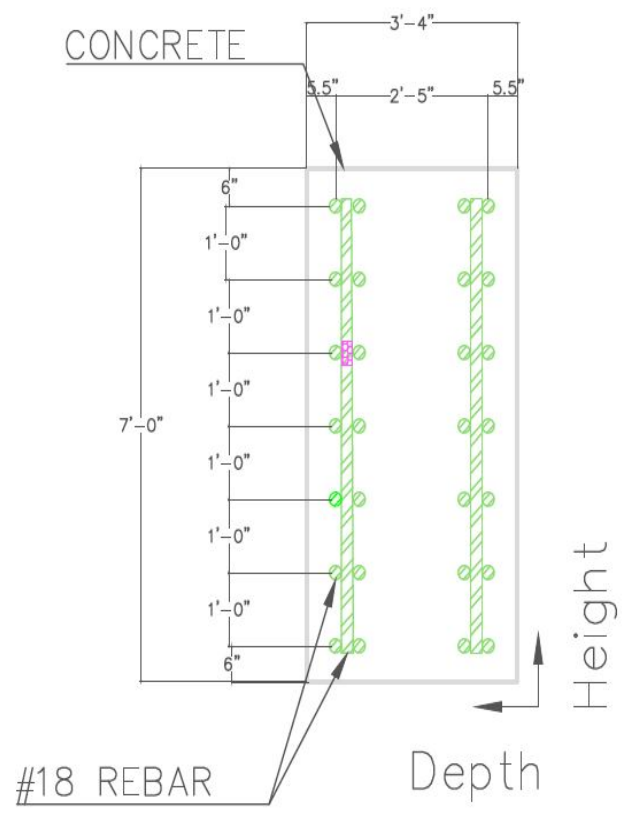

Fig. A.45. D05 height by depth.

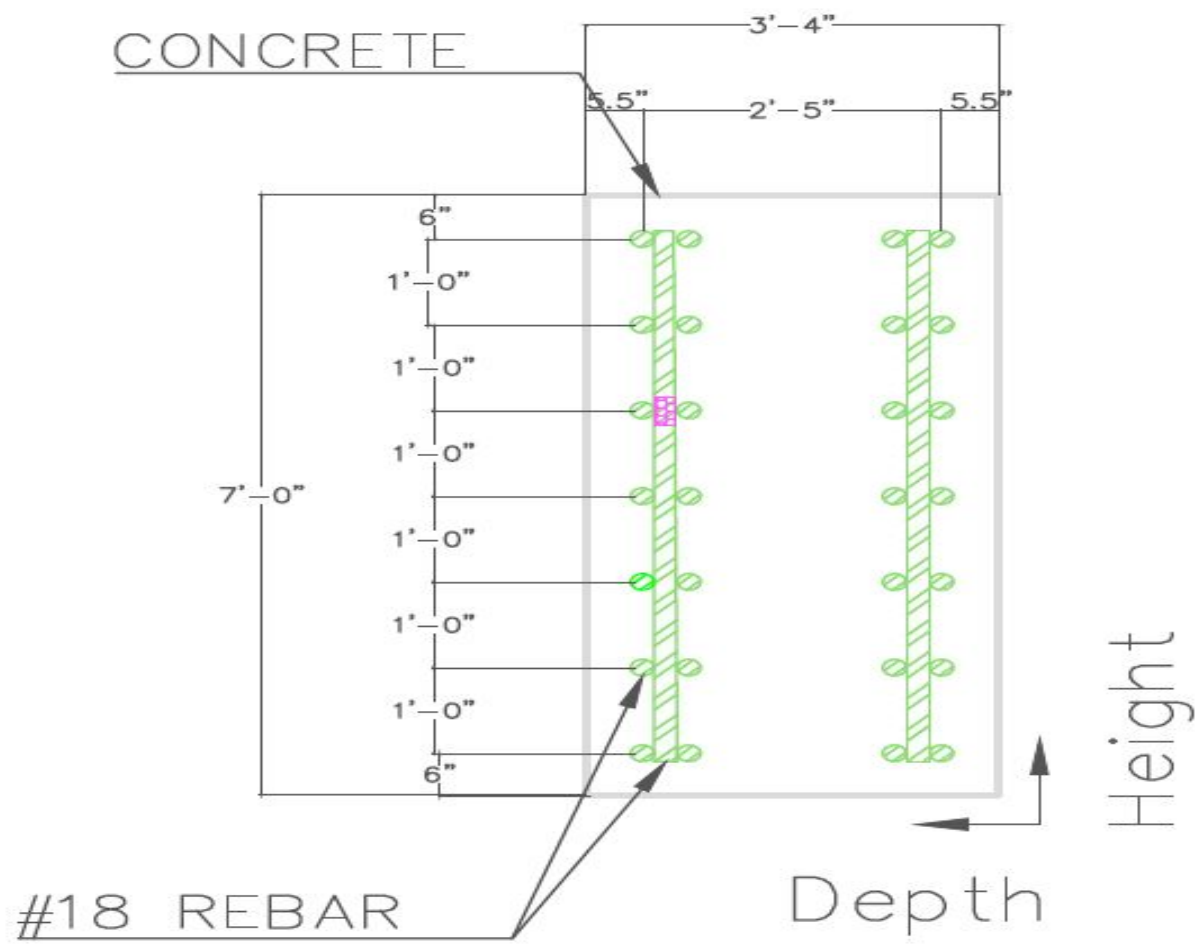

Fig. A.46. D05 height by depth NL. 


\begin{tabular}{|c|c|c|}
\hline \multicolumn{3}{|c|}{ DEFECT TRQ:E } \\
\hline o neveser & Descontion & Ueal \\
\hline or & 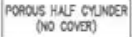 & \\
\hline 02 & 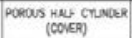 & \\
\hline as & 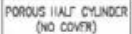 & \\
\hline Det & 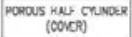 & \\
\hline Ds & 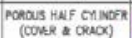 & \\
\hline$\infty$ & pre & \\
\hline 07 & PVC & \\
\hline$\infty$ & $\begin{array}{l}\text { Oessa veng smarom } \\
\text { (ThOS) }\end{array}$ & \\
\hline 09 & Stmorow (Tiס) & \\
\hline 010 & simoranen (IKM) & \\
\hline Dil & mexalass & \\
\hline 012 & 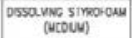 & \\
\hline mis & sinarau (NEDew) & \\
\hline 014 & provouss & \\
\hline 015 & 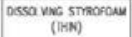 & \\
\hline 018 & ILNase $\left(2 x t^{\prime}\right)$ & \\
\hline 017 & a.oves & \\
\hline 018 & 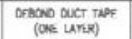 & \\
\hline 019 & 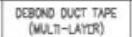 & \\
\hline 020 & WOUNC REBNA & \\
\hline
\end{tabular}

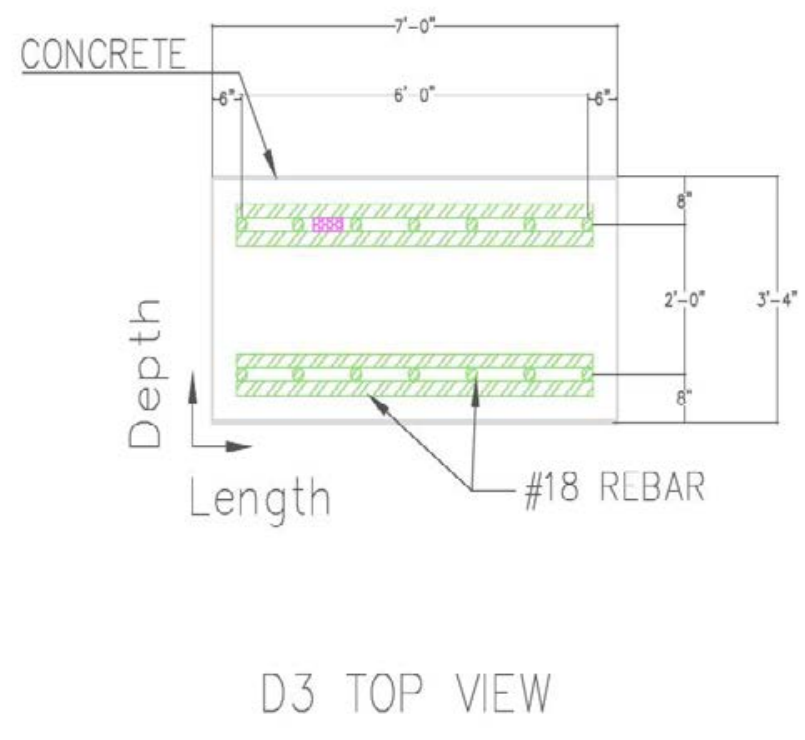

Fig. A.47. D05 length by depth.

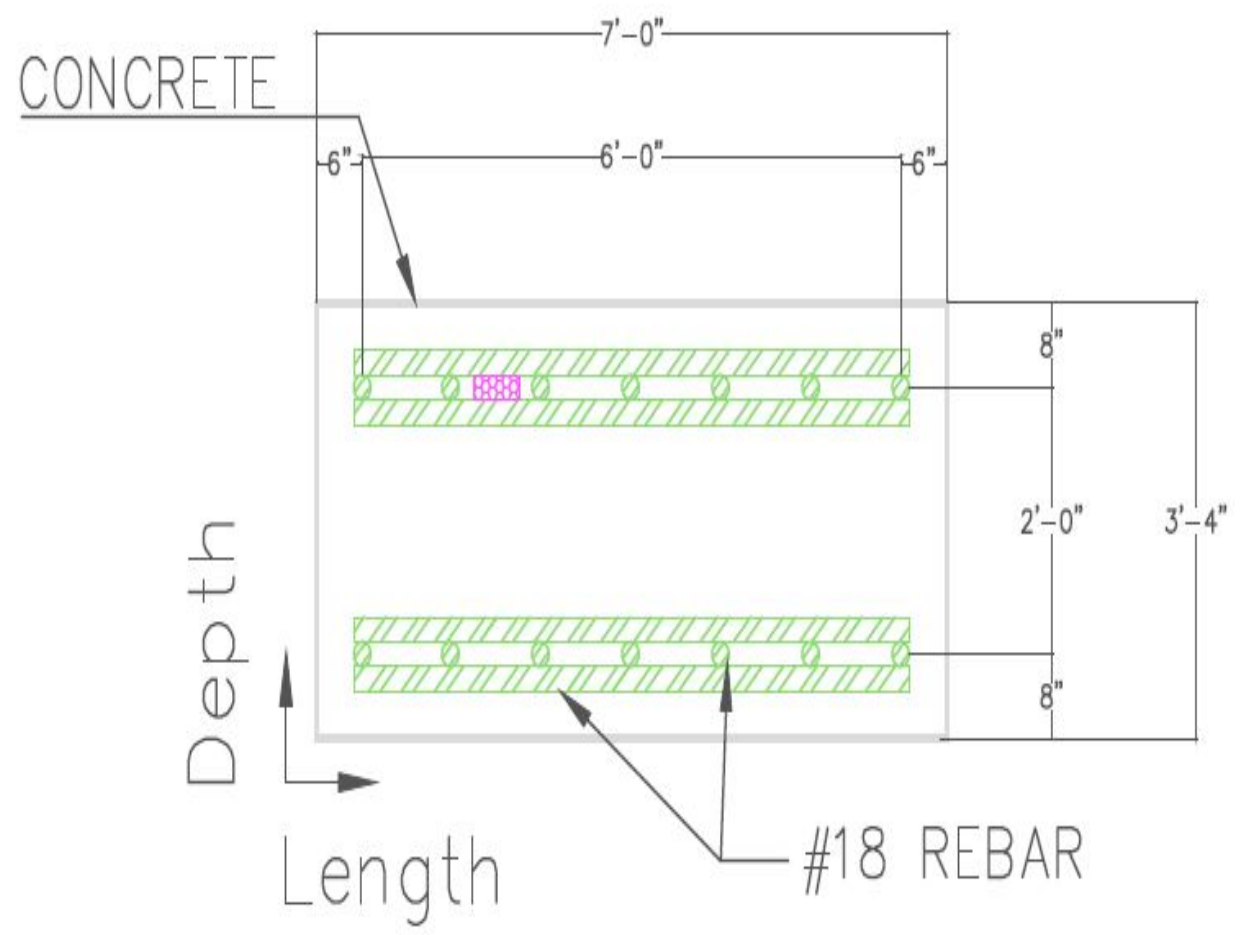

Fig. A.48. D05 length by depth NL. 

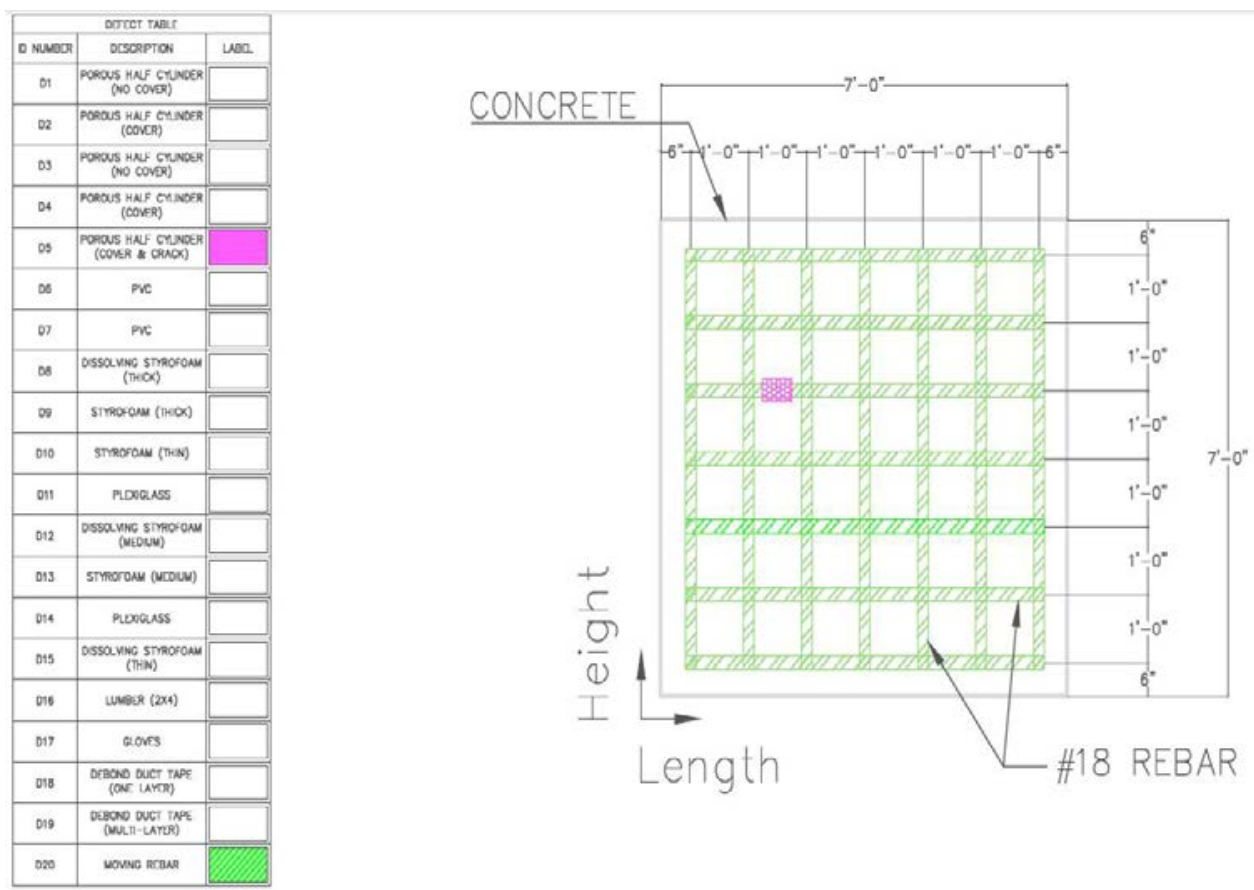

SIDE VIEW

Fig. A.49. D05 length by height.

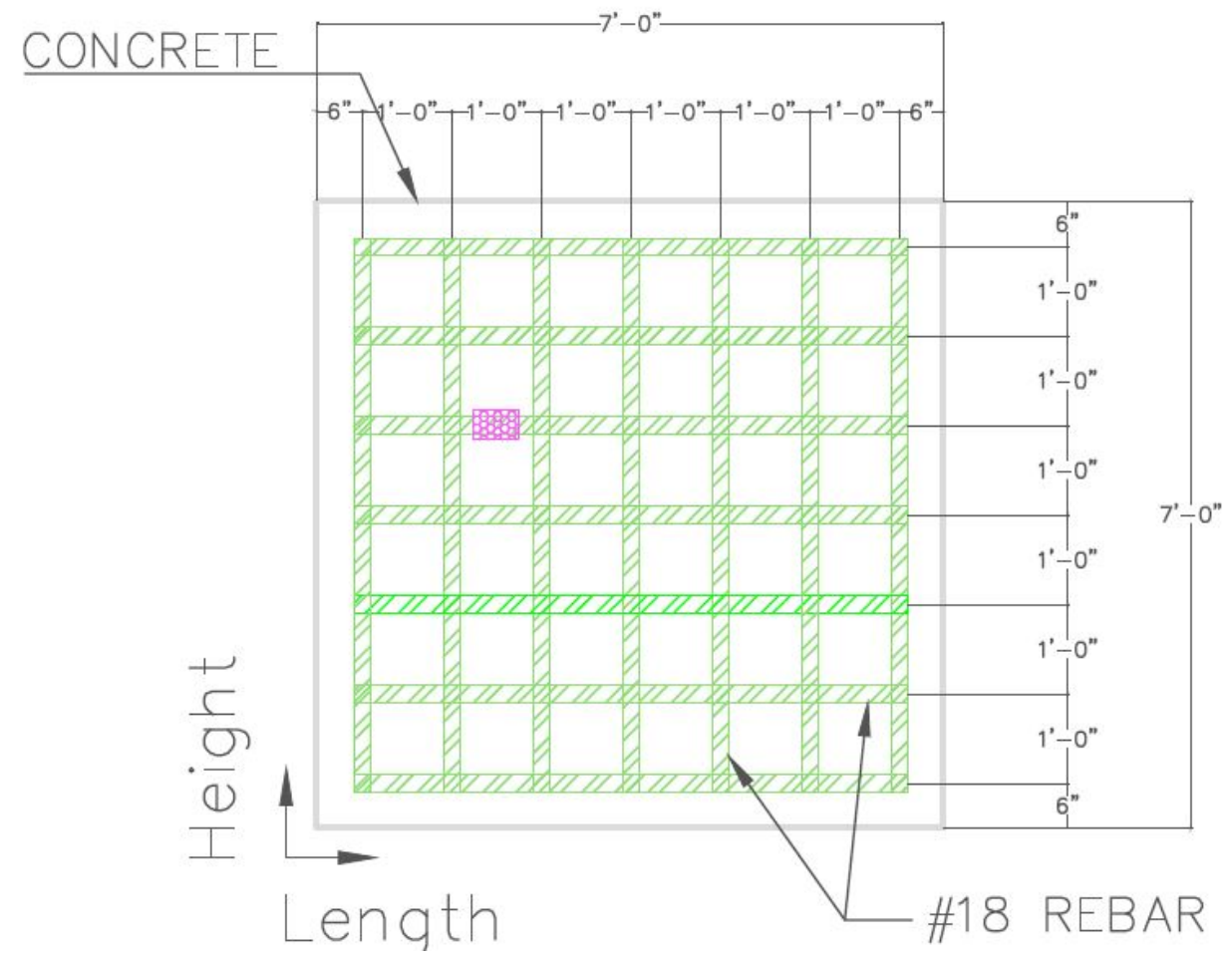

Fig. A.50. D05 length by height NL. 


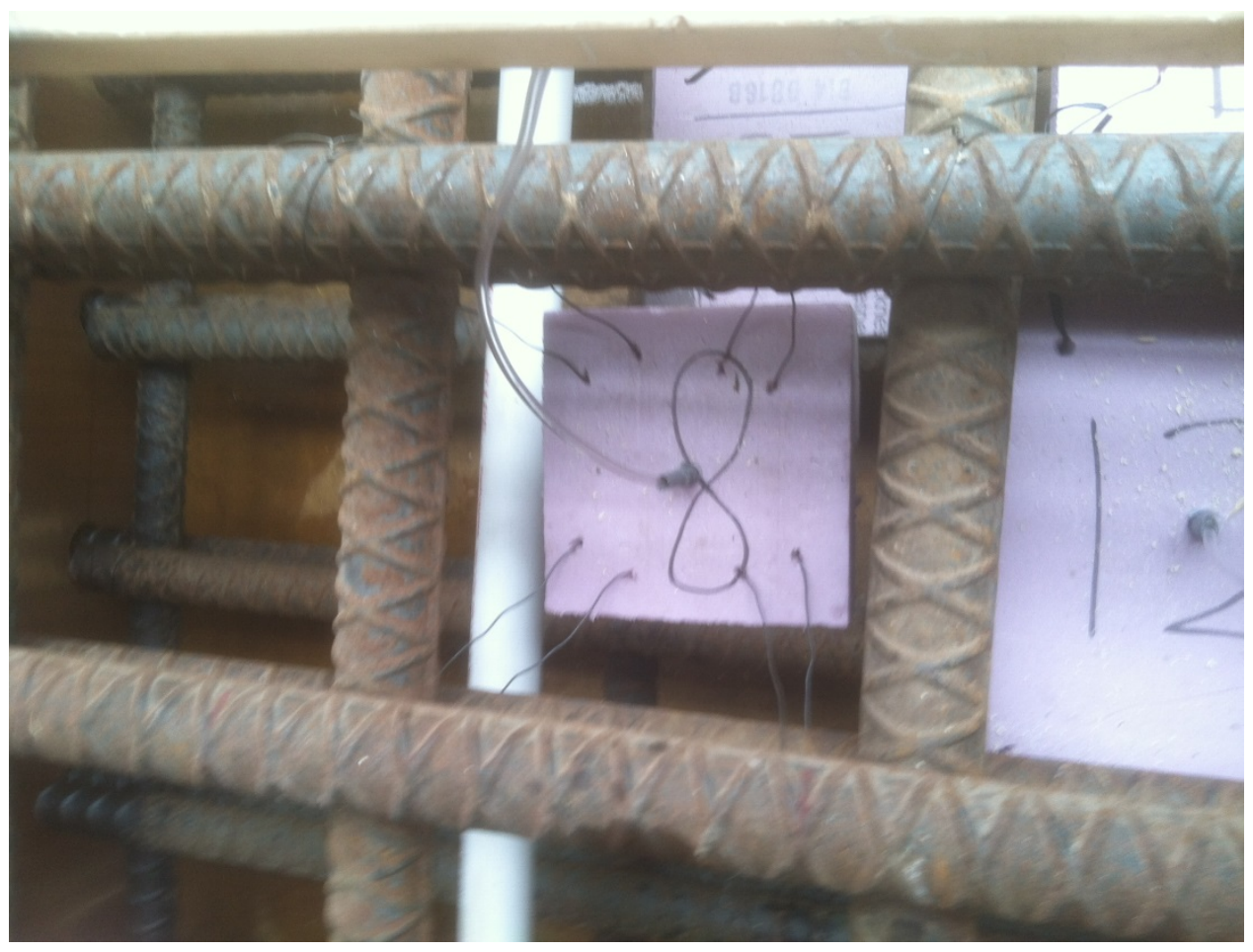

Fig. A.51. D06 close-up.
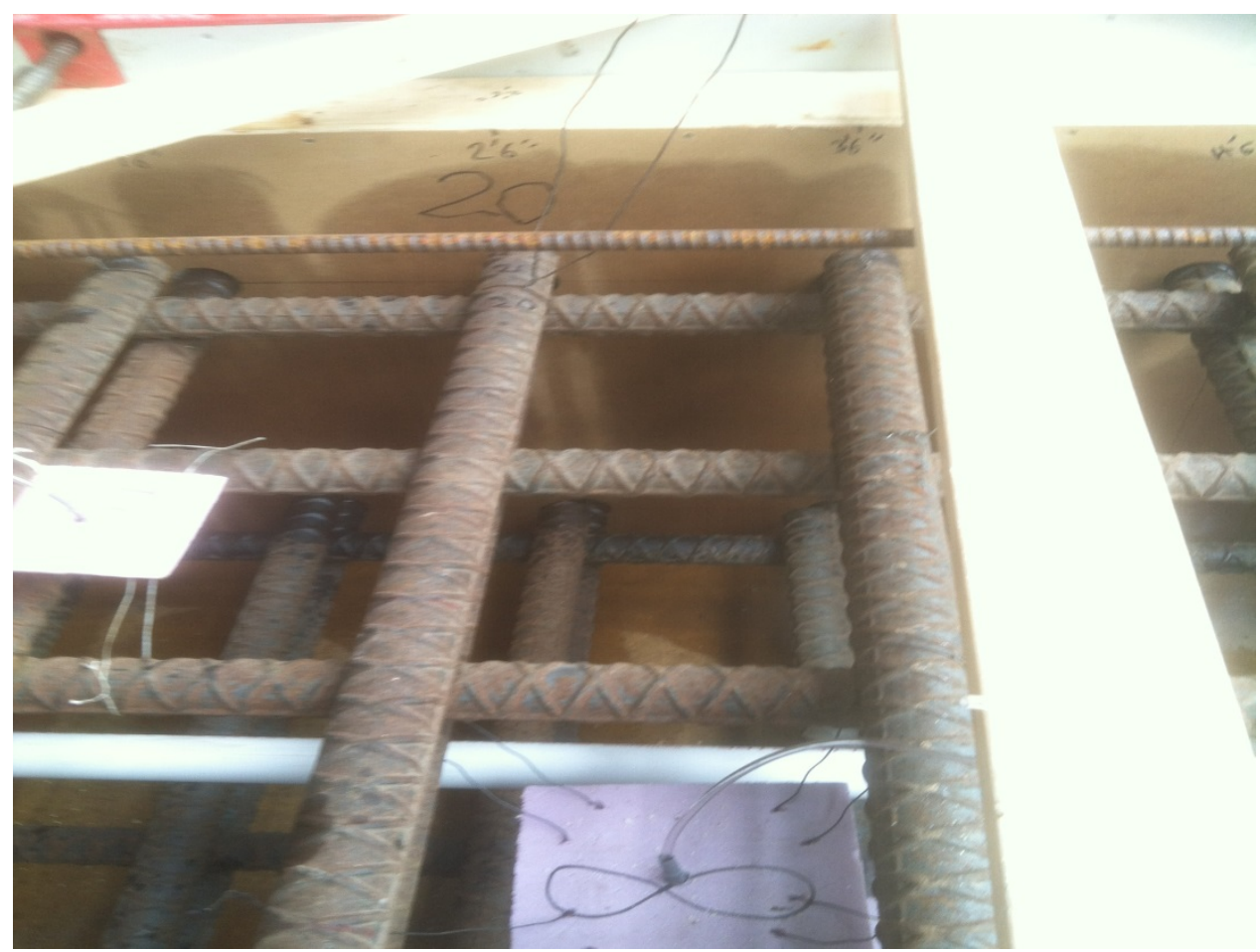

Fig. A.52. D06 height 4 bars 3.5ft $\times 1067 \mathrm{~mm}$. 


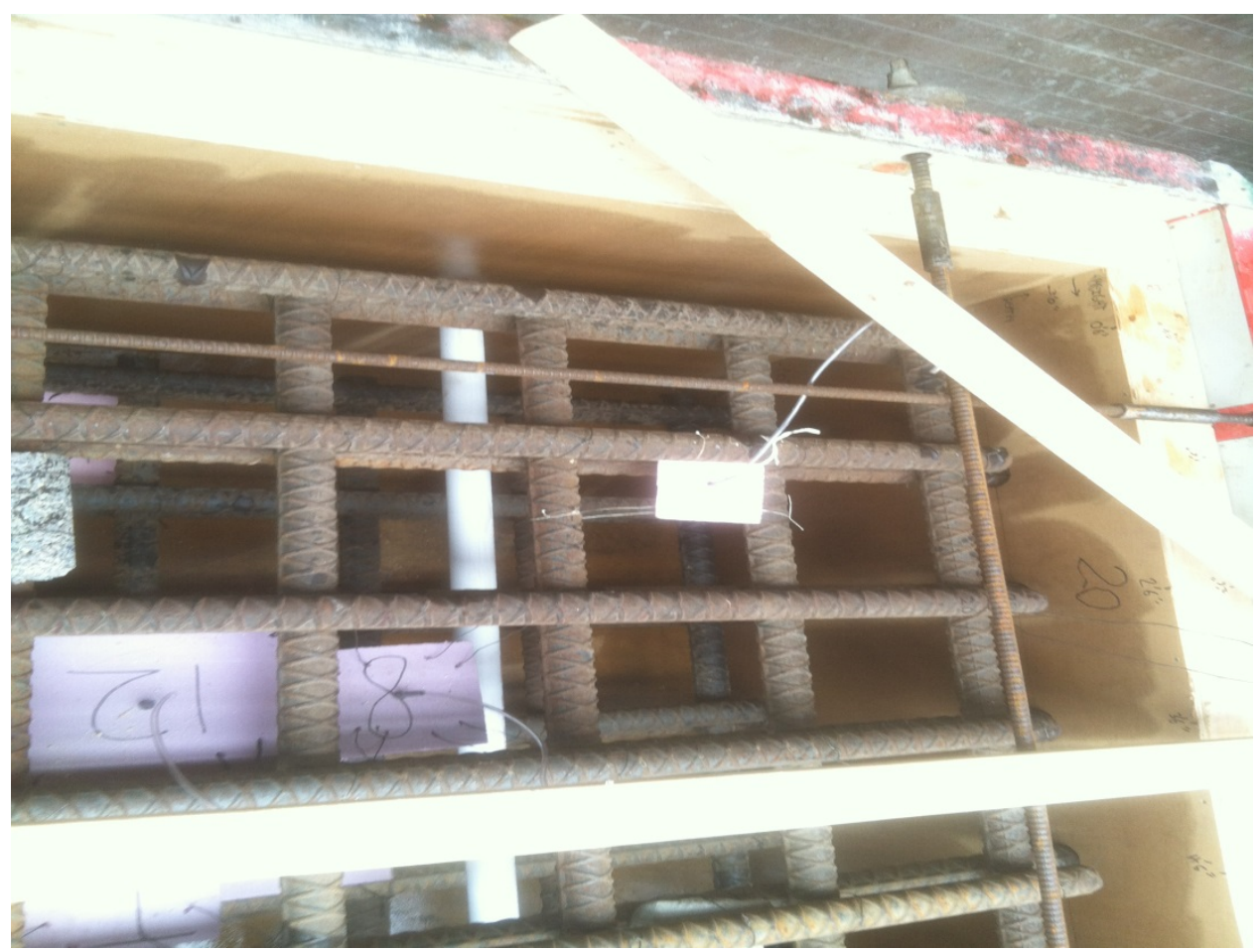

Fig. A.53. D06 length 2.8bars $2.33 \mathrm{ft} \times 711 \mathrm{~mm}$.

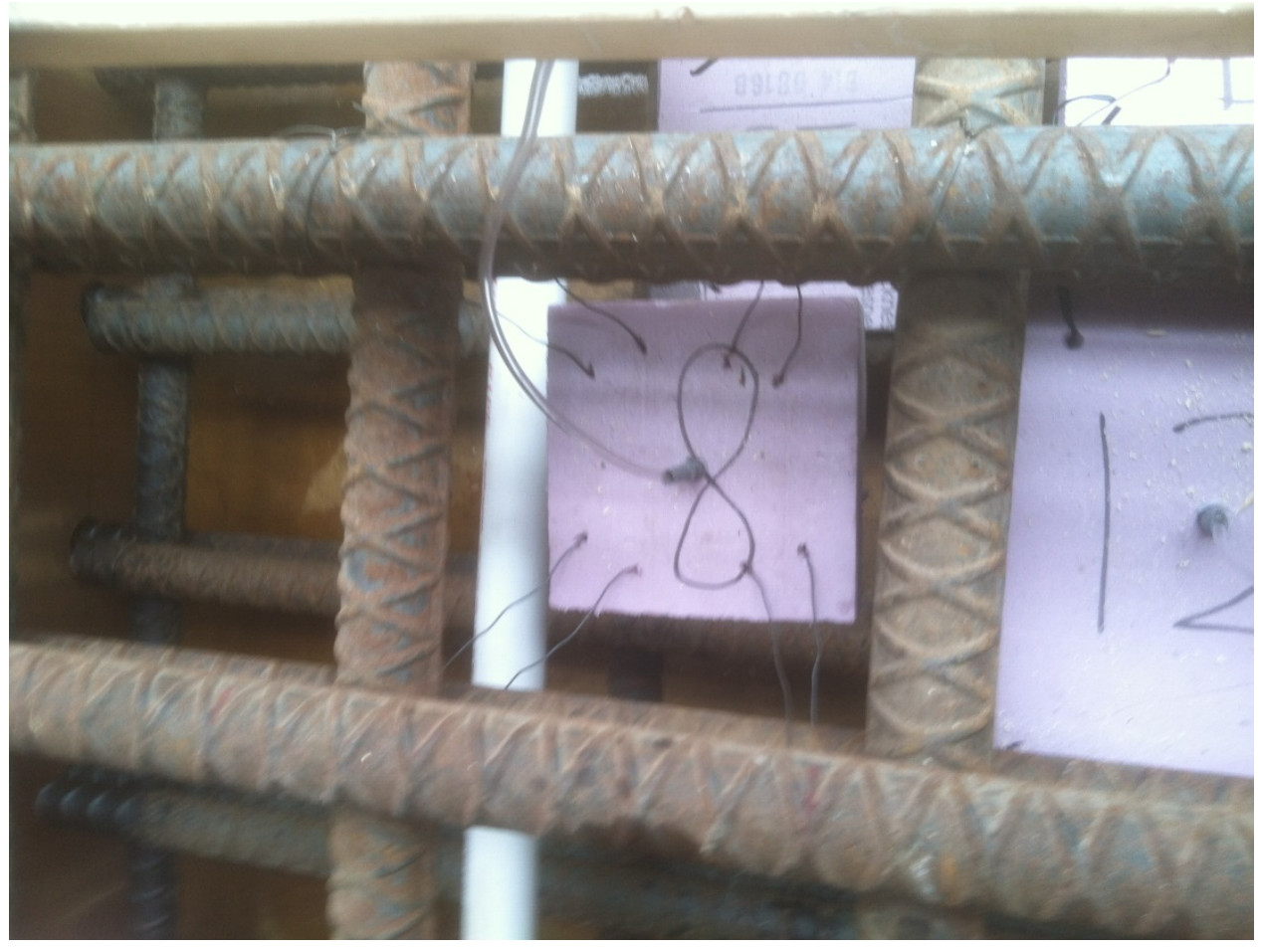

Fig. A.54. D06 R-depth middle 508mm. 


\begin{tabular}{|c|c|c|}
\hline \multicolumn{3}{|c|}{ DEFECT TABLE } \\
\hline 1D NUMBER & DESCRPTION & LABE. \\
\hline d1 & $\begin{array}{l}\text { POROUS HALF CYINDER } \\
\text { (NO COVER) }\end{array}$ & \\
\hline 02 & $\begin{array}{l}\text { POROUS HALF CYINDER } \\
\text { (COVER) }\end{array}$ & \\
\hline 03 & $\begin{array}{l}\text { POROUS HALF CYINDER } \\
\text { (NO COVER) }\end{array}$ & \\
\hline 04 & $\begin{array}{l}\text { POROUS HALF CYINDER } \\
\text { (COVER) }\end{array}$ & \\
\hline D5 & $\begin{array}{c}\text { POROUS HALF CYINDER } \\
\text { (COVER \& CRACK) }\end{array}$ & \\
\hline D6 & PVC & \\
\hline 07 & PVC & \\
\hline 08 & $\begin{array}{c}\text { DISSOLUNG STYROFOAM } \\
\text { (THICK) }\end{array}$ & \\
\hline Dg & STIROFOAM (THIIK) & \\
\hline 010 & STYROFOAM (THIN) & \\
\hline D11 & PLDXGLASS & \\
\hline 012 & $\begin{array}{c}\text { DISSOLUNG STRROFOAM } \\
\text { (MEDIUM) }\end{array}$ & \\
\hline 013 & STTROFOAM (MEDUM) & \\
\hline 014 & PLDXGLASS & \\
\hline 015 & $\begin{array}{c}\text { DISSOLUNG STYROFOAM } \\
\text { (THIN) }\end{array}$ & \\
\hline 016 & LUMBER $(2 \times 4)$ & \\
\hline 017 & GLOVES & \\
\hline 018 & $\begin{array}{l}\text { DEBONO DUCT TAPE } \\
\text { (ONE LAYER) }\end{array}$ & \\
\hline$D 19$ & $\begin{array}{l}\text { DEBONO DUCT TAPE } \\
\text { (MULT-LAYER) }\end{array}$ & \\
\hline 020 & MOUNG REBAR & \\
\hline
\end{tabular}

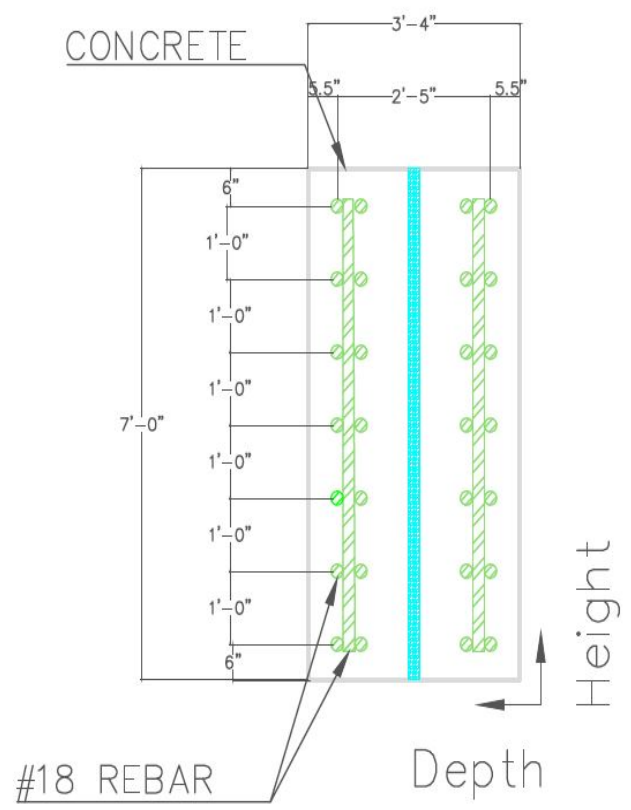

Fig. A.55. D06 height by depth.

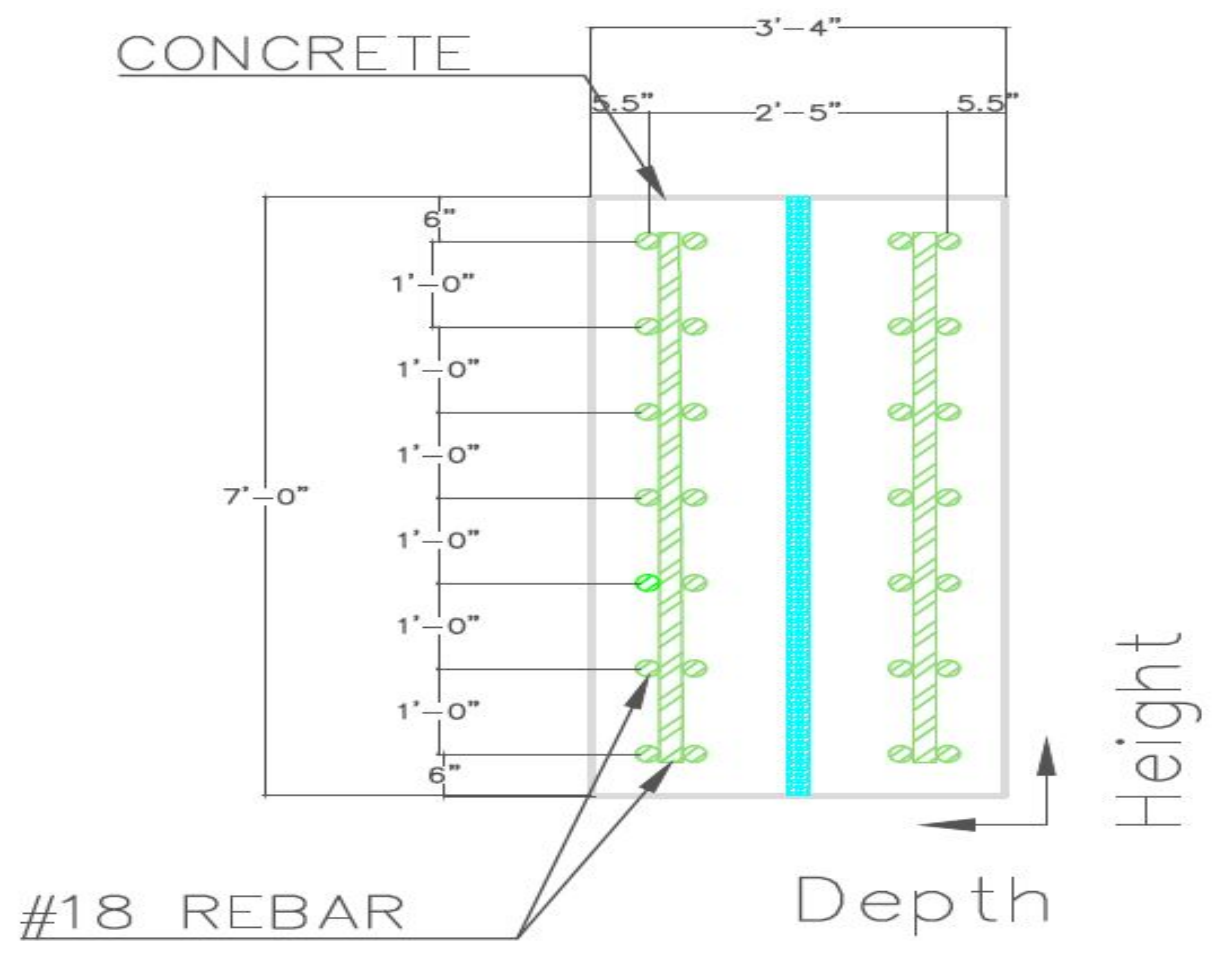

Fig. A.56. D06 height by depth NL. 


\begin{tabular}{|c|c|c|}
\hline \multicolumn{3}{|c|}{ DFFet Thalif } \\
\hline D nuese & Descrapion & เมตร \\
\hline or & 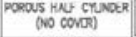 & \\
\hline 02 & 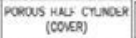 & \\
\hline os & 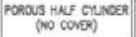 & \\
\hline 04 & 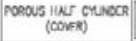 & \\
\hline os & 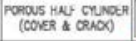 & \\
\hline 06 & PVC & \\
\hline 07 & PVC & \\
\hline$\infty$ & 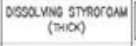 & \\
\hline$\infty 9$ & STROFOAN (THIO) & \\
\hline 010 & smorow (nive) & \\
\hline o11 & ploxauss & \\
\hline 012 & $\begin{array}{c}\text { DSsavNa STROFONM } \\
\text { (MLOUN) }\end{array}$ & \\
\hline 013 & snnoroun (NeOUn) & \\
\hline 014 & Ploxouss & \\
\hline 015 & 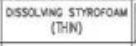 & \\
\hline 016 & แNese (2at) & \\
\hline 017 & soves & \\
\hline 010 & $\begin{array}{l}\text { DERONO DUCT TNAE } \\
\text { (OAC URRA) }\end{array}$ & \\
\hline 010 & 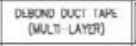 & \\
\hline 020 & Wowo REevr & \\
\hline
\end{tabular}

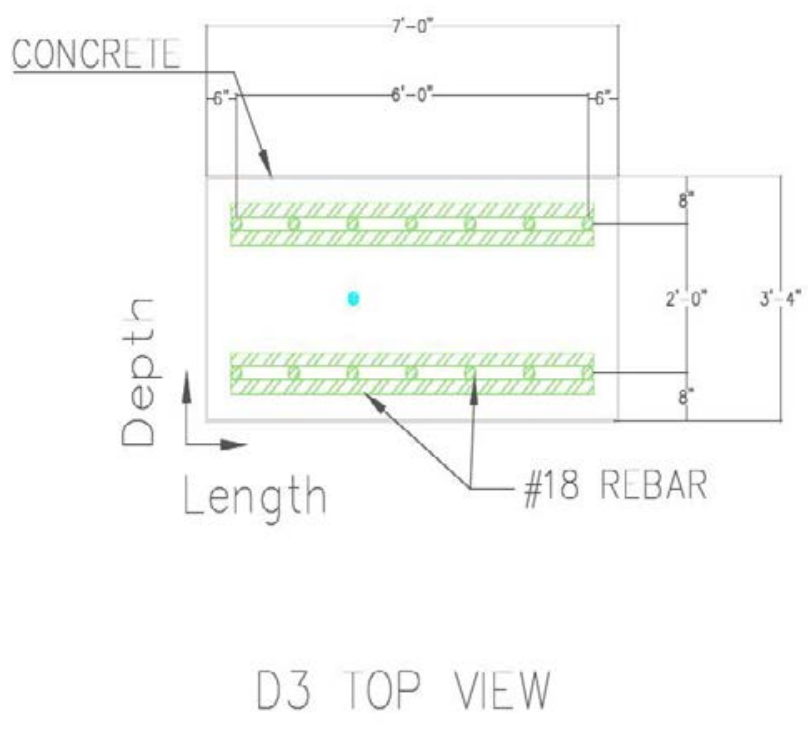

Fig. A.57. D06 length by depth.

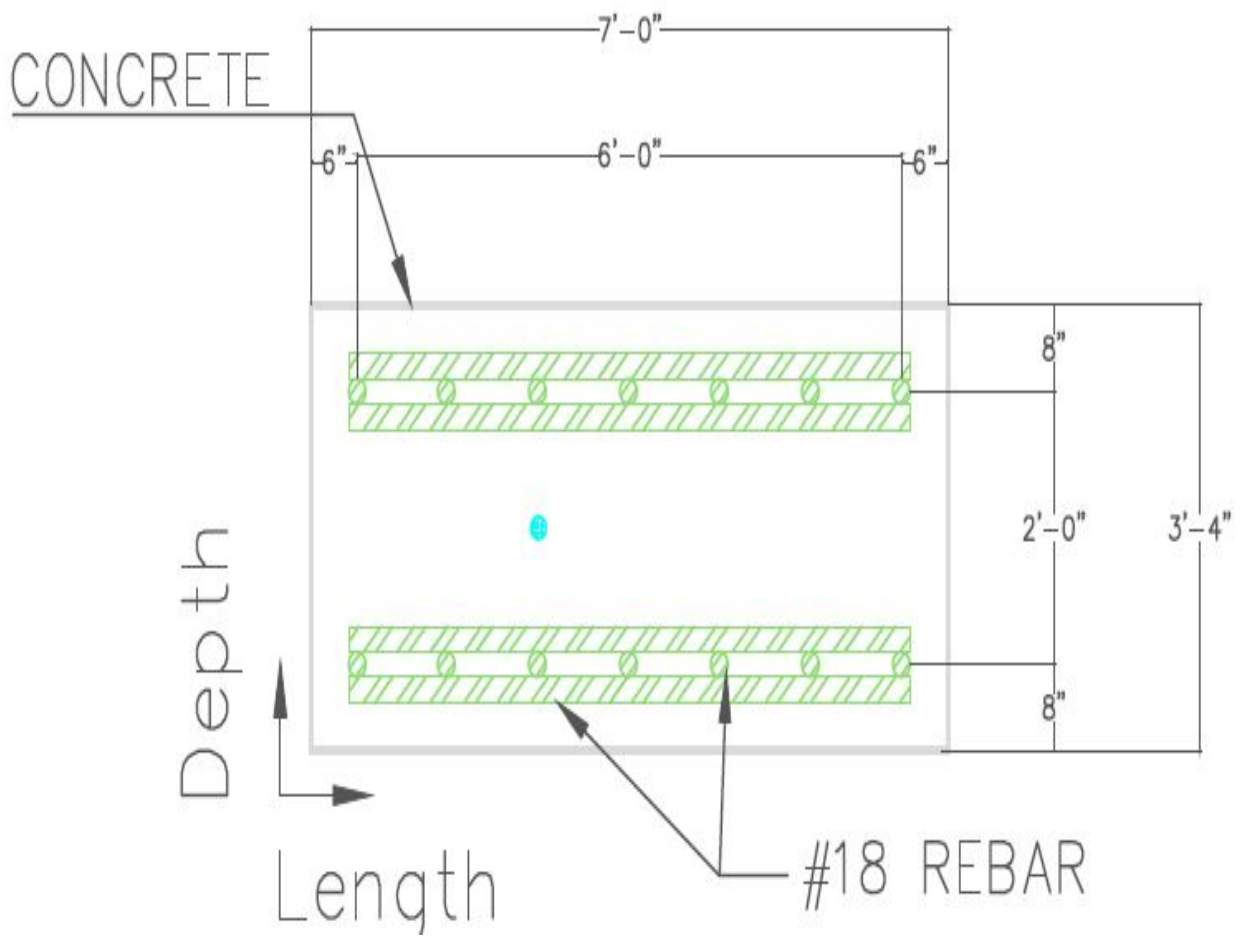

Fig. A.58. D06 length by depth NL. 


\begin{tabular}{|c|c|c|}
\hline \multicolumn{3}{|c|}{ DEECTT TASE } \\
\hline - moneca & DESSAPTON & nea. \\
\hline or & 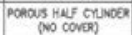 & \\
\hline 02 & 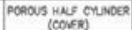 & \\
\hline os & 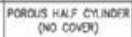 & \\
\hline 04 & 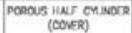 & \\
\hline os & 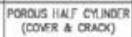 & \\
\hline$\infty$ & $\mathrm{PWC}$ & \\
\hline o) & $\mathrm{puc}$ & \\
\hline$\infty$ & 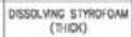 & \\
\hline$\infty$ & STracoonu (Mido) & \\
\hline 90 & SThoroun (MMN) & \\
\hline o11 & noxcouss & \\
\hline 012 & 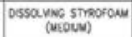 & \\
\hline O13 & strearouw (rediw) & \\
\hline 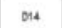 & noxauss & \\
\hline o1s & 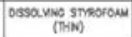 & \\
\hline 018 & 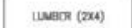 & \\
\hline ort & g.ovs & \\
\hline D18 & 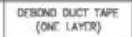 & \\
\hline 019 & 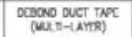 & \\
\hline 020 & Wonvg REBNR & \\
\hline
\end{tabular}

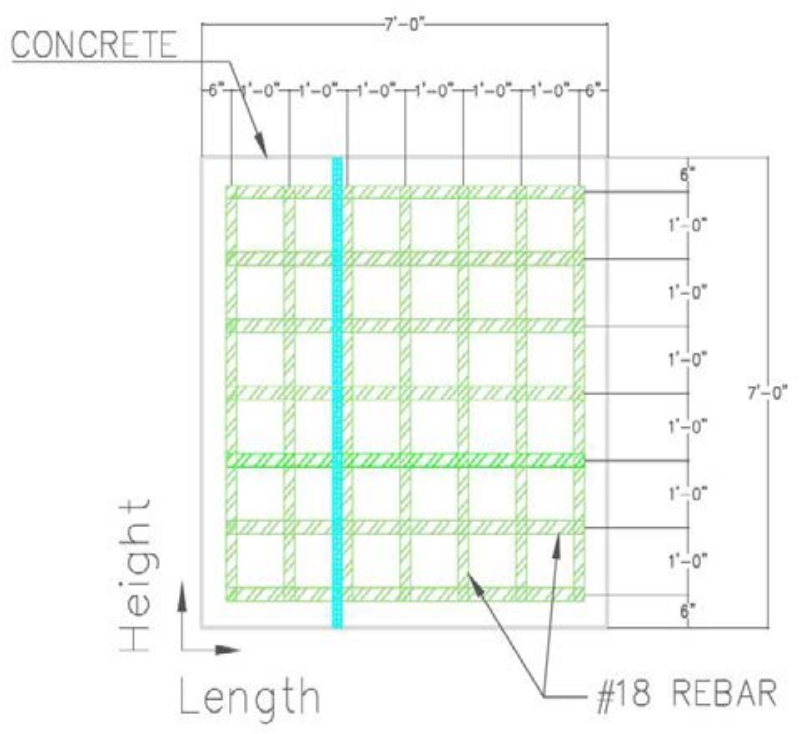

SIDE VIEW

Fig. A.59. D06 length by height.

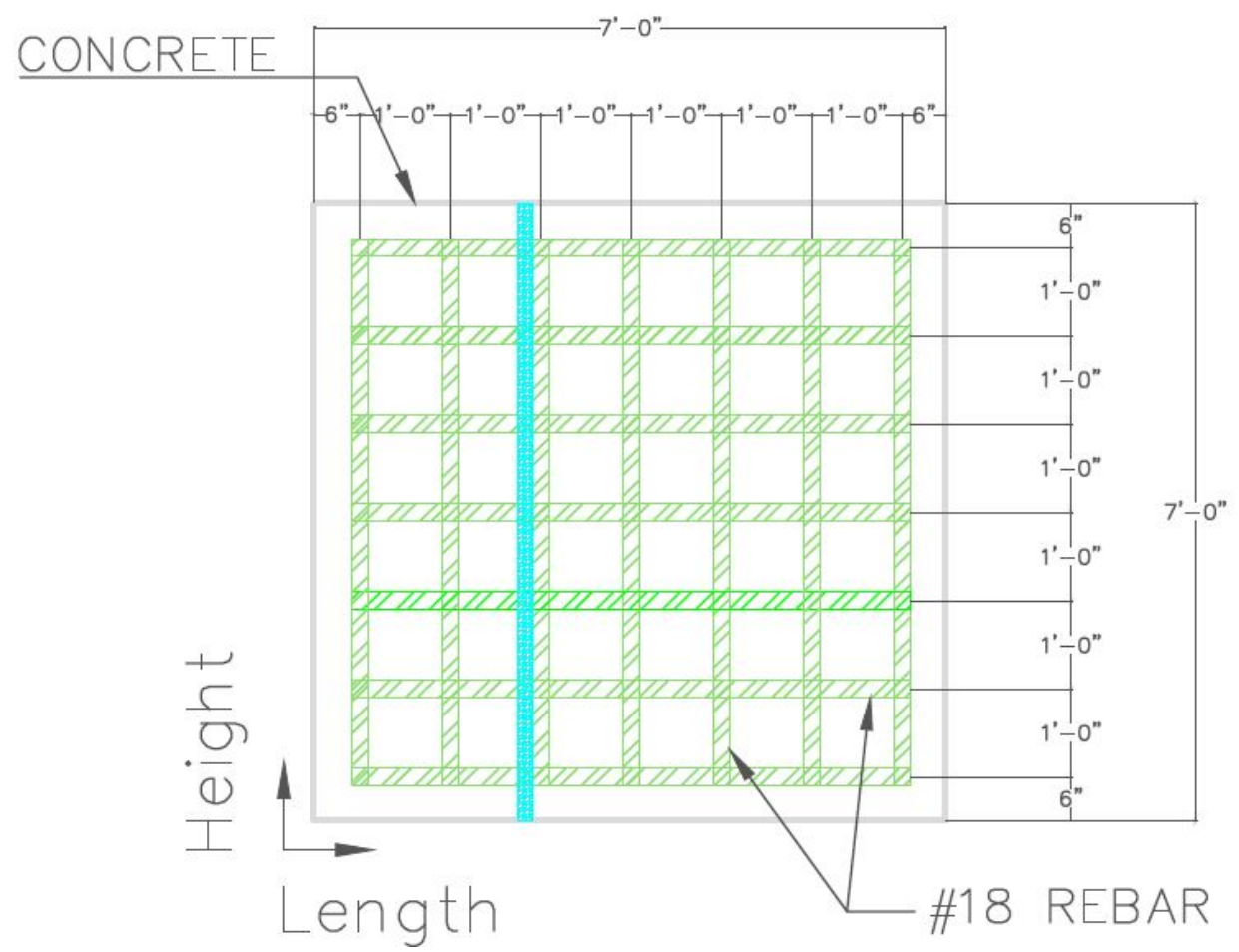

Fig. A.60. D06 length by height NL. 


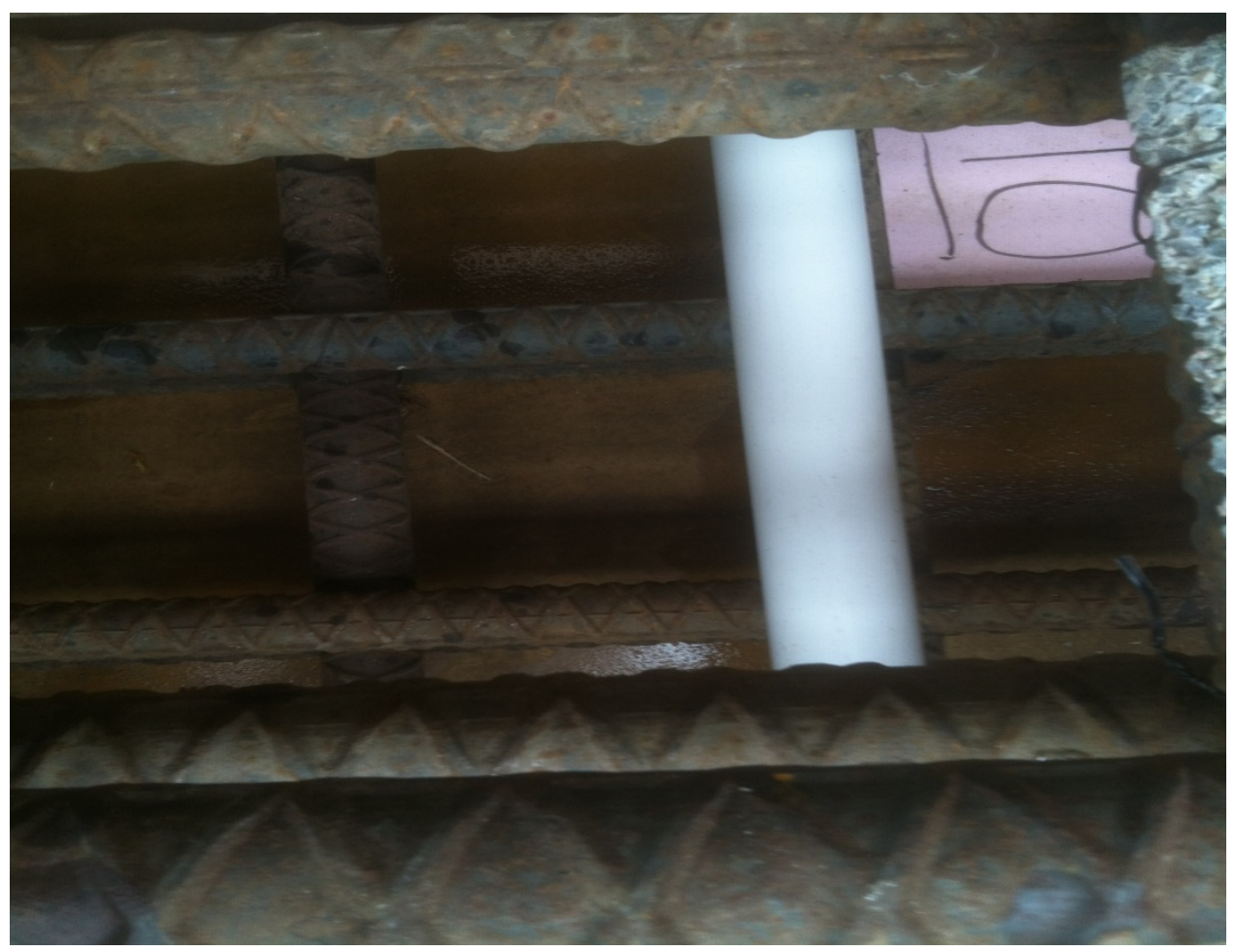

Fig. A.61. D07 close-up.

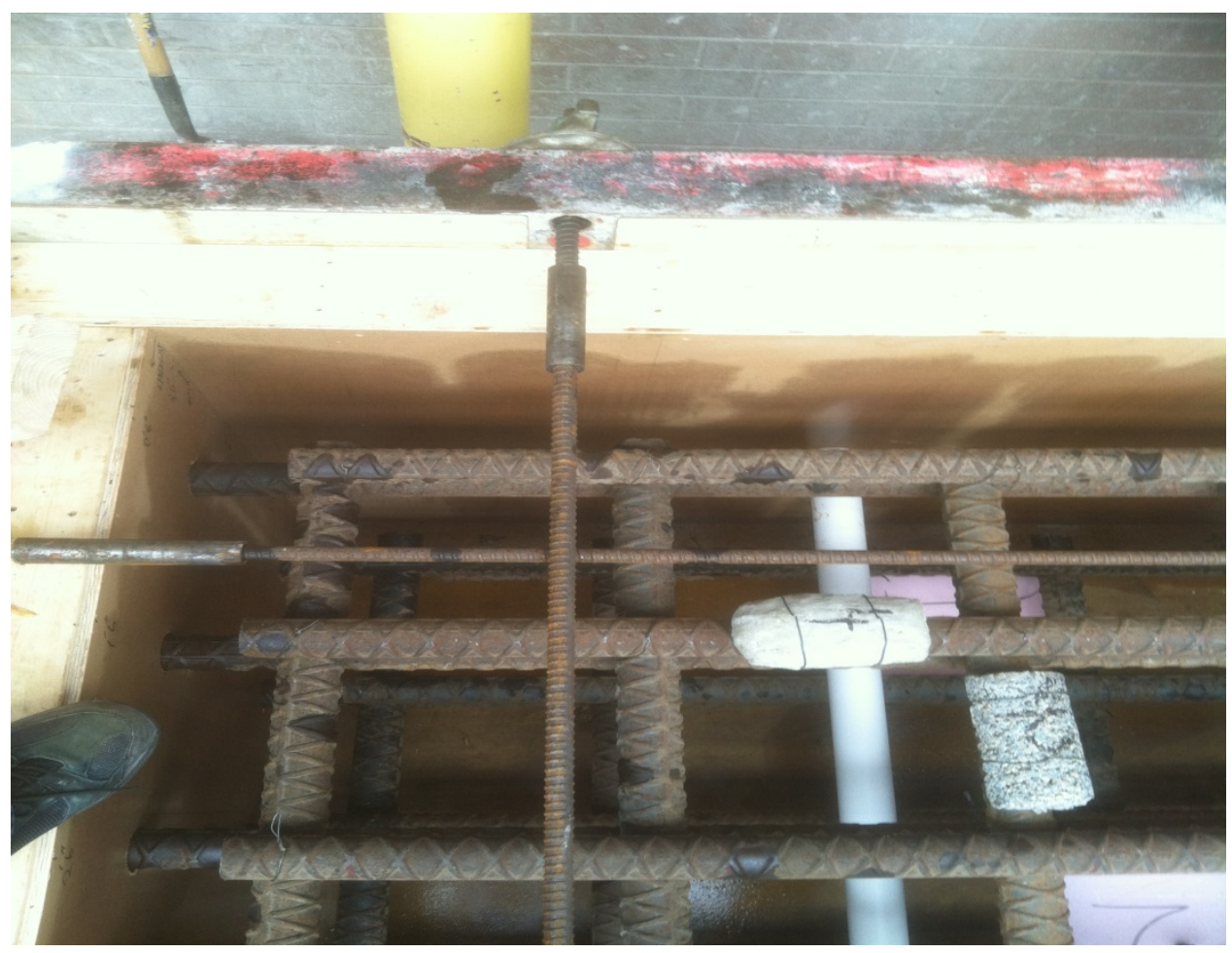

Fig. A.62. D07 Height 4 bars 3.5ft $\times 1067 \mathrm{mm1}$. 


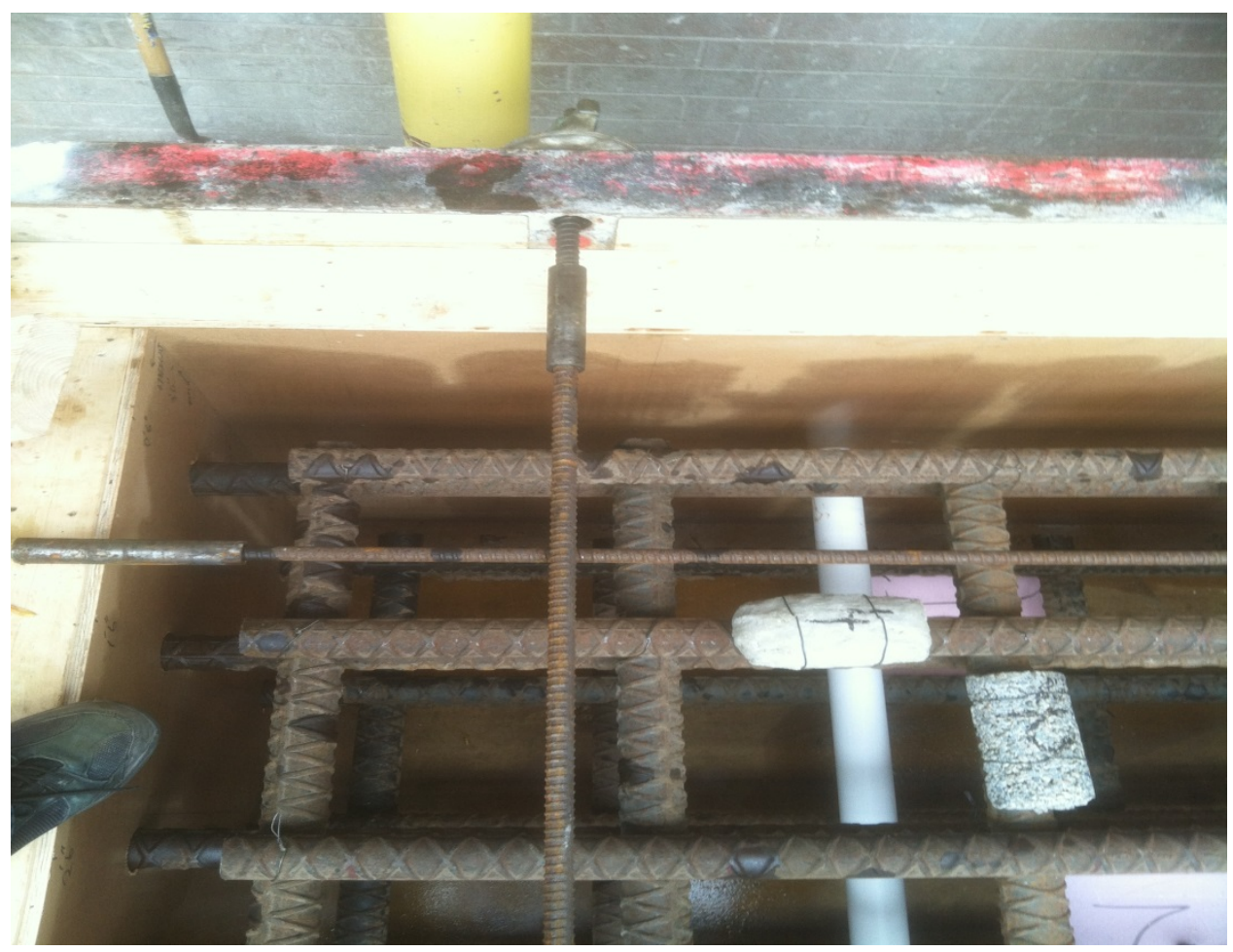

Fig. A.63. D07 Length $5.2 \mathrm{bars} 4.67 \mathrm{ft} \times 711 \mathrm{~mm}$.

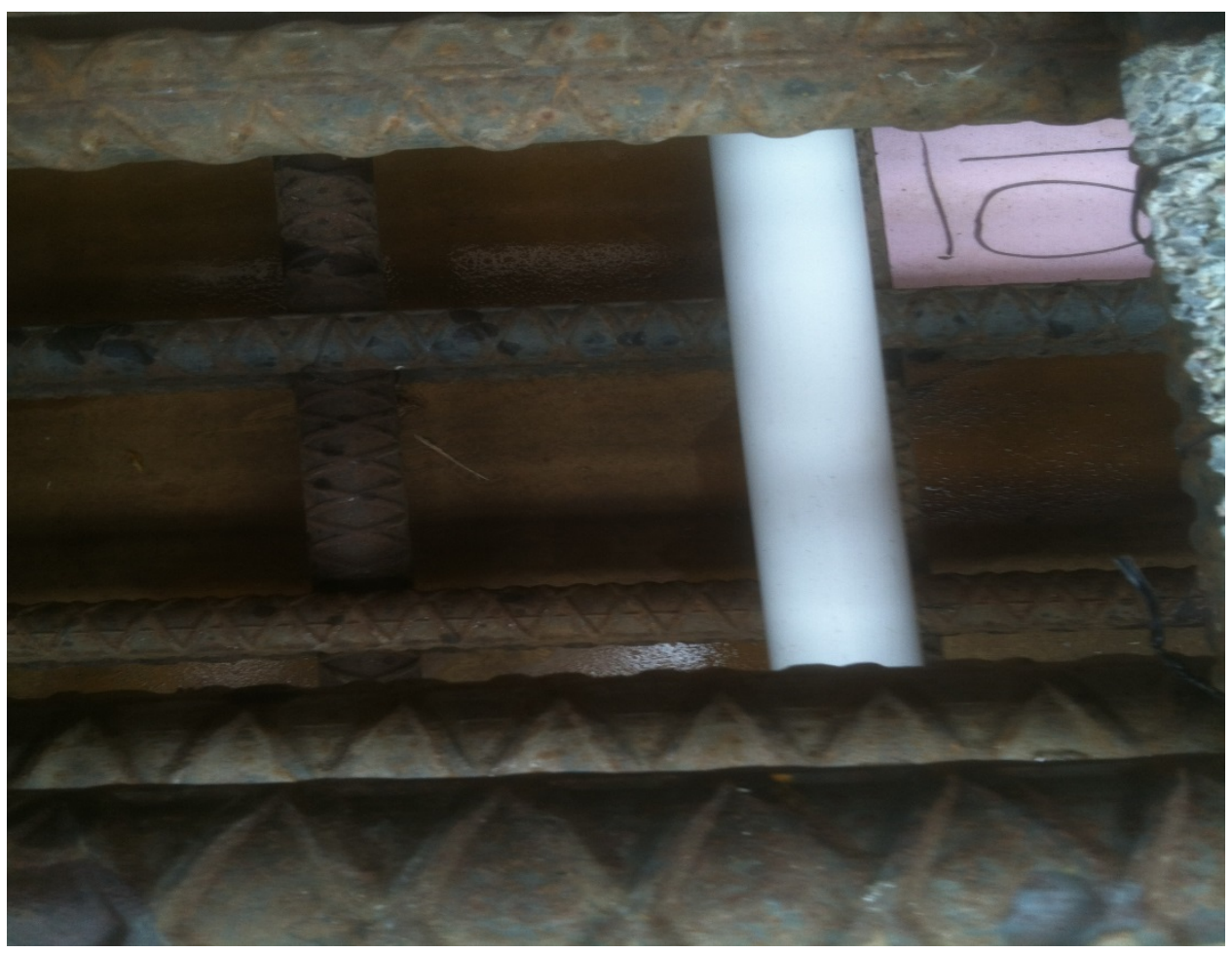

Fig. A.64. D07 R-depth Middle 508mm. 


\begin{tabular}{|c|c|c|}
\hline \multicolumn{3}{|c|}{ DEECT TABLE } \\
\hline 10 NUMBER & DESCRPTION & ᄂАВВ \\
\hline D1 & $\begin{array}{l}\text { POROUS HALF CYUNDER } \\
\text { (NO COVER) }\end{array}$ & \\
\hline D2 & $\begin{array}{l}\text { POROUS HALF CYUNDER } \\
\text { (COVER) }\end{array}$ & \\
\hline D3 & $\begin{array}{l}\text { POROUS HALF CYNNDER } \\
\text { (NO COVER) }\end{array}$ & \\
\hline D4 & $\begin{array}{l}\text { POROUS HALF CYINDER } \\
\text { (COVER) }\end{array}$ & \\
\hline 05 & $\begin{array}{l}\text { POROUS HALF CYMNDER } \\
\text { (COVER \& CRACK) }\end{array}$ & \\
\hline DE & PVC & \\
\hline 07 & PVC & \\
\hline 08 & $\begin{array}{l}\text { DISSOLUNG STRROFOAM } \\
\text { (THICK) }\end{array}$ & \\
\hline Dg & STYROFOAM (THIOK) & \\
\hline 010 & STYROFOAM (THIN) & \\
\hline D11 & PLEXGLASS & \\
\hline D12 & $\begin{array}{l}\text { DISSOLUNG STROFOAM } \\
\text { (MEDUM) }\end{array}$ & \\
\hline 013 & STRROFOAM (MEDOUM) & \\
\hline 014 & PLEXIGLASS & \\
\hline 015 & $\begin{array}{c}\text { DISSOLUNG STRROFOAM } \\
\text { (THIN) }\end{array}$ & \\
\hline 016 & LUMBER (2X4) & \\
\hline 017 & GLOVES & \\
\hline 018 & $\begin{array}{l}\text { DEBOND DUCT TAPE } \\
\text { (ONE LAYER) }\end{array}$ & \\
\hline 019 & $\begin{array}{l}\text { DEBONOD DUCT TAPE } \\
\text { (MULT-LAYRR) }\end{array}$ & \\
\hline 020 & MOUNG REBAR & \\
\hline
\end{tabular}

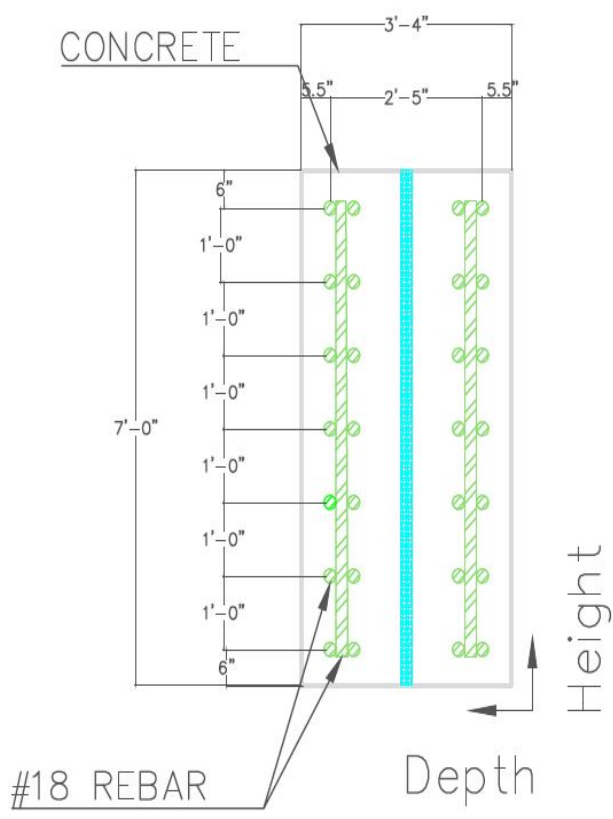

Fig. A.65. D07 Height by Depth.

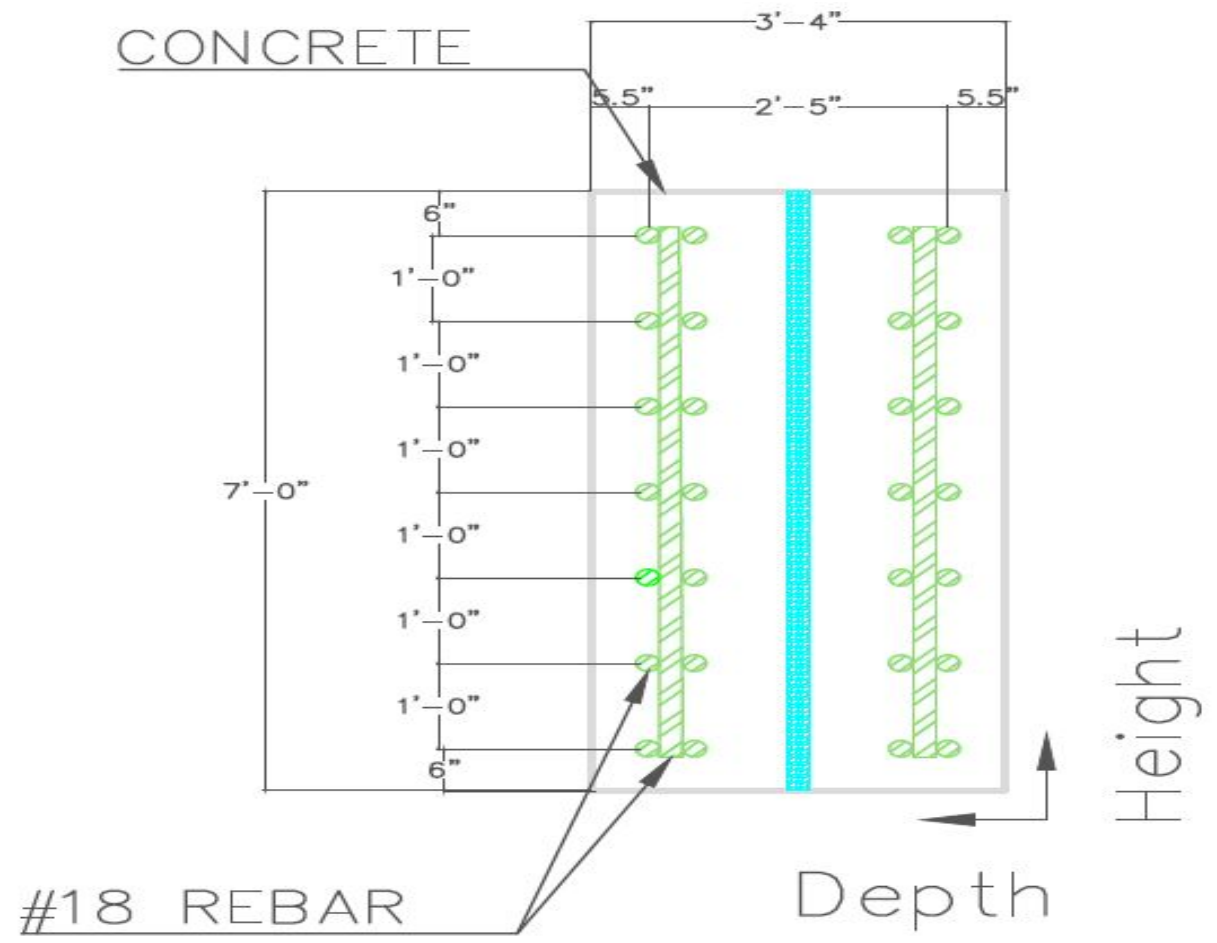

Fig. A.66. D07 Height by DepthNL. 


\begin{tabular}{|c|c|c|}
\hline \multicolumn{3}{|c|}{ DEECT TRQLE } \\
\hline o nueser & OESSORPION & wes: \\
\hline or & 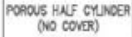 & \\
\hline 02 & 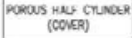 & \\
\hline as & 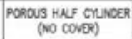 & \\
\hline D4 & 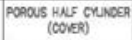 & \\
\hline DS & 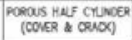 & \\
\hline$\infty$ & $P x$ & \\
\hline 07 & PXC & \\
\hline ob & 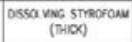 & \\
\hline$\infty$ & simoroun (HIOX) & \\
\hline 010 & SThoronu (MM) & \\
\hline DII & moxouss & \\
\hline 012 & 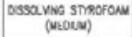 & \\
\hline 013 & 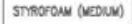 & \\
\hline 0,4 & PLDERASS & \\
\hline 015 & $\begin{array}{c}\text { cassaving sngoroum } \\
\text { (ThM) }\end{array}$ & \\
\hline 016 & LweER (zat) & \\
\hline 017 & a.0ves & \\
\hline 018 & 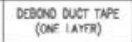 & \\
\hline D:9 & 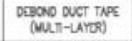 & \\
\hline 020 & WOUNO REQNR & \\
\hline
\end{tabular}

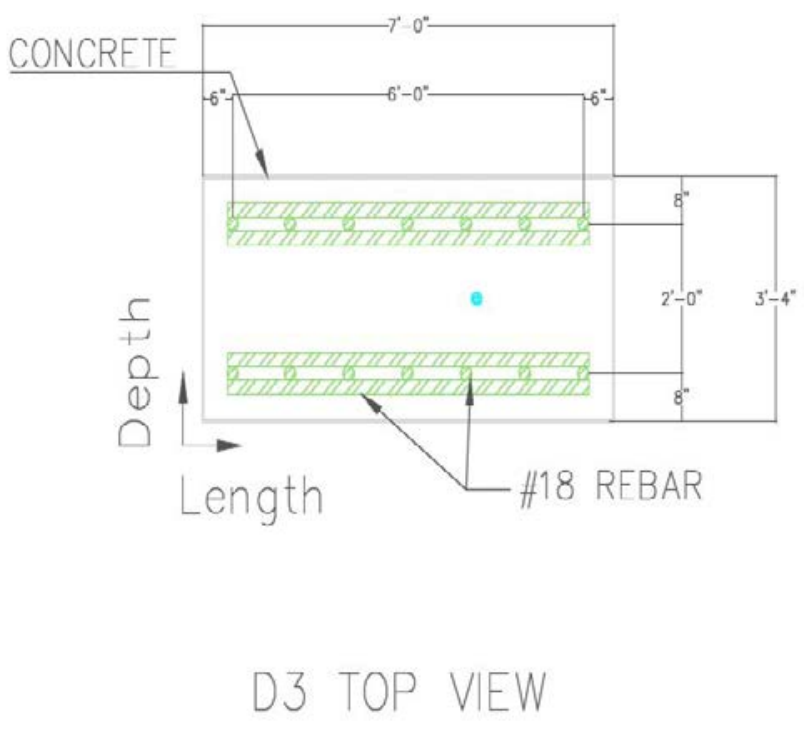

Fig. A.67. D07 Length by Depth.

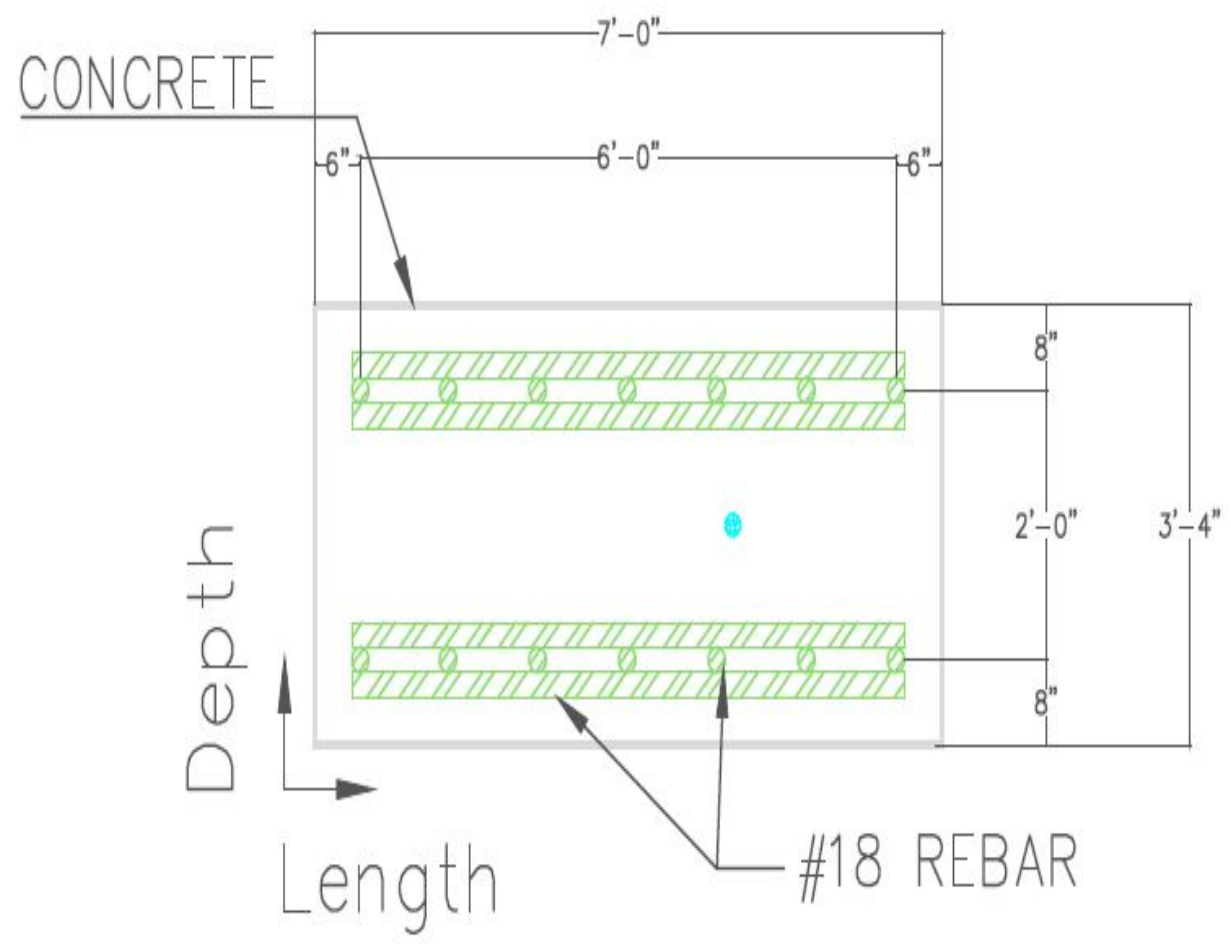

Fig. A.68. D07 Length by DepthNL. 

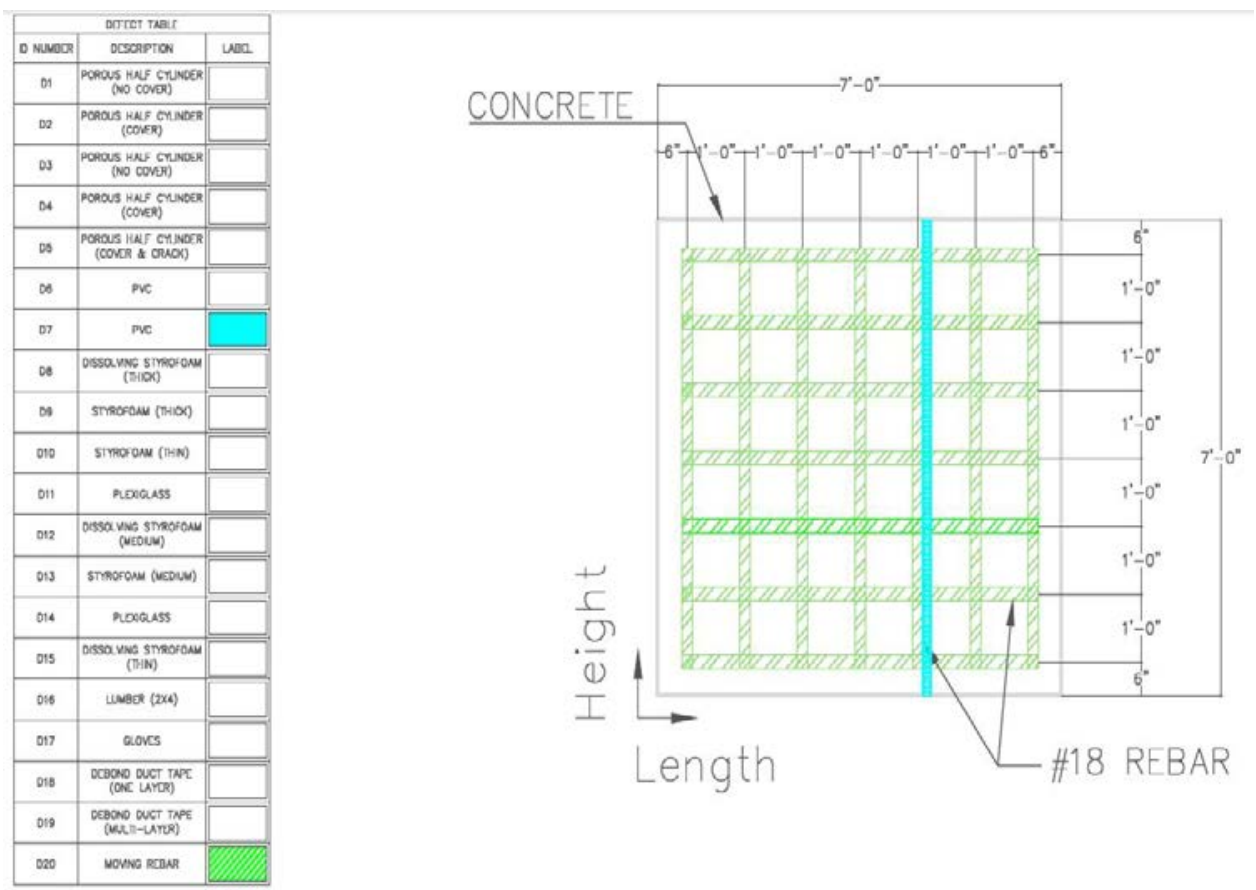

SIDE VIEW

Fig. A.69. D07 Length by Height.

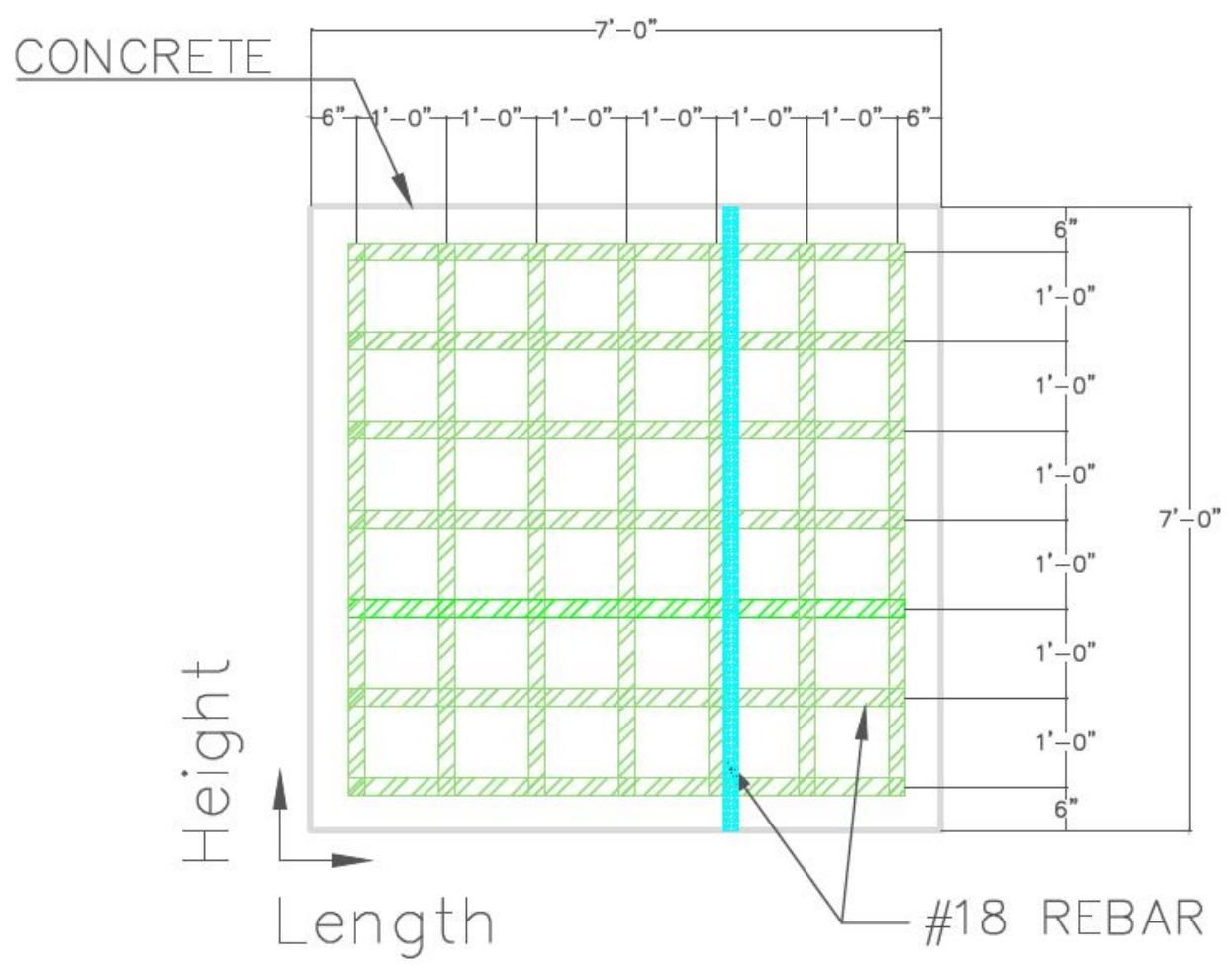

Fig. A.70. D07 Length by Height NL. 


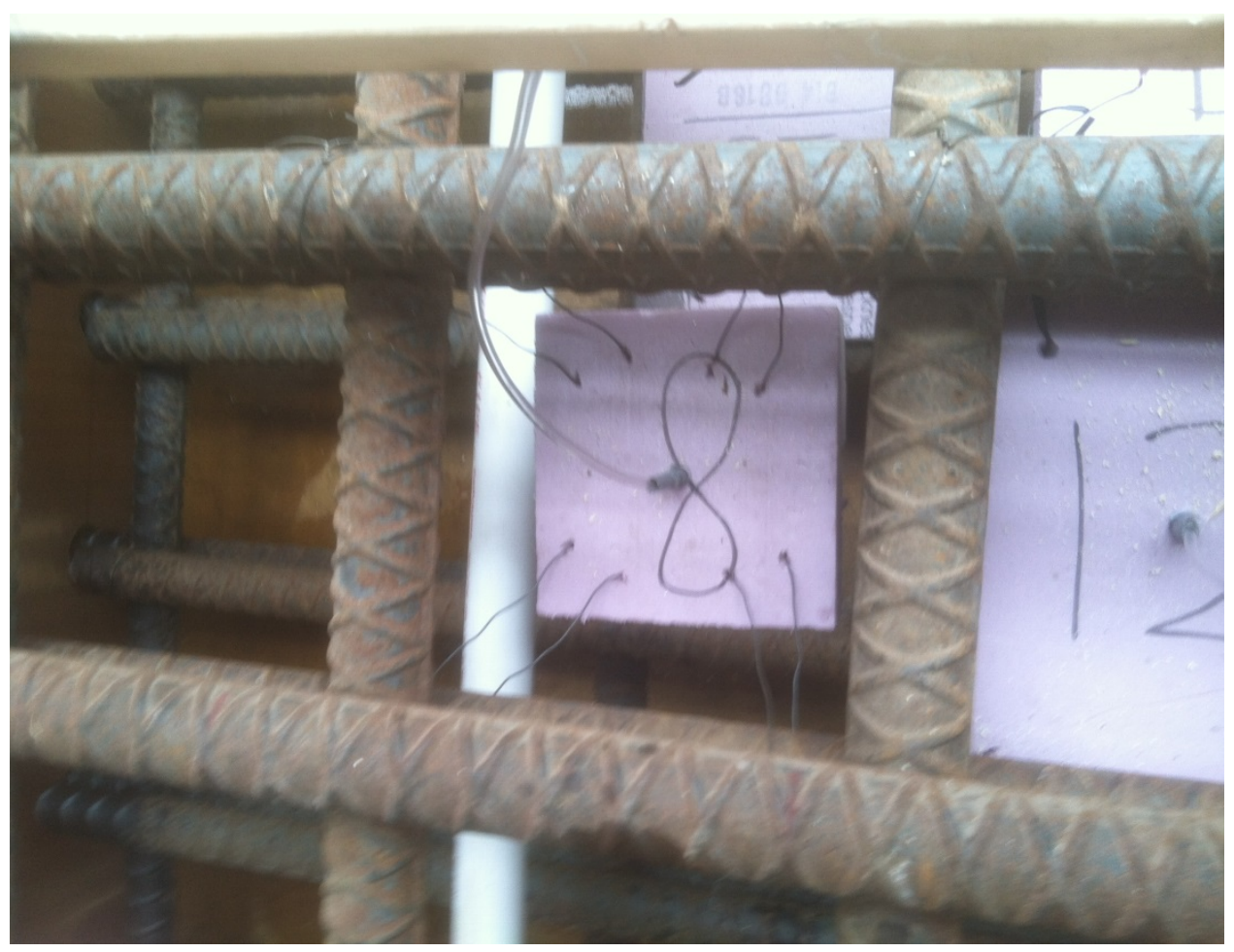

Fig. A.71. D08 close-up.
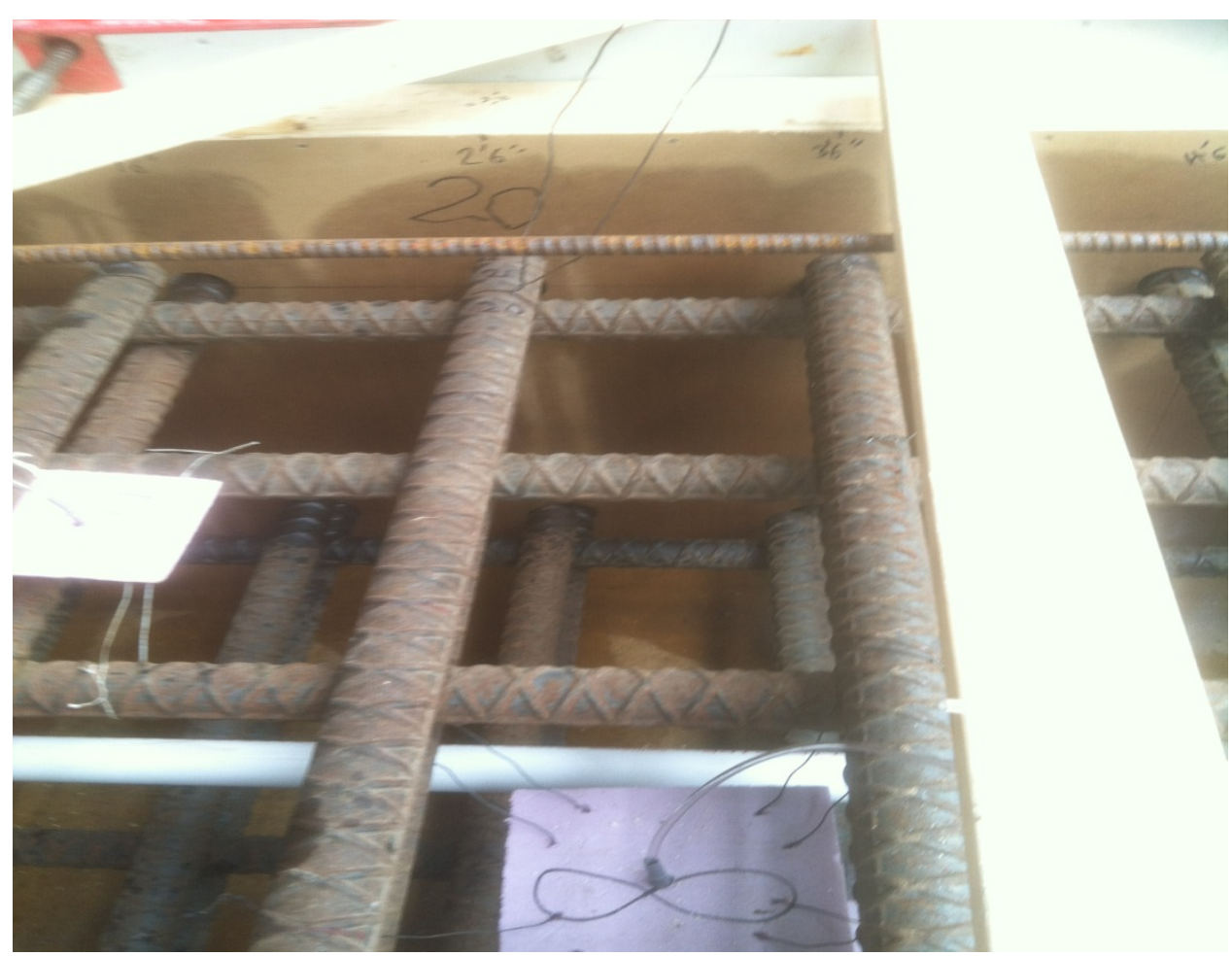

Fig. A.72. D08 Height 3.5bars 3ft $\times$ 914mm. 


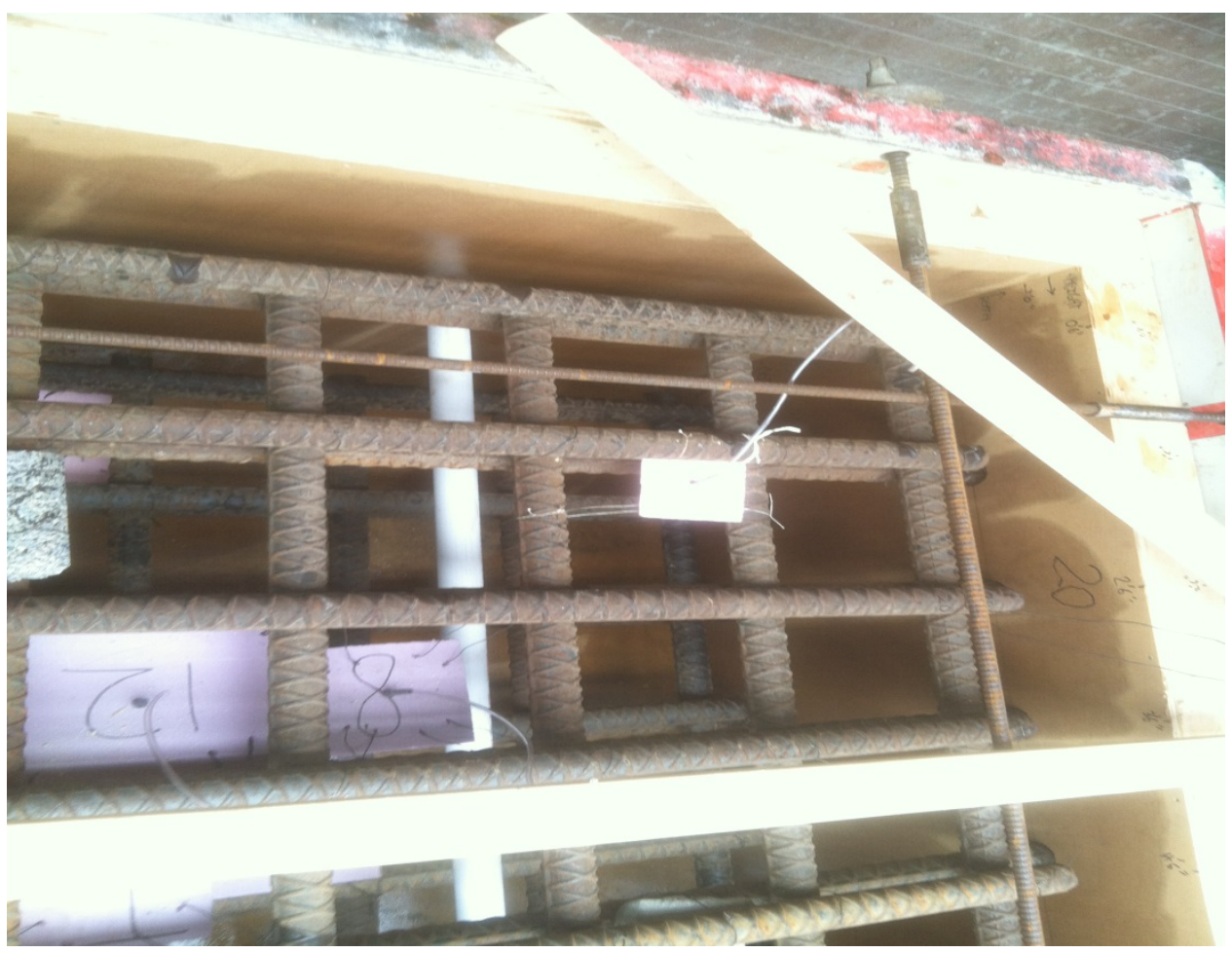

Fig. A.73. D08 Length3.5bars 3ft $\times 914 \mathrm{~mm}$.

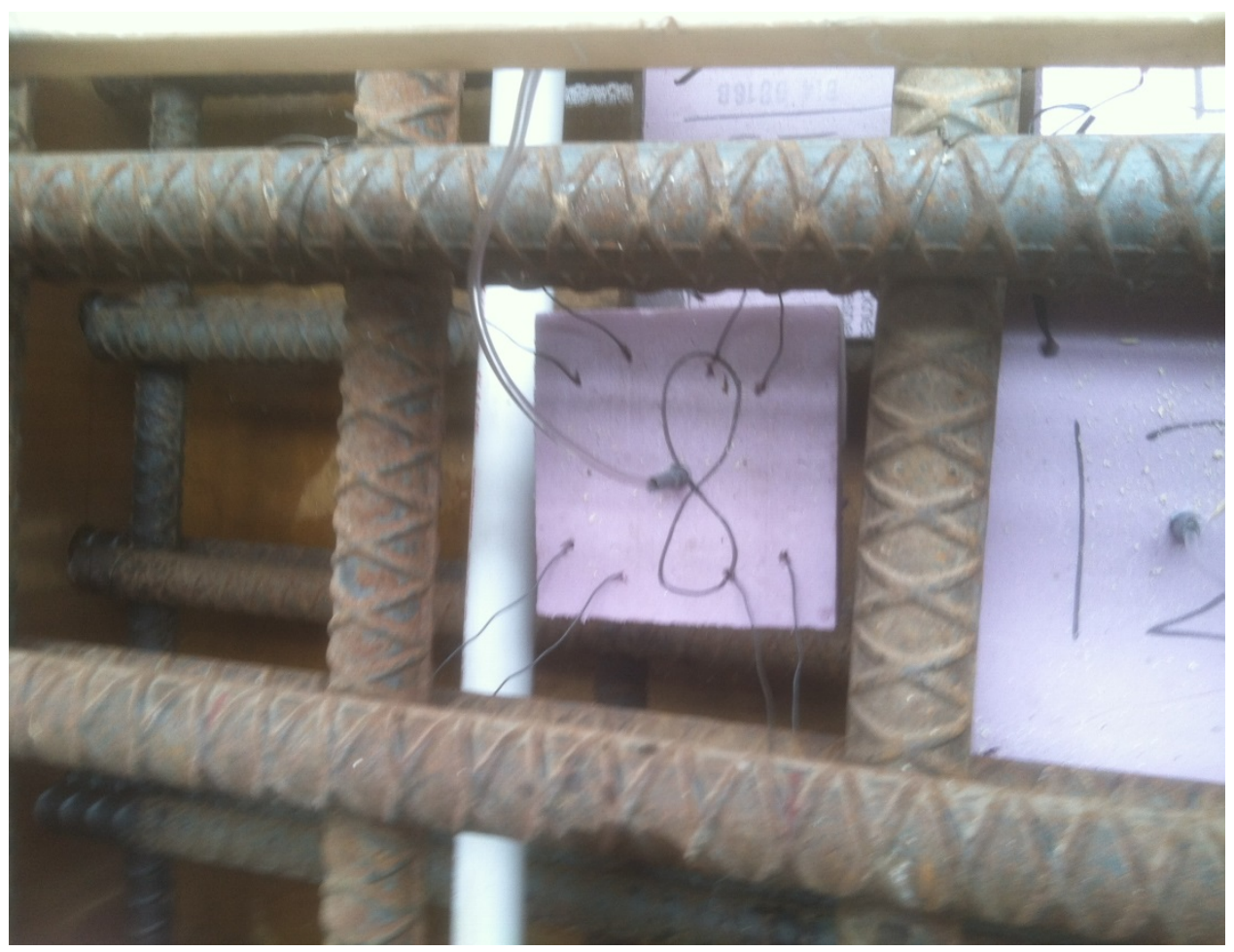

Fig. A.74. D08 R-depth rod measured $197 \mathrm{~mm}$. 


\begin{tabular}{|c|c|c|}
\hline \multicolumn{3}{|c|}{ DEFECT TABLE } \\
\hline 10 NUMBER & DESCRPPTION & LABE \\
\hline D1 & $\begin{array}{l}\text { POROUS HALF CYINDER } \\
\text { (NO COVER) }\end{array}$ & \\
\hline 02 & $\begin{array}{l}\text { POROUS HALF CYUNDER } \\
\text { (COVER) }\end{array}$ & \\
\hline 03 & \begin{tabular}{|c|} 
POROUS HALF CYUNDER \\
(NO COVER)
\end{tabular} & \\
\hline $\mathrm{D} 4$ & $\begin{array}{l}\text { POROUS HALF CYINOER } \\
\text { (COVER) }\end{array}$ & \\
\hline DS & $\begin{array}{l}\text { POROOS HALF CYINDER } \\
\text { (COVER \& CRACX) }\end{array}$ & \\
\hline D6 & PVC & \\
\hline 07 & PVC & \\
\hline DB & $\begin{array}{c}\text { DISSOLVNG STYROFOAM } \\
\text { (THICK) }\end{array}$ & 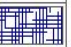 \\
\hline Dg & STYROFOAM (THICK) & \\
\hline 010 & STYROFOAM (THIN) & \\
\hline 011 & PLEXGLASS & \\
\hline 012 & \begin{tabular}{|c|} 
DISSOLUNG STRROFOAM \\
(MEDIUM)
\end{tabular} & \\
\hline 013 & STRROFOAM (MEDUUM) & \\
\hline 014 & PLEXGLASS & \\
\hline 015 & $\begin{array}{c}\text { DISSOLUNG STYROFOAM } \\
\text { (THIN) }\end{array}$ & \\
\hline 016 & LUMBER $(2 \times 4)$ & \\
\hline 017 & GLOVES & \\
\hline 018 & $\begin{array}{l}\text { DEBOND DUCT TAPE } \\
\text { (ONE LAYER) }\end{array}$ & \\
\hline 019 & $\begin{array}{l}\text { DEBOND DUCT TAPE } \\
\text { (MULT-LAYRR) }\end{array}$ & \\
\hline 020 & MOUNG REBAR & \\
\hline
\end{tabular}

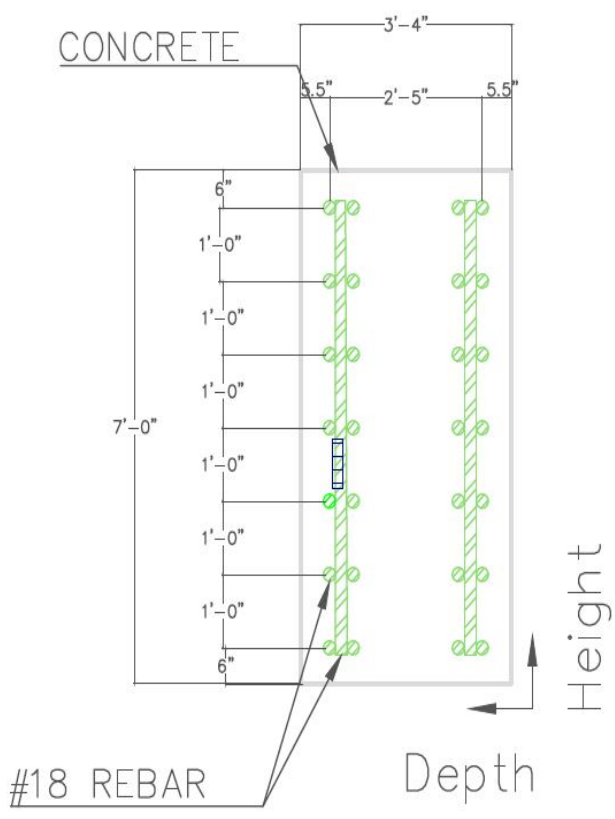

Fig. A.75. D08 height by depth.

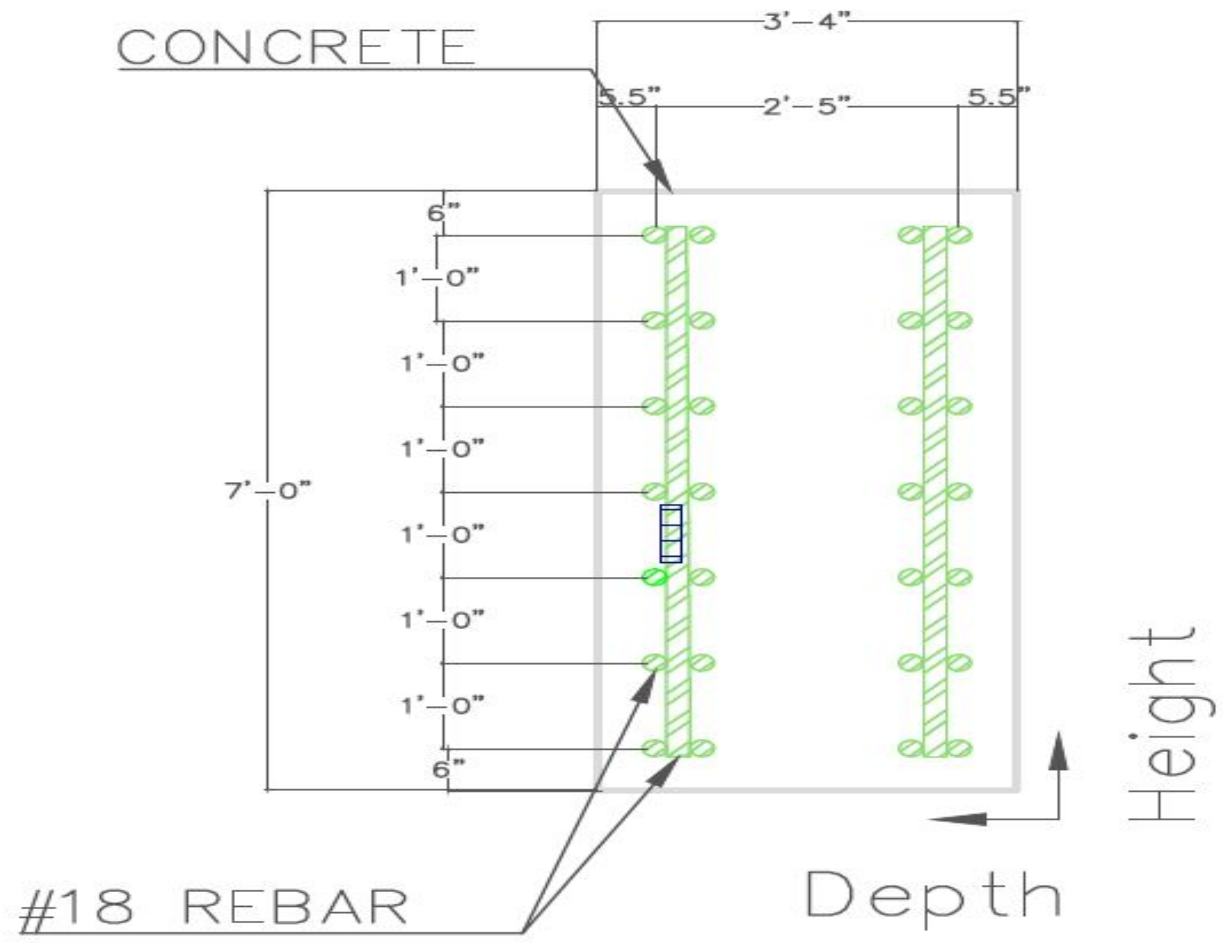

Fig. A.76. D08 height by depth NL. 


\begin{tabular}{|c|c|c|}
\hline \multicolumn{3}{|c|}{ CEFECT TABUE } \\
\hline D Nuger & DESCRPTON & Wea. \\
\hline or & 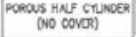 & \\
\hline 02 & $\begin{array}{l}\text { POEOWS HAL CIUMOCR } \\
\text { (COOKCR) }\end{array}$ & \\
\hline os & $\begin{array}{l}\text { PCocous HNE CYUNDER } \\
\text { (NO COVER] }\end{array}$ & \\
\hline of & $\begin{array}{l}\text { PCOOUS HNF CMINOFR } \\
\text { (CONCVI) }\end{array}$ & \\
\hline 05 & $\begin{array}{l}\text { POROCOS HALF CYUNOER } \\
\text { (COVER \& CQUOX) }\end{array}$ & \\
\hline D6 & PVC & \\
\hline 07 & PVC & \\
\hline$\infty$ & $\begin{array}{c}\text { Dasso ung gnemorom } \\
\text { (THOS) }\end{array}$ & + \\
\hline$\infty$ & sirnoroun (IIIIX) & \\
\hline 010 & STrocoum (TTMN) & \\
\hline on & PLowass & \\
\hline 012 & 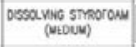 & \\
\hline 013 & 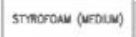 & \\
\hline 014 & novouss & \\
\hline Dis & 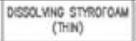 & \\
\hline M16 & twers (2xa) & \\
\hline 017 & coves & \\
\hline Dis & $\begin{array}{l}\text { DEBONO DUCT TAPE } \\
\text { (OAE LARR) }\end{array}$ & \\
\hline 019 & $\begin{array}{l}\text { OCBONO OUCT TAPE } \\
\text { (WLIT-LITR) }\end{array}$ & \\
\hline 020 & NOWNC REBAR & \\
\hline
\end{tabular}

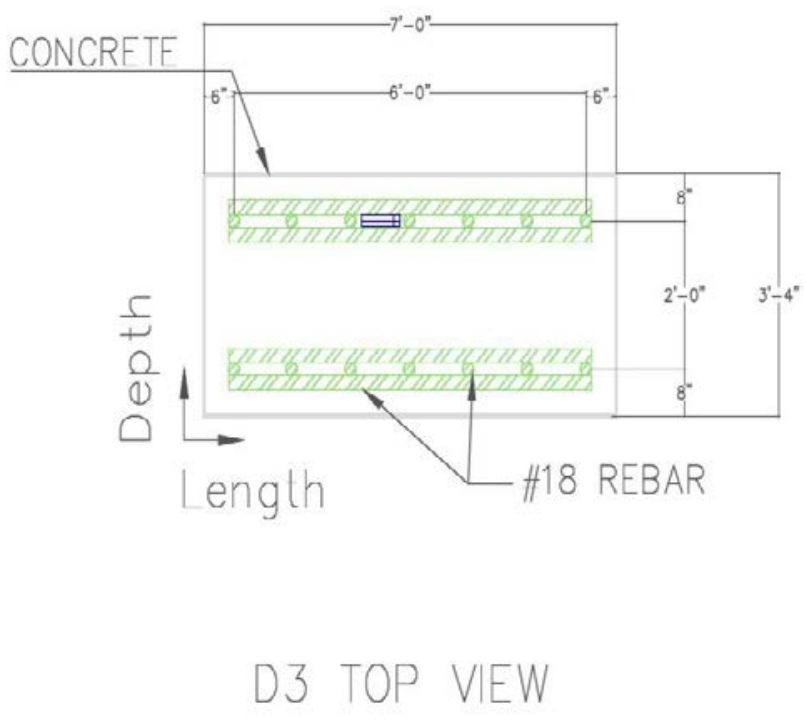

Fig. A.77. D08 length by depth.

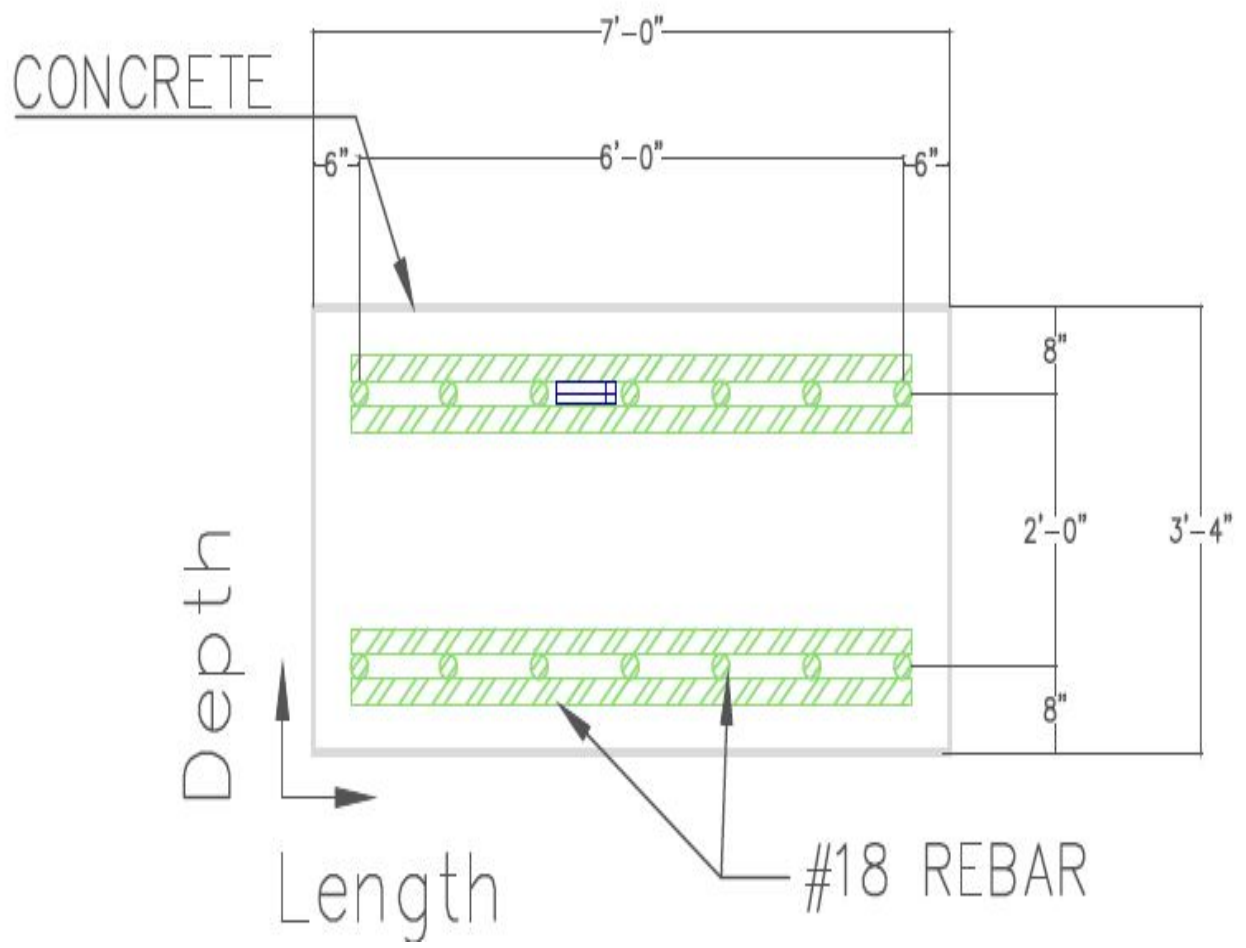

Fig. A.78. D08 length by depth NL. 

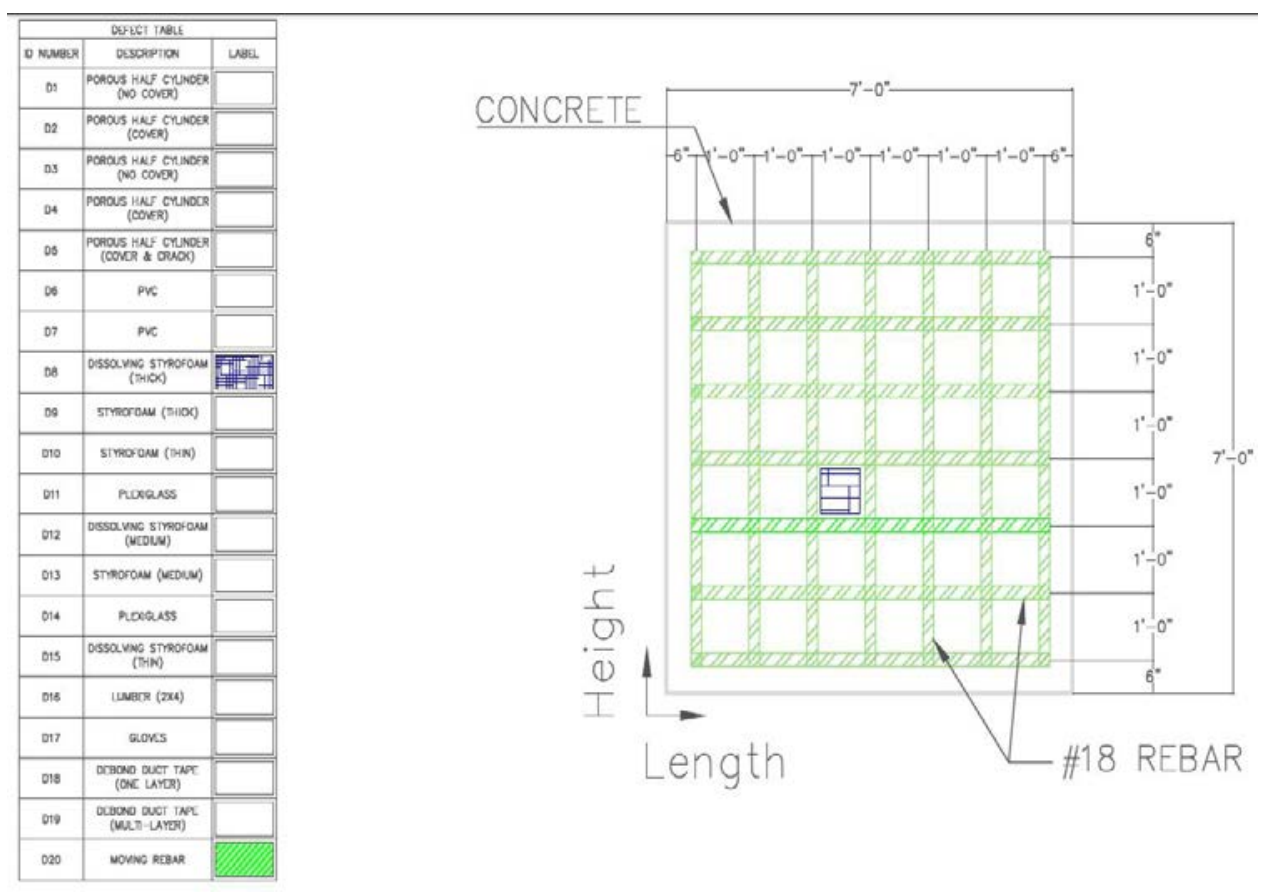

\section{SIDE VIEW}

Fig. A.79. D08 length by height.

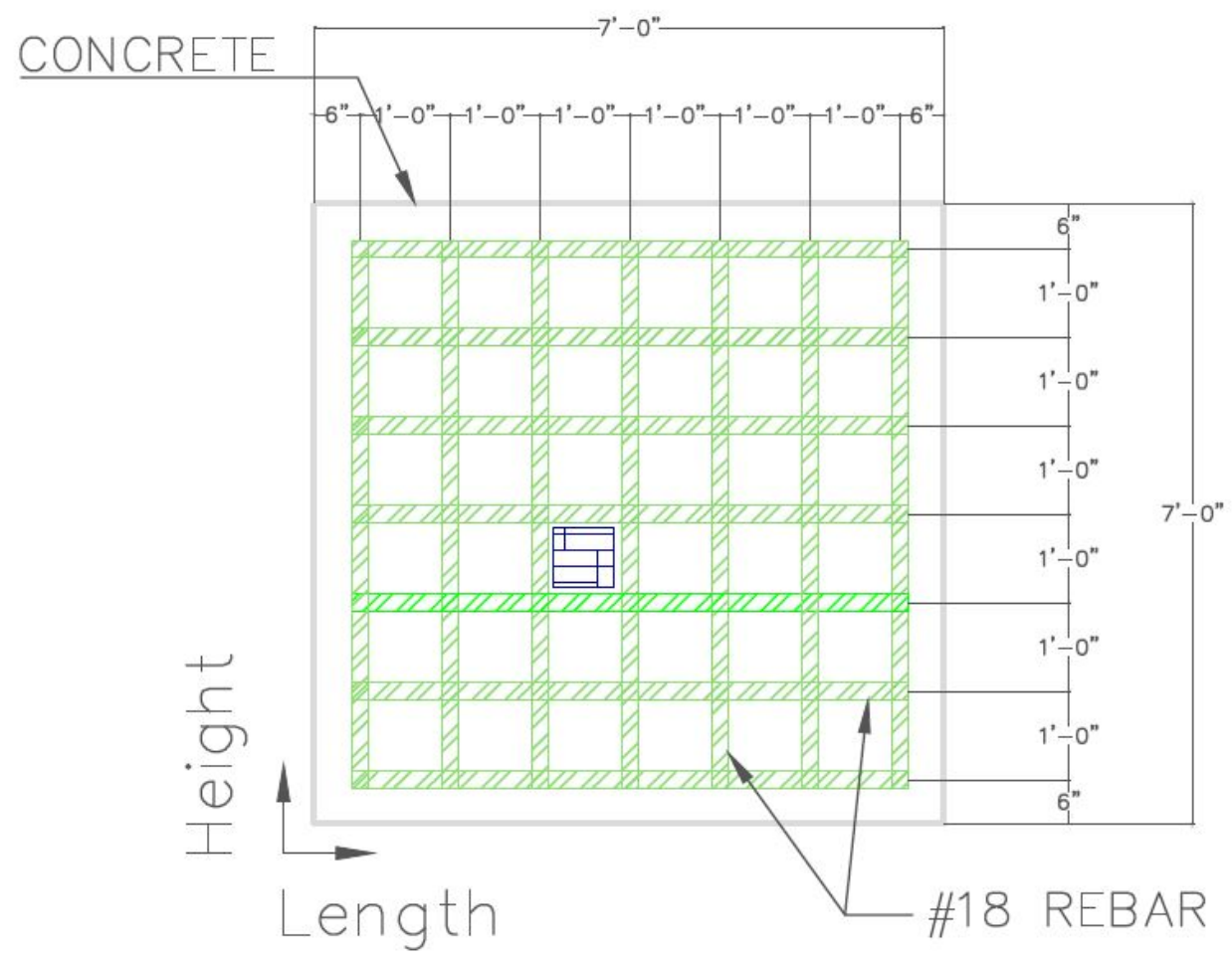

Fig. A.80. D08 length by height NL. 


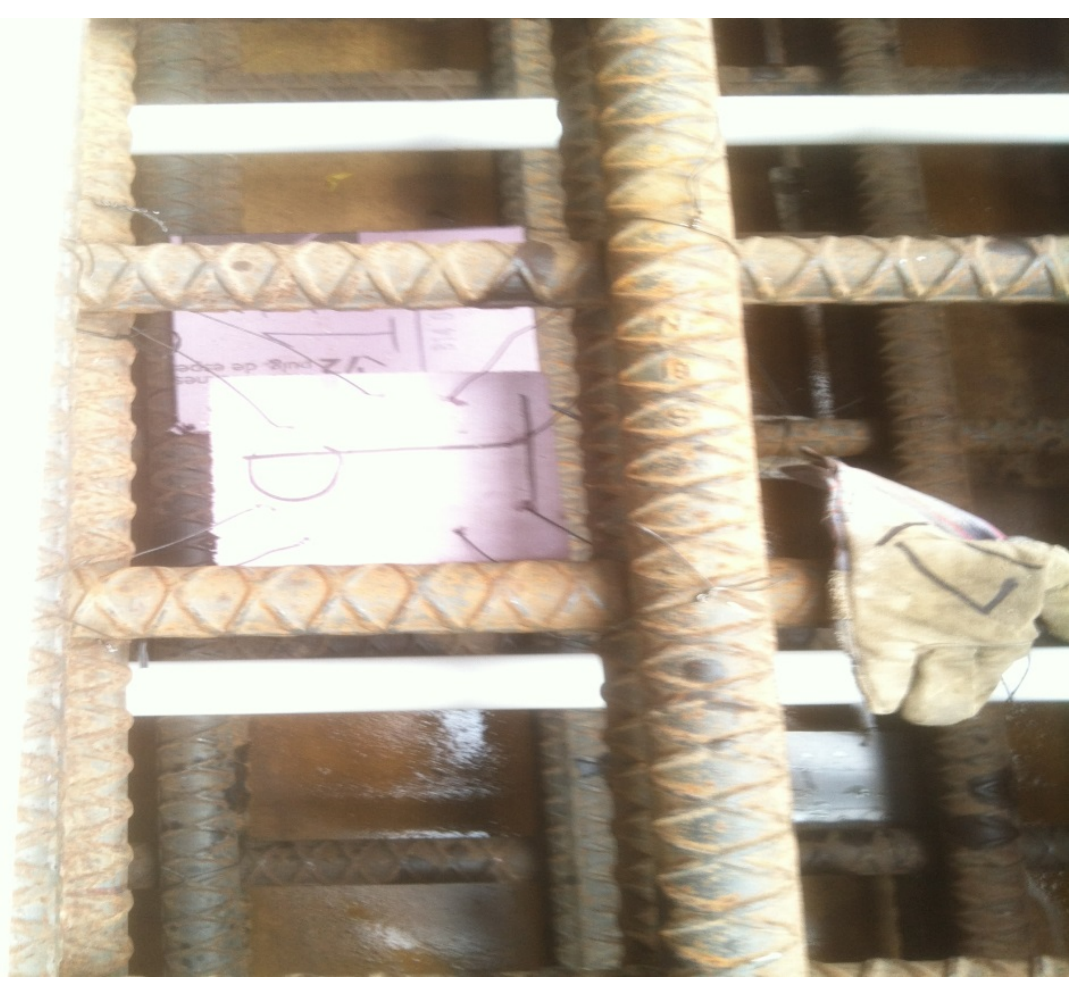

Fig. A.81. D09 close-up.

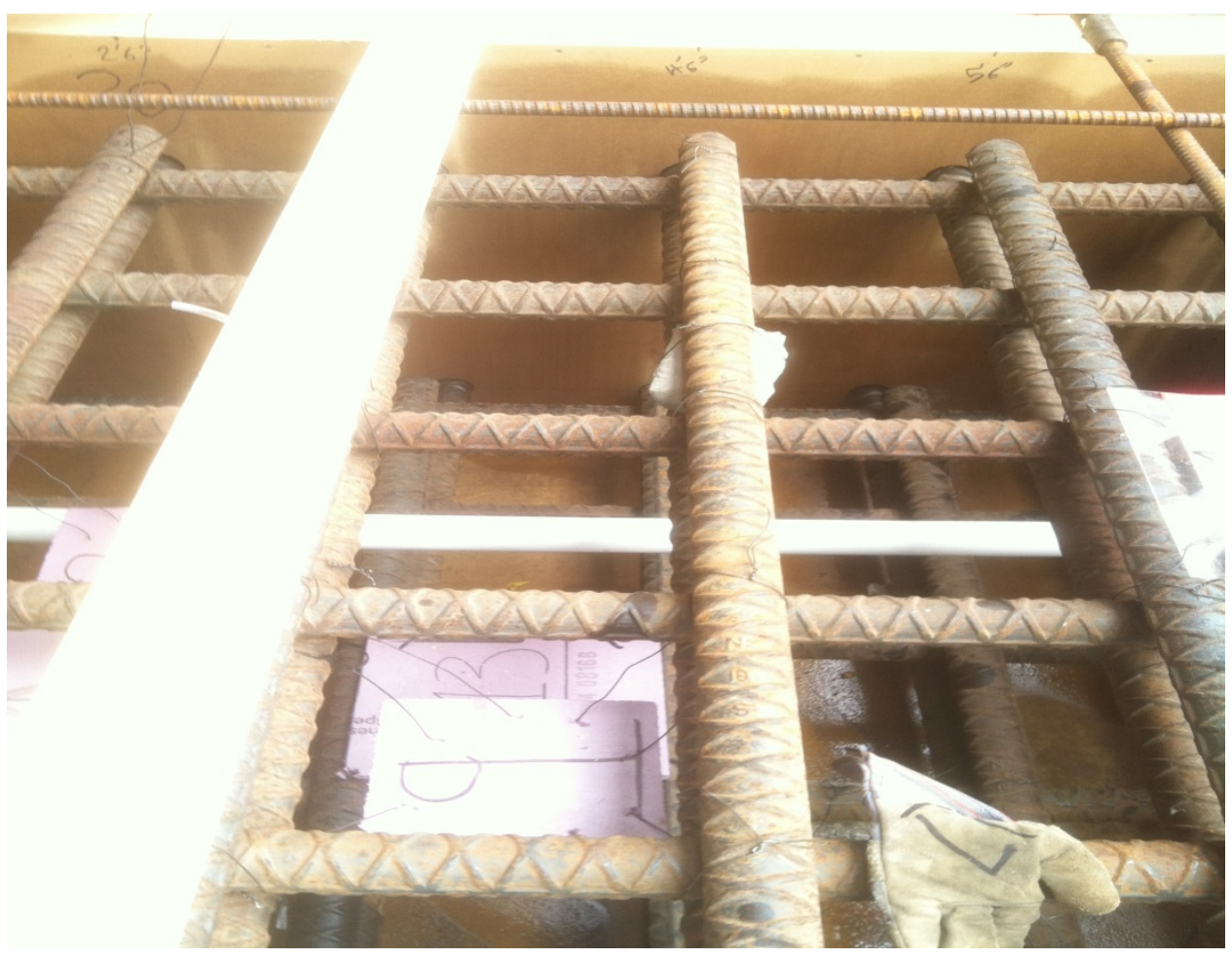

Fig. A.82. D09 height 4.5bars $4 \mathrm{ft} \times 1219 \mathrm{~mm}$. 


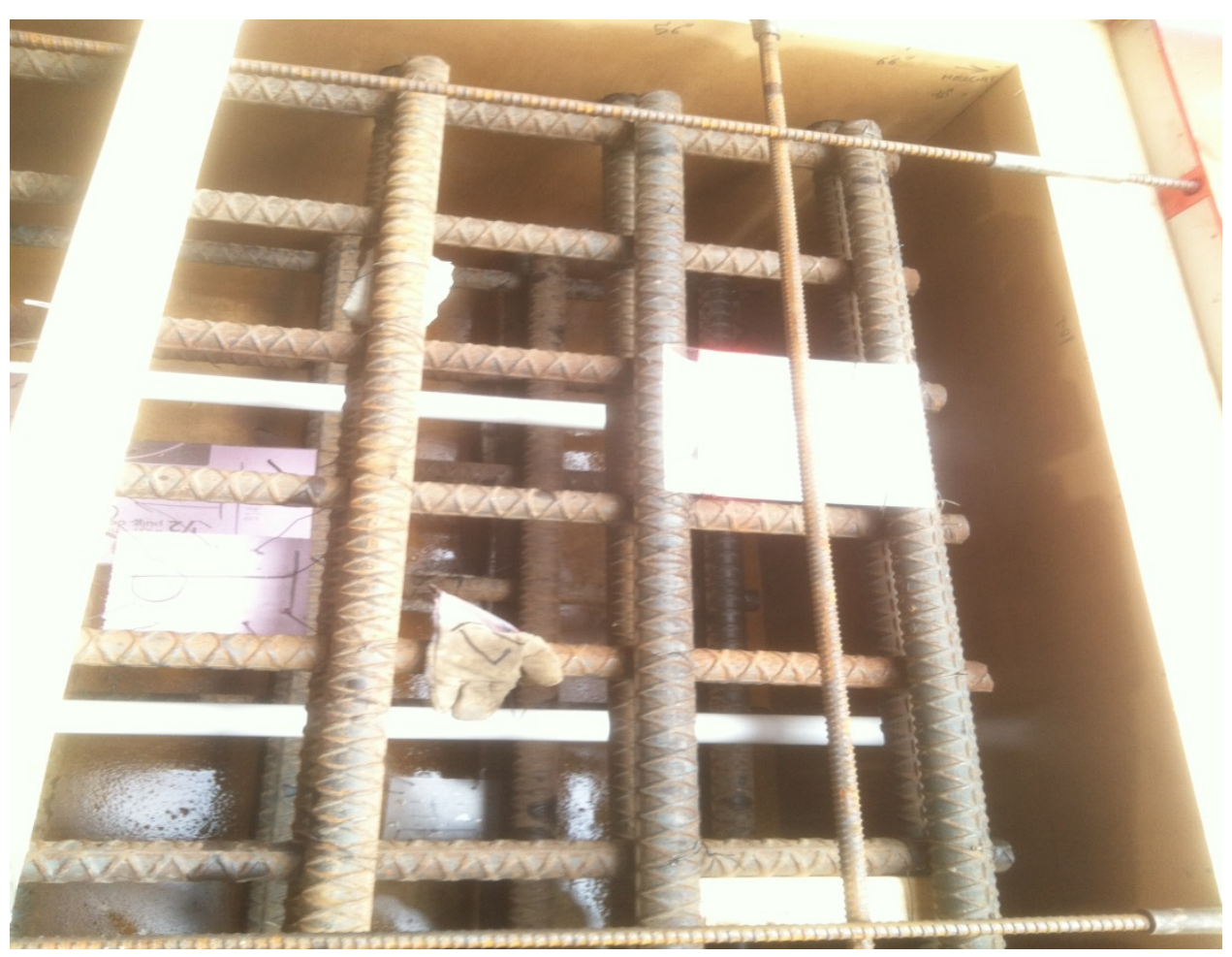

Fig. A.83. D09 Length 4.5 bars $4 \mathrm{ft} \times 914 \mathrm{~mm}$.

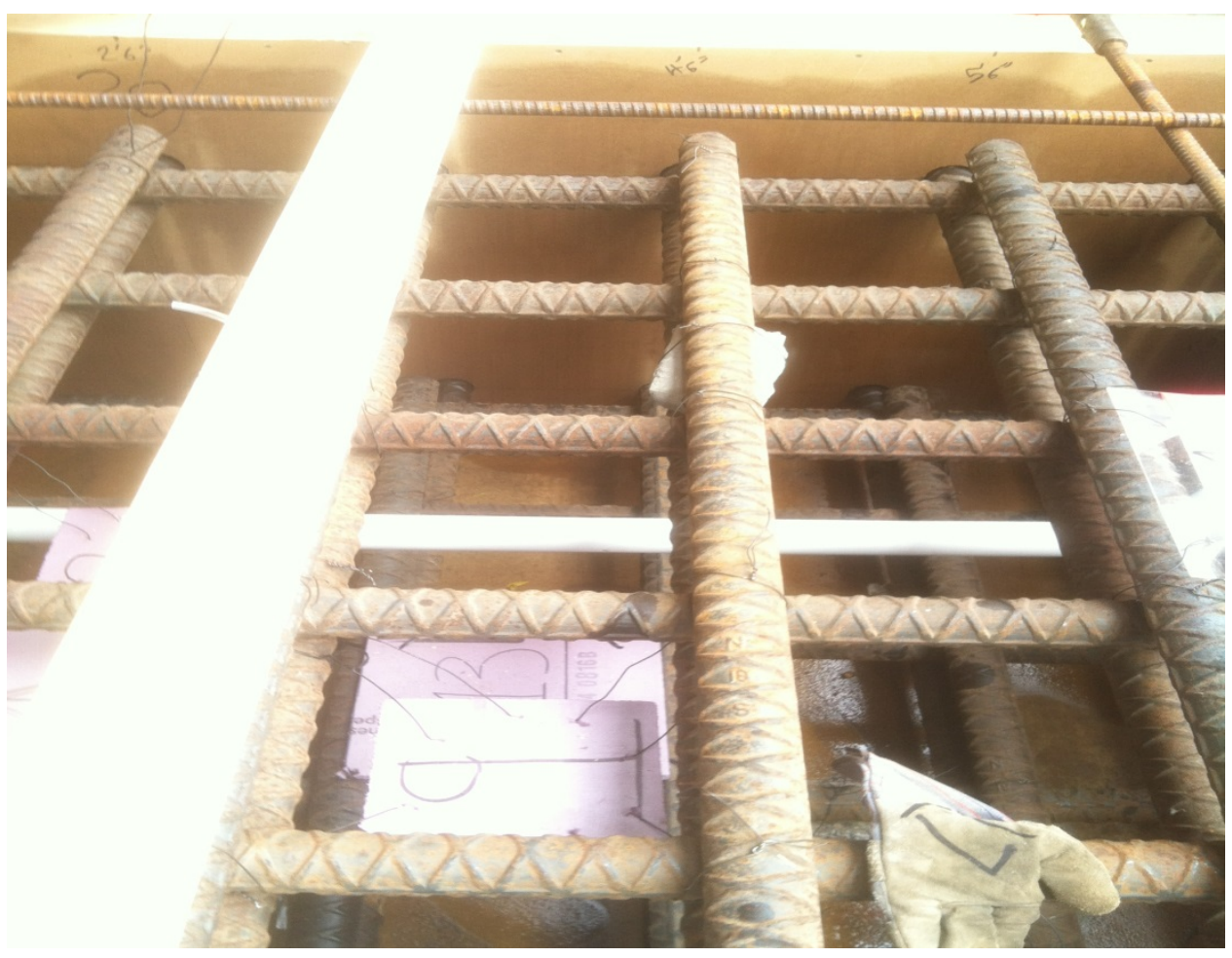

Fig. A.84. D09 R-depth rod measured $248 \mathrm{~mm}$. 


\begin{tabular}{|c|c|c|}
\hline \multicolumn{3}{|c|}{ DEFECT TABLE } \\
\hline ID NUMBER & DESCRIPTION & LАвב \\
\hline D1 & $\begin{array}{l}\text { POROUS HALF CYINDER } \\
\text { (NO COVER) }\end{array}$ & \\
\hline D2 & $\begin{array}{l}\text { POROUS HALF CYINDER } \\
\text { (COVER) }\end{array}$ & \\
\hline 03 & $\begin{array}{l}\text { POROUS HALF CYUNDER } \\
\text { (NO COVER) }\end{array}$ & \\
\hline 04 & $\begin{array}{c}\text { POROUS HALF CYINDER } \\
\text { (COVER) }\end{array}$ & \\
\hline 05 & $\begin{array}{l}\text { POROUS HALF CYNDOER } \\
\text { (COVER \& CRACK) }\end{array}$ & \\
\hline 06 & PVC & \\
\hline 07 & PVC & \\
\hline DB & $\begin{array}{c}\text { DISSOLUNG STYROFOAM } \\
\text { (THICK) }\end{array}$ & \\
\hline 09 & STYROFOAM (THICK) & \\
\hline 010 & STTROFOAM (THIN) & \\
\hline 011 & PLEXIGLASS & \\
\hline 012 & $\begin{array}{c}\text { DISSOLUNG STRROFOMM } \\
\text { (MEDUM) }\end{array}$ & \\
\hline 013 & STTROFOAM (MEDUM) & \\
\hline 014 & PLEXKGLASS & \\
\hline D15 & $\begin{array}{c}\text { DISSOLVNG STYROFOAM } \\
\text { (THIN) }\end{array}$ & \\
\hline 016 & LUMBER $(2 \times 4)$ & \\
\hline 017 & GLoves & \\
\hline 018 & $\begin{array}{l}\text { DEBOND DUCT TAPE } \\
\text { (ONE LAYER) }\end{array}$ & \\
\hline D19 & $\begin{array}{l}\text { DEBOND DUCT TAPE } \\
\text { (MULI-LAYRR) }\end{array}$ & \\
\hline 020 & MOUNG REBAR & \\
\hline
\end{tabular}

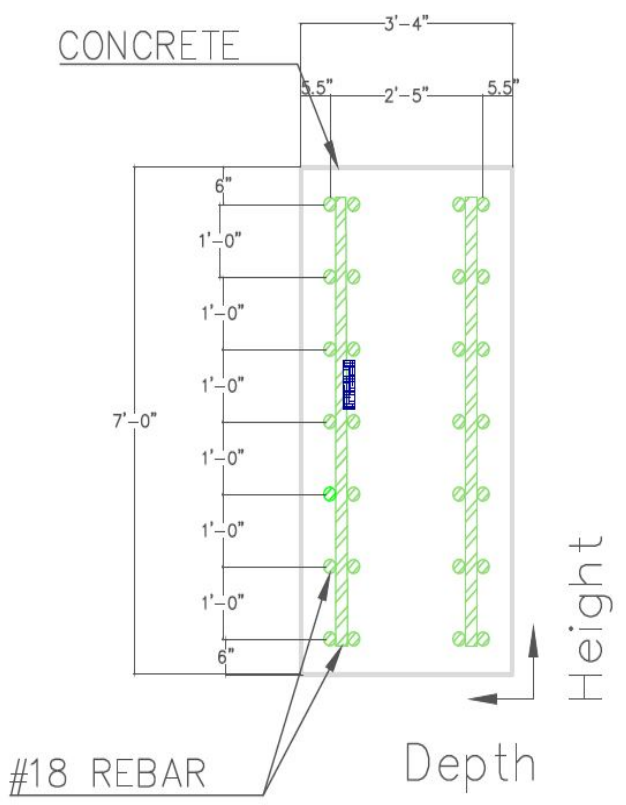

Fig. A.85. D09 height by depth.

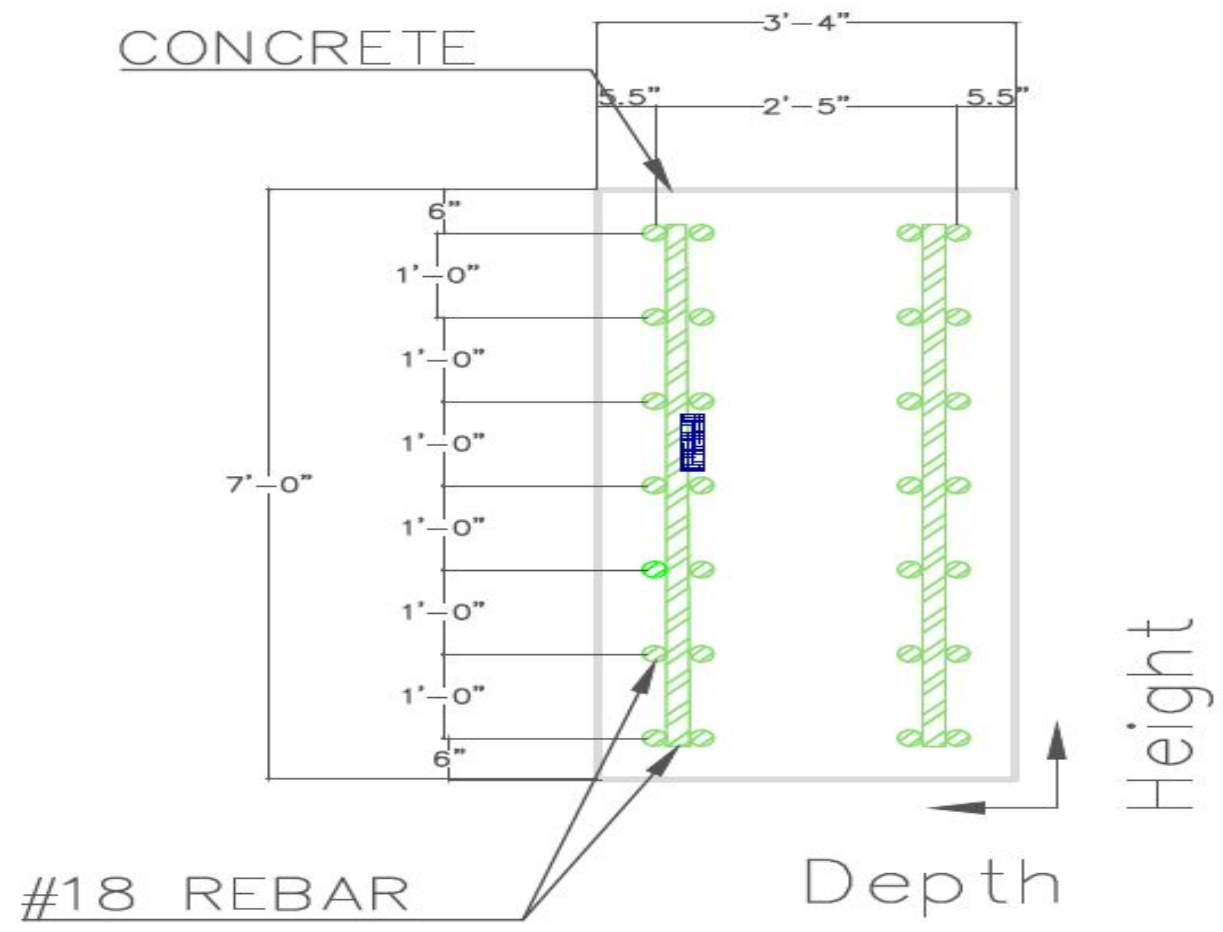

Fig. A.86. D09 height by depth NL. 


\begin{tabular}{|c|c|c|}
\hline \multicolumn{3}{|c|}{ DEFECT TRELE } \\
\hline O NWOCR & OCSERPTOA & won. \\
\hline or & 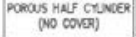 & \\
\hline 02 & $\begin{array}{l}\text { POROUS HAF OUNOER } \\
\text { (COVFR) }\end{array}$ & \\
\hline as & 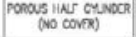 & \\
\hline ot & 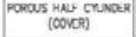 & \\
\hline Do & 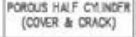 & \\
\hline$\infty$ & $P x$ & \\
\hline 07 & Pre & \\
\hline$\infty$ & $\begin{array}{c}\text { acssavesc simerom } \\
(\pi / \alpha)\end{array}$ & \\
\hline$\infty$ & simeroum (thos) & \\
\hline 010 & streoroun (that) & \\
\hline ont & PDovanss & \\
\hline 012 & 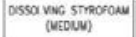 & \\
\hline 013 & 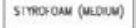 & \\
\hline 014 & Provatss & \\
\hline 015 & $\begin{array}{c}\text { Dossa vwe sTmorowu } \\
\text { (TIIN) }\end{array}$ & \\
\hline 016 & Lues: $(2 \times 4)$ & \\
\hline 017 & goves & \\
\hline ois & 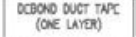 & \\
\hline 010 & 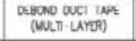 & \\
\hline 020 & NOVMC REBNR & \\
\hline
\end{tabular}

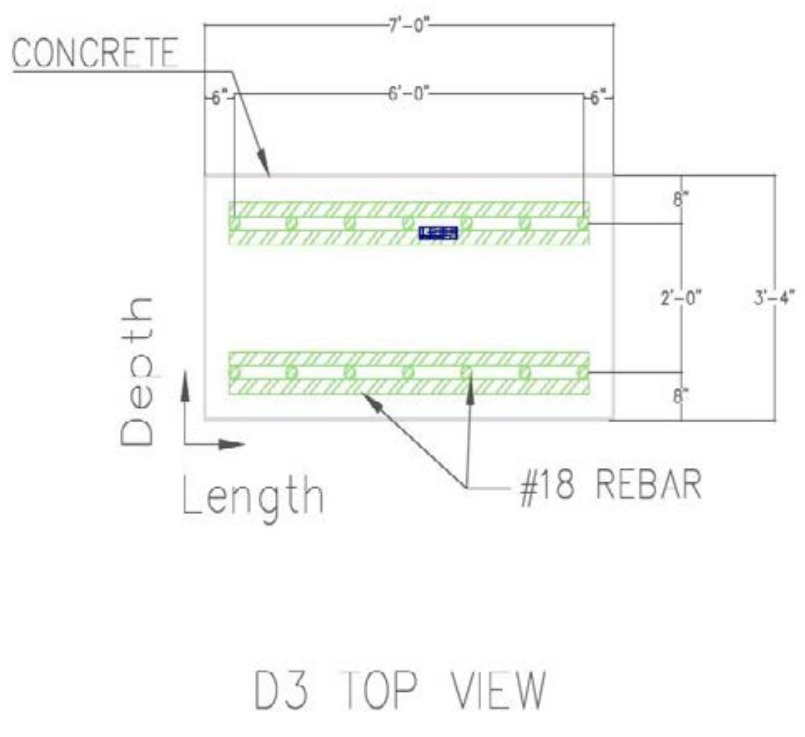

Fig. A.87. D09 length by depth.

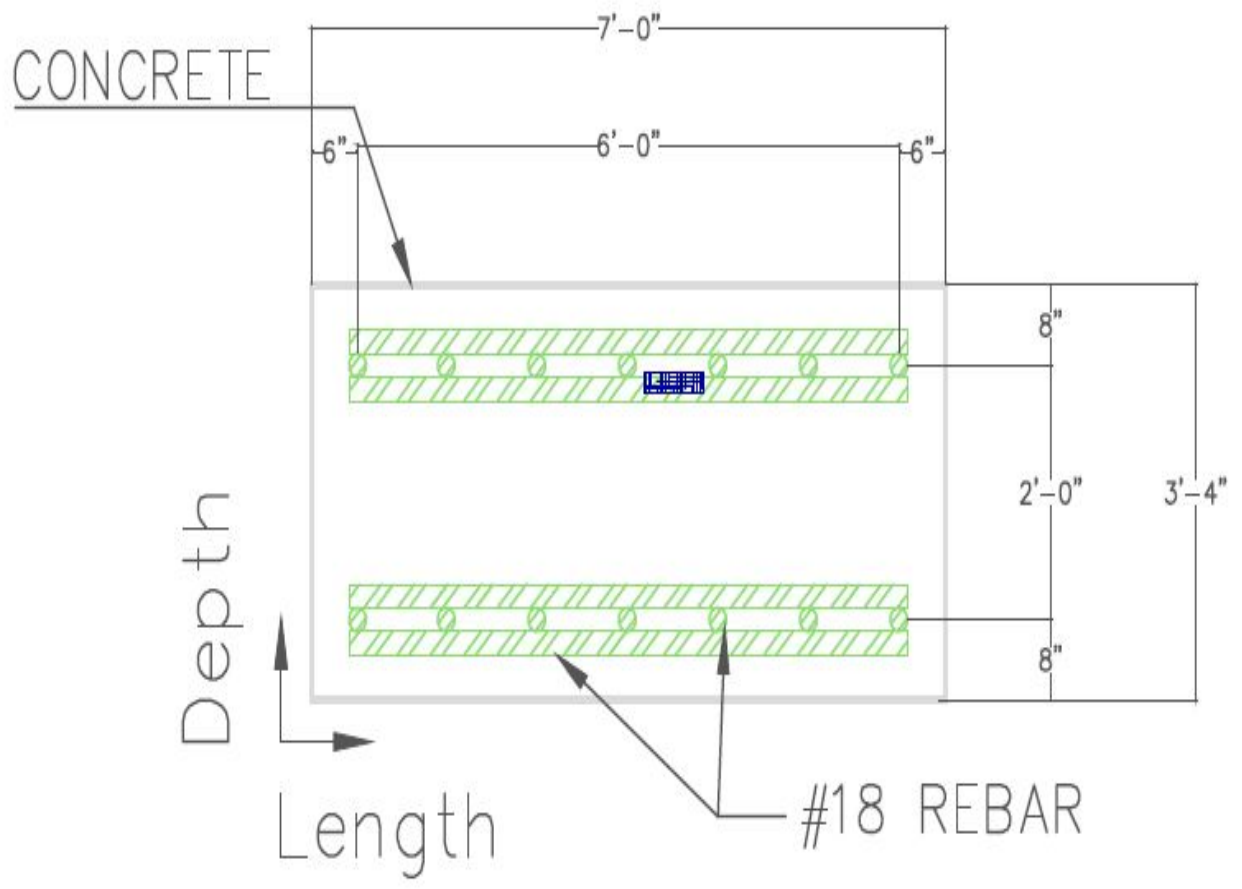

Fig. A.88. D09 length by depth NL. 


\begin{tabular}{|c|c|c|}
\hline \multicolumn{3}{|c|}{ OEECT TRALE } \\
\hline D nueca & OESCRPTOA & weal \\
\hline or & 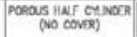 & \\
\hline$\infty 2$ & $\begin{array}{l}\text { POROWS HAN CENOCCR } \\
\text { (CONCR) }\end{array}$ & \\
\hline os & 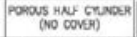 & \\
\hline os & 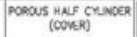 & \\
\hline os & 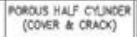 & \\
\hline$\infty 6$ & $\mathrm{mex}$ & \\
\hline 07 & $\mathrm{px}$ & \\
\hline$\infty$ & $\begin{array}{l}\text { Dssaunc smacom } \\
\text { (nimo) }\end{array}$ & \\
\hline$\infty$ & smoofous (mox) & \\
\hline 010 & srmorow (nia) & \\
\hline O11 & PLDRans & \\
\hline 012 & 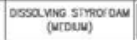 & \\
\hline 013 & stmoronu (netoun) & \\
\hline 014 & movouss & \\
\hline nis & $\begin{array}{c}\text { ossaning smoosom } \\
\text { (Timen) }\end{array}$ & \\
\hline 916 & uvers $(2 x)$ & \\
\hline 017 & arons & \\
\hline Die & 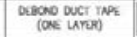 & \\
\hline 019 & 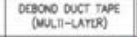 & \\
\hline 000 & Wovag grant & \\
\hline
\end{tabular}

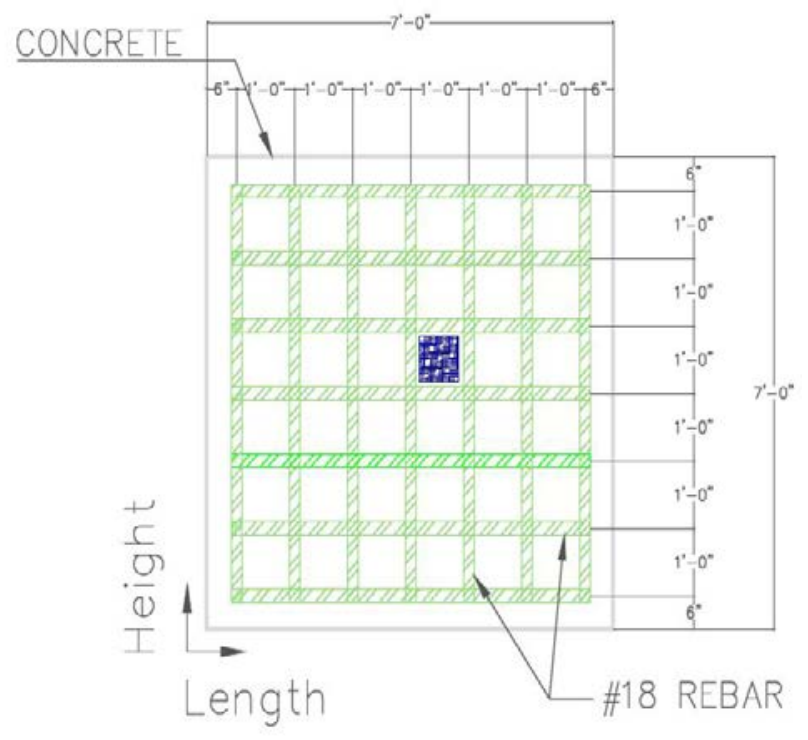

\section{SIDE VIEW}

Fig. A.89. D09 length by height.

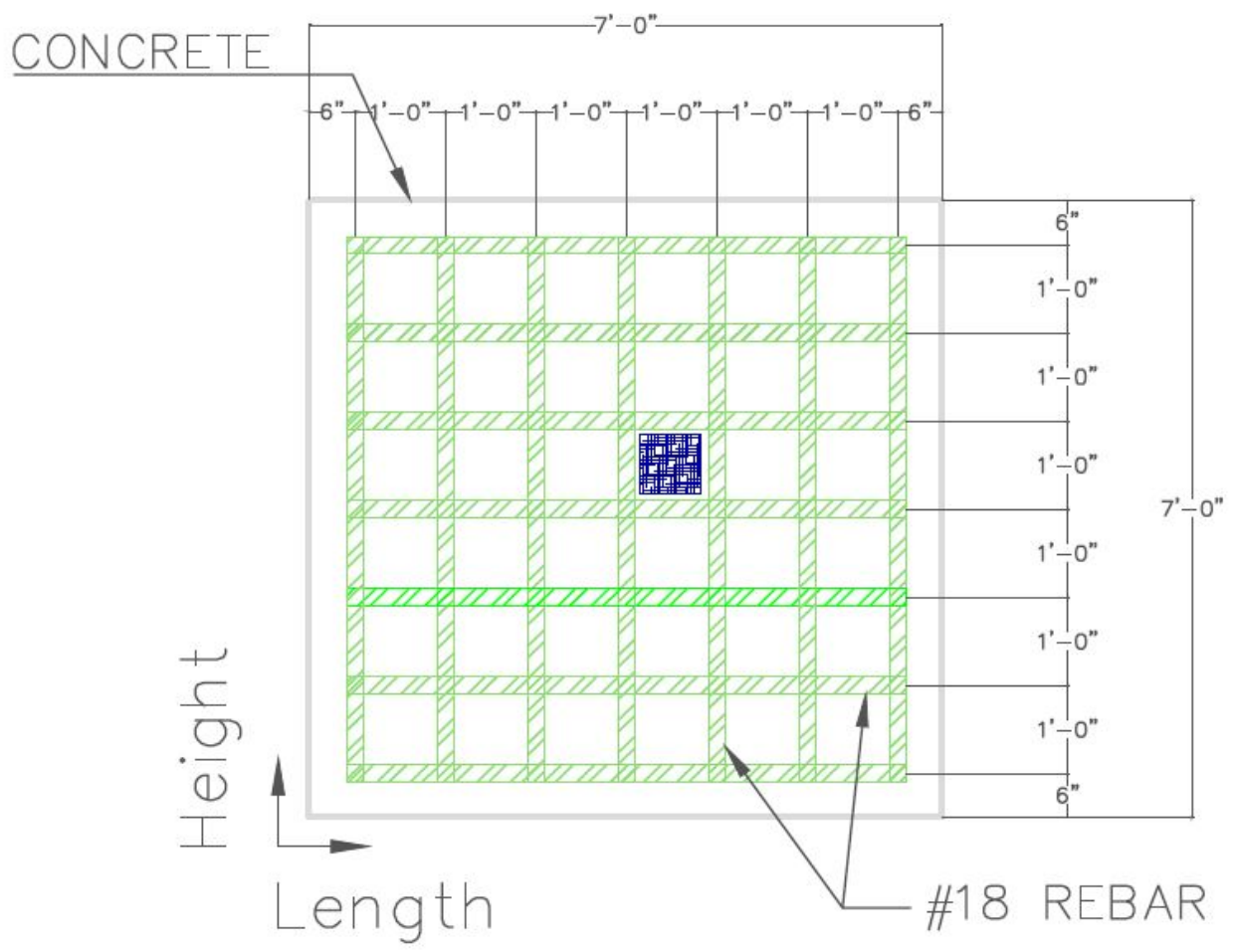

Fig. A.90. D09 length by height NL. 


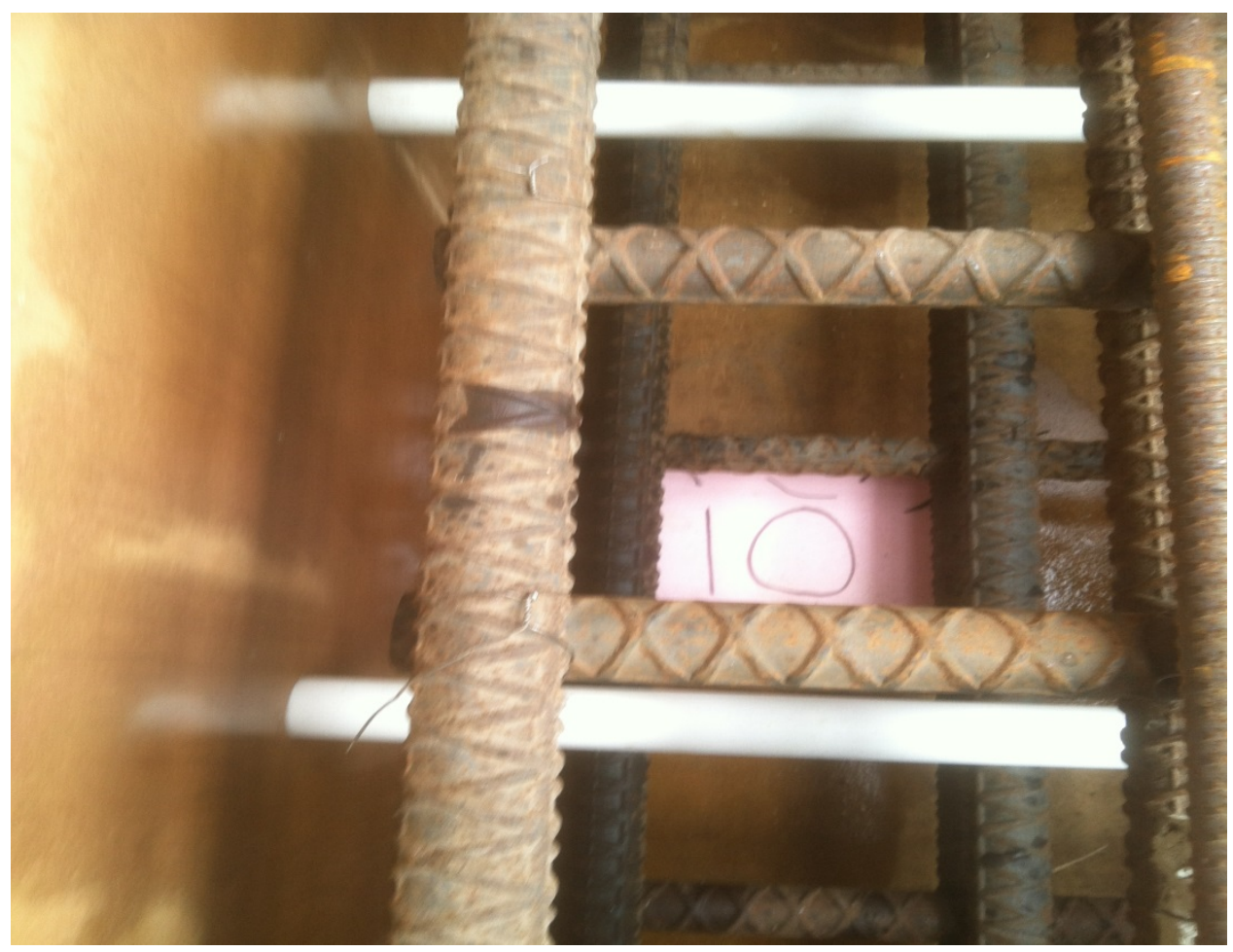

Fig. A.91. D10 close-up.

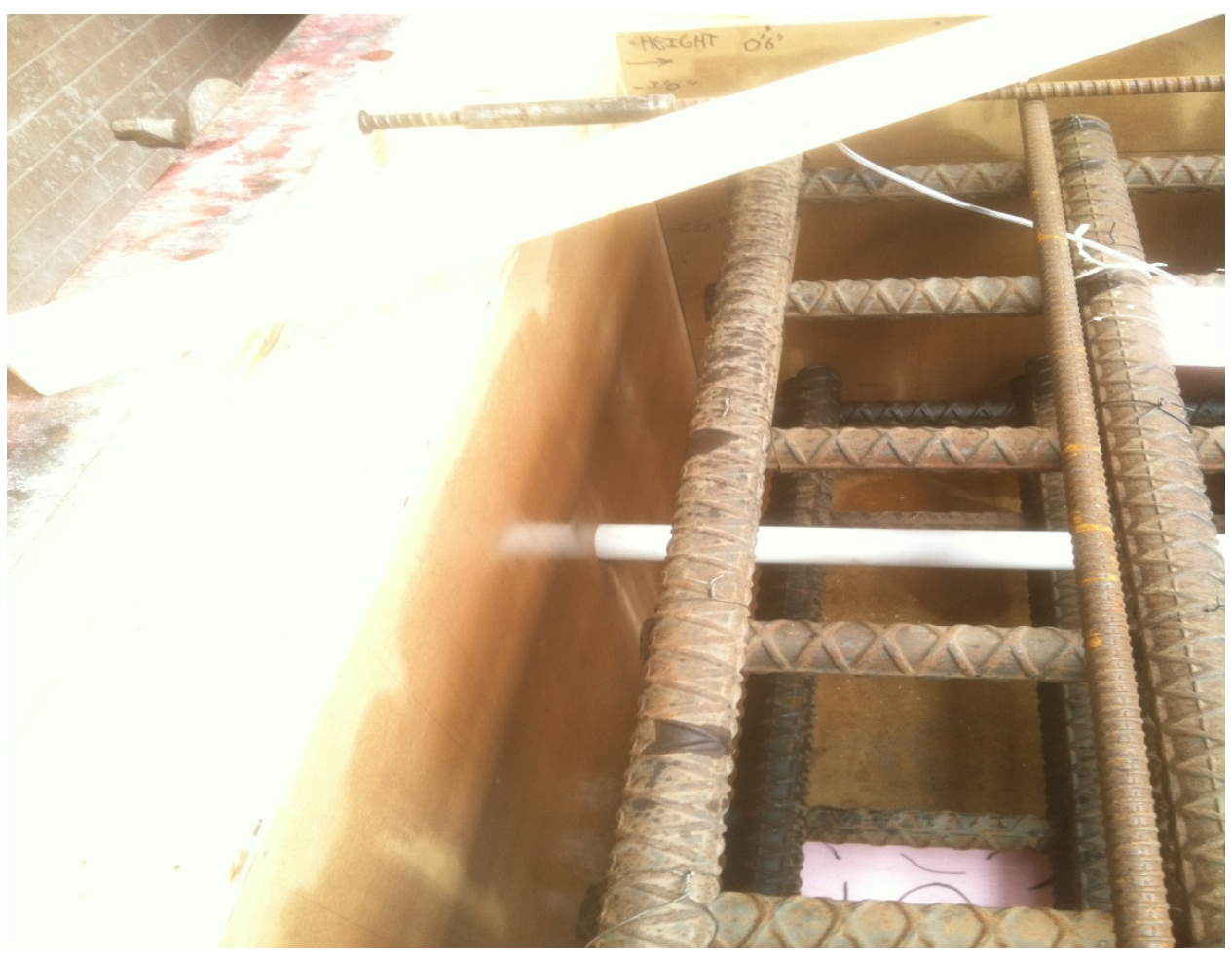

Fig. A.92. D10 height 1.5bars $1 \mathrm{ft} \times 305 \mathrm{~mm}$. 


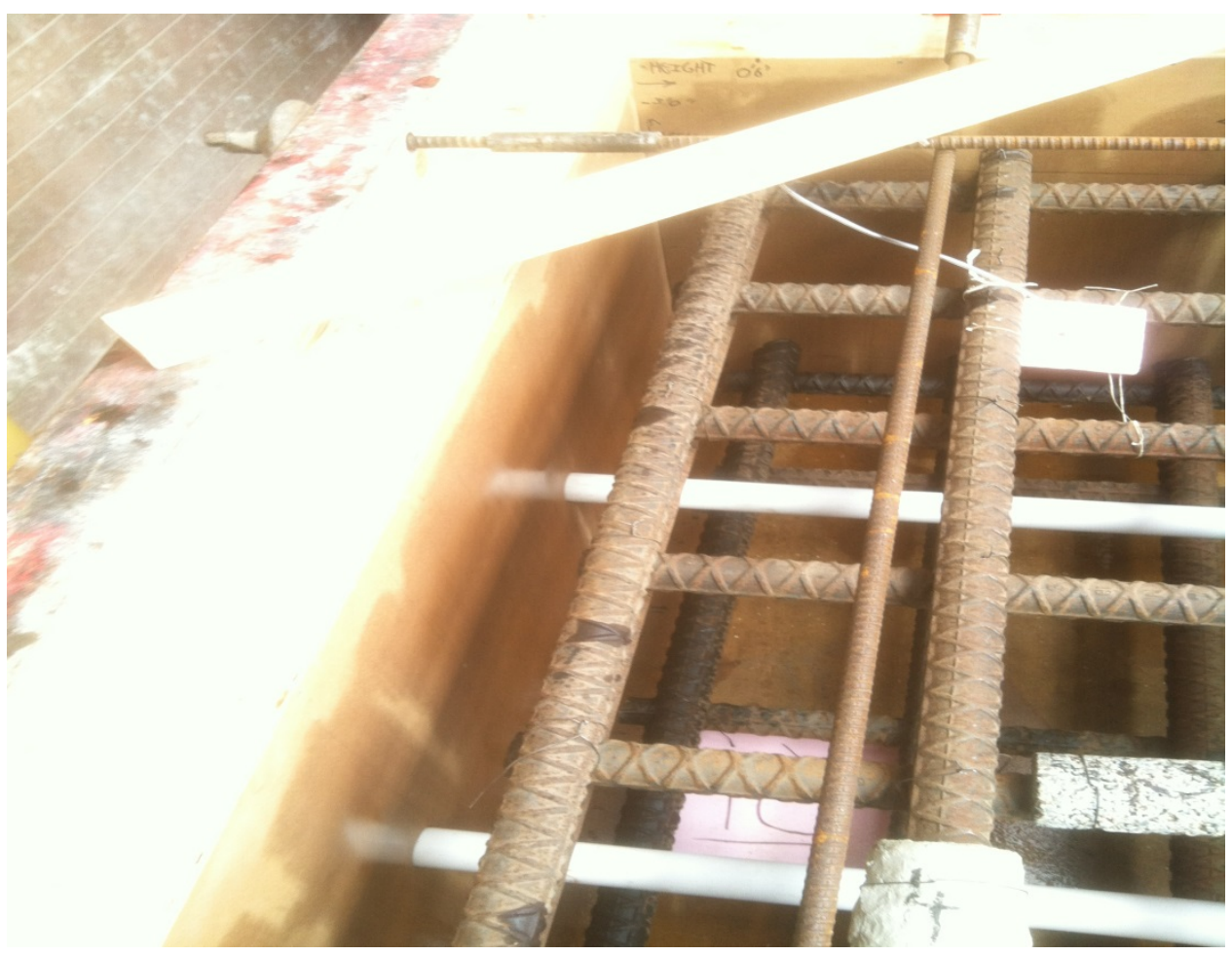

Fig. A.93. D10 length $4.5 \mathrm{bars} 4 \mathrm{ft} \times 1219 \mathrm{~mm}$.

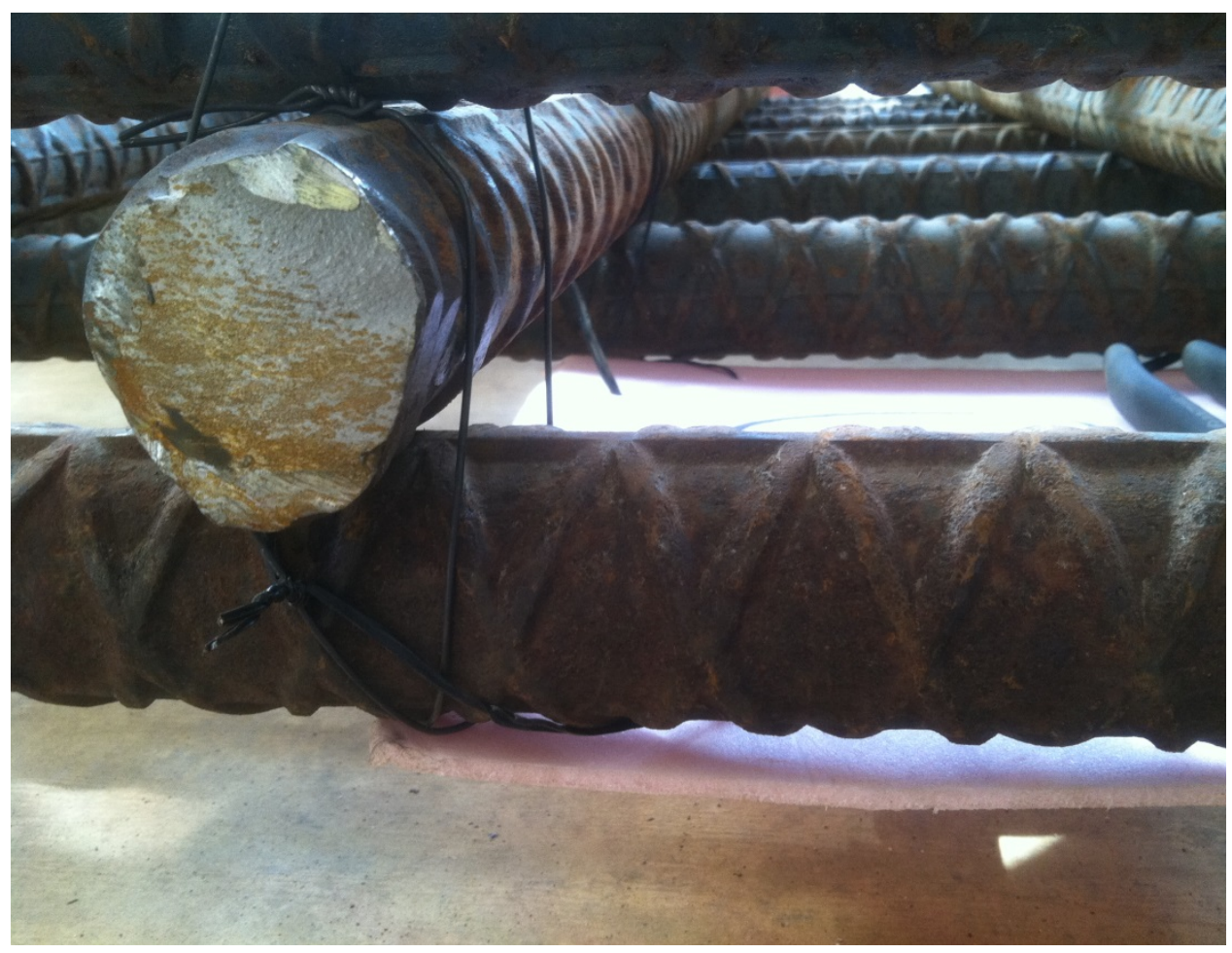

Fig. A.94. D10 R-depth bottom of bottom bar $908 \mathrm{~mm}$. 


\begin{tabular}{|c|c|c|}
\hline \multicolumn{3}{|c|}{ DEFECT TABLE } \\
\hline ID NUMBER & DESCRIPTION & LABE \\
\hline D1 & $\begin{array}{l}\text { POROUS HALF CYINDER } \\
\text { (NO COVER) }\end{array}$ & \\
\hline D2 & $\begin{array}{l}\text { POROUS HALF CYINDER } \\
\text { (COVER) }\end{array}$ & \\
\hline 03 & $\begin{array}{c}\text { POROUS HALF CYINDER } \\
\text { (NO COVER) }\end{array}$ & \\
\hline 04 & $\begin{array}{l}\text { POROUS HALF CYINDER } \\
\text { (COVER) }\end{array}$ & \\
\hline D5 & $\begin{array}{c}\text { POROOS HALF CYUNDER } \\
\text { (COVER \& CRACK) }\end{array}$ & \\
\hline D6 & PVC & \\
\hline 07 & PVC & \\
\hline D8 & $\begin{array}{l}\text { DISSOLUNG STYROFOAM } \\
\text { (THICK) }\end{array}$ & \\
\hline Dg & STRROFOAM (THICK) & \\
\hline 010 & STYROFOAM (THIN) & \\
\hline D11 & PLEXGLASS & \\
\hline D12 & $\begin{array}{l}\text { DISSOLYNG STRROFOAM } \\
\text { (MEDUUM) }\end{array}$ & \\
\hline 013 & STRROFOAM (MEDOUM) & \\
\hline 014 & PLEXGGLASS & \\
\hline D15 & $\begin{array}{l}\text { DISSOLUNG STYROFOAM } \\
\text { (THIN) }\end{array}$ & \\
\hline 016 & LUMBER $(2 \times 4)$ & \\
\hline 017 & GLoves & \\
\hline 018 & $\begin{array}{l}\text { DEBONO DUCT TAPE } \\
\text { (ONE LAYER) }\end{array}$ & \\
\hline 019 & $\begin{array}{l}\text { DEBONO DUCT TAPE } \\
\text { (MULT-LAYRR) }\end{array}$ & \\
\hline 020 & MOUNG REBAR & \\
\hline
\end{tabular}

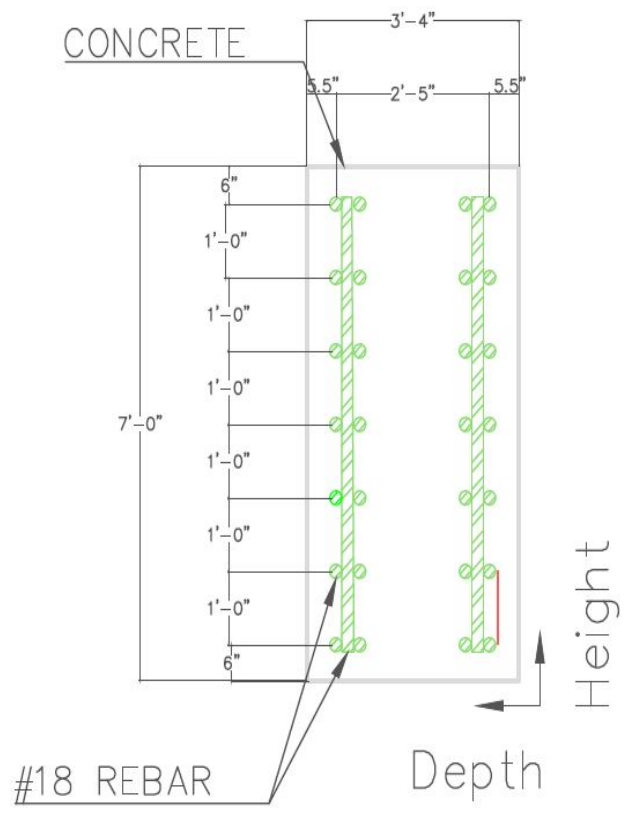

Fig. A.95. D10 height by depth.

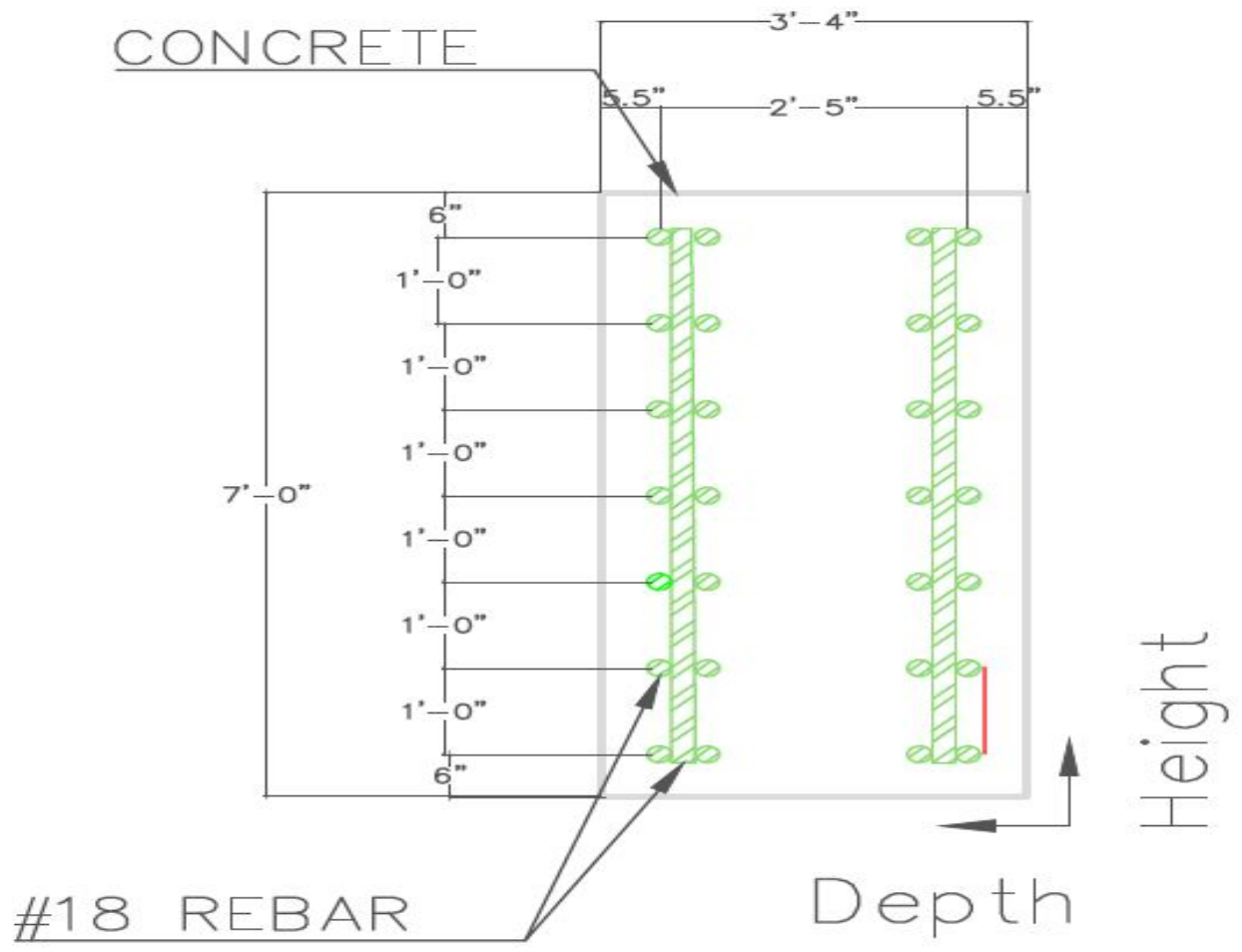

Fig. A.96. D10 height by depth NL. 


\begin{tabular}{|c|c|c|}
\hline \multicolumn{3}{|c|}{ OFECCT TRQLE } \\
\hline D Nevars & DEsctepton & เล9ก \\
\hline or & $\begin{array}{l}\text { PCROS HNG CUUNDR } \\
\text { (No CONGR) }\end{array}$ & \\
\hline 02 & $\begin{array}{l}\text { POROWS HAF EVLNOER } \\
\text { (COVER) }\end{array}$ & \\
\hline 03 & 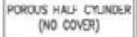 & \\
\hline of & 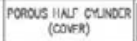 & \\
\hline D5 & 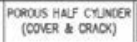 & \\
\hline$\infty$ & $\mathrm{pre}$ & \\
\hline 07 & PXC & \\
\hline$D B$ & 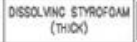 & \\
\hline$\infty$ & sincoroun (liex) & \\
\hline 010 & streorow (nak) & \\
\hline on & P.Deranss & \\
\hline 012 & 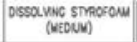 & \\
\hline Dis & Simoroum (NeDew) & \\
\hline 014 & provenass & \\
\hline 015 & $\begin{array}{c}\text { Dossaviwe smoronu } \\
\text { (TheN) }\end{array}$ & \\
\hline 016 & weor $(2 x 4)$ & \\
\hline 017 & Govers & \\
\hline 018 & 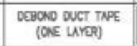 & \\
\hline 019 & 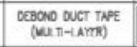 & \\
\hline 020 & NONNO RCONR & \\
\hline
\end{tabular}

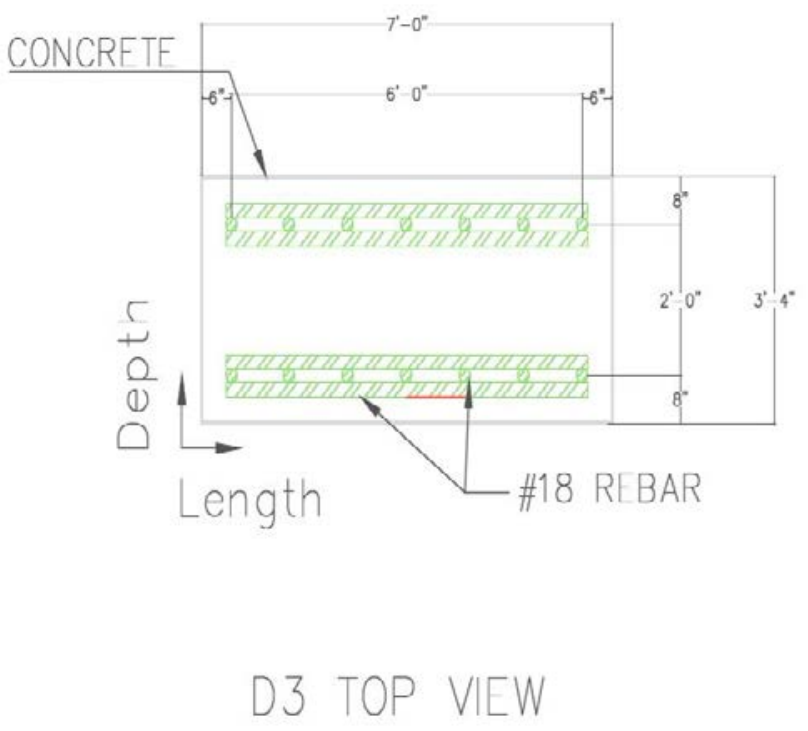

Fig. A.97. D10 length by depth.

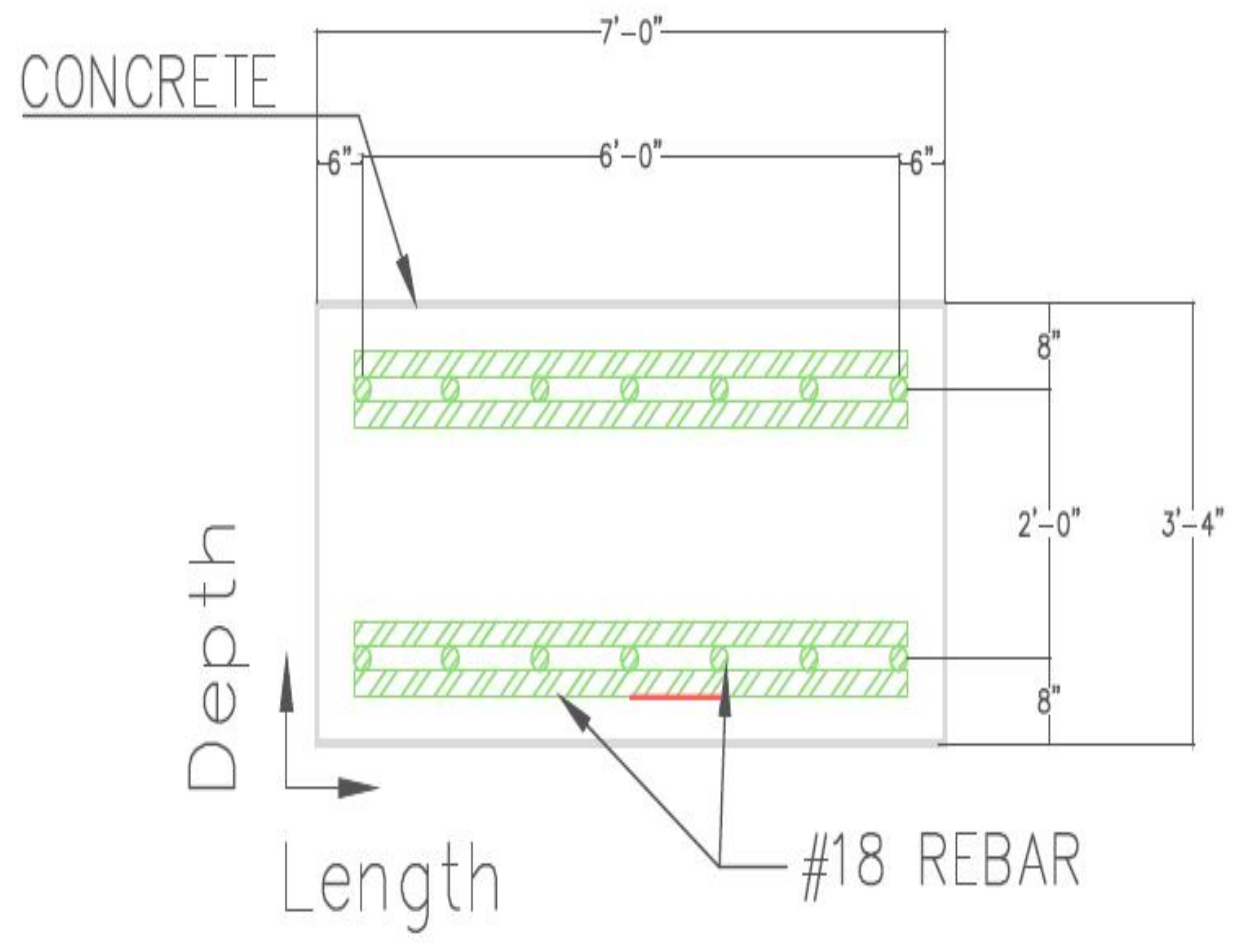

Fig. A.98. D10 length by depth NL. 


\begin{tabular}{|c|c|c|}
\hline \multicolumn{3}{|c|}{ offect theat } \\
\hline D Mvact & orsognton & wan \\
\hline or & 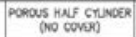 & \\
\hline 02 & 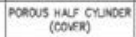 & \\
\hline as & 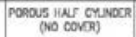 & \\
\hline 04 & $\begin{array}{l}\text { POHOWS HNE CTNOCER } \\
\text { (CONG) }\end{array}$ & \\
\hline os & 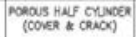 & \\
\hline or & $\mathrm{PWC}$ & \\
\hline or & sce & \\
\hline$\infty$ & 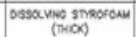 & \\
\hline$\infty$ & strotorew (IMTX) & \\
\hline 010 & strecoum (them) & \\
\hline m & pionacss & \\
\hline 012 & 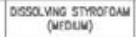 & \\
\hline D13 & Strocrow (uedow) & \\
\hline 0,4 & Proxouss & \\
\hline 015 & \begin{tabular}{|c|} 
ossa ving smorocoum \\
(7Tin)
\end{tabular} & \\
\hline 016 & unact $(2 x t)$ & \\
\hline 017 & coves & \\
\hline ols & 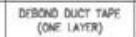 & \\
\hline 010 & 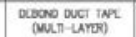 & \\
\hline ono & 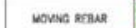 & \\
\hline
\end{tabular}

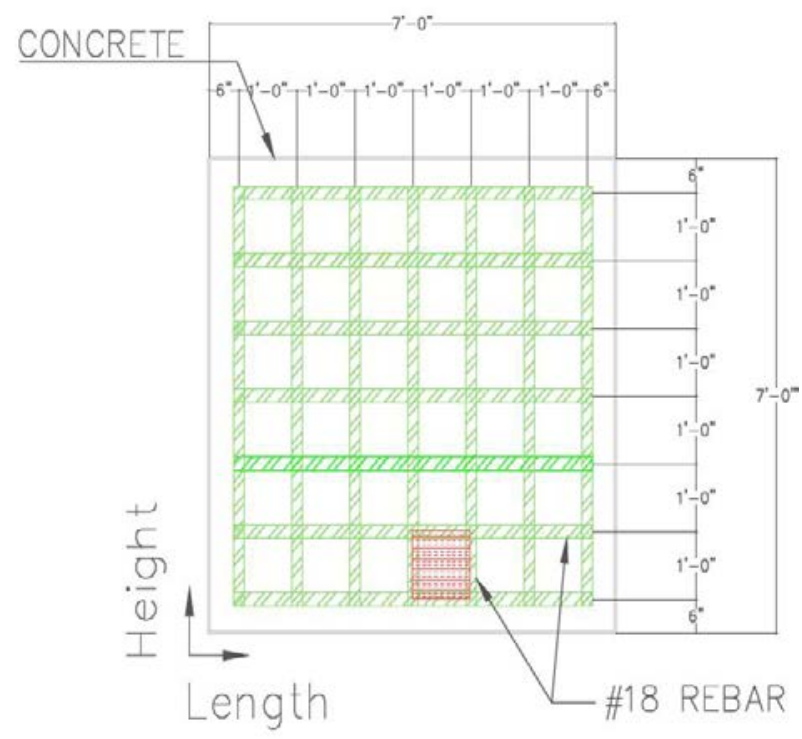

SIDE VIEW

Fig. A.99. D10 Length by height.

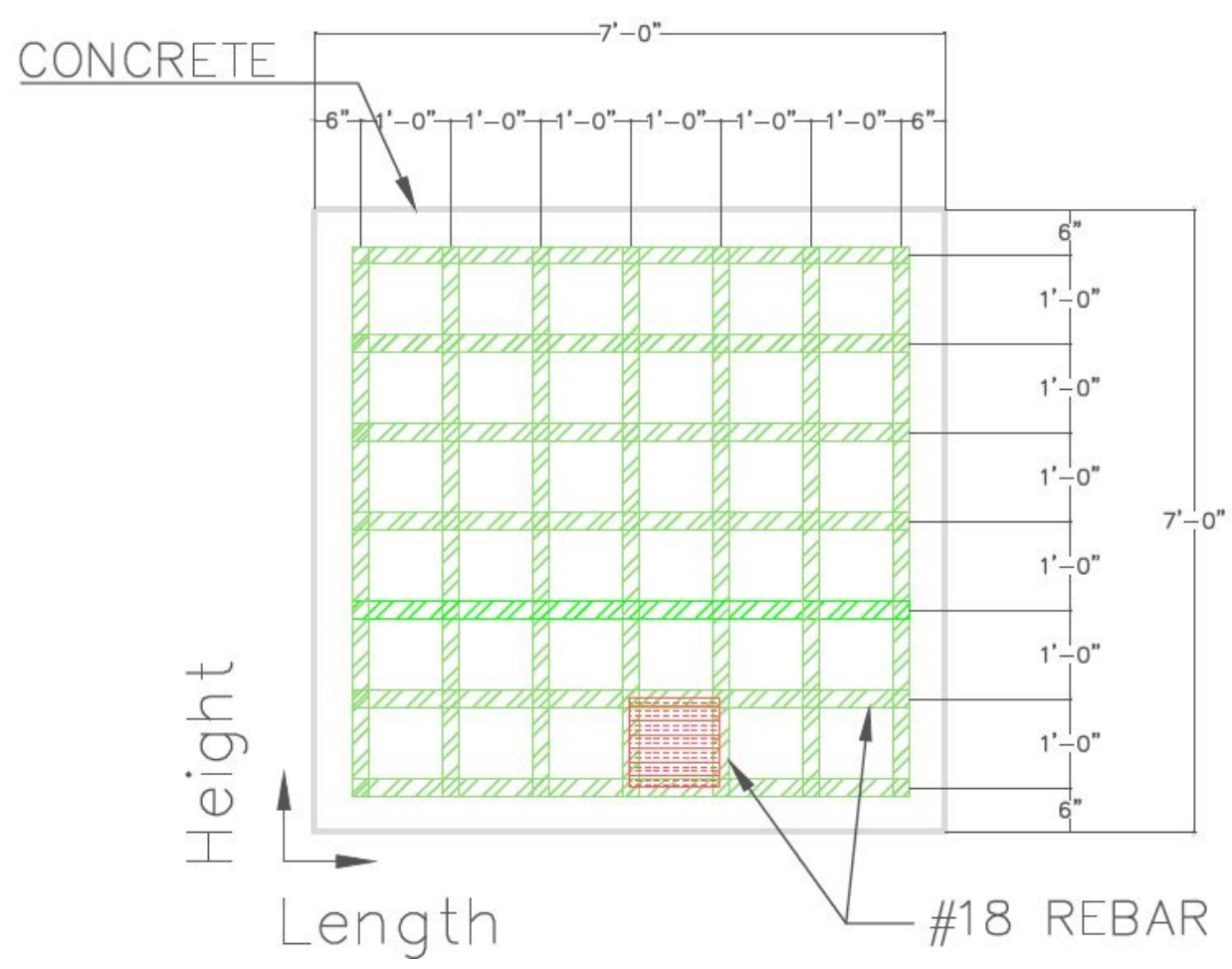

Fig. A.100. D10 Length by height NL. 


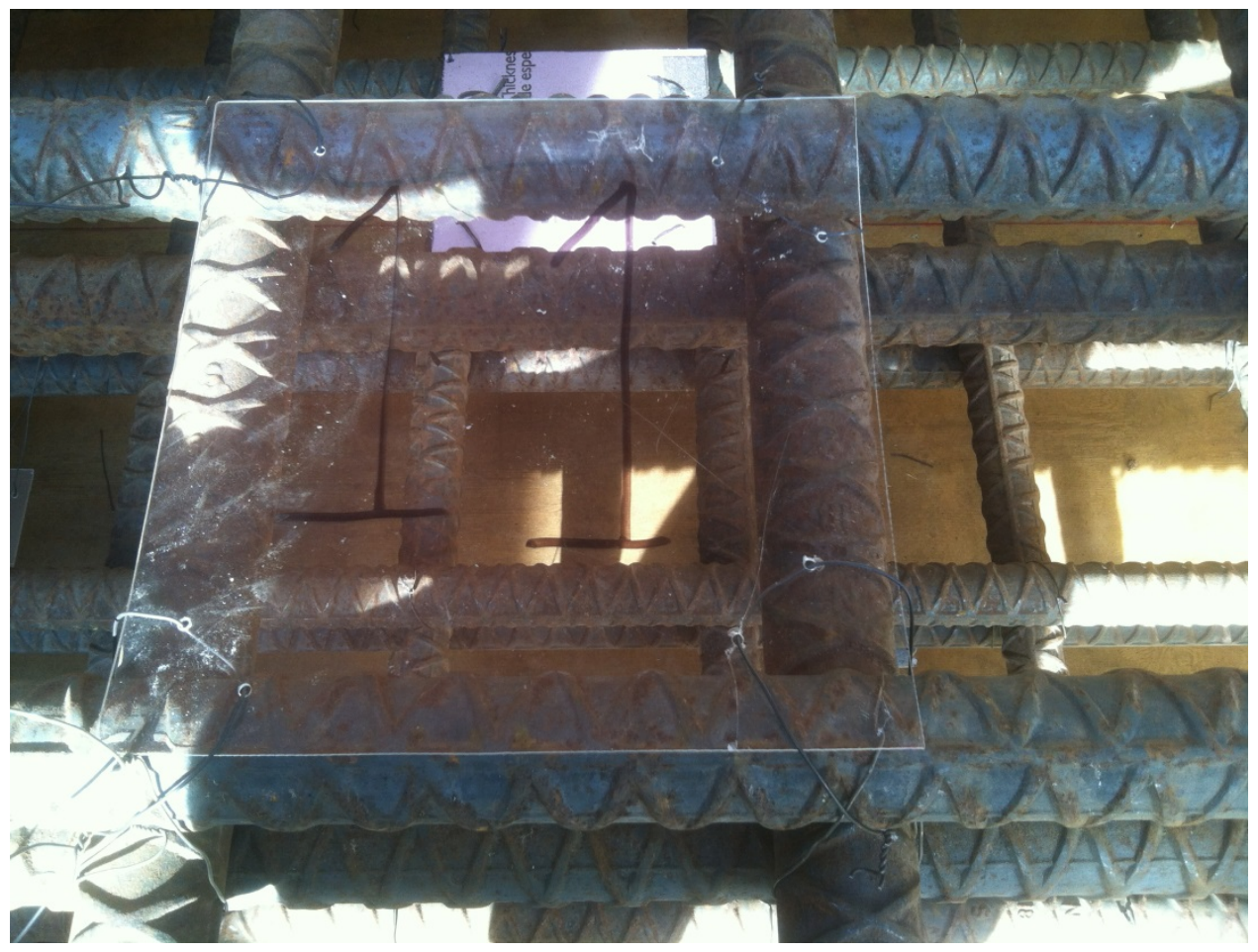

Fig. A.101. D11 close-up.

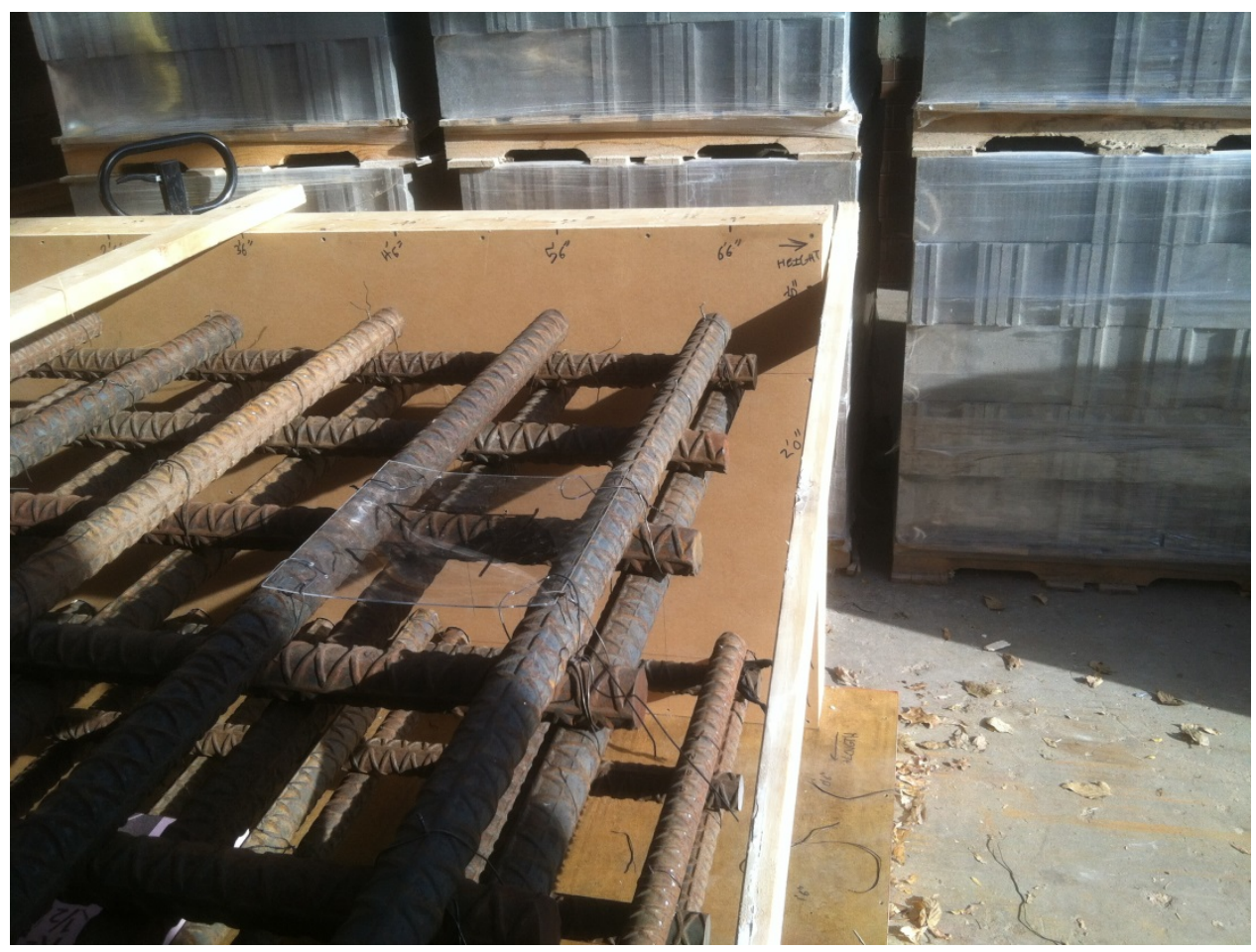

Fig. A.102. D11 height 6.6 bars $6 \mathrm{ft} \times 1829 \mathrm{~mm}$. 


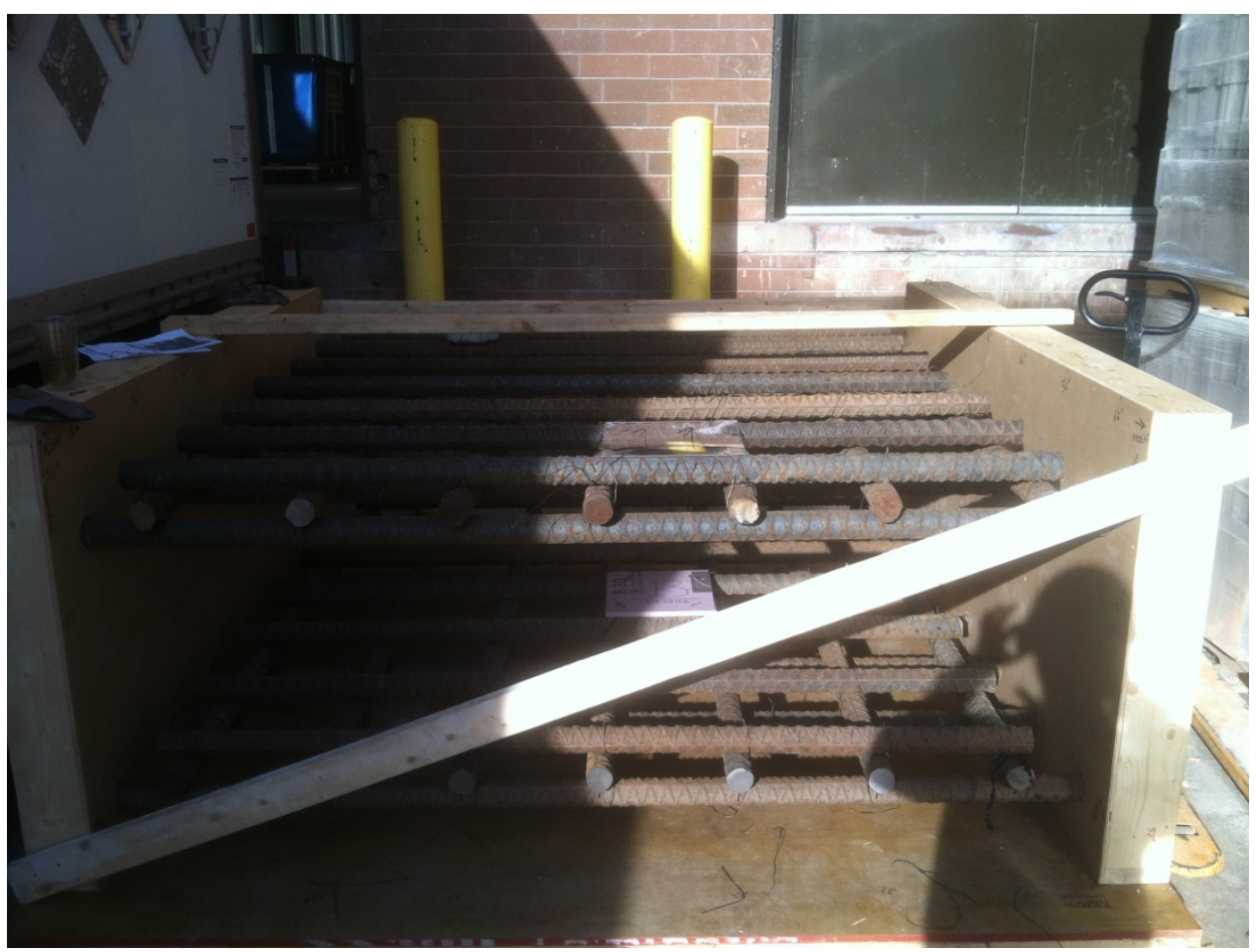

Fig. A.103. D11 length 3.5 bars 3ft $914 \mathrm{~mm}$.

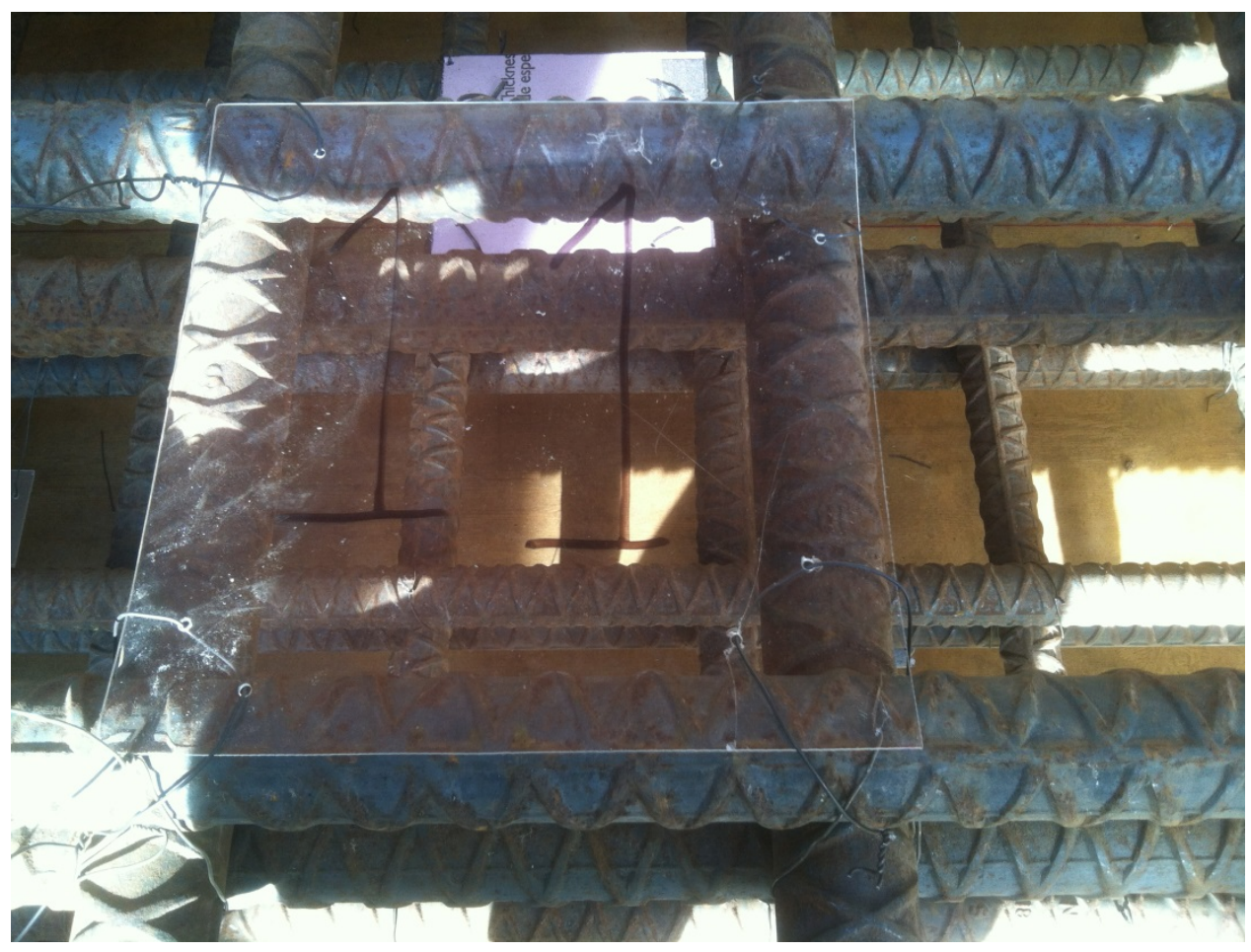

Fig. A.104. D11 R-depthTopof Top Bar 111mm. 


\begin{tabular}{|c|c|c|}
\hline \multicolumn{3}{|c|}{ DEEECT TABLE } \\
\hline ID NUMBER & DESCRPPTION & LABE \\
\hline D1 & $\begin{array}{l}\text { POROUS HALF CYNNDER } \\
\text { (NO COVER) }\end{array}$ & \\
\hline D2 & $\begin{array}{l}\text { POROUS HALF CYINDER } \\
\text { (COVER) }\end{array}$ & \\
\hline 03 & $\begin{array}{l}\text { POROUS HALF CYINDER } \\
\text { (NO COVER) }\end{array}$ & \\
\hline 04 & $\begin{array}{l}\text { POROUS HALF CYINDER } \\
\text { (COVER) }\end{array}$ & \\
\hline D5 & $\begin{array}{l}\text { POROUS HALF CYNNDER } \\
\text { (COVER \& CRACK) }\end{array}$ & \\
\hline D6 & PVC & \\
\hline 07 & PVC & \\
\hline D8 & $\begin{array}{l}\text { DISSOLUNG STRROFOAM } \\
\text { (THICK) }\end{array}$ & \\
\hline D9 & STYROFOAM (THICK) & \\
\hline 010 & STYROFOAM (THIN) & \\
\hline D11 & PLEXGLASS & \\
\hline 012 & $\begin{array}{l}\text { DISSOLUNG STROFOAM } \\
\text { (MEDUMM) }\end{array}$ & \\
\hline 013 & STIROFOAM (MEDIUM) & \\
\hline 014 & PLEXGLASS & \\
\hline 015 & $\underset{\text { (THIN) }}{\text { DISSOLUNG STMOAM }}$ & \\
\hline D16 & LUMBER $(2 \times 4)$ & \\
\hline 017 & GLoves & \\
\hline 018 & $\begin{array}{l}\text { DEBOND DUCT TAPE } \\
\text { (ONE LAYER) }\end{array}$ & \\
\hline$D 19$ & $\begin{array}{l}\text { DEBOND DUCT TAPE } \\
\text { (MULT-LAYRR) }\end{array}$ & \\
\hline 020 & MOUNG REBAR & \\
\hline
\end{tabular}

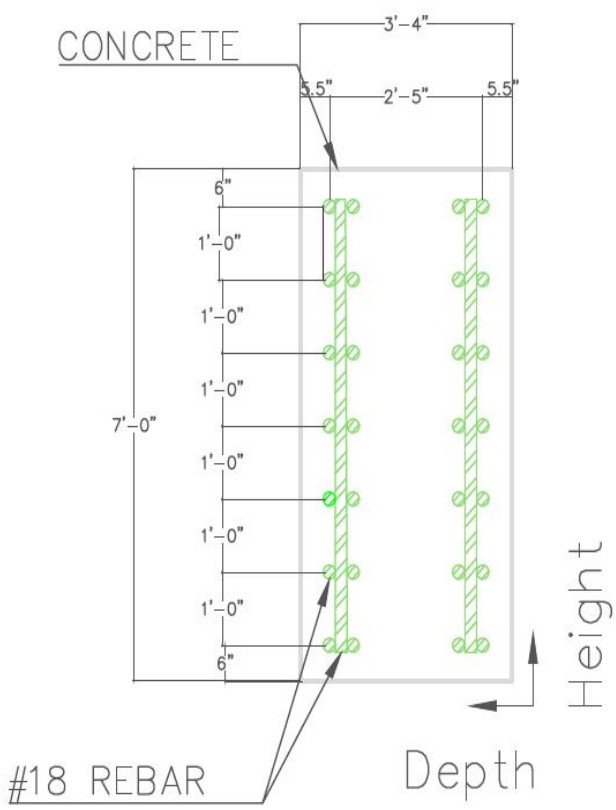

Fig. A.105. D11 height by depth.

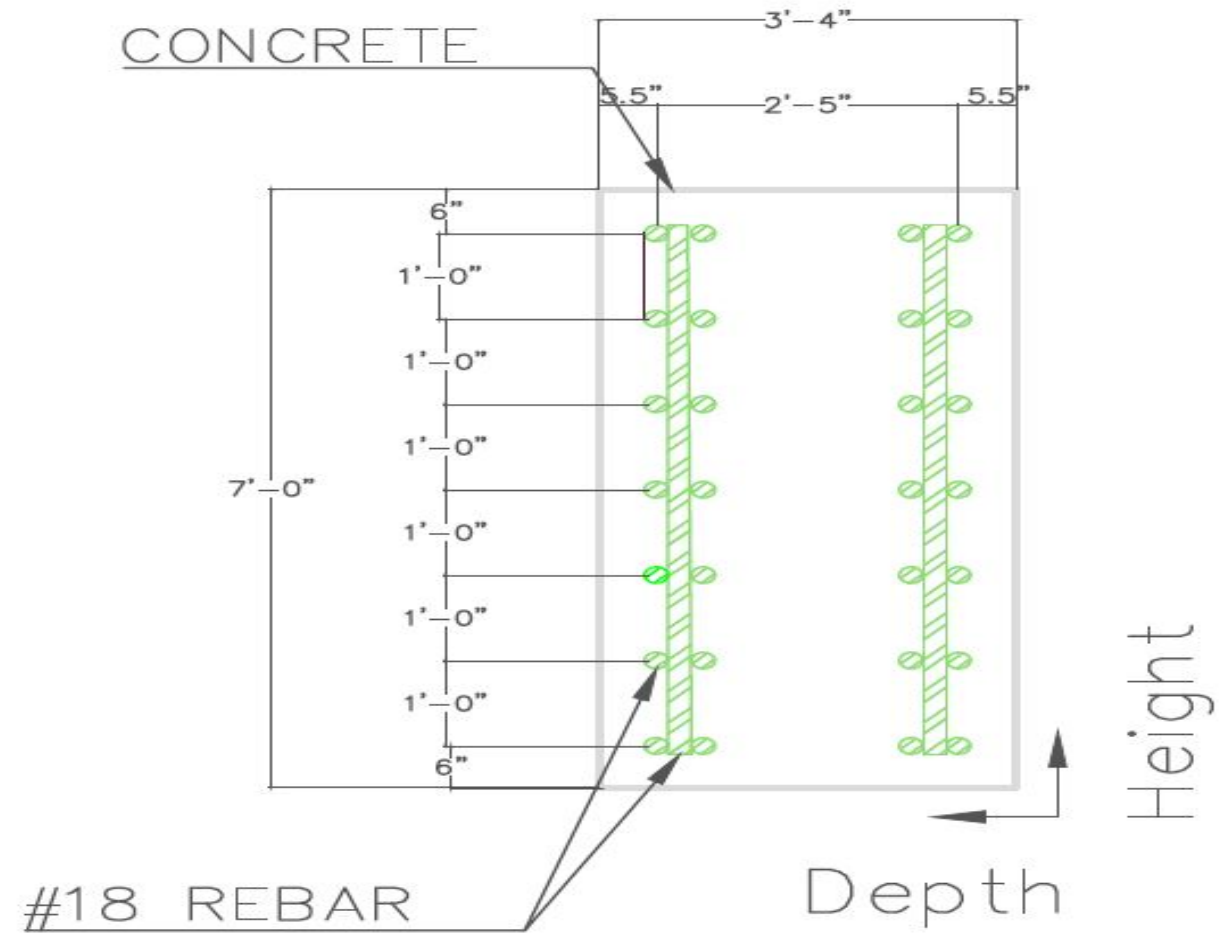

Fig. A.106. D11 height by depth NL. 


\begin{tabular}{|c|c|c|}
\hline \multicolumn{3}{|c|}{ DEFFET TAREF } \\
\hline o nueser & OESCRPTION & UBe. \\
\hline or & 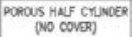 & \\
\hline$\infty$ & $\begin{array}{l}\text { POROS HNF GLUNOER } \\
\text { (CONGR) }\end{array}$ & \\
\hline os & 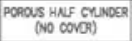 & \\
\hline or & $\begin{array}{l}\text { Produs HNF Chivore } \\
\text { (COVER) }\end{array}$ & \\
\hline os & 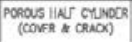 & \\
\hline$\infty$ & $\mathrm{PC}$ & \\
\hline 07 & PCC & \\
\hline D & 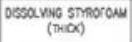 & \\
\hline$\infty$ & streorous (Tion) & \\
\hline 010 & SInerow (IHA) & \\
\hline ont & procauss & \\
\hline 012 & 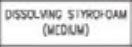 & \\
\hline בוב & STmoroun (NEDUN) & \\
\hline 014 & novanss & \\
\hline 015 & $\begin{array}{c}\text { Oassoung simorown } \\
\text { (THN) }\end{array}$ & \\
\hline 016 & unere (2xc) & \\
\hline 017 & goves & \\
\hline 018 & 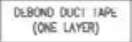 & \\
\hline 019 & 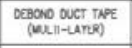 & \\
\hline 020 & NOWNG REBAR & \\
\hline
\end{tabular}

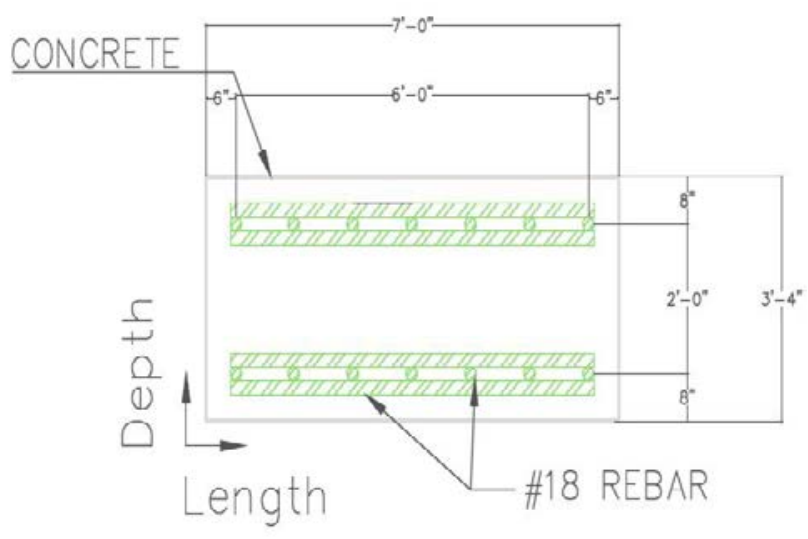

D3 TOP VIEW

Fig. A.107. D11 length by depth.

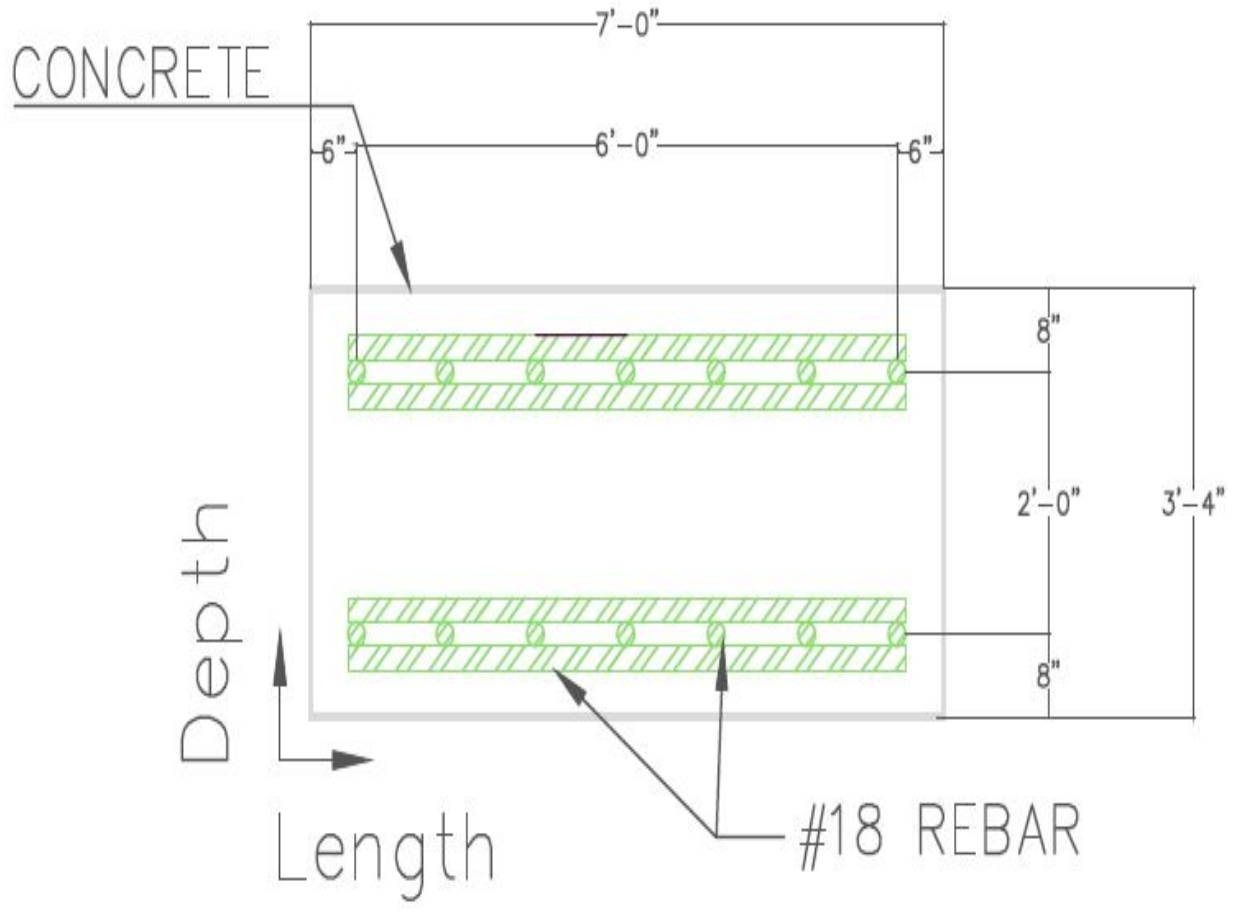

Fig. A.108. D11 length by depth NL. 


\begin{tabular}{|c|c|c|}
\hline \multicolumn{3}{|c|}{ CEECT Thalf } \\
\hline D nuver & ossseptor & LAB. \\
\hline a & 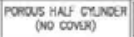 & \\
\hline D2 & 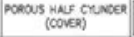 & \\
\hline as & 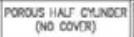 & \\
\hline$\infty$ & 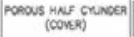 & \\
\hline os & 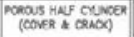 & \\
\hline$\infty$ & $P x$ & \\
\hline 07 & $P x$ & \\
\hline De & $\begin{array}{l}\text { nessa vasa smporoum } \\
\text { (Timos) }\end{array}$ & \\
\hline$\infty$ & STrocoun (TMOC) & \\
\hline ato & smearow (TiM) & \\
\hline an & provouss & 世m \\
\hline 012 & 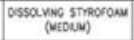 & \\
\hline Dis & simorowu (NeDUN) & \\
\hline 014 & Rowouss & \\
\hline Dos & $\begin{array}{c}\text { cossa ving smescoun } \\
\text { (TMN) }\end{array}$ & \\
\hline 016 & urear (2xt) & \\
\hline 017 & aoves & \\
\hline 018 & 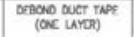 & \\
\hline 019 & 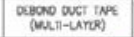 & \\
\hline 020 & Nowvo Rcase & \\
\hline
\end{tabular}

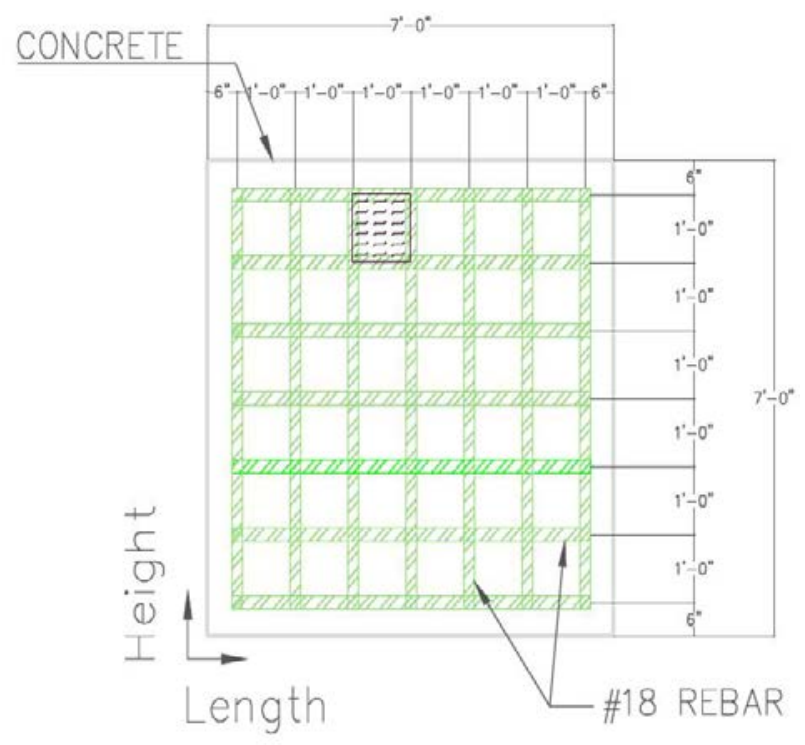

SIDE VIEW

Fig. A.109. D11 length by height.

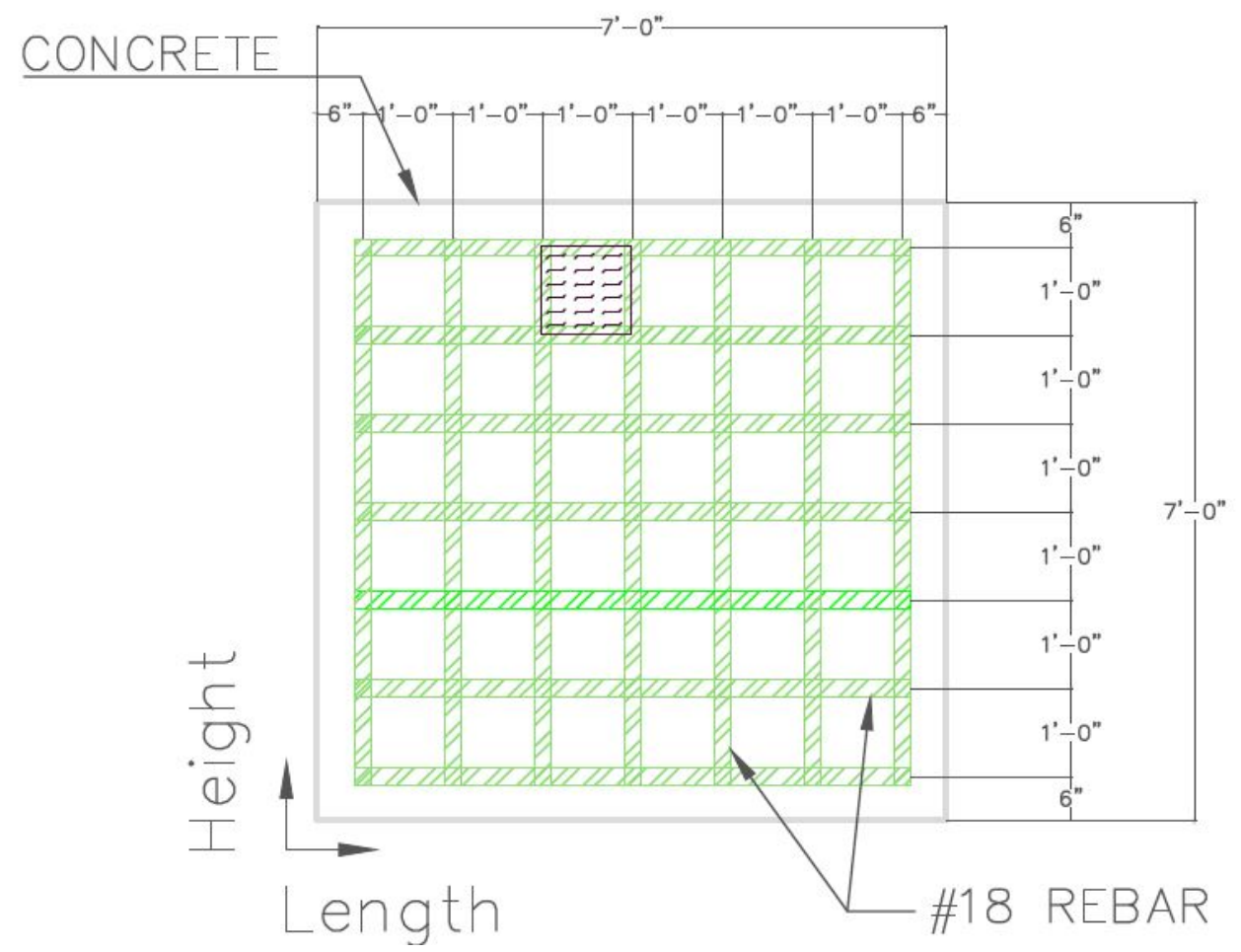

Fig. A.110. D11 length by height NL. 


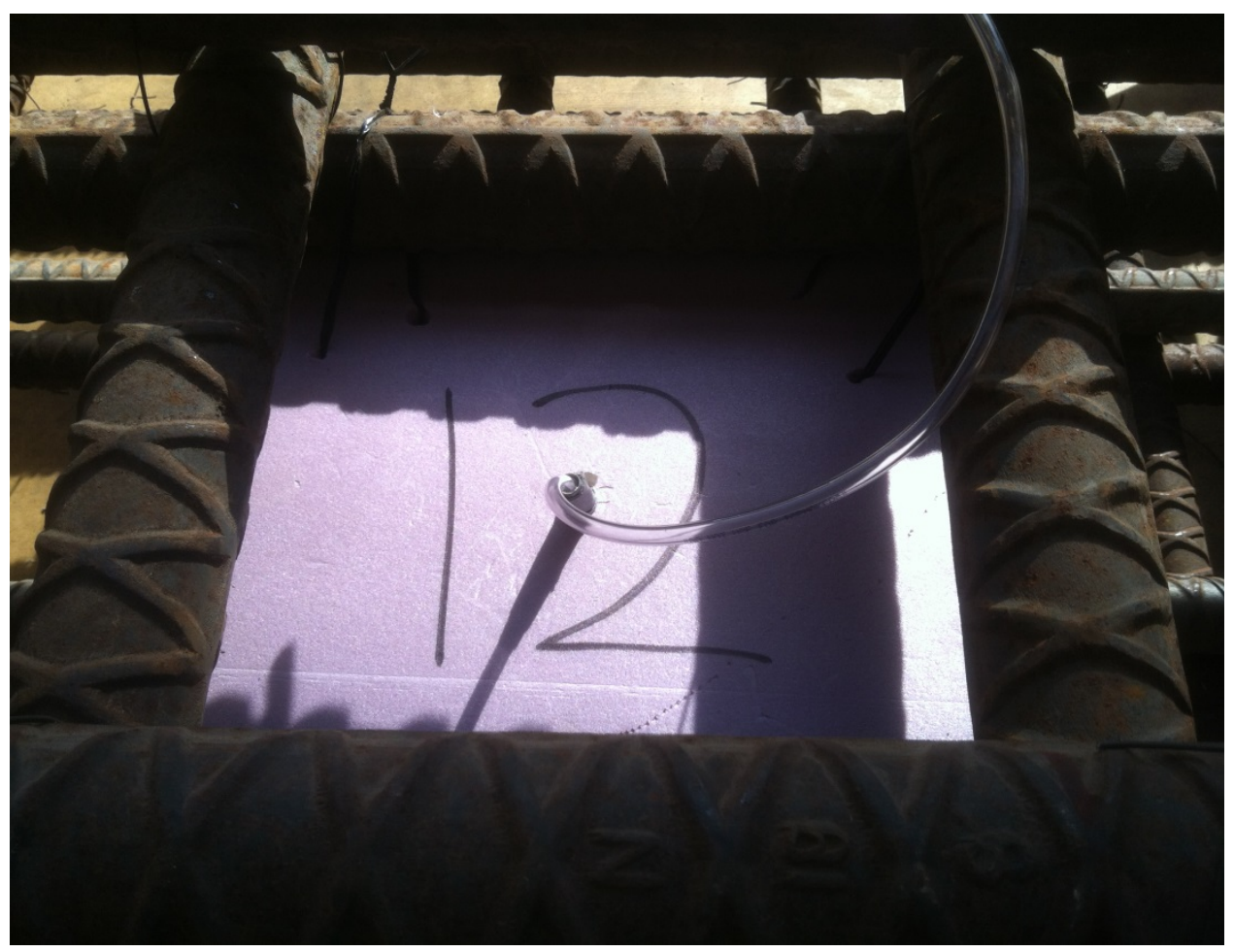

Fig. A.111. D12 close-up.

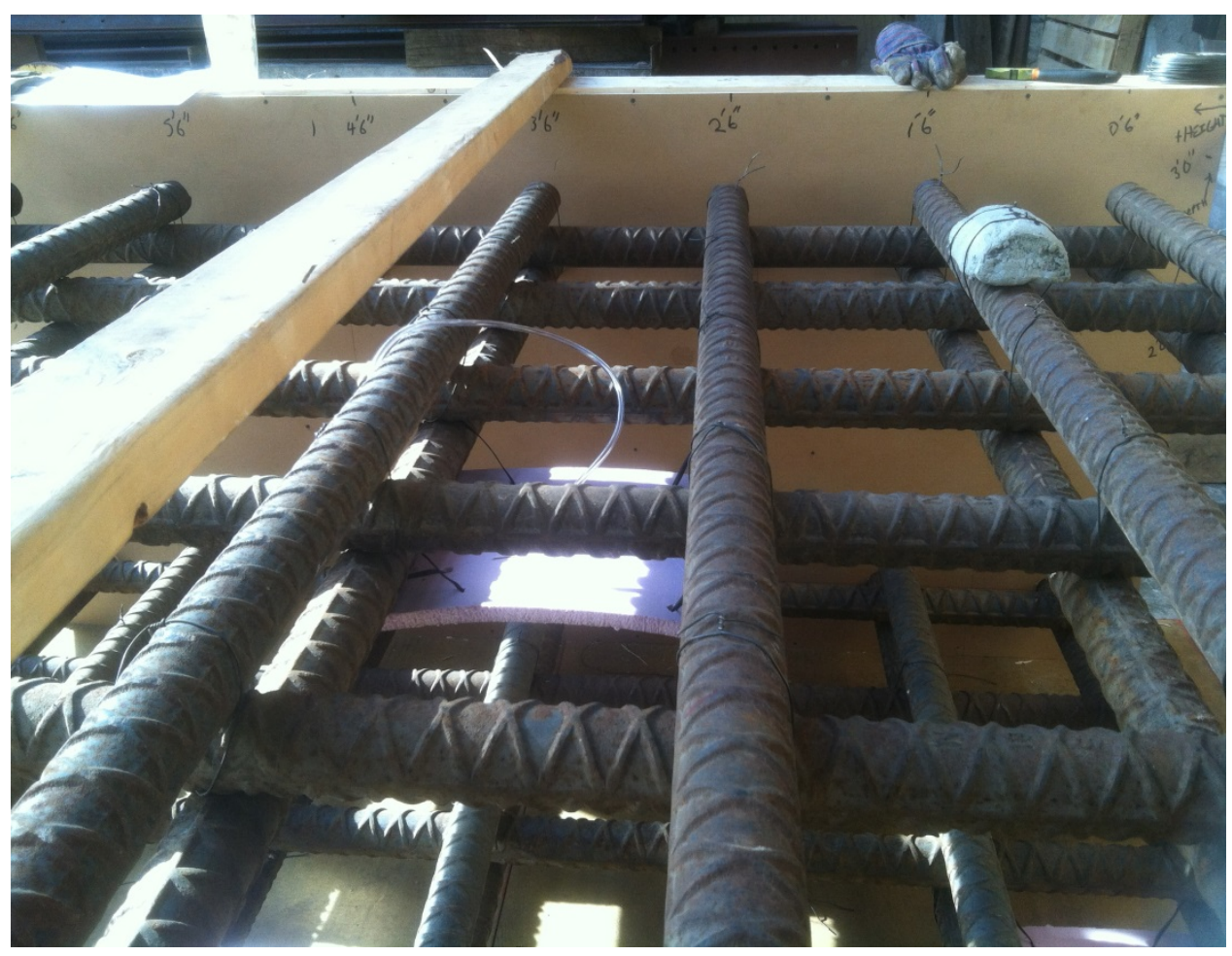

Fig. A.112. D12 Height 3.5bars 3ft $\times$ 914mm. 


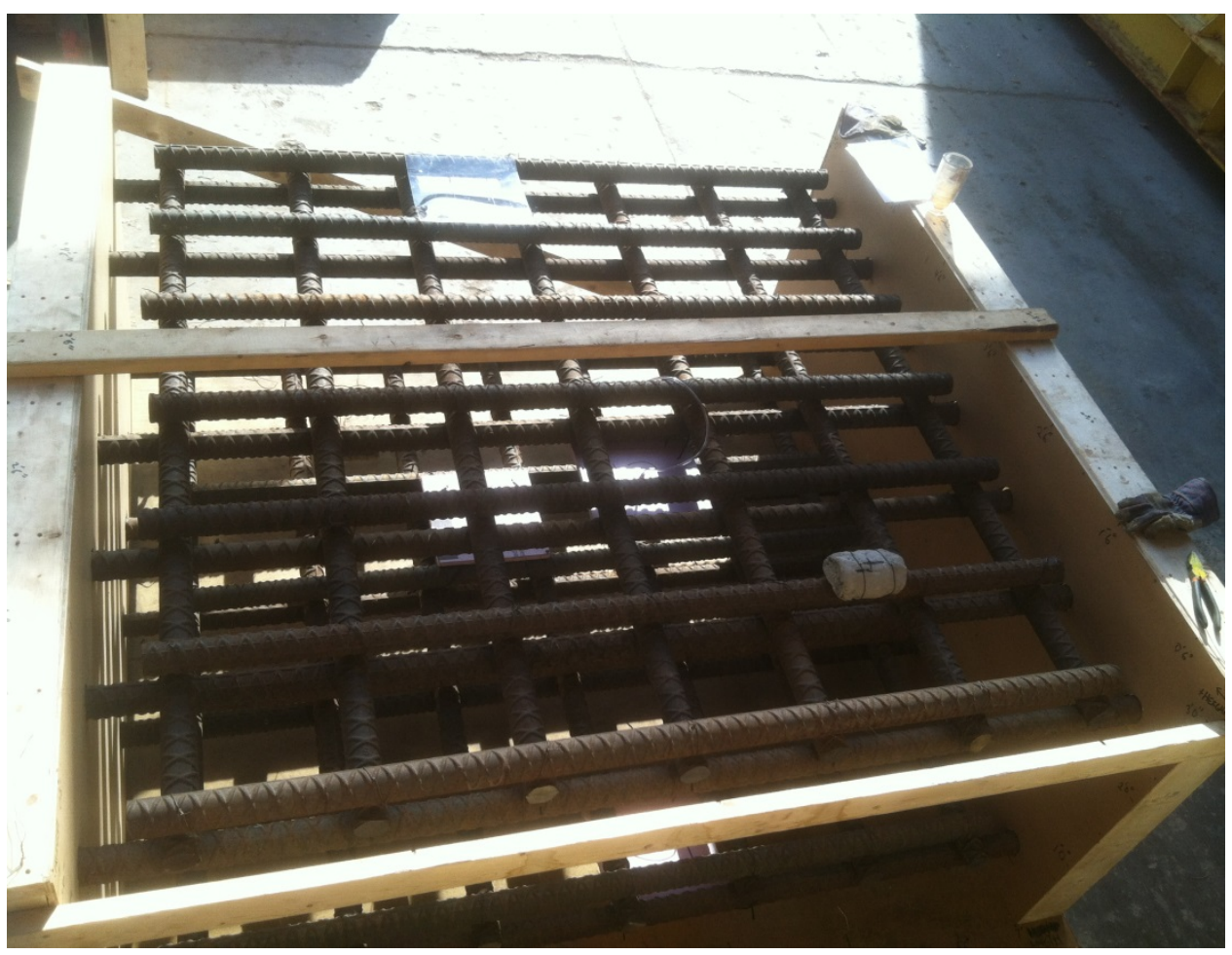

Fig. A.113. D12 Length 4.5bars 4ft 1219mm.

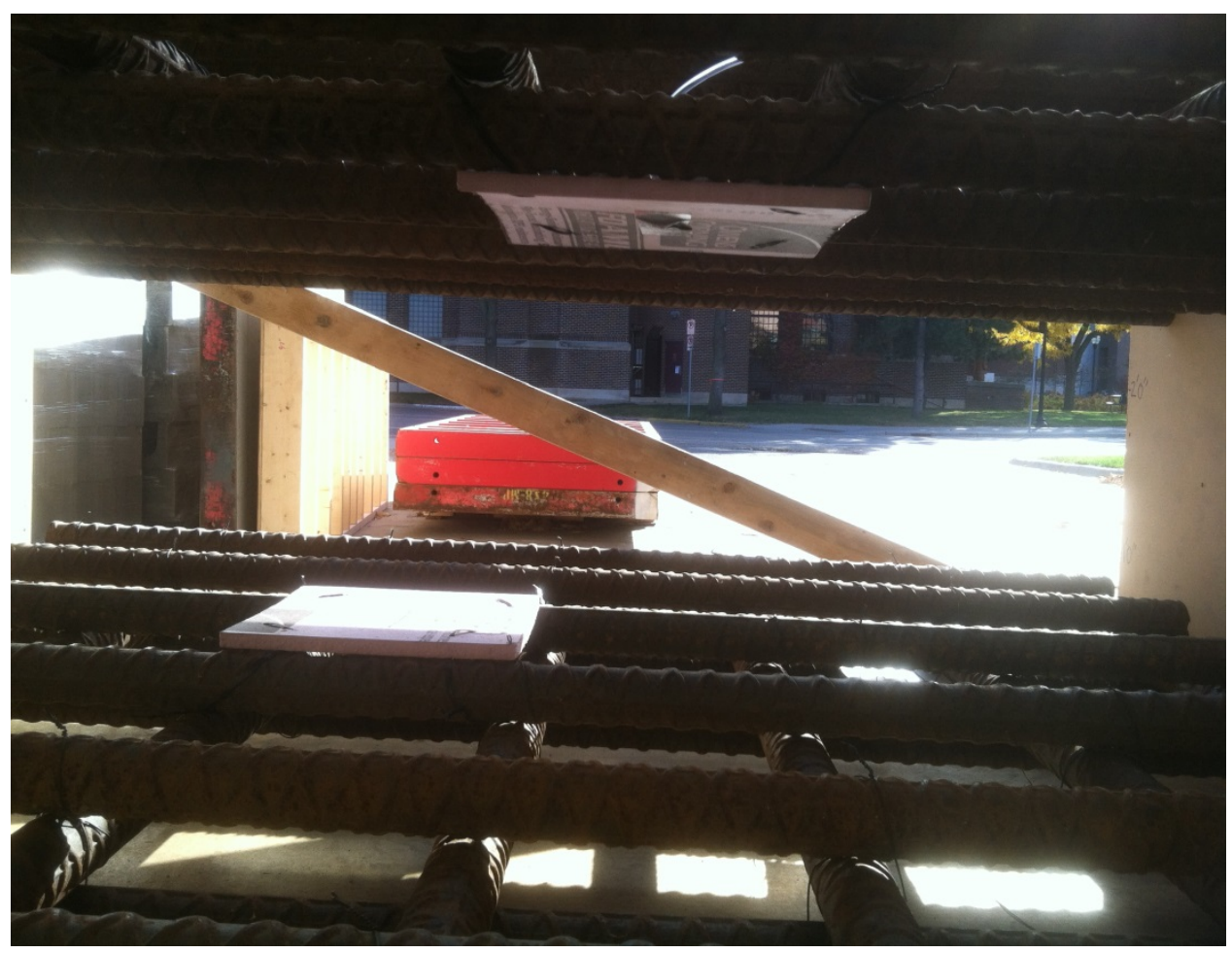

Fig. A.114. D12 R-depth bottom of 3rd Bar 283mm. 


\begin{tabular}{|c|c|c|}
\hline \multicolumn{3}{|c|}{ DEFECT TABLE } \\
\hline ID NUMBER & DESCRIPTION & САВЕ \\
\hline Dr & $\begin{array}{l}\text { POROUS HALF CYINDER } \\
\text { (NO COVER) }\end{array}$ & \\
\hline 02 & $\begin{array}{l}\text { POROUS HALF CYINDER } \\
\text { (COVER) }\end{array}$ & \\
\hline 03 & $\begin{array}{l}\text { POROUS HALF CYINOER } \\
\text { (NO COVER) }\end{array}$ & \\
\hline 04 & $\begin{array}{l}\text { POROUS HALF CYINOER } \\
\text { (COVER) }\end{array}$ & \\
\hline DS & $\begin{array}{c}\text { POROUS HALF CYINDER } \\
\text { (COVER \& CRACK) }\end{array}$ & \\
\hline D6 & PVC & \\
\hline 07 & PVC & \\
\hline DB & $\begin{array}{c}\text { DISSOLUNG STYROFOAM } \\
\text { (THICK) }\end{array}$ & \\
\hline 09 & STTROFOAM (THICK) & \\
\hline 010 & STYROFOAM (THIN) & \\
\hline 011 & PLEXGLASS & \\
\hline 012 & $\begin{array}{c}\text { DISSOLYNG STRROFOAM } \\
\text { (MEDIUM) }\end{array}$ & \\
\hline 013 & STRROFOAM (MEDUM) & \\
\hline 014 & PLEXGLLASS & \\
\hline 015 & $\begin{array}{l}\text { DISSOLUNG STYROFOAM } \\
\text { (THIN) }\end{array}$ & \\
\hline 016 & LUMBER $(2 \times 4)$ & \\
\hline 017 & GLoves & \\
\hline 018 & $\begin{array}{l}\text { DEBOND DUCT TAPE } \\
\text { (ONE LAYER) }\end{array}$ & \\
\hline 019 & $\begin{array}{l}\text { DEBOND DUCT TAPE } \\
\text { (MULT-LAYER) }\end{array}$ & \\
\hline 020 & MOUNG REBAR & \\
\hline
\end{tabular}

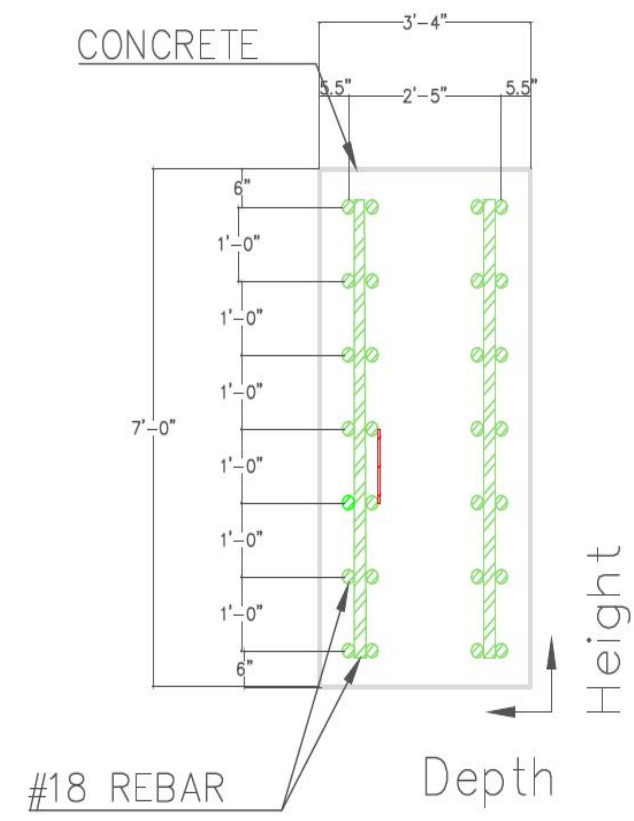

Fig. A.115. D12 height by depth.

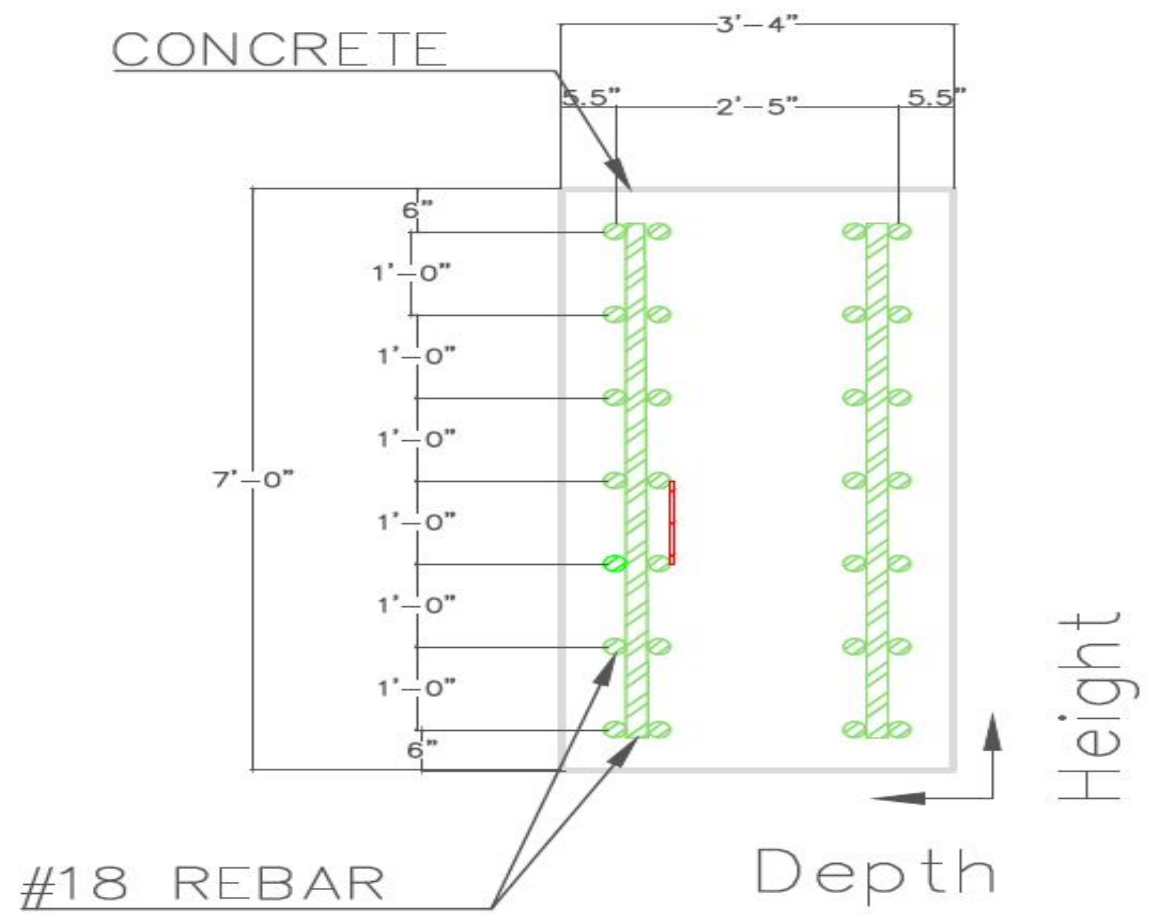

Fig. A.116. D12 height by depth NL. 


\begin{tabular}{|c|c|c|}
\hline \multicolumn{3}{|c|}{ DUCCET TALLC } \\
\hline o nupers & OESSOPTIOH & Lea. \\
\hline or & 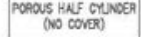 & \\
\hline 02 & 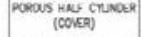 & \\
\hline os & 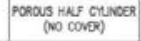 & \\
\hline of & 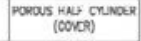 & \\
\hline bo & 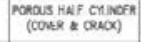 & \\
\hline$\infty$ & PYC & \\
\hline 07 & PVC & \\
\hline$\infty$ & 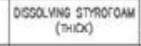 & \\
\hline$\theta$ & STrocolu (THIX) & \\
\hline 010 & strocoum (MN) & \\
\hline ont & Provenss & \\
\hline 012 & 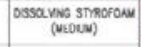 & \\
\hline S13 & sneorow (NeDUN) & \\
\hline 014 & Proxouss & \\
\hline ons & 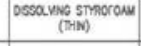 & \\
\hline 016 & uwean (2xt) & \\
\hline 017 & Qoves & \\
\hline 018 & $\begin{array}{l}\text { DCBOBO DUCT TNPE } \\
\text { (OKC LADR) }\end{array}$ & \\
\hline 019 & 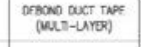 & \\
\hline 020 & WOWNG REGR & \\
\hline
\end{tabular}

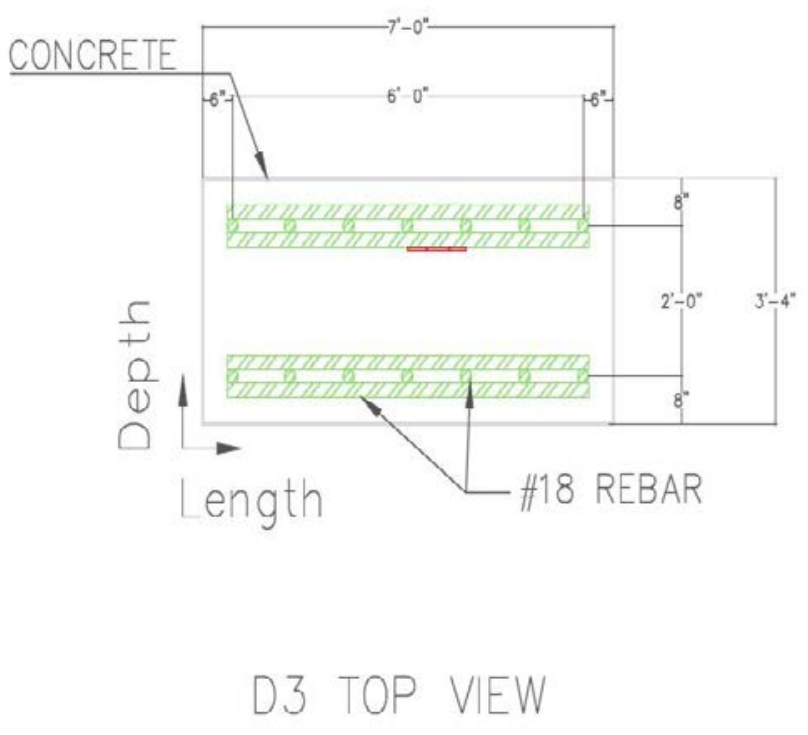

Fig. A.117. D12 length by depth.

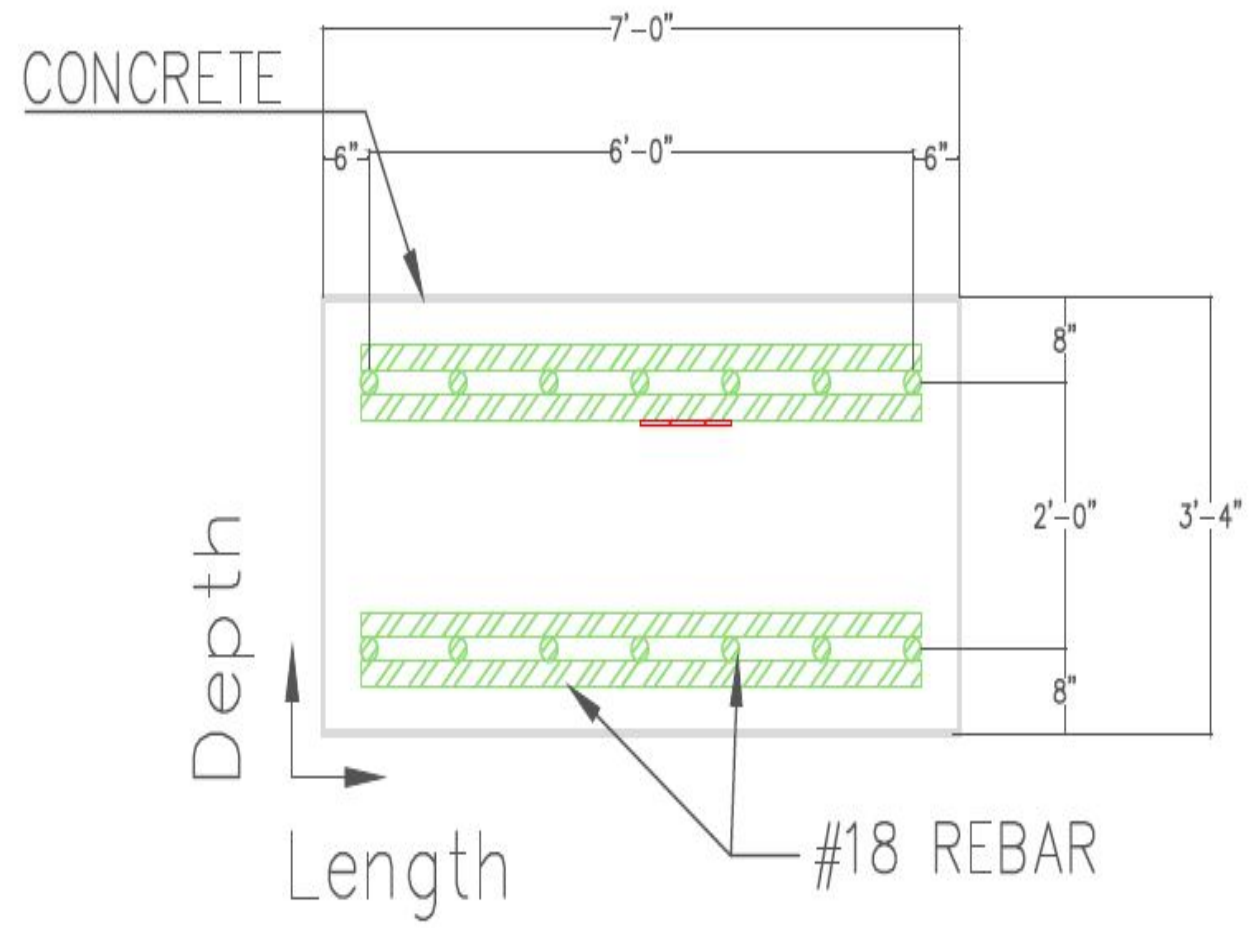

Fig. A.118. D12 length by depth NL 


\begin{tabular}{|c|c|c|}
\hline \multicolumn{3}{|c|}{ OELCT TALE } \\
\hline D nuvere & oesceppion & LAB \\
\hline or & 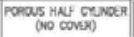 & \\
\hline D2 & 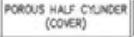 & \\
\hline as & 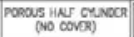 & \\
\hline$\infty$ & 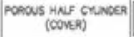 & \\
\hline os & 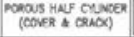 & \\
\hline$\infty$ & ex & \\
\hline 07 & Pre & \\
\hline$\infty$ & $\begin{array}{c}\text { Desa vas Smporou } \\
\text { (Thes) }\end{array}$ & \\
\hline$\infty$ & 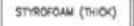 & \\
\hline oto & streoroun (Tia) & \\
\hline ont & provouss & \\
\hline 012 & 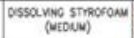 & \\
\hline ois & sincrowu (NESUV) & \\
\hline 0.4 & honouss & \\
\hline 015 & $\begin{array}{c}\text { cossa vine snnoroum } \\
\text { (ThN) }\end{array}$ & \\
\hline 010 & unear (2xit) & \\
\hline 017 & acoves & \\
\hline 018 & 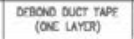 & \\
\hline 019 & 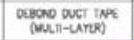 & \\
\hline 020 & WONGO REANR & \\
\hline
\end{tabular}

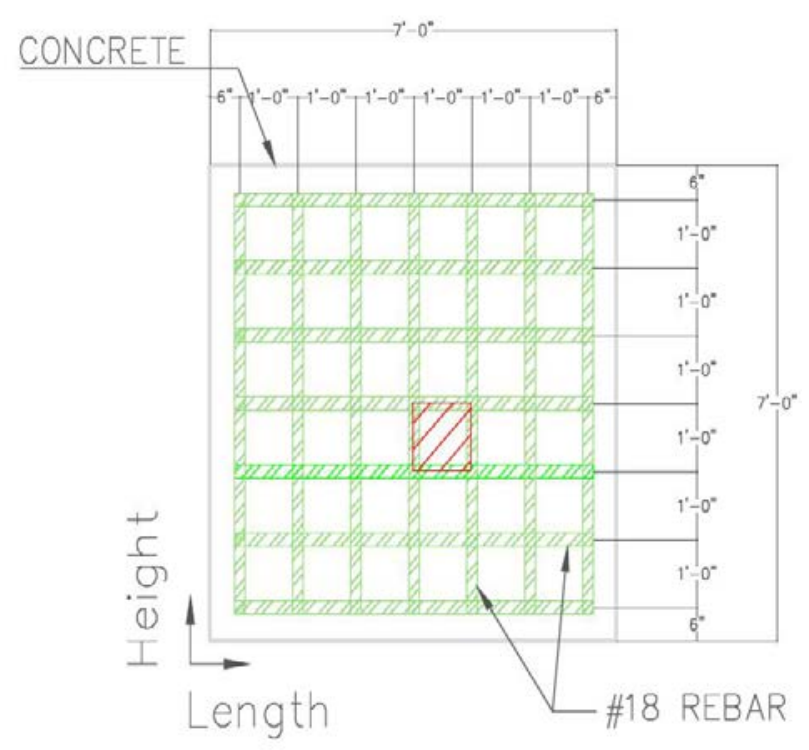

SIDE VIEW

Fig. A.119. D12 length by height.

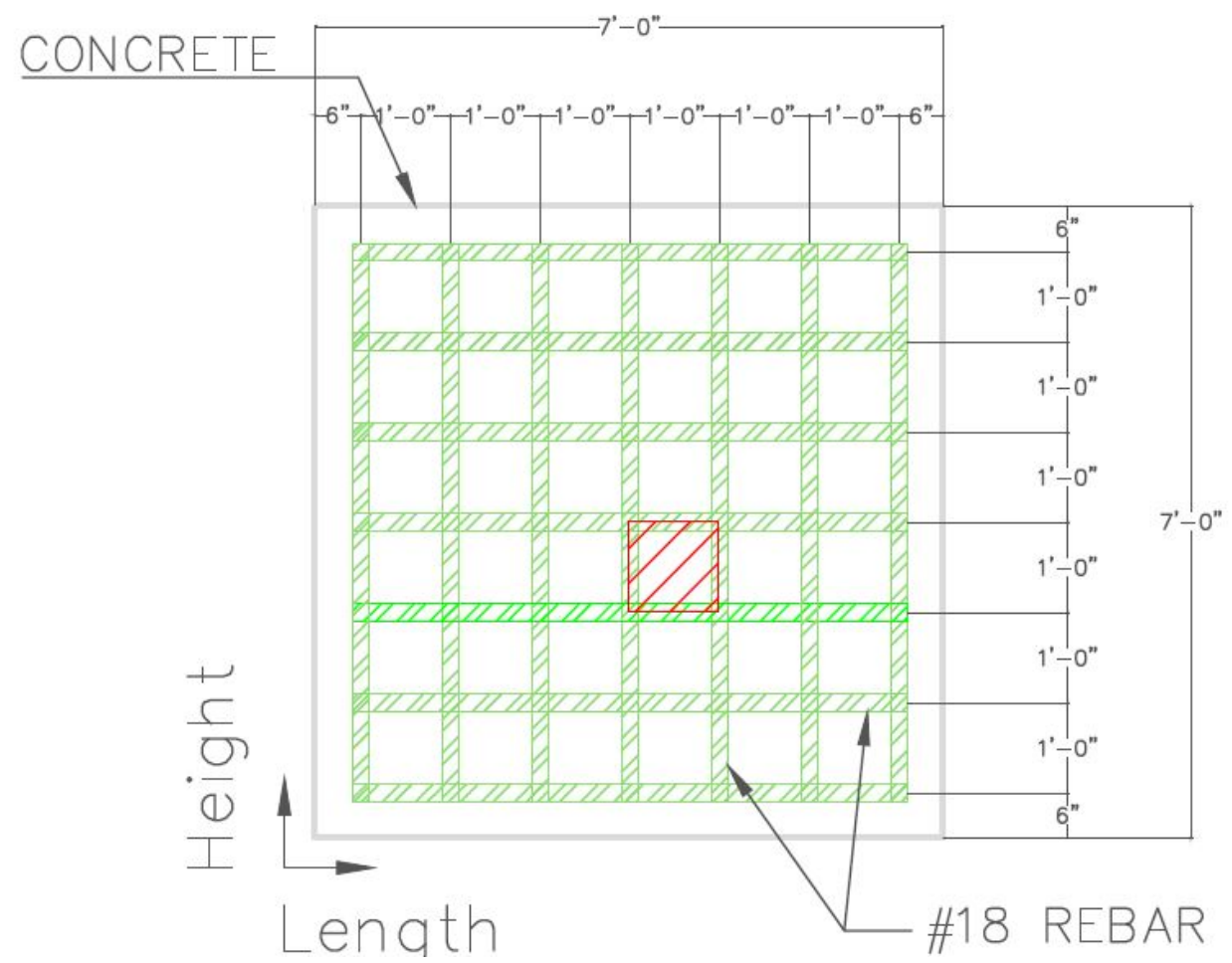

Fig. A.120. D12 length by height NL. 


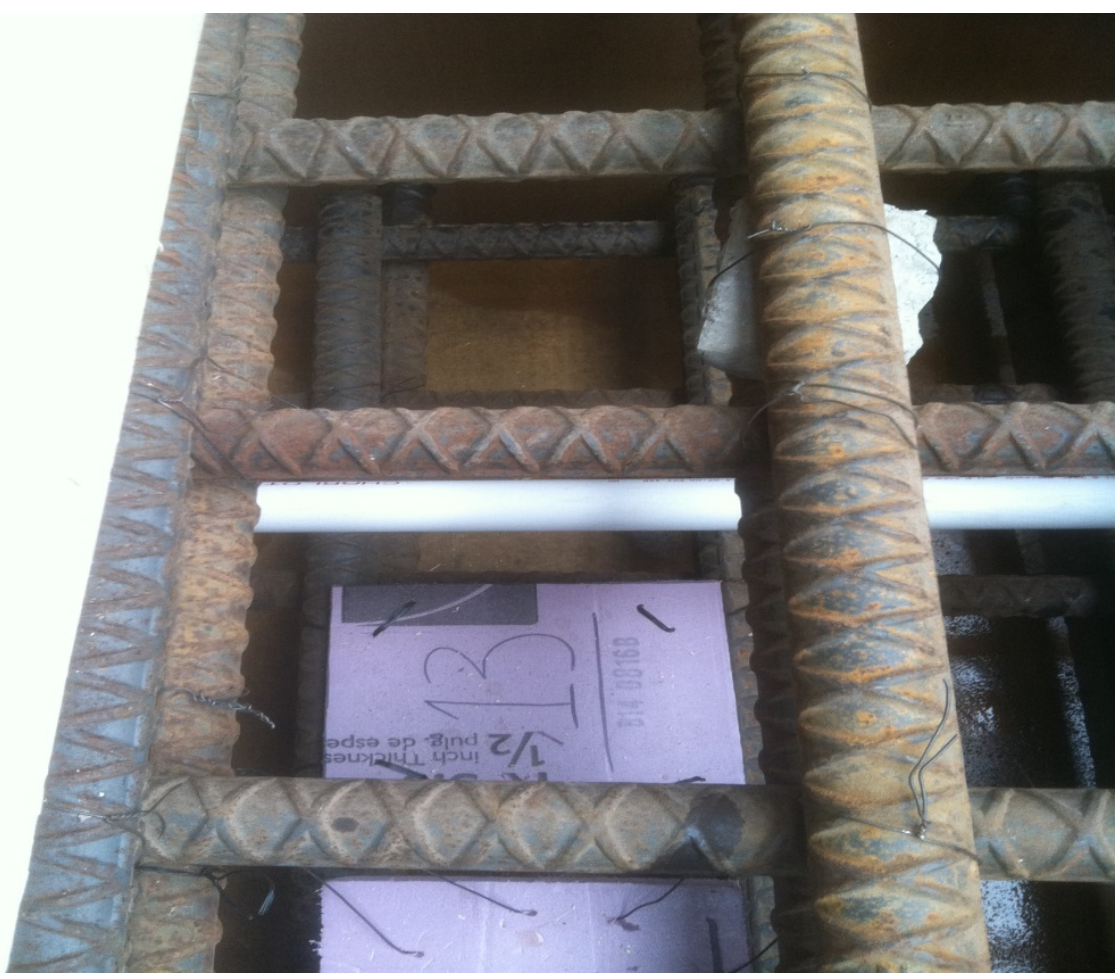

Fig. A.121. D13 close-up.

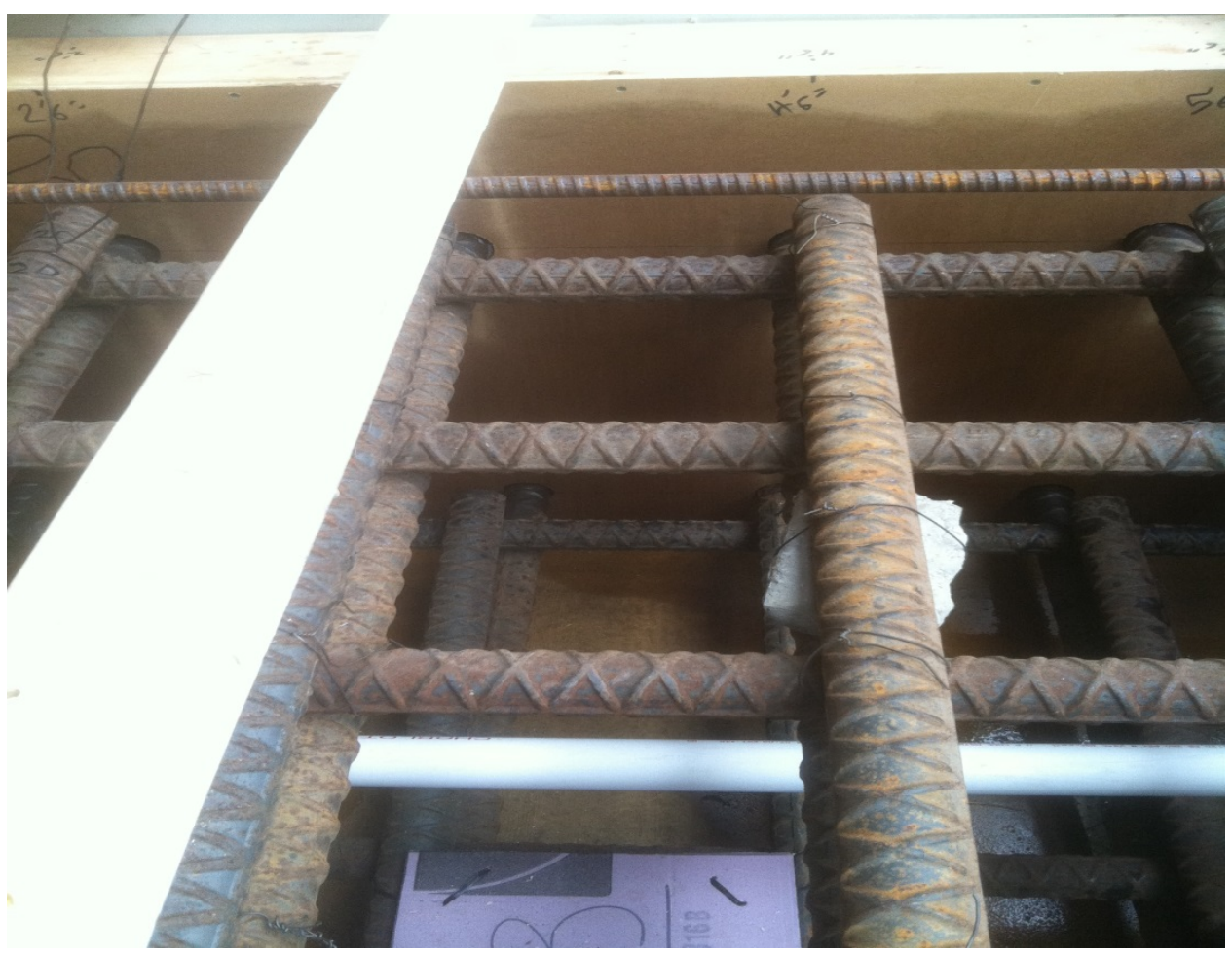

Fig. A.122. D13 height 4.5bars 4ft 1219mm. 


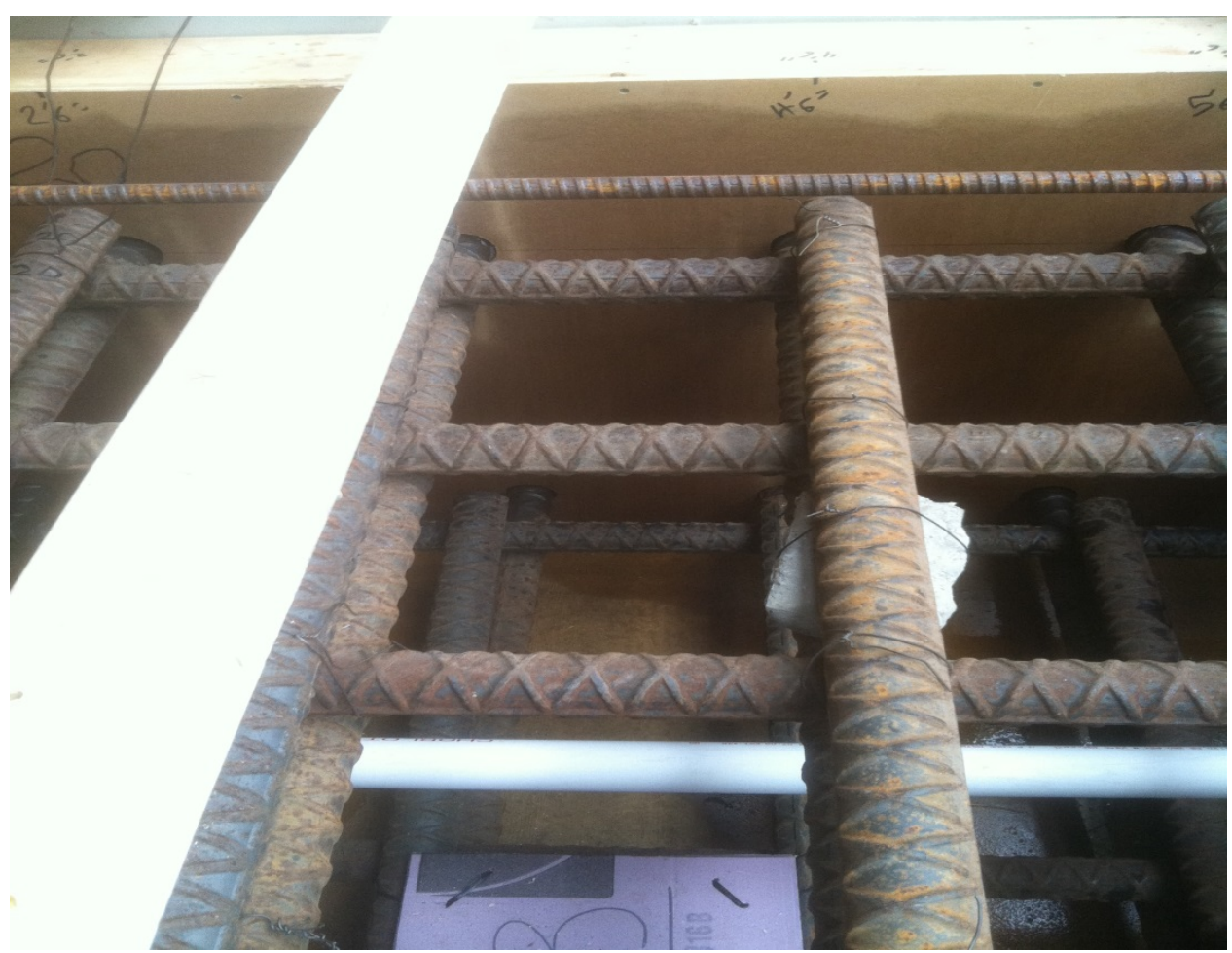

Fig. A.123. D13 length 3.5bars 3ft 914mm.

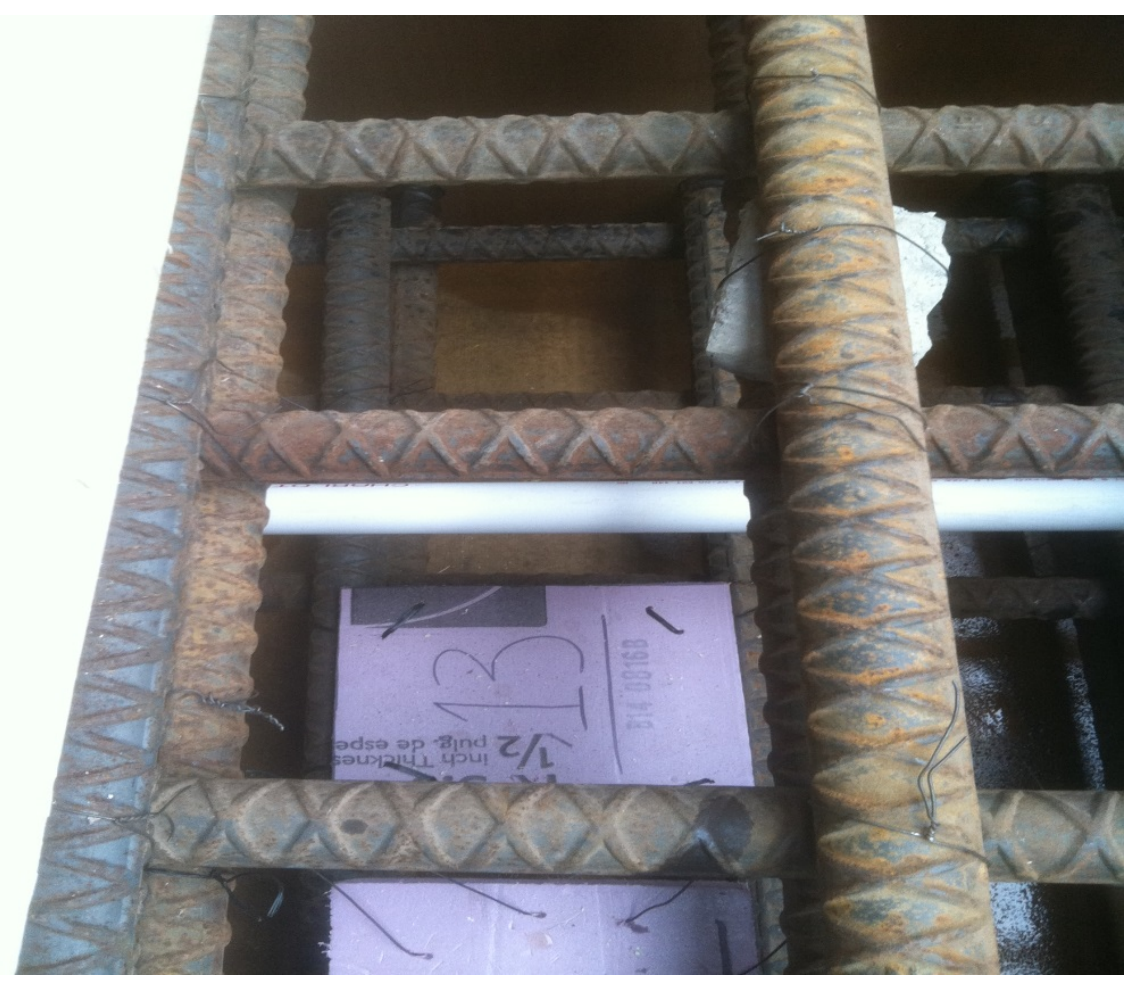

Fig. A.124. D13 R-depth top of 4th bar 733mm. 


\begin{tabular}{|c|c|c|}
\hline \multicolumn{3}{|c|}{ DEEECT TABLE } \\
\hline D NUMBER & DESCRPPTION & LABE \\
\hline 01 & $\begin{array}{c}\text { POROUS HALF CYINOER } \\
\text { (NO COVER) }\end{array}$ & \\
\hline 02 & $\mid \begin{array}{c}\text { POROUS HALF CYINDER } \\
\text { (COVER) }\end{array}$ & \\
\hline 03 & $\begin{array}{l}\text { POROUS HALF CYINOER } \\
\text { (NO CONRE) }\end{array}$ & \\
\hline 04 & $\begin{array}{l}\text { POROUS HALF CYINOER } \\
\text { (COVER) }\end{array}$ & \\
\hline DS & $\begin{array}{l}\text { POROUS HALF CYINDER } \\
\text { (COVER \& CRACK) }\end{array}$ & \\
\hline D6 & PVC & \\
\hline 07 & PVC & \\
\hline 08 & $\begin{array}{l}\text { DISSOLUNG STYROFOAM } \\
\text { (THICK) }\end{array}$ & \\
\hline 09 & STRROFOAM (THICK) & \\
\hline 010 & STROOFOAM (THIN) & \\
\hline D11 & PLEXGLASS & \\
\hline 012 & $\begin{array}{l}\text { DISSOLUNG STRROFOAM } \\
\text { (MEDIUM) }\end{array}$ & \\
\hline 013 & STRROFOAM (MEDUM) & \\
\hline 014 & PLEXIGLASS & \\
\hline 015 & $\begin{array}{c}\text { DISSOLUNG STYROFOAM } \\
\text { (THIN) }\end{array}$ & \\
\hline 016 & LUMBER $(2 \times 4)$ & \\
\hline 017 & GLOVES & \\
\hline D18 & $\begin{array}{l}\text { DEBONO DUCT TAPE } \\
\text { (ONE LAYER) }\end{array}$ & \\
\hline D19 & $\begin{array}{l}\text { DEBONO DUCT TAPE } \\
\text { (MULT-LAYRR) }\end{array}$ & \\
\hline 020 & MOUNG REBAR & \\
\hline
\end{tabular}

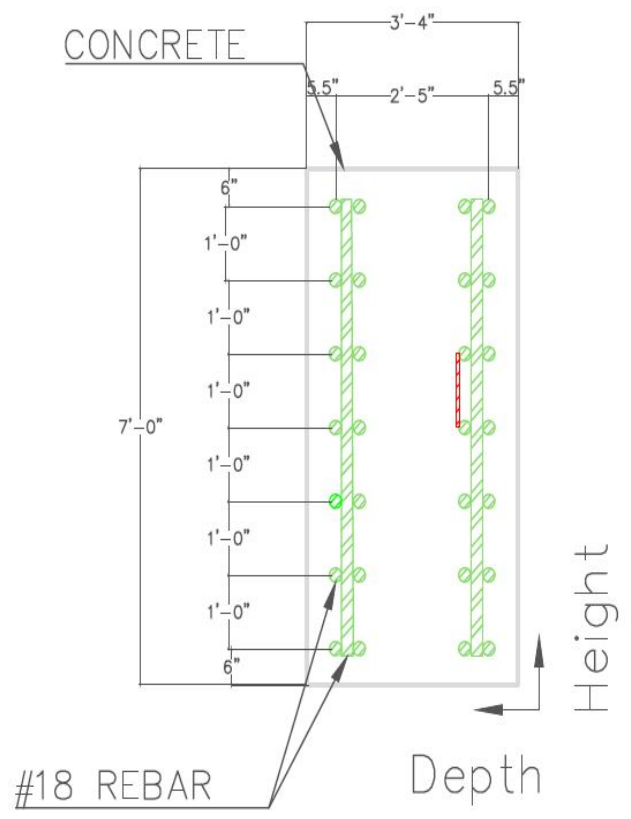

Fig. A.125. D13 height by depth.

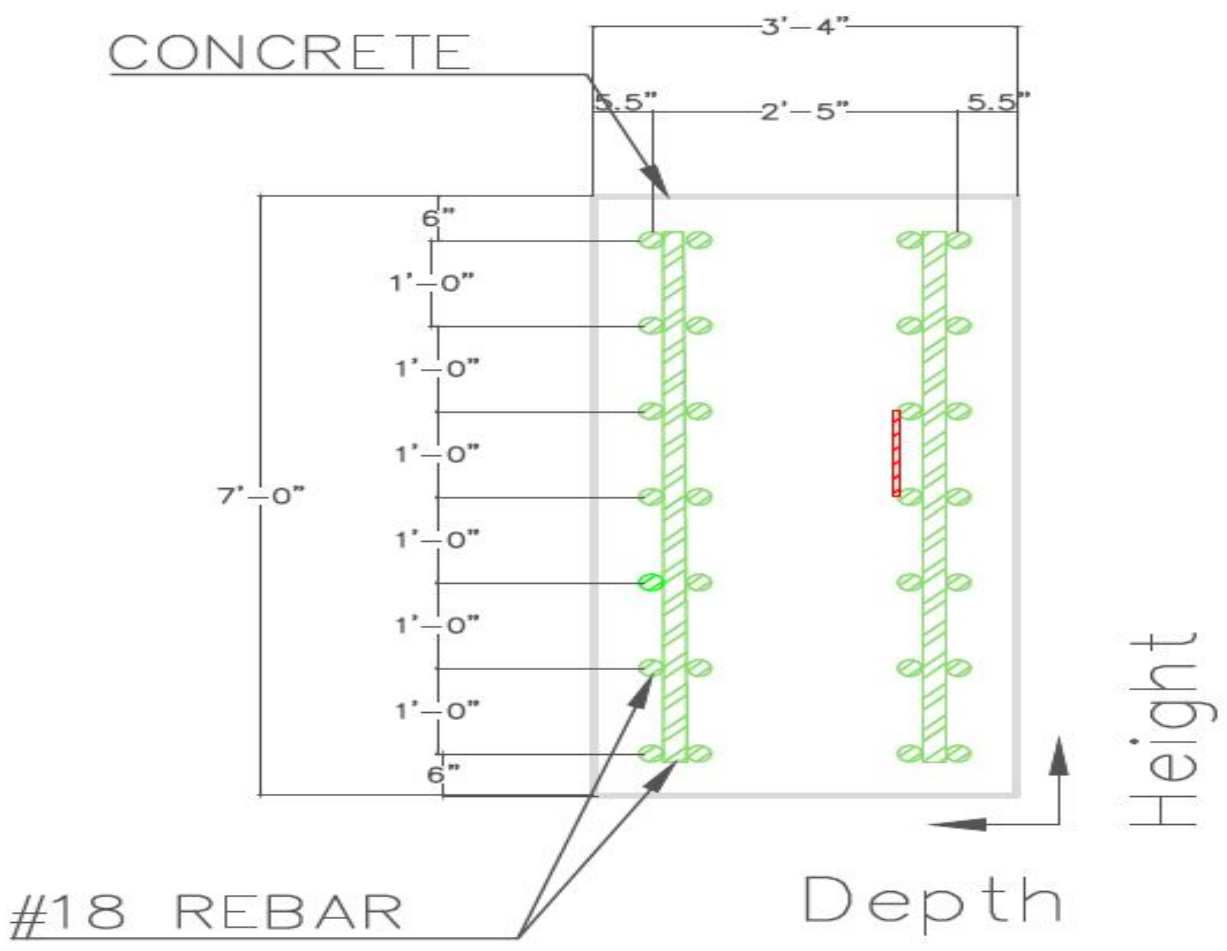

Fig. A.126. D13 height by depth NL. 


\begin{tabular}{|c|c|c|}
\hline \multicolumn{3}{|c|}{ DOCCET TRQ:L } \\
\hline o nuser & DESORPION & Laber \\
\hline or & 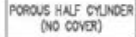 & \\
\hline 02 & 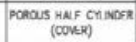 & \\
\hline os & 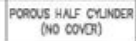 & \\
\hline D4 & 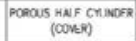 & \\
\hline DS & 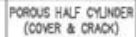 & \\
\hline 06 & $\mathrm{pxc}$ & \\
\hline 07 & $P$ PC & \\
\hline DB & 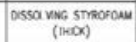 & \\
\hline$\infty$ & STRoroun (TIOS) & \\
\hline 010 & SIryoroum (IRN) & \\
\hline oil & popouss & \\
\hline $\mathrm{D} 12$ & $\begin{array}{c}\text { Oassa vwo streorow } \\
\text { (Mtouv) }\end{array}$ & \\
\hline O13 & STheroun (Nedw) & \\
\hline DI4 & plonouss & \\
\hline 015 & $\begin{array}{c}\text { assa ninc stmeorown } \\
\text { (TIN) }\end{array}$ & \\
\hline 016 & unese $(2 x t)$ & \\
\hline 017 & coves & \\
\hline D18 & 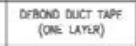 & \\
\hline 019 & 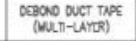 & \\
\hline 020 & NONO REBNR & \\
\hline
\end{tabular}

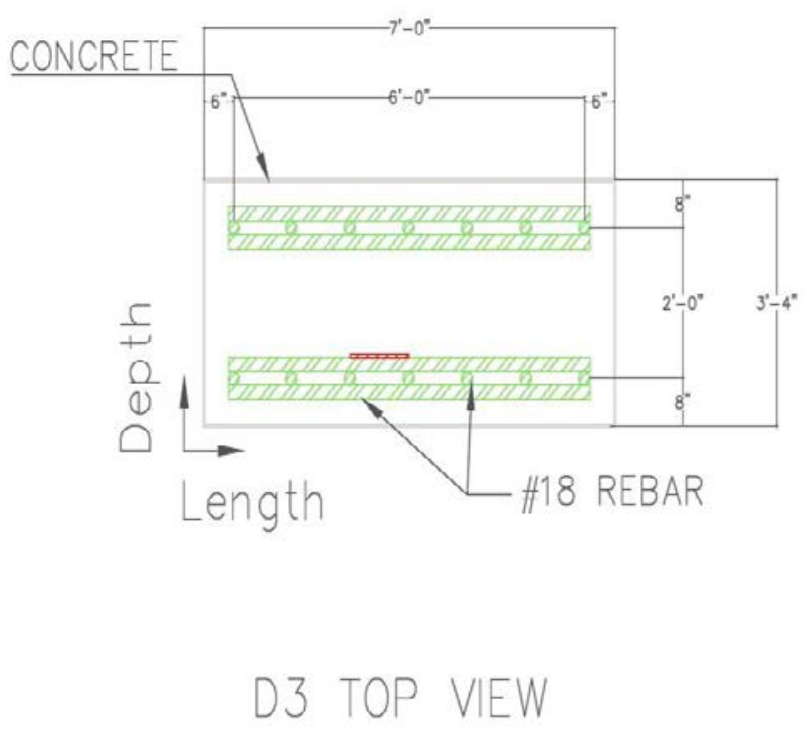

Fig. A.127. D13 length by depth.

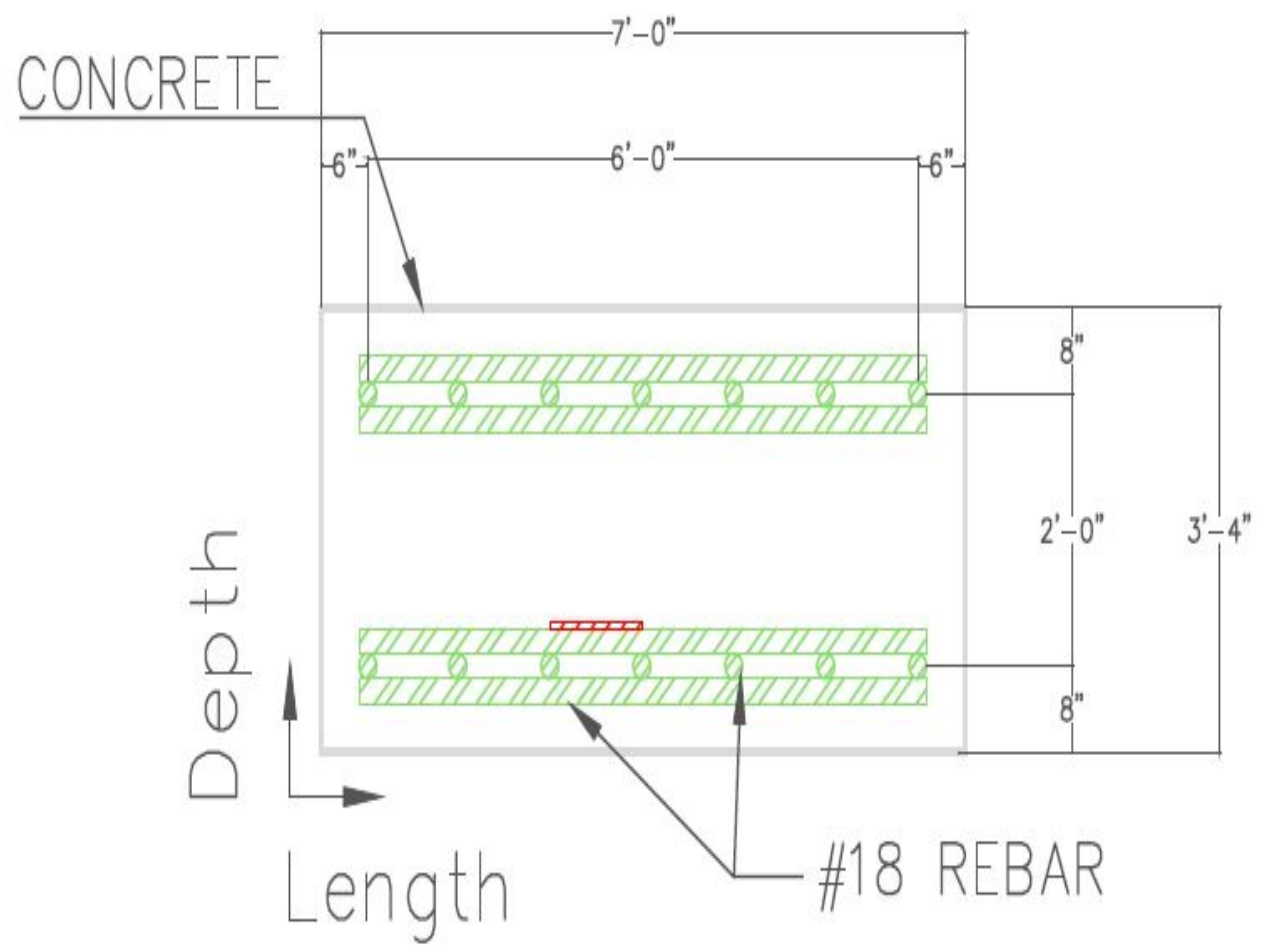

Fig. A.128. D13 length by depth NL 


\begin{tabular}{|c|c|c|}
\hline \multicolumn{3}{|c|}{ Derbit Thale } \\
\hline O nuear & DESCRPTON & uac. \\
\hline or & 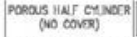 & \\
\hline 02 & 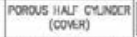 & \\
\hline as & 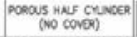 & \\
\hline D4 & $\begin{array}{l}\text { Porous HNF EeNDER } \\
\text { (COVER) }\end{array}$ & \\
\hline os & 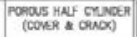 & \\
\hline$\infty$ & ne & \\
\hline 07 & $\mathrm{PNC}$ & \\
\hline of & $\begin{array}{c}\text { ossaung smorom } \\
\text { (thios) }\end{array}$ & \\
\hline$\infty$ & 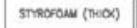 & \\
\hline 010 & STrorow (THAS) & \\
\hline o"11 & pisolouss & \\
\hline 012 & 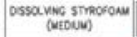 & \\
\hline ons & 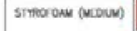 & \\
\hline ons & modouss & \\
\hline ons & 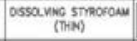 & \\
\hline 016 & WVerr (2x4) & \\
\hline 017 & choves & \\
\hline 010 & 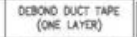 & \\
\hline 010 & 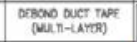 & \\
\hline 020 & wovesc resere & \\
\hline
\end{tabular}

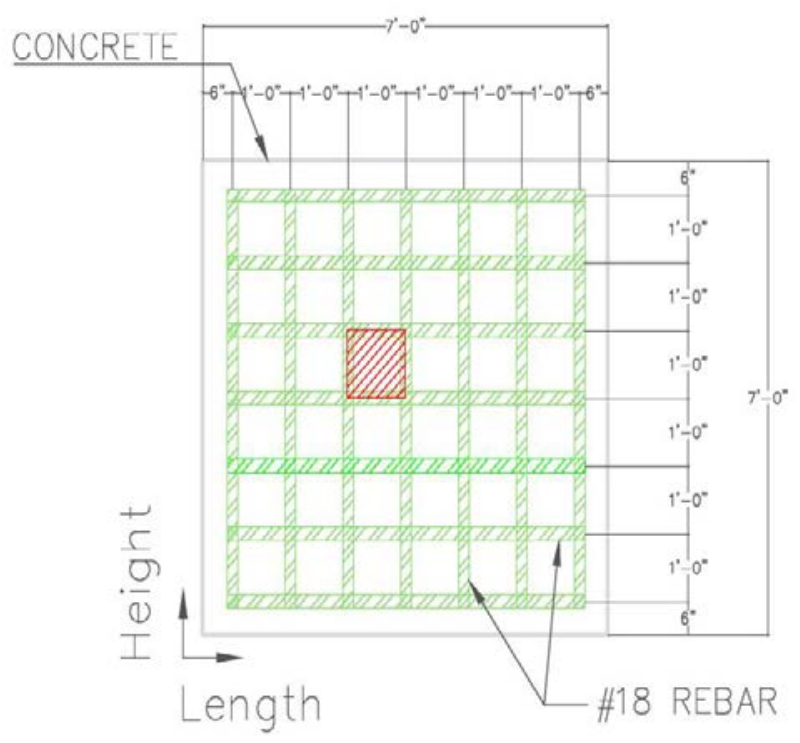

SIDE VIEW

Fig. A.129. D13 length by height.

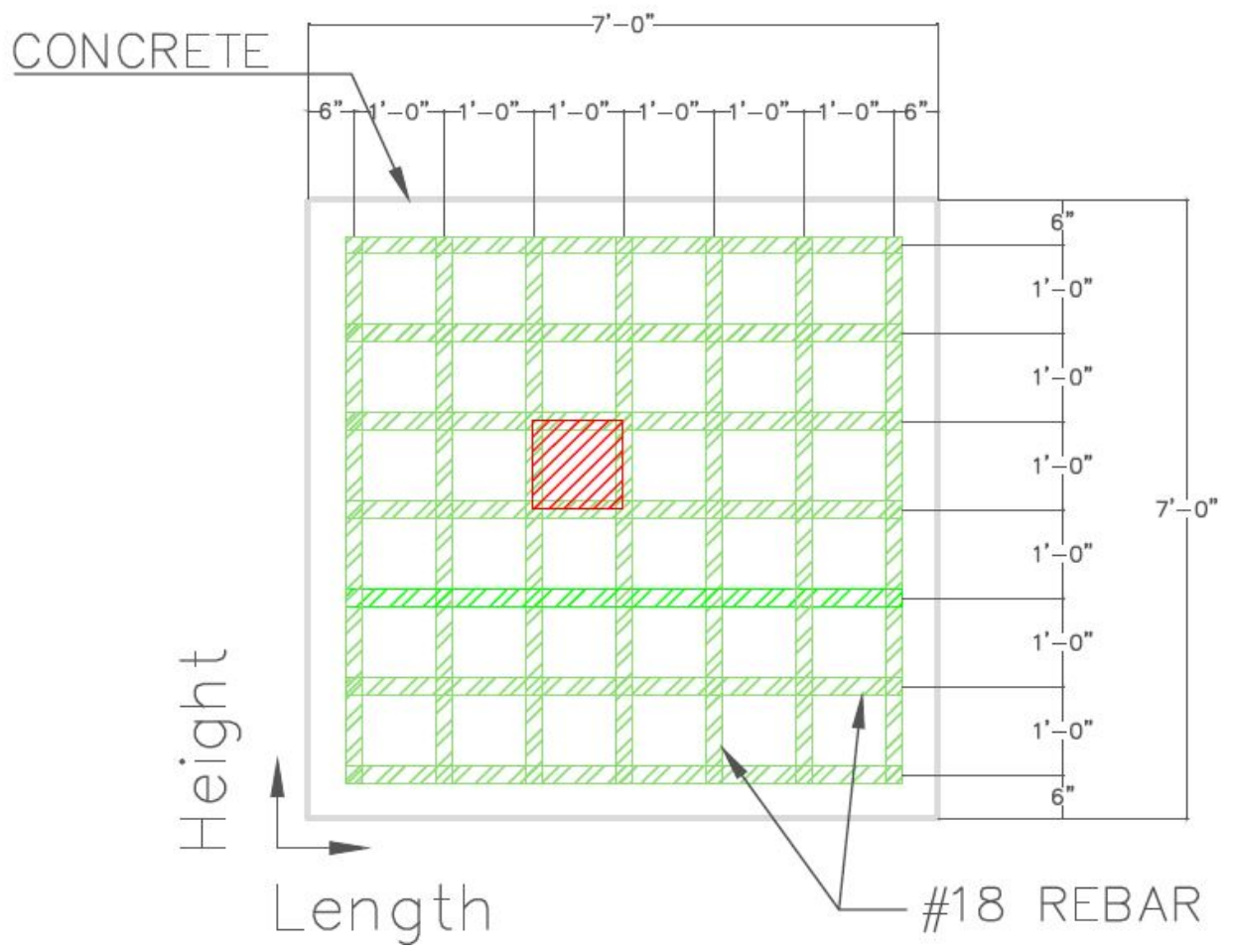

Fig. A.130. D13 length by height NL. 


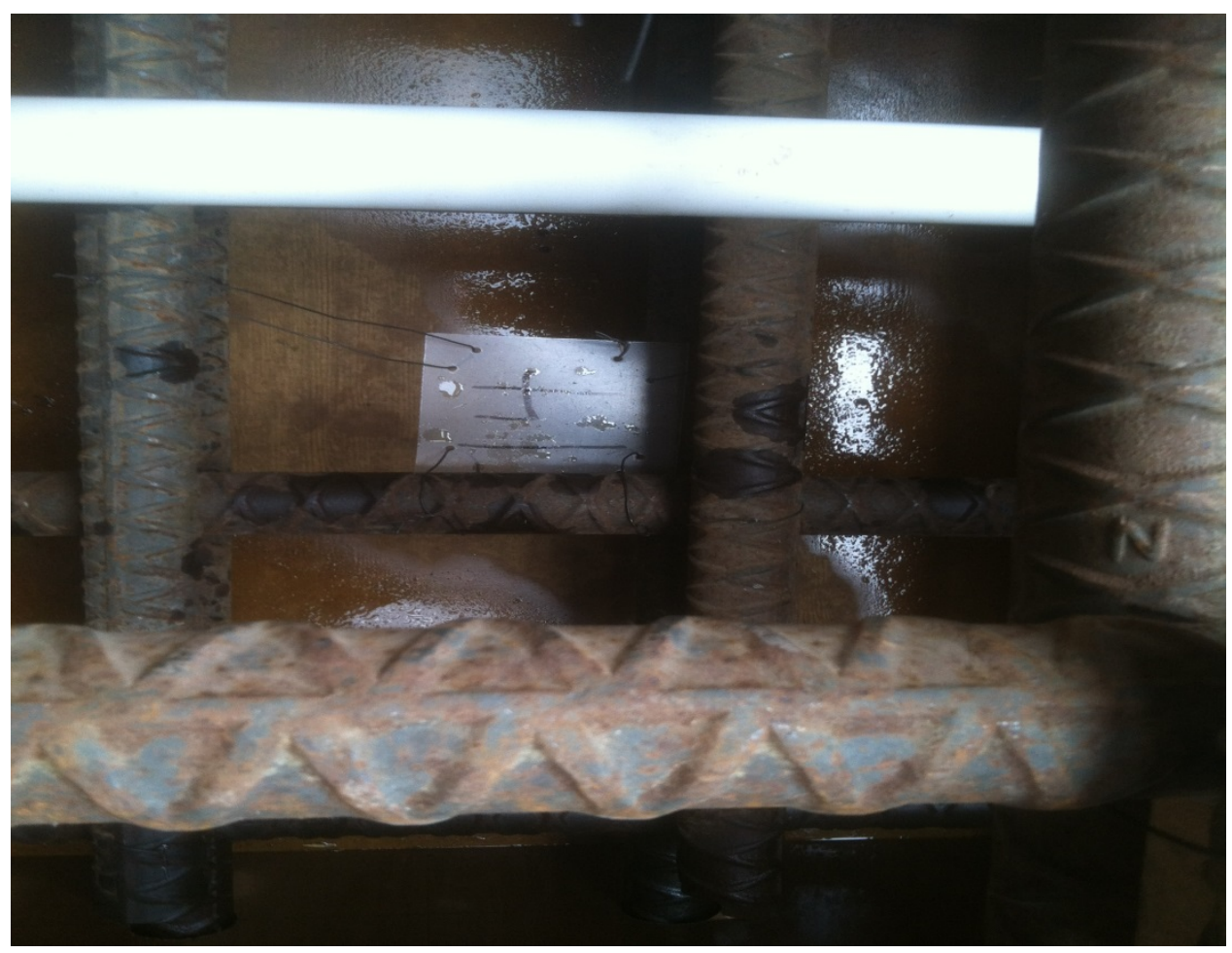

Fig. A.131. D14 close-up.

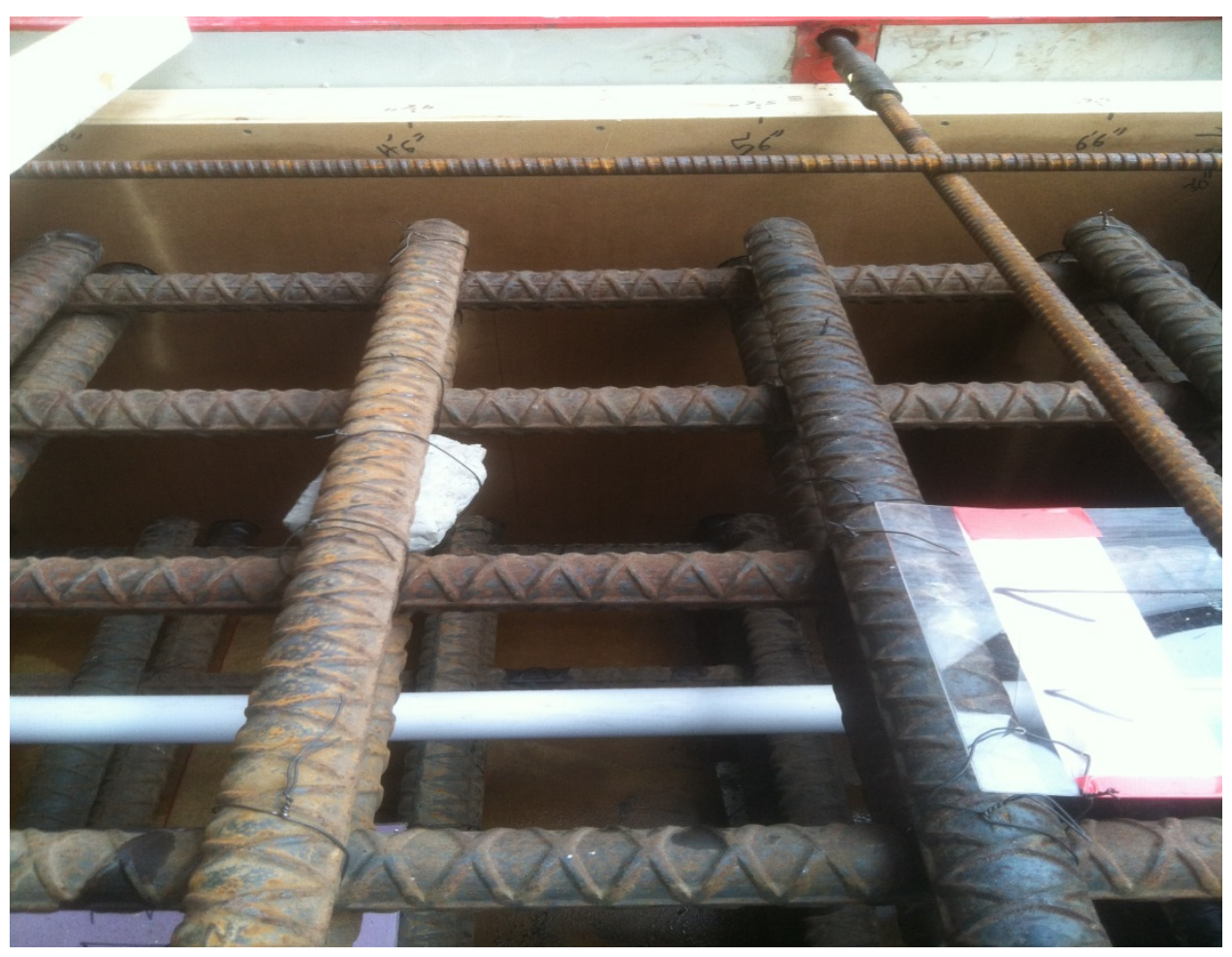

Fig. A.132. D14 height 5.75 bars $5.25 \mathrm{ft} 1219 \mathrm{~mm}$. 


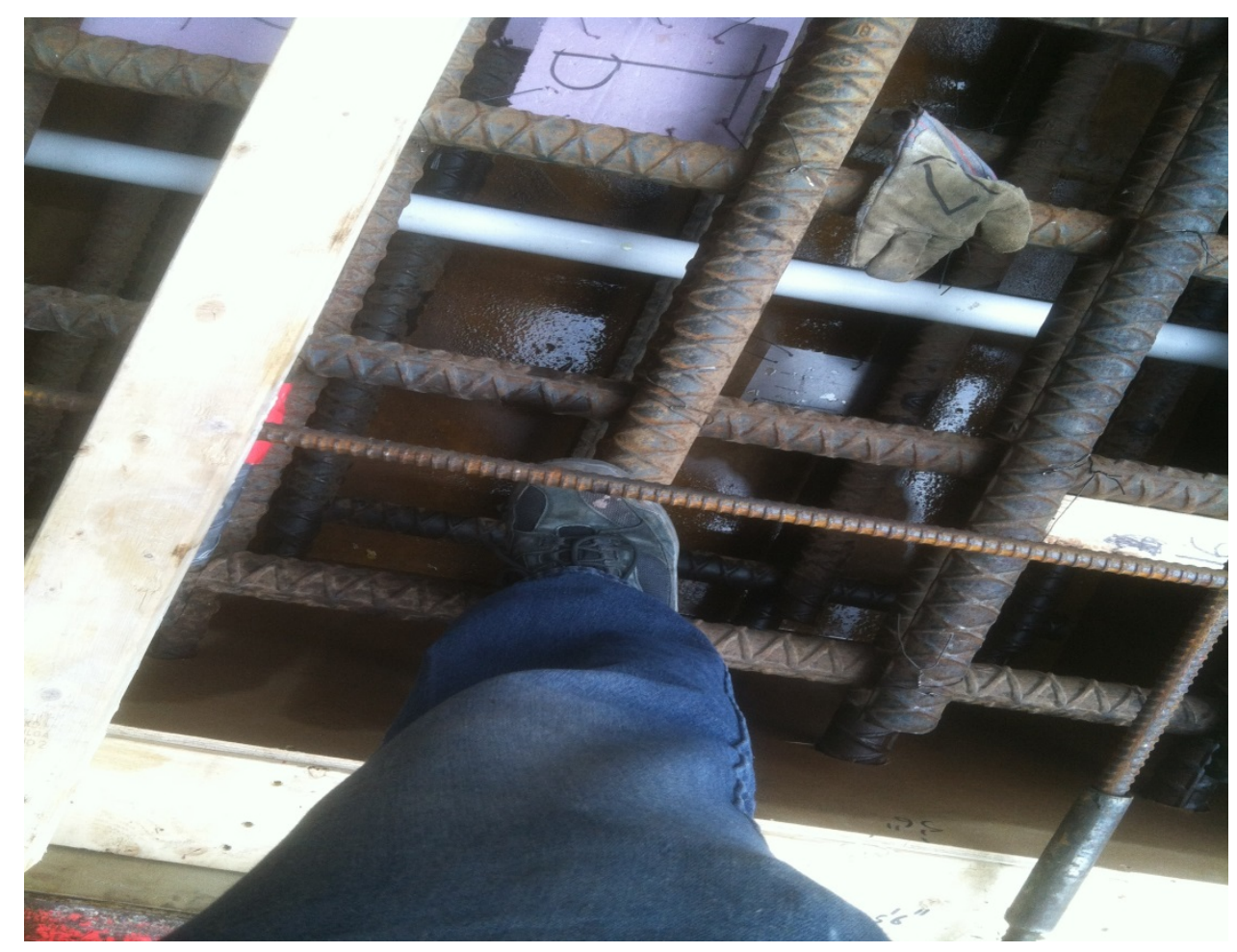

Fig. A.133. D14 length 5.75bars 5.25ft 914mm.

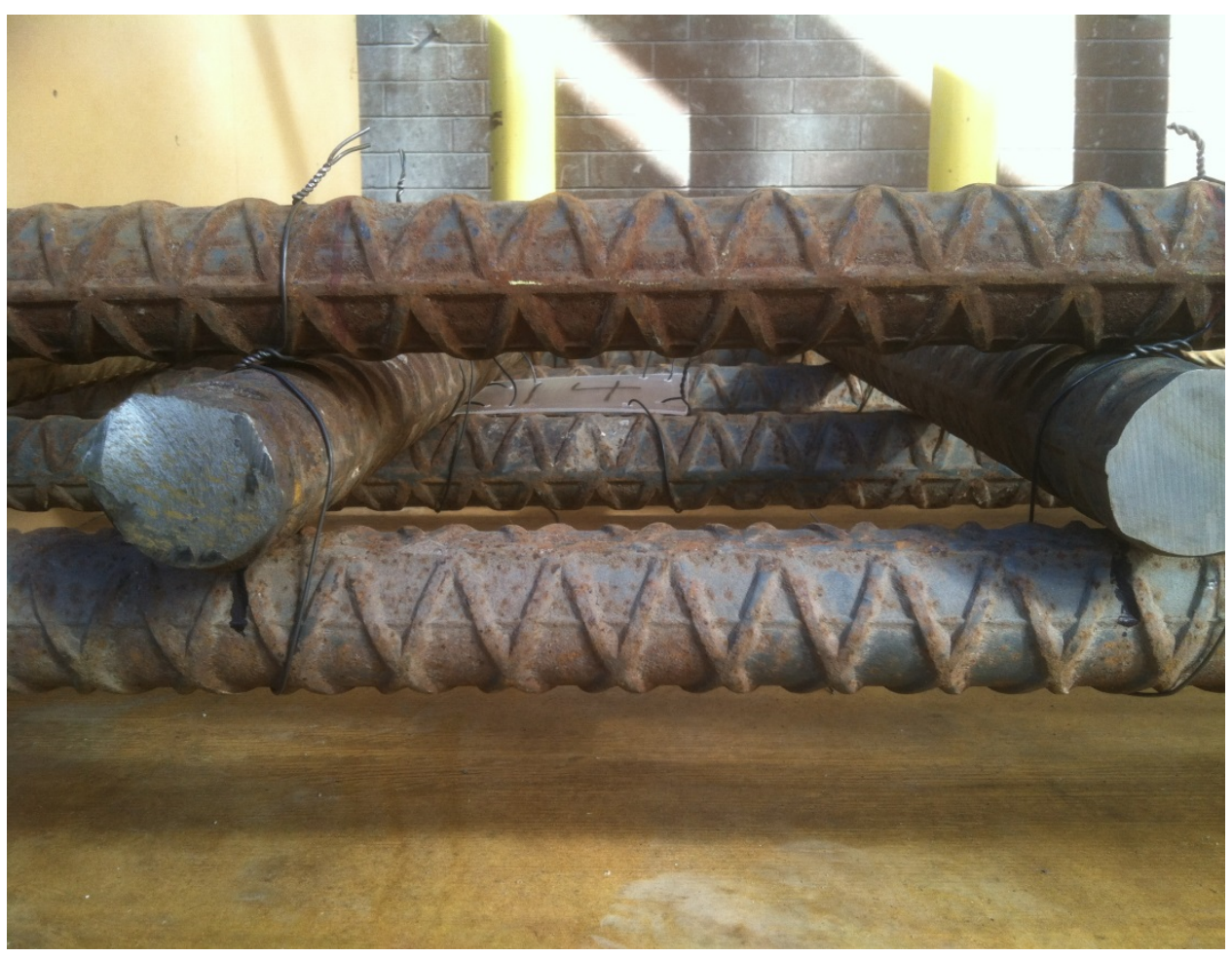

Fig. A.134. D14 R-depth bottom of 5th bar 848mm. 


\begin{tabular}{|c|c|c|}
\hline \multicolumn{3}{|c|}{ DEFECT TABLE } \\
\hline ID NUMEER & DESCRIPTION & LABE \\
\hline 01 & $\begin{array}{l}\text { POROUS HALF CYINDER } \\
\text { (NO COVER) }\end{array}$ & \\
\hline 02 & $\begin{array}{l}\text { POROUS HALF CYINDER } \\
\text { (COVER) }\end{array}$ & \\
\hline 03 & $\begin{array}{l}\text { POROUS HALF CYUNDER } \\
\text { (NO COVER) }\end{array}$ & \\
\hline 04 & $\begin{array}{l}\text { POROUS HALF CYINDER } \\
\text { (COVER) }\end{array}$ & \\
\hline D5 & $\begin{array}{l}\text { POROUS HALF CYINDER } \\
\text { (COVER \& CRACK) }\end{array}$ & \\
\hline D6 & PVC & \\
\hline D7 & PVC & \\
\hline 08 & $\begin{array}{l}\text { DISSOLUNG STRROFOAM } \\
\text { (THICK) }\end{array}$ & \\
\hline Dg & STTROFOAM (THICK) & \\
\hline D10 & STYROFOAM (THIN) & \\
\hline 011 & PLEXIGLASS & \\
\hline 012 & $\begin{array}{l}\text { DISSOUNNG STRROFOAM } \\
\text { (MEDUUM) }\end{array}$ & \\
\hline 013 & STRROFOAM (MEDIUM) & \\
\hline 014 & PLEXXGLASS & \\
\hline 015 & $\begin{array}{l}\text { DISSOLUNG STYROFOAM } \\
\text { (THN) }\end{array}$ & \\
\hline 016 & LUMBER $(2 \times 4)$ & \\
\hline 017 & GLOVES & \\
\hline 018 & $\begin{array}{l}\text { DEBONO DUCT TAPE } \\
\text { (ONE LAYER) }\end{array}$ & \\
\hline 019 & $\begin{array}{l}\text { DEBONO DUCT TAPE } \\
\text { (MULT-LAYRR) }\end{array}$ & \\
\hline 020 & MOUNG REBAR & \\
\hline
\end{tabular}

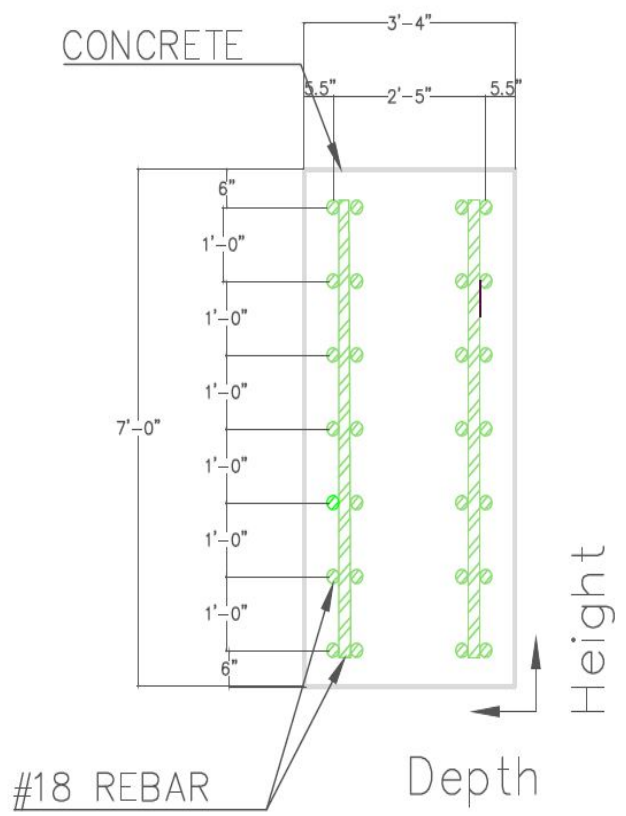

Fig. A.135. D14 height by depth.

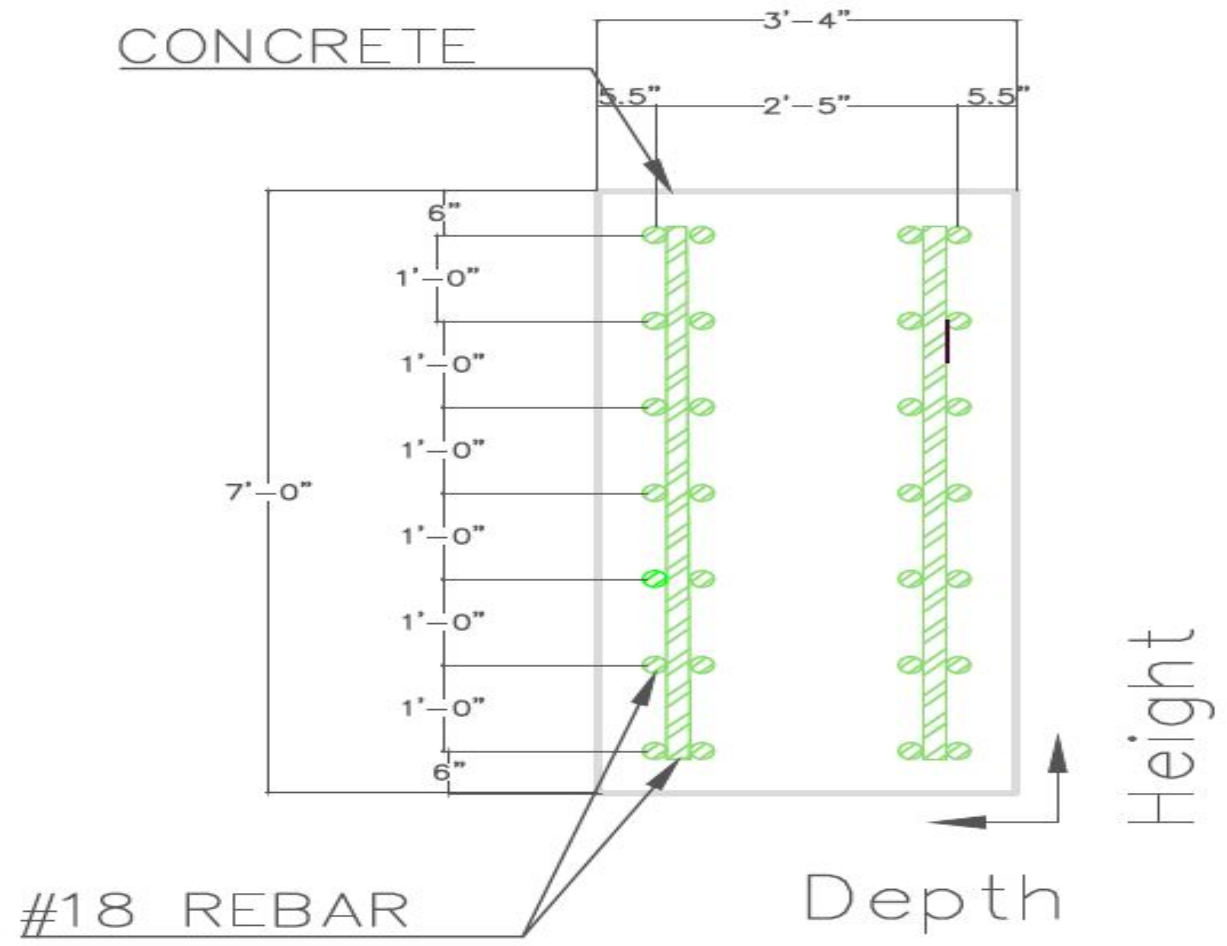

Fig. A.136. D14 height by depth NL. 


\begin{tabular}{|c|c|c|}
\hline \multicolumn{3}{|c|}{ BEFECT TABUE } \\
\hline O NuESer & DESCQPTION & Uen. \\
\hline of & 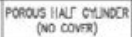 & \\
\hline 02 & 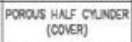 & \\
\hline os & $\begin{array}{l}\text { Porous HNF CUNGER } \\
\text { (No Cover) }\end{array}$ & \\
\hline of & 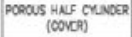 & \\
\hline DS & 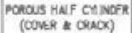 & \\
\hline$\infty$ & $P M C$ & \\
\hline 07 & PNC & \\
\hline 08 & 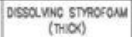 & \\
\hline$\infty$ & STrRorow (TH: $)$ & \\
\hline 010 & shaoronw (Th:1) & \\
\hline 011 & proxanss & \\
\hline 012 & 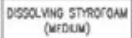 & \\
\hline 013 & STMRorOAN (NEDUU) & \\
\hline 014 & Revolass & 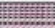 \\
\hline 015 & 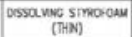 & \\
\hline 016 & unest (2xt) & \\
\hline 017 & aons & \\
\hline 018 & 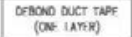 & \\
\hline 019 & $\begin{array}{c}\text { OCgONO OUCT TNAE } \\
\text { (WLIT-LITER) }\end{array}$ & \\
\hline 020 & WOWNo ReBare & \\
\hline
\end{tabular}

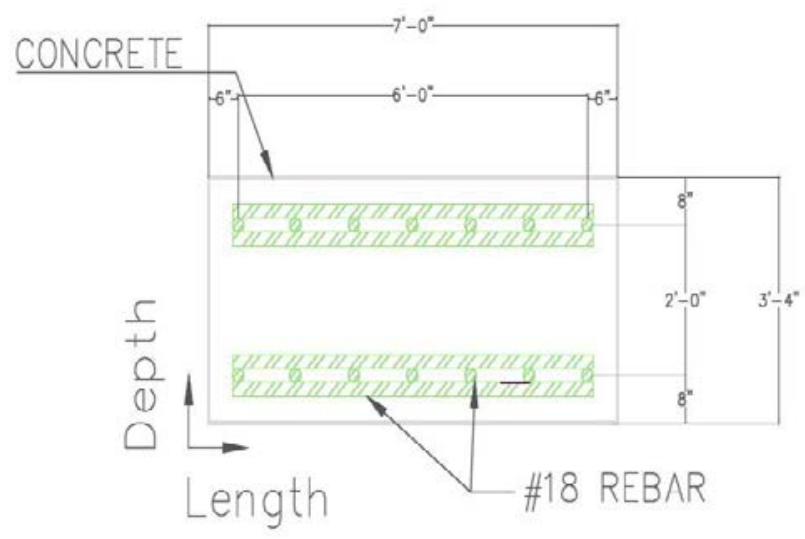

D3 TOP VIEW

Fig. A.137. D14 length by depth.

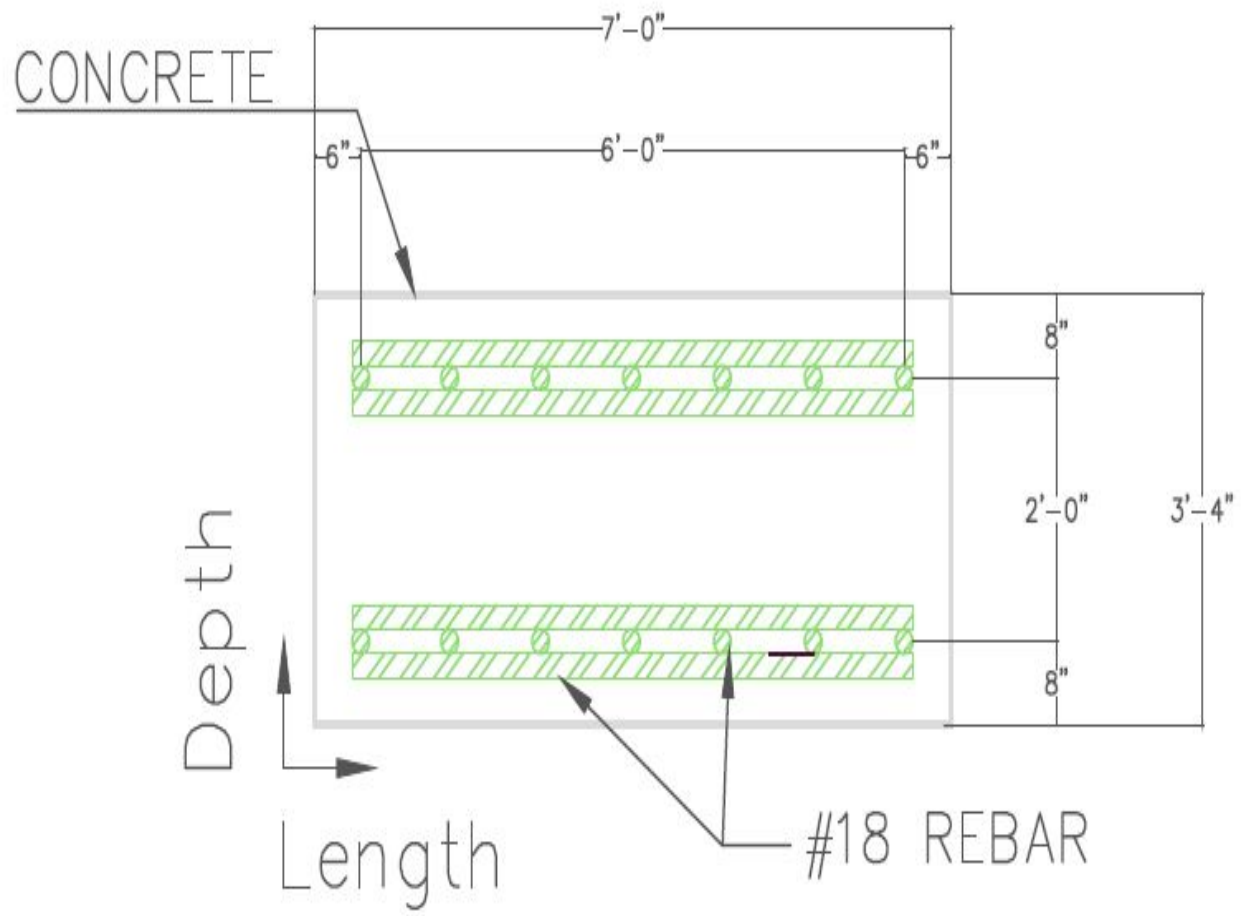

Fig. A.138. D14 length by depth NL. 


\begin{tabular}{|c|c|c|}
\hline \multicolumn{3}{|c|}{ DEECT TRALE } \\
\hline o nupare & Descaption & was. \\
\hline or & 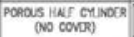 & \\
\hline 02 & 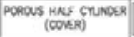 & \\
\hline as & 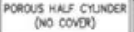 & \\
\hline of & 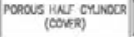 & \\
\hline os & 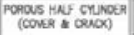 & \\
\hline$\infty$ & pac & \\
\hline 07 & $\mathrm{puc}$ & \\
\hline 00 & 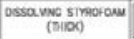 & \\
\hline os & sาnoroum (\$10) & \\
\hline 010 & stmorowu (SIN) & \\
\hline on1 & moxecuss & \\
\hline 012 & 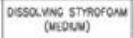 & \\
\hline ors & 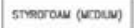 & \\
\hline on & moxacuss & mant \\
\hline 015 & 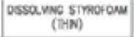 & \\
\hline ois & LWare (2xa) & \\
\hline ort & aons & \\
\hline 1818 & 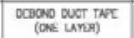 & \\
\hline 019 & 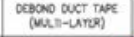 & \\
\hline 020 & WOUNA RENR & \\
\hline
\end{tabular}

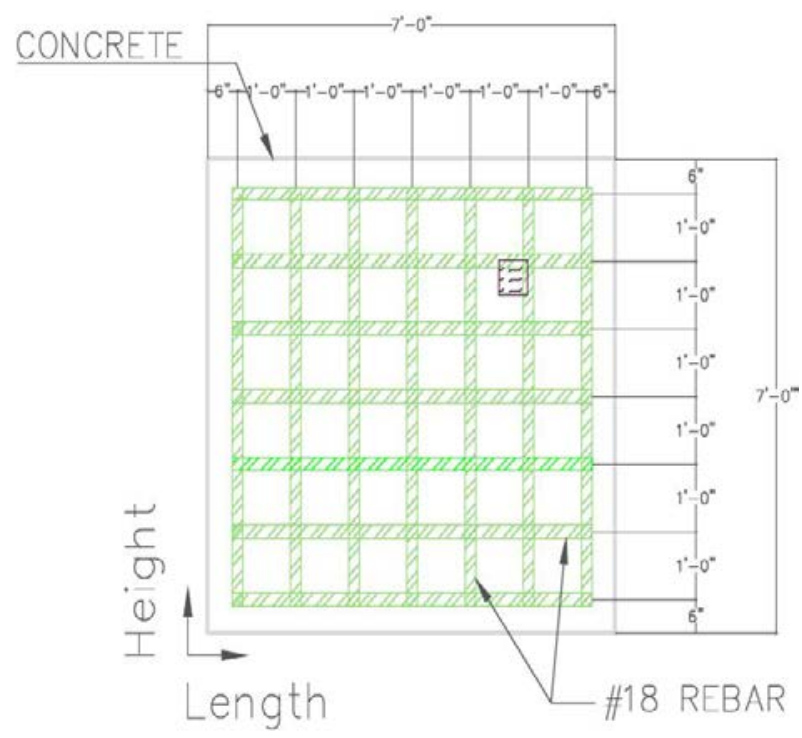

SIDE VIEW

Fig. A.139. D14 length by height.

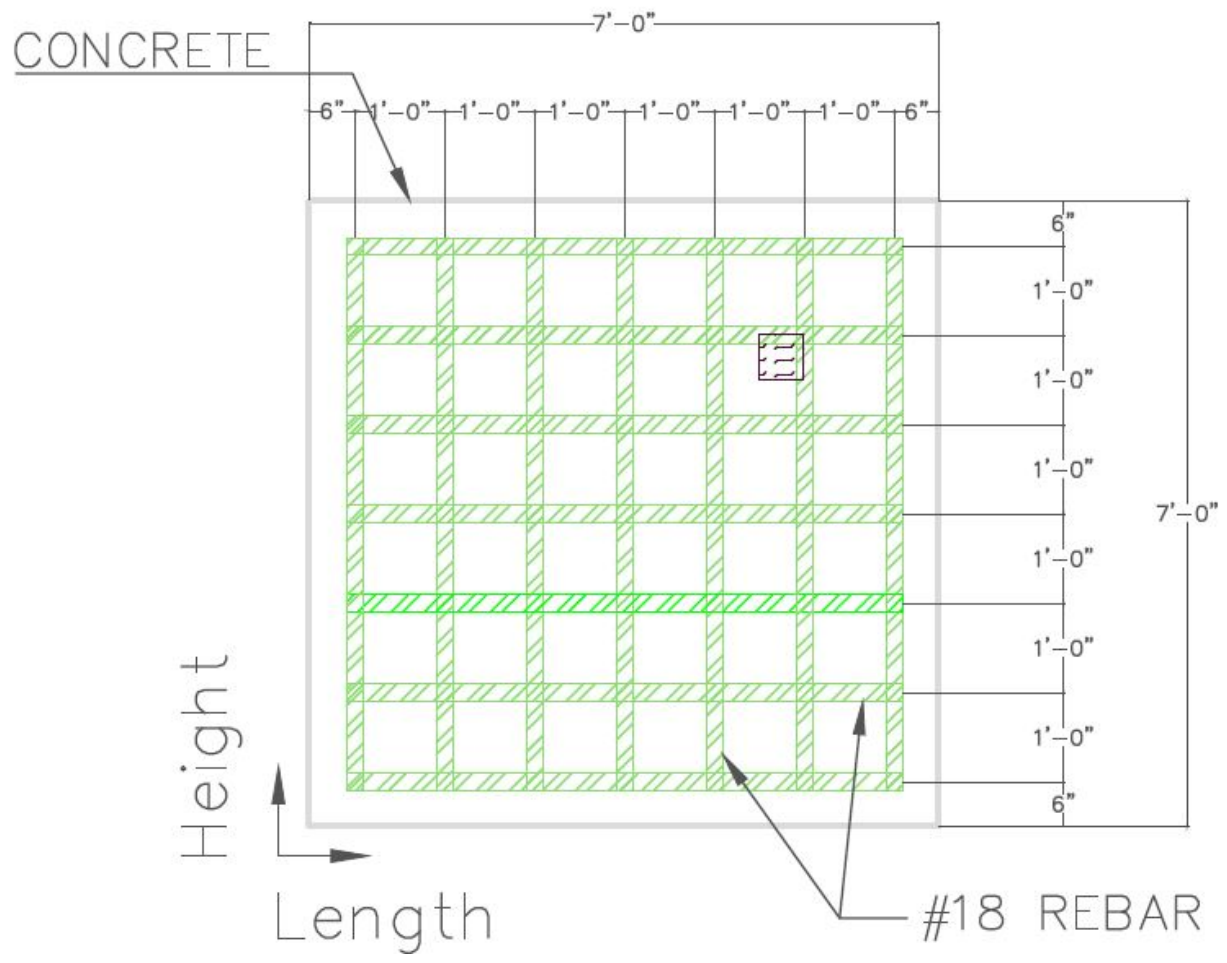

Fig. A.140. D14 length by height NL. 


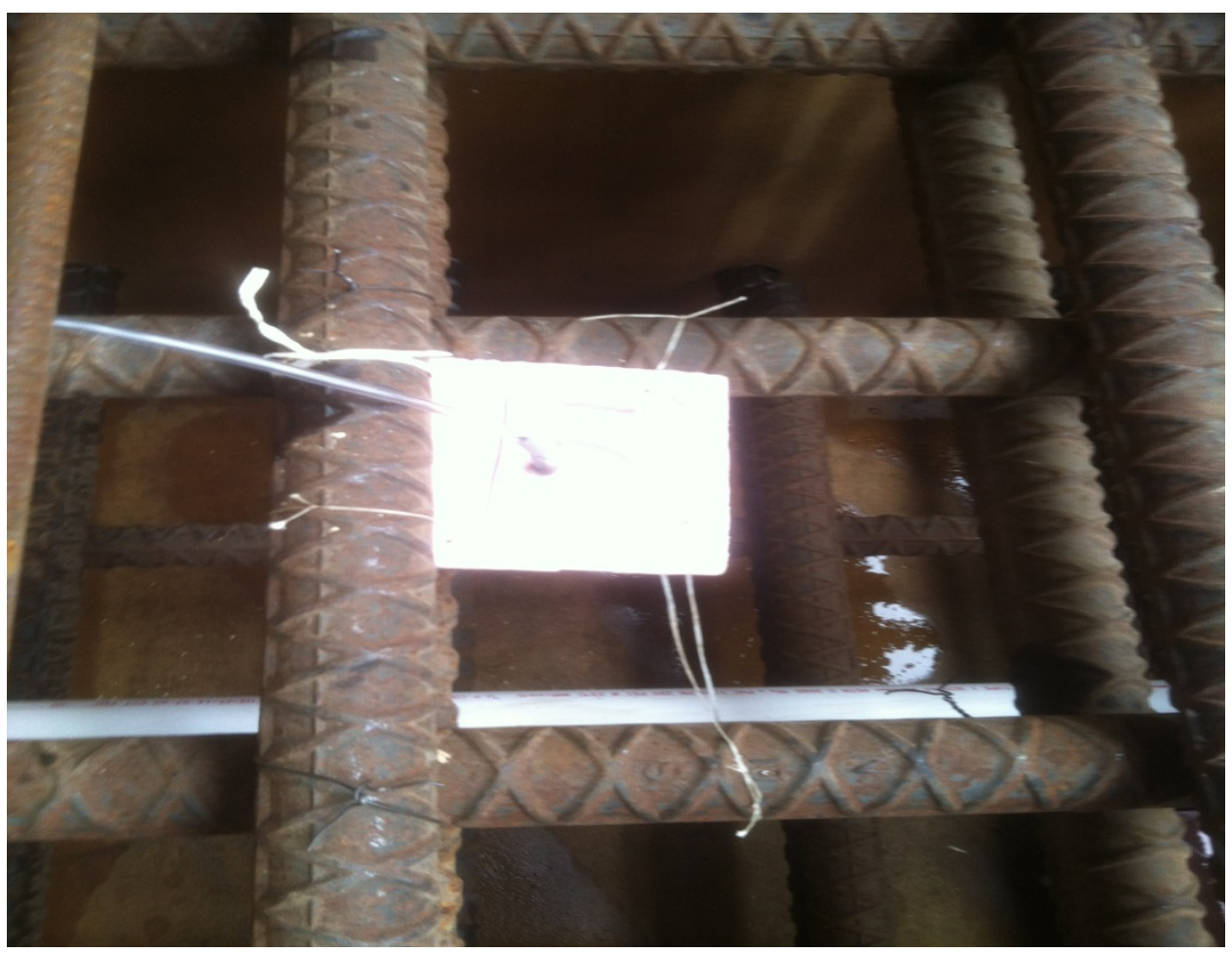

Fig. A.141. D15 close-up.

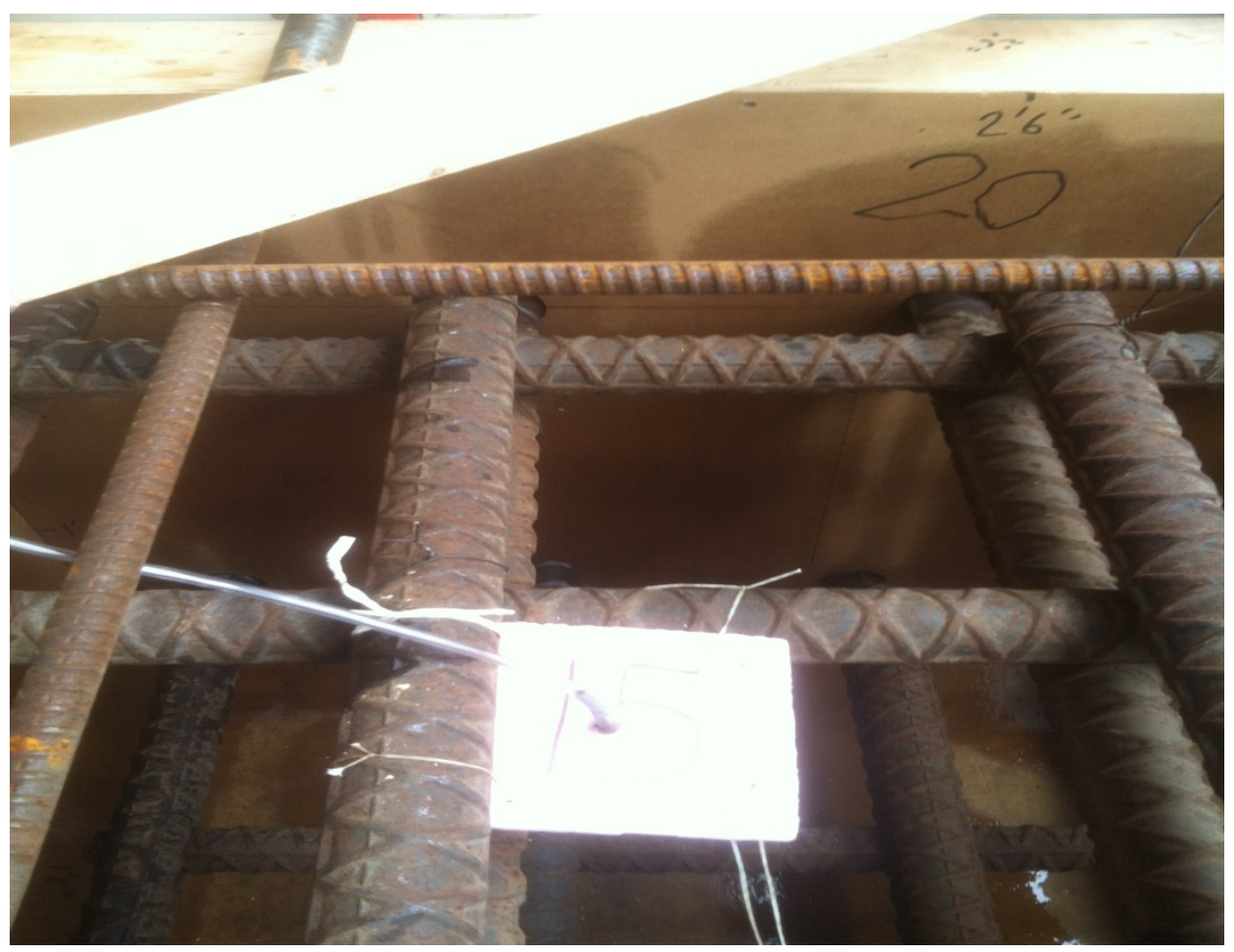

Fig. A.142. D15 height 2.25 bars 1.75ft 533mm. 


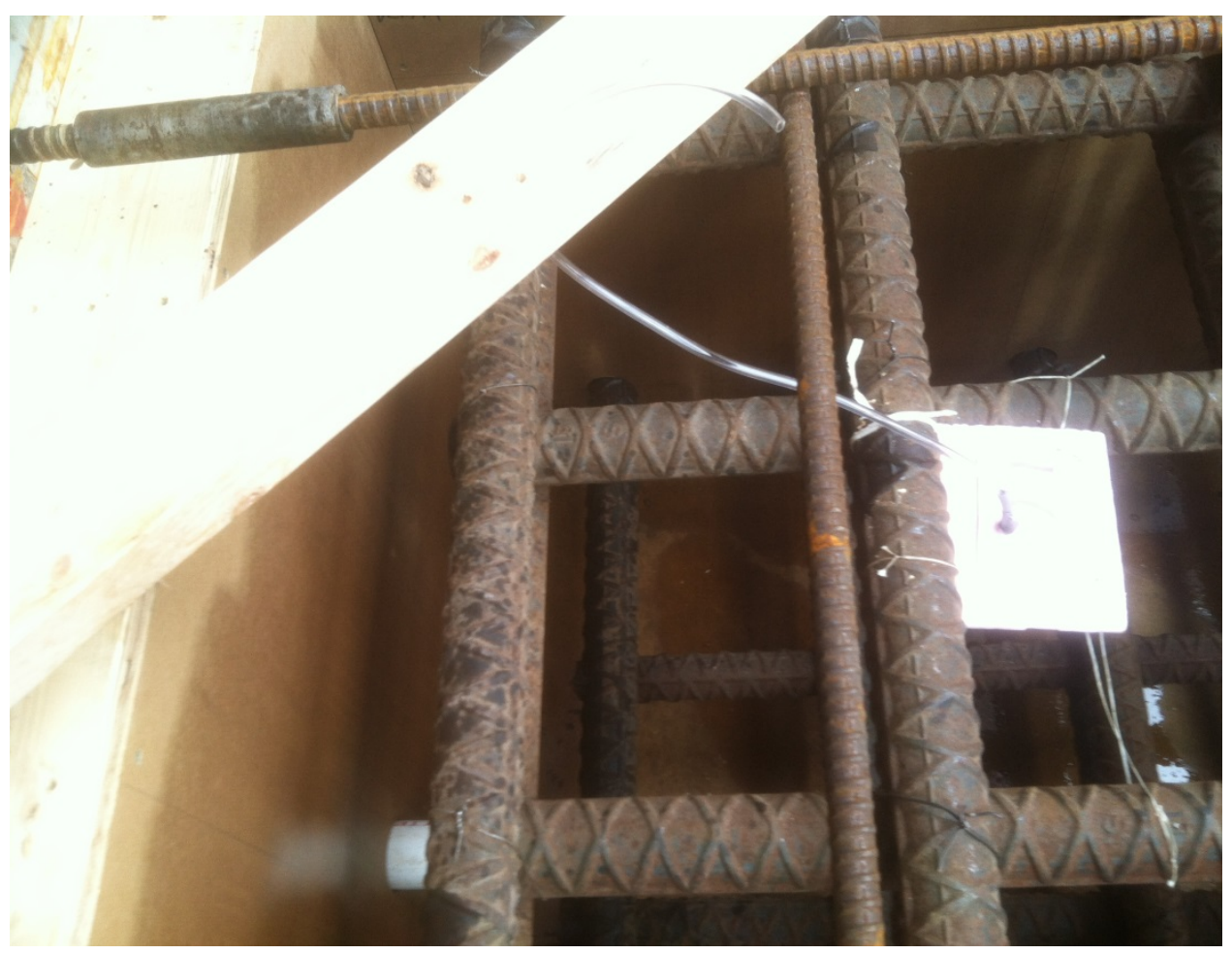

Fig. A.143. D15 length 2.25bars 1.75ft 533mm.

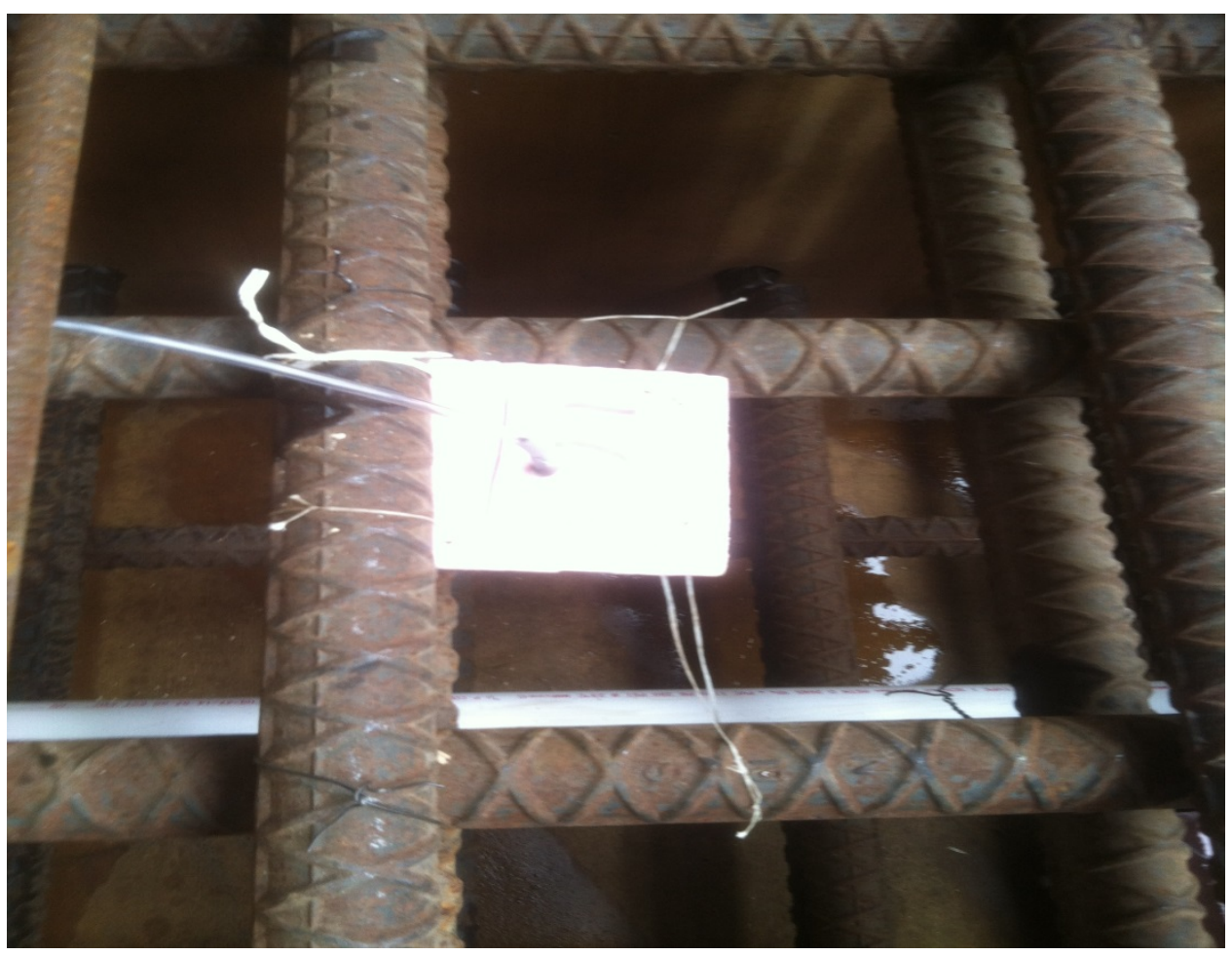

Fig. A.144. D15 R-depth bottom of top bar 168mm. 


\begin{tabular}{|c|c|c|}
\hline \multicolumn{3}{|c|}{ DEECCT TABLE } \\
\hline IO NUMBER & DESCRIPTION & САBE \\
\hline 01 & $\begin{array}{c}\text { POROUS HAL CYUNDER } \\
\text { (NO COVER) }\end{array}$ & \\
\hline D2 & $\begin{array}{l}\text { POROUS HALF CYINDER } \\
\text { (COVER) }\end{array}$ & \\
\hline D3 & $\begin{array}{l}\text { POROUS HALE CYUNDER } \\
\text { (NO COVER) }\end{array}$ & \\
\hline D4 & $\begin{array}{l}\text { POROUS HALF CYINDER } \\
\text { (COVER) }\end{array}$ & \\
\hline D5 & $\begin{array}{l}\text { POROUS HALF CYINDER } \\
\text { (COVER \& CRACK) }\end{array}$ & \\
\hline DG & PVC & \\
\hline 07 & PVC & \\
\hline DB & $\begin{array}{l}\text { DISSOLUNG STROFOAM } \\
\text { (THICK) }\end{array}$ & \\
\hline DQ & STTROFOAM (THICK) & \\
\hline 010 & STRROFOAM (THN) & \\
\hline D11 & PLDXGLASS & \\
\hline 012 & $\begin{array}{l}\text { DISSOLUNG STRROFOAM } \\
\text { (MEDUUM) }\end{array}$ & \\
\hline 013 & STRROFOAM (MEDOUM) & \\
\hline 014 & PLEXIGLASS & \\
\hline 015 & $\begin{array}{c}\text { DISSOLUNG STRROFOAM } \\
\text { (THN) }\end{array}$ & \\
\hline 016 & LUMEER $(2 \times 4)$ & \\
\hline 017 & GLOVES & \\
\hline 018 & $\begin{array}{l}\text { DEBOND DUCT TAPE } \\
\text { (ONE LAYCR) }\end{array}$ & \\
\hline 019 & $\begin{array}{l}\text { DEBOND DUCT TAPE } \\
\text { (MULT-LAYER) }\end{array}$ & \\
\hline 020 & MOUNG REBAR & \\
\hline
\end{tabular}

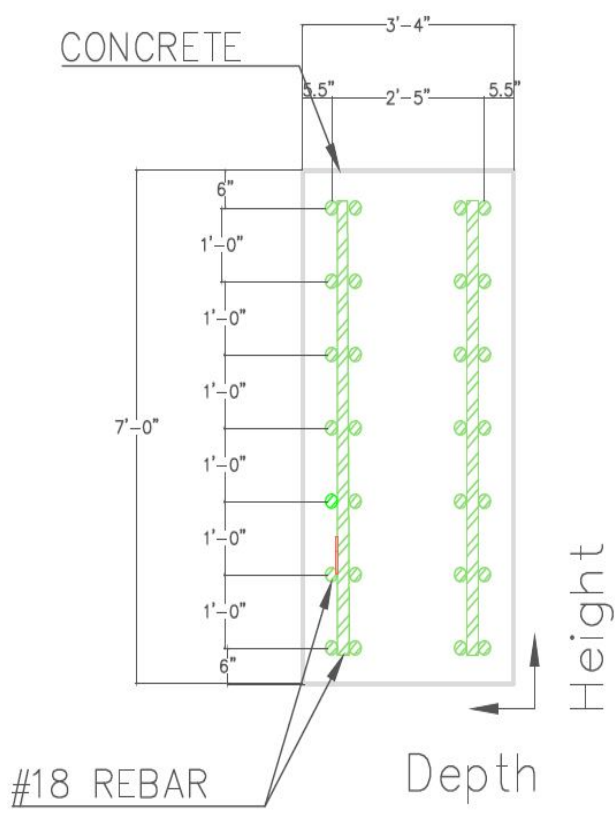

Fig. A.145. D15 height by depth.

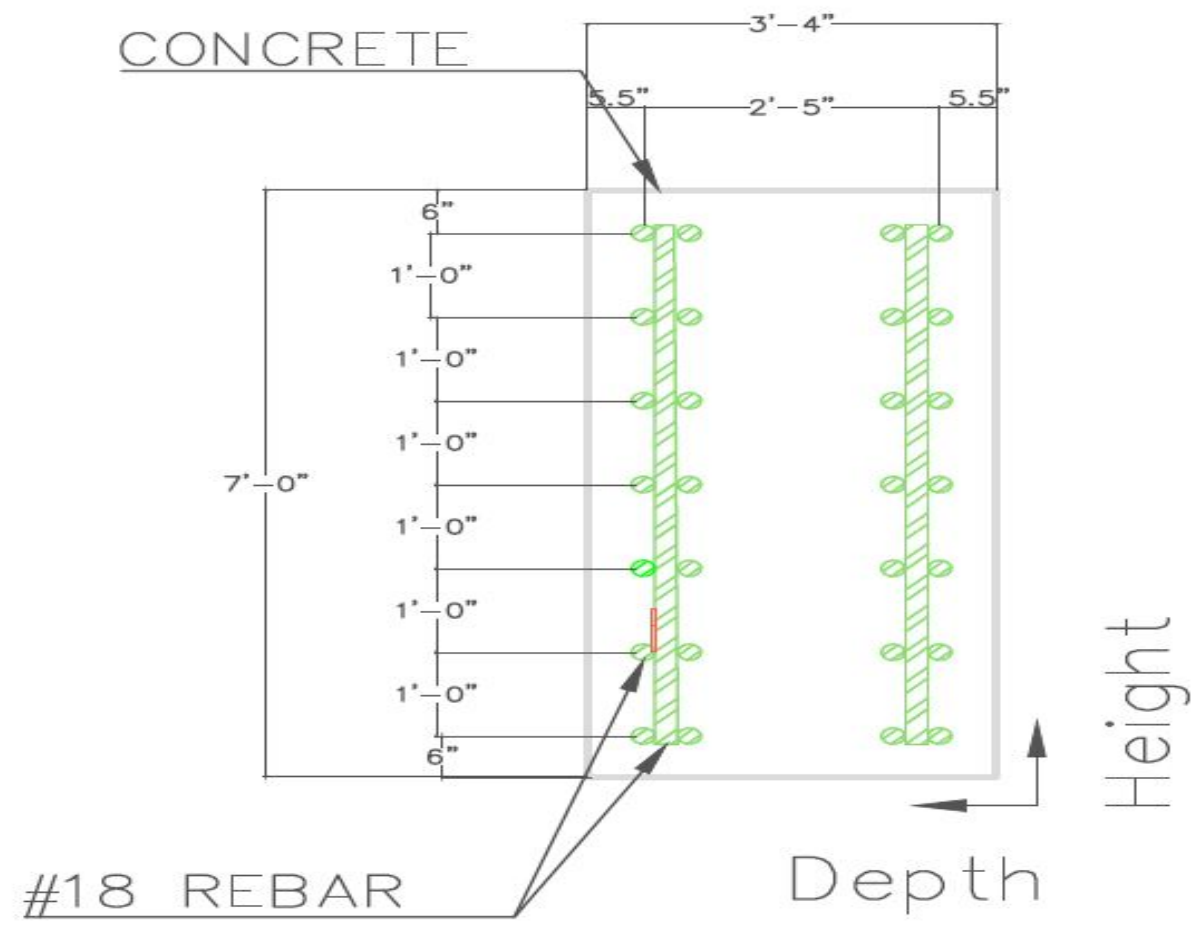

Fig. A.146. D15 height by depth NL. 


\begin{tabular}{|c|c|c|}
\hline \multicolumn{3}{|c|}{ DEFFCT TRABE } \\
\hline D Neverr & DEsGtPTON & บea \\
\hline or & 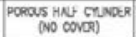 & \\
\hline 02 & 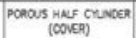 & \\
\hline Ds & 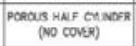 & \\
\hline os & 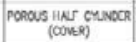 & \\
\hline 05 & $\begin{array}{l}\text { POOOUS HNF COMGER } \\
\text { (CONFA \& CROC) }\end{array}$ & \\
\hline$\infty$ & $\mathrm{PAC}$ & \\
\hline 07 & $\mathrm{Ax}$ & \\
\hline DB & $\begin{array}{l}\text { Dissa VWG smocom } \\
\text { (THIO) }\end{array}$ & \\
\hline$\infty$ & Sincoroum (inox) & \\
\hline D10 & Strocour (THA) & \\
\hline o11 & ponoa ass & \\
\hline 012 & 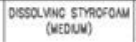 & \\
\hline 013 & stmporanu (NCDUV) & \\
\hline Dit & poxauss & \\
\hline 015 & $\begin{array}{c}\text { ossa vana sineoronu } \\
\text { (IIM) }\end{array}$ & \\
\hline 016 & unear $(2 x c)$ & \\
\hline or & aoves & \\
\hline 018 & 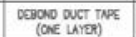 & \\
\hline 010 & 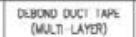 & \\
\hline 020 & NONOC RESR & \\
\hline
\end{tabular}

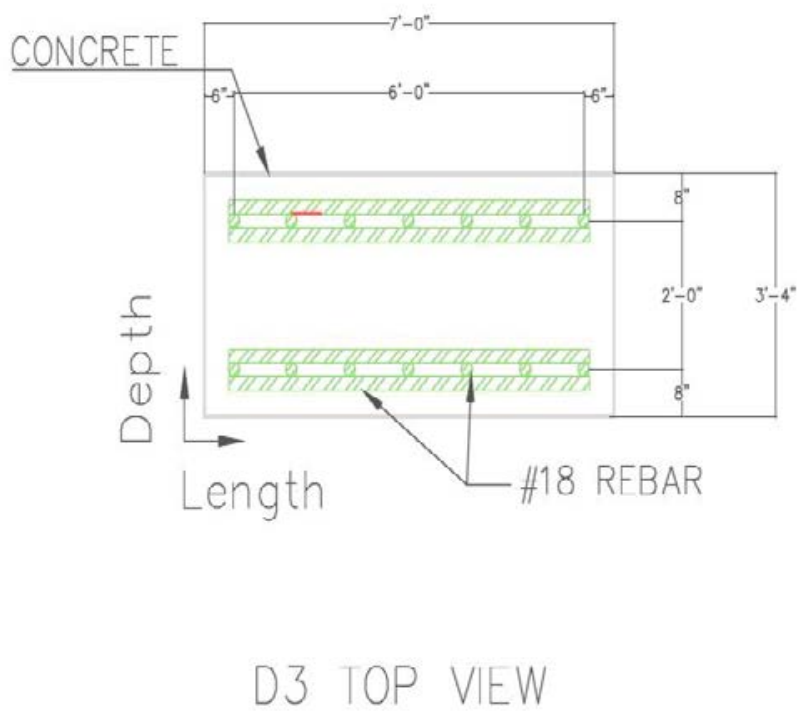

Fig. A.147. D15 length by depth.

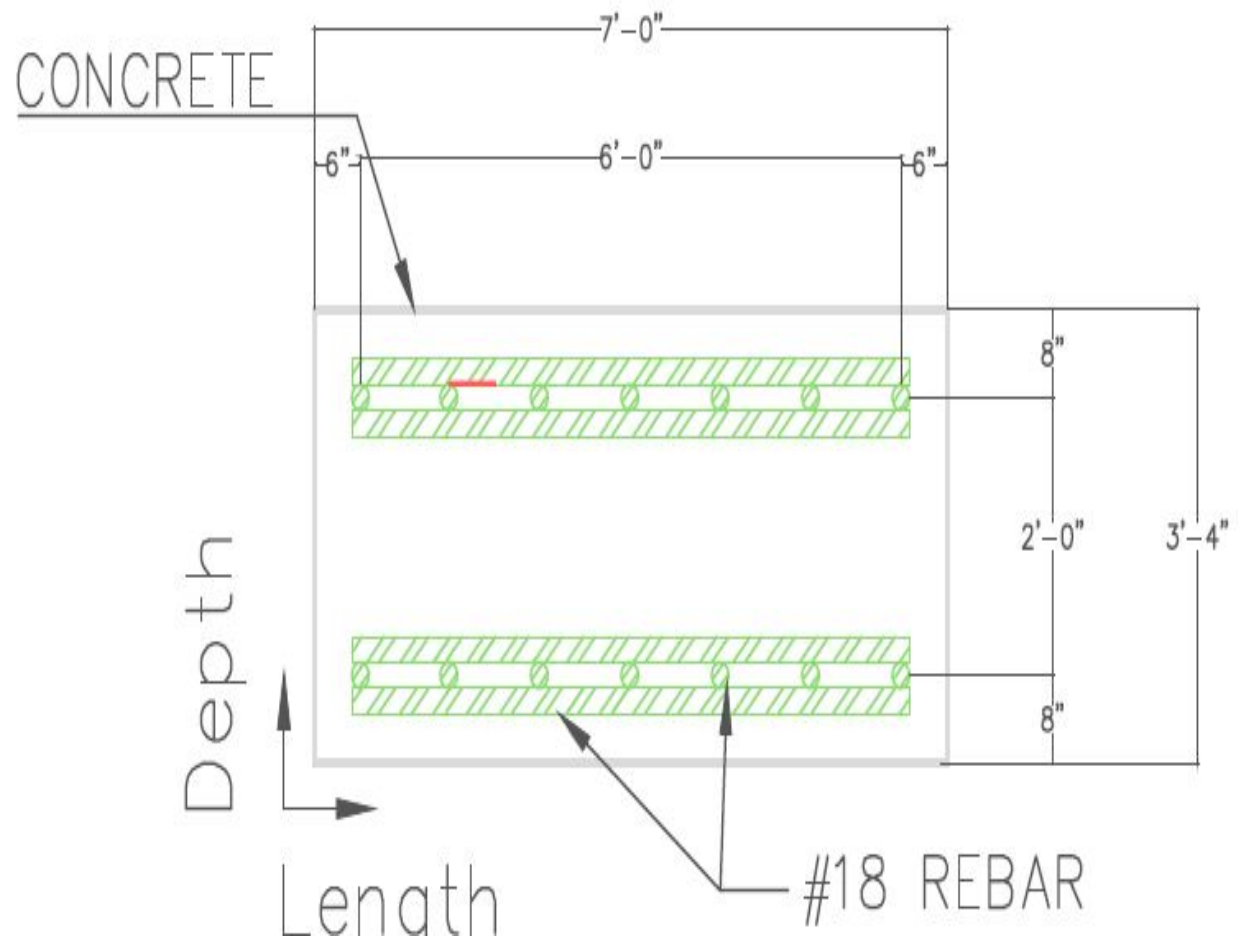

Fig. A.148. D15 length by depth NL 


\begin{tabular}{|c|c|c|}
\hline \multicolumn{3}{|c|}{ DULCT TNAUT } \\
\hline o musers & osscrpition & Weal \\
\hline on & $\begin{array}{l}\text { Pchous Haf enveer } \\
\text { (wo coves) }\end{array}$ & \\
\hline 02 & 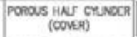 & \\
\hline as & 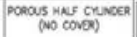 & \\
\hline of & 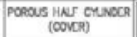 & \\
\hline os & 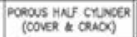 & \\
\hline$\infty$ & $P X$ & \\
\hline 07 & $p x$ & \\
\hline$D$ & 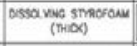 & \\
\hline$\infty$ & 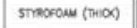 & \\
\hline 010 & stracouw (niw) & \\
\hline OtI & rodouss & \\
\hline 012 & 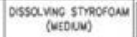 & \\
\hline ors & stmoronu (Meduv) & \\
\hline 014 & horauss & \\
\hline D15 & $\begin{array}{c}\text { ossa. vwa smpofonu } \\
\text { (TiN) }\end{array}$ & \\
\hline 016 & weat (2xi) & \\
\hline 017 & aovs & \\
\hline 018 & 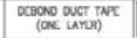 & \\
\hline Dto & 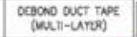 & \\
\hline 020 & NONNG RLave & \\
\hline
\end{tabular}

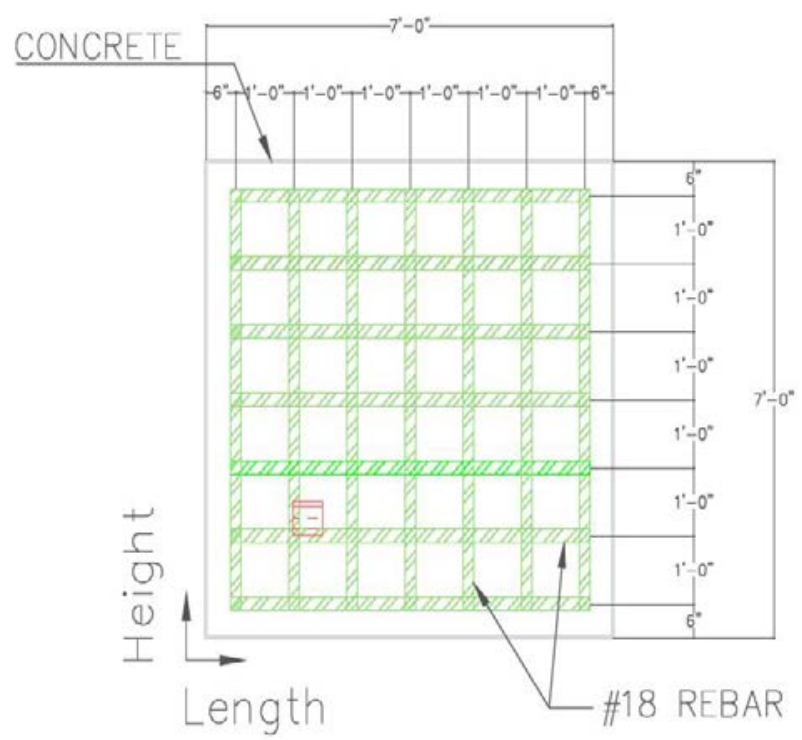

SIDE VIEW

Fig. A.149. D15 length by height.

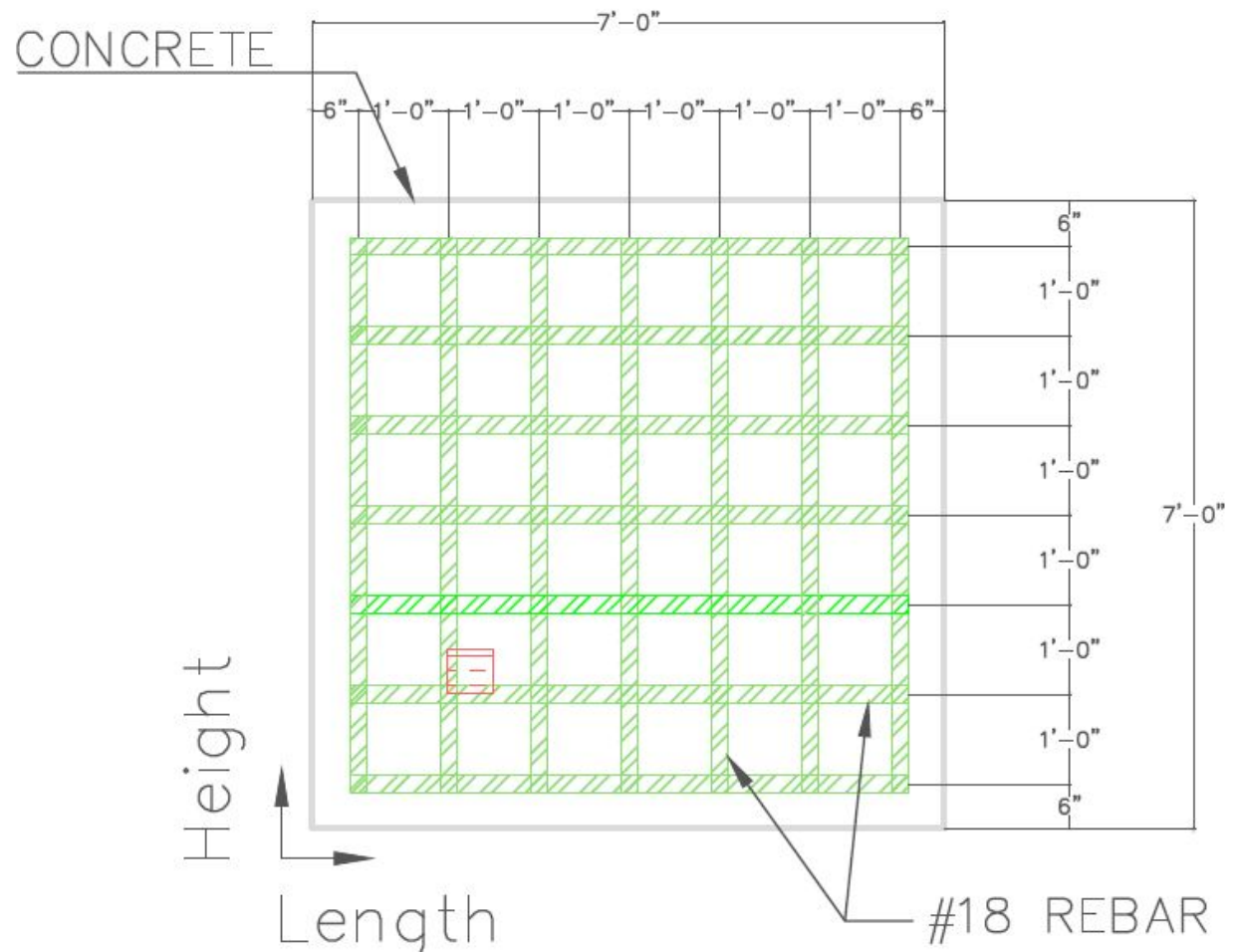

Fig. A.150. D15 length by height NL. 


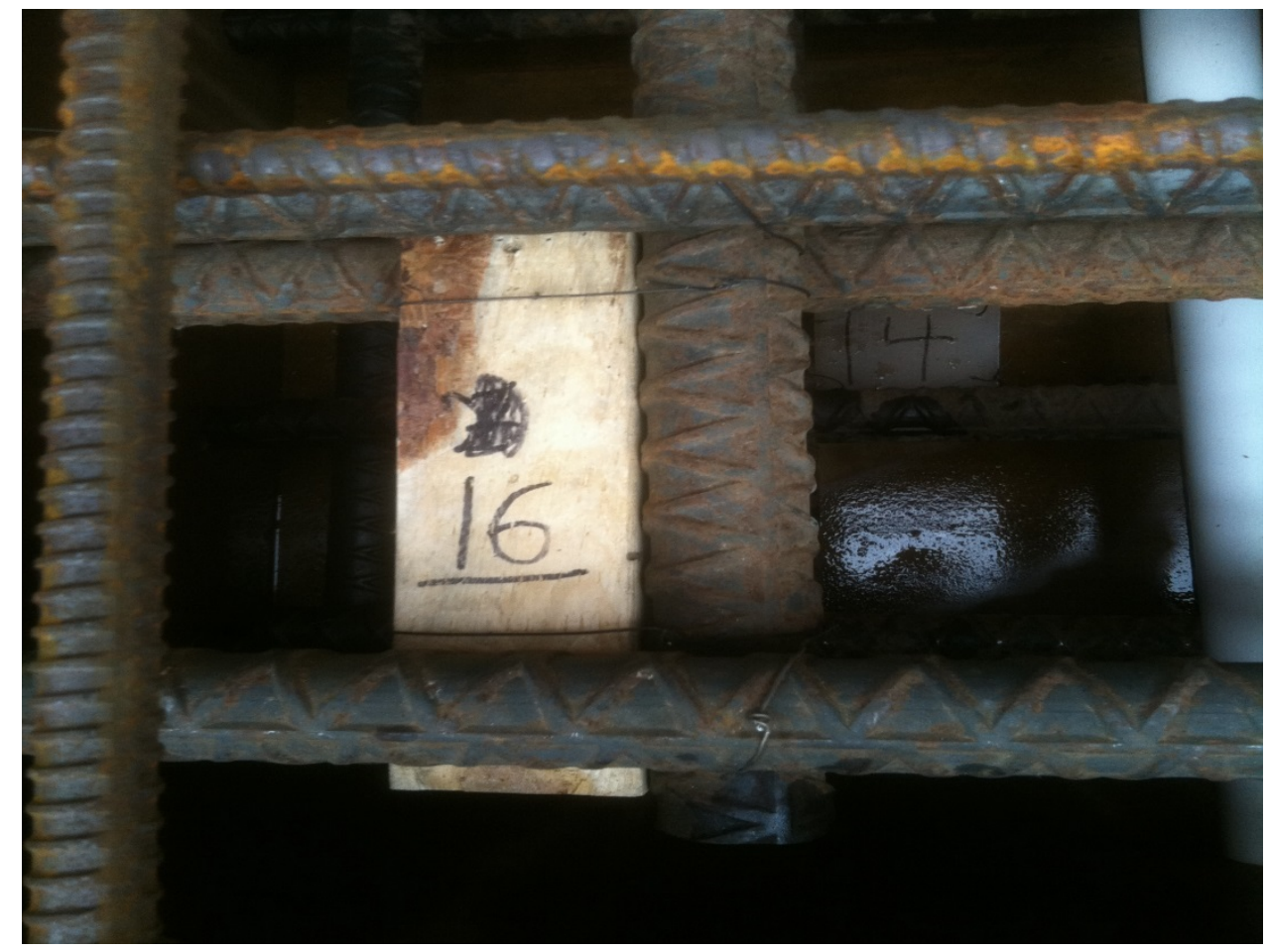

Fig. A.151. D16 close-up.

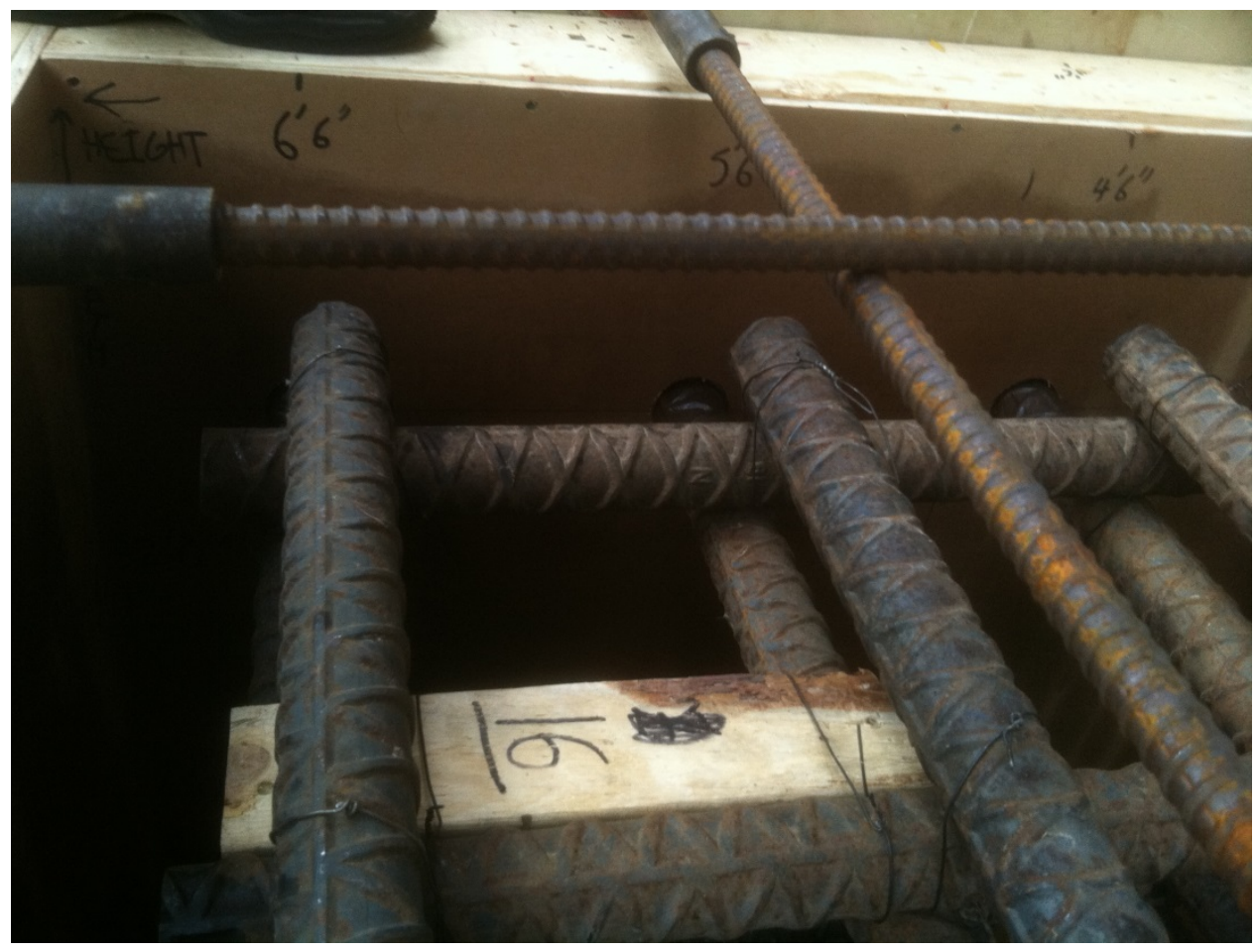

Fig. A.152. D16 height 6.5bars 6ft 1829mm. 


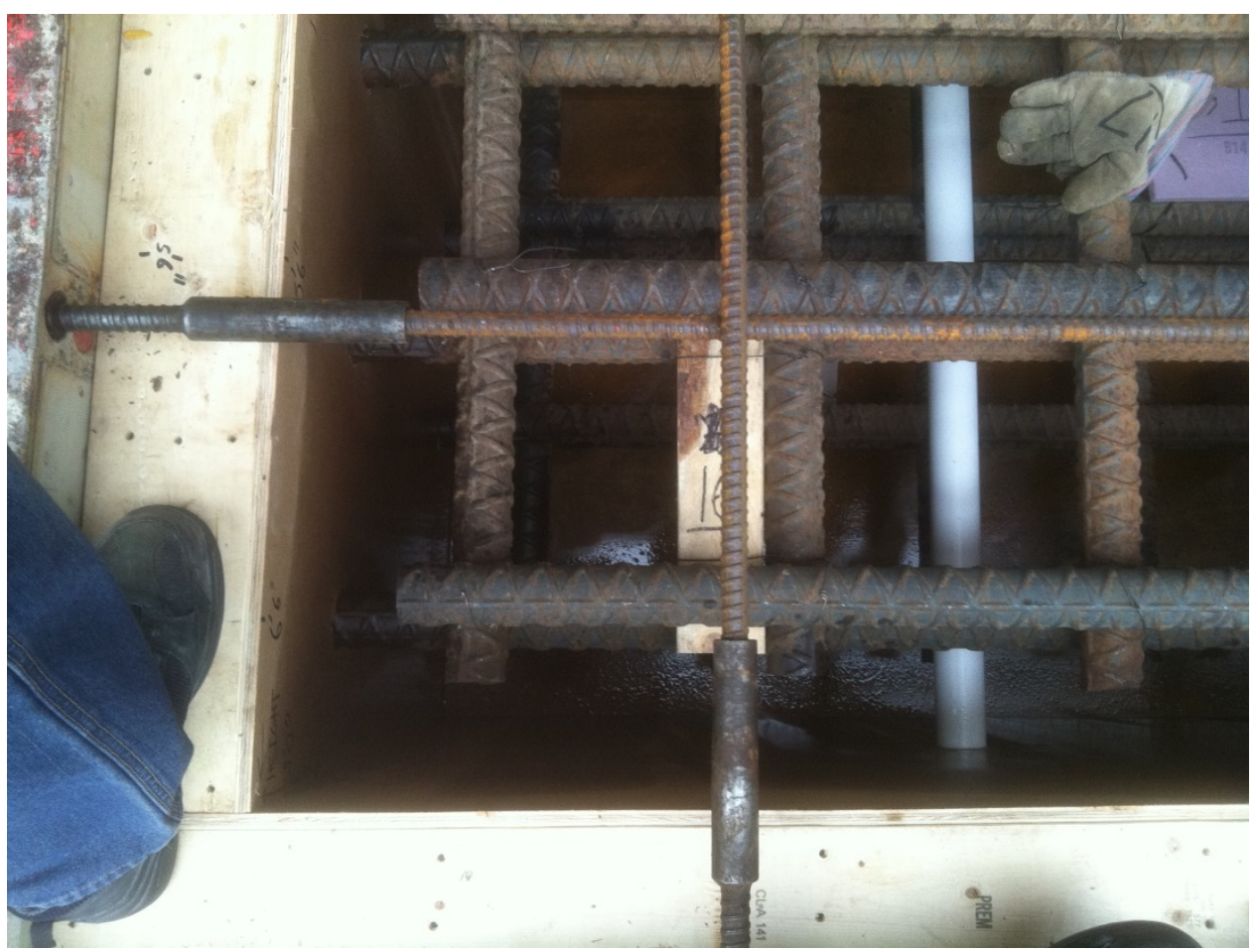

Fig. A.153. D16 length 6.25bars 5.75ft 753mm.

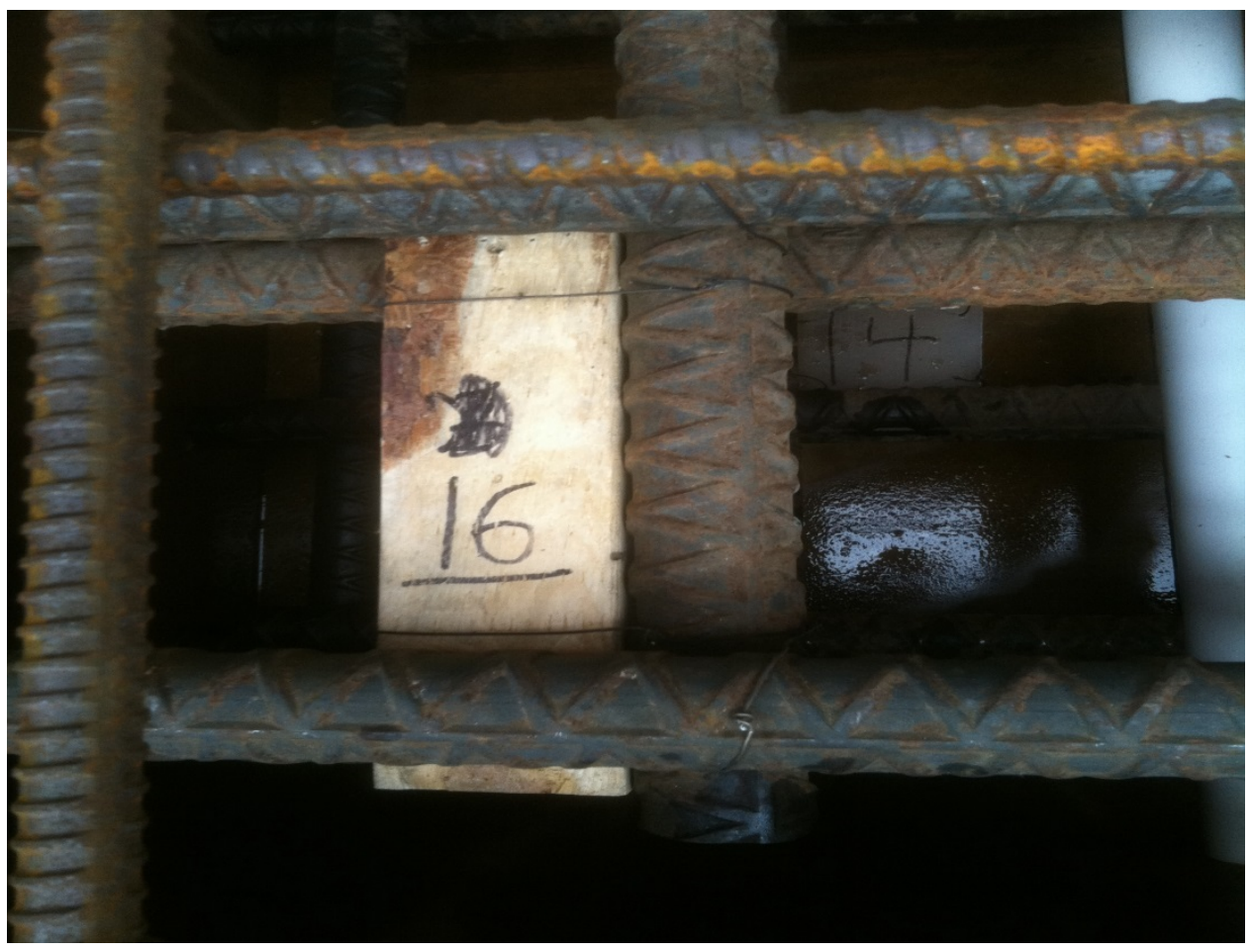

Fig. A.154. D16 R-depth middle of second bar $197 \mathrm{~mm}$. 


\begin{tabular}{|c|c|c|}
\hline \multicolumn{3}{|c|}{ DEECCT TABLE } \\
\hline ID NUMBER & DESCRIPTION & LABE \\
\hline D1 & $\begin{array}{l}\text { POROUS HALF CYINDER } \\
\text { (NO COVER) }\end{array}$ & \\
\hline 02 & $\begin{array}{l}\text { POROUS HALF CYINDER } \\
\text { (COVER) }\end{array}$ & \\
\hline 03 & $\begin{array}{l}\text { POROUS HALE CYUNDER } \\
\text { (NO COVER) }\end{array}$ & \\
\hline 04 & $\begin{array}{l}\text { POROUS HALF CYINDER } \\
\text { (COVER) }\end{array}$ & \\
\hline 05 & $\begin{array}{l}\text { POROUS HALF CYINDER } \\
\text { (COVER \& CRACK) }\end{array}$ & \\
\hline DG & PVC & \\
\hline D7 & PVC & \\
\hline DE & $\begin{array}{l}\text { DISSOLUNG STROFOAM } \\
\text { (THICK) }\end{array}$ & \\
\hline D9 & STYROFOAM (THIOK) & \\
\hline 010 & STYROFOAM (THIN) & \\
\hline D11 & PLEXIGLASS & \\
\hline D12 & $\begin{array}{l}\text { DISSOLUNG STRROFOAM } \\
\text { (MEDUUM) }\end{array}$ & \\
\hline 013 & STRROFOAM (MEDIUM) & \\
\hline D14 & PLEXIGLASS & \\
\hline 015 & $\begin{array}{c}\text { DISSOLUNG STROFOAM } \\
\text { (THN) }\end{array}$ & \\
\hline D16 & LUMEER $(2 \times 4)$ & \\
\hline D17 & GLovES & \\
\hline D18 & $\begin{array}{l}\text { DEBOND DUCT TAPE } \\
\text { (ONE LAYER) }\end{array}$ & \\
\hline 019 & $\begin{array}{l}\text { DEBOND DUCT TAPE } \\
\text { (MULT-LAYRR) }\end{array}$ & \\
\hline 020 & MOUNG REBAR & \\
\hline
\end{tabular}

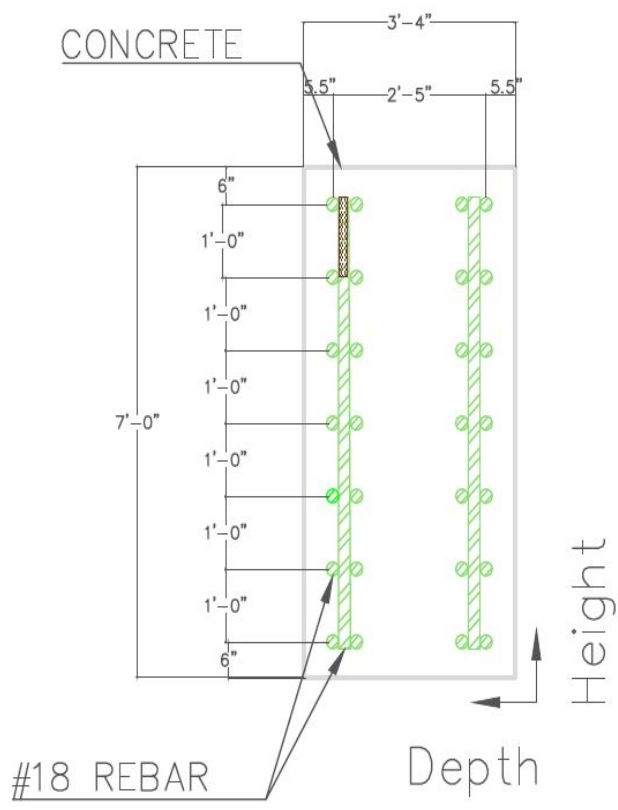

Fig. A.155. D16 height by depth.

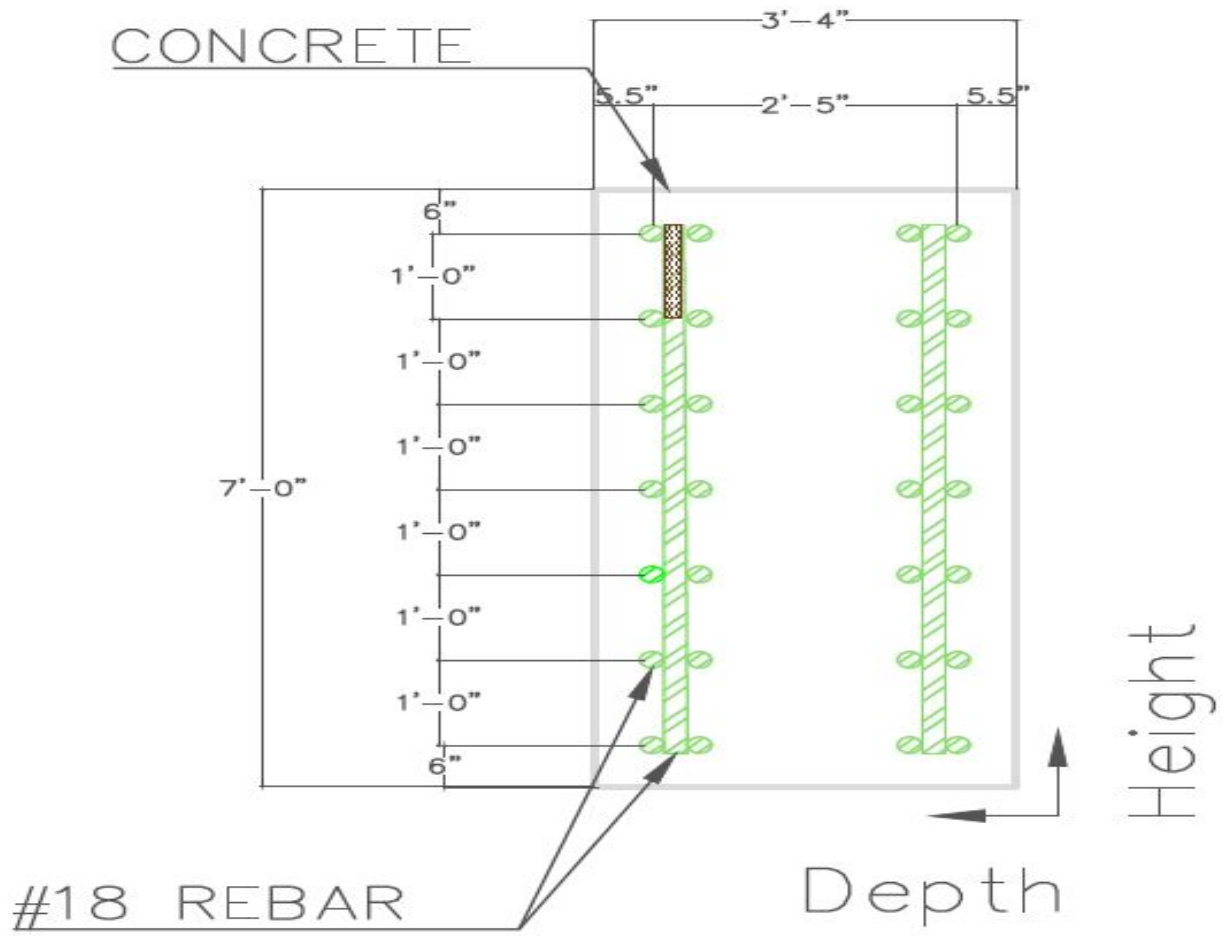

Fig. A.156. D16 height by depth NL. 


\begin{tabular}{|c|c|c|}
\hline \multicolumn{3}{|c|}{ DEFECT TAQLE } \\
\hline D nuedr & OCSOAPTIOA & won \\
\hline or & 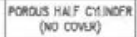 & \\
\hline 02 & $\begin{array}{l}\text { POROOS INS CYUSECR } \\
\text { (CONER) }\end{array}$ & \\
\hline os & 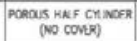 & \\
\hline Da & 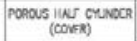 & \\
\hline DS & $\begin{array}{l}\text { POROUS HN CYUNOER } \\
\text { (COVDR \& COAO) }\end{array}$ & \\
\hline$\infty 6$ & pve & \\
\hline דם & $P Q C$ & \\
\hline 08 & $\begin{array}{l}\text { Oassa vens Smporoau } \\
\text { (THIO) }\end{array}$ & \\
\hline Do & STMoroun (THiox) & \\
\hline 010 & smeorow (niN) & \\
\hline on & pLrocuss & \\
\hline on & 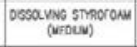 & \\
\hline Dis & streacow (MEDUU) & \\
\hline 014 & nuxiass & \\
\hline 015 & $\begin{array}{c}\text { ossayne smpofon } \\
\text { (nim) }\end{array}$ & \\
\hline 016 & LNGER (2xi) & \\
\hline 017 & Qoves & \\
\hline 010 & $\begin{array}{l}\text { OCDOPOO OUCT TNPE } \\
\text { (AC UACR) }\end{array}$ & \\
\hline 019 & 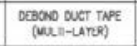 & \\
\hline 020 & WOWNO REMR & \\
\hline
\end{tabular}

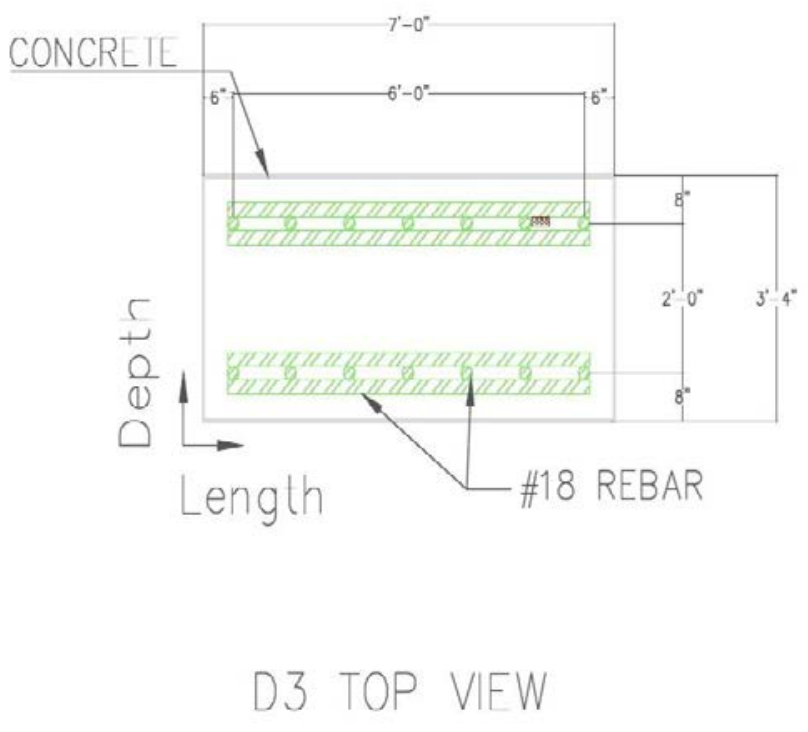

Fig. A.157. D16 length by depth.

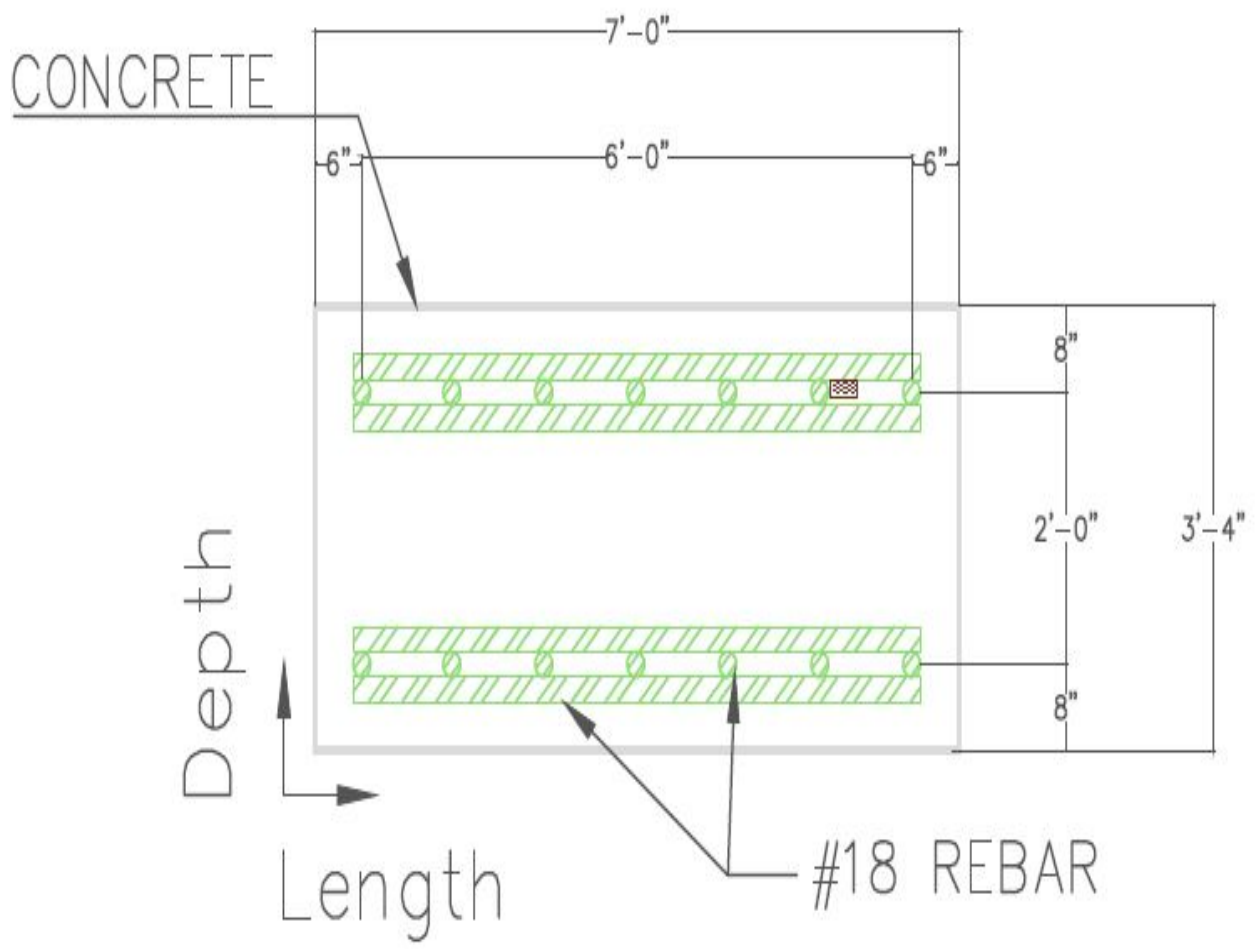

Fig. A.158. D16 length by depth NL 

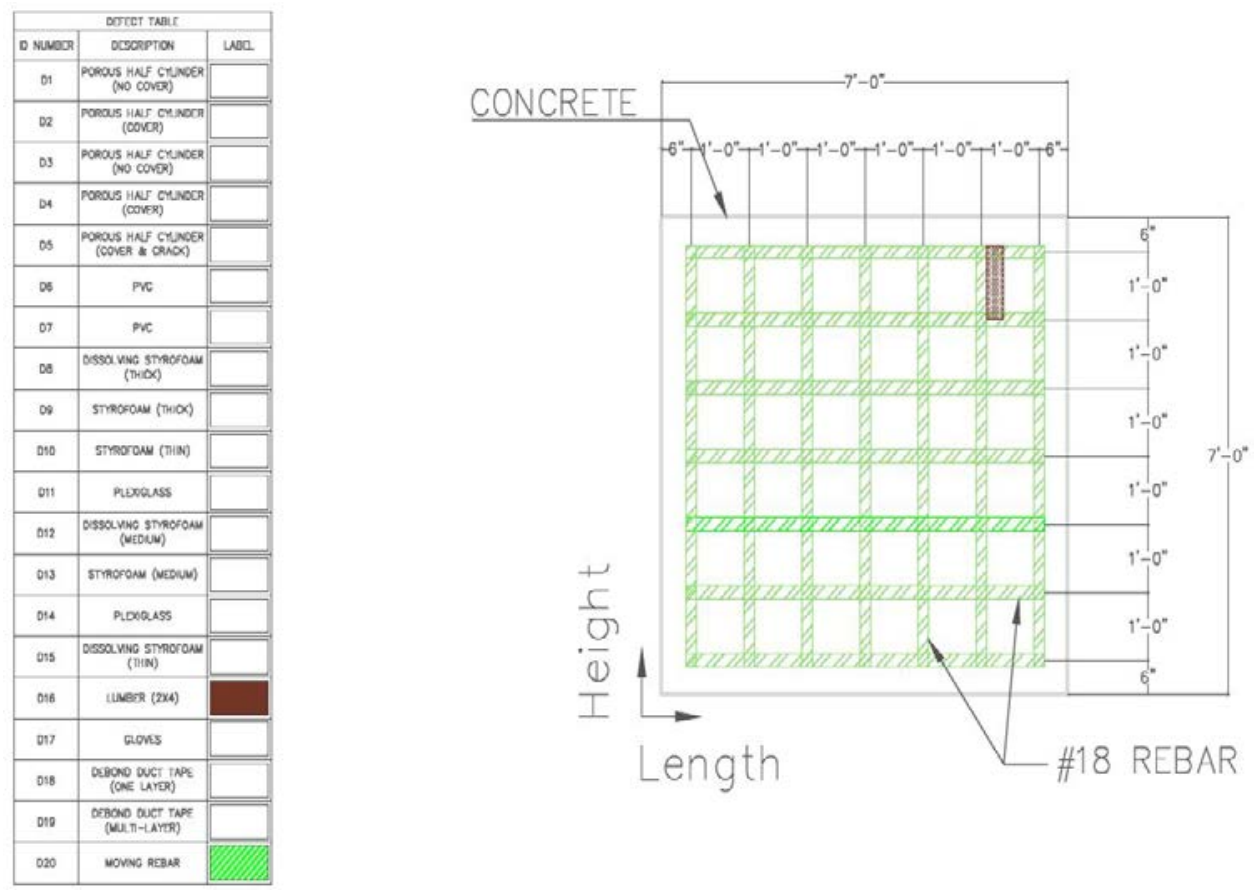

SIDE VIEW

Fig. A.159. D16 length by height.

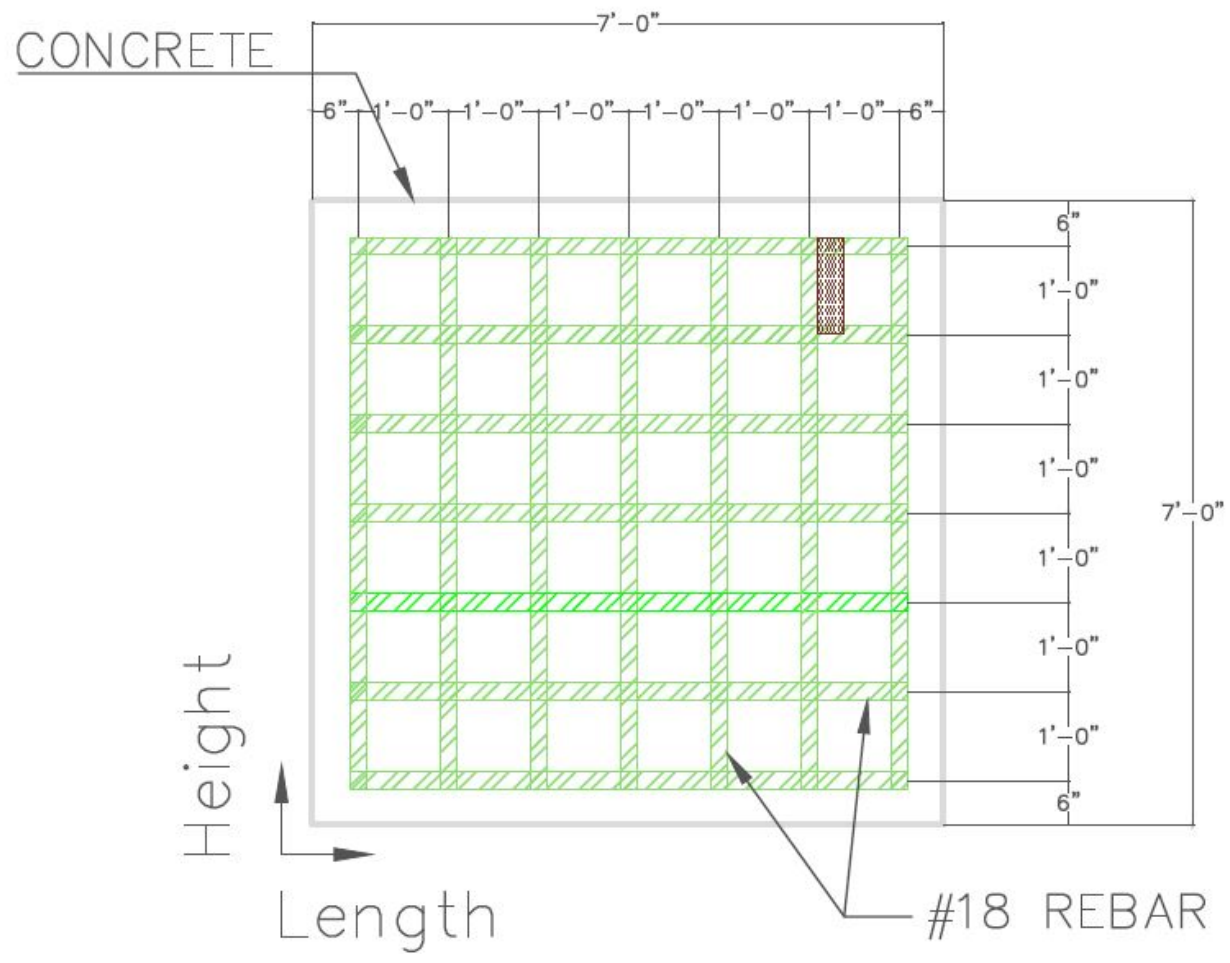

Fig. A.160. D16 length by height NL. 


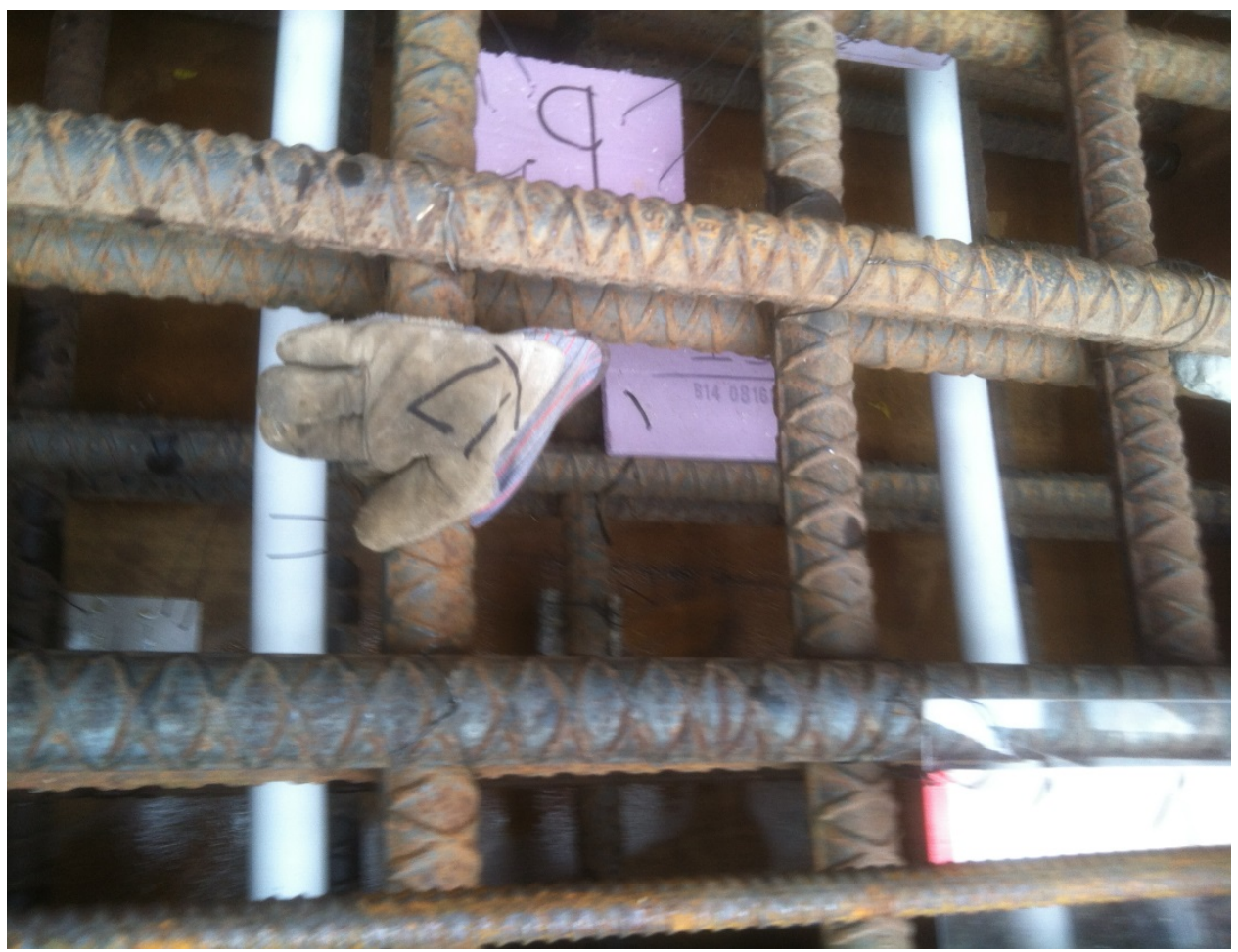

Fig. A.161. D17 close-up.

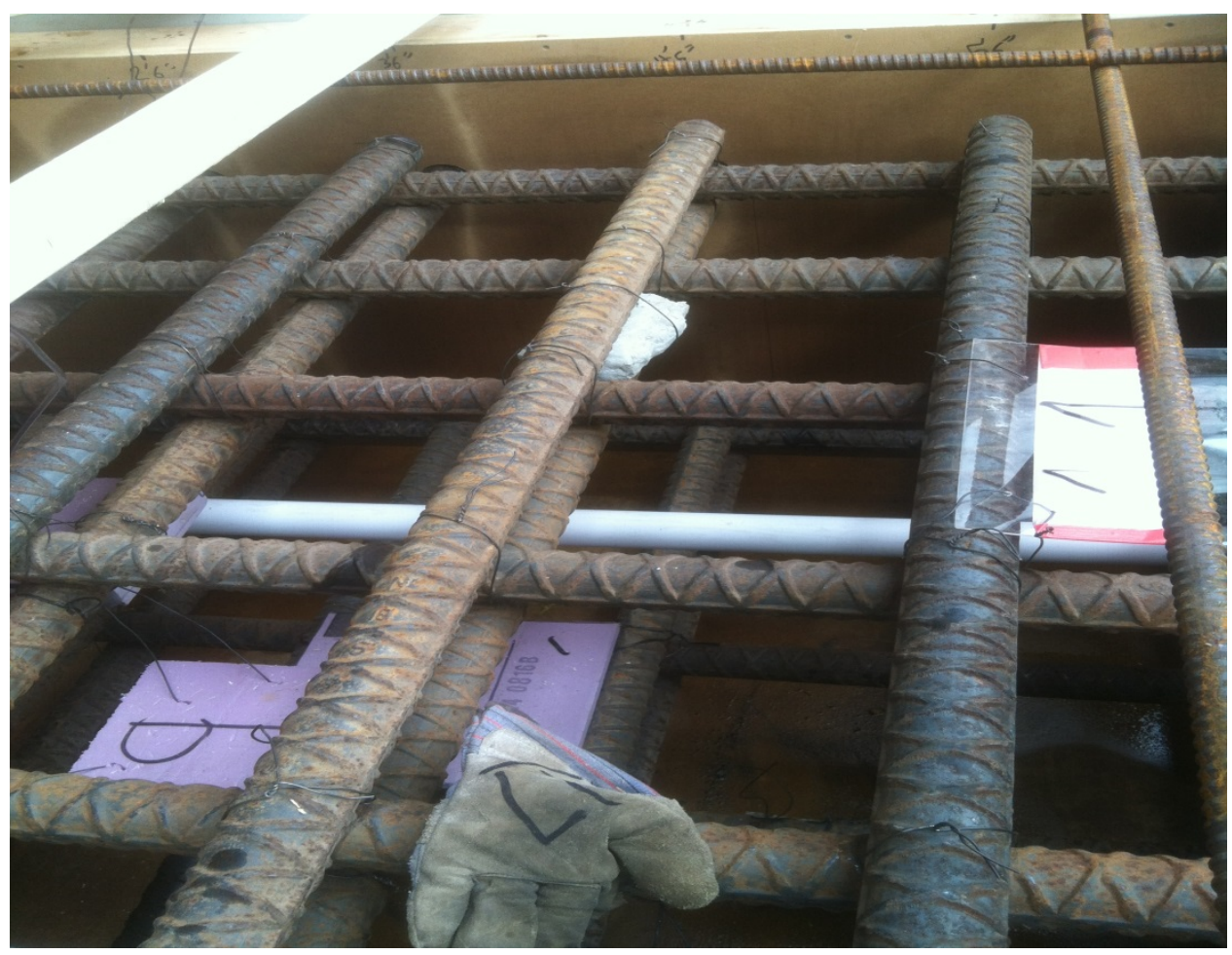

Fig. A.162. D17 height 5.5bars 5ft 1524mm. 


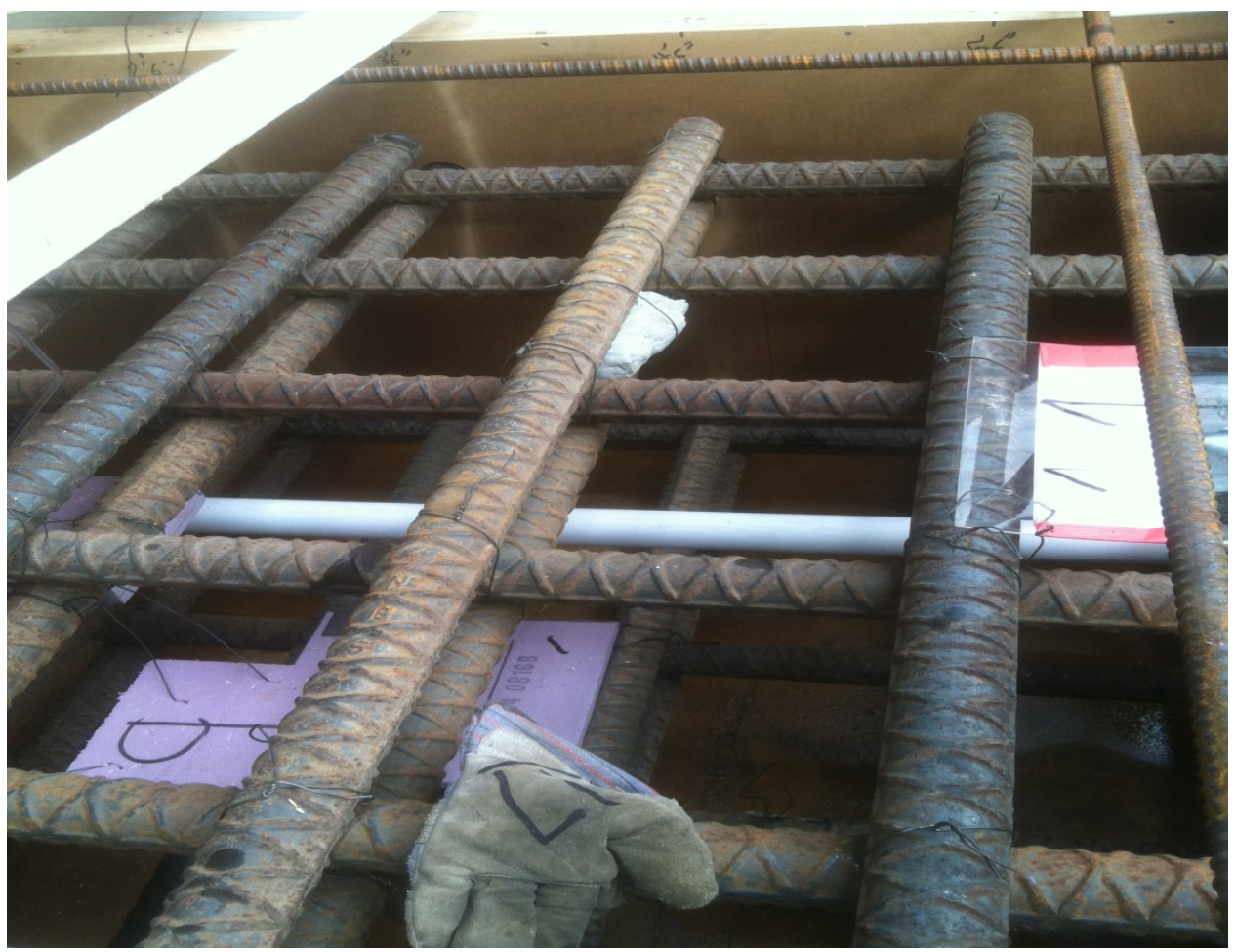

Fig. A.163. D17 length 5bars 4.5ft 1372mm.

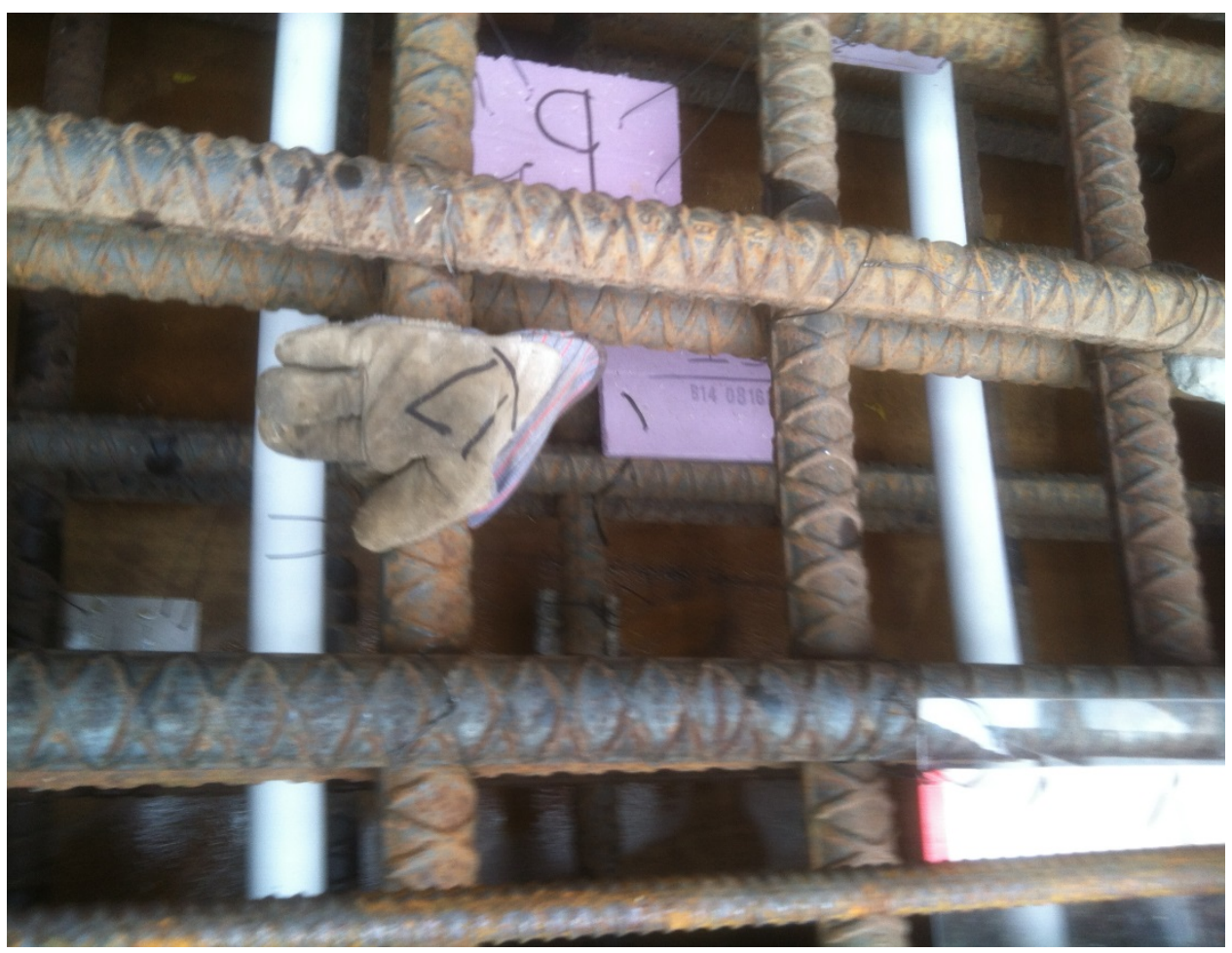

Fig. A.164. D17 R-depth top of second bar 168mm. 


\begin{tabular}{|c|c|c|}
\hline \multicolumn{3}{|c|}{ DEFECT TABLE } \\
\hline ID NUMBER & DESCRIPTION & LABE \\
\hline 01 & $\begin{array}{l}\text { POROUS HALF CYINDER } \\
\text { (NO COVER) }\end{array}$ & \\
\hline 02 & $\begin{array}{l}\text { POROUS HALF CYINDER } \\
\text { (COVER) }\end{array}$ & \\
\hline D3 & \begin{tabular}{|l|} 
POROUS HALF CYINDER \\
(NO COVER)
\end{tabular} & \\
\hline 04 & $\begin{array}{l}\text { POROUS HALF CYINOER } \\
\text { (COVER) }\end{array}$ & \\
\hline D5 & \begin{tabular}{|} 
POROUS HALF CYINOER \\
(COVER \& CRACK)
\end{tabular} & \\
\hline 06 & PVC & \\
\hline 07 & PVC & \\
\hline D8 & $\begin{array}{l}\text { DISSOLUNG SIRROFOAM } \\
\text { (THICK) }\end{array}$ & \\
\hline Dg & STTROFOAM (THICK) & \\
\hline 010 & STYROFOAM (THIN) & \\
\hline 011 & PLEXIGLASS & \\
\hline 012 & \begin{tabular}{l|} 
DISSOLUNG STRROFOAM \\
(MEDUUM)
\end{tabular} & \\
\hline 013 & STYROFOAM (MEDIUM) & \\
\hline 014 & PLEXIGLASS & \\
\hline 015 & $\underset{\text { DISSOLUNG STROFOAM }}{(\text { THN) }}$ & \\
\hline 016 & LUMBER $(2 \times 4)$ & \\
\hline 017 & GLOVES & \\
\hline D18 & $\begin{array}{l}\text { DEBONO DUCT TAPE } \\
\text { (ONE LAYER) }\end{array}$ & \\
\hline 019 & $\begin{array}{l}\text { DEBONO DUCT TAPE } \\
\text { (MULT-LAYER) }\end{array}$ & \\
\hline 020 & MOUNG REBAR & \\
\hline
\end{tabular}

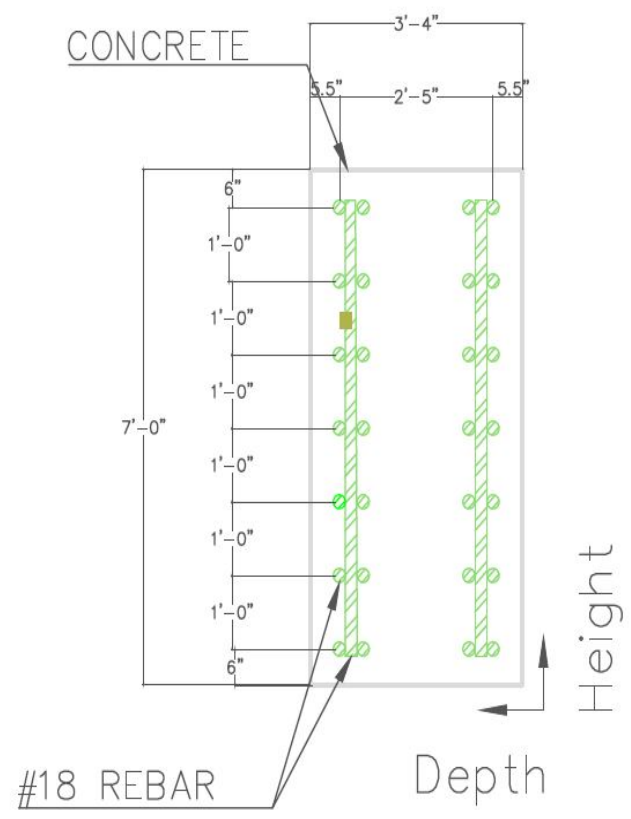

Fig. A.165. D17 height by depth.

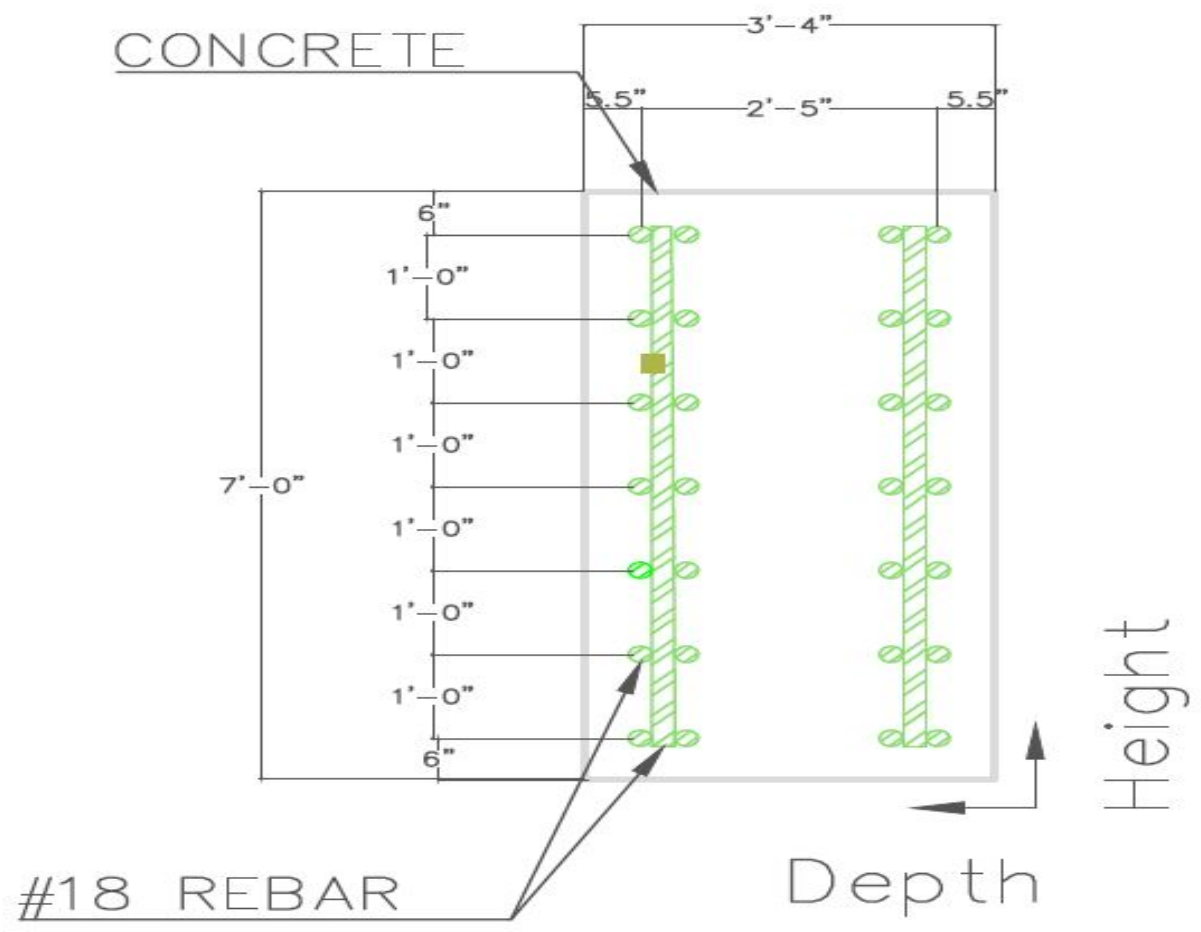

Fig. A.166. D17 height by depth NL. 


\begin{tabular}{|c|c|c|}
\hline \multicolumn{3}{|c|}{ OFFELT TRAEF } \\
\hline 0 Naver & DEsQRPTON & Wo2 \\
\hline of & 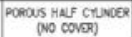 & \\
\hline 02 & 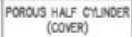 & \\
\hline D3 & 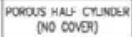 & \\
\hline as & 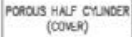 & \\
\hline os & 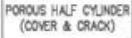 & \\
\hline D6 & PC & \\
\hline ø7 & $p x$ & \\
\hline 06 & $\begin{array}{l}\text { orssaver simporam } \\
\text { (7) }\end{array}$ & \\
\hline Do & simaroun (IHCX) & \\
\hline 010 & snecrow (TTM) & \\
\hline o11 & noxauss & \\
\hline 012 & 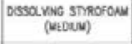 & \\
\hline 013 & smporows (ncouw) & \\
\hline DrA & podocuss & \\
\hline Dis & $\begin{array}{c}\text { Dessaving smarow } \\
\text { (Tin) }\end{array}$ & \\
\hline 016 & wher (2x) & \\
\hline का & cooves & \\
\hline ois & $\begin{array}{l}\text { OCBODO DUCT TNR } \\
\text { (ONE LATRE) }\end{array}$ & \\
\hline 019 & 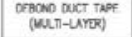 & \\
\hline $0 x 0$ & WOWNG RFRAR & \\
\hline
\end{tabular}

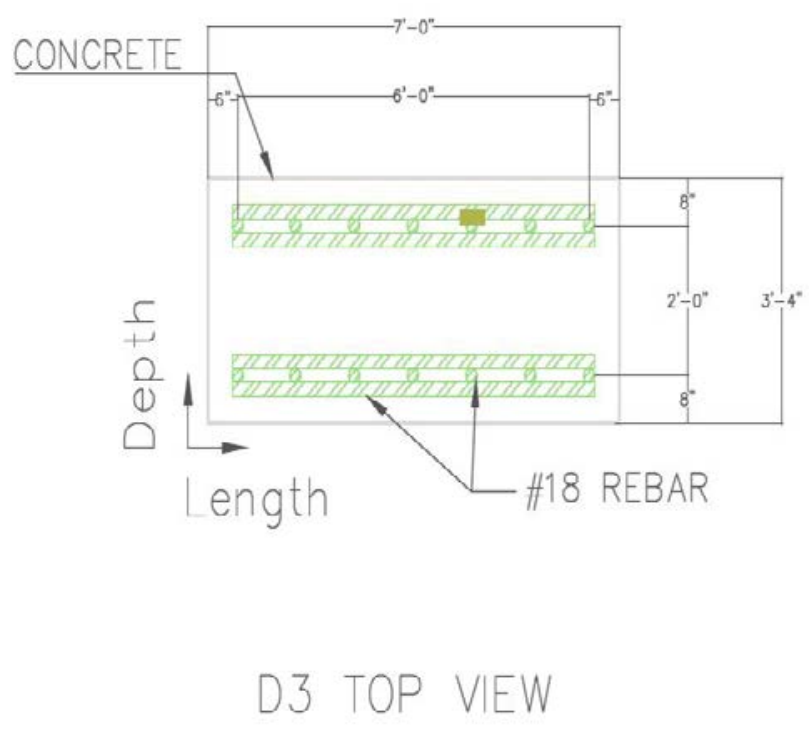

Fig. A.167. D17 length by depth.

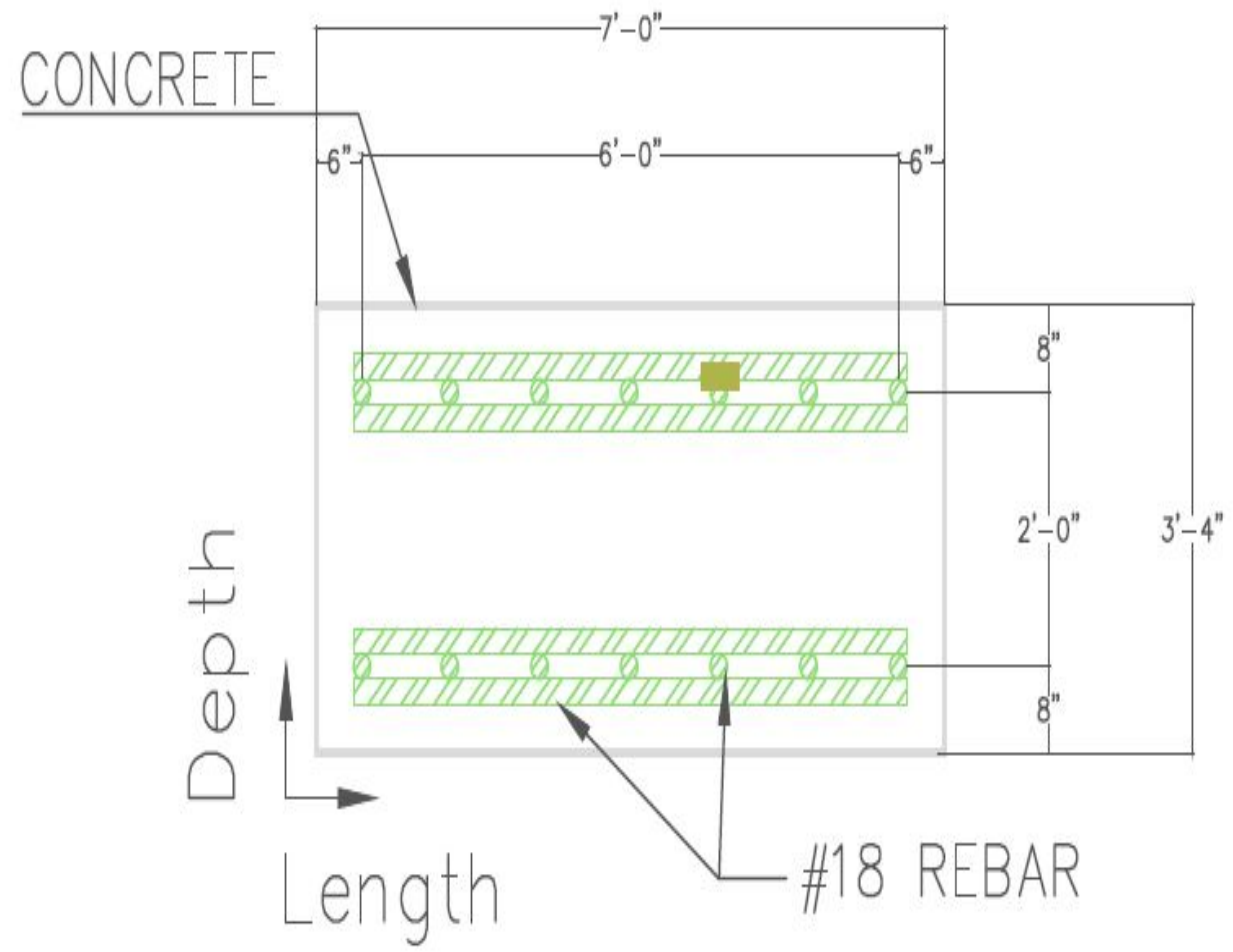

Fig. A.168. D17 length by depth NL. 


\begin{tabular}{|c|c|c|}
\hline \multicolumn{3}{|c|}{ OETCET ThaC: } \\
\hline O NeNAER & DESCRPTON & wan. \\
\hline or & 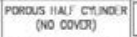 & \\
\hline 02 & 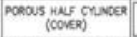 & \\
\hline as & 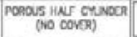 & \\
\hline od & 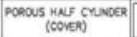 & \\
\hline 00 & 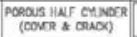 & \\
\hline$\infty$ & ne & \\
\hline 07 & PNe & \\
\hline$\infty$ & 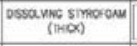 & \\
\hline 09 & sthorow (niod) & \\
\hline 910 & strocolour (trat) & \\
\hline on & prowass & \\
\hline 012 & $\begin{array}{l}\text { Dessa uns simoronu } \\
\text { (NCOUW) }\end{array}$ & \\
\hline OAs & stmerour (Mrouw) & \\
\hline 014 & proveuss & \\
\hline 015 & 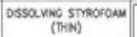 & \\
\hline vor & wese $(2 x)$ & \\
\hline 017 & coves & \\
\hline 018 & 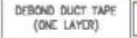 & \\
\hline 019 & 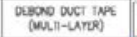 & \\
\hline 020 & wouso RCONR & \\
\hline
\end{tabular}

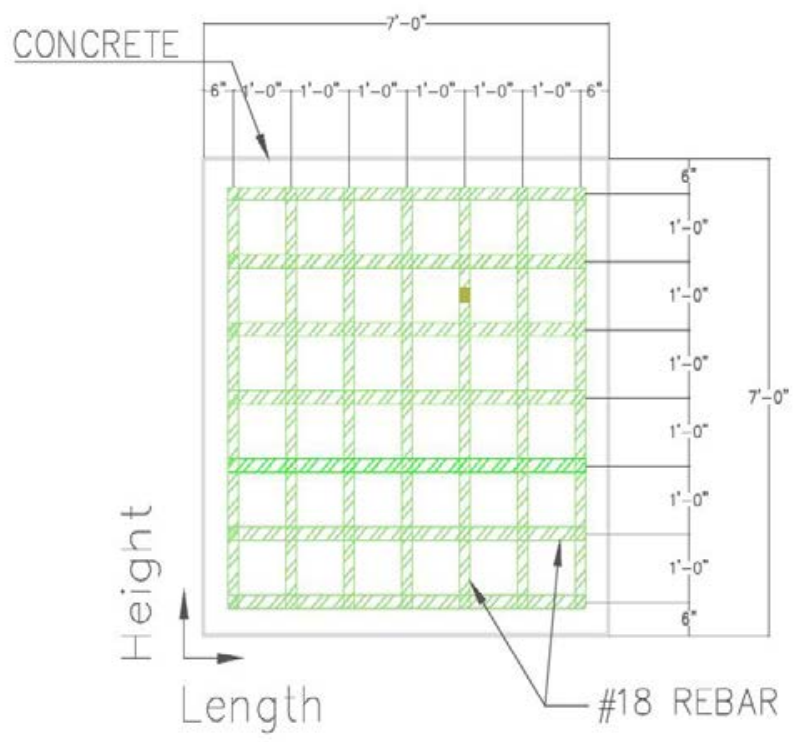

SIDE VIEW

Fig. A.169. D17 length by height.

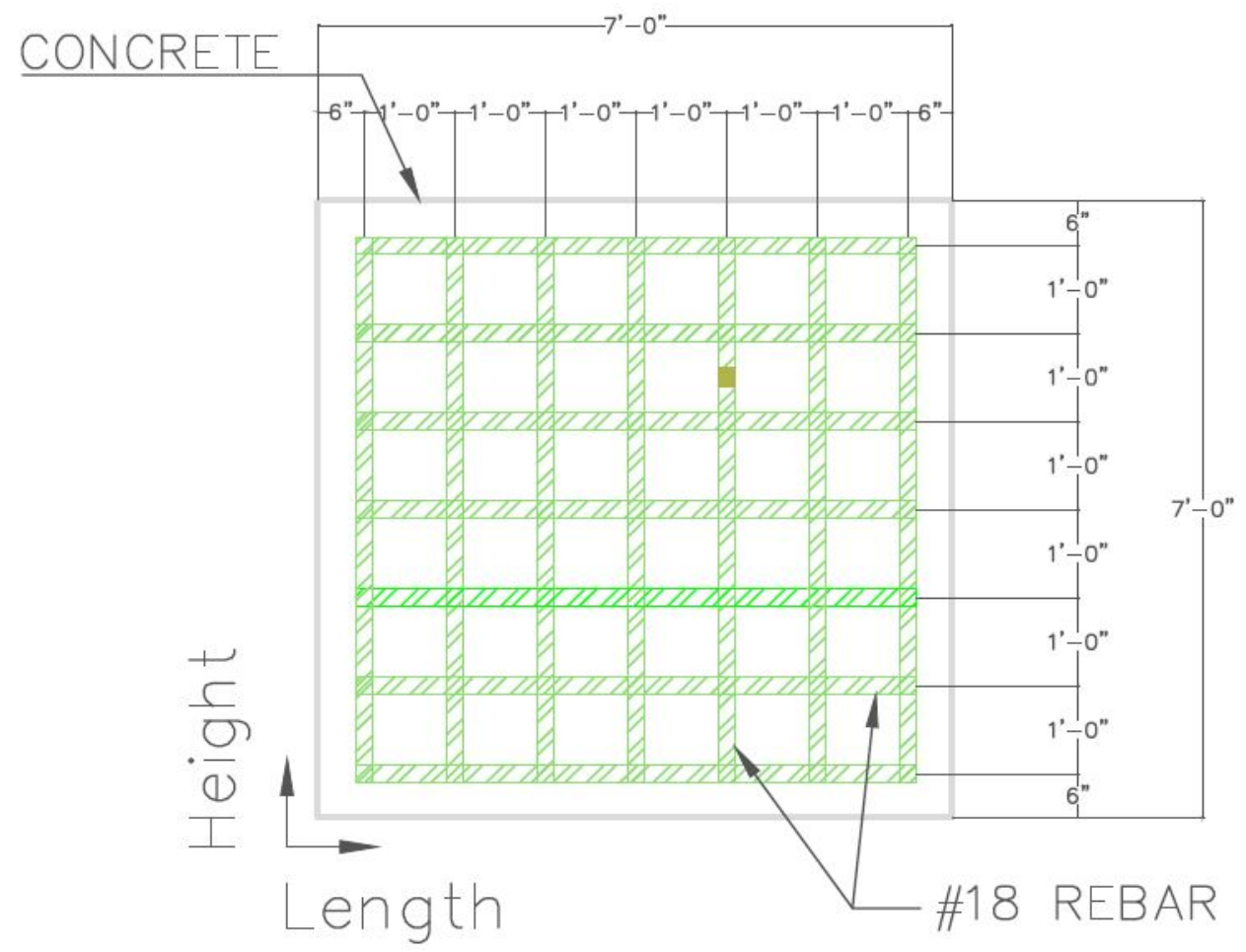

Fig. A.170. D17 length by height NL. 


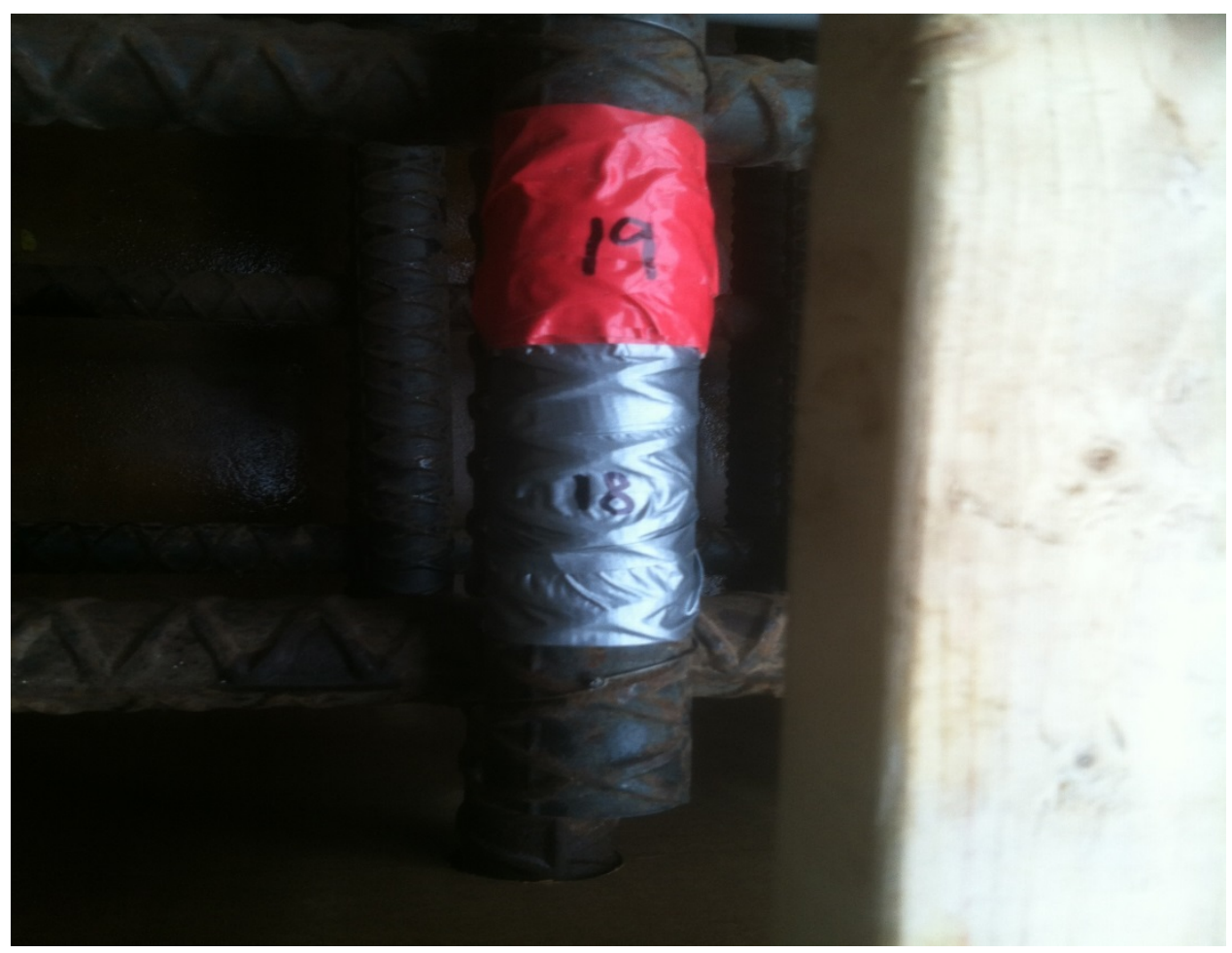

Fig. A.171. D18 close-up.

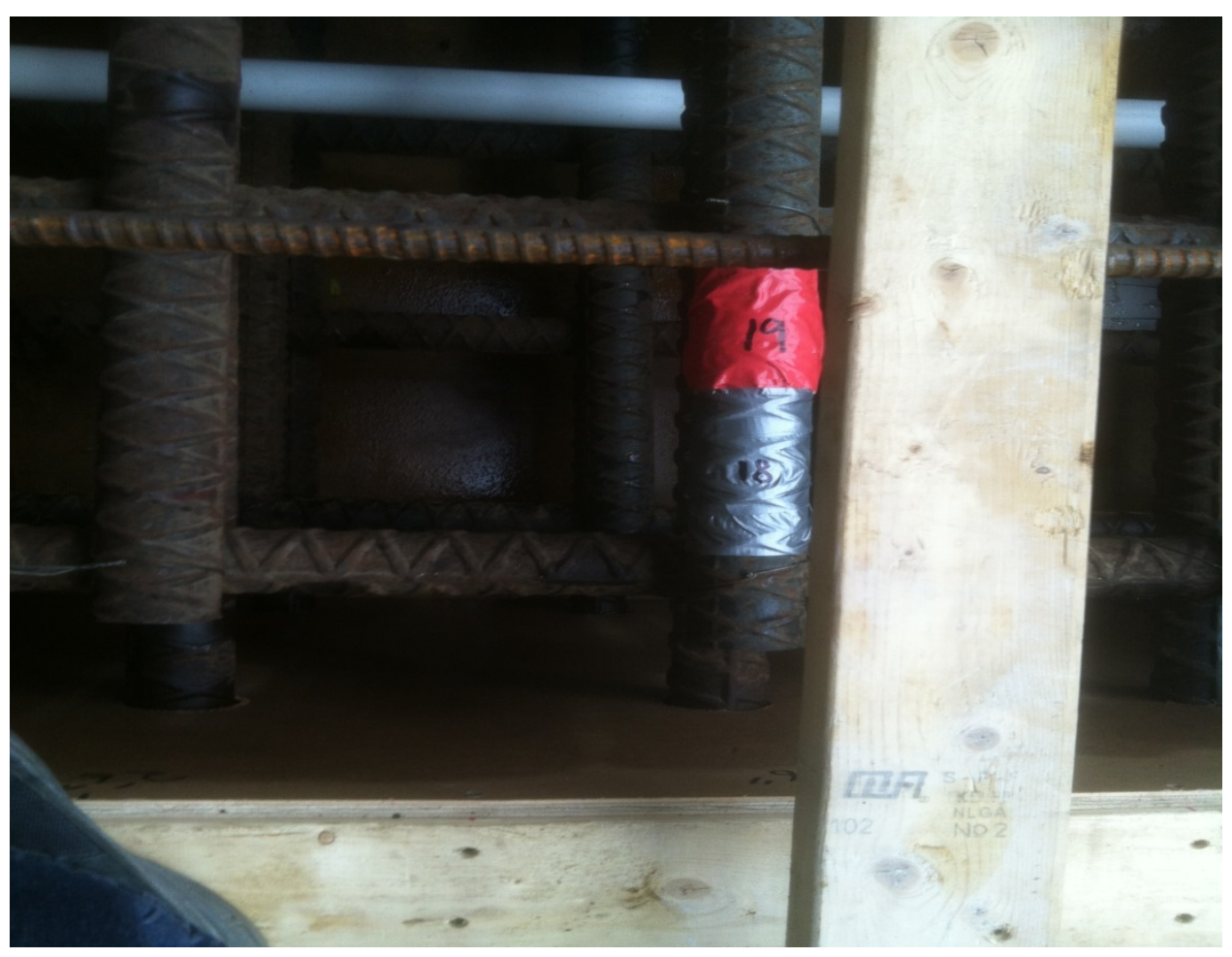

Fig. A.172. D18 height 4 bars 3.5ft 1067mm. 


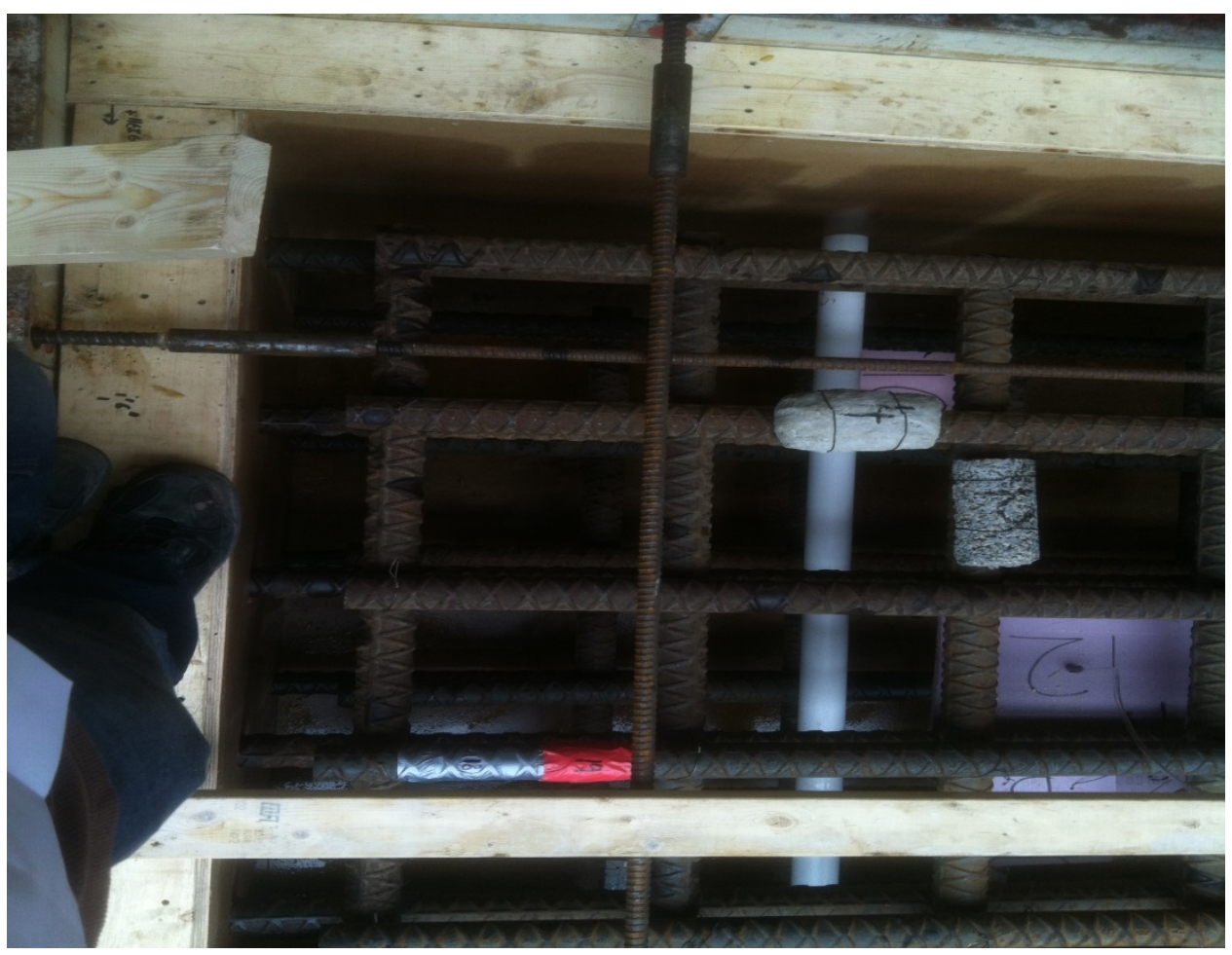

Fig. A.173. D18 length 6.75 bars $6.25 \mathrm{ft} 1905 \mathrm{~mm}$.

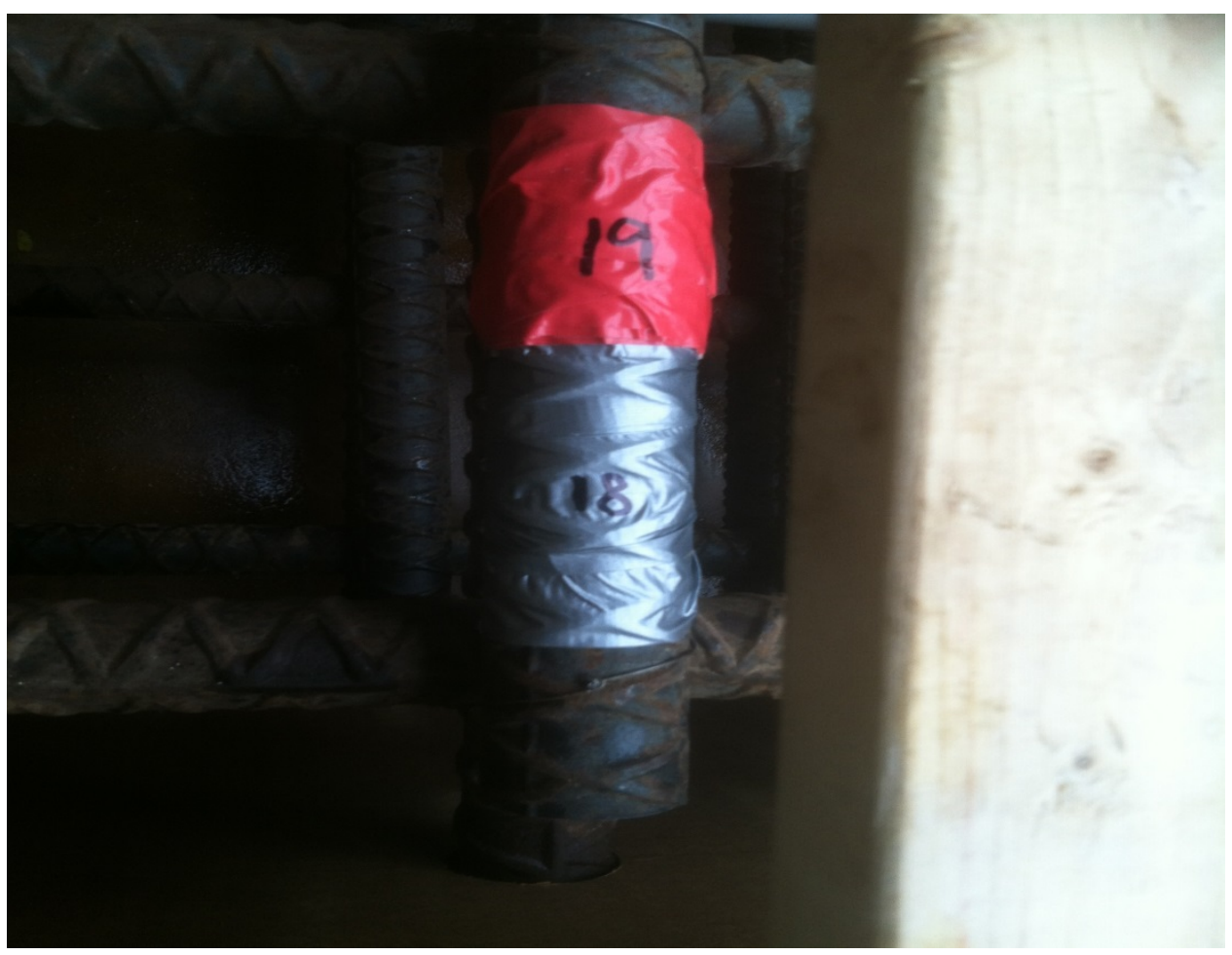

Fig. A.174. D18 R-depth of top bar 140mm. 


\begin{tabular}{|c|c|c|}
\hline \multicolumn{3}{|c|}{ DEFECT TABLE } \\
\hline IO NUMERR & DESCRPTION & LABE \\
\hline D1 & $\begin{array}{c}\text { POROUS HAL CYUNDER } \\
\text { (NO COVER) }\end{array}$ & \\
\hline 02 & $\begin{array}{l}\text { POROUS HAL CYINDER } \\
\text { (COVER) }\end{array}$ & \\
\hline 03 & $\begin{array}{c}\text { POROUS HALF CYINDER } \\
\text { (No COVER) }\end{array}$ & \\
\hline 04 & $\begin{array}{l}\text { POROUS HALF CYINDER } \\
\text { (COVER) }\end{array}$ & \\
\hline D5 & $\begin{array}{l}\text { POROUS HALF CYINDER } \\
\text { (COVER \& CRACK) }\end{array}$ & \\
\hline D6 & PVC & \\
\hline 07 & PVC & \\
\hline D8 & $\begin{array}{l}\text { DISSOLUNG STRROFOAM } \\
\text { (THICK) }\end{array}$ & \\
\hline 09 & STYROFOAM (THIC) & \\
\hline D10 & STYROFOAM (THIN) & \\
\hline 011 & PLEXGLASS & \\
\hline 012 & $\begin{array}{c}\text { DISSOLNNG STROAOAM } \\
\text { (MEDUUM) }\end{array}$ & \\
\hline 013 & STYROFOAM (MEDUUM) & \\
\hline 014 & PLEXGLASS & \\
\hline D15 & $\begin{array}{c}\text { DISSOLUNG STYROFOAM } \\
\text { (THIN) }\end{array}$ & \\
\hline D16 & LUMBER $(2 \times 4)$ & \\
\hline D17 & GLOVES & \\
\hline D18 & $\begin{array}{l}\text { DEBONO DUCT TAPE } \\
\text { (ONE LAYER) }\end{array}$ & \\
\hline D19 & $\begin{array}{l}\text { DEBONO DUCT TAPE } \\
\text { (MULT-LAYRR) }\end{array}$ & \\
\hline 020 & MOUNG REBAR & \\
\hline
\end{tabular}

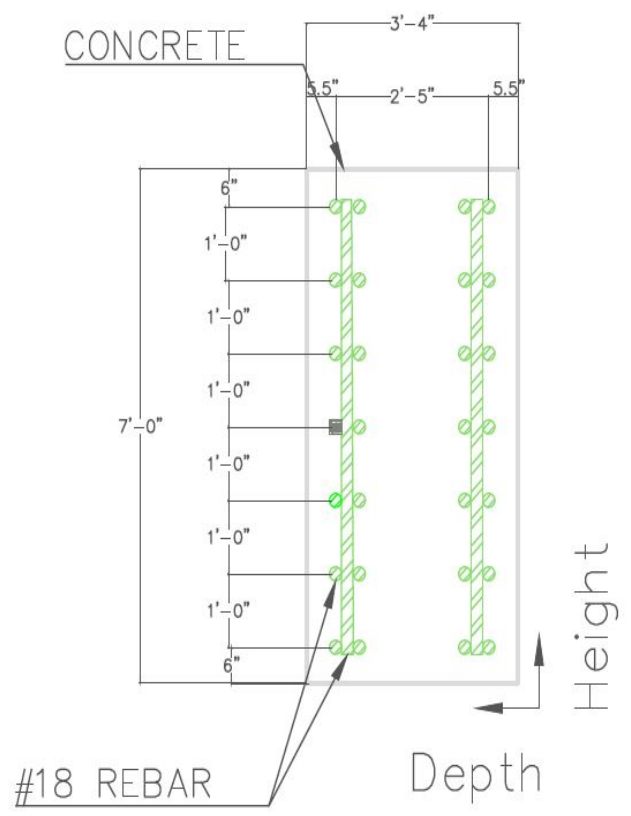

Fig. A.175. D18 height by depth.

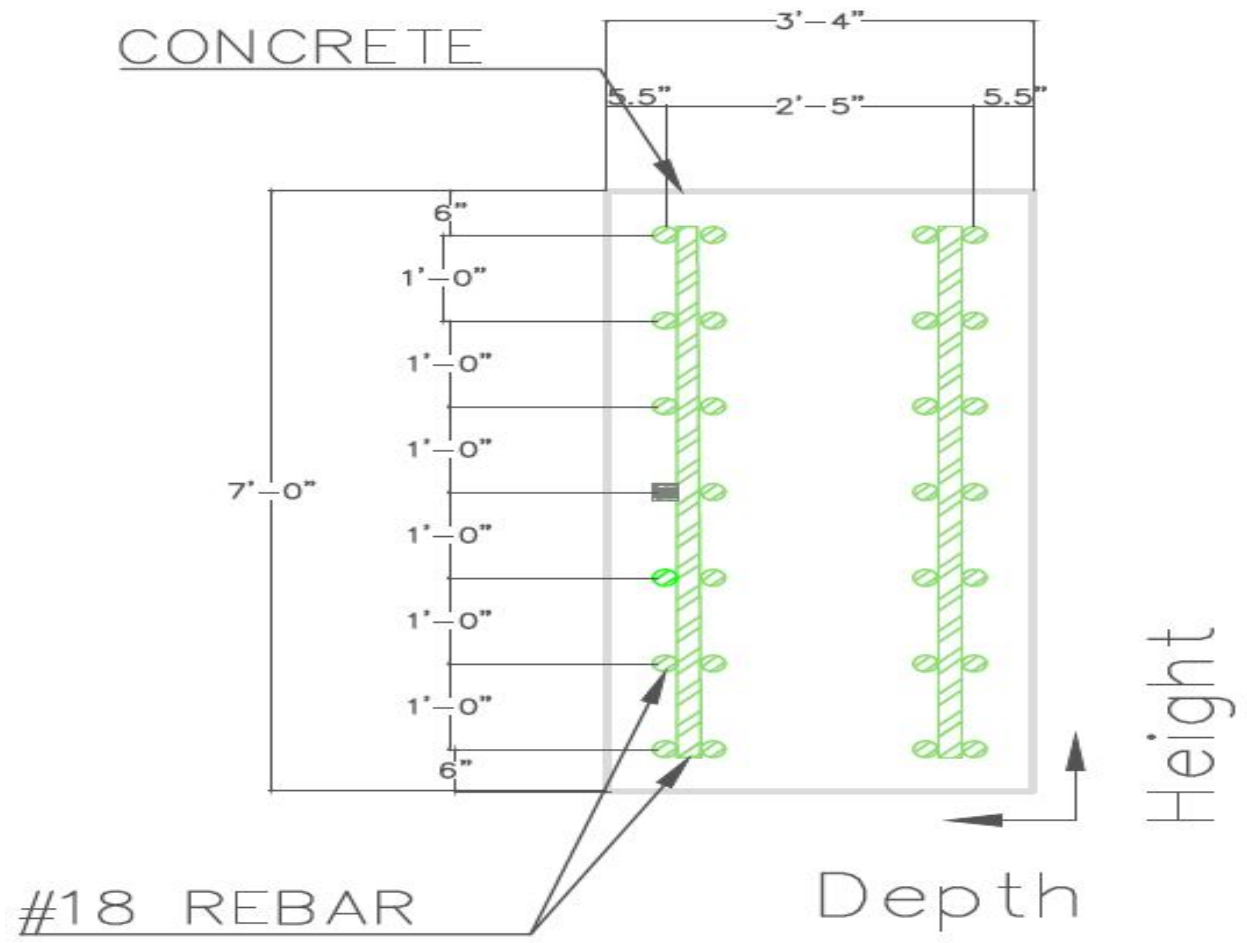

Fig. A.176. D18 height by depth NL. 


\begin{tabular}{|c|c|c|}
\hline \multicolumn{3}{|c|}{ DEECT TRQLE } \\
\hline o nueser & DESOEPIION & WeL. \\
\hline or & $\begin{array}{l}\text { POAOUS HNF CYNASA } \\
\text { OD CONRE) }\end{array}$ & \\
\hline 02 & 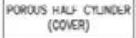 & \\
\hline as & $\begin{array}{l}\text { POROUS HNF GUNGER } \\
\text { (No COVDE) }\end{array}$ & \\
\hline D4 & $\begin{array}{l}\text { POAOUS HNE CYUNGER } \\
\text { (CONER) }\end{array}$ & \\
\hline OS & 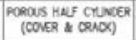 & \\
\hline$\infty$ & $P V C$ & \\
\hline 07 & PVC & \\
\hline De & $\begin{array}{c}\text { Dassa VNG streosonu } \\
\text { (THOC) }\end{array}$ & \\
\hline$\infty$ & STMoroum (Timo) & \\
\hline 010 & smeorowu (niva) & \\
\hline on & pobcouss & \\
\hline 012 & $\begin{array}{c}\text { Dssa uno smporons } \\
\text { (NFace) }\end{array}$ & \\
\hline Iום & STheorow (NCOUN) & \\
\hline Dit & movelass & \\
\hline Dis & $\begin{array}{c}\text { ossaunna smporony } \\
\text { (ivin) }\end{array}$ & \\
\hline 016 & LNACR $(2 \times 4)$ & \\
\hline רוס & o.0ns & \\
\hline ans & 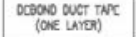 & \\
\hline 010 & 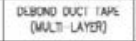 & \\
\hline 000 & nowo resur & \\
\hline
\end{tabular}

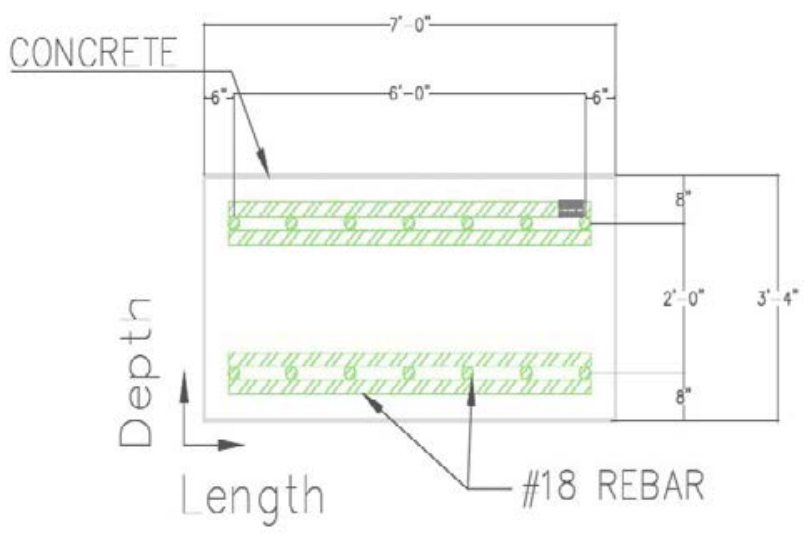

03 TOP VIEW

Fig. A.177. D18 length by depth.

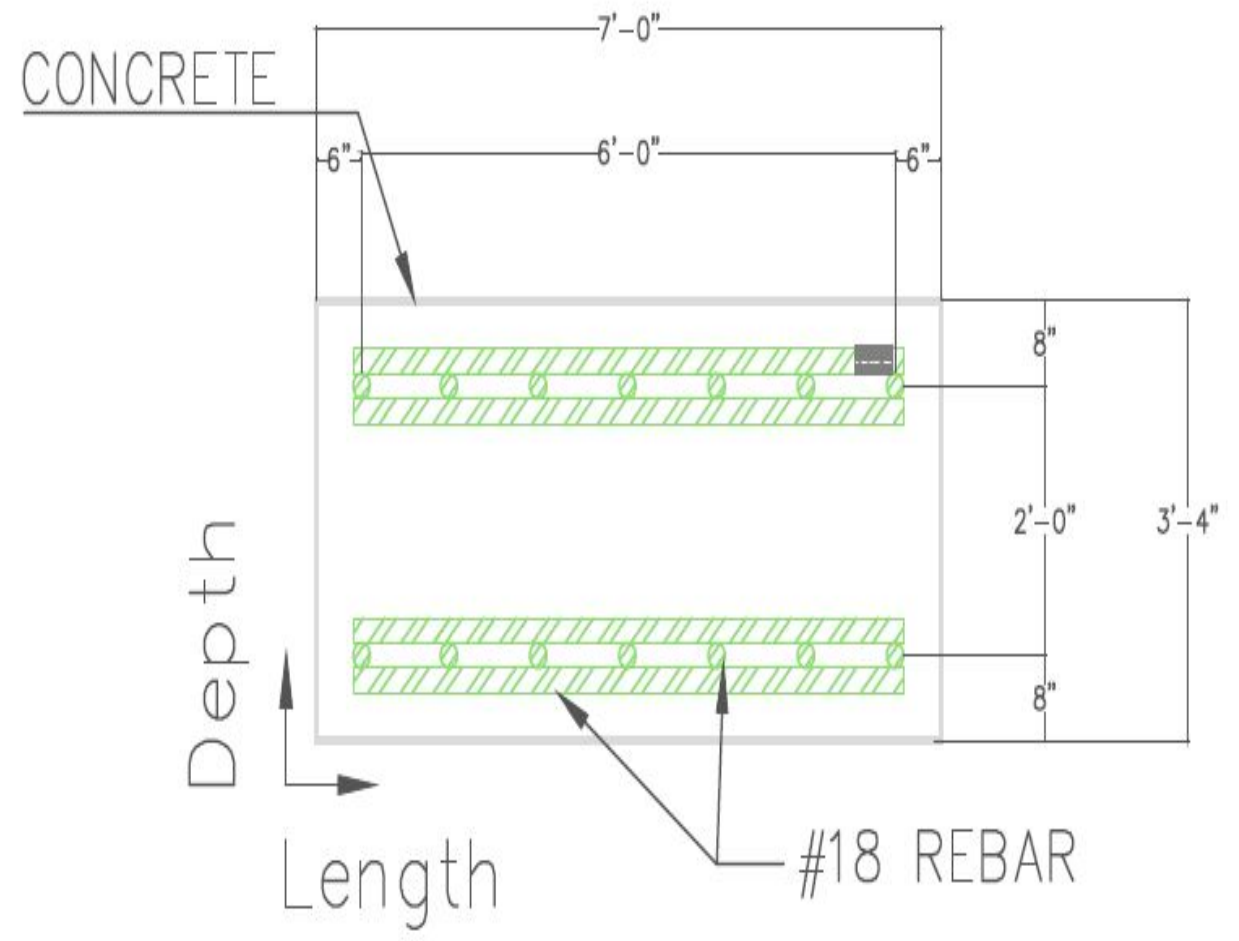

Fig. A.178. D18 length by depth NL. 


\begin{tabular}{|c|c|c|}
\hline \multicolumn{3}{|c|}{ OFFECT Theis } \\
\hline o nuger & OEscretion & U⿻上丨. \\
\hline or & 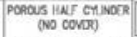 & \\
\hline 02 & 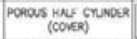 & \\
\hline DS & 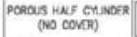 & \\
\hline 04 & $\begin{array}{l}\text { POHCOS HNG CWUADER } \\
\text { (COMSE) }\end{array}$ & \\
\hline DS & 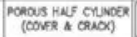 & \\
\hline$\infty$ & PKC & \\
\hline or & $P C$ & \\
\hline Do & 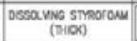 & \\
\hline$\infty$ & 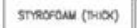 & \\
\hline 010 & STreroun (IMN) & \\
\hline on & moxouss & \\
\hline 012 & 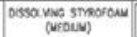 & \\
\hline 013 & stmoroum (NeDa) & \\
\hline 014 & Arowans & \\
\hline O15 & 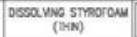 & \\
\hline 016 & LNeER (2x) & \\
\hline on & couss & \\
\hline 018 & 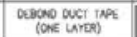 & \\
\hline 010 & 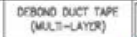 & \\
\hline 020 & WOWNG REBNA & \\
\hline
\end{tabular}

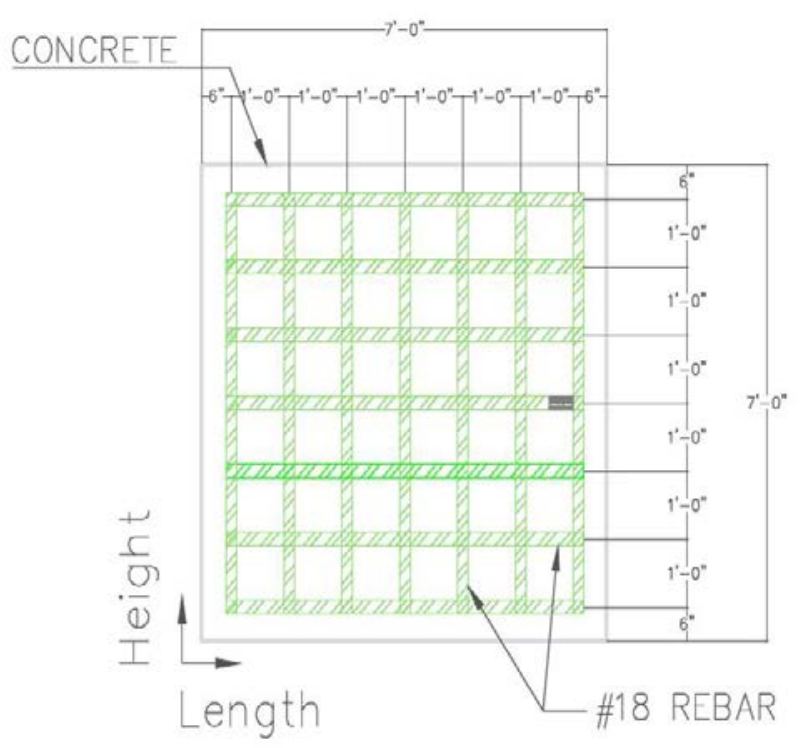

SIDE VIEW

Fig. A.179. D18 length by height.

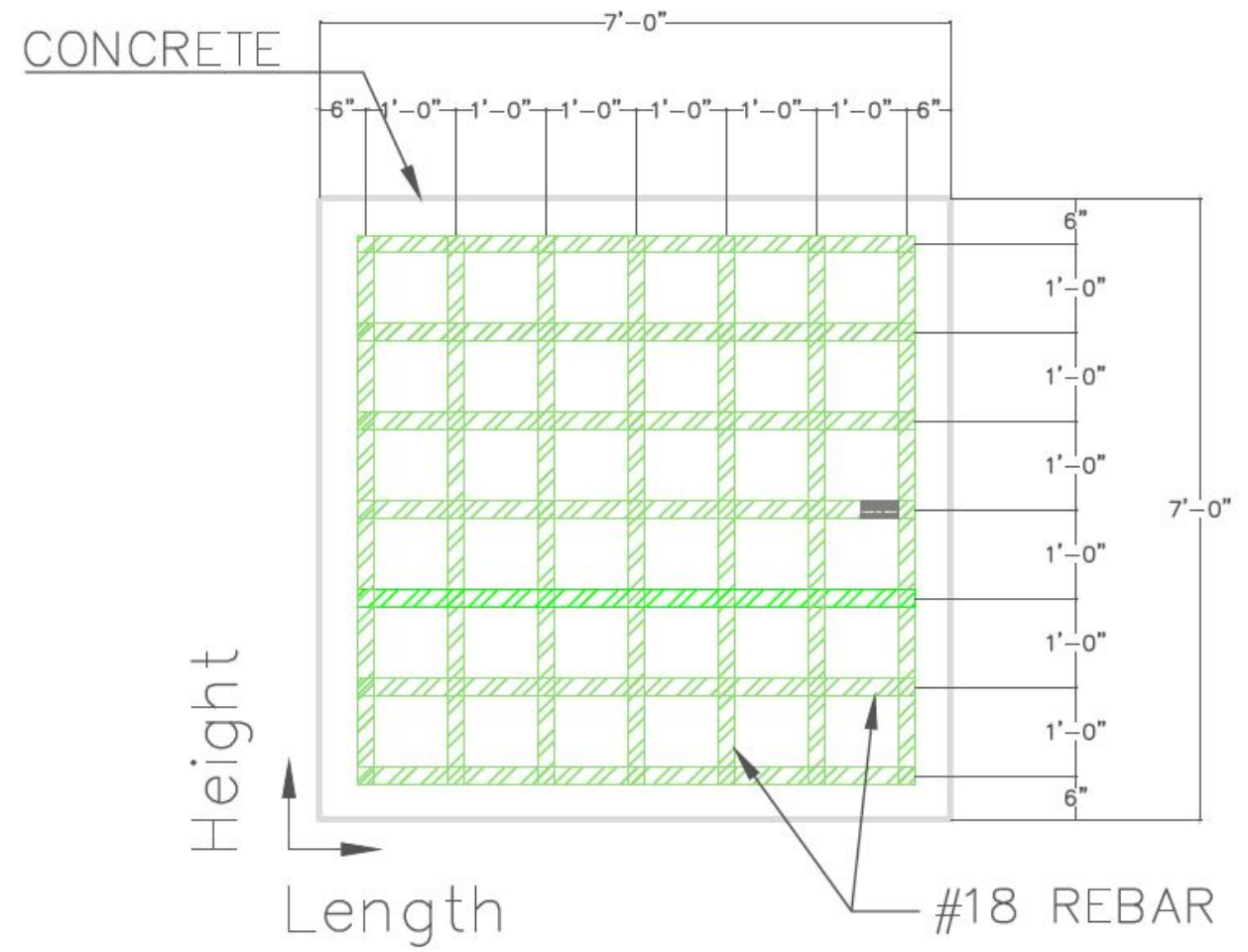

Fig. A.180. D18 length by height NL. 


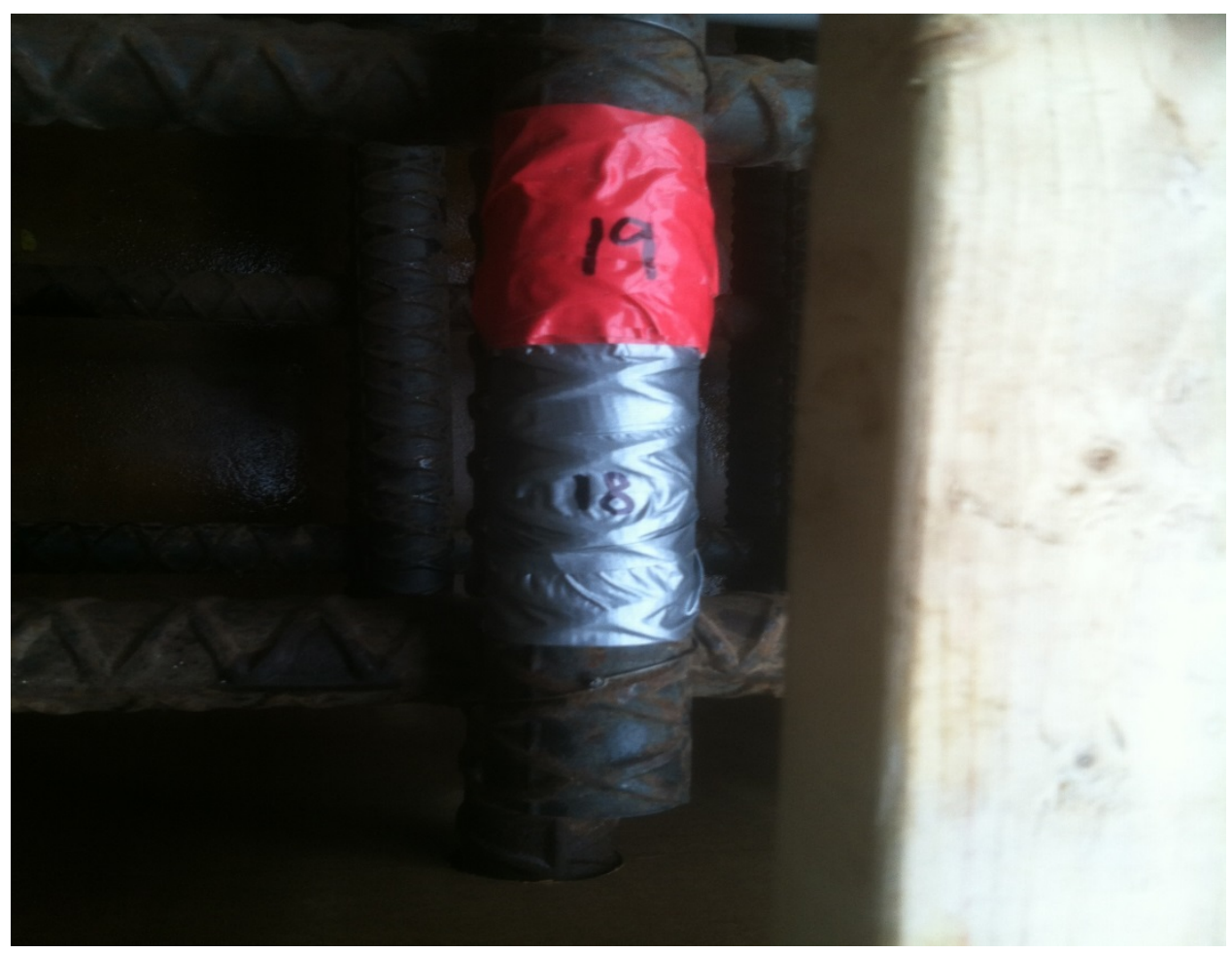

Fig. A.181. D19 close-up.

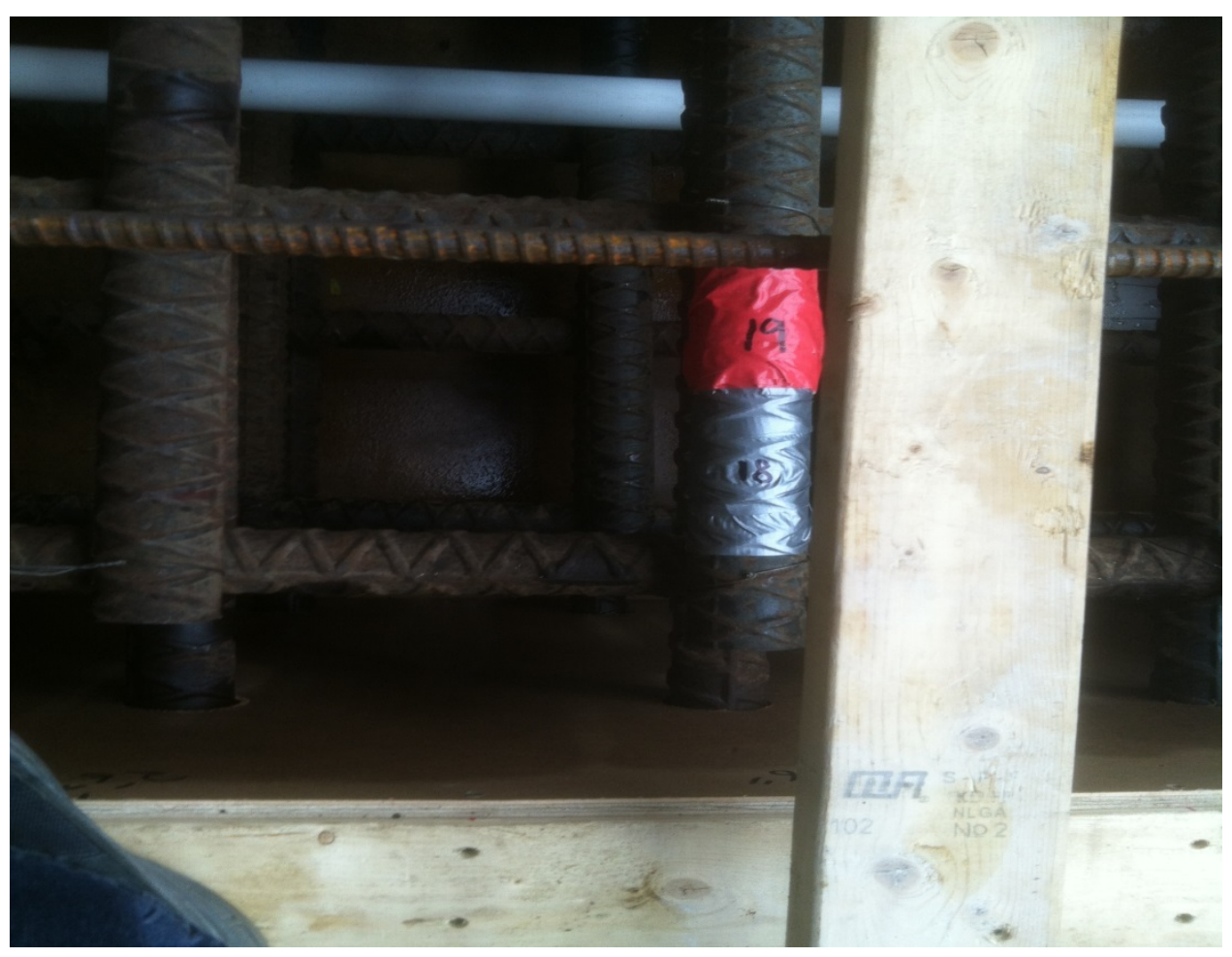

Fig. A.182. D19 height 4 bars 3.5ft 1067mm. 


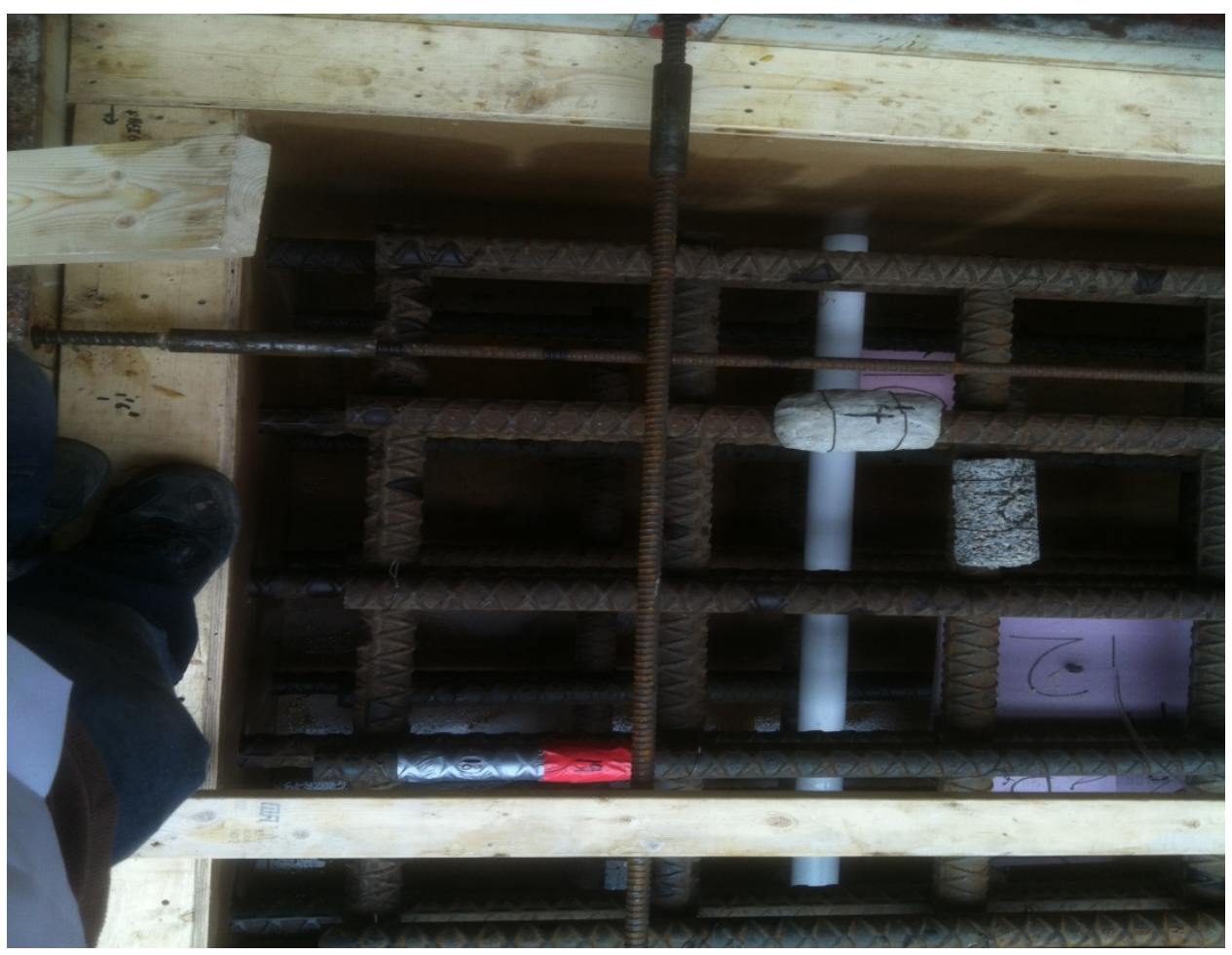

Fig. A.183. D19 length 6.25 bars 5.75ft 1753mm.

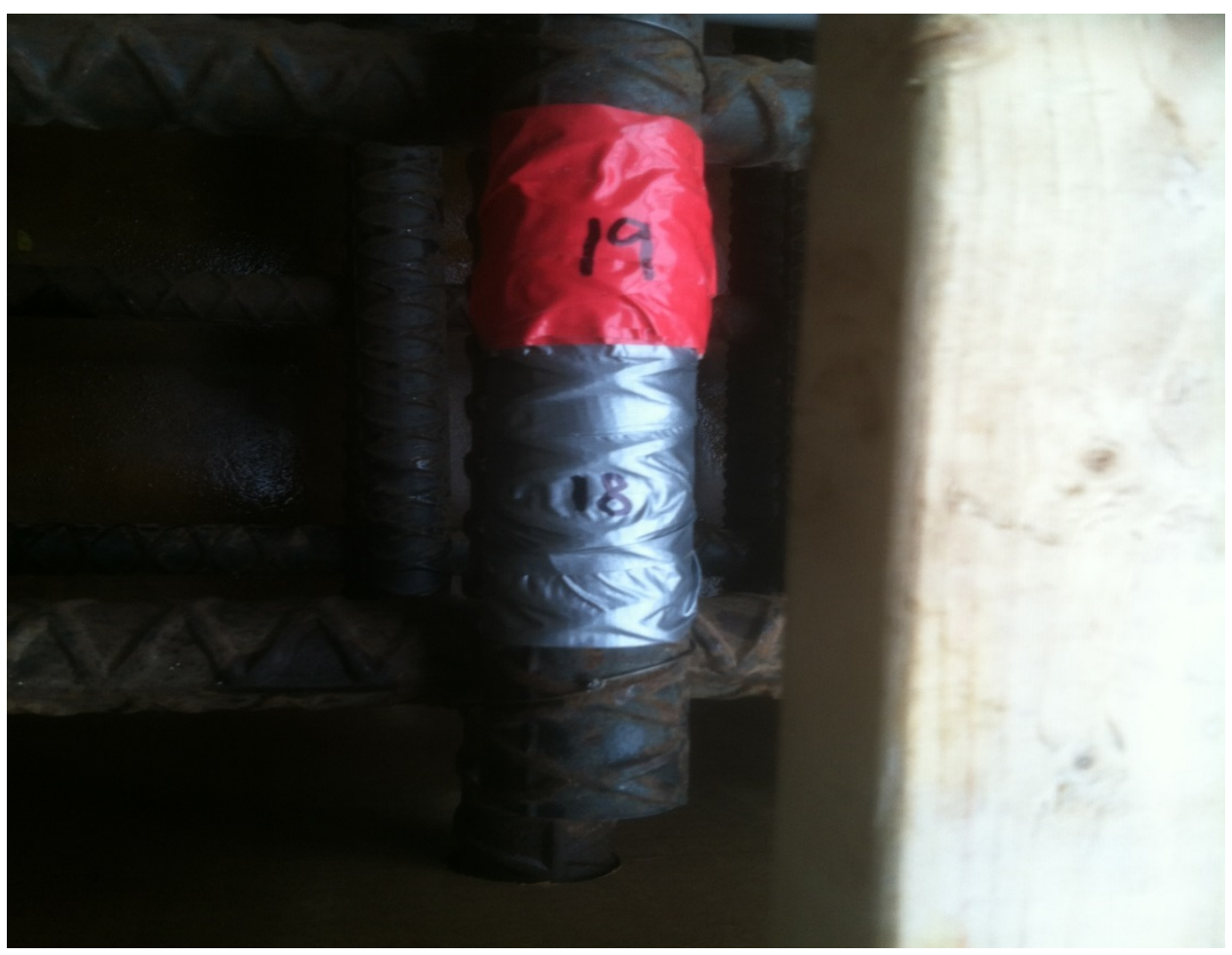

Fig. A.184. D19 R-depth of top bar140mm. 


\begin{tabular}{|c|c|c|}
\hline \multicolumn{3}{|c|}{ DEEECT TABLE } \\
\hline ID NUMBER & DESCRIPTION & LABE \\
\hline D1 & $\begin{array}{c}\text { POROUS HAL CYINDER } \\
\text { (NO COVER) }\end{array}$ & \\
\hline 02 & $\begin{array}{c}\text { POROUS HALF CYINDER } \\
\text { (COVER) }\end{array}$ & \\
\hline 03 & $\begin{array}{l}\text { POROUS HALF CYINDER } \\
\text { (NO COVER) }\end{array}$ & \\
\hline 04 & $\begin{array}{l}\text { POROUS HALE CYINDER } \\
\text { (COVER) }\end{array}$ & \\
\hline DS & $\begin{array}{c}\text { POROUS HALF CYINDER } \\
\text { (COVER \& CRACK) }\end{array}$ & \\
\hline D6 & PVC & \\
\hline 07 & PVC & \\
\hline D8 & $\begin{array}{c}\text { DISSOLUNG STRROFOAM } \\
\text { (THICK) }\end{array}$ & \\
\hline Dg & STTROFOAM (THICK) & \\
\hline D10 & STRROFOAM (THIN) & \\
\hline D11 & PLEXIGLASS & \\
\hline D12 & \begin{tabular}{|c|} 
DISSOLYNG STRROFOAM \\
(MEOUM)
\end{tabular} & \\
\hline 013 & STRROFOAM (MEDIUM) & \\
\hline 014 & PLEXIGLASS & \\
\hline D15 & $\begin{array}{c}\text { DISSOLUNG STRROFOAM } \\
\text { (THIN) }\end{array}$ & \\
\hline 016 & LUMBER $(2 \times 4)$ & \\
\hline 017 & GLOVES & \\
\hline 018 & $\begin{array}{l}\text { DEBOND DUCT TAPE } \\
\text { (ONE LAYRR) }\end{array}$ & \\
\hline D19 & $\begin{array}{l}\text { DEBONO DUCT TAPE } \\
\text { (MULT-LAYER) }\end{array}$ & \\
\hline 020 & MOUNG REBAR & \\
\hline
\end{tabular}

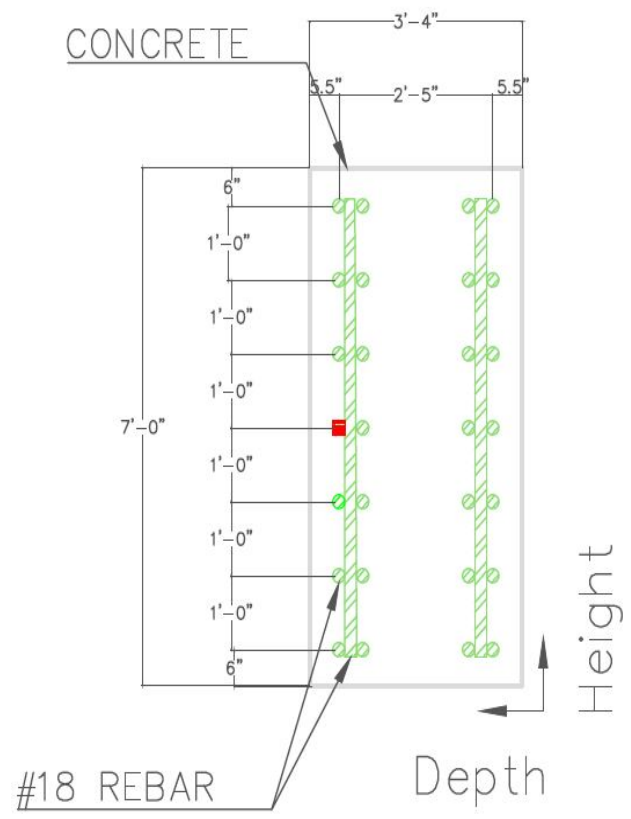

Fig. A.185. D19 height by depth.

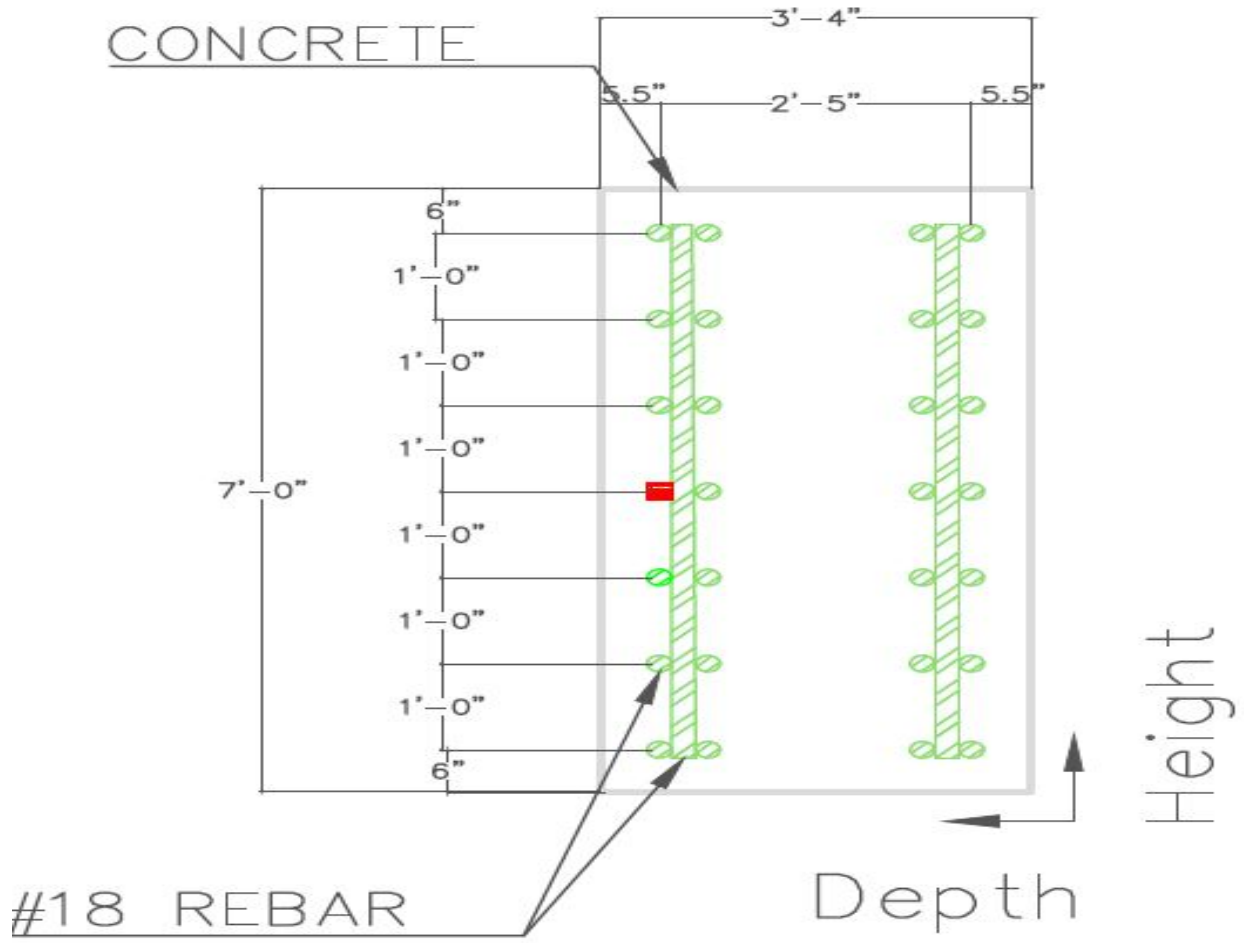

Fig. A.186. D19 height by depth NL. 


\begin{tabular}{|c|c|c|}
\hline \multicolumn{3}{|c|}{ DFFECT TRQLE } \\
\hline o nuges: & Descepition & weel \\
\hline or & $\begin{array}{l}\text { POROOS HNF CYUNGER } \\
\text { (ND COVERT }\end{array}$ & \\
\hline 02 & 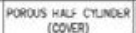 & \\
\hline as & POROUS iWU CYUNeCR & \\
\hline DA & 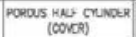 & \\
\hline DS & 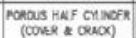 & \\
\hline$\infty$ & pre & \\
\hline 07 & $P X$ & \\
\hline$\infty$ & 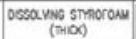 & \\
\hline$\infty$ & streorow (tilox) & \\
\hline 010 & simoroun (HN) & \\
\hline ont & moxacuss & \\
\hline 012 & $\begin{array}{l}\text { DossavNG simorow } \\
\text { (NCOWU) }\end{array}$ & \\
\hline ors & sinoroun (vediv) & \\
\hline 0,4 & hoxauss & \\
\hline 015 & $\begin{array}{c}\text { Dossa vas smporow } \\
\text { (MN) }\end{array}$ & \\
\hline 016 & INARE (2xit) & \\
\hline 017 & Q.0vs & \\
\hline 018 & 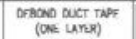 & \\
\hline 019 & $\begin{array}{l}\text { OEBOAO OUCT TNAE } \\
\text { (WUT-1ATRS) }\end{array}$ & \\
\hline 020 & WOUNC PEBSR & \\
\hline
\end{tabular}

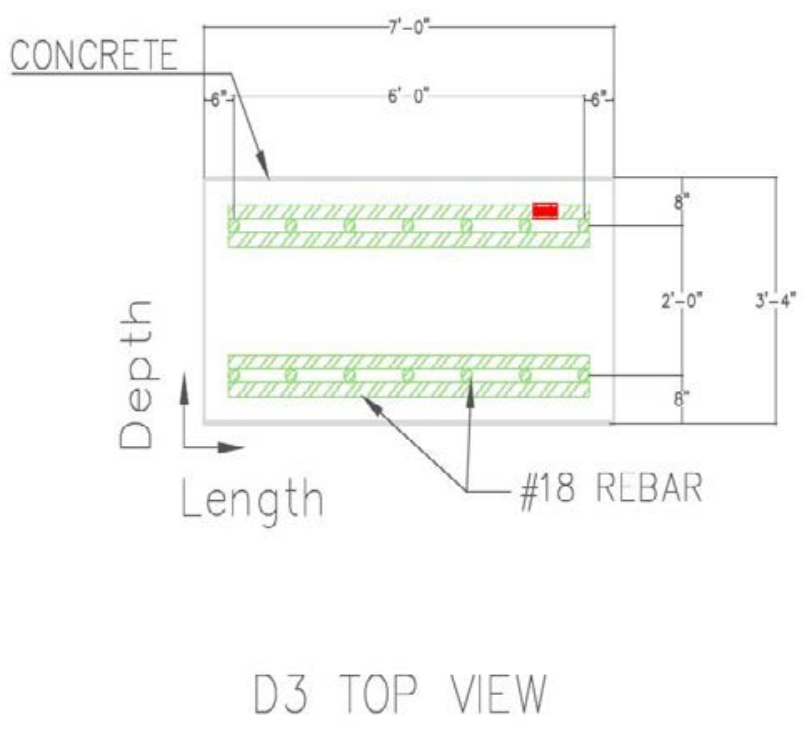

Fig. A.187. D19 length by depth.

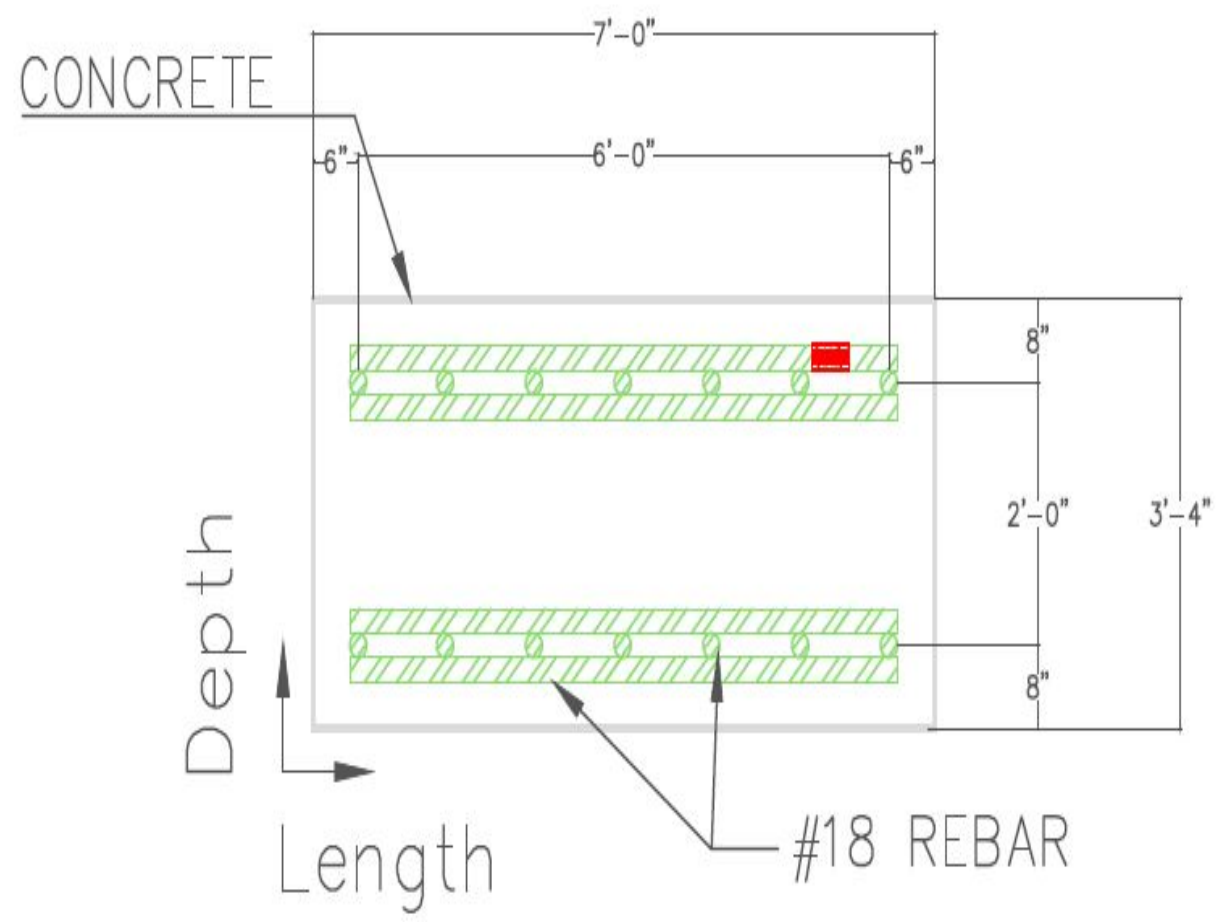

Fig. A.188. D19 length by depth NL. 


\begin{tabular}{|c|c|c|}
\hline \multicolumn{3}{|c|}{ DOFECI TRER } \\
\hline O MUNes & Deschption & Uer. \\
\hline or & 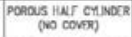 & \\
\hline 02 & 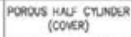 & \\
\hline os & 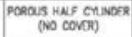 & \\
\hline$\infty$ & 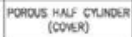 & \\
\hline Ds & 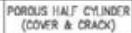 & \\
\hline$\infty$ & ne & \\
\hline 07 & PVE & \\
\hline$\infty$ & ossa whe singoroum & \\
\hline$\infty$ & stmorow (THO) & \\
\hline 010 & smescouw (TNM) & \\
\hline on & noxauss & \\
\hline 012 & 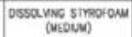 & \\
\hline als & smerouw (YconN) & \\
\hline 014 & movouss & \\
\hline 015 & $\begin{array}{l}\text { ossa ving sneofou } \\
\text { (thin) }\end{array}$ & \\
\hline 016 & Unege (2xut) & \\
\hline 017 & aovs & \\
\hline ots & 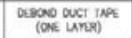 & \\
\hline 019 & 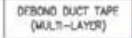 & \\
\hline 020 & Woveno REank & \\
\hline
\end{tabular}

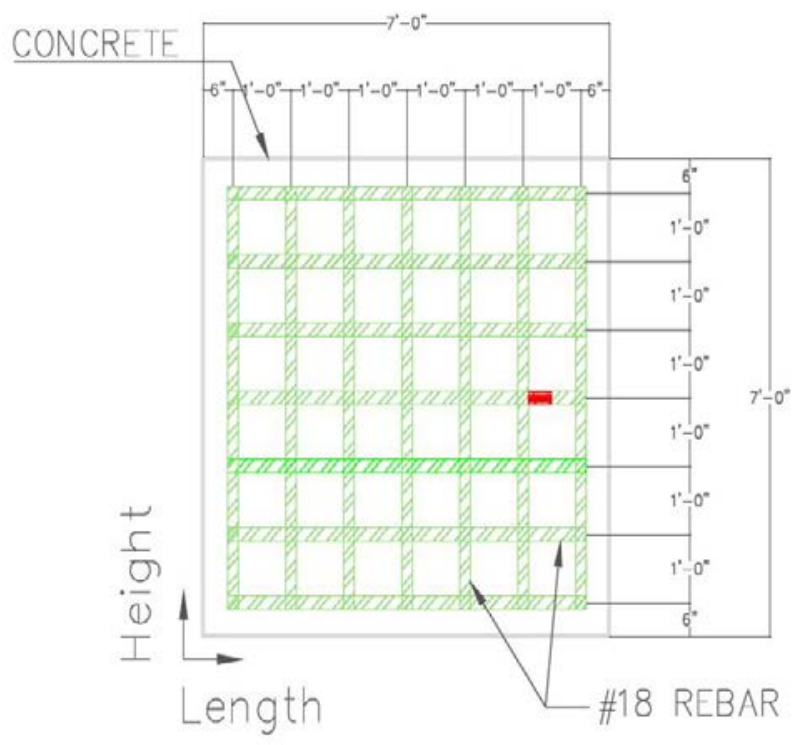

SIDE VIEW

Fig. A.189. D19 length by height.

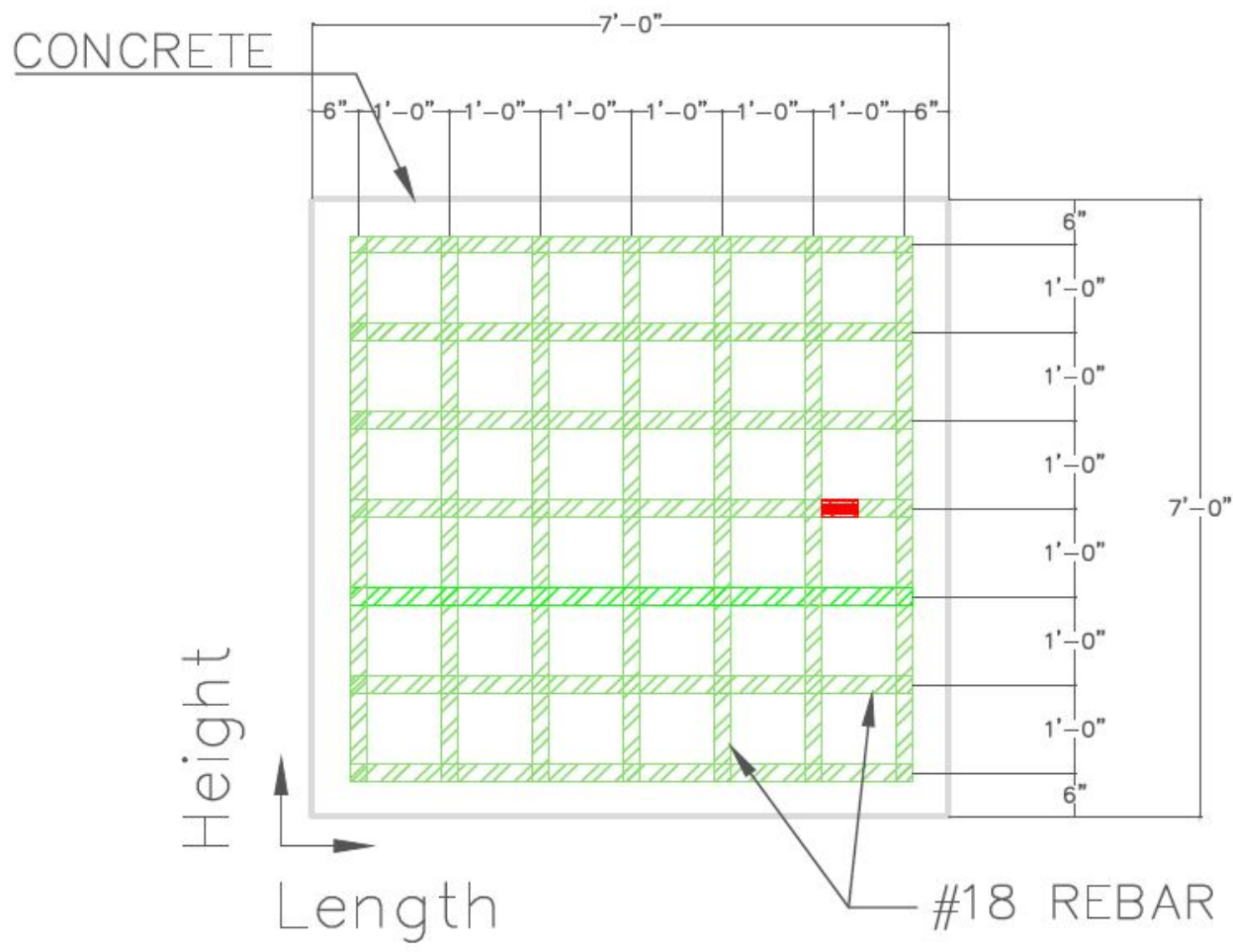

Fig. A.190. D19 length by height NL. 


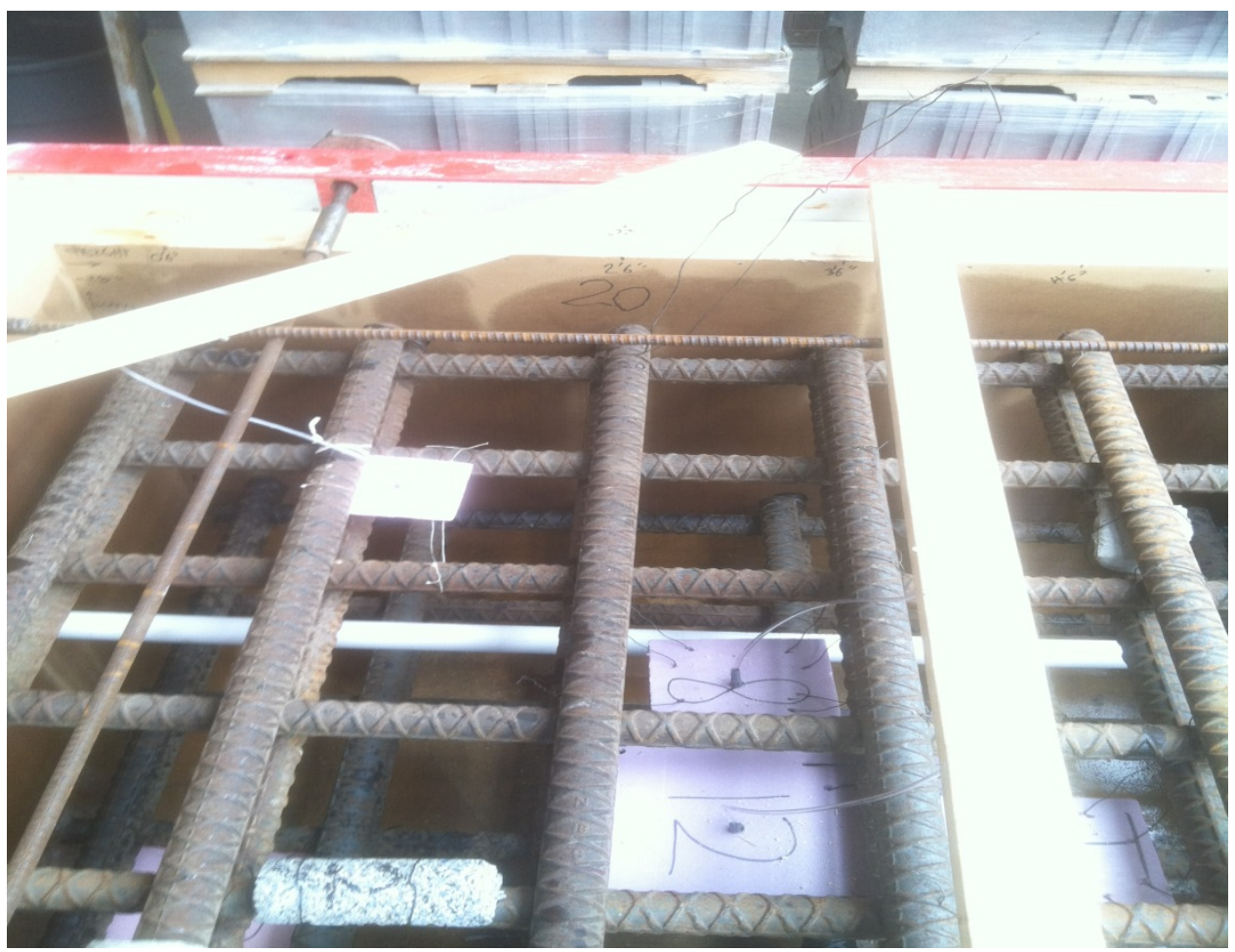

Fig. A.191. D20 close-up.

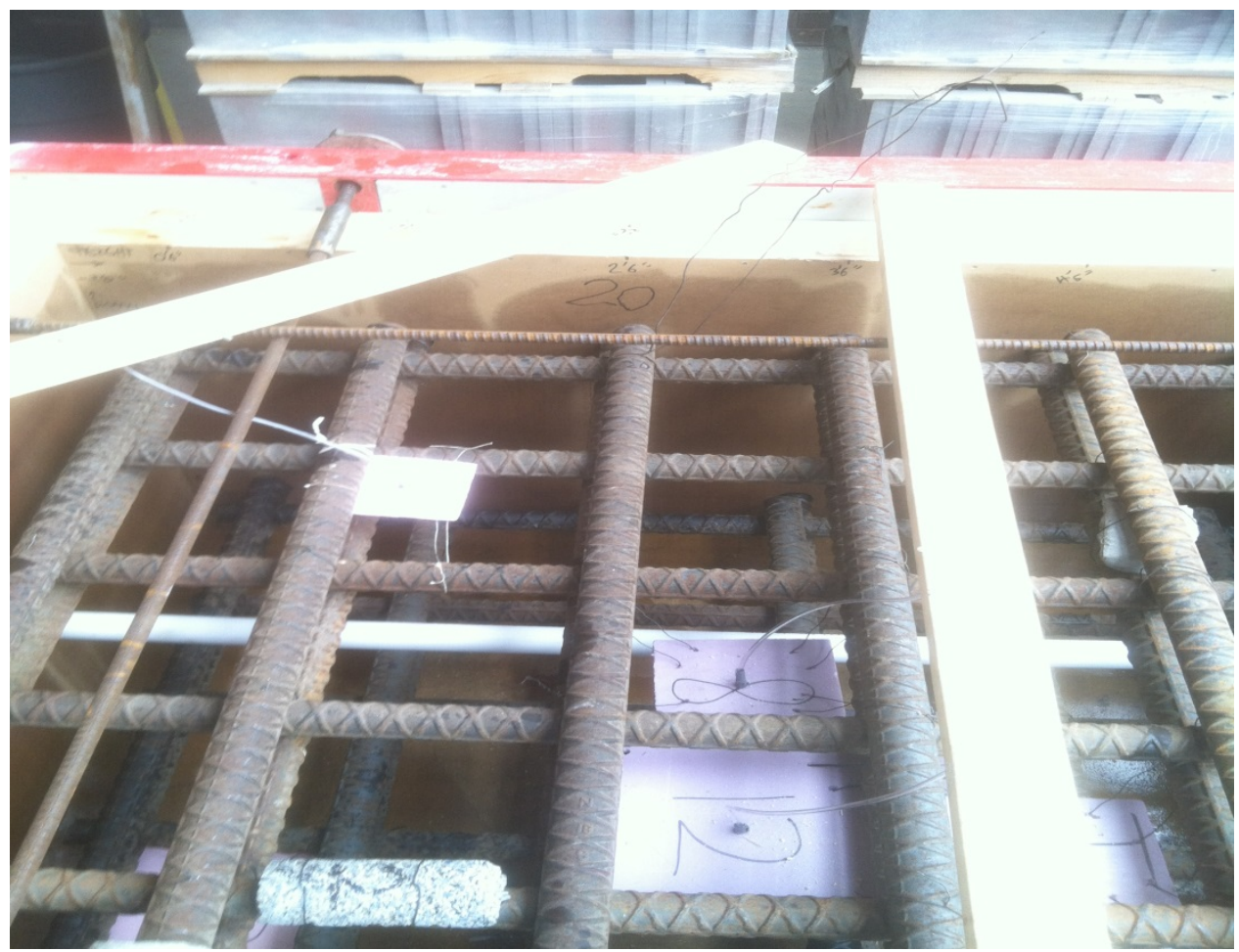

Fig. A.192. D20 height 3 bars 2.5ft 1067mm. 


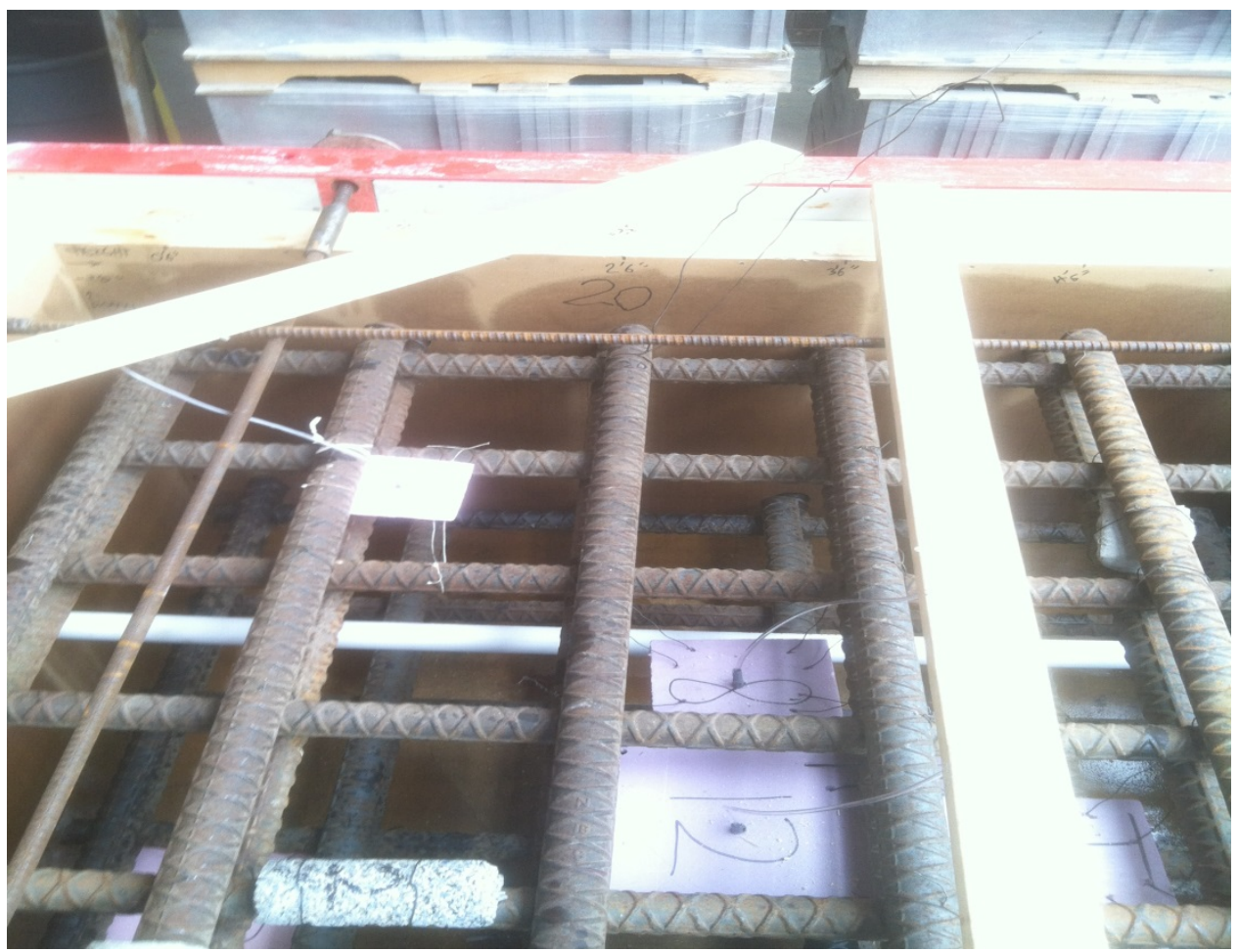

Fig. A.193. D20 length 6.25 bars $5.75 \mathrm{ft} 1905 \mathrm{~mm}$.

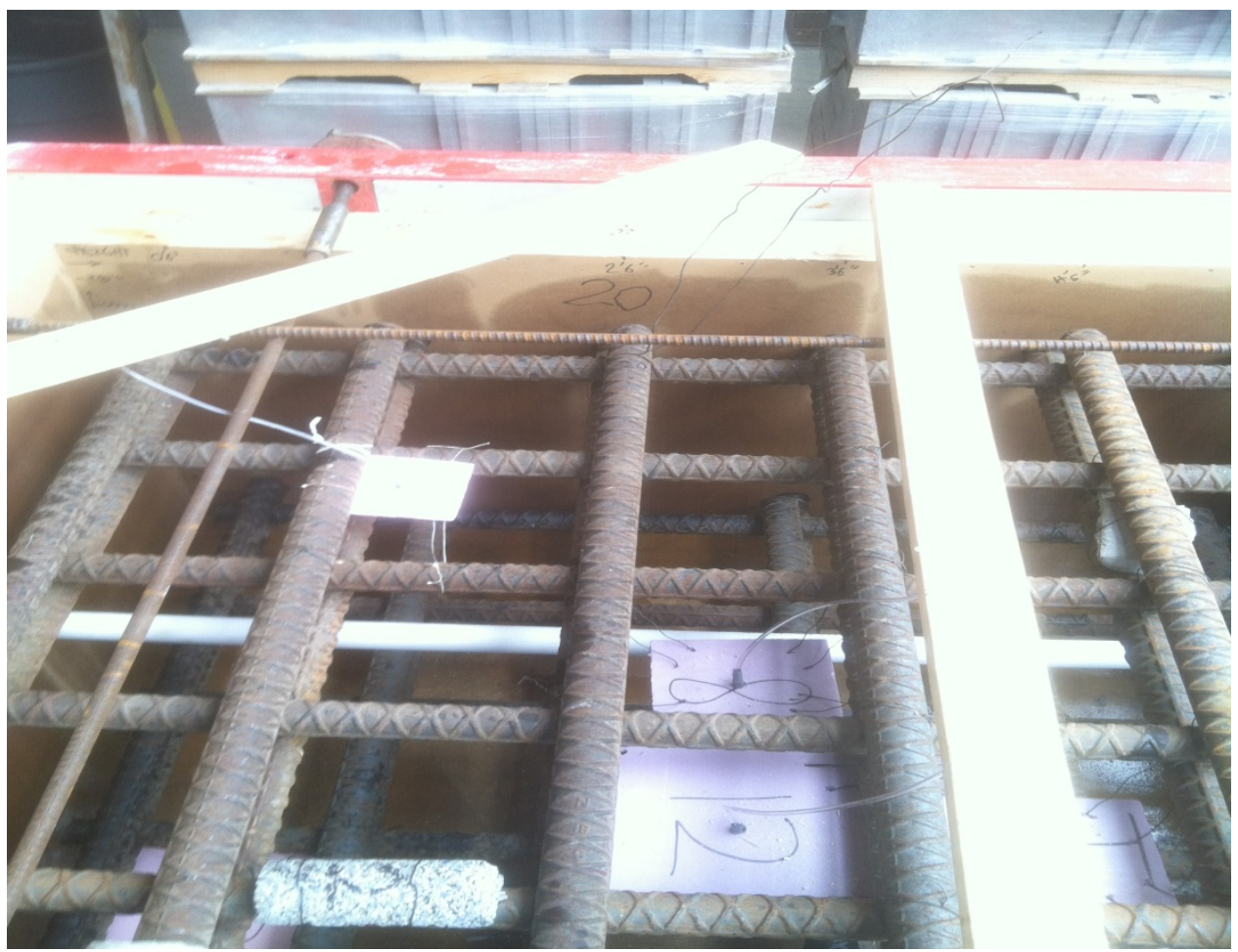

Fig. A.194. D20 R-depth of top bar 140mm. 


\begin{tabular}{|c|c|c|}
\hline \multicolumn{3}{|c|}{ DEFECT TABLE } \\
\hline D NUMEER & DESCRIPTION & LABE \\
\hline 01 & $\begin{array}{l}\text { POROUS HALF CYINDER } \\
\text { (NO COVER) }\end{array}$ & \\
\hline 02 & $\begin{array}{l}\text { POROUS HALF CYINDER } \\
\text { (COVER) }\end{array}$ & \\
\hline D3 & $\begin{array}{l}\text { POROUS HALF CYINOER } \\
\text { (NO COVER) }\end{array}$ & \\
\hline 04 & $\begin{array}{l}\text { POROUS HALF CYINDER } \\
\text { (COVER) }\end{array}$ & \\
\hline 05 & \begin{tabular}{l|} 
POROOS HALF CYINDER \\
(COVER \& CRACK)
\end{tabular} & \\
\hline D6 & PVC & \\
\hline D7 & PVC & \\
\hline 08 & $\begin{array}{l}\text { DISSOLUNG STYROFOAM || } \\
\text { (THICK) }\end{array}$ & \\
\hline Dg & STYROFOAM (THICK) & \\
\hline 010 & STRROFOAM (THIN) & \\
\hline D11 & PLEXGLASS & \\
\hline 012 & $\begin{array}{l}\text { DISSOLYNG STRROFOAM } \\
\text { (MEDUUM) }\end{array}$ & \\
\hline 013 & STTROFOAM (MEDUM) & \\
\hline 014 & PLEXGLASS & \\
\hline D15 & $\mid \begin{array}{c}\text { DISSOLNNG STYROFOAM } \\
\text { (THIN) }\end{array}$ & \\
\hline 016 & LUMBER $(2 \times 4)$ & \\
\hline 017 & GLOVES & \\
\hline 018 & $\begin{array}{l}\text { DEBONO DUCT TAPE } \\
\text { (ONE LAYER) }\end{array}$ & \\
\hline D19 & $\begin{array}{l}\text { DEBONO DUCA TAPE } \\
\text { (MULTI-LAYRR) }\end{array}$ & \\
\hline 020 & MOUNG REBAR & \\
\hline
\end{tabular}

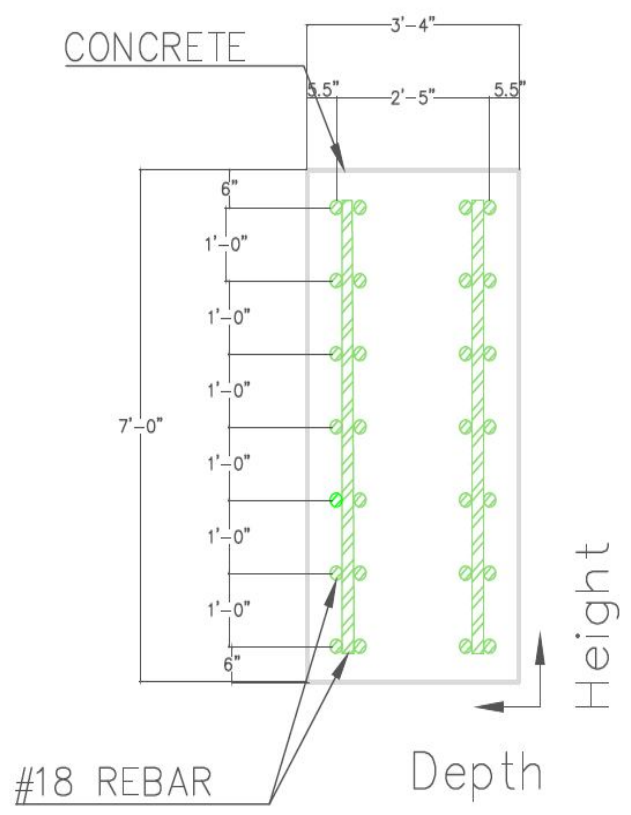

Fig. A.195. D20 height by depth.

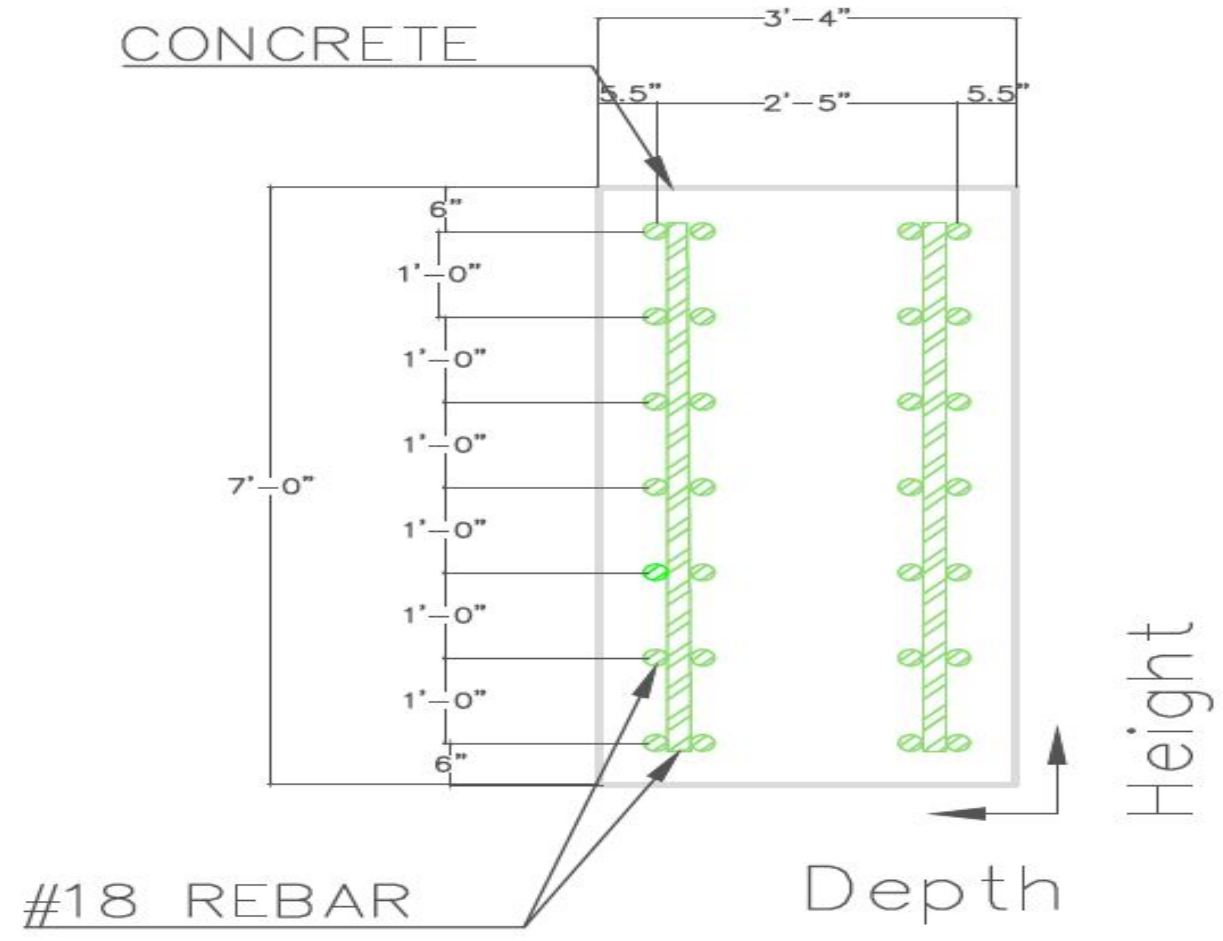

Fig. A.196. D20 height by depth NL. 


\begin{tabular}{|c|c|c|}
\hline \multicolumn{3}{|c|}{ DERECT TRELE } \\
\hline O NLWESR & DESCQPTON & uen \\
\hline or & POROUS HIN CYUUDCR & \\
\hline 02 & $\begin{array}{l}\text { POSOOS HNF CUNOCR } \\
\text { (CONGP) }\end{array}$ & \\
\hline as & $\begin{array}{l}\text { POROUS HAEF CUUVER } \\
\text { (No COVDR) }\end{array}$ & \\
\hline of & 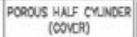 & \\
\hline$D s$ & 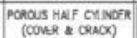 & \\
\hline Do & $P Y C$ & \\
\hline 07 & PVC: & \\
\hline$D B$ & 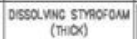 & \\
\hline$\infty$ & STreocour (Th $\propto$ ) & \\
\hline 010 & STRorow (TRM) & \\
\hline ont & Provauss & \\
\hline 012 & $\begin{array}{l}\text { Dessaveno smporoum } \\
\text { (NeONu) }\end{array}$ & \\
\hline O13 & stroforou (NEDUW) & \\
\hline 014 & Reoncass & \\
\hline 015 & $\begin{array}{l}\text { ocsavenc simosomu } \\
\text { (THM) }\end{array}$ & \\
\hline 018 & wreas $(2 x \boldsymbol{t})$ & \\
\hline 017 & a.ovcs & \\
\hline 018 & 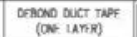 & \\
\hline 019 & $\begin{array}{l}\text { OCBONO DUCT TAEE } \\
\text { (WUTH-LATRR) }\end{array}$ & \\
\hline 0,0 & Wowng Resue & \\
\hline
\end{tabular}

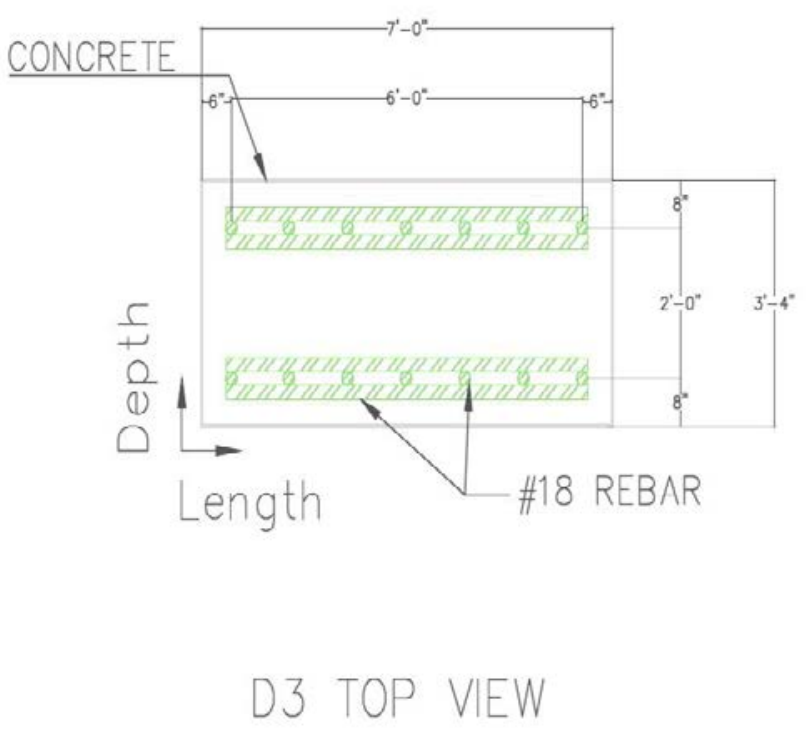

Fig. A.197. D20 length by depth.

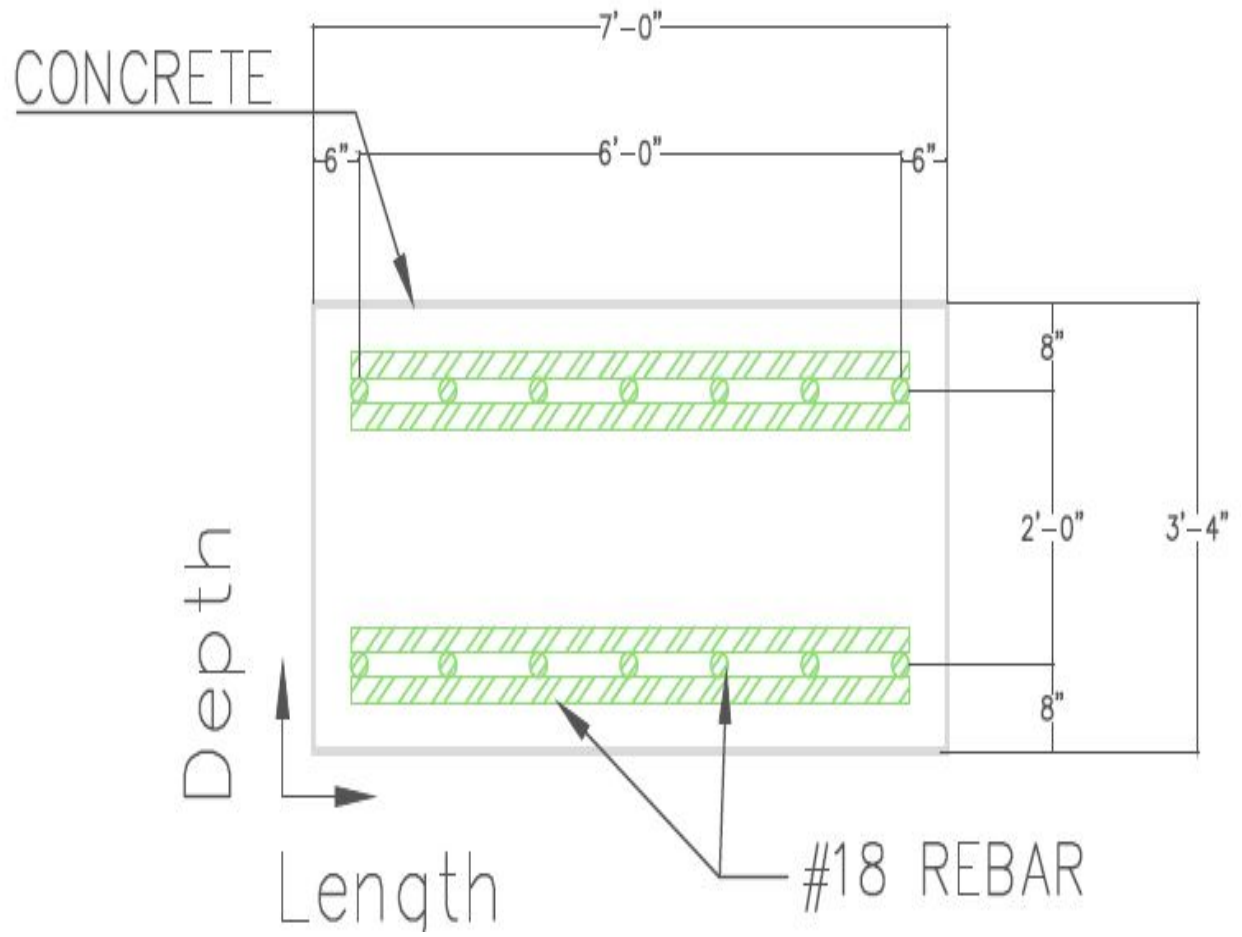

Fig. A.198. D20 length by depth NL 


\begin{tabular}{|c|c|c|}
\hline \multicolumn{3}{|c|}{ DEECT TRACE } \\
\hline O muara & DEsception & wac. \\
\hline or & 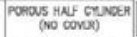 & \\
\hline 02 & 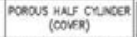 & \\
\hline as & 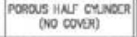 & \\
\hline a & 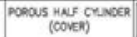 & \\
\hline os & 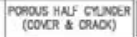 & \\
\hline$\infty$ & De & \\
\hline 07 & 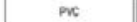 & \\
\hline$\infty$ & $\begin{array}{l}\text { assauno smaceom } \\
\text { (Theos) }\end{array}$ & \\
\hline$\infty$ & 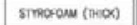 & \\
\hline 010 & straoroun (Tia) & \\
\hline ont & poovenss & \\
\hline 012 & 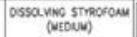 & \\
\hline ors & simorow (vesuv) & \\
\hline 014 & provauss & \\
\hline ors & $\begin{array}{c}\text { ossa ving smoroum } \\
\text { (thiN) }\end{array}$ & \\
\hline 016 & uneer $(2 x 4)$ & \\
\hline 017 & conss & \\
\hline 016 & $\begin{array}{l}\text { OEBCDO DUCT TAPE } \\
\text { (OQE UTRE) }\end{array}$ & \\
\hline 010 & 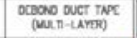 & \\
\hline 080 & Wowo REsure & \\
\hline
\end{tabular}

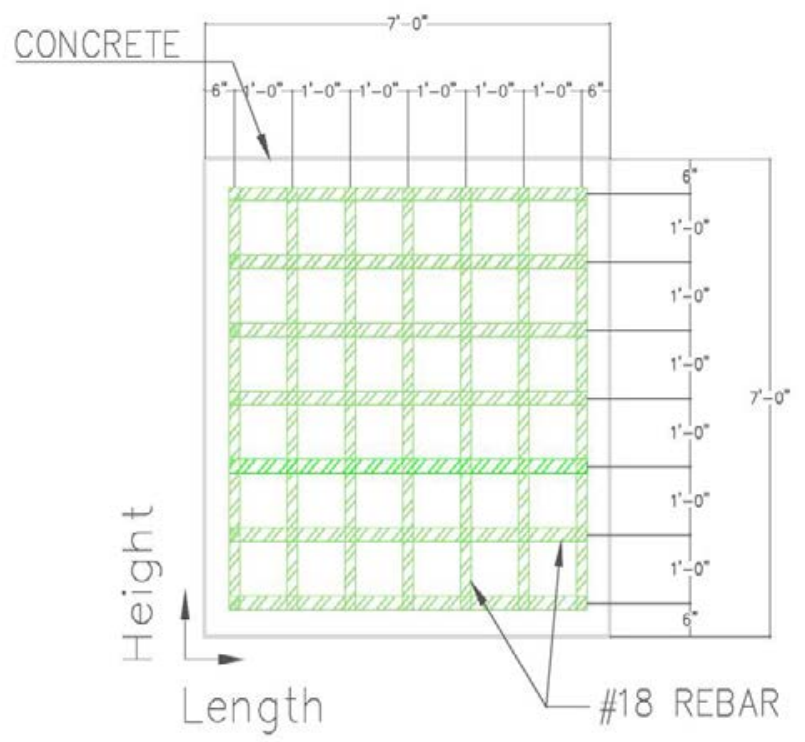

SIDE VIEW

Fig. A.199. D20 length by height.

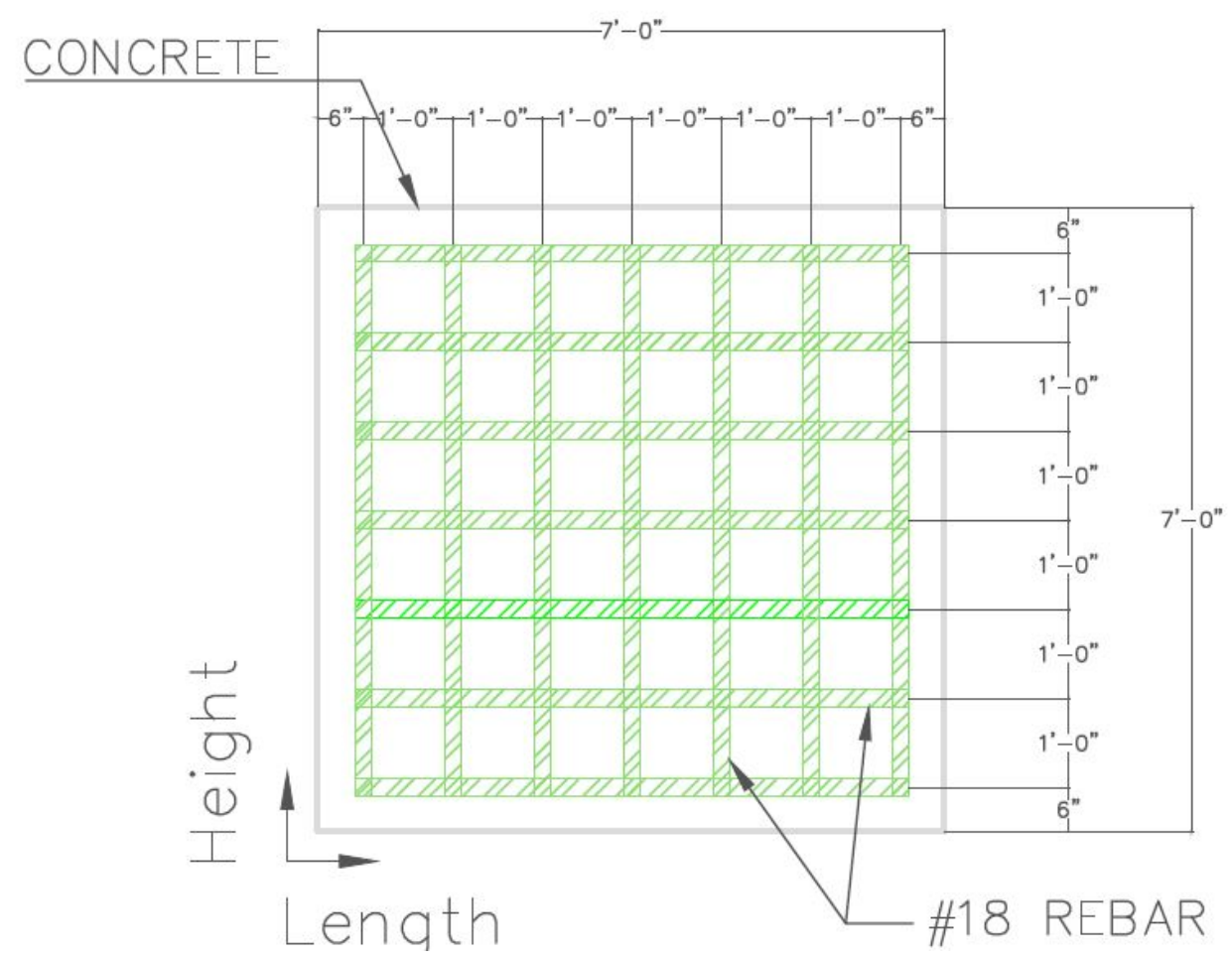

Fig. A.200. D20 length by height NL. 

APPENDIX B. MIRA DATA LOCATIONS 

A large reinforced concrete specimen was constructed with artificial defects at predefined locations. The specimen was constructed to be $7 \mathrm{ft}(2.134 \mathrm{~m})$ in height (y-dir), $7 \mathrm{ft}(2.134 \mathrm{~m})$ in length (x-dir), and $3 \mathrm{ft} 4$ in. (1.016 m) in thickness (z-dir). MIRA ultrasound measurements were taken independently on both sides of the specimen thickness. The height and length origin was constant for both data sets, while the depth origin was set equal to the testing surface location, with "R_Depth" denoting the depth from the rough (finished) surface and "S_Depth" denoting the depth from the smooth (formwork floor) surface.

The use of overlapping measurements along the cross section of each individual SAFT B-scan can allow for an extended reconstruction of the entire width and length of the specimen. To allow for a systematic testing procedure, the specimen was gridded in 4 in. $(102 \mathrm{~mm})$ squares covering the $84 \mathrm{in}$. $\times$ 84 in. total length and width of the specimen. Since the width of the device is approximately 16 in. $(407 \mathrm{~mm})$, the first and last measurement of each reconstruction was centered 8 in. (203.2 $\mathrm{mm})$ from the edge, resulting in a total of 18 overlapping measurements within each extended reconstruction covering the entire dimension of the specimen in the direction of the current set of scans. Due to boundary effects near the edge of the specimen, the first and last extended scans were taken centered 6 in. away from the edge perpendicular to the scan orientation, resulting in a total of 19 extended reconstructions per orientation. The extended ultrasound reconstruction of an entire span is referred to herein as a synthetic aperture focusing technique panoramic (SAFT-Panoramic). To accomplish this grid testing, 342 positions were scanned on each side in both height and length orientations. The rough and smooth surfaces and grids can be observed in Figs. B.1 and B.2. Representations of data collection for both orientations of the device used to generate SAFT-Panoramics are given in Figs. B.3 and B.4. Figure B.3 represents the data collected to create a SAFT-Panoramic reconstruction spanning the length direction on the smooth surface. Figure B.4 represents the data collected to create a SAFT-Panoramic reconstruction spanning the height direction. Each individual scan covers approximately 16 in. Measurements were taken in 4 in. step sizes within each SAFT-Panoramic, allowing for use of overlapping measurements to create the full reconstruction. The scans were taken following two rules for consistency in creating and labeling SAFTPanoramics: all scans within a panoramic reconstruction moved left to right in the direction of increasing length or height, depending on the current orientation, and subsequent panoramics move in the direction the device is facing. To fulfill these criteria the testing procedure included increasing panoramics moving in opposite directions when testing on the rough and smooth side. Schematics for the testing procedure to create panoramics for rough and smooth side measurements are shown in Figs. B.5 to B.8. Figures B.5 and B.6 show the length orientation panoramics for the rough and smooth sides, respectively. Figures B.7 and B.8 show the height orientation panoramics for the rough and smooth sides, respectively. Table B.1 contains adjacent SAFT-panoramic scan information for each of the twenty defects. 


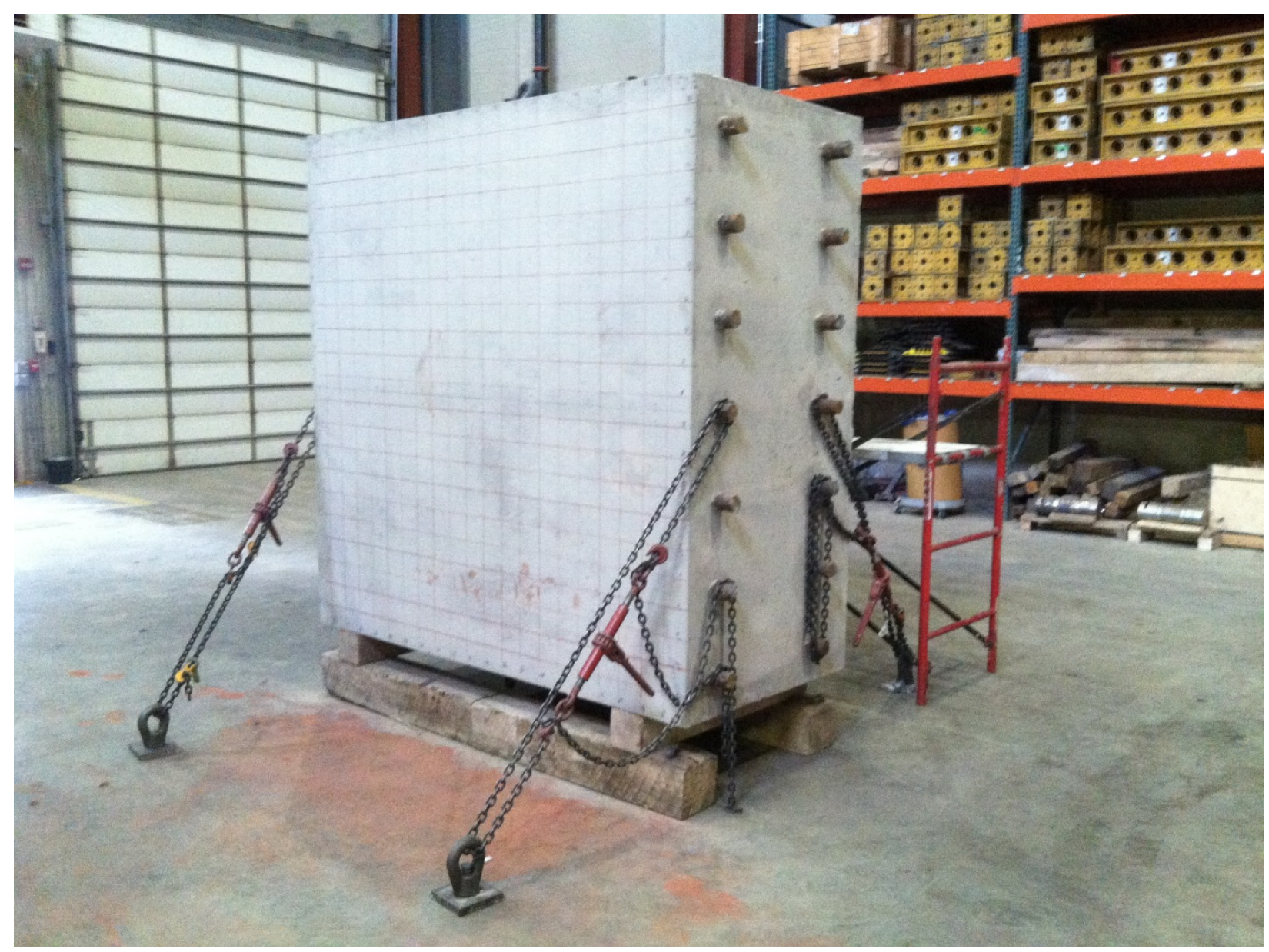

Fig. B.1. Smooth surface of the specimen. 


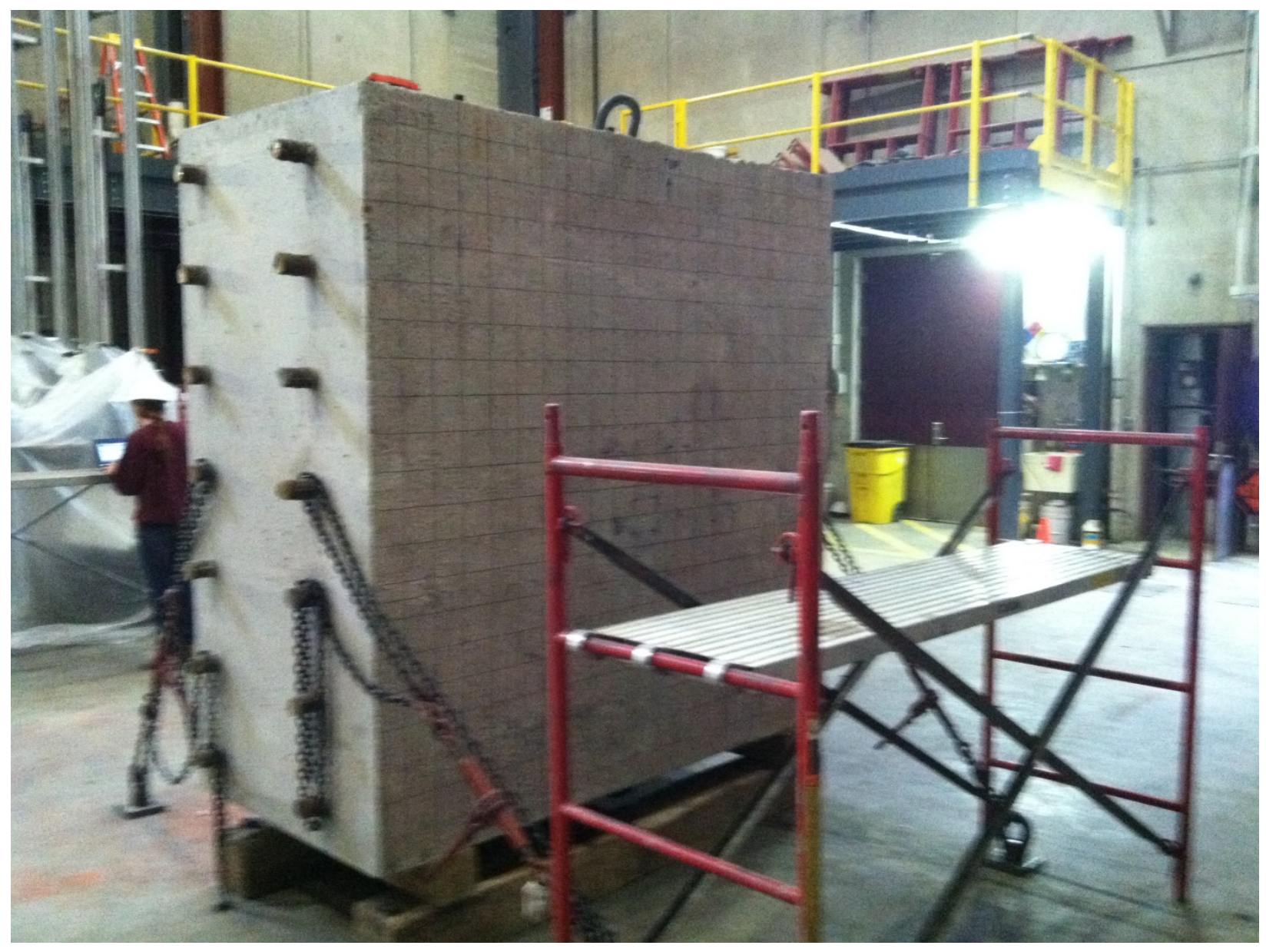

Fig. B.2. Rough surface of the specimen. 


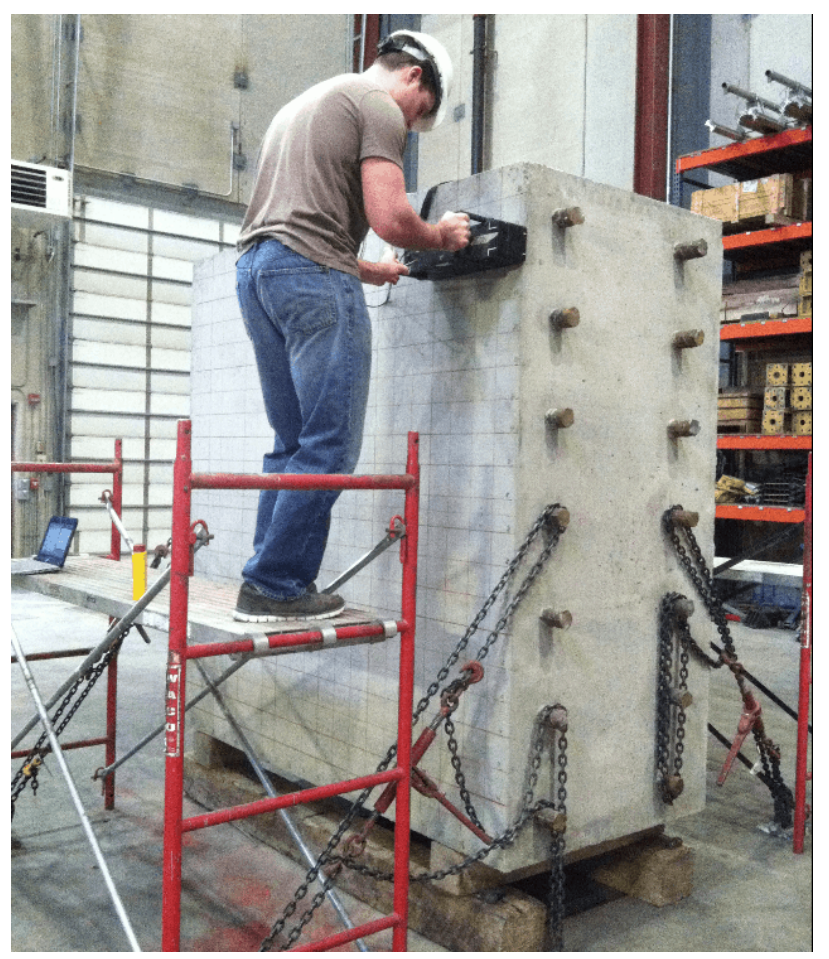

Fig. B.3. Length data collection used to create a SAFT-Panoramic reconstruction.

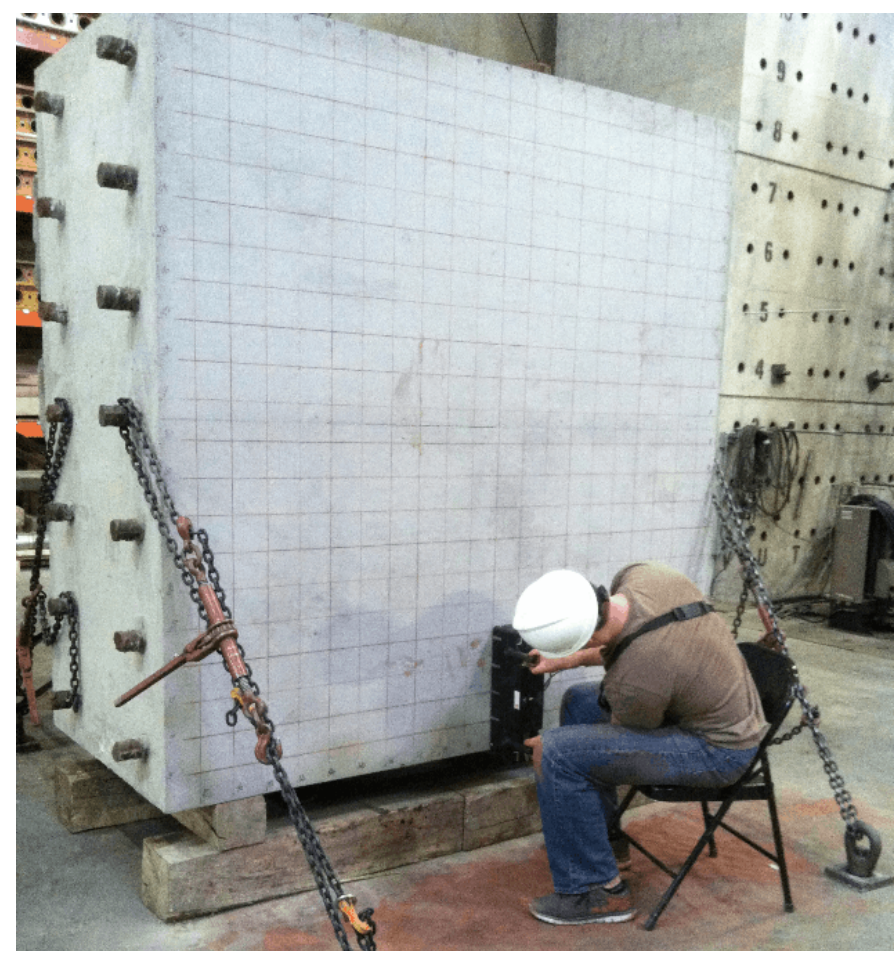

Fig. B.4. Height data collection used to create a SAFT-Panoramic reconstruction. 


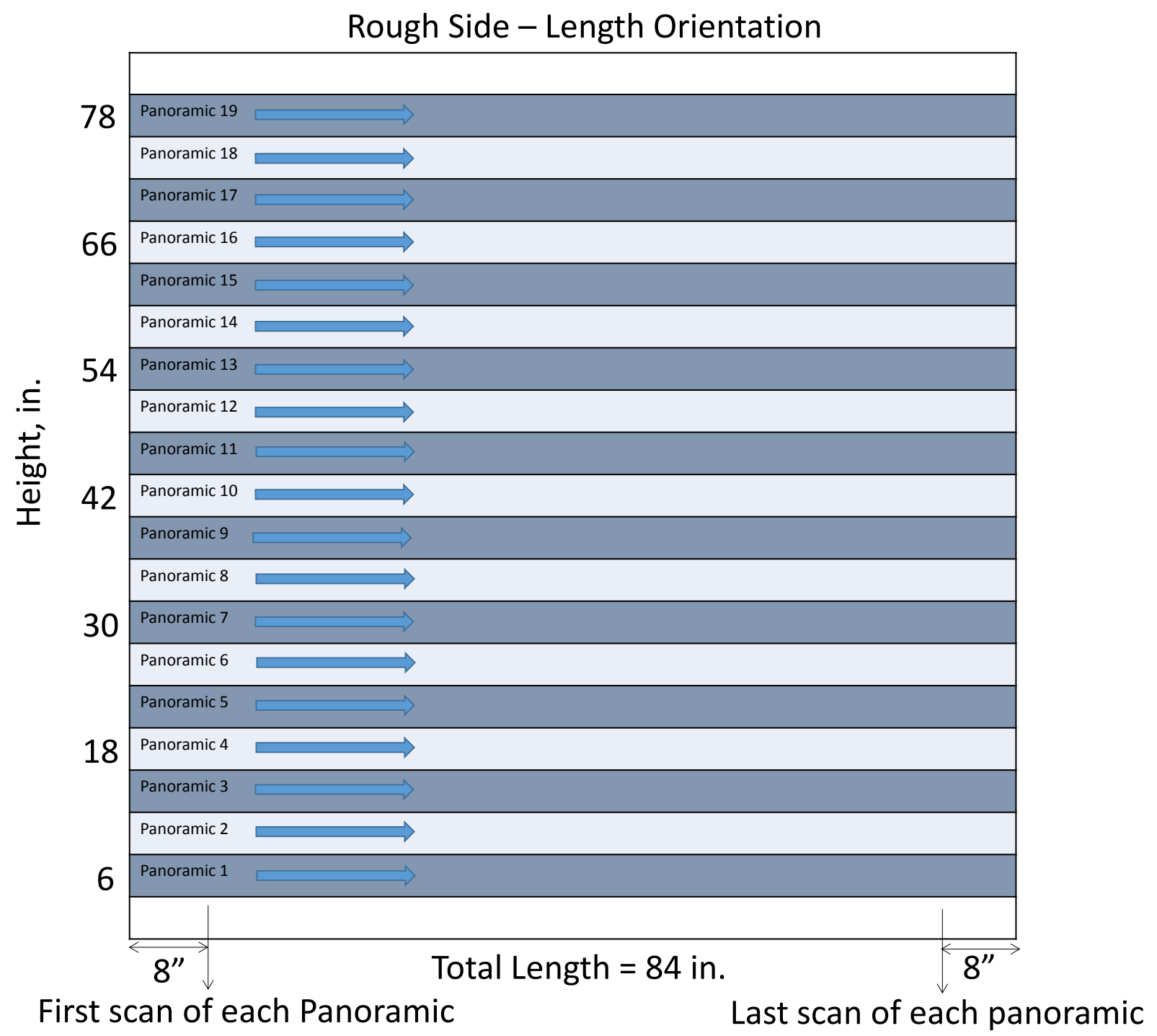

Fig. B.5. Rough side measurement procedure for length orientation measurements. 


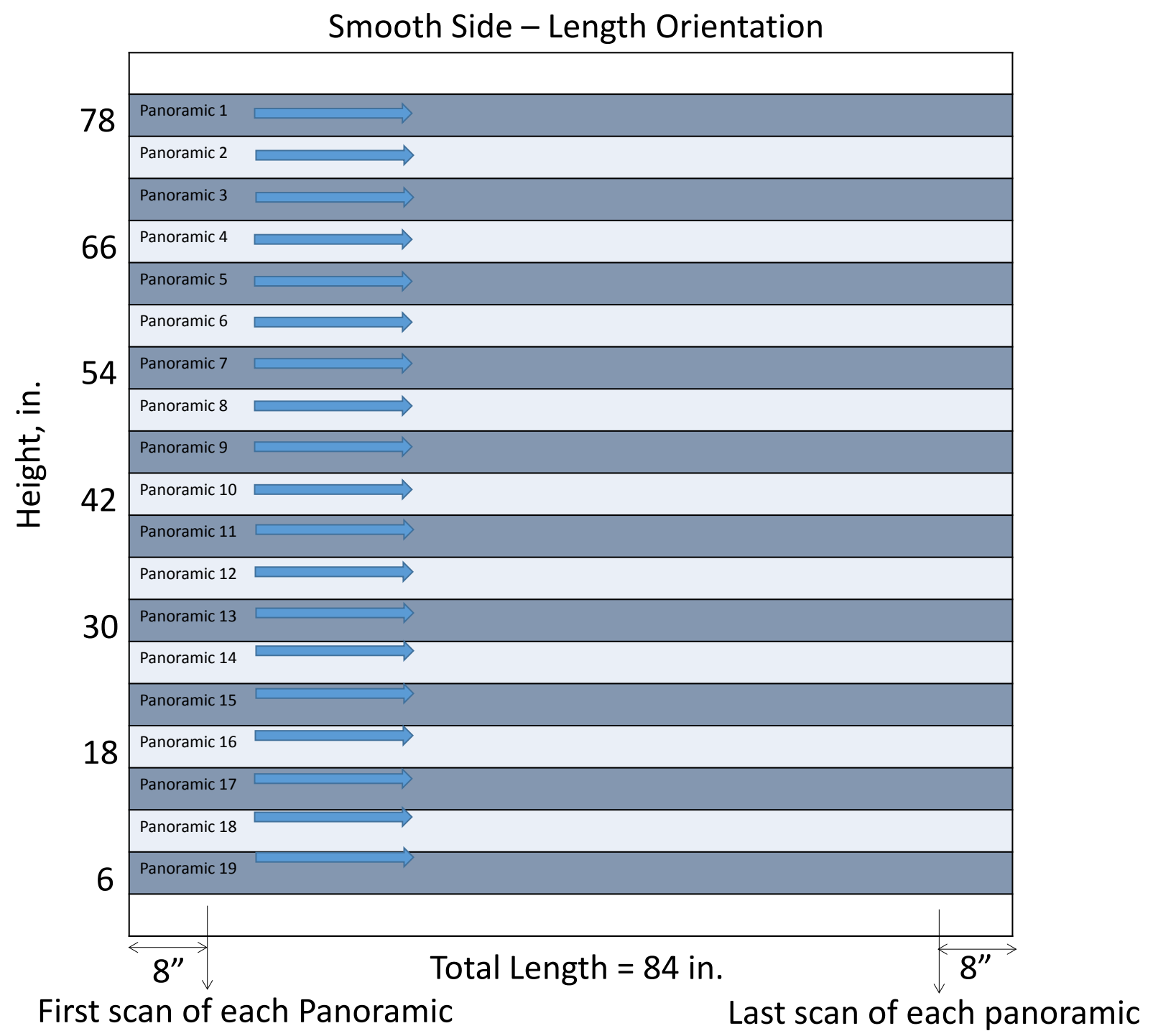

Fig. B.6. Smooth side measurement procedure for length orientation measurements. 


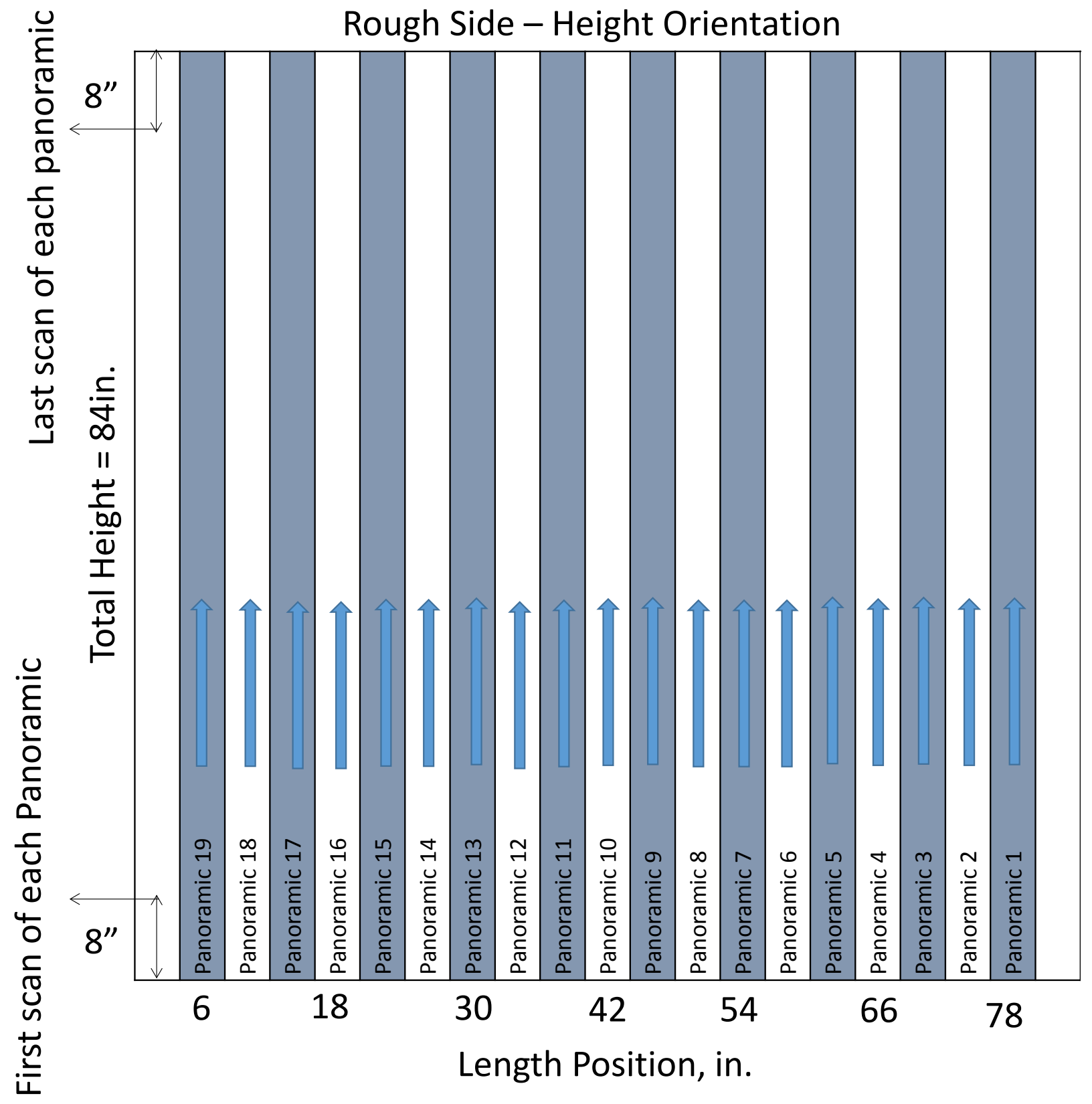

Fig. B.7. Rough side measurement procedure for height orientation measurements. 


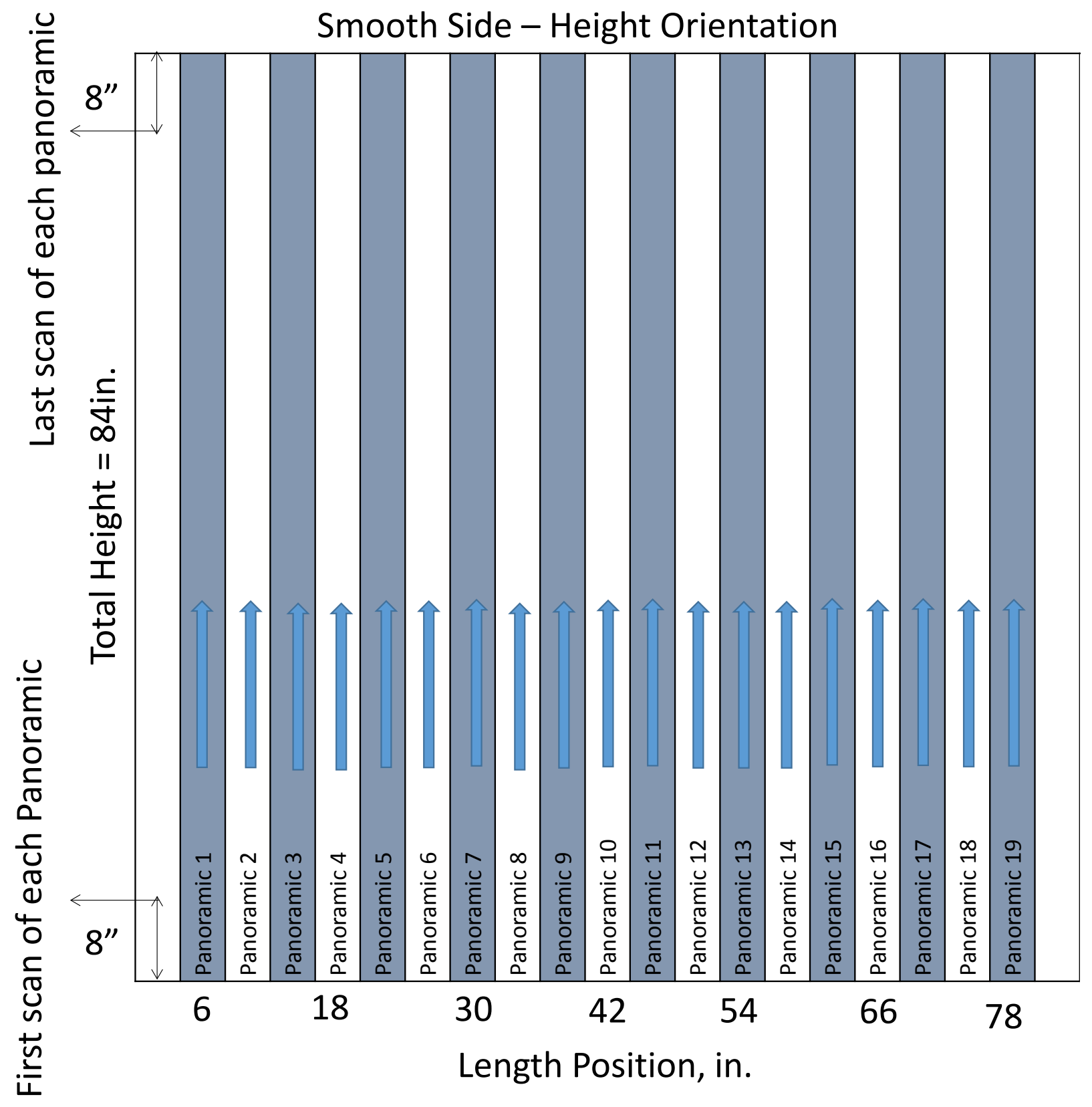

Fig. B.8. Smooth side measurement procedure for height orientation measurements. 
Table B.1. Adjacent SAFT-Panoramic scan information

\begin{tabular}{|c|c|c|c|c|}
\hline \multirow{2}{*}{$\begin{array}{l}\text { Defect } \\
\text { ID }\end{array}$} & \multicolumn{2}{|c|}{$\begin{array}{c}\text { Rough side MIRA testing } \\
\text { adjacent panoramic index } \\
\text { numbers }\end{array}$} & \multicolumn{2}{|c|}{$\begin{array}{l}\text { Smooth side MIRA testing } \\
\text { adjacent panoramic index } \\
\text { numbers }\end{array}$} \\
\hline & $\begin{array}{c}\text { Height } \\
\text { orientation }\end{array}$ & $\begin{array}{c}\text { Length } \\
\text { orientation }\end{array}$ & $\begin{array}{c}\text { Height } \\
\text { orientation }\end{array}$ & $\begin{array}{c}\text { Length } \\
\text { orientation }\end{array}$ \\
\hline 1 & 14.5 & 16.0 & 5.5 & 4.0 \\
\hline 2 & 7.0 & 5.5 & 13.0 & 14.5 \\
\hline 3 & 10.0 & 14.5 & 10.0 & 5.5 \\
\hline 4 & 5.5 & 4.0 & 14.5 & 16.0 \\
\hline 5 & 14.5 & 13.0 & 5.5 & 7.0 \\
\hline 6 & 13.5 & 10.0 & 6.5 & 10.0 \\
\hline 7 & 6.5 & 10.0 & 13.5 & 10.0 \\
\hline 8 & 11.5 & 8.5 & 8.5 & 11.5 \\
\hline 9 & 8.5 & 11.5 & 11.5 & 8.5 \\
\hline 10 & 8.5 & 2.5 & 11.5 & 17.5 \\
\hline 11 & 11.5 & 17.5 & 8.5 & 2.5 \\
\hline 12 & 8.5 & 8.5 & 11.5 & 11.5 \\
\hline 13 & 11.5 & 11.5 & 8.5 & 8.5 \\
\hline 14 & 4.8 & 15.3 & 15.3 & 4.7 \\
\hline 15 & 15.3 & 4.8 & 4.8 & 15.2 \\
\hline 16 & 3.3 & 17.5 & 16.8 & 2.5 \\
\hline 17 & 7.0 & 14.5 & 13.0 & 5.5 \\
\hline 18 & 1.8 & 10.0 & 18.3 & 10.0 \\
\hline 19 & 3.3 & 10.0 & 16.8 & 10.0 \\
\hline 20 & 10.0 & 7.0 & 10.0 & 13.0 \\
\hline
\end{tabular}



APPENDIX C. ANNOTATED RECONSTRUCTIONS 

Annotated SAFT-Panoramic reconstruction results are given in Figs. C.5 through C.80, corresponding to the general locations described by Figs. C.1 through C.4. More information on how the data collection process was used to create the SAFT-Panoramics, along with a description of Figs. C.1 through C.4, is given in Appendix B Figures C.5 through C.23 correspond to SAFT-Panoramics 1 through 19 from Fig. C.1. Figures C.24 through C.42 correspond to SAFT-Panoramics 1 through 19 from Fig. C.2. Figures C.43 through C.61 correspond to SAFT-Panoramics 1 through 19 from Fig. C.3. Figures C.62 through C.80 correspond to SAFT-Panoramics 1 through 19 from Fig. C.4. The filepaths and filenames given as the caption of the figures are an artifact of the batch mode appendix creation, but contain some information about each figure based on the reconstruction folder name and cataloging procedure. If any defect was located within 2 in. of the lateral location of the displayed SAFT-Panoramic, it was labeled with an arrow pointing to the location where the defect was designed to be embedded. This systematic presentation of the results can be used to determine the type of defect, environment, and depths that are indicated by an increase in reflectivity using conventional reconstructions versus situations where conventional analysis is insufficient.

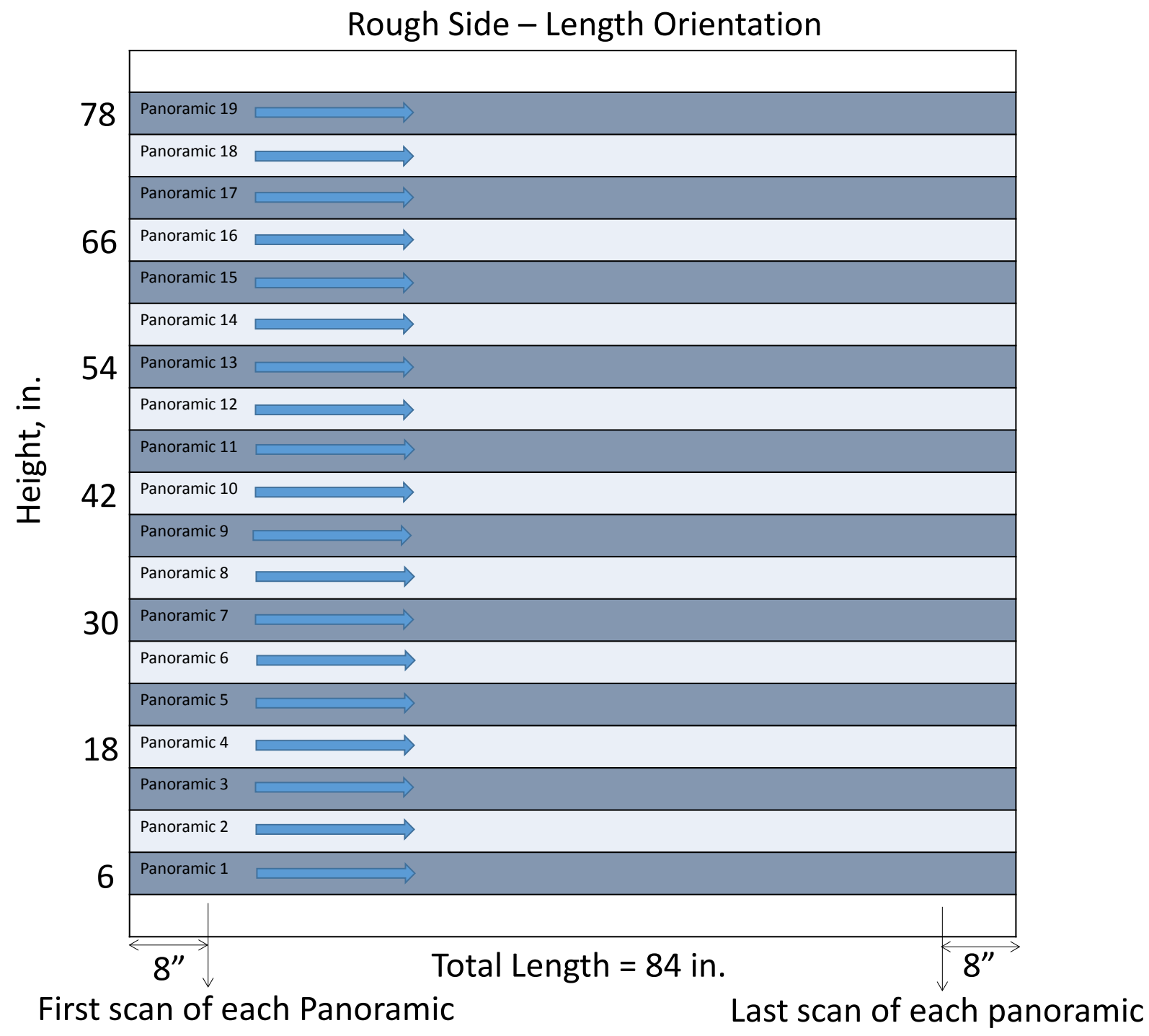

Fig. C.1. Rough side measurement procedure for length orientation measurements. 


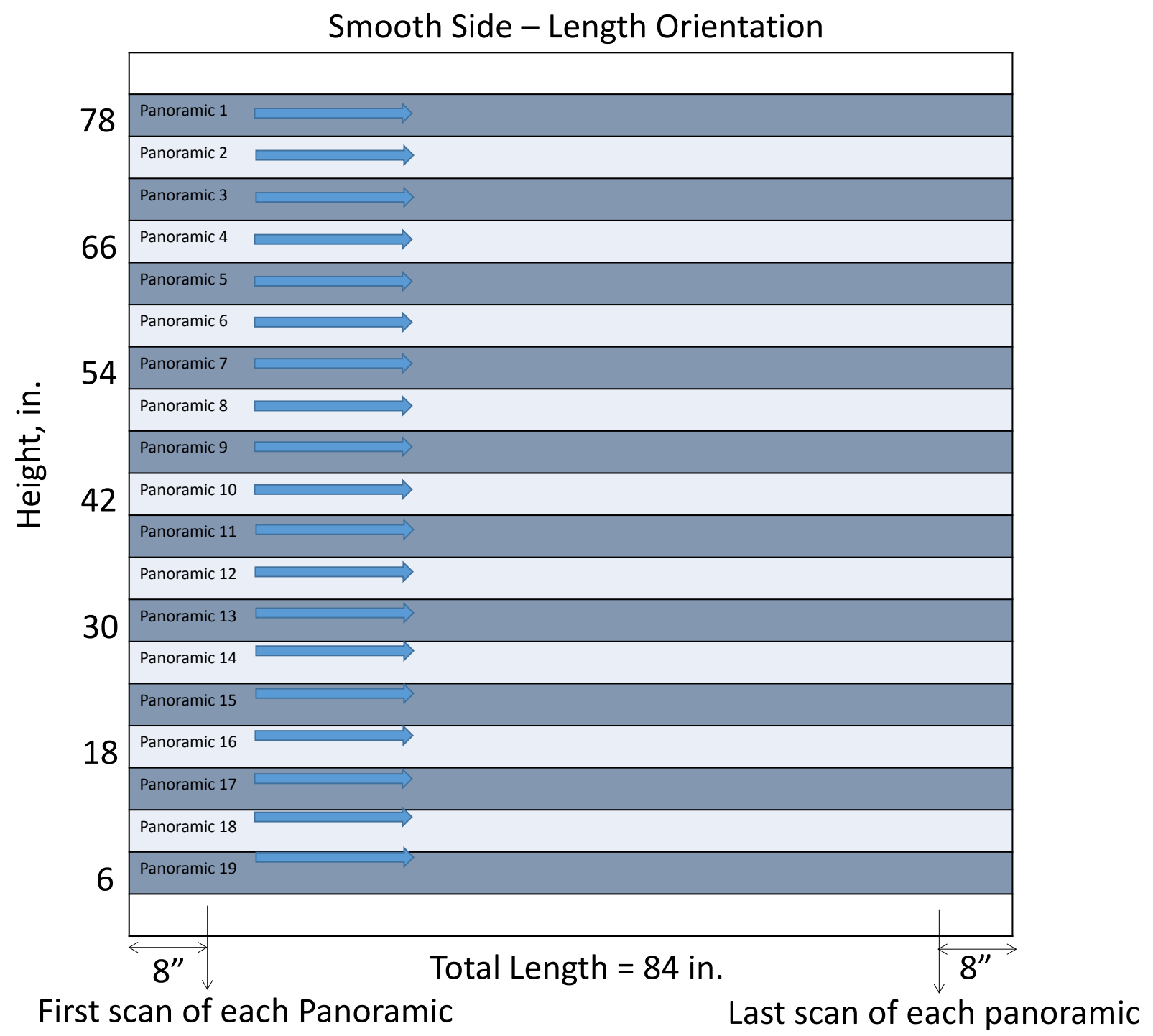

Fig. C.2. Smooth side measurement procedure for length orientation measurements. 


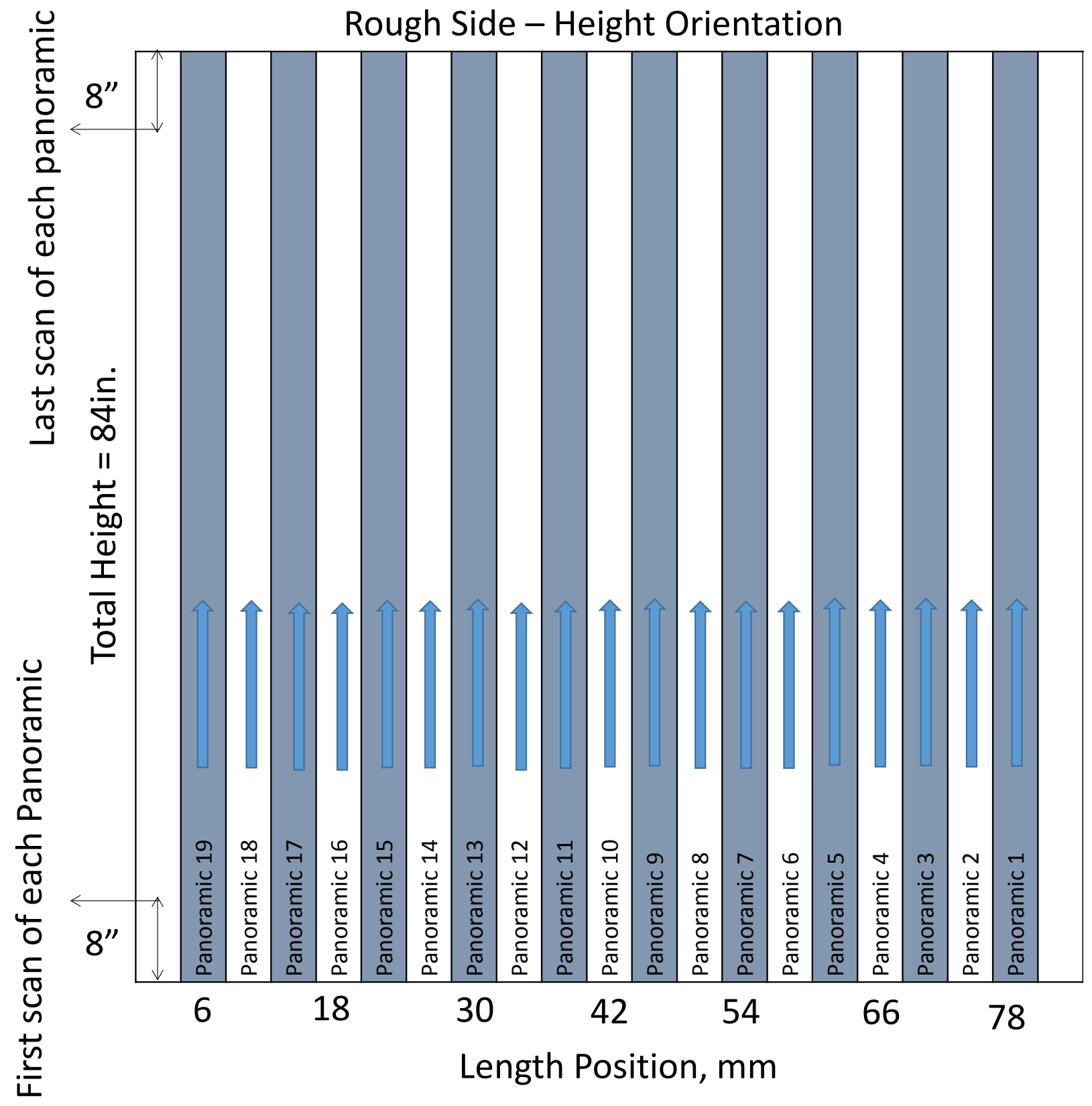

Fig. C.3. Rough side measurement procedure for height orientation measurements. 


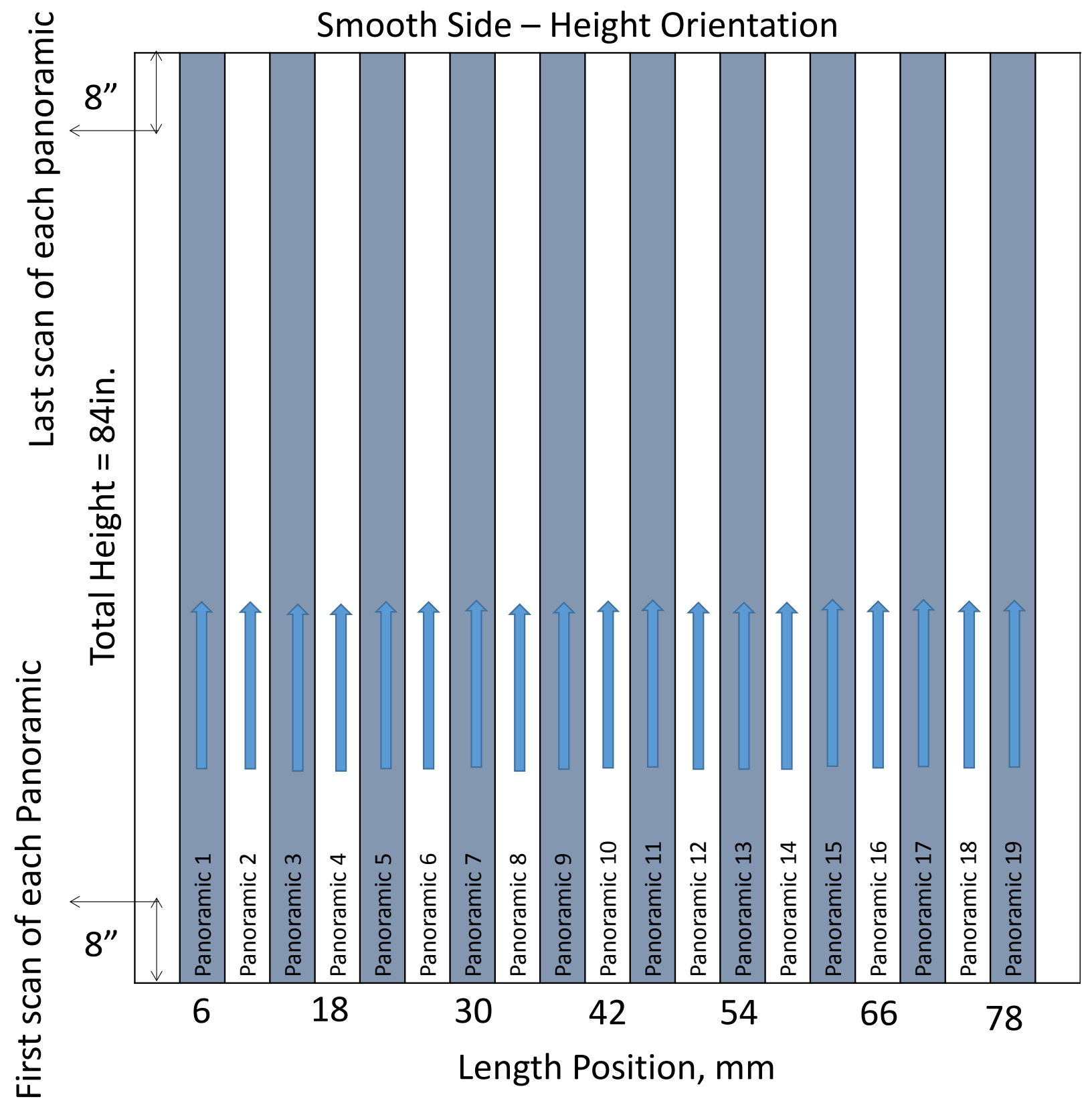

Fig. C.4. Smooth side measurement procedure for height orientation measurements. 


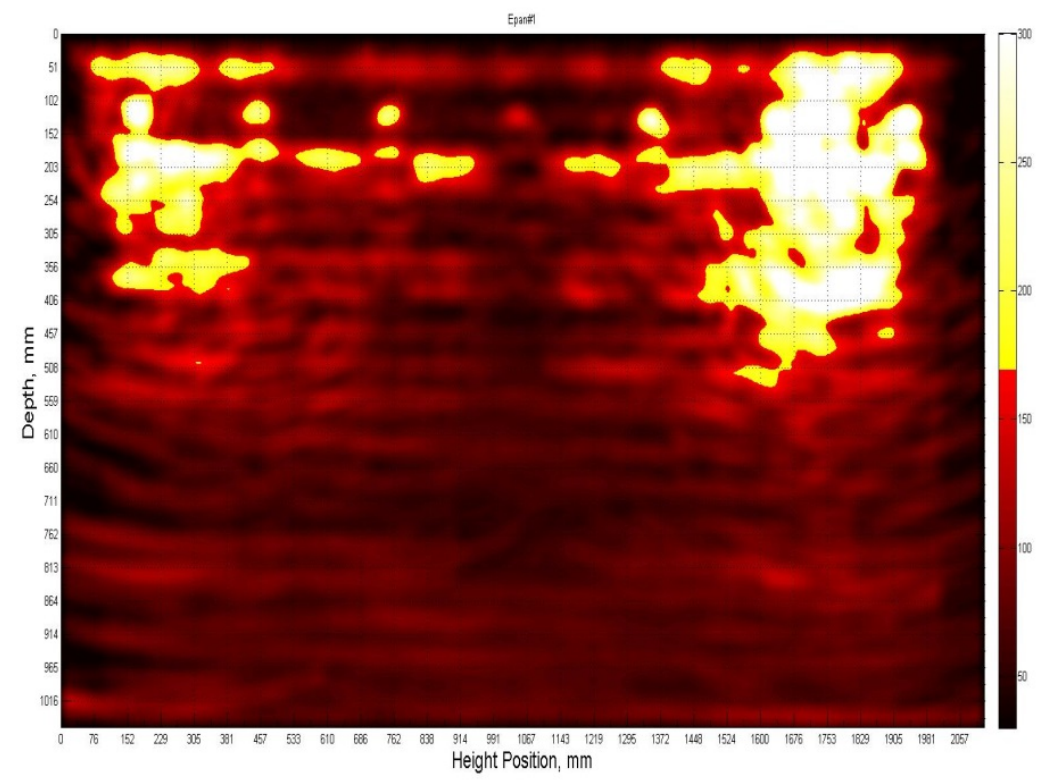

Fig. C.5. Rough side height - Epan 1 m18.

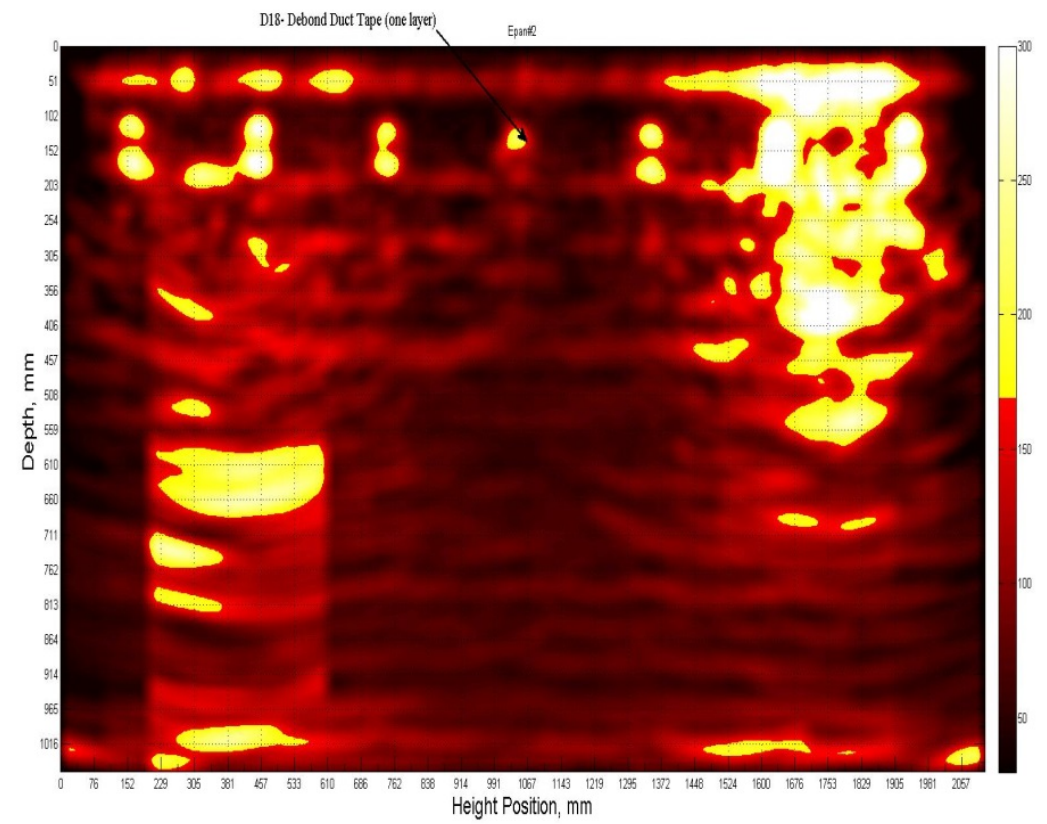

Fig. C.6. Rough side height - Epan 2 m36 done. 


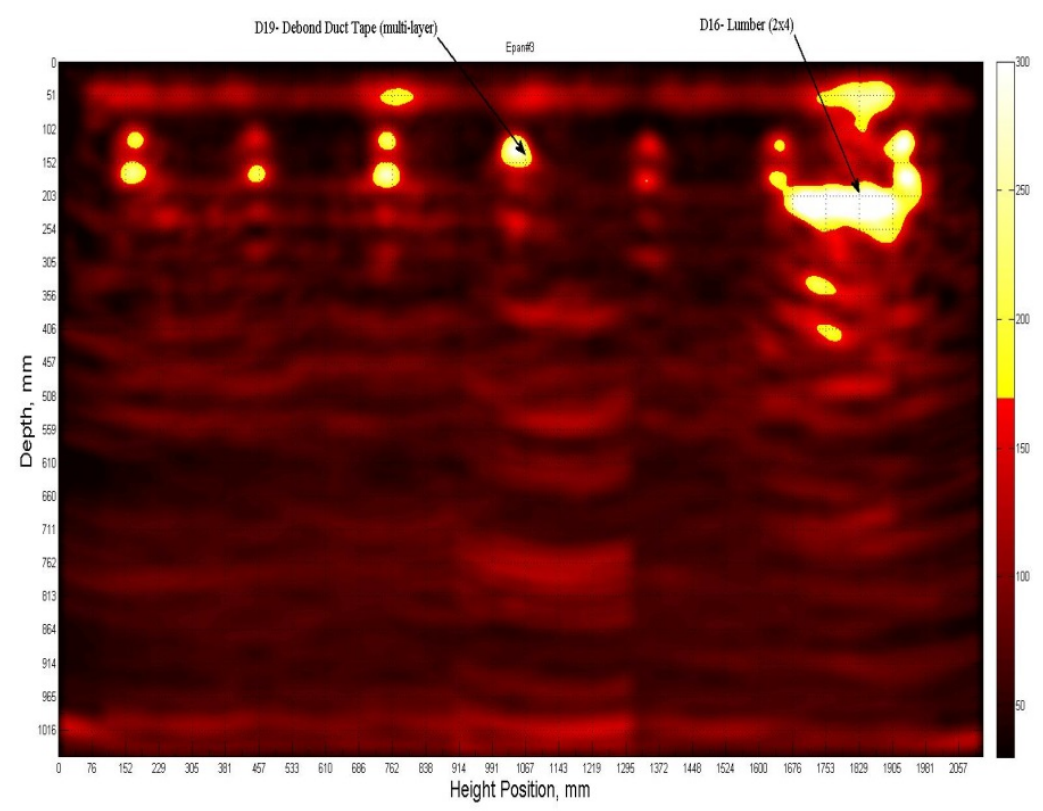

Fig. C.7. Rough side height - Epan 3 m54.

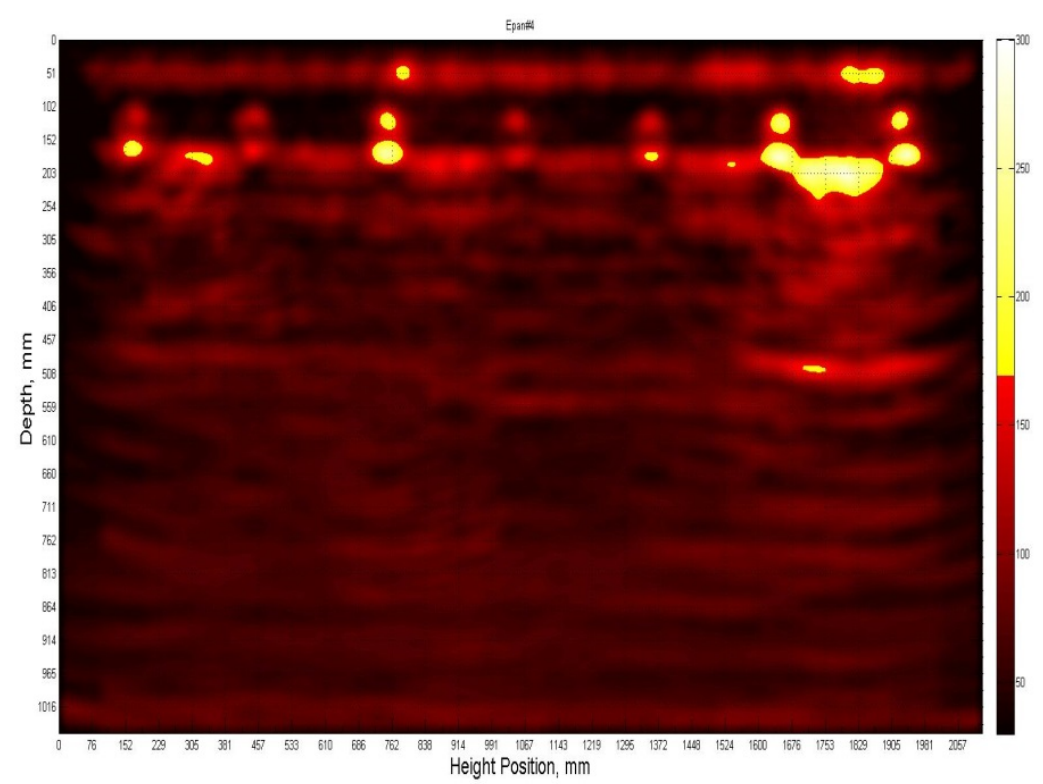

Fig. C.8. Rough side height - Epan 4 m72. 


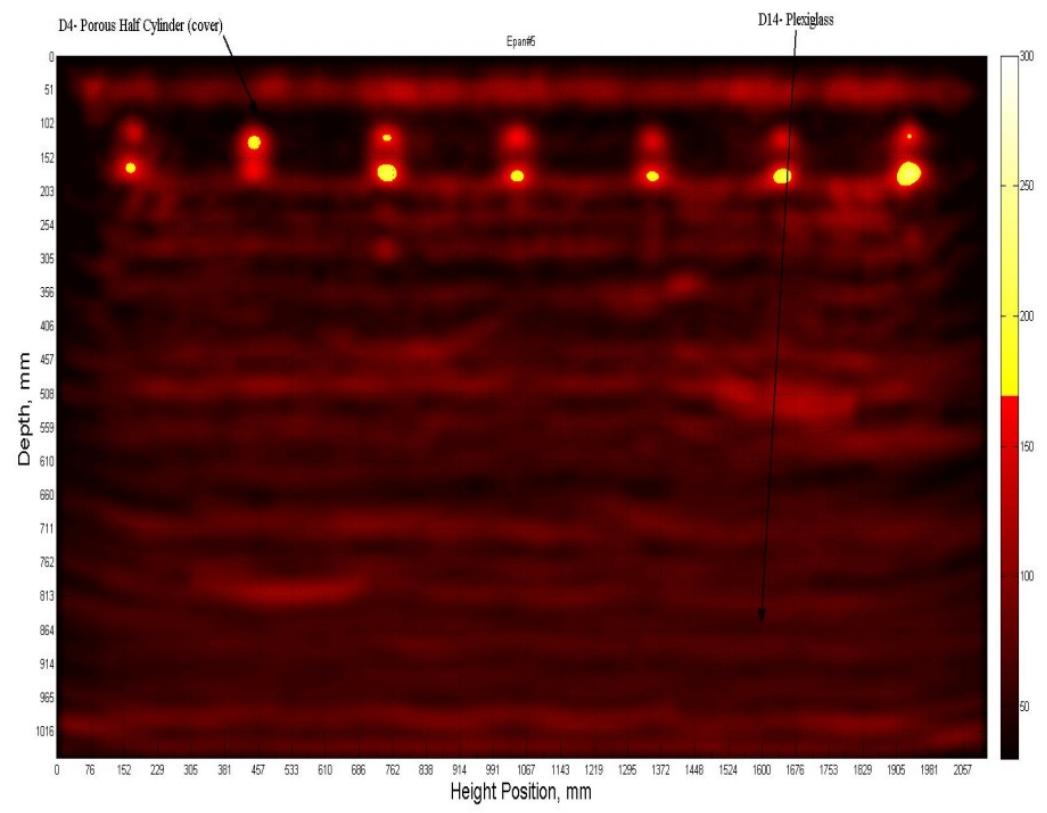

Fig. C.9. Rough side height - Epan 5 m90.

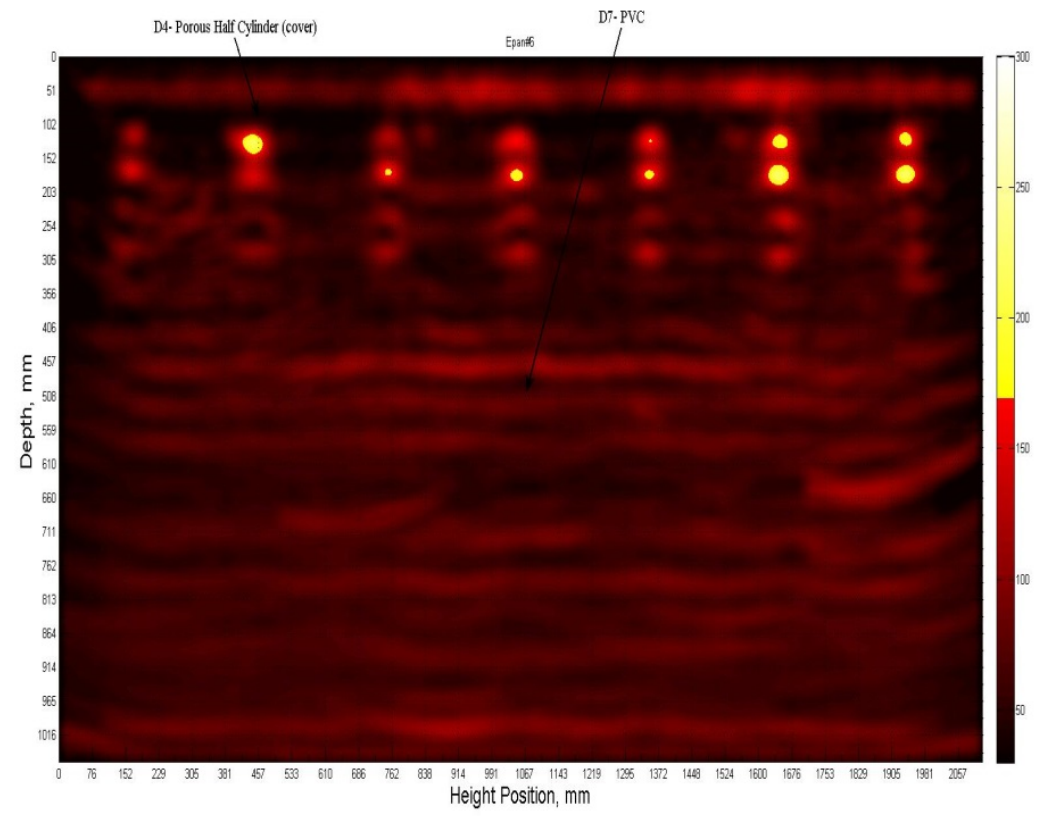

Fig. C.10. Rough side height - Epan 6 m108 done. 


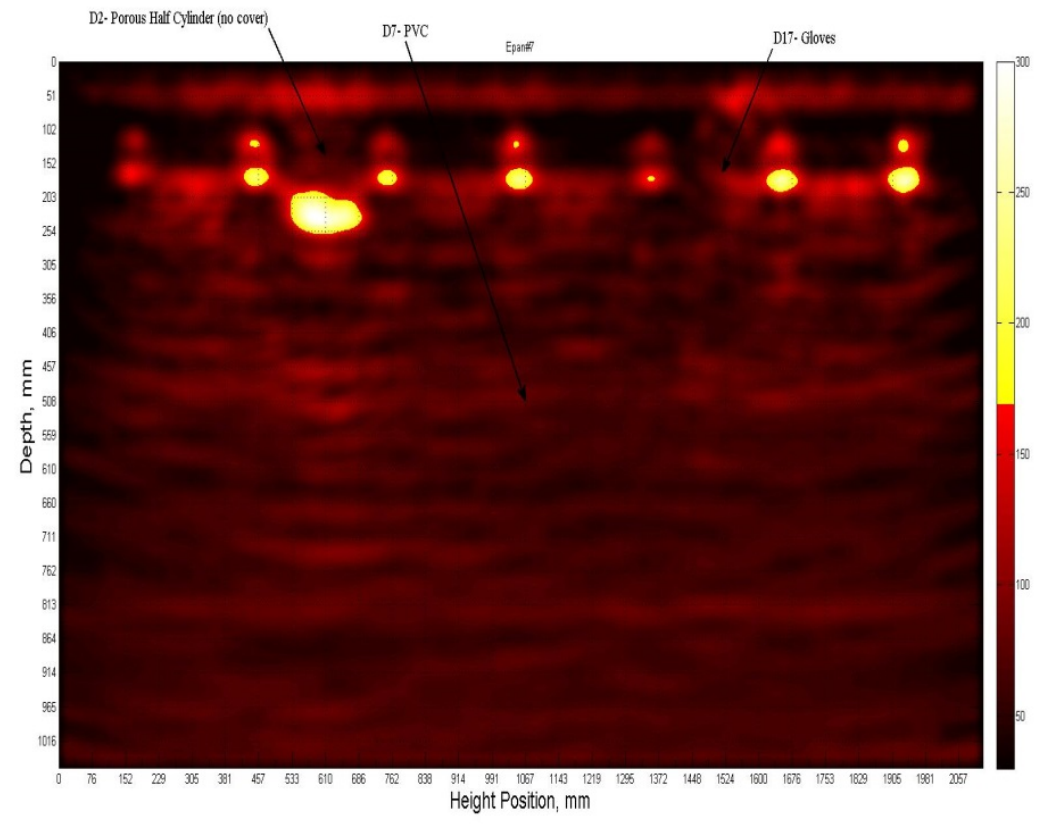

Fig. C.11. Rough side height - Epan 7 m126.

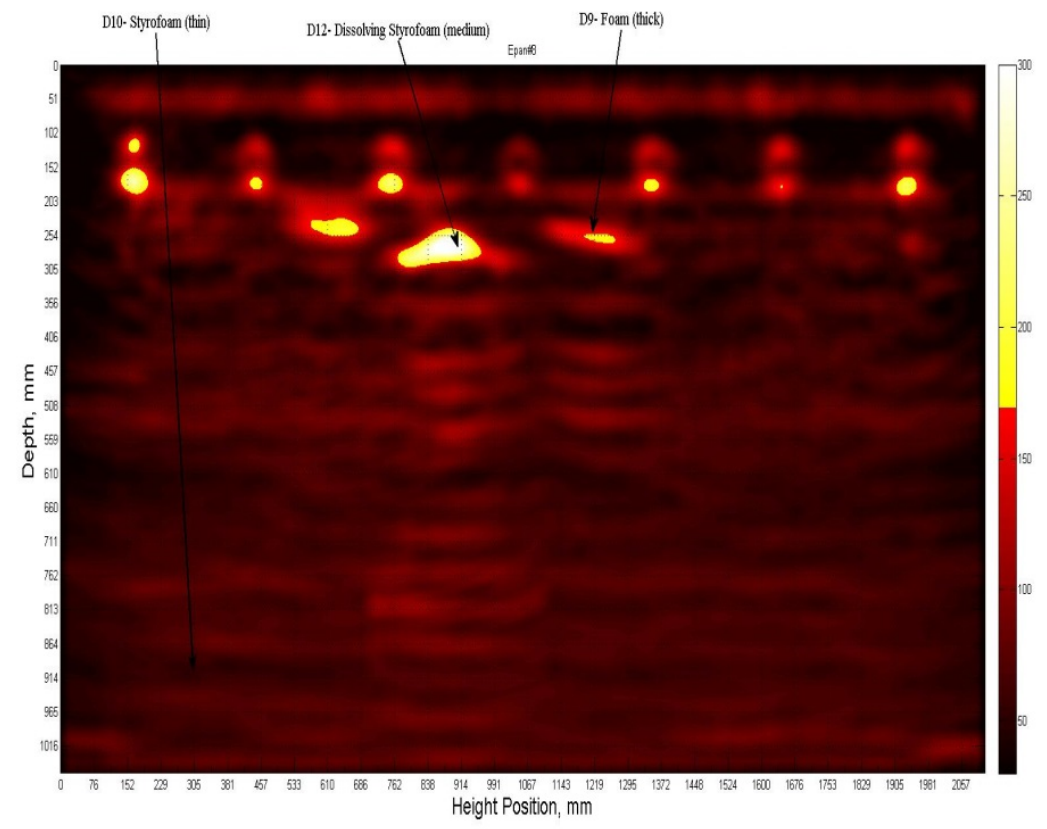

Fig. C.12. Rough side height - Epan 8 m144. 


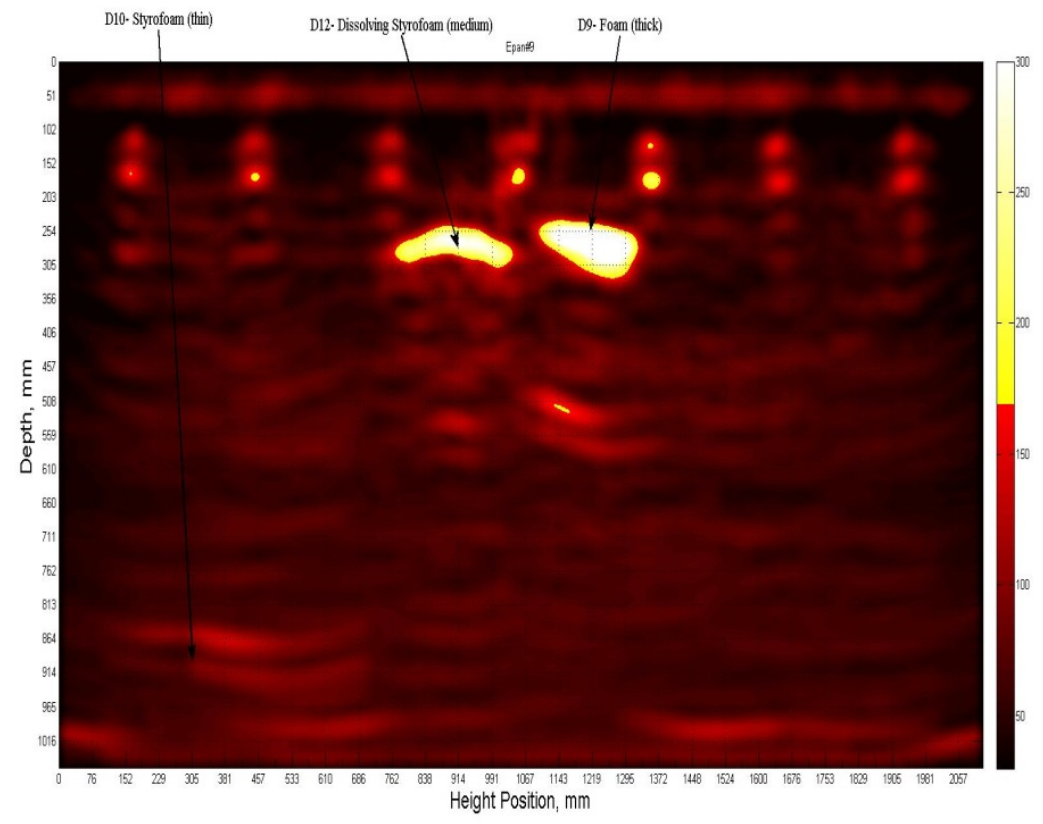

Fig. C.13. Rough side height - Epan 9 m162.

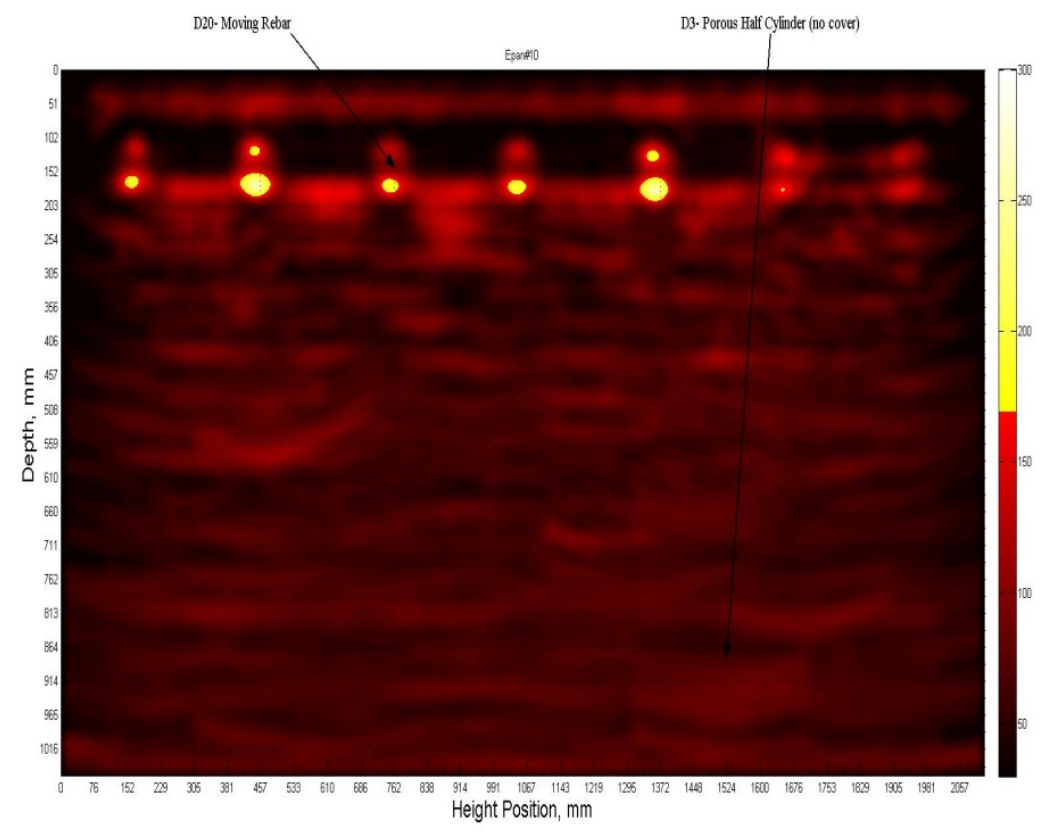

Fig. C.14. Rough side height- Epan $10 \mathrm{m180}$. 


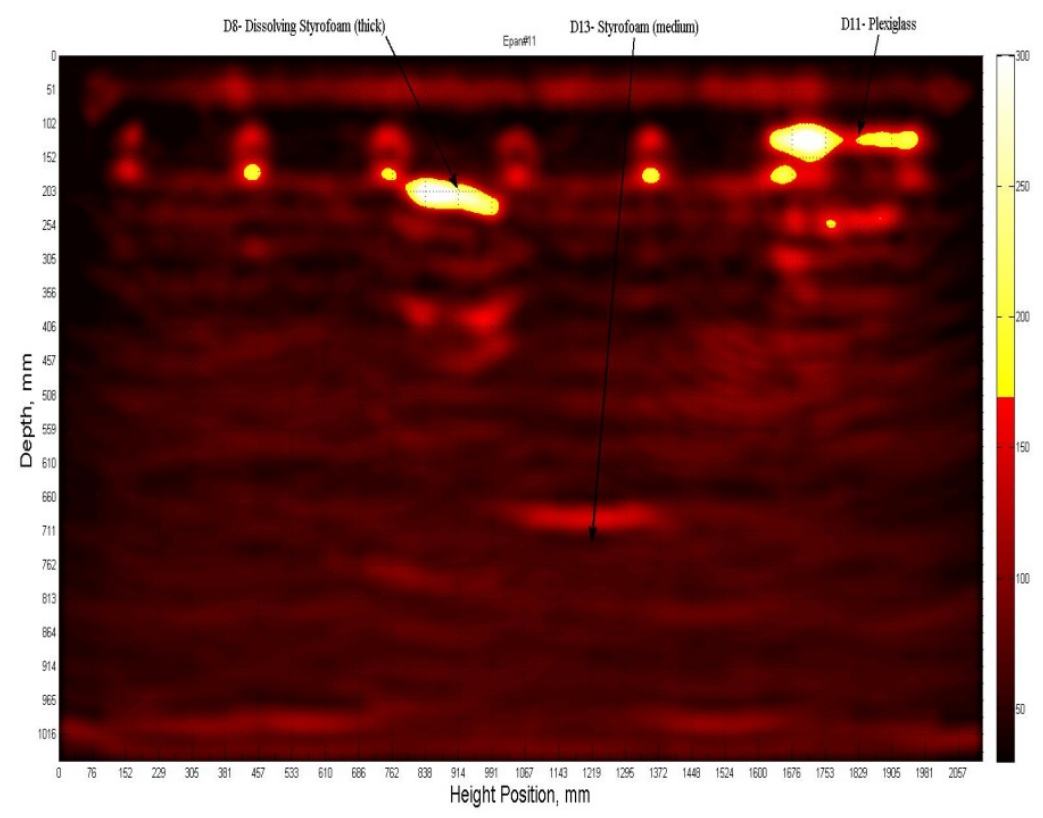

Fig. C.15. Rough side height - Epan 11 m198.

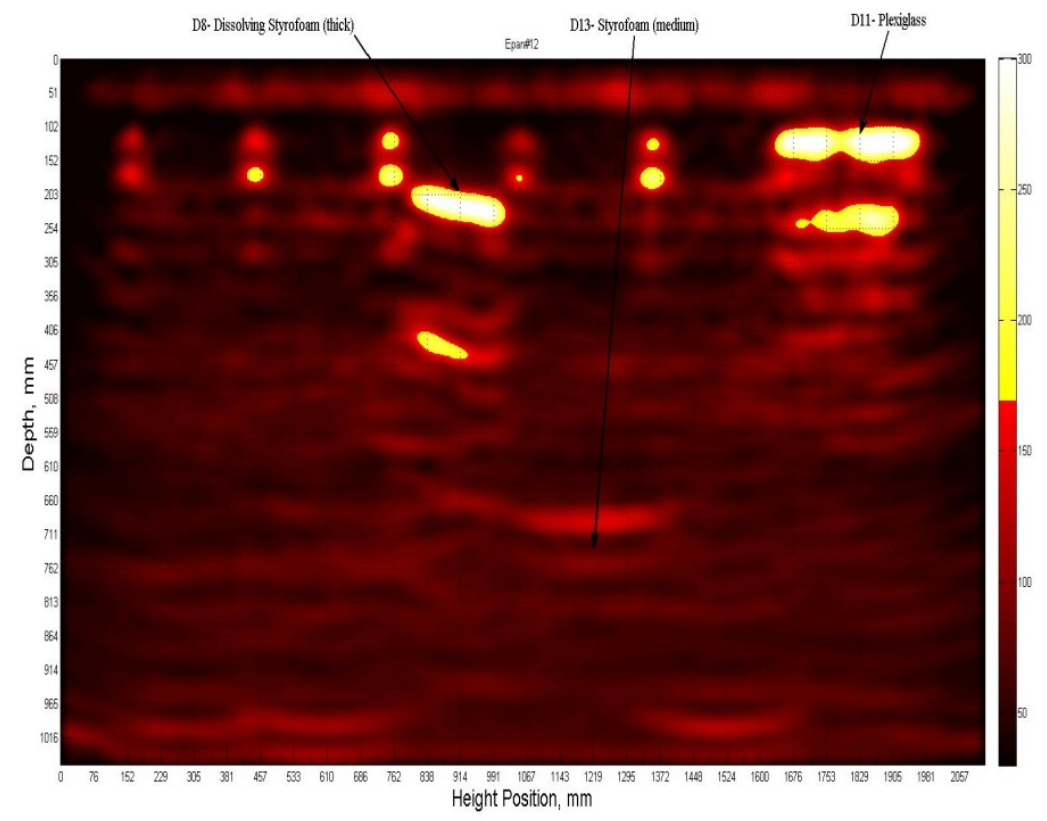

Fig. C.16. Rough side height - Epan 12 m216. 


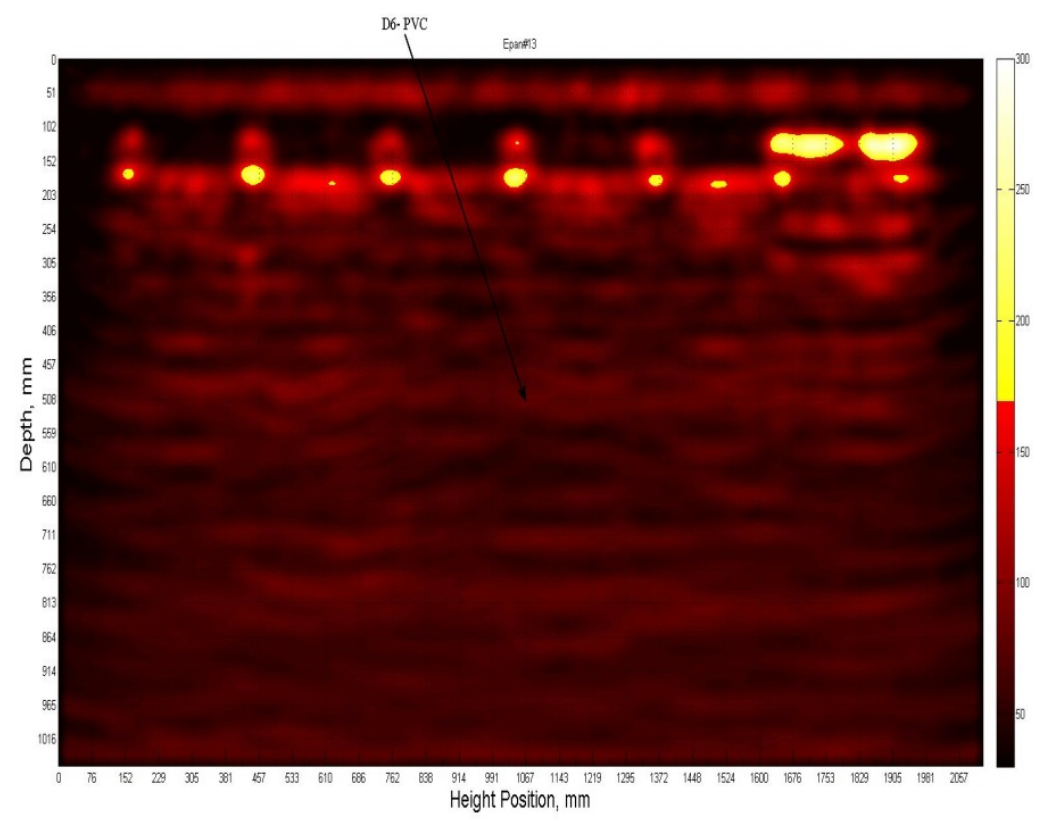

Fig. C.17. Rough side height - Epan 13 m234.

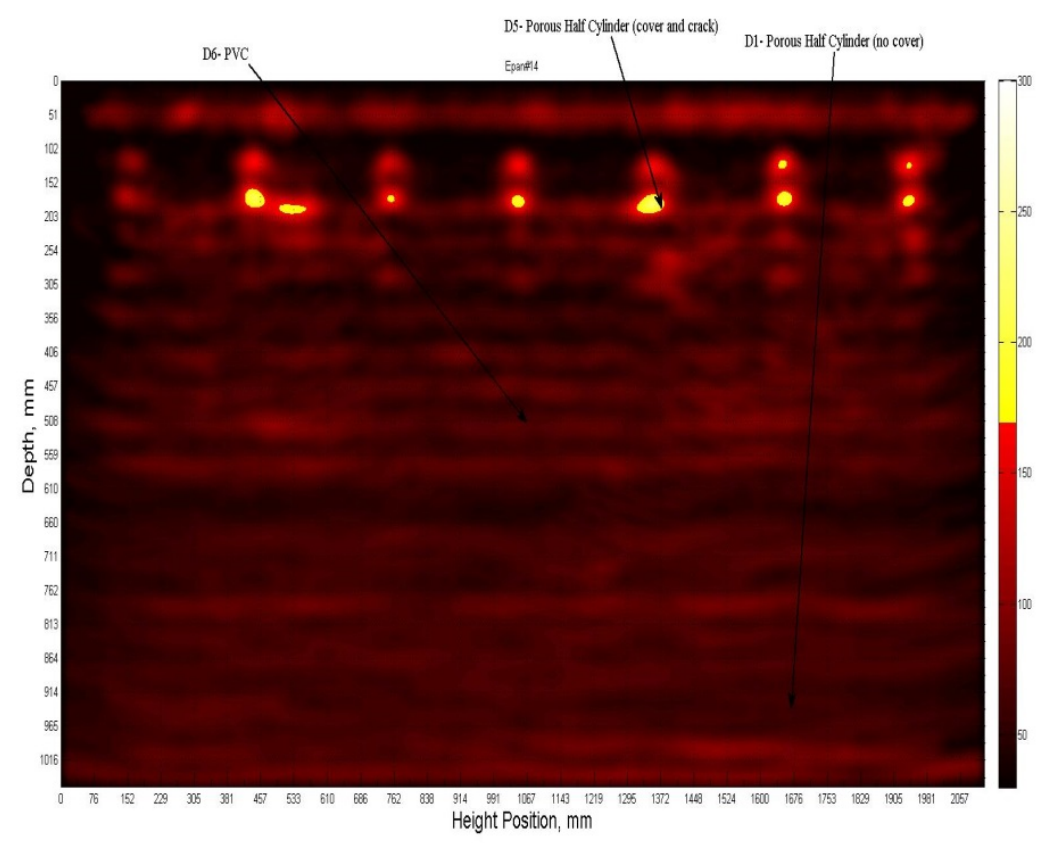

Fig. C.18. Rough side height - Epan 14 m252. 


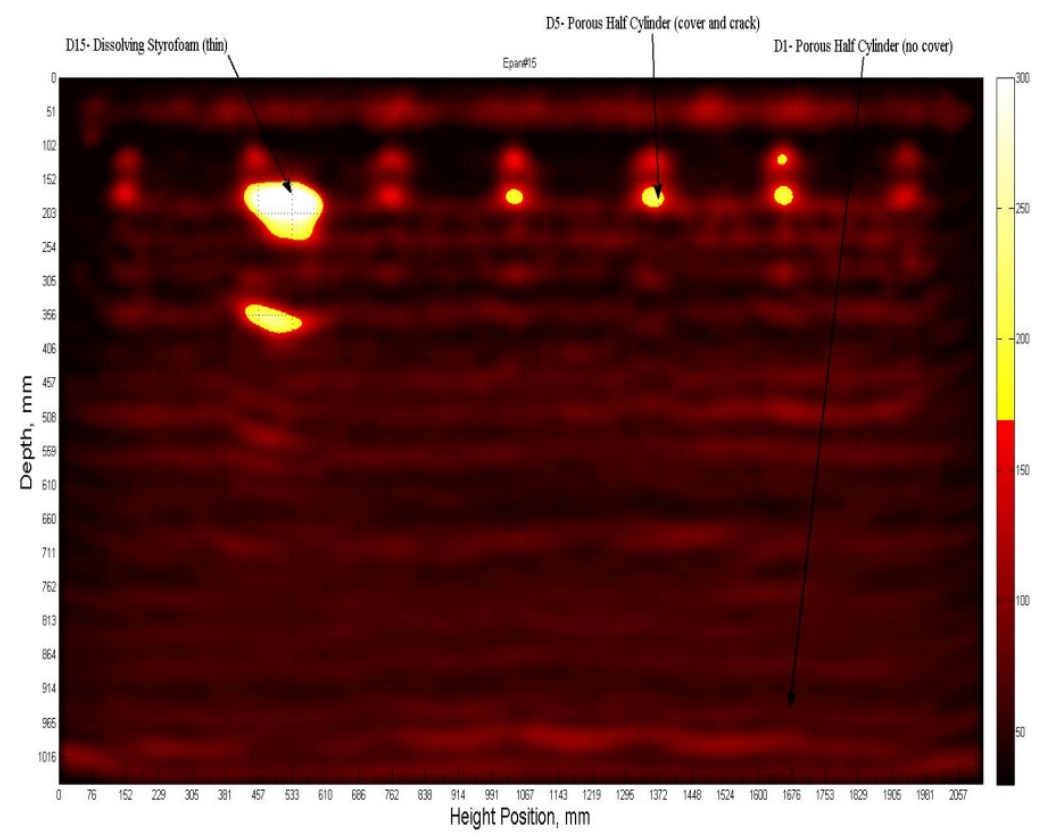

Fig. C.19. Rough side height - Epan 15 m270.

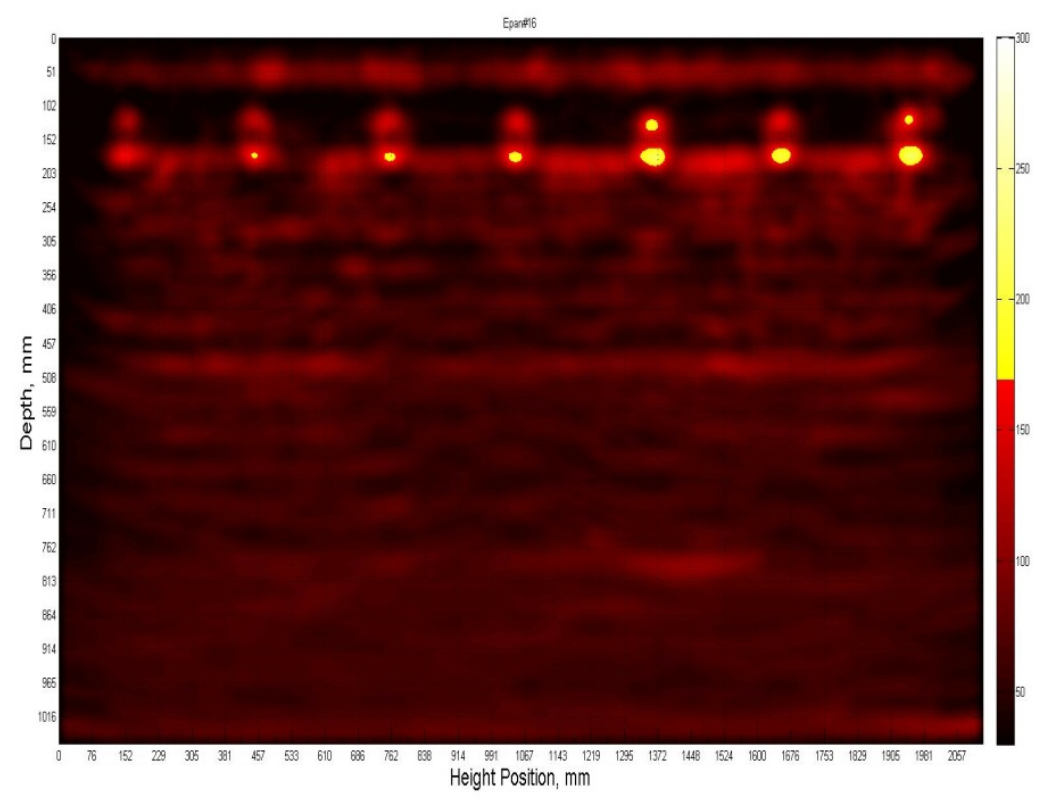

Fig. C.20. Rough side height - Epan 16 m288. 


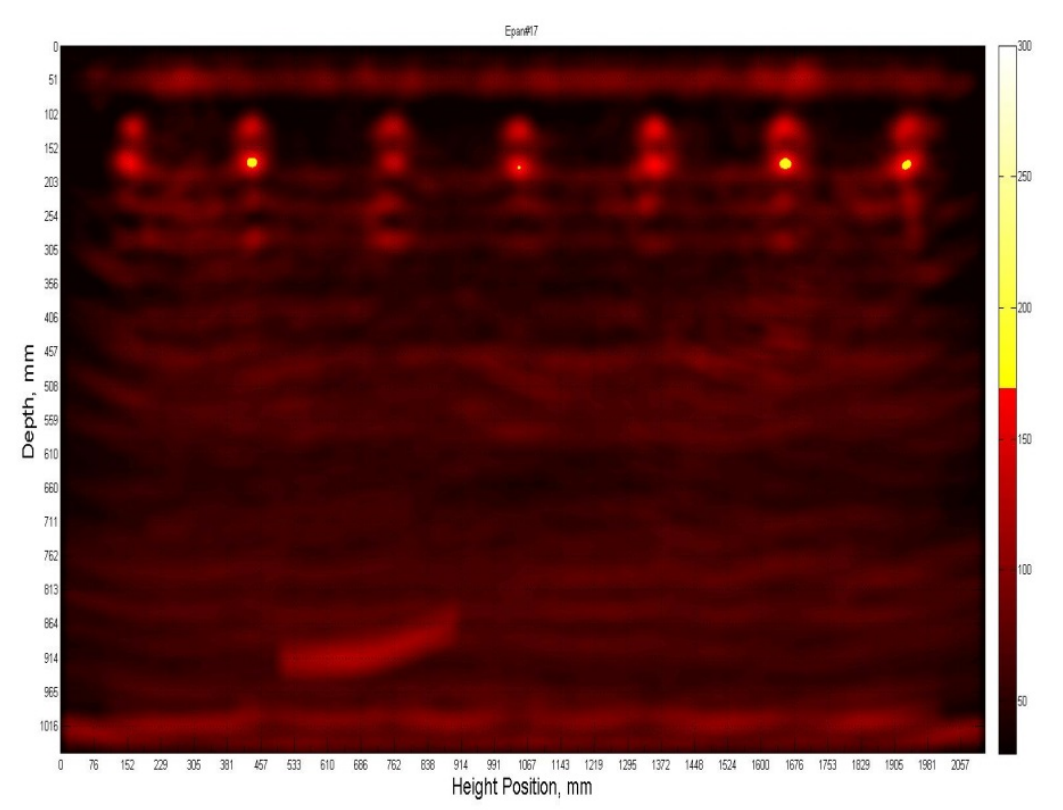

Fig. C.21. Rough side height - Epan 17 m306.

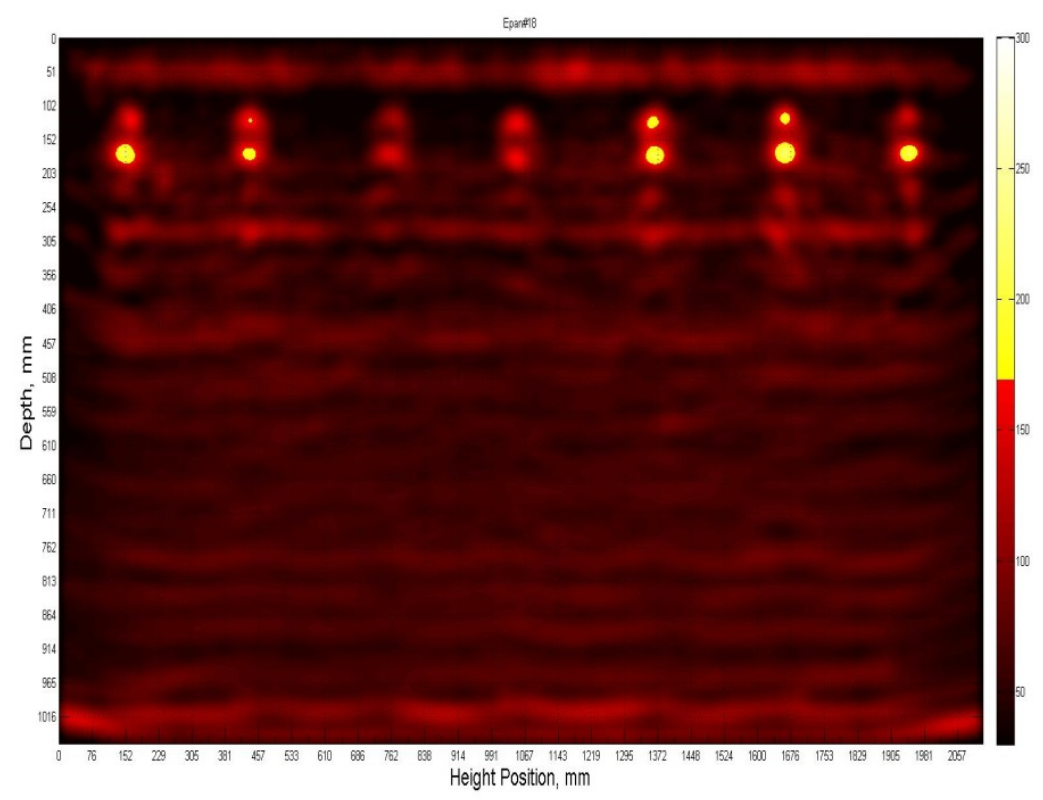

Fig. C.22. Rough side height - Epan 18 m324. 


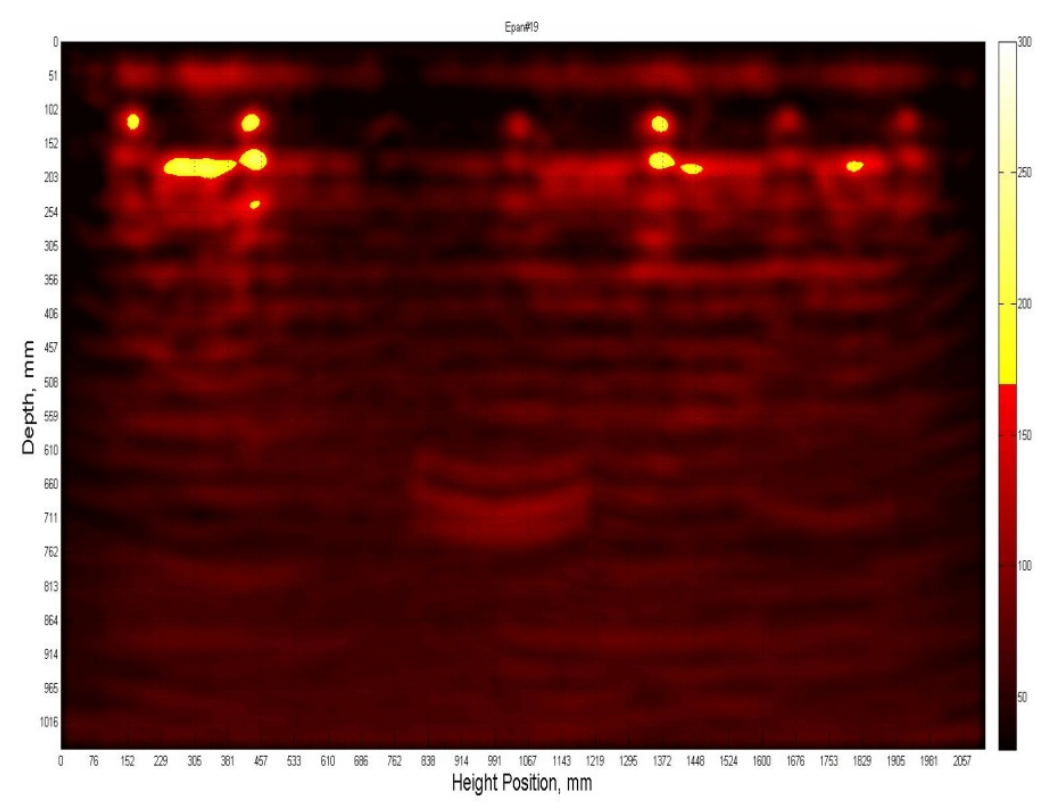

Fig. C.23. Rough side height - Epan 19 m342.

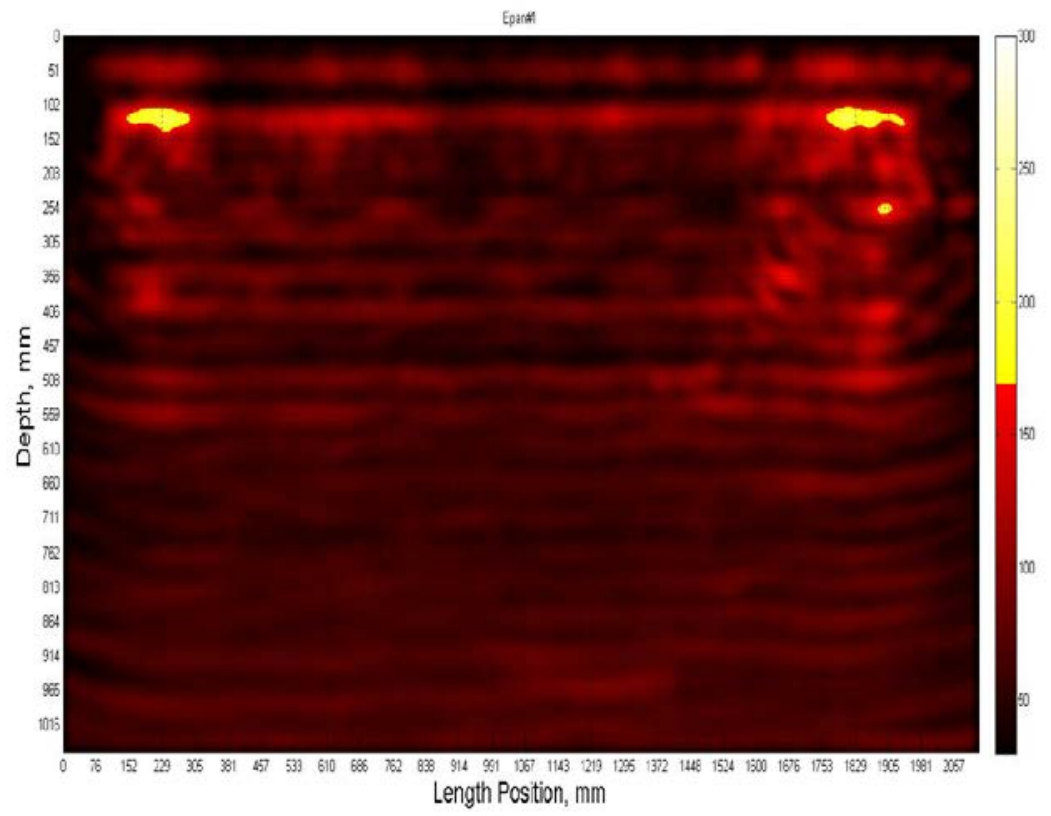

Fig. C.24. Rough side length - Epan $1 \mathrm{m18}$. 


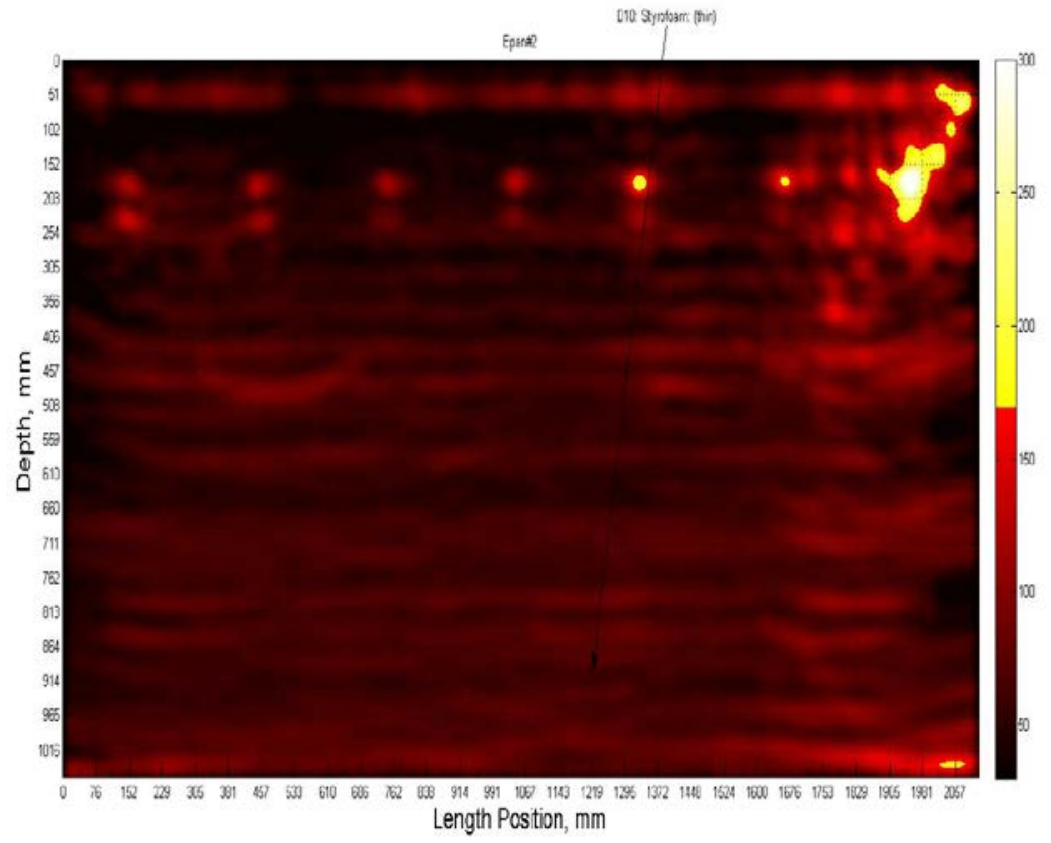

Fig. C.25. Rough side length - Epan 2 m36.

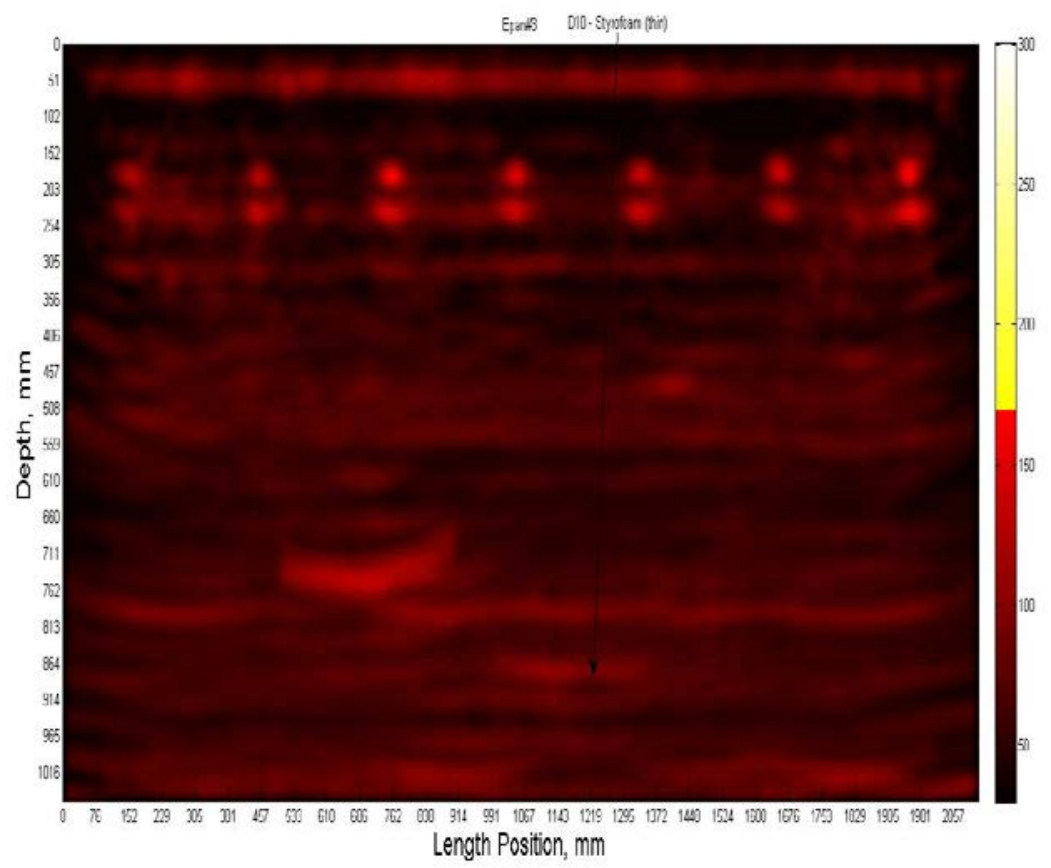

Fig. C.26. Rough side length - Epan 3 m54. 


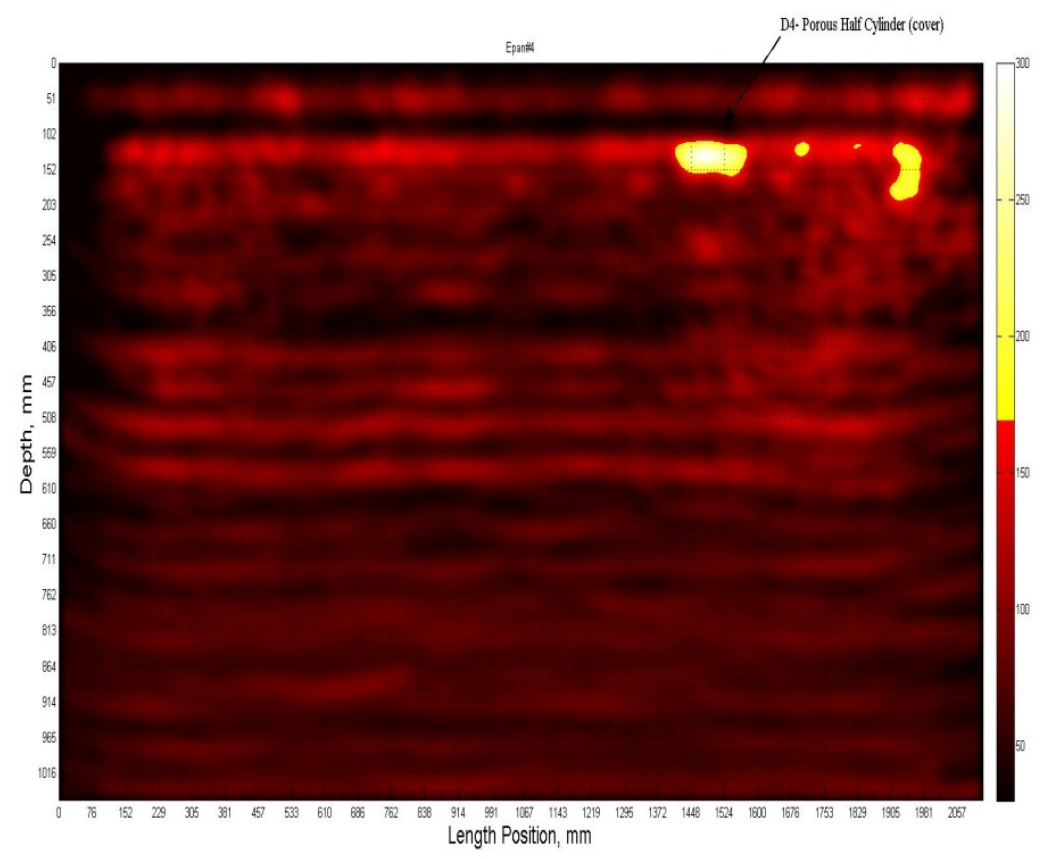

Fig. C.27. Rough side length - Epan 4 m72.

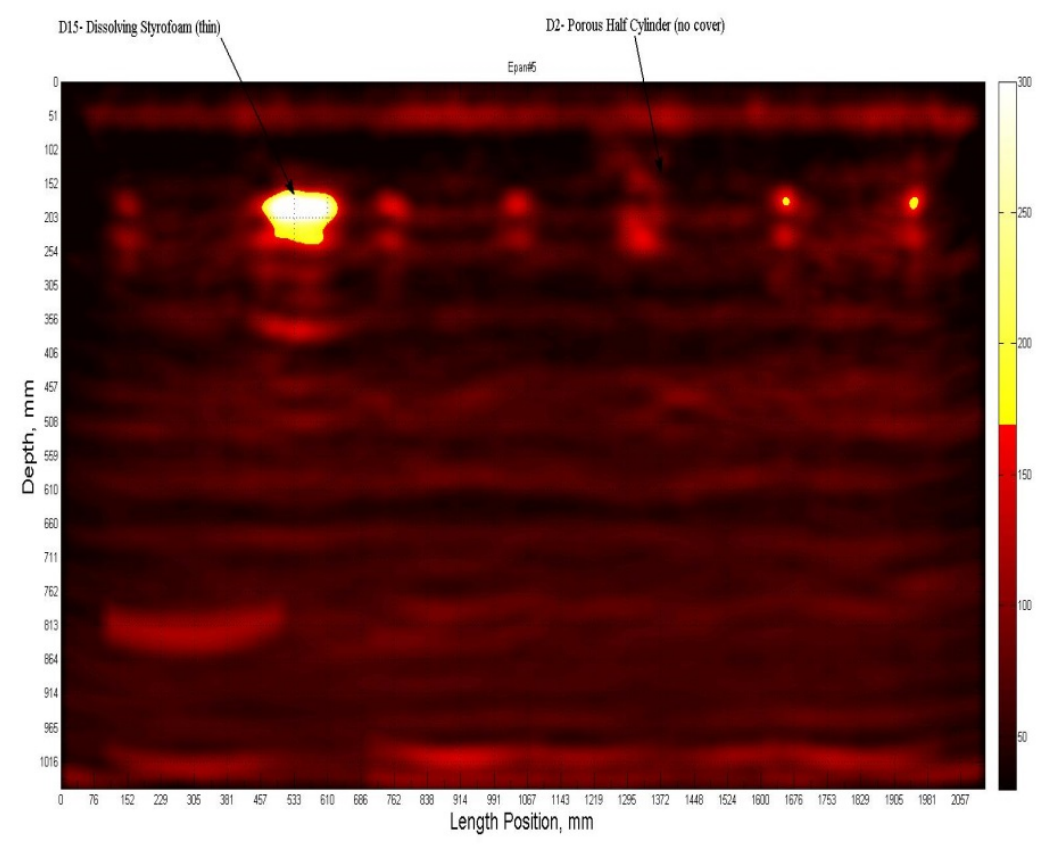

Fig. C.28. Rough side length - Epan 5 m90. 


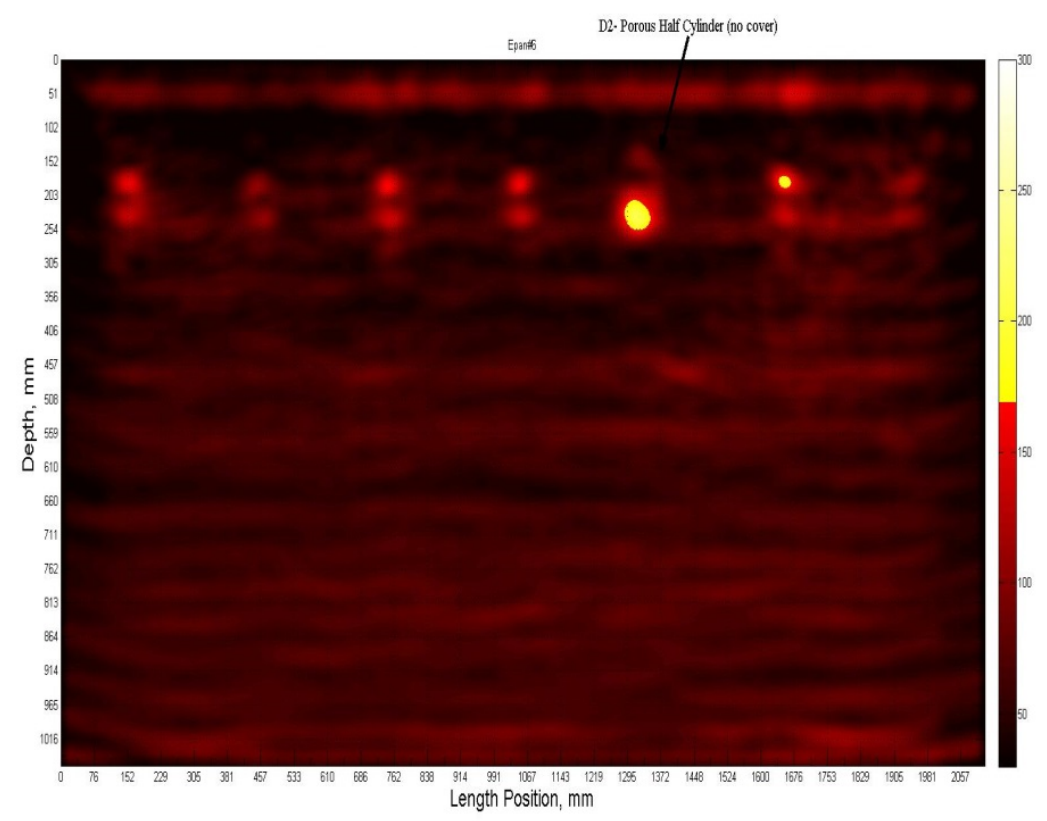

Fig. C.29. Rough side length - Epan 6 m108.

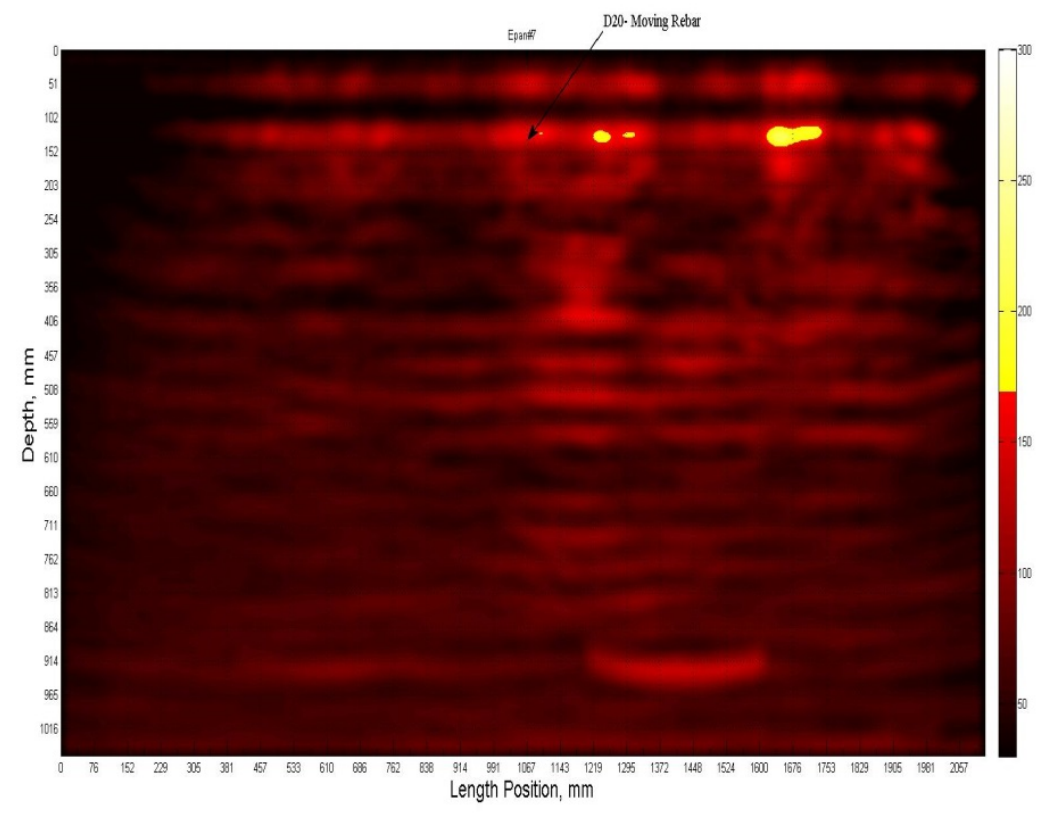

Fig. C.30. Rough side length - Epan 7 m126. 


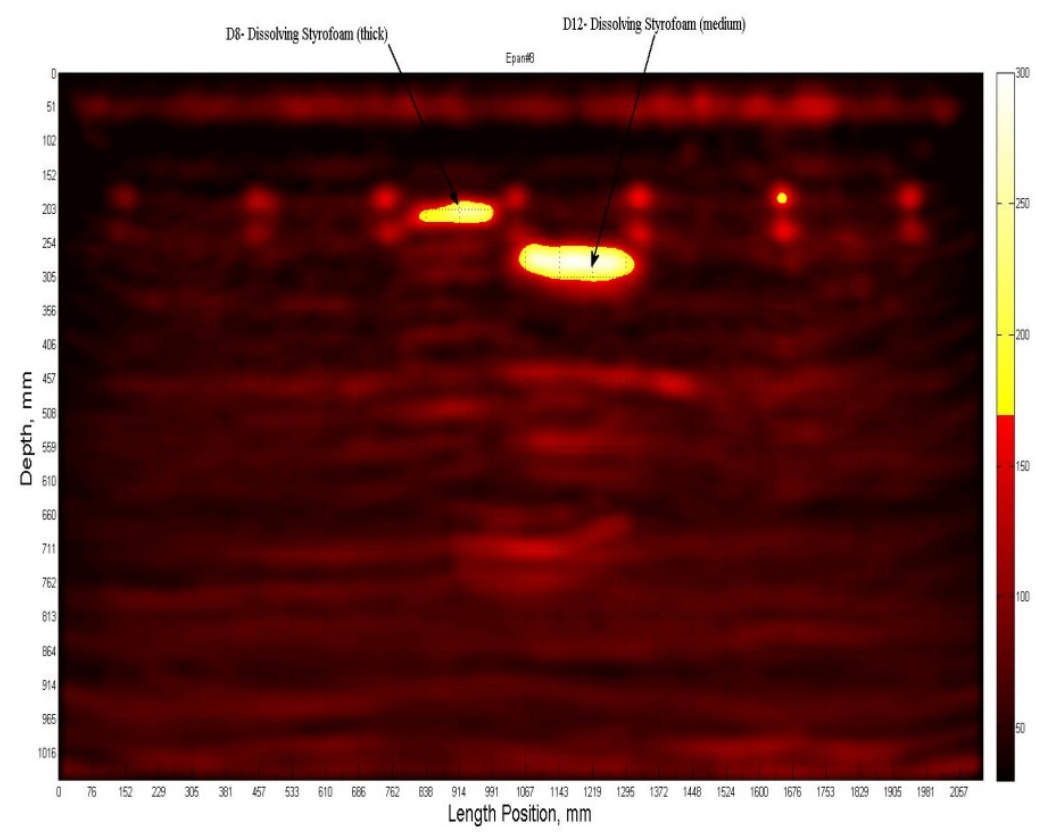

Fig. C.31. Rough side length - Epan 8 m144.

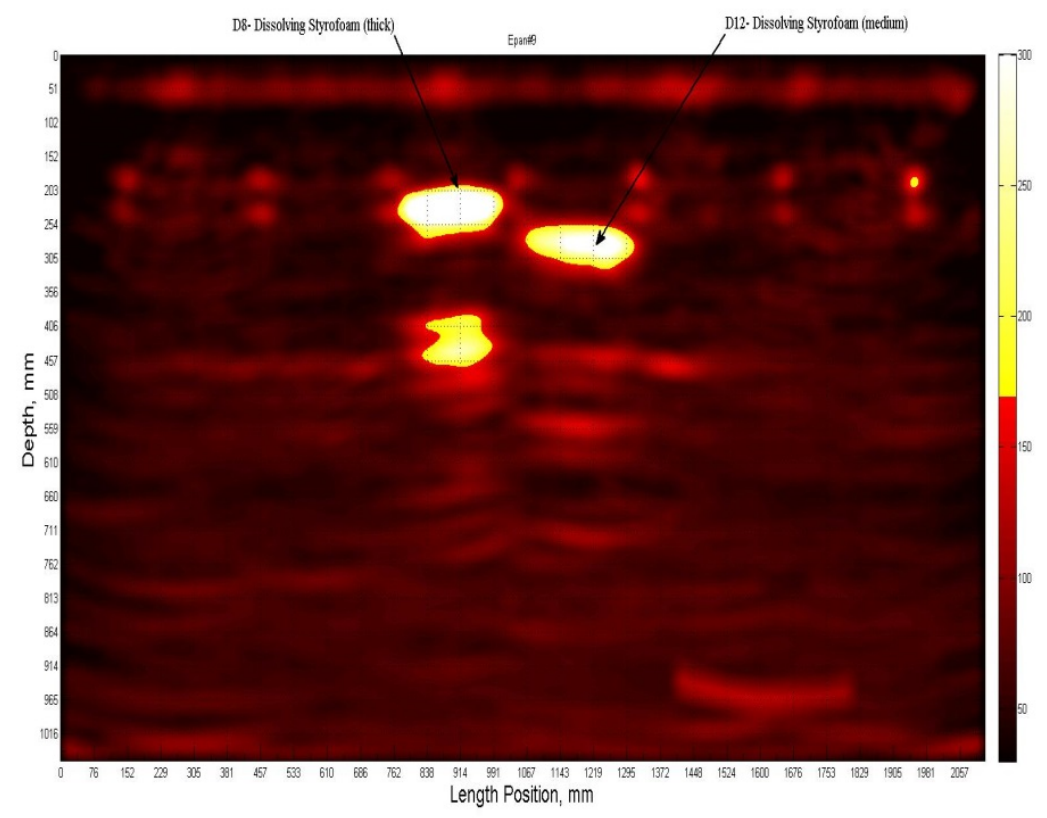

Fig. C.32. Rough side length - Epan 9 m162. 


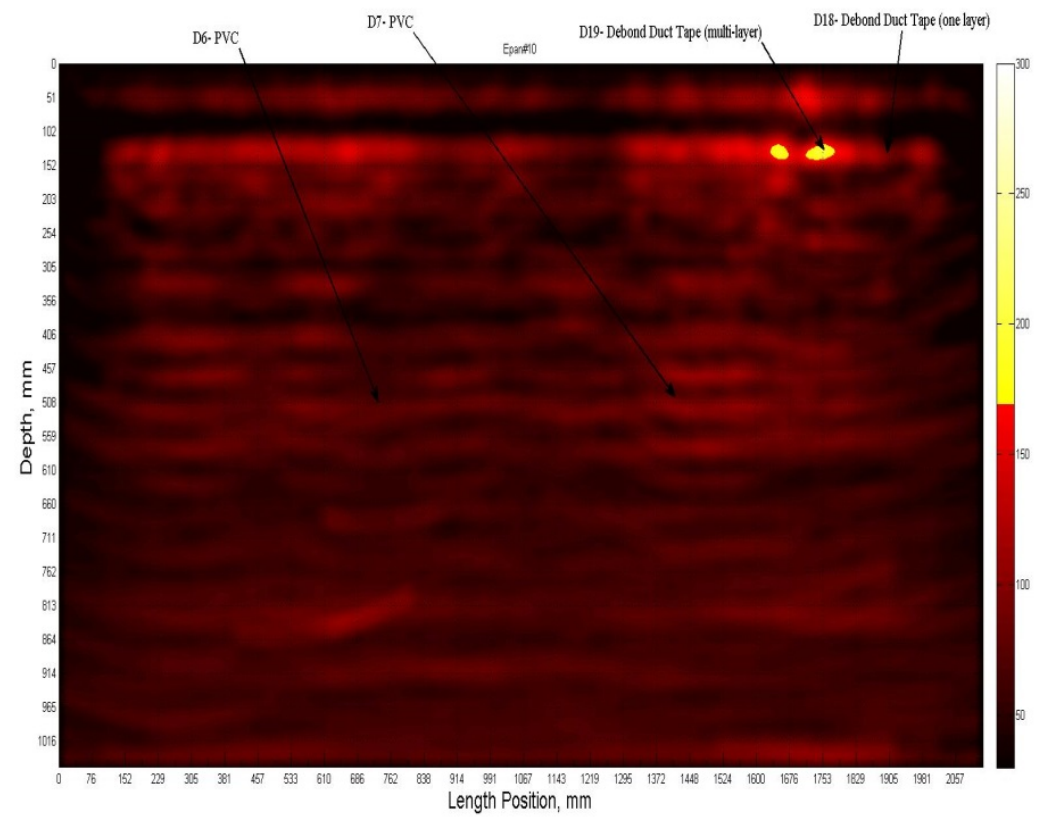

Fig. C.33. Rough side length - Epan 10 m180.

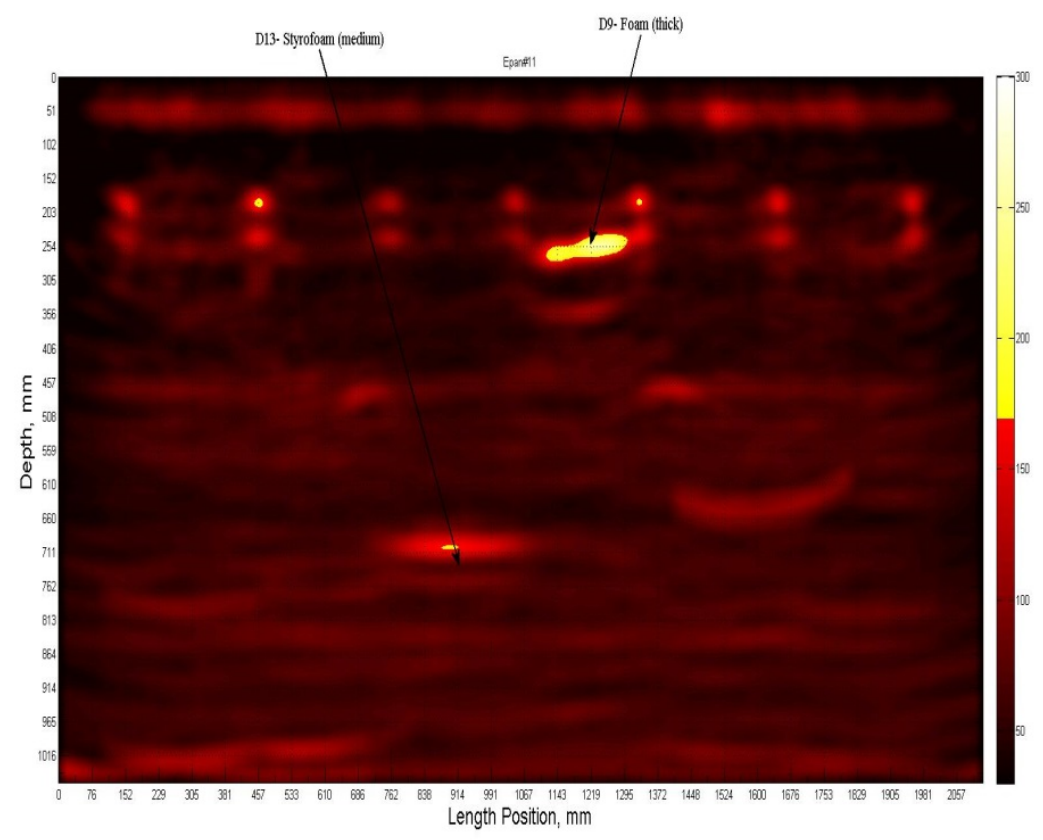

Fig. C.34. Rough side length - Epan 11 m198. 


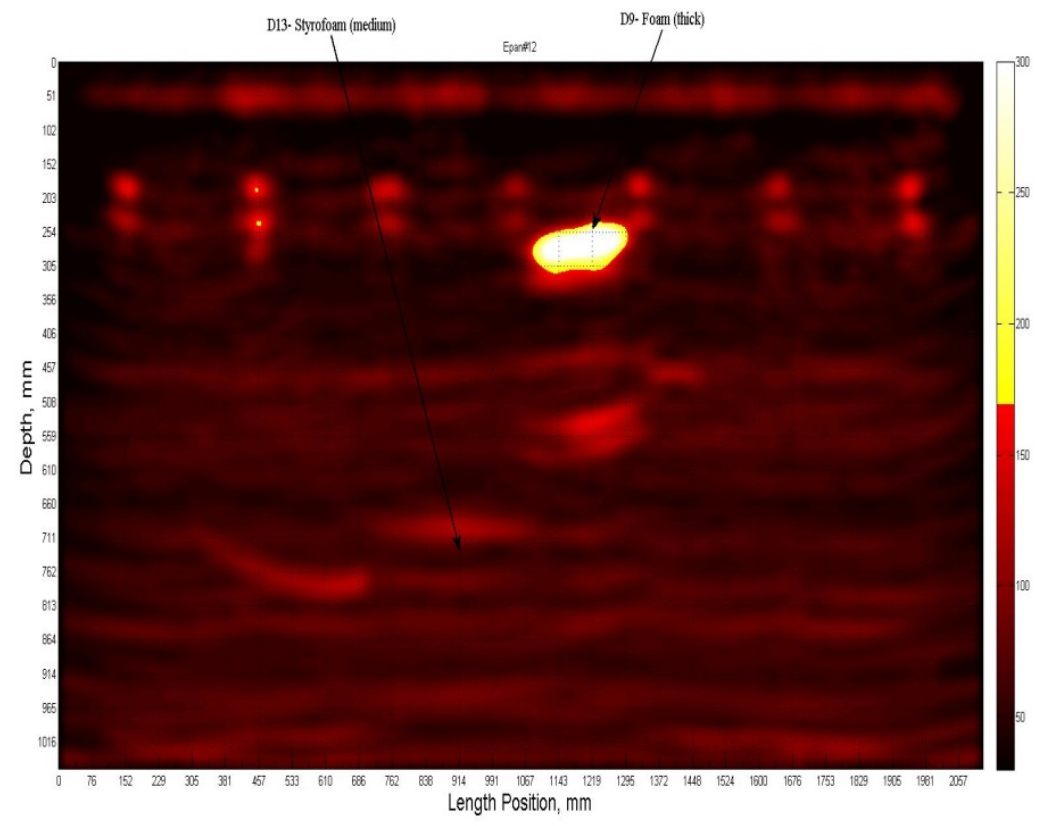

Fig. C.35. Rough side length - Epan 12 m216.

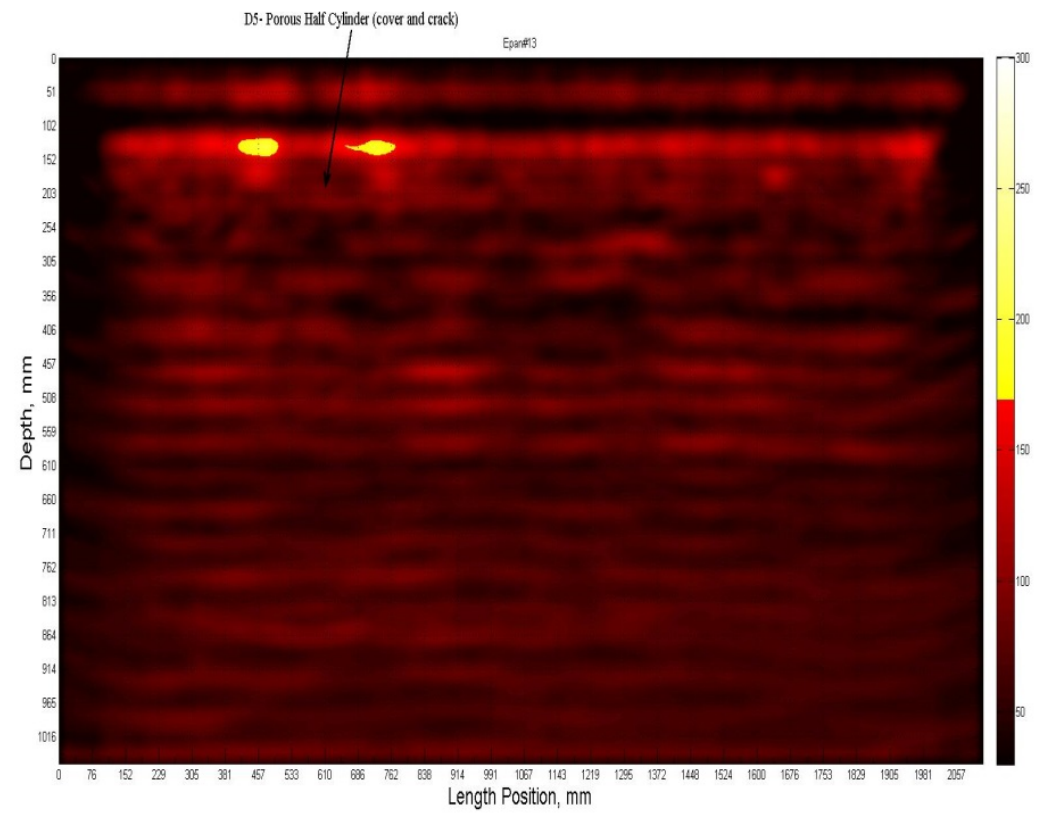

Fig. C.36. Rough side length - Epan 13 m234. 


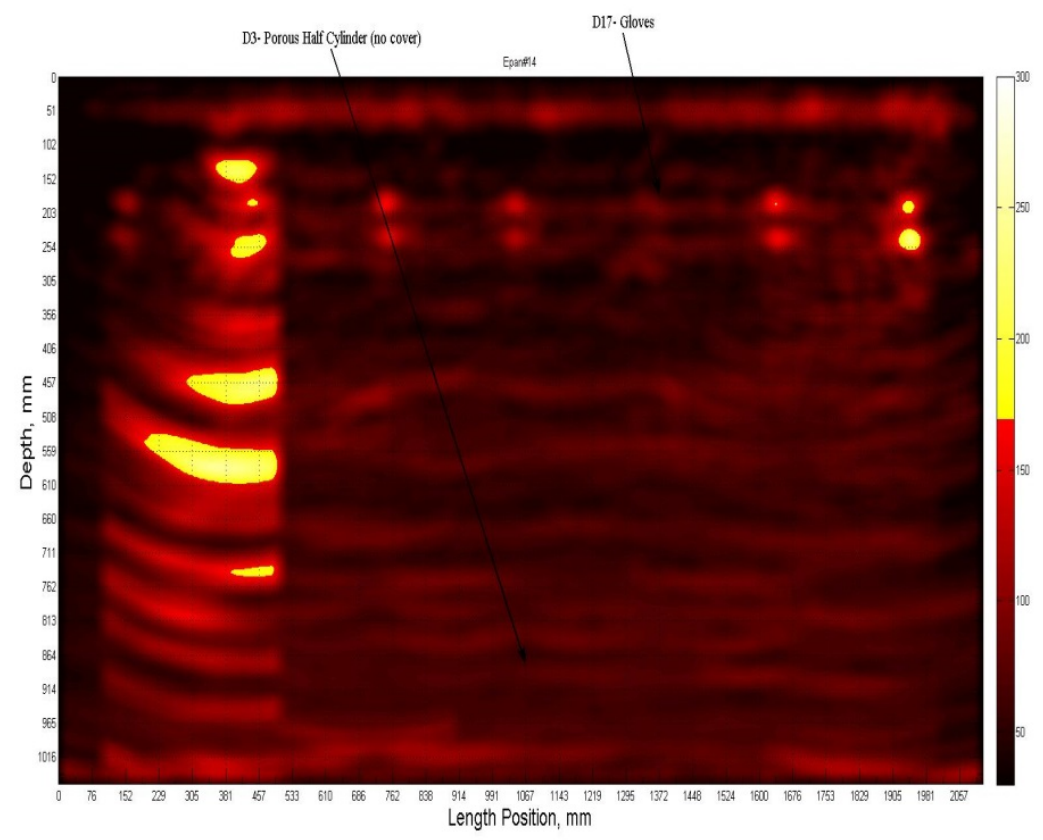

Fig. C.37. Rough side length - Epan 14 m252.

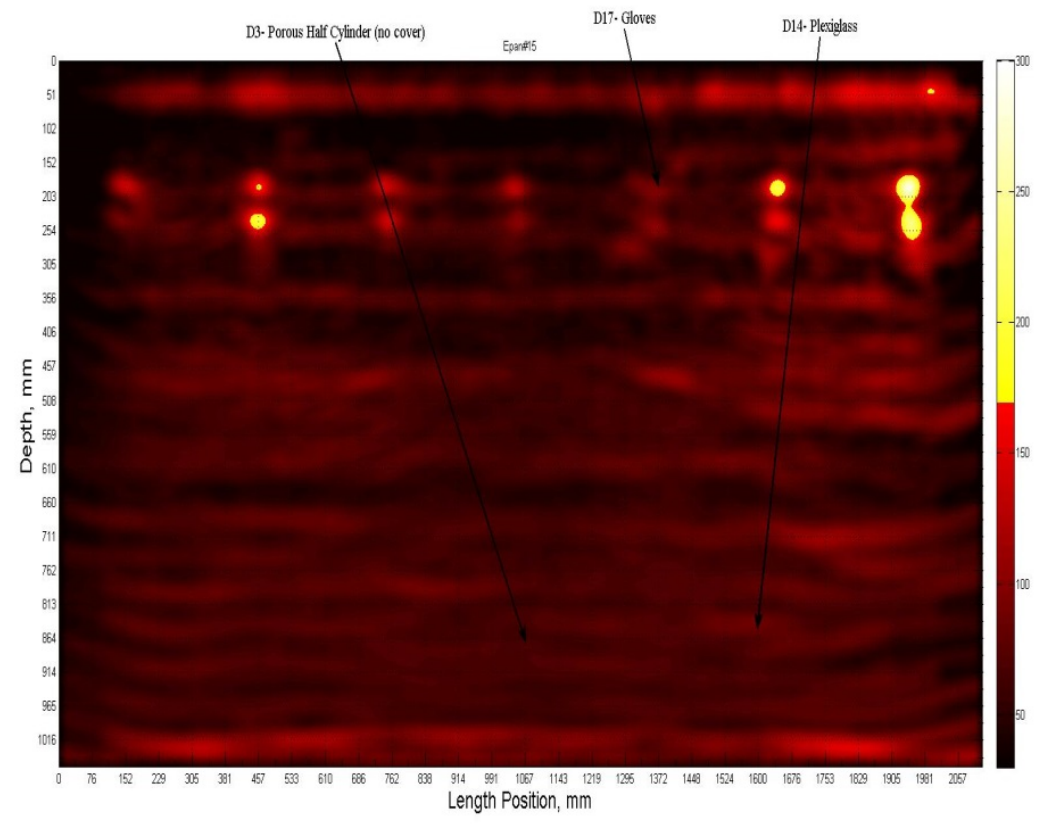

Fig. C.38. Rough side length - Epan 15 m270. 


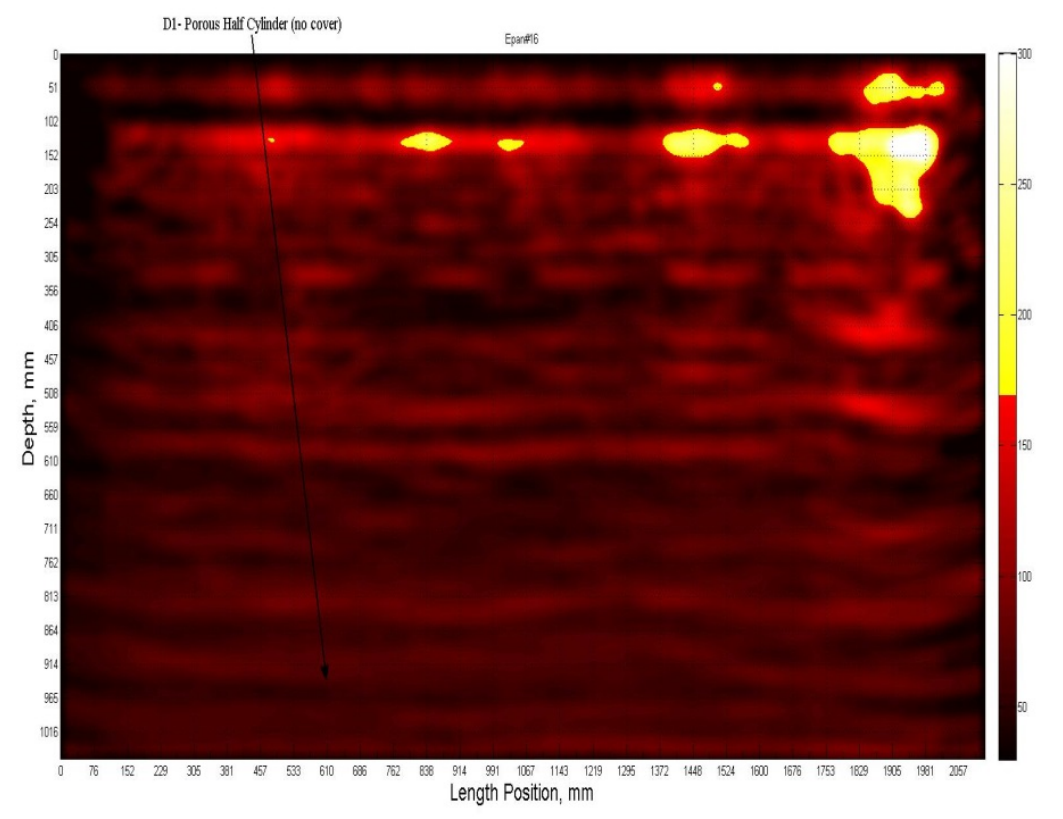

Fig. C.39. Rough side length - Epan 16 m288.

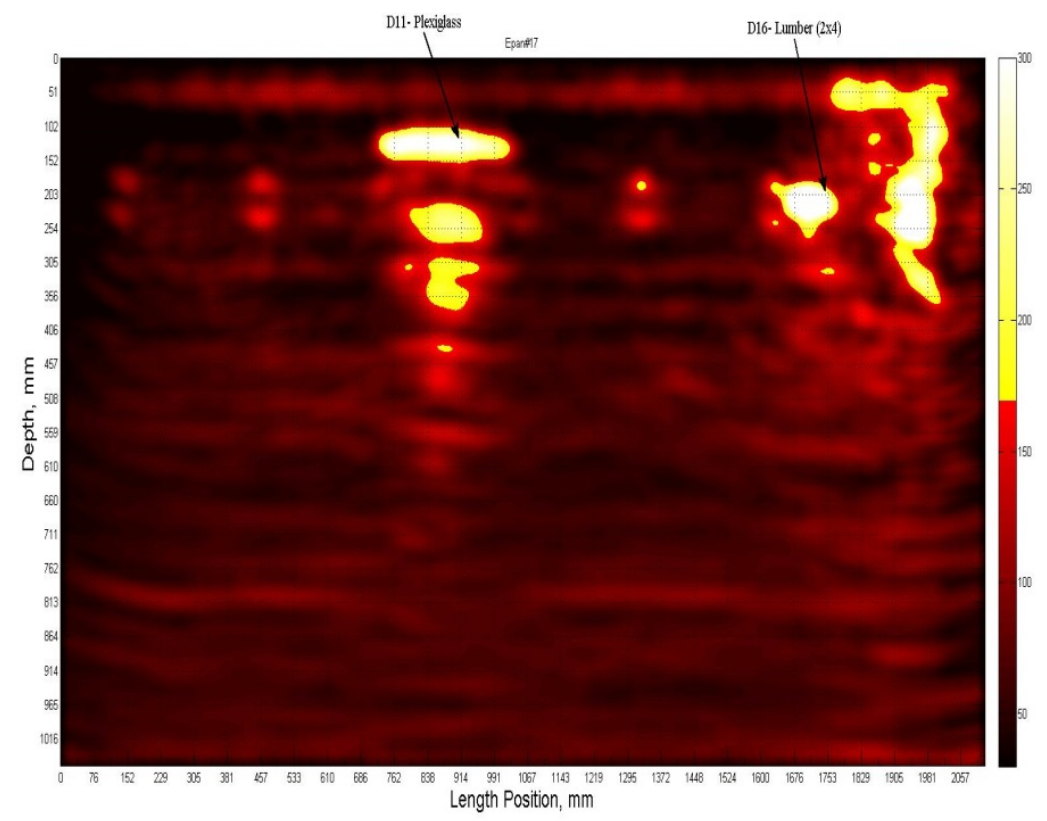

Fig. C.40. Rough side length - Epan 17 m306. 


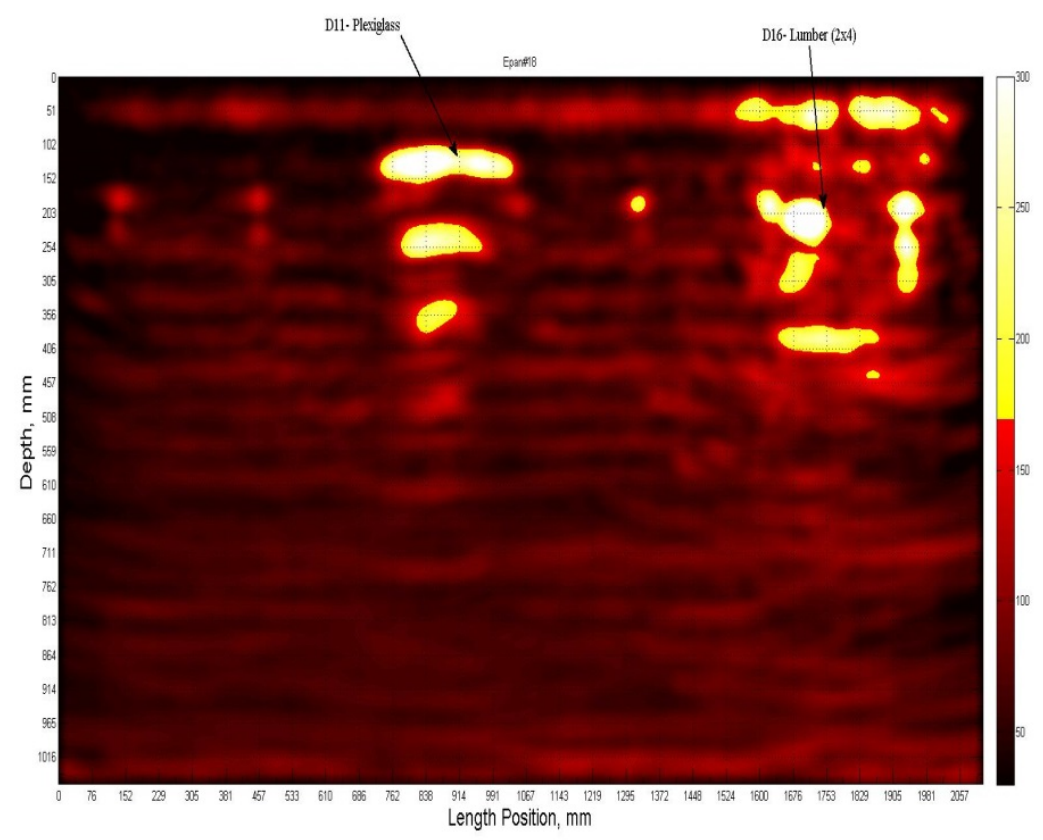

Fig. C.41. Rough side length - Epan 18 m324.

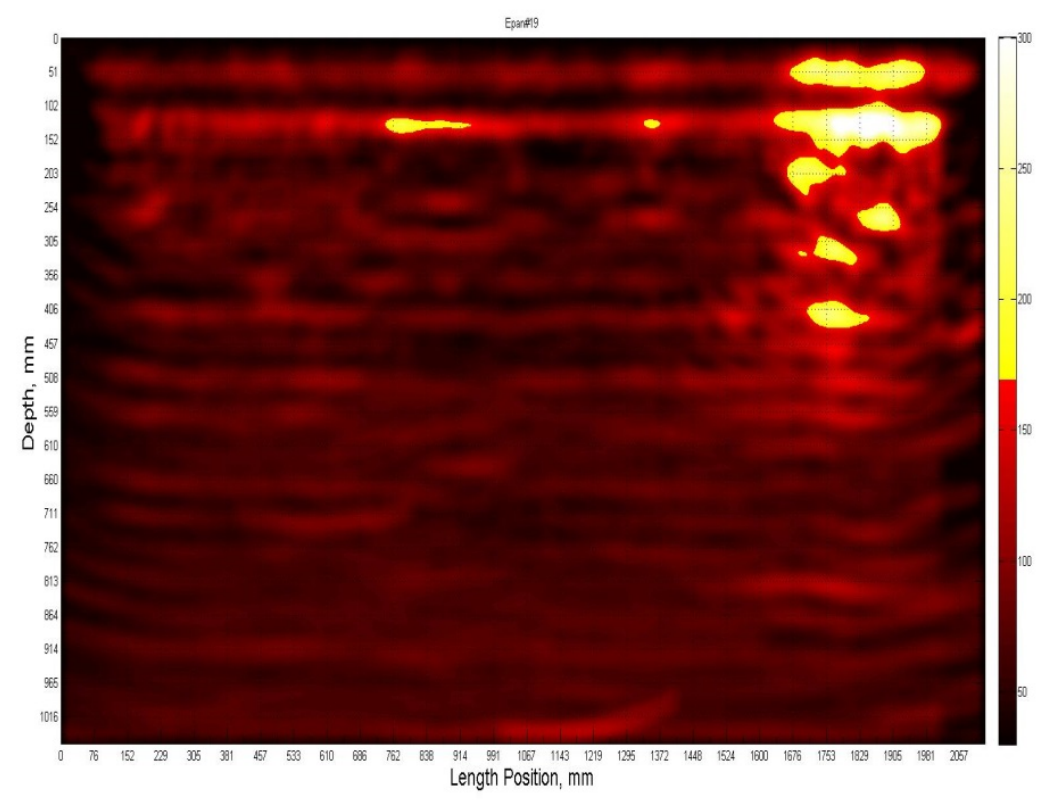

Fig. C.42. Rough side length - Epan 19 m342. 


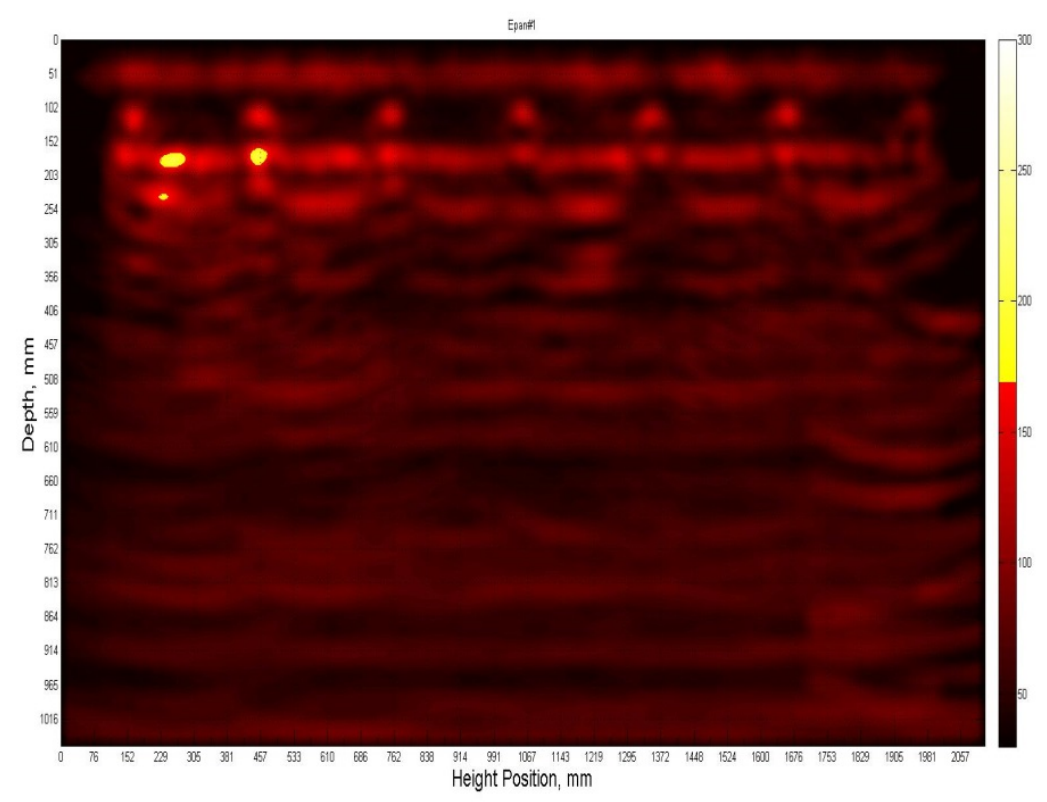

Fig. C.43. Short side height - Epan 1 m18.

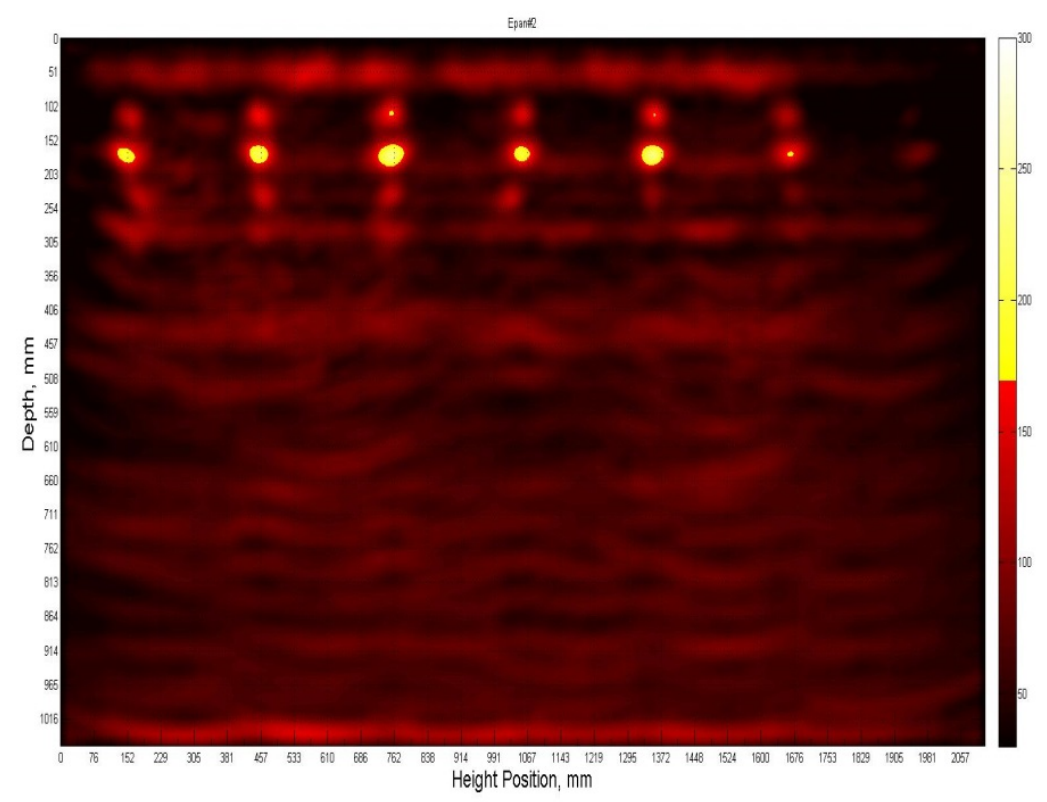

Fig. C.44. Short side height - Epan 2 m36. 


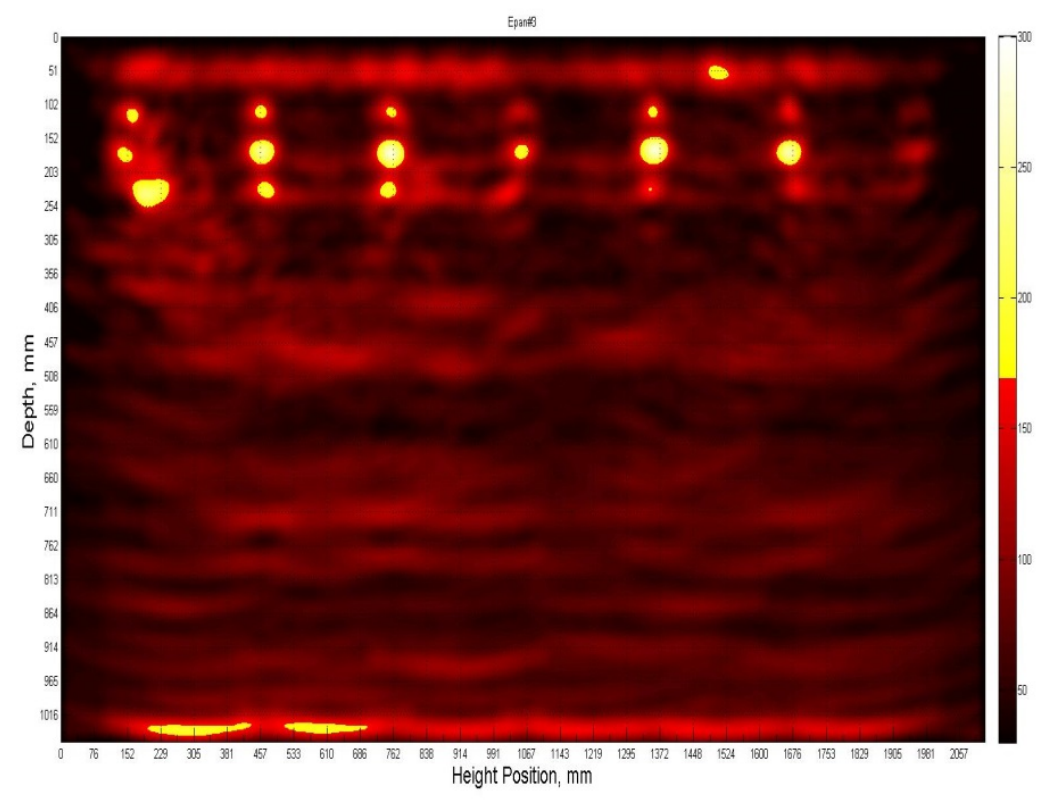

Fig. C.45. Short side height - Epan 3 m54.

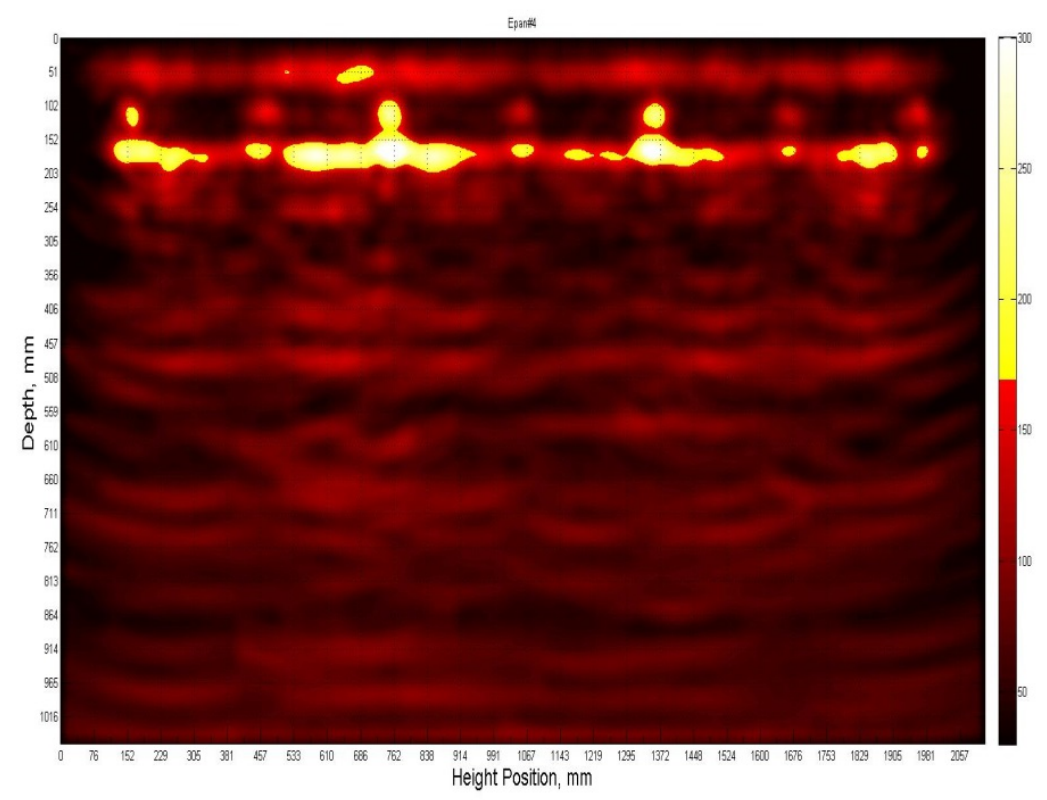

Fig. C.46. Short side height - Epan 4 m72. 


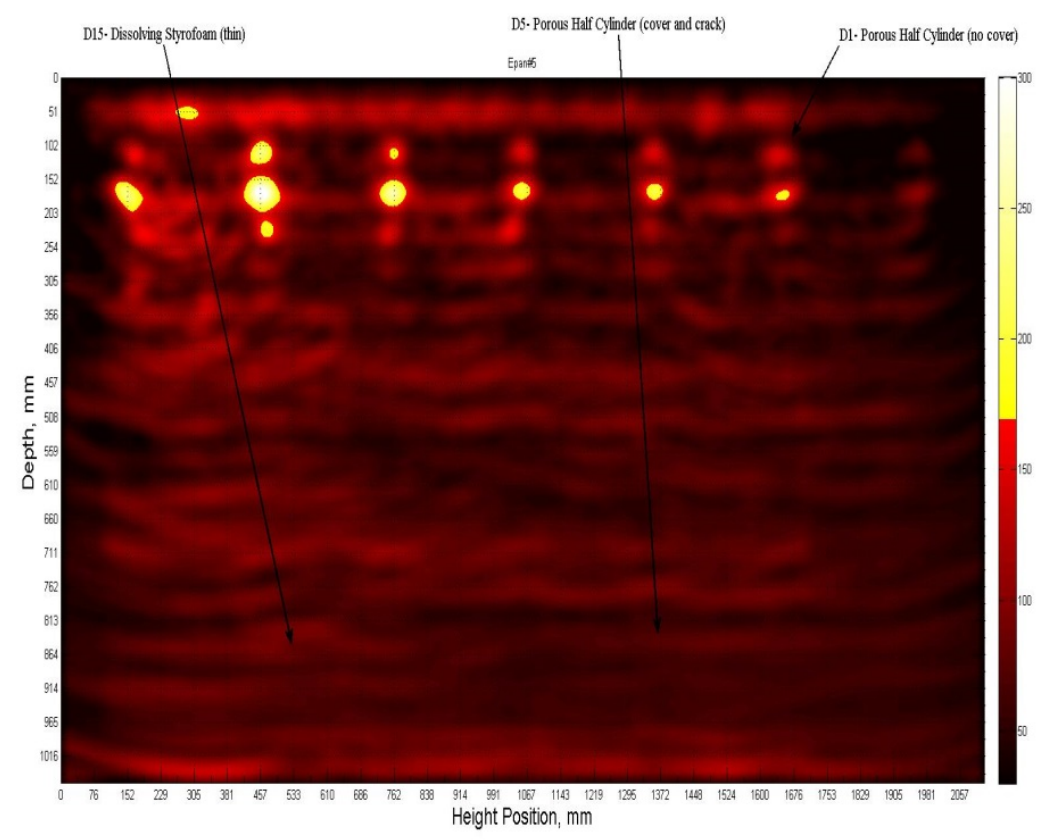

Fig. C.47. Short side height - Epan 5 m90.

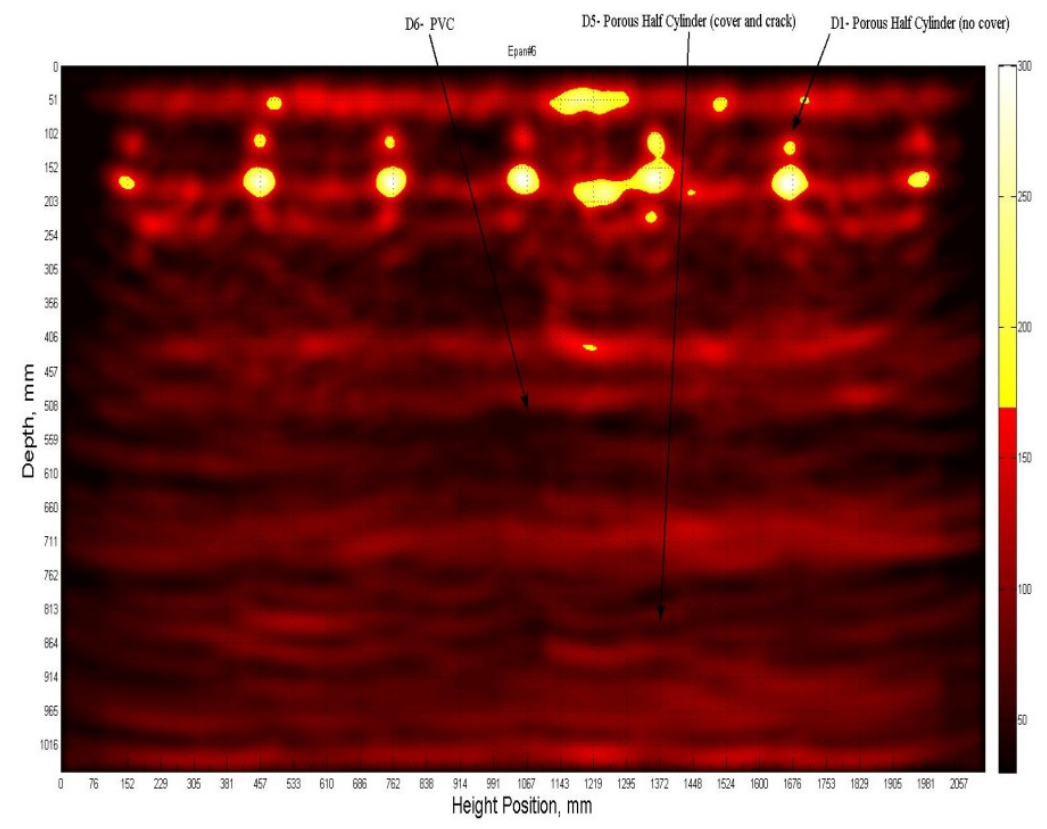

Fig. C.48. Short side height - Epan 6 m108. 


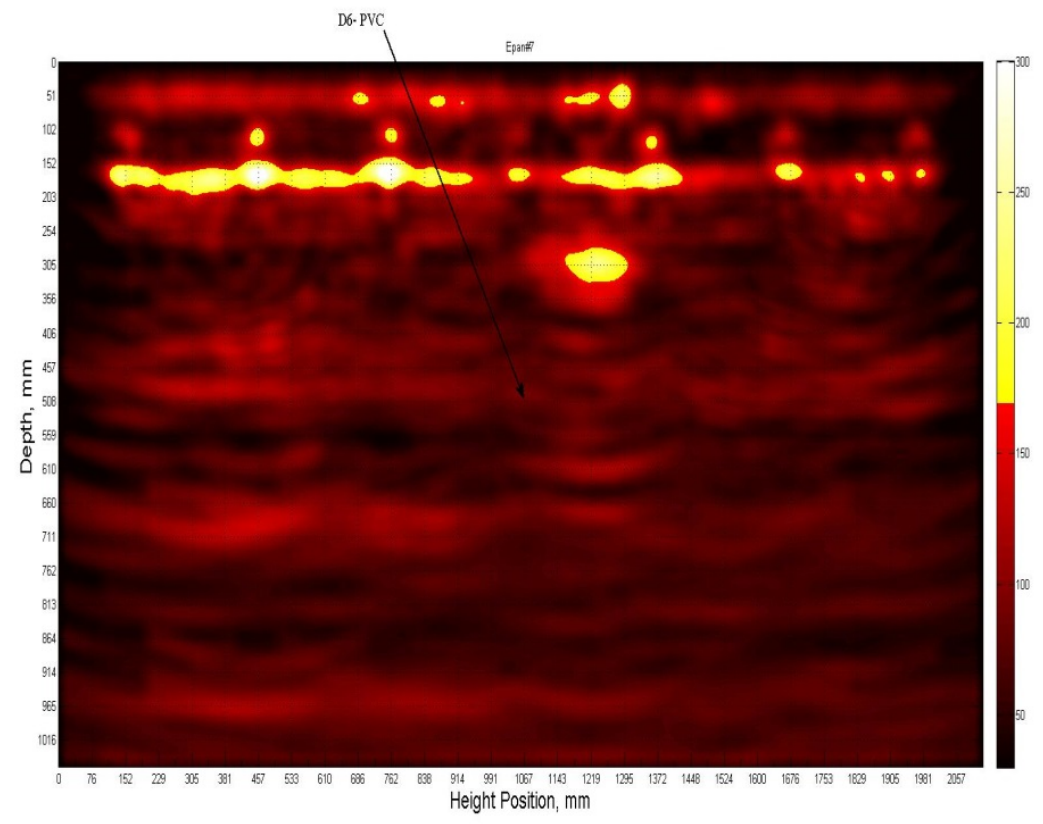

Fig. C.49. Short side height - Epan 7 m126.

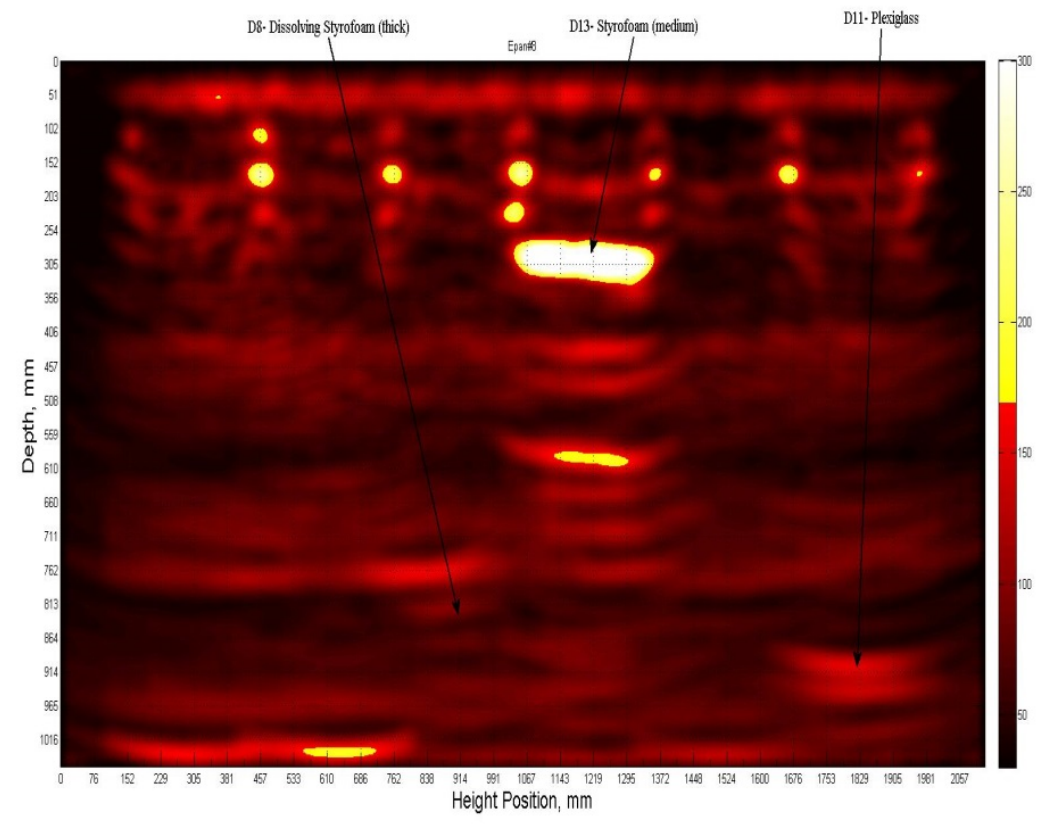

Fig. C.50. Short side height - Epan 8 m144. 


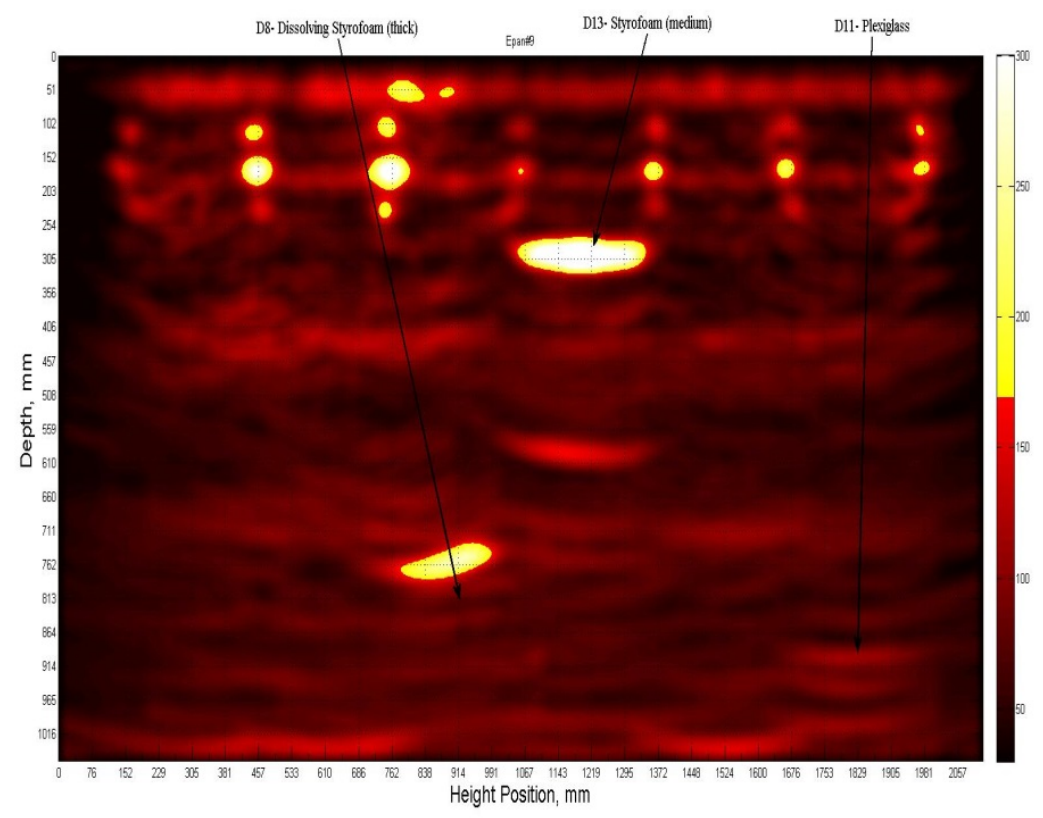

Fig. C.51. Short side height - Epan 9 m162.

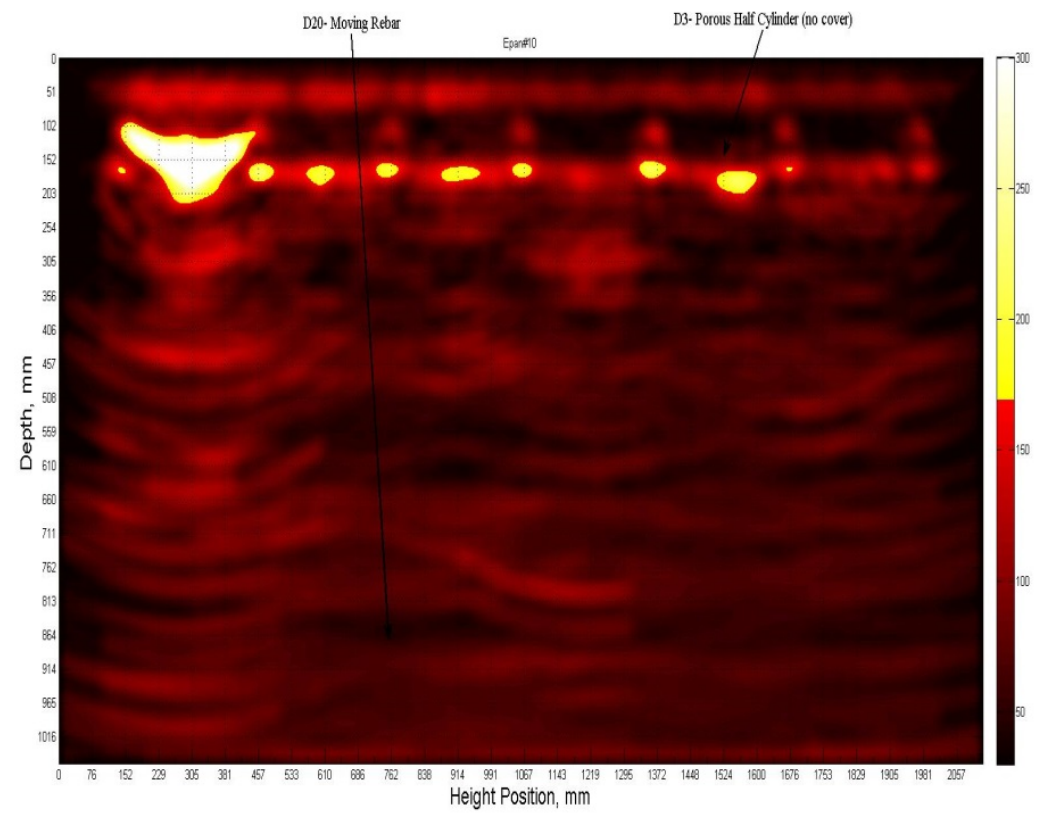

Fig. C.52. Short side height - Epan $10 \mathrm{m180}$. 


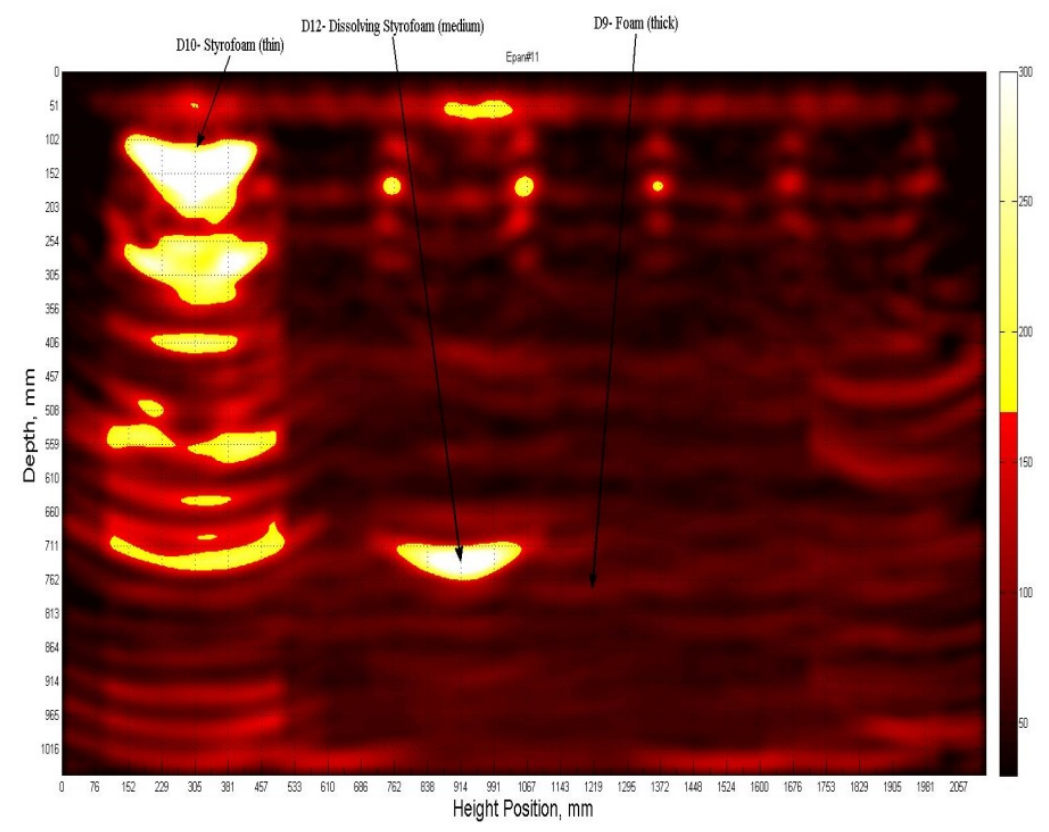

Fig. C.53. Short side height - Epan 11 m198.

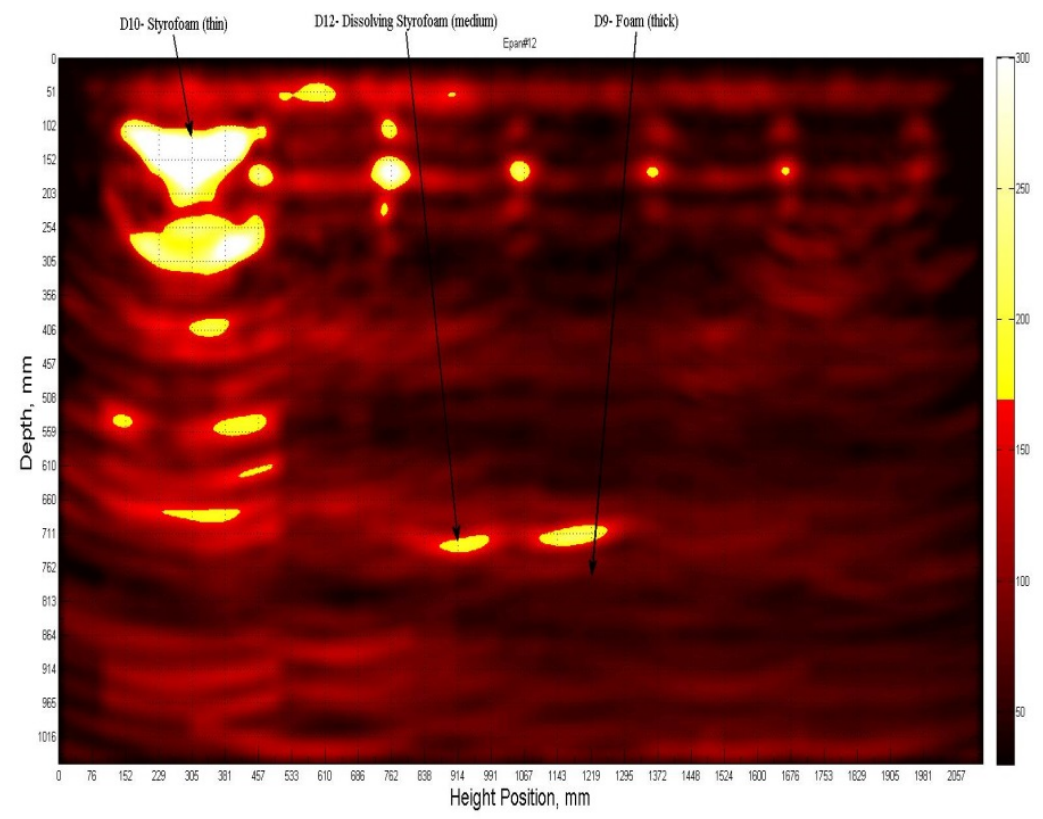

Fig. C.54. Short side height - Epan 12 m216. 


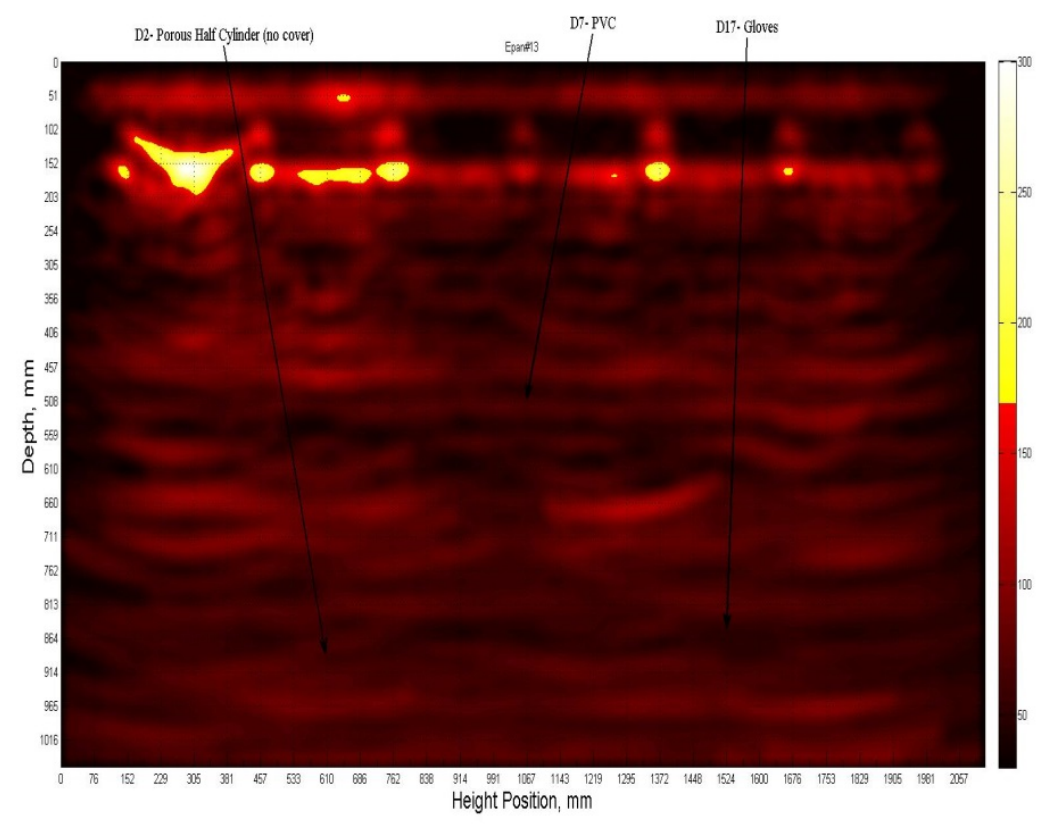

Fig. C.55. Short side height - Epan 13 m234.

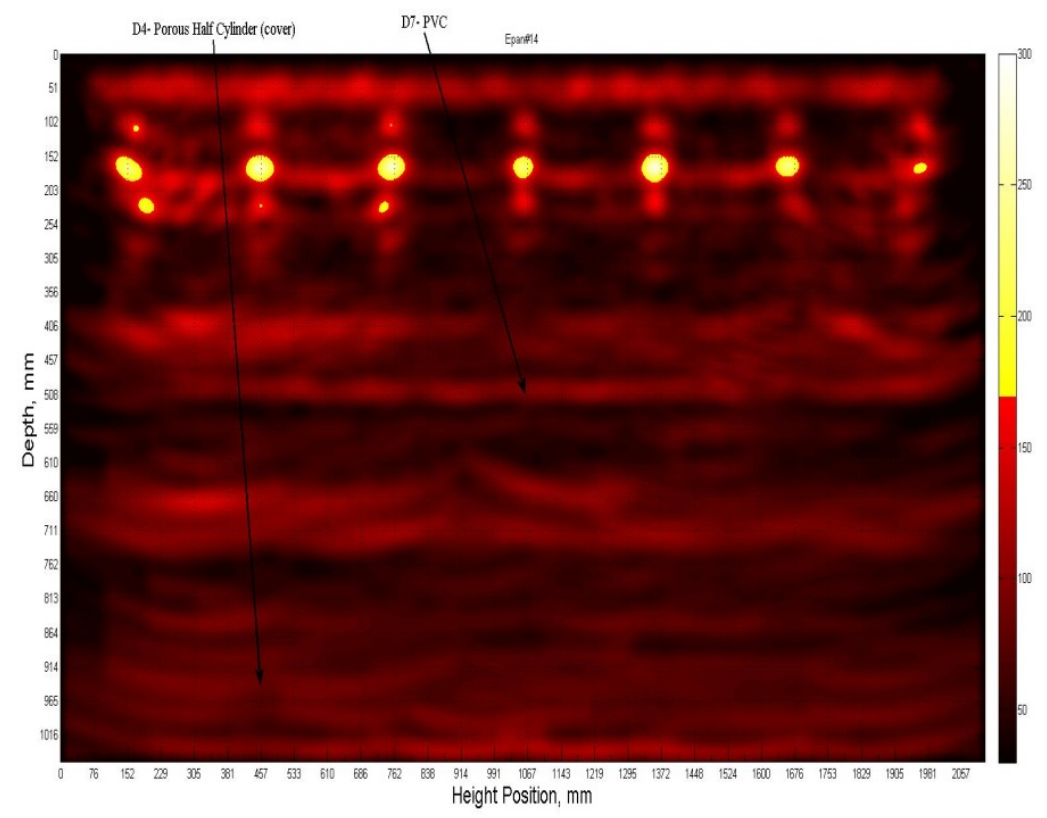

Fig. C.56. Short side height - Epan 14 m252. 


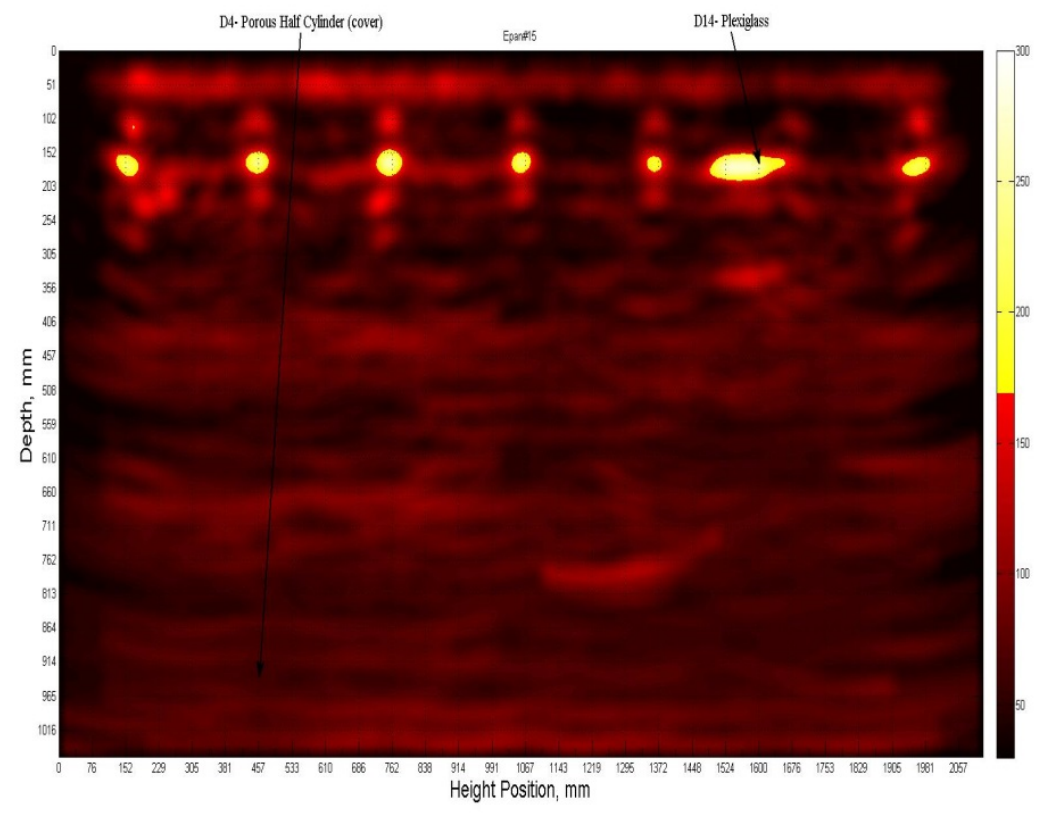

Fig. C.57. Short side height - Epan 15 m270.

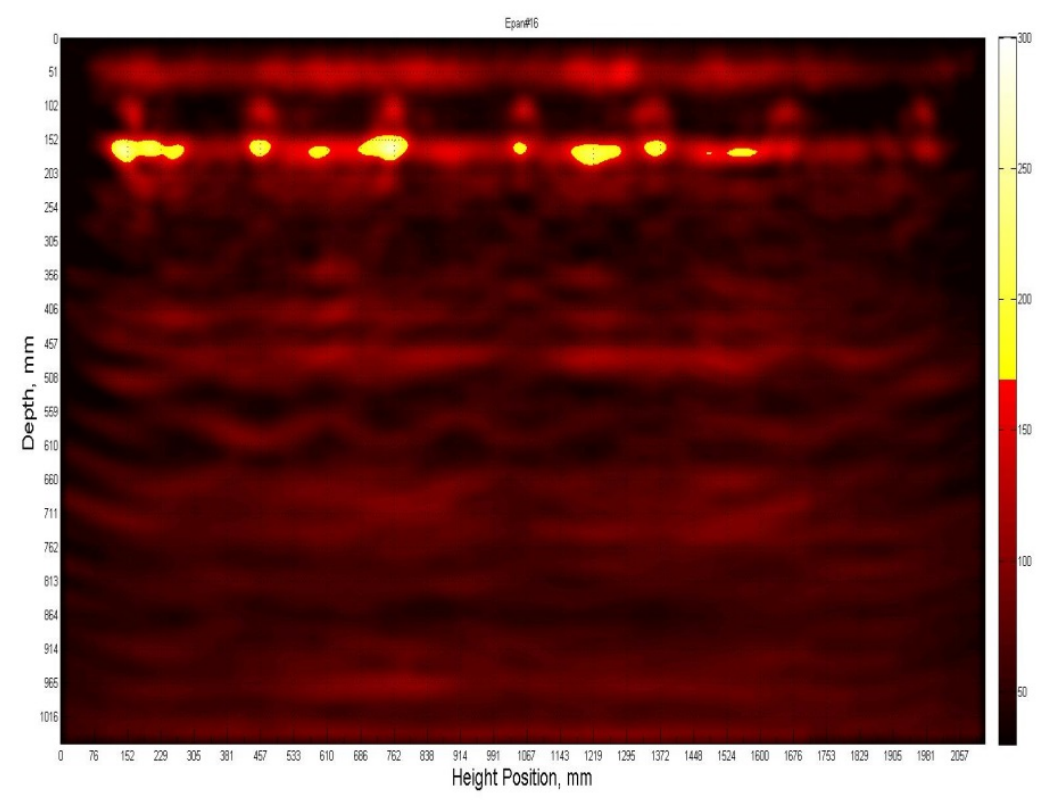

Fig. C.58. Short side height - Epan 16 m288. 


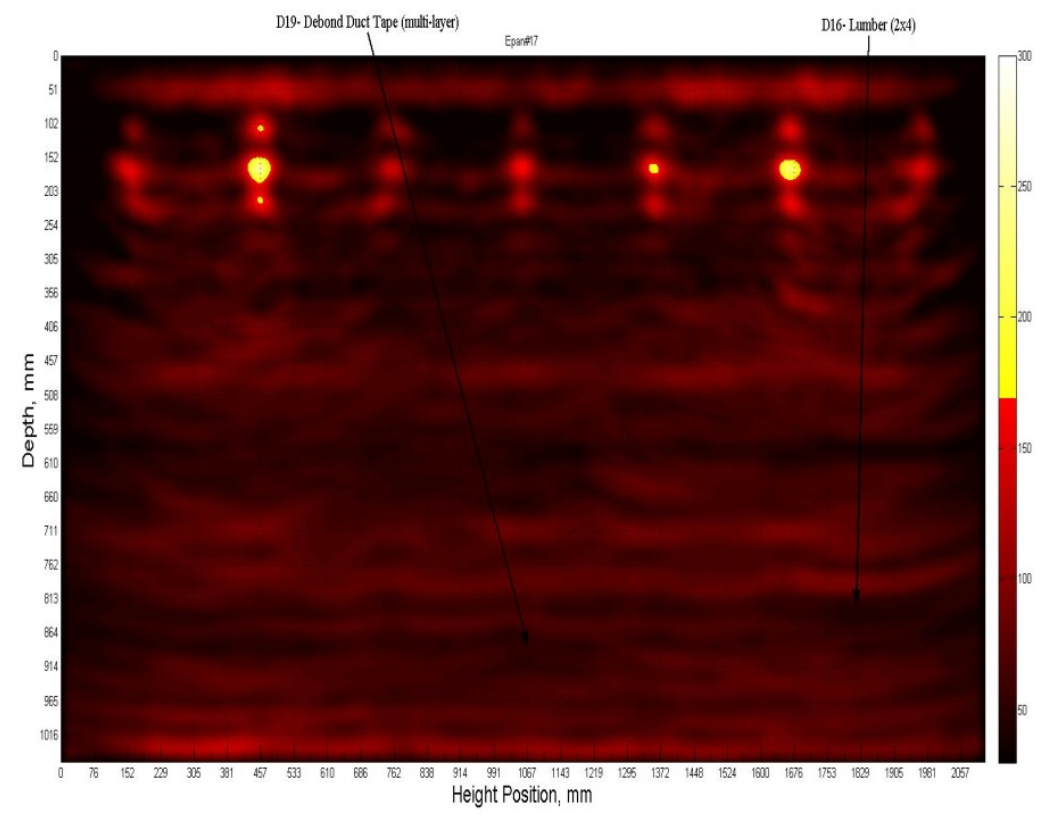

Fig. C.59. Short side height - Epan 17 m306.

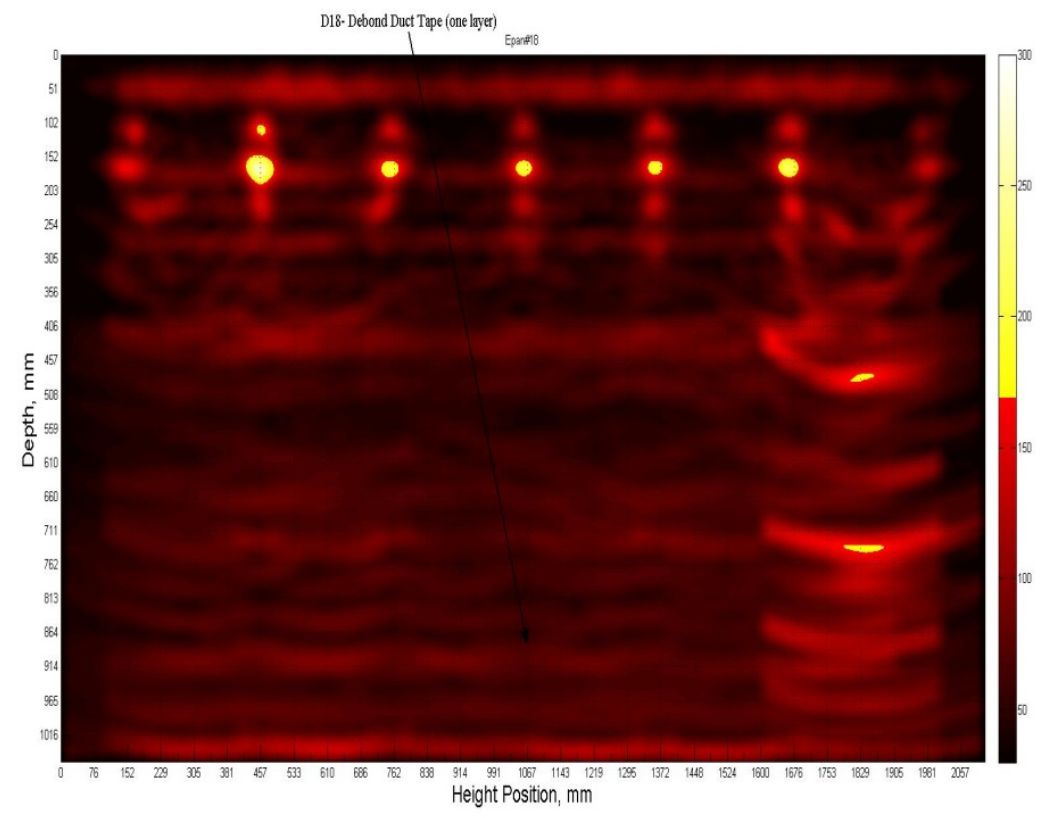

Fig. C.60. Short side height - Epan 18 m324. 


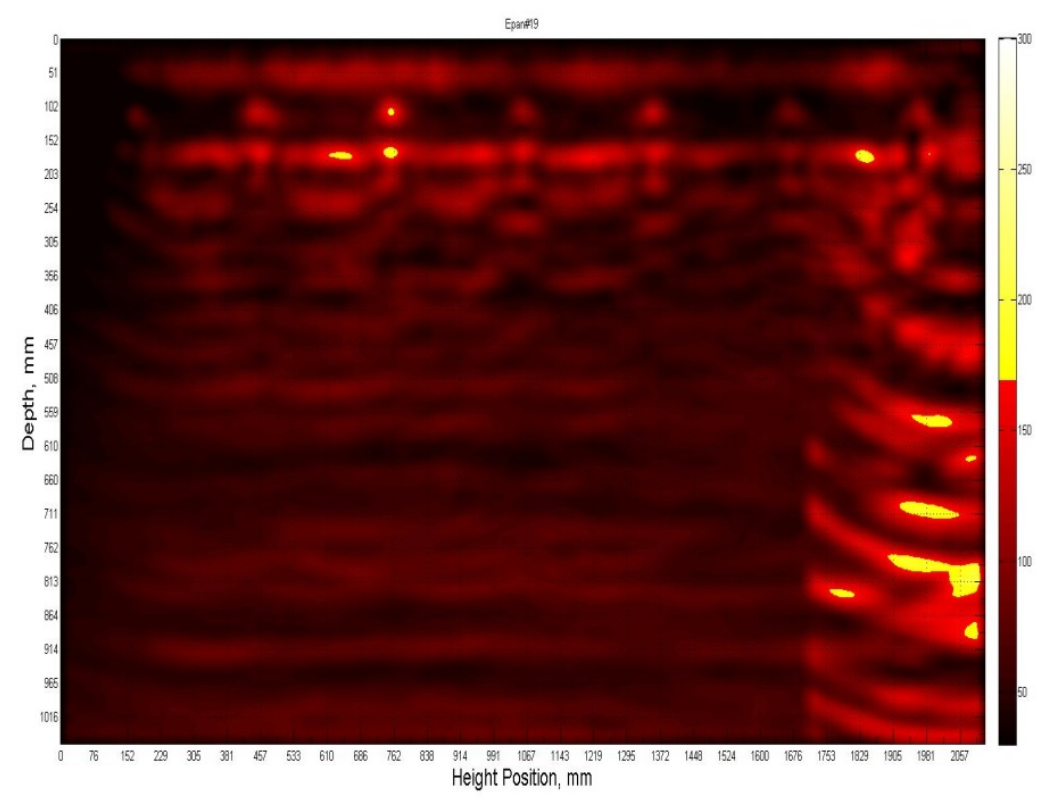

Fig. C.61. Short side height - Epan 19 m342.

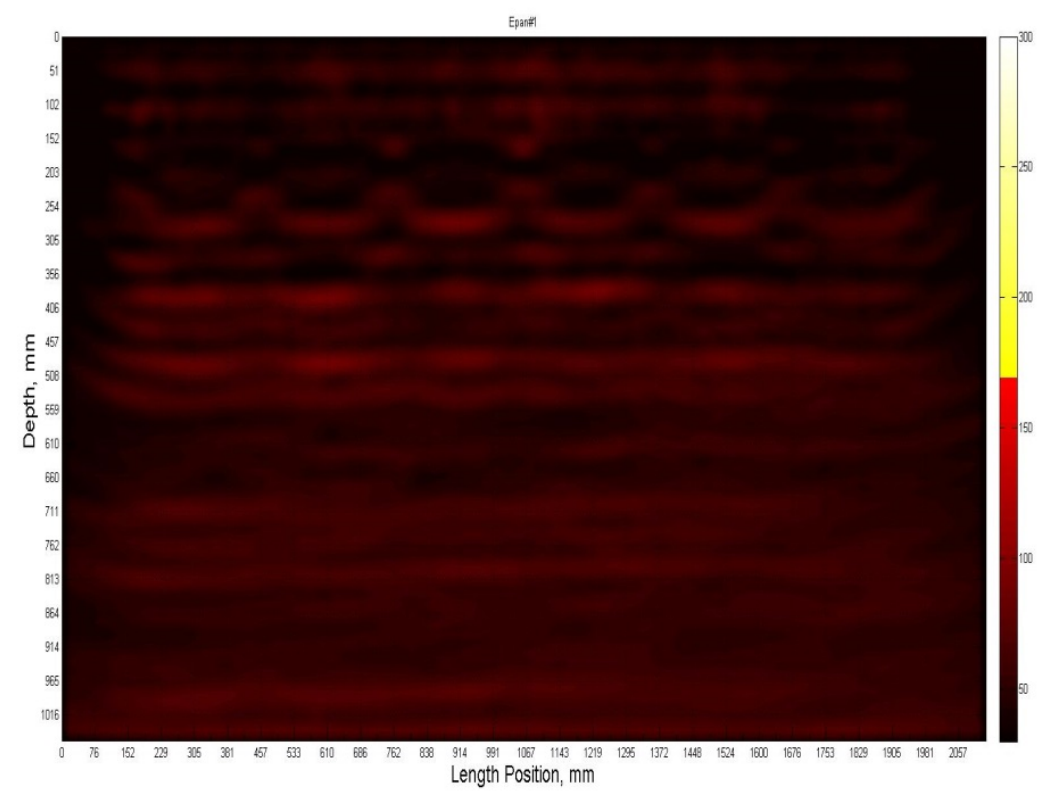

Fig. C.62. Short side length - Epan 1 m18. 


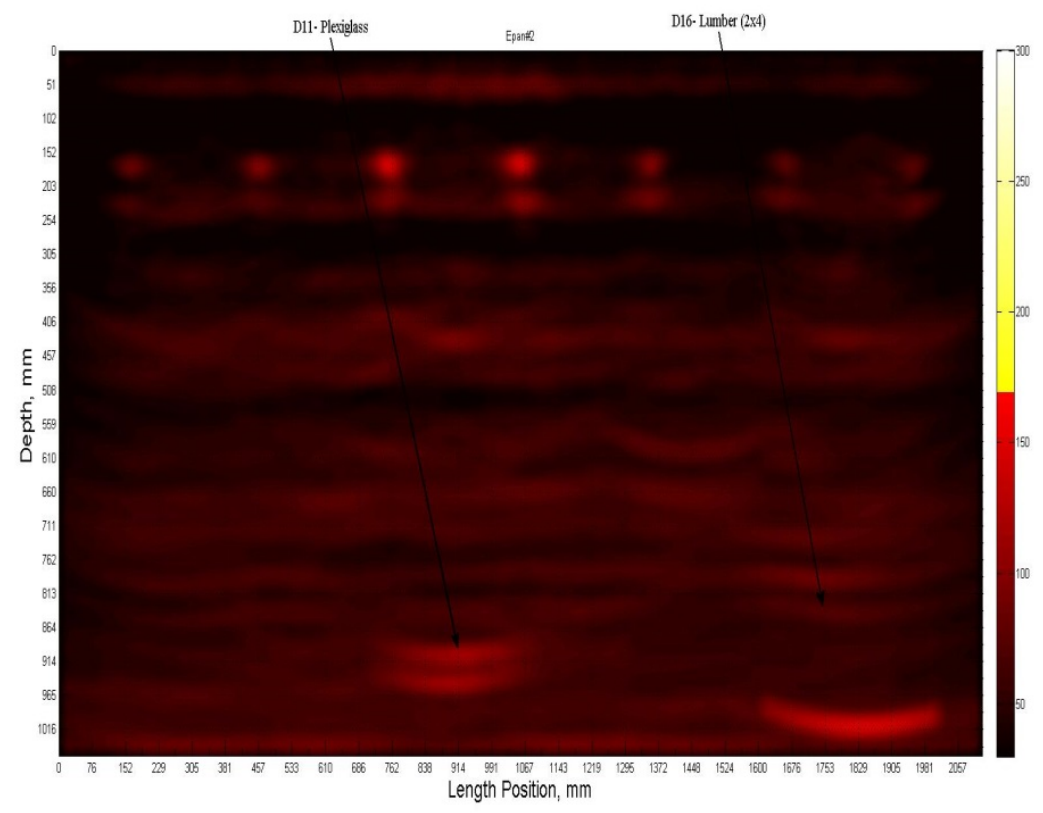

Fig. C.63. Short side length - Epan 2 m36.

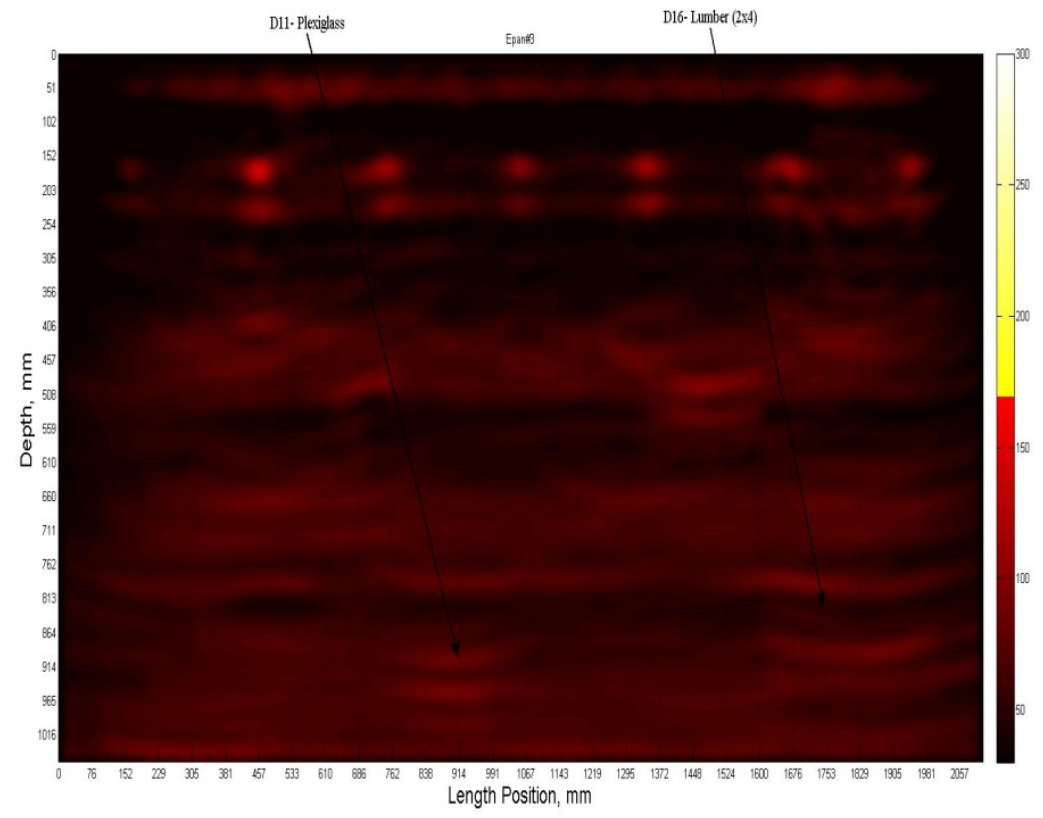

Fig. C.64. Short side length - Epan 3 m54. 


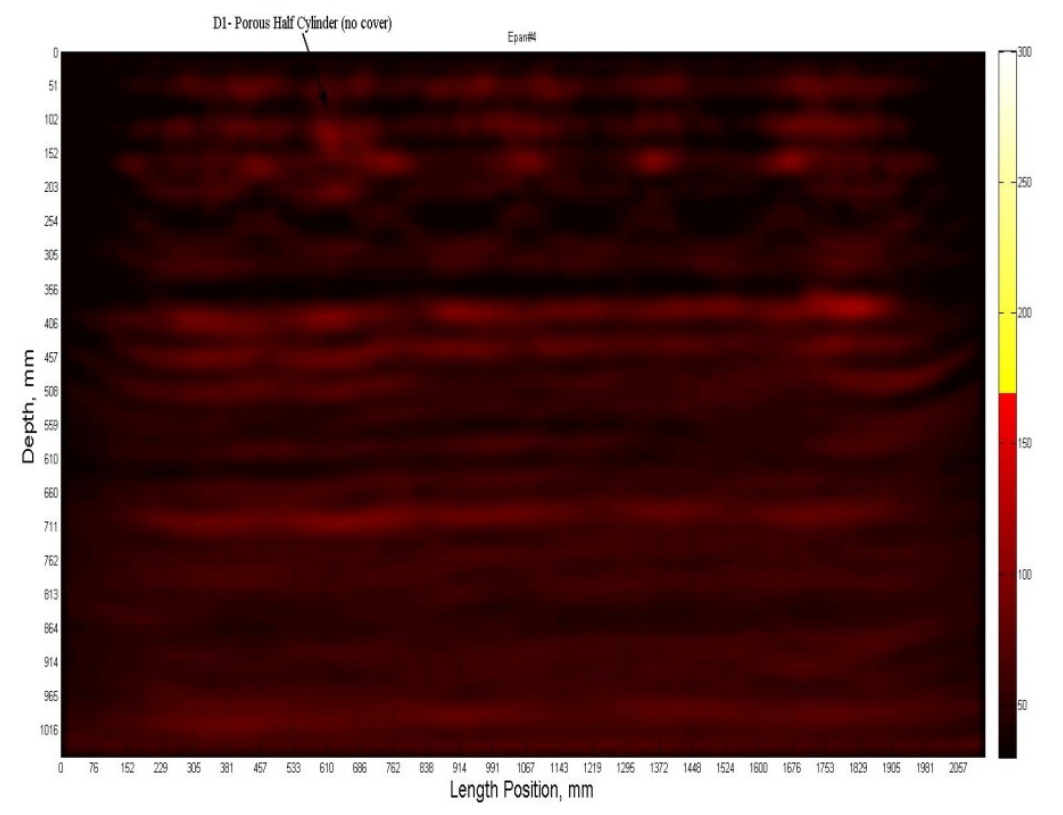

Fig. C.65. Short side length - Epan 4 m72.

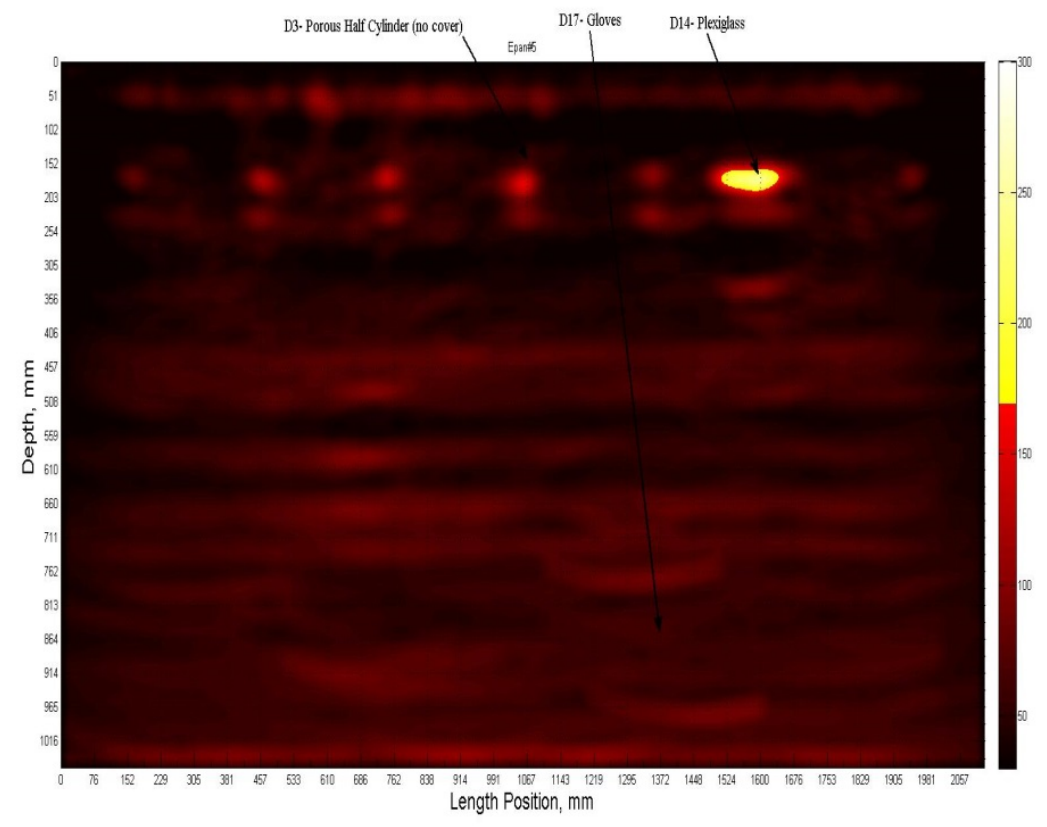

Fig. C.66. Short side length - Epan 5 m90. 


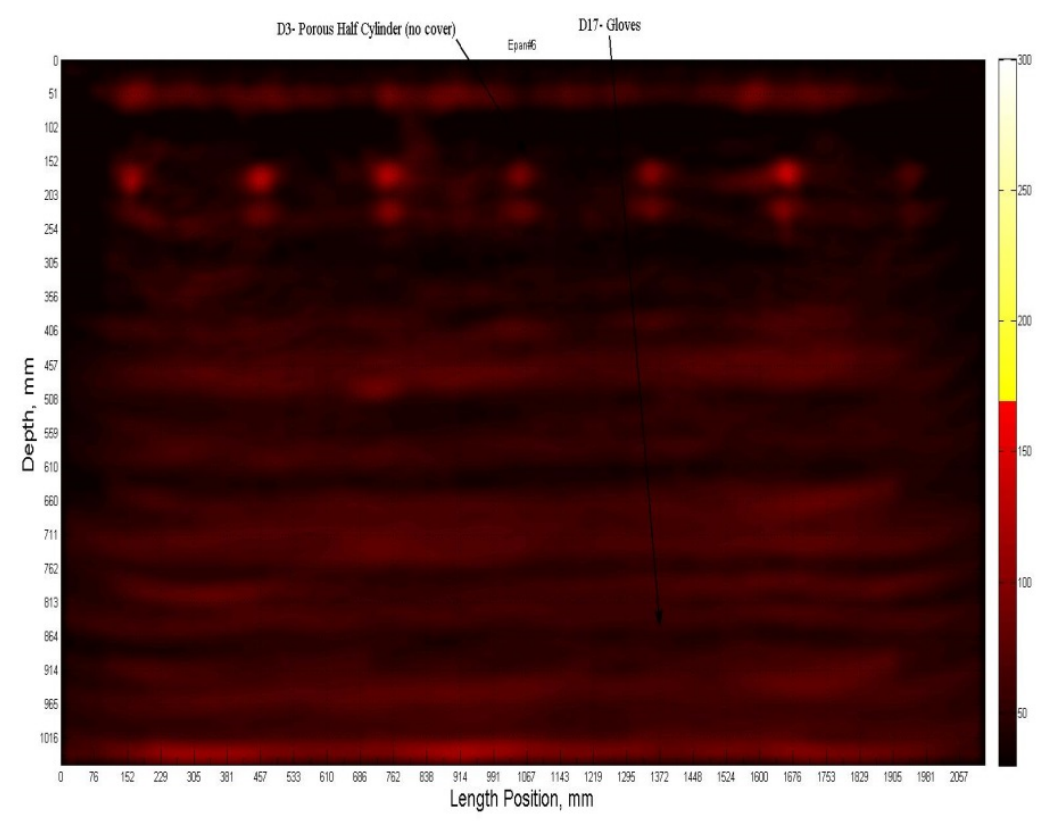

Fig. C.67. Short side length - Epan 6 m108.

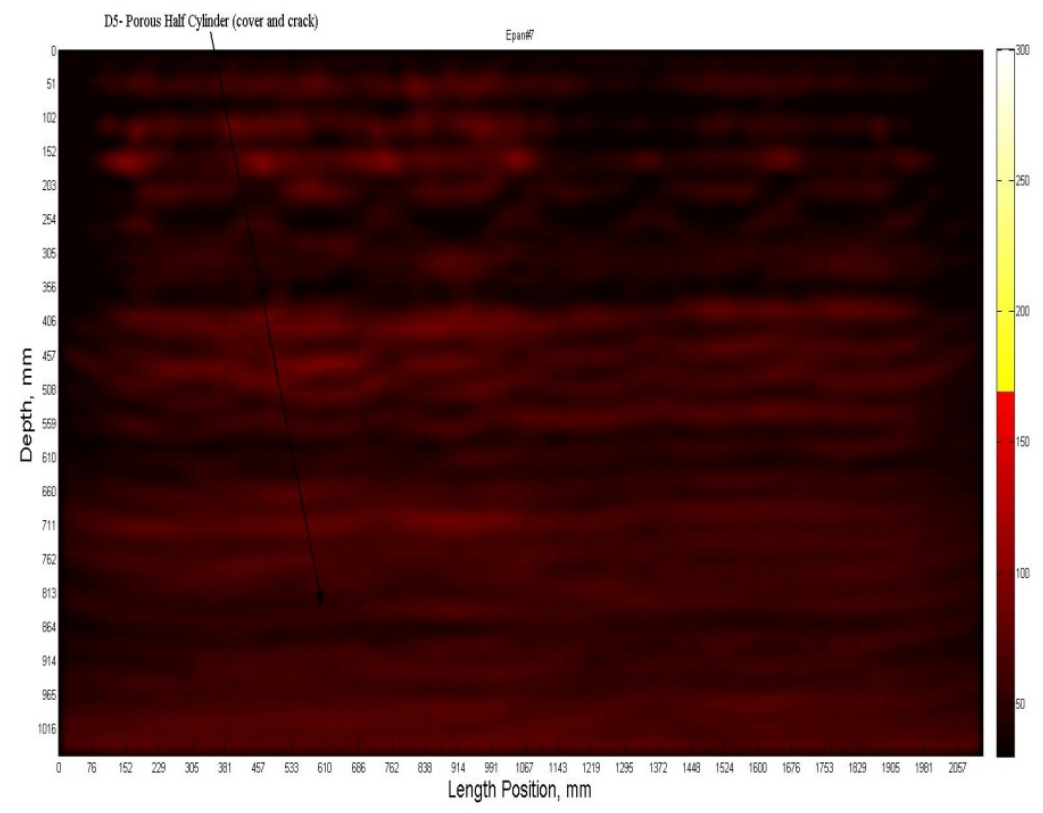

Fig. C.68. Short side length - Epan 7 m126. 


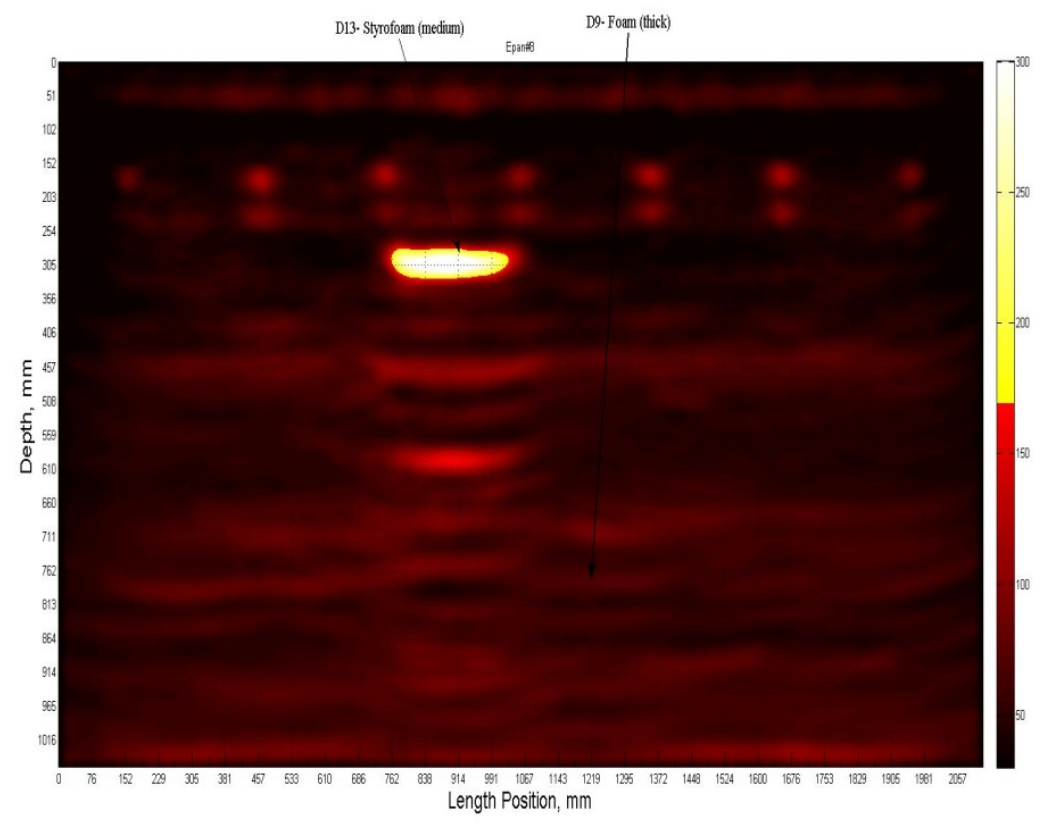

Fig. C.69. Short side length - Epan 8 m144.

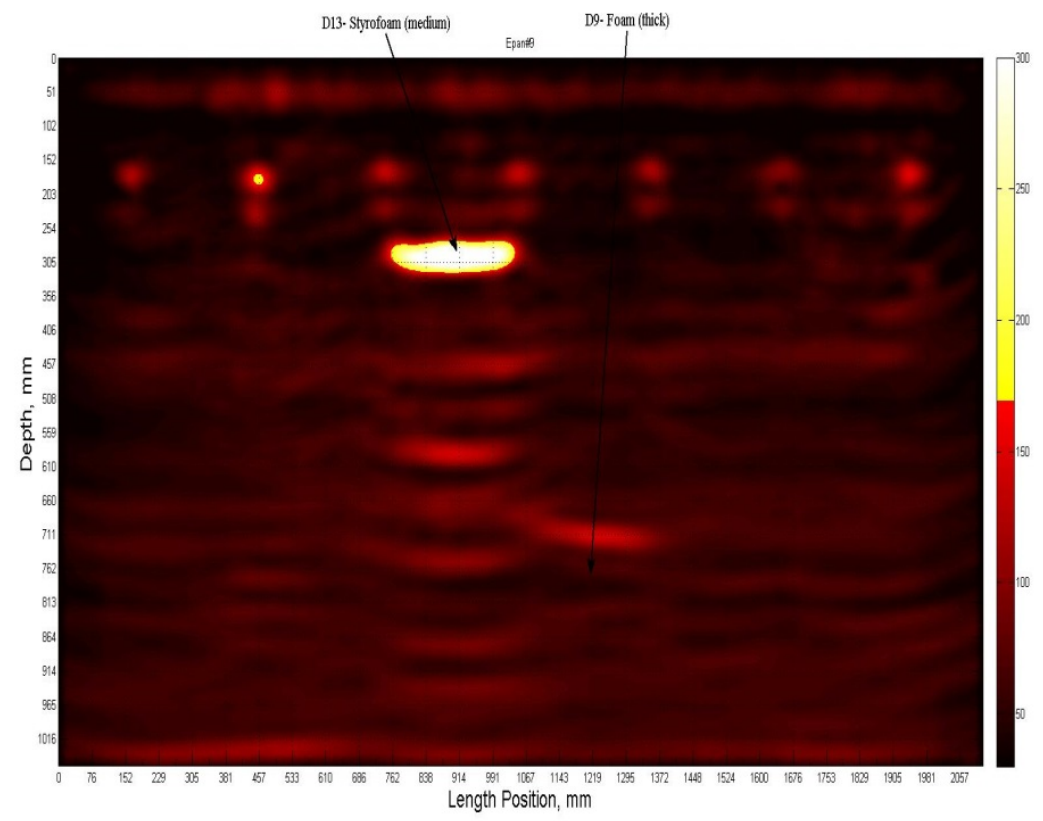

Fig. C.70. Short side length - Epan 9 m162. 


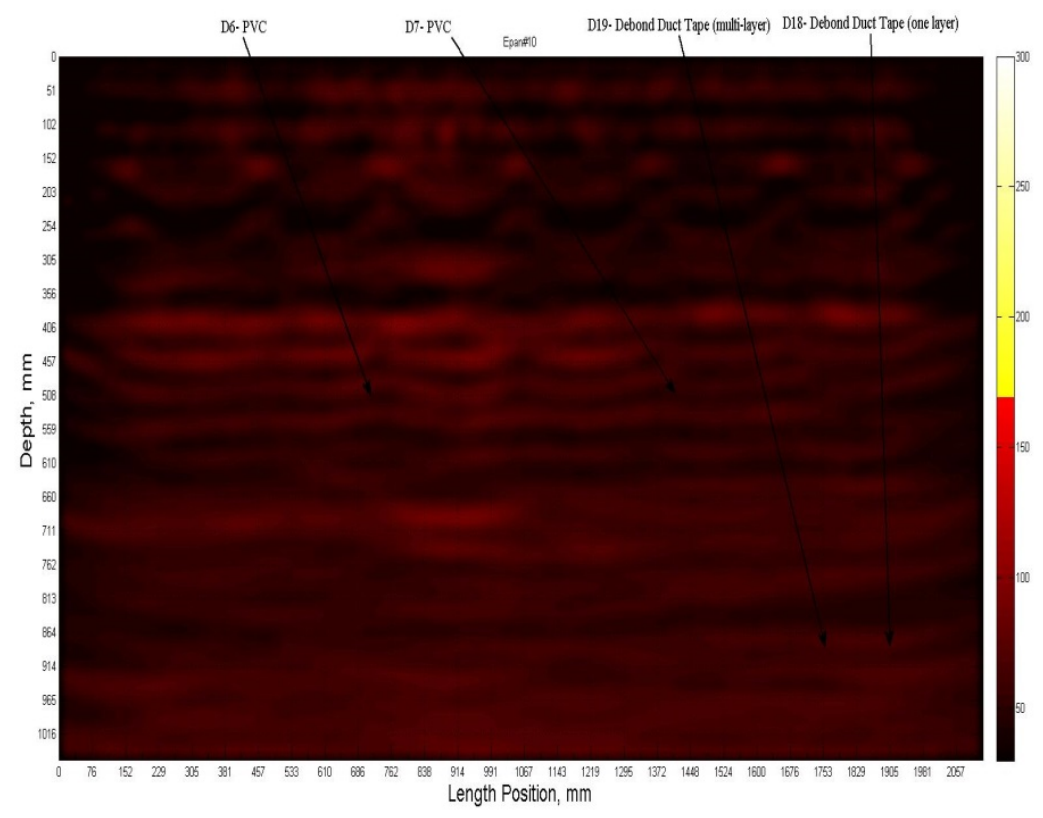

Fig. C.71. Short side length - Epan $10 \mathrm{m180}$.

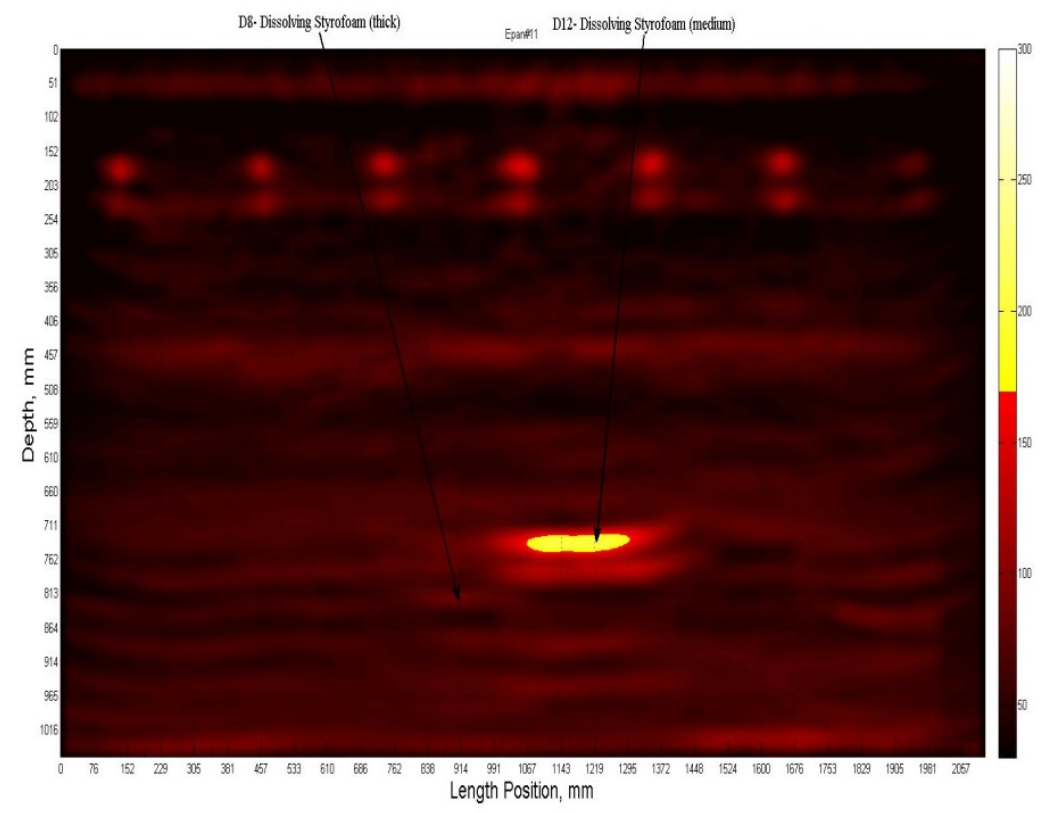

Fig. C.72. Short side length - Epan 11 m198. 


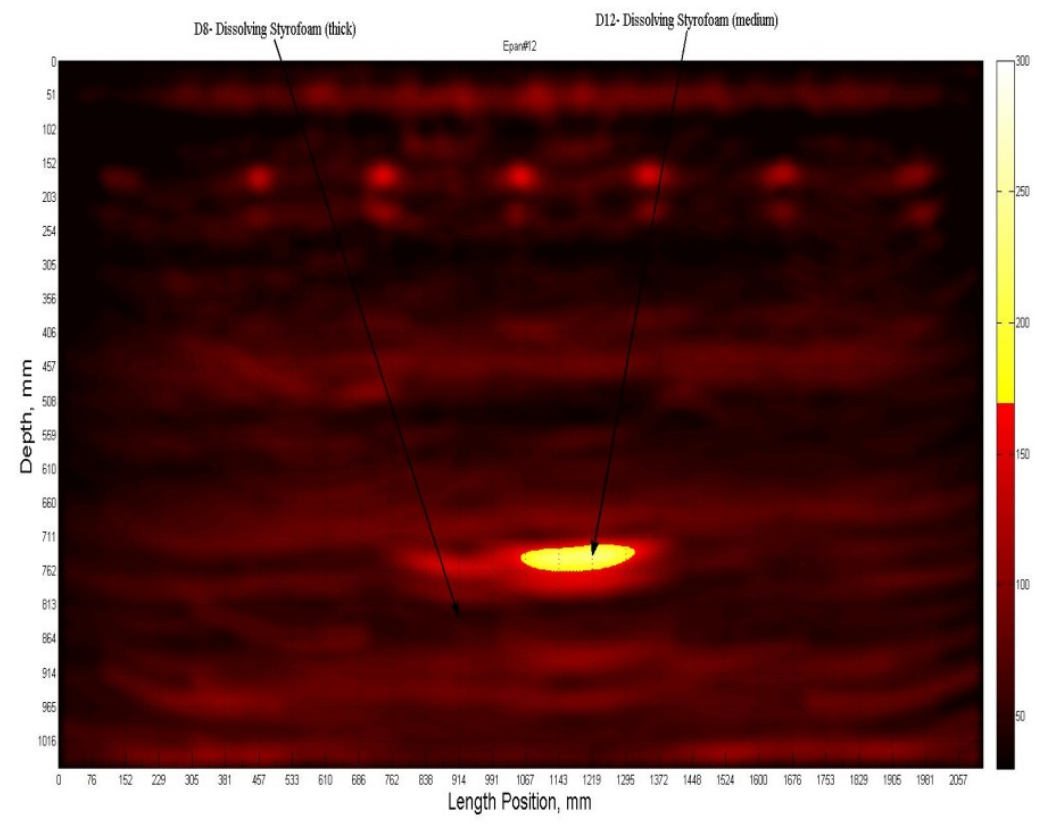

Fig. C.73. Short side length - Epan 12 m216.

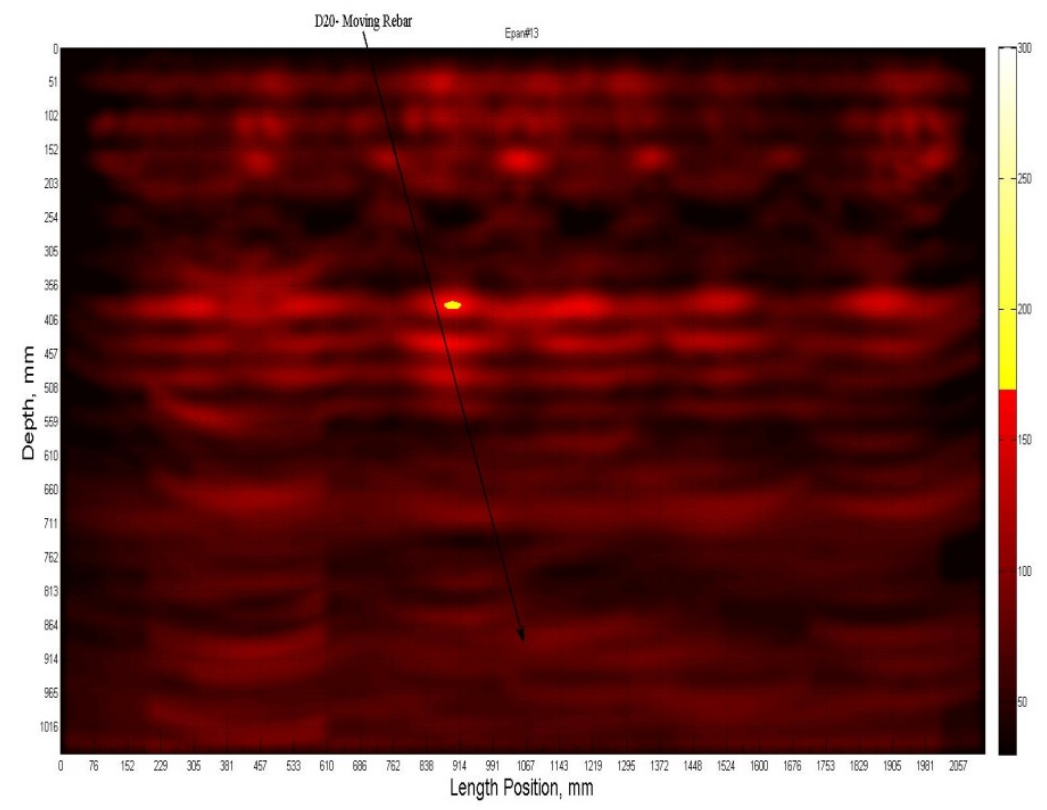

Fig. C.74. Short side length - Epan 13 m234. 


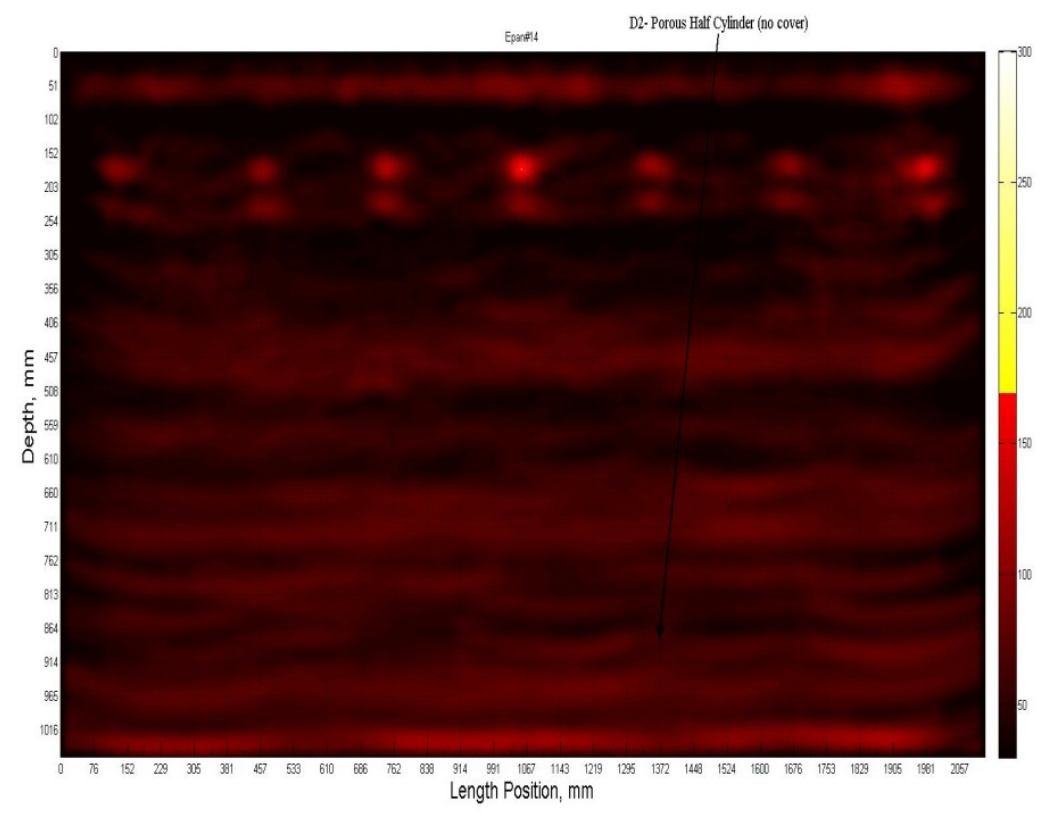

Fig. C.75. Short side length - Epan 14 m252.

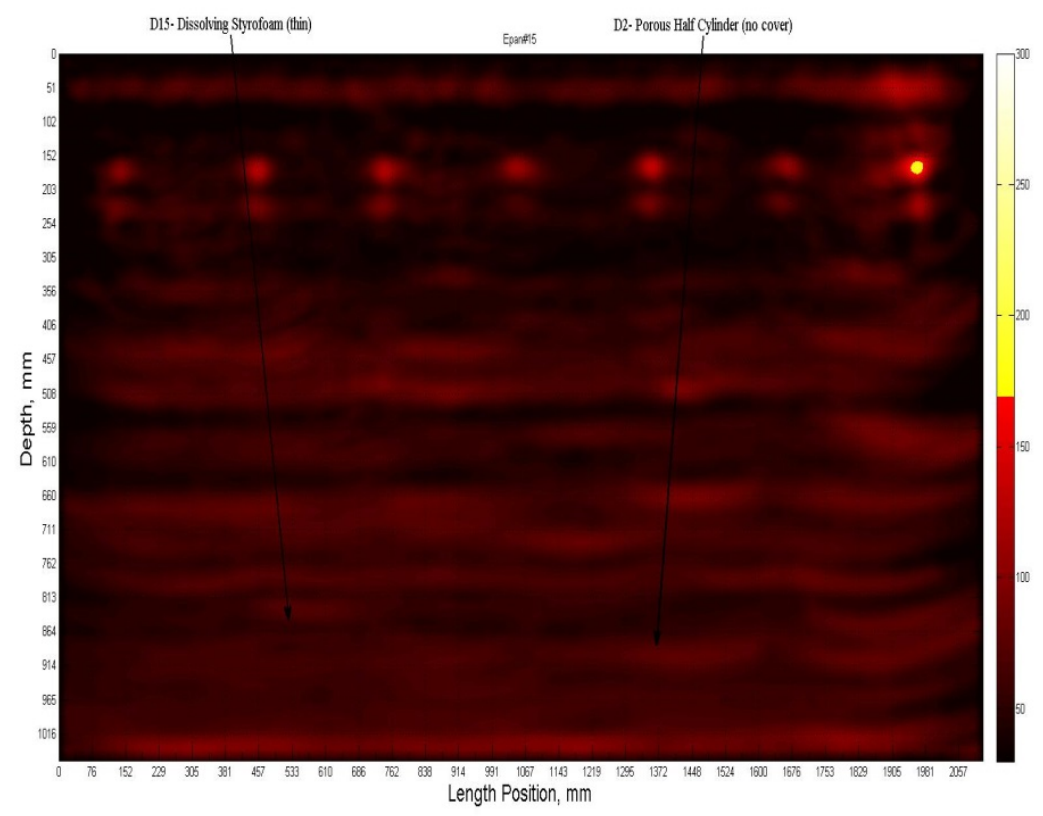

Fig. C.76. Short side length - Epan 15 m270. 


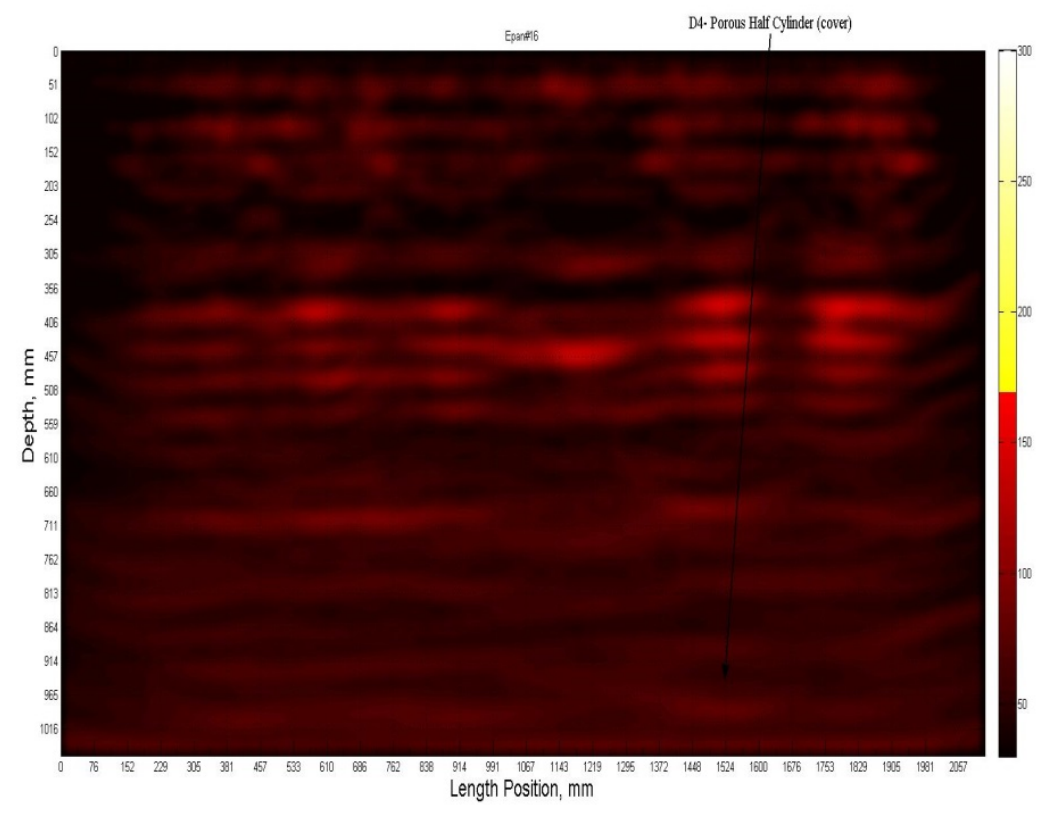

Fig. C.77. Short side length - Epan 16 m288.

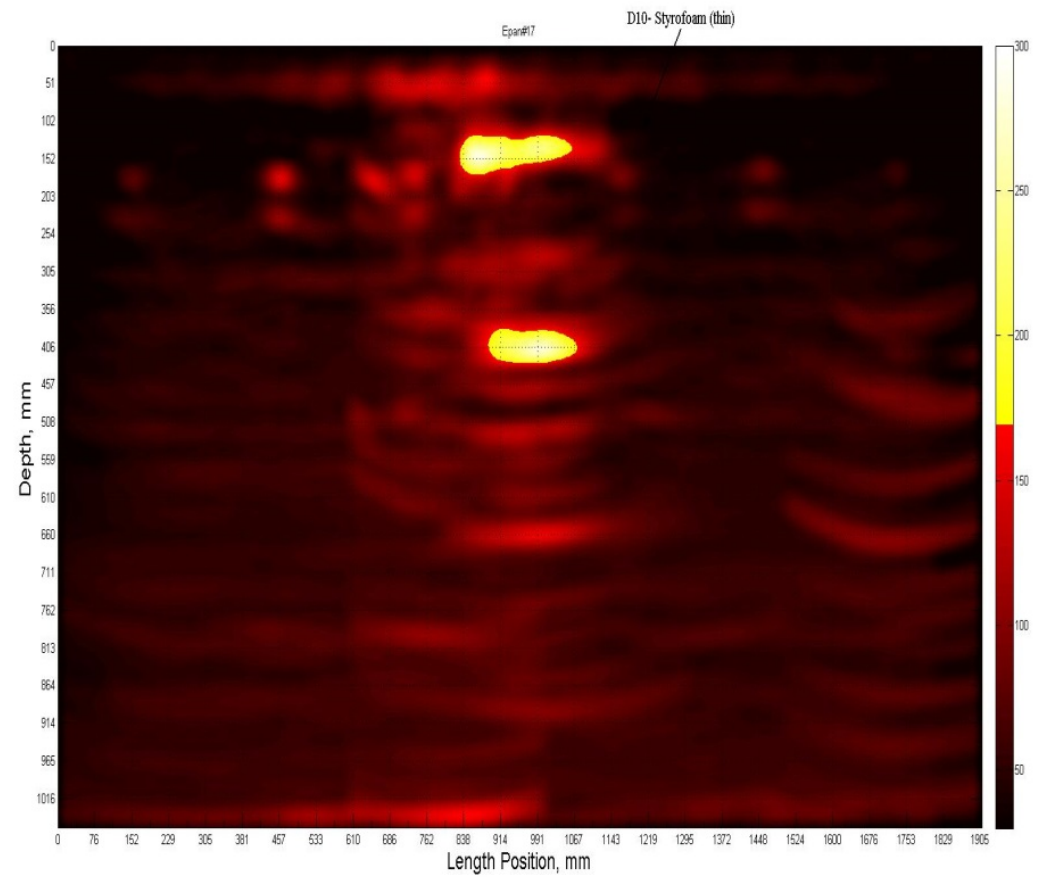

Fig. C.78. Short side length - Epan 17 m306. 


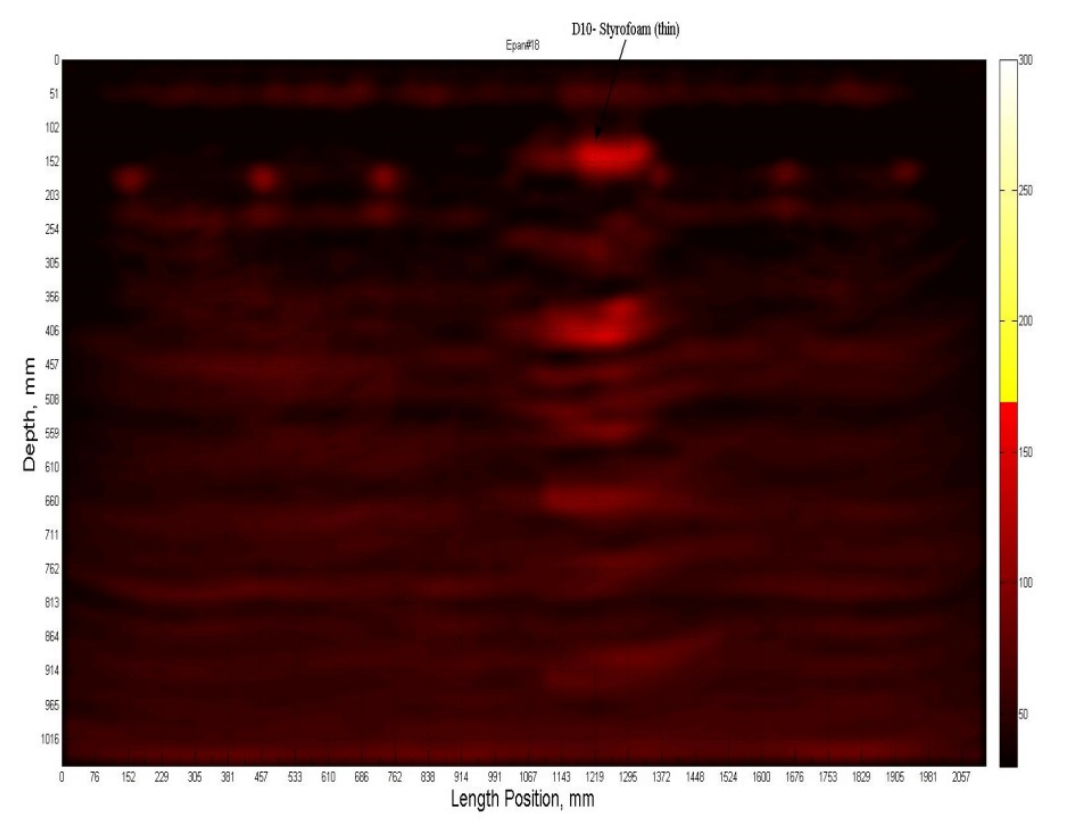

Fig. C.79. Short side length - Epan 18 m324.

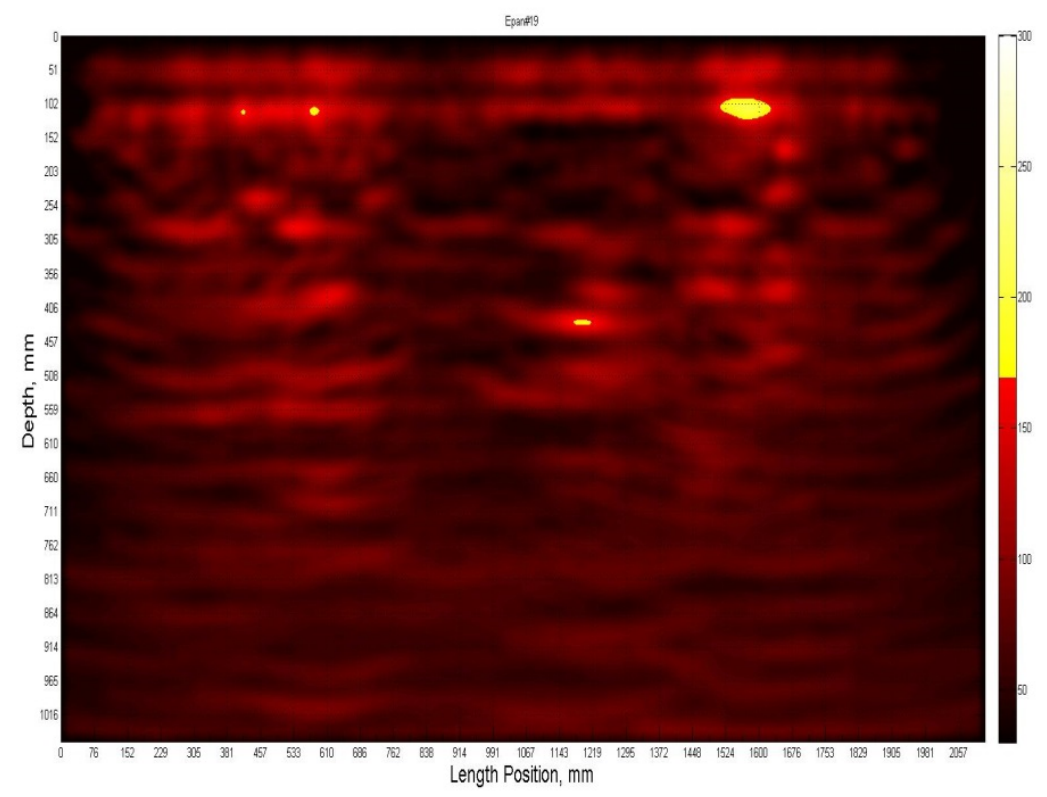

Fig. C.80. Short side length - Epan 19 m342. 